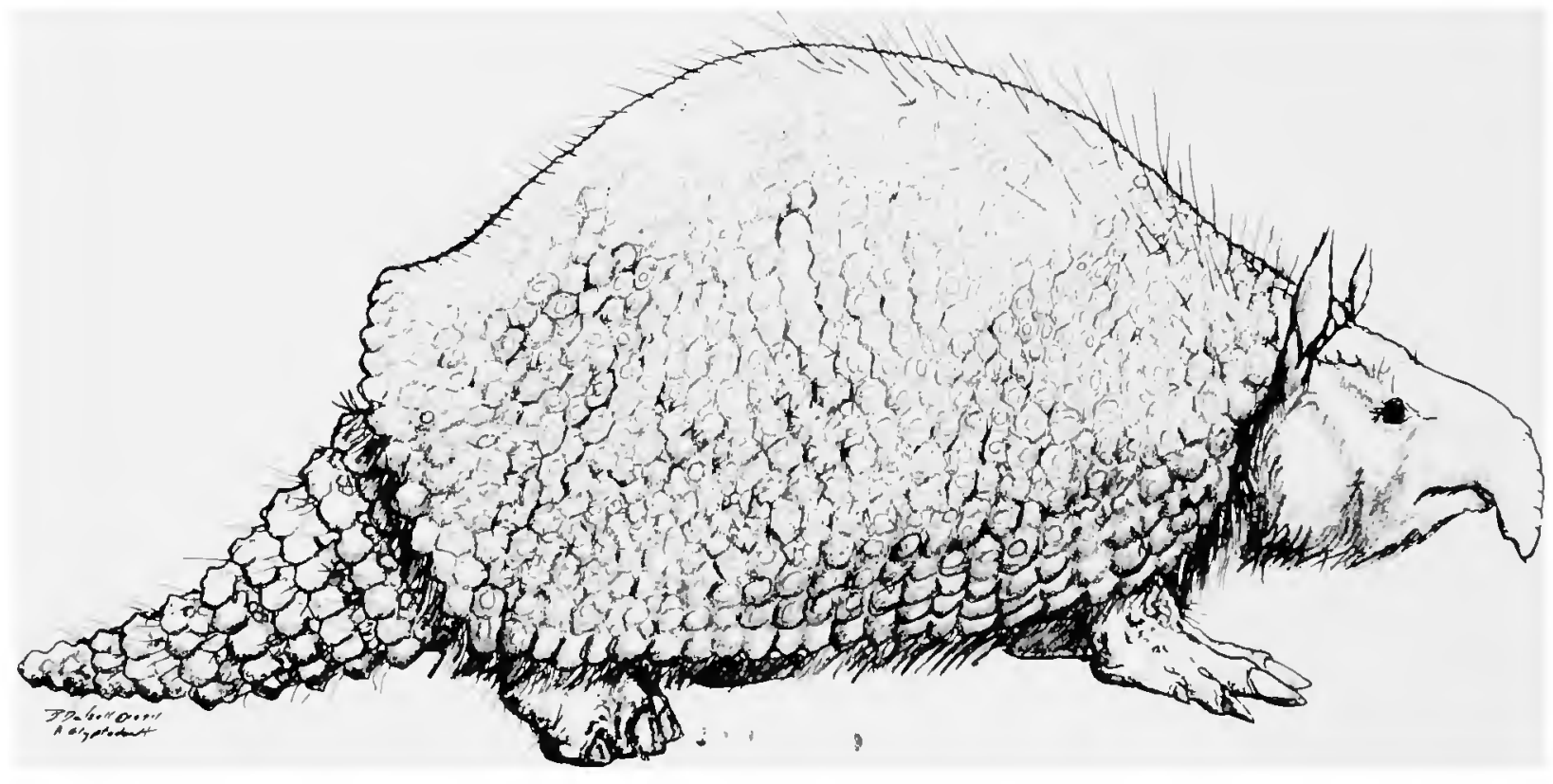

FrontisPiece.-Reconstruction of Glyptotherium arizonae.

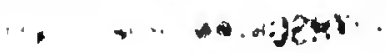


SMITHSONIAN CONTRIBUTIONS TO PALEOBIOLOGY • NUMBER 40

\title{
Glyptodonts of North America
}

\author{
David D. Gillette \\ and \\ Clayton E. Ray
}

\section{ISSUED \\ DEC 211981}

SMTHSONIAN PUBLICATIONS

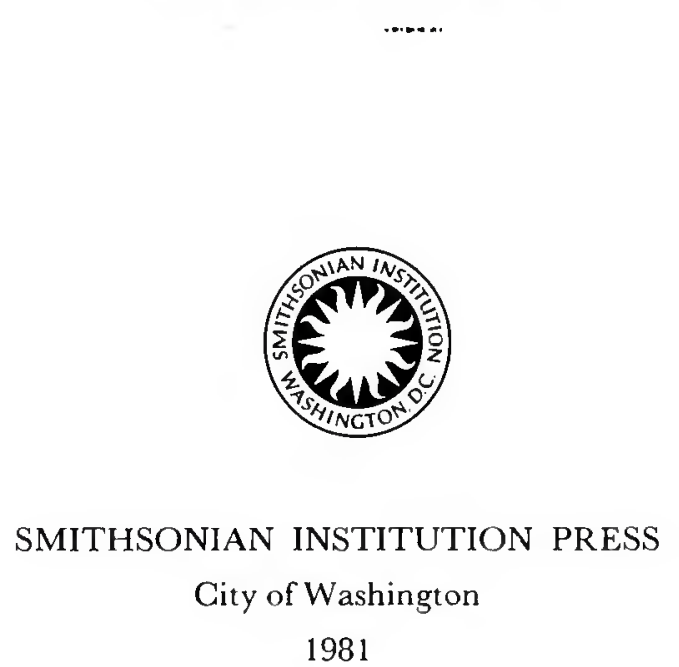

1981 


\section{A B S T R A C T}

Gillette, David D., and Clayton E. Ray. Glyptodonts of North America. Smithsonian Contributions to Paleobiology, number 40, 255 pages, 97 figures, 70 tables, 1981.-All known North American glyptodonts belong in the genus Glyptotherium Osborn, 1903 (Family Glyptodontidae, Subfamily Glyptodontinae). Junior synonyms are Brachyostracon Brown, 1912; Boreostracon Simpson, 1929; Xenoglyptodon Meade, 1953; and all assignments of North American specimens to Glyptodon Owen, 1838. The ancestral species is Glyptotherium texanum from the Early Pleistocene Tusker (Arizona) and Blanco (Texas) local faunas of the Blancan Land Mammal Age; G. texanum is smaller and lacks many of the exaggerated features of the descendant species. The descendant species are $G$, arizonae (Blancan? and Irvingtonian); $G$. floridanum (Rancholabrean); and two species known from isolated localities in Mexico, G. cylindricum and $G$. mexicanum. The taxonomic validity of $G$. mexicanum is questionable.

The geographic distribution and faunal associations of Glyptotherium clearly indicate tropical or subtropical habitats. North American glyptodonts exhibit extreme tendencies toward hypsodonty and homodonty in the dentition, and they lack both incisiform and caniniform teeth. They probably fed on soft vegetation near permanent bodies of water. Graviportal limb proportions and details of the gross osteology suggest slow and cumbersome locomotion, which probably precluded occupation of upland habitats.

A substantial expansion in the number of specimens available for study has extensively improved our knowledge of the gross osteology of Glyptotherium, especially for $G$. texanum and $G$. arizonae.

OfFicial publication date is handstamped in a limited number of initial copies and is recorded in the Institution's annual report, Smithsonian Year. SERIES COVER DESIGN: The trilobile Phacops rana Green.

Library of Congress Cataloging in Publication Data

Gillette, David D.

Glyptodonts of North America

(Smithsonian contributions to palcobiology; no. 40)

Bibliography: p.

Supt. of Does. no.: SI 1.30:40

1. Glyptodontidae. 2. Paleontology-North America. I. Ray, Clayton Edward, joint author. II. Title. III. Series: Smithsonian Institution. Smithsonian contributions to paleobiology; no. 40.

QE701.S56 no. 40 [QE882.E2] 560s $\left[569^{\prime} .31\right] \quad 80.607040$ 


\section{Contents}

Preface

Introduction

Previous Work

Systematics

3

Subfamily GLyptodontinae 10

Genus Glyptotherium Osborn $\quad 10$

Glyptotherium texanum Osborn 11

Glyptotherium arizonae Gidley 12

Glyptotherium floridanum (Simpson), new combination 14

Glyptotherium cylindricum (Brown), new combination $\quad 15$

Glyptotherium mexicanum (Cuatáparo and Ramirez), new combination $\quad 16$

Distribution 18

$\begin{array}{ll}\text { Osteology } & 27\end{array}$

$\begin{array}{ll}\text { Skull } & 27\end{array}$

Presacral Axial Skeleton $\quad 68$

Front Limb $\quad 81$

Pelvis $\quad 112$

Hind Limb 124

Caudal Vertebrae $\quad$. 162

Carapace 168

Caudal Armor 194

Selected Aspects of Glyptodont Paleobiology 199

Functional Morphology 200

Habitat . 207

Evolutionary History of Glyptotherium . 208

Conclusions 209

Appendix: Tables of Measurements 212

Literature Cited 252 
We respectfully dedicate the present monograph to the late Ted Galusha, whose expert field work made this revision possible. 


\section{Preface}

"Mother," he said, "there are two new animals in the woods today, and the one that you said couldn't swim, swims, and the one that you said couldn't curl up, curls; and they've gone shares in their prickles, I think, because both of them are scaly all over, instead of one being smooth and the other very prickly; and besides that, they are rolling round and round in circles, and I don't feel comfy."

"Son, son," said Mother Jaguar ever so many times, graciously waving her tail, "a Hedgehog is a Hedgehog, and can't be anything but a Hedgehog; and a Tortoise is a Torioise, and can never be anylhing else."

"But it isn't a Hedgehog, and it isn't a Torıoise. I's a little bit of both, and I don't know its proper name."

"Nonsense!" said Mother Jaguar. "Everything has its proper name. I should call it "Armadillo' till I found out the real one. And I should leave it alone."-Rudyard Kipling, "The Beginning of the Armadillos"

Had Kipling chronicled the Pleistocene instead of modern times, he no doubt would have passed over the armadillos in this parable for the even more bizarre glyptodonts. For these extinct creatures of the past outwardly resembled modern armadillos and turtles, and ecologically perhaps represented an animal somewhere between a land tortoise and a hippopotamus. Just as armadillos today are among the strangest of mammals, the glyptodonts of the Pleistocenc, representing a branch of the same order, present a perplexing combination of unlikely characters. If their fossil remains had gone undiscovered, glyptodonts could only have been the product of a poet's imagination, for their very existence could never be predicted within the confines of modern science and logic. Their improbable existence notwithstanding, glyptodonts comprised an important southern group of characteristic North American mammals of the Pleistocene Epoch. They were large and cumbersome, dwarfing the largest of modern armadillos. In many respects their anatomy reflects extreme adaptation for massive build and heavy weight. They have no living counterparts, except within our poetic imagination. Picture, if you will, a giant tortoise as a mammal, behaving as a lowland herbivore, with kinship to armadillos and the extinct ground sloths. Such are the glyptodonts, the North American representatives of which are reviewed here. 


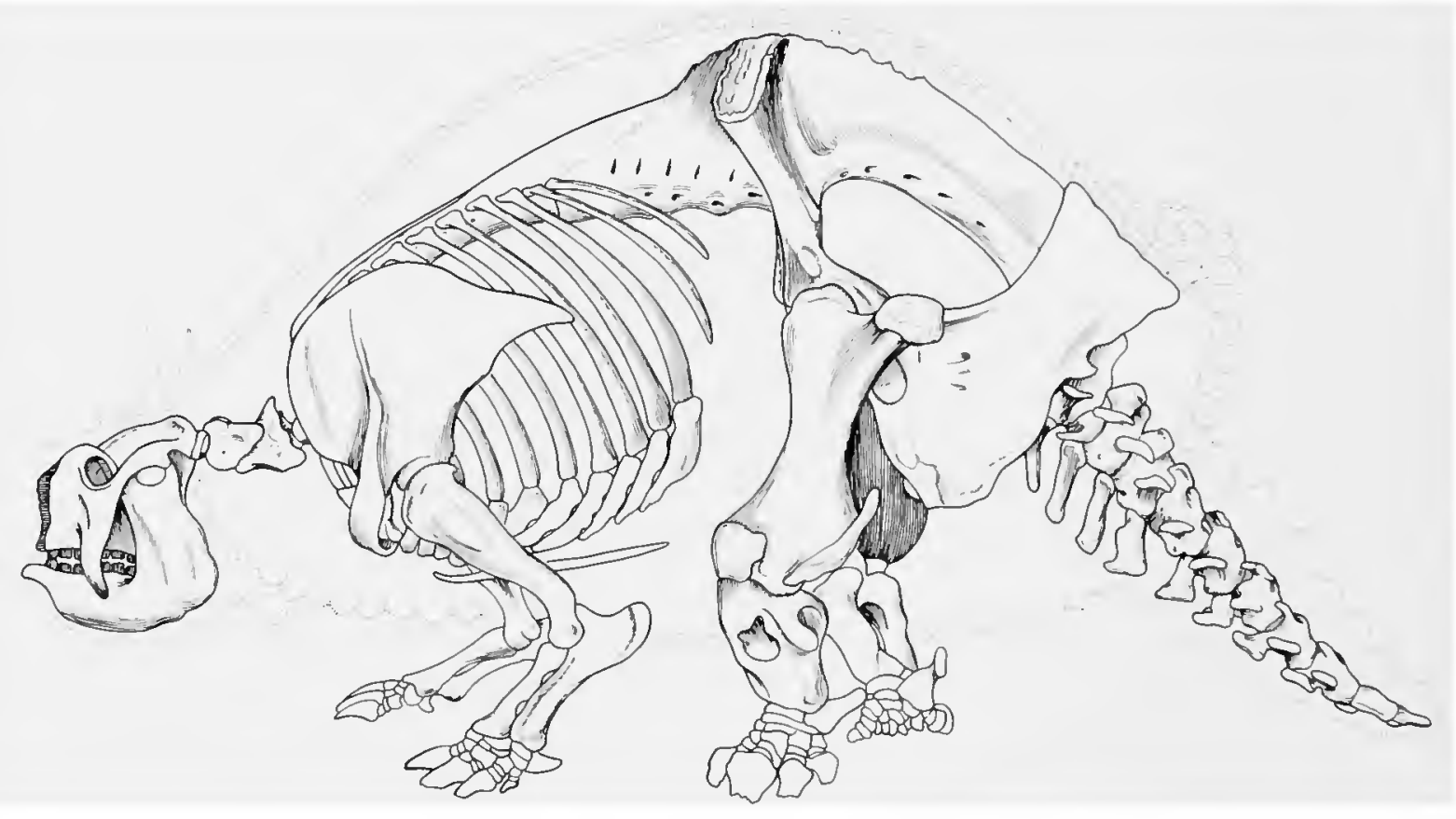

Fígure 1.-Schematic illustration of skeleton of Glyplotherium arizonae (modified for Glyplotherium after Burmeister and Hoffstetter). 


\title{
Glyptodonts of North America
}

\author{
David D. Gillette \\ and Clayton E. Ray
}

\section{Introduction}

The extinct group of cdentates commonly called "glyptodonts" (Greek: "carved tooth" or freely, "grooved tooth") has perplexed students of natural history since their discovery early in the 19 th century. These former occupants of the New World tropics and subtropics combine an unlikely array of characteristics usually considered unique to other vertebrates. The predominant feature is their turtle-like shell, or carapace (Figure 1). Differing from the typical armadillo armor by being almost entirely immobile, the glyptodont carapace afforded excellent protection. Attendant specializations in the axial skeleton are convergent with chelonian anatomy: extensive fusion of most of the vertebral column and fusion of the pelvic girdle to the carapace, rendering the pelvis entirely immobile.

The glyptodont dentition resembles in its construction that found in certain rodents, notably microtines and capybaras. But glyptodont teeth lack enamel, as do those of other edentates, and glyptodonts also lack incisiform and caniniform teeth. Glyptodont cheek teeth are the "most hypsodont" and the "most homodont" among terrestrial mammals.

The glyptodont skull has modifications not

David D. Gillelle, Shuler Museum of Paleonlology, Department of Geological Sciences, Southern Methodisl University, Dallas, Texas 75275. Clayton E. Ray, Department of Paleobiology, Nalional Museum of Nalural History, Smithsonian Institution, Washington, D. C. 20560. found in other mammalian skulls. The bones surrounding the dental battery (maxilla, palatine) are vertically expanded to accommodate the peculiar dentition, while bones of the basicranium are brachycephalic. The skull roof was protected by an articulated set of dermal bones or "cephalic shield." We propose that there was a large fleshy snout or a proboscis similar to that found in elephants, tapirs, and pyrotheres.

The legs, especially the hind limb, are elephantine. Glyptodonts surpass the proboscidean proportions classically illustrated as graviportal and represent one of the "most graviportal" groups ever to have lived. Their large tail probably functioned as a counterbalance in locomotion, as an accommodation for the lack of pelvic and axial mobility. The caudal vertebrae of the North American representatives were encased in complete articulating rings of bony scutes. Despite some reconstructions for North American glyptodonts showing an elaborate terminal mace, this construction is found only in some of their South American relatives. Instead, the tail of North American representatives ended in a blunt terminal tube formed by the fusion of two or three caudal rings.

Classically included as members of the extinct Pleistocene megafauna, glyptodonts reached North America relatively late in the history of the family. Already diversified and widespread in South America in the Miocene, it was at the close of the Pliocene Epoch or perhaps in the earliest 
Pleistocene that glyptodonts finally invaded North America. There they experienced only modest success, surviving until the Late Pleistocene. The North American representatives are descendants of probably a single invasion of their South American relatives into Central America. Subsequent evolution from this early Pleistocenc ancestry resulted in the North American species reviewed in the present study.

Ecologically, glyptodonts indicate tropical or subtropical habitats, with quiet or standing water and dense, lush vegetation. These requirements are indicated by their anatomy, distribution, faunal associations, and geologic occurrences.

Although present in only a few North American Pleistocene faunas, wherever they exist glyptodont remains are not likely to be overlooked, for the scutes comprising their carapace number some 1800 or more per individual. Once a paleontologist has seen an isolated glyptodont scute, he or she is unlikely to forget its construction; scutes are unmistakable and can scarcely be identified as belonging to any other organism.

North American glyptodonts, previously referred to as many as five genera, are herein assigned to one genus, Glyptotherium, and five species, G. texanum, G. arizonae, G. floridanum, $G$. cylindricum, and nominally, G. mexicanum. Until now, classification of North American glyptodonts has been largely inferential, as material has been generally inadequate to establish credible taxonomic assignments.

Through the courtesy of the Department of Vertebrate Paleontology, American Museum of Natural History, scveral excellent glyptodont specimens from Arizona, previously unreported, provided a solid foundation for the present review. This collection includes several complete and ncarly complete carapaces, one of which is associated with a nearly complete skeleton, the first such recovered in North Amcrica. These specimens were collected under the able direction of the late Ted Galusha of the Frick Laboratory in the years 1938-1939, 1943, 1948, and 1954. These Arizona glyptodonts are identified as Glyptotherium texanum, representing the ancestral stock for at least two other North American species, and probably for two others as well. Without these specimens and the courteous assistance provided by members of the American Museum of Natural History, in particular that of Mr. Galusha, this study could never have been initiated, much less concluded.

The present review is weighted heavily toward osteology and taxonomy in the belief that establishing adequate morphological and taxonomic foundations for future studies is of paramount importance.

Abbreviations.-Specimens from the following institutions and departments have been examined for this review: American Museum of Natural History, Department of Vertcbrate Paleontology (AMNH) and Frick Collection (F: AM); Charleston Museum (ChM); Midwestern University, Collection of Vertebrate Fossils (MWU); Texas Memorial Museum (TMM); University of Florida, Collection of Vertebrate Fossils (UF), and Collection of the Florida Geological Survey [UF(FGS)]; University of Michigan Museum of Paleontology (UMMP); collections of the former United States National Museum, (USNM) in the National Museum of Natural History, Smithsonian Institution; West Texas State University (WT), and the Johnston Collection (JWT).

Acknowledgments. - We are deeply indebted for support and assistance to many friends among whom the following deserve special recognition: Claude Albritton, Jr.; Lynett Anderson; Catherine Casey; Walter W. Dalquest; Robert J. Emry; Ralph Eshelman; the late Ted Galusha; Robert Habetler; Billy Harrison; the late Claude W Hibbard; Nicholas Hotton III; Lawrence Isham; Karoli Kutasi; Joshua Laern; Wann Langston, Jr.; Arnold Lcwis; Everett Lindsay; Ernest L. Lundclius, Jr.; Malcolm McKenna; William Melton; Gary Morgan; Stanley J. Olsen; Frank Pearcc, Robcrt W. Purdy; Albert Sanders; Bobb Schaeffer; Bob H. Slaughter; Gladwyn Sullivan; Bcryl Taylor; Richard Tedford; S. David Webb; John A. Wilson; and Jiri Zidek. We wish particularly to thank the members of the Department 
of Vertebrate Paleontology at the American Museum of Natural History for making available the superb material from Arizona, which constitutes the principal basis for this study. As always, they have been generous with specimens, data, and their time. Most of hundreds of hours of delicate laboratory preparation of these and other specimens for this study was done by Gladwyn B. Sullivan with unfailing skill and good cheer. Lawrence Isham prepared Figures $1-4$ and 95 , and he provided expert advice on the preparation of illustrations. Bonnie Dalzell prepared the frontispiece and assisted in the completion of some of the figures. We are especially grateful to David Webb, Robert Emry, and Elaine Anderson for critical reviews of the manuscript. Bob Slaughter served as a catalyst in initiating our collaboration and in sustaining it through completion.

David Gillette's 1974 research was supported by a Smithsonian Institution predoctoral fellowship, a National Science Foundation Doctoral Dissertation Improvement Grant in the Field Sciences, and a Smithsonian Institution Short-Term Visitors Award. We are grateful for the opportunities that these organizations have provided.

Besides those persons and institutions already mentioned, we acknowledge gratefully the assistance of administration, scientific staff, and supporting personnel at the Institute for the Study of Earth and Man, Southern Methodist University; the Texas Memorial Museum, University of Texas; Midwestern University, Wichita Falls, Texas; the Charleston Museum; the National Museum of Natural History (Smithsonian Institution); and the American Museum of Natural History.

\section{Previous Work}

Cuatáparo and Ramirez (1875), two astute civil engineers, were the first to report on the existence of glyptodonts north of South America, describing a complete carapace and associated skeletal remains from the Valley of Mexico as Glyptodon mexicanus. Subsequent recoveries of Mexican glyptodonts were reported by Felix and Lenk
(1889), who named a new species, Glyptodon nathorsti from Ejutla, Oaxaca, and by Brown (1912), who named and described Brachyostracon cylindricus from Ameca, Jalisco, and proposed that Glyptodon mexicanus pertained to his genus. Maldonado-Koerdell (1948) rejected Glyptodon nathorsti Felix and Lenk, considering it a junior synonym of Brachyostracon mexicanus. Hibbard (1955) followed Maldonado-Koerdell in this regard, but he acknowledged that "until the range and variation of Brachyostracon mexicanus is known, however, there is as much justification for recognizing B. nathorsti as for recognizing B. cylindricus" (Hibbard, 1955:51). We recognize $B$. cylindricus (= Glyptotherium cylindricum) and, nominally, B. mexicanus (= Glyptotherium mexicanum); the status of $B$. nathorsti (unseen) remains uncertain, and we also provisionally follow Maldonado-Koerdell.

Brown's (1912) descriptions were the last substantial contributions on Mexican glyptodonts, although several others have recorded additional recoveries of glyptodonts in Mexico (Hibbard, 1955; Dalquest, 1961; Silva-Barcenas, 1969; Mooser and Dalquest, 1975). New material of good quality and reevaluation of the named Mexican taxa will be of great importance in the eventual improved understanding of glyptodonts found in the United States, which form the primary focus of the present investigation.

Cope's (1888) report of an isolated glyptodont scute from Nueces County, Texas, which he named Glyptodon petaliferus, has generally been considered the first indication of glyptodonts north of Mexico. Two years earlier, however, Cope (1886) had reported the recovery of several scutes and a phalanx from the Loup Fork beds of Kansas, designating them as a new genus and species Caryoderma snovianum. Apparently only Flower and Lydekker (1891) acknowledged this species; they identified the genus as Carioderma, evidently a lapsus. Hay (1908:446) credited S. W. Williston for recognizing that these bones were in reality chelonian; Hay assigned them to Testudo and stated that they are in the collection at the University of Kansas. We follow Hay's determination. 
Soon after Cope's reports, Osborn (1903) described Glyptotherium texanum from the Blanco beds of Texas. This is the genotypic species for all known North American glyptodonts. The specimens described by Osborn were the first wellrepresented glyptodont remains recovered north of Mexico. Osborn's description predated Brown's (1912) description of Brachyostracon from Mcxico, which is here regarded as a junior synonym of Osborn's genus although Brown's species is valid.

Following Brown's (1912) and Osborn's (1903) definitive studies, an implicit controversy developed concerning the propriety of the South American generic name Glyptodon for some of the North Anerican recoveries. The controversy has continued up to the present time and, as demonstrated below and in the taxonomy section, is not yet adequately resolved. Hay $(1916,1926)$ reported glyptodonts from two Texan localities, referring them to Glyptodon petaliferus Cope. Simpson (1929b) commented on the improbability of the genus Glyplodon itself occurring in North America, declared Glyptodon petaliferus a nomen nudum, and established for some Florida recoveries the genus and species Boreostracon floridanus. He did not designate a new name for the Texas fossils, however, and their status remained unresolved until the present study revcaled their identity as equivalent to the Florida fossils. Simpson (1929b) also questioned the status of the Arizona species Glyptotherium arizonae which Gidley had described a few years earlier. Simpson apparently believed that the Arizona species represented a distinct and unnamed genus.

At the time of Gidley's (1926) description of Glyptotherium arizonae a sccond complete carapace from the type locality had not been prepared, and lay in storage in the American Museum of Natural History. This carapace was prepared at approximately the time of publication of Gidley's (1926) report, but he evidently never had the opportunity to cxamine it, for if he had, he certainly would have altered his ideas concerning the Arizona species.

Interest in North American glyptodonts soon abated. Once Gidley, Hay, and Simpson had established the certainty of Pleistocene glyptodonts in North America and the probability of scveral taxa, glyptodonts received only sporadic attention. Sellards (1940) maintained the unresolved controversy concerning the existence of Glyptodon in North America, referring several specimens from Bee County, Texas, to Glyptodon petaliferus.

Meade (1953) appears to have been partly influenced by prior remarks concerning the Holloman Gravel Pit (Oklahoma) glyptodont that Hay and Cook (1930) had reported some years earlier. Simpson (1929b) stated in a footnote that he had examined the Holloman specimens and that they probably represent an undescribed species. Meade (1953), in reporting the Holloman fauna, believed that the glyptodont belonged in a separate genus, and he accordingly established Xenoglyptodon fredericensis.

The discovery of glyptodonts in the Gilliland faunal horizon of the Seymour Formation in northern Texas was reported first by Melton (1964) and soon thereafter by Hibbard and Dalquest (1966). Melton briefly described this extensive series of specimens, including excellent skull material; he assigned them to the genus Glyptodon and correctly recognized their identity with the Holloman glyptodont. The comprehensive study of the Seymour faunas by Hibbard and Dalquest (1966) firmly established the contemporaneity of the Seymour and Holloman faunas, lending support to Melton's specific determination. Comparing the Seymour glyptodonts to published accounts of South American representatives, Melton found the closest resemblance to the genus Glyptodon, in the classic sense, and he thereforc referred to Nenoglyptodon as a junior synonym; he retained Meade's species, however, recording the Seymour and Holloman glyptodonts as Glyptodon fredericensis.

A comprehensive examination of North American glyptodonts in the present study indicates that the Seymour and Holloman glyptodonts are inscparable from Glyptotherium arizonae. At the time of Melton's (1964) and Hibbard and Dalquest's (1966) studies, it was believed that the 
Seymour fauna represents the mid-Pleistocene, Kansan glacial age. Thus there was believed to have been representative species from the Blancan (Glyptotherium texanum), early Irvingtonian ( $G$. arizonae), late Irvingtonian (Glyptodon fredericensis), and Rancholabrean (Boreostracon floridanus). With the revision of the age of the Seymour fauna by Hibbard and Dalquest (1973), it is clear that the Curtis Ranch fauna (containing the early Irvingtonian glyptodont) is not as greatly separated in time from the Seymour fauna as previously believed, for Hibbard and Dalquest (1973) have proposed that the Seymour Gilliland fauna is preKansan in age. The glyptodonts support their contention, for there are no significant differences between the Seymour and Curtis Ranch representatives. Thus Glyptodon fredericensis is here considered to be a junior synonym of Glyptotherium arizonae.

Perhaps the principal cause of confusion regarding the taxonomy of North American glyptodonts has been the general lack of cranial material. Only the incomplete skull remains of the Wolfe City, Texas, glyptodont described by Hay (1916) were known with any measure of confidence prior to Melton's (1964) report of the Seymour collection, which includes some excellent skull material. Lacking adequate reference material for the Seymour skulls, Melton resorted to published descriptions of South American glyptodont skulls. Melton's study was the first attempt to place taxonomy of North American representatives on a foundation comparable to that established for South American glyptodonts, for which cranial and carapacial elements have received approximately equal attention.

The addition of several excellent skulls of the Arizona population of Glyptotherium texanum in this study has substantially modified the conclusions reached by previous workers concerned with North American glyptodonts and has revealed the close relationship among all North American representatives.

Recent reports on North American glyptodonts include that of Ray (1965), who recorded a partial skull of a glyptodont recovered from coastal
South Carolina, identified here as Glyptotherium floridanum; and that of Lundelius (1972), who discussed the glyptodont in the Late Pleistocene Ingleside fauna from San Patricio County, Texas. Lundelius's study is the most recent taxonomic review of North American glyptodonts.

\section{Systematics}

Taxonomy of North American glyptodonts has been based primarily on carapacial and pelvic characters, a consequence of the limited number and character of specimens available. It is fortunate that glyptodonts were not recognized in North America until late in the 19th century, when the number of proposed species and genera for South American glyptodonts reached its zenith. At that time several authors (e.g., Burmeister, 1874; Lydekker, 1894) sought to evaluate the existing array of names from a more "balanced" perspective. The origin of the confusion lay in the insistence of previous workers on establishing new species (and even genera) whenever a new carapace, or a partial carapace, was found. Apparently this early tendency of excessive "splitting" occurred because no two individual glyptodont carapaces are exactly alike, nor are restorations ever exactly alike, which undoubtedly affects a description despite an author's awareness that a particular aspect is not exactly correct. The plethora of names evidently exasperated those who sought an overview, as expressed by Lydekker (1894:3):

A large number of the so-called genera and species have been established on the evidence of such fragmentary and imperfect specimens that it is frequently almost or quite impossible to determine to what forms they really belong, and I have accordingly made no attempt to give the complete synonomy of a group whose sludy has been made unnecessarily complex by incompetent workers. In addition to the fact that many nominal genera and species have been formed upon the evidence of specimens that ought never to have been described at all, others have been made by taking portions of the carapace from a different region from that to which the type of the form to which they really belong pertained. Others, again, have been established on the remains of immature or young animals; and we thus have, in 
what is really a rather small group, a host of meaningless names which it is almost impossible to correlate.

It was approximately at the time of Lydekker's study that the existence of glyptodonts in North America became established, and North American authors wisely were reluctant to counter Lydekker's (1894) and Burmeister's (1874) admonitions. Indeed, only three names have been proposed for carapacial remains alone, to the exclusion of noncarapacial characters. These are $G l y p$ todon rivipacis Hay, Glyptodon petaliferus Cope, and Boreostracon floridanus Simpson.

Glyptodon rivipacis Hay obviously was proposed improperly and has not been considered as valid. Because it was proposed for some of the glyptodont scutes from Peace Creek, Florida, without designation or description, Simpson (1929b) correctly considered Glyptodon rivipacis a nomen nudum.

Cope's species was based on an isolated and fragmentary scute. Recognizing the futility of taxonomic characterization based on isolated scutes, Simpson (1929b) also declared Glyptodon petaliferus a nomen nudum, implicitly replacing this name with Boreostracon floridanus. (Simpson also believed that the Texas glyptodonts, referred to $G$. petaliferus by Cope, 1888,1889 , and by Hay, 1916, 1926, actually belonged to a species distinct from the Florida species, but he did not designatc a new name.)

Boreostracon floridanus Simpson was erected for a large series of partial carapaces and isolated scutes from Florida. Simpson effectively expanded Cope's procedure of rcliance on carapacial features, compounding the impropriety of taxonomic designation of type spccimens without noncarapacial remains. Because the hypodigm of Simpson's species is distinctive and fully representative, this name is here retained.

Brown (1912), Gidlcy (1926), and Lundelius (1972), among others, have considered noncarapacial elements in their taxonomic determinations. The unusual situation of having pclvic elements for almost all of the various North American populations has prompted the consideration of pelvic characters as principal taxonomic detcr- minants. Skulls and dentitions have been largely unknown, even among South American taxa, thus necessitating subordination of these traditionally important skeletal parts. We rely heavily on characteristics of the skulls and dentitions as principal taxonomic features, thus placing North American glyptodont taxonomy on a footing similar to that of most other mammalian taxa. The detailed study of the total osteology of North American representatives reveals their close, rather than distant, relationships. Skulls and dentitions receive important consideration in the taxonomy proposed here. This new information is augmented strongly by the reexamination of carapacial and pelvic features, revealing that many of the differences previously considered to be fundamental indications of distant relationships are either misinterpretations or unjustified inflation of the relative importance of noted distinctions.

To the category of misinterpretations belongs the taxonomic framework based on carapacial features. Inproper restoration of the type specimens of Glyptolherium arizonae, as an example, has been important. Subsequent misinterpretations of Gidley's (1926) description, owing to its inconpletencss and a misleading photograph, soon followed, and became incorporated as fact.

Anothcr example of misinterpretation of carapacial features resides in the series of specimens that Simpson (1929b) designated as paratypes for Boreostracon floridanus. As postulated in the osteological description of the carapace, most of the specimens Simpson chose apparently represent female individuals, while carapacial remains of males were regarded as "abnormally large." Had his description included the numerous large scutes, there likely would have becn early recognition of the congeneric rclationship of his species with other North Amcrican species. Instead, becausc Simpson's series heavily favored the smaller scutes (becausc they were by chance in most extensive articulation) those of the males have bcen ignorcd, and Simpson's claim of generic distinction has bcen perpetuated.

To the sccond category, that of unjustified 
inflation of the importance of noted distinctions, belongs the usage of pelvic characters in separation of higher categories. For example, Brown (1912), in part because of the nature of the pelvis, not only established the genus Brachyostracon, but he also placed this genus in a family separate from the only other North American species (Glyptotherium texanum) known at the time. Familial and subfamilial separation on the basis of pelvic characters is unwarranted and even generic separation on the basis of pelvic characters is here denied, in the belief that carapacial and dental similarities far outweigh the importance of pelvic distinctions. This assertion is founded on the reexamination of the carapaces, dentitions, and pelves of North American representatives; the supporting arguments are drawn from the gross osteology of these and other skeletal regions. The question of relative importance of pelvic characters deserves further comment, however, since the pelvis has received considerable attention.

It is impossible to determine whether there is sexual dimorphism in glyptodont pelves on the basis of the small North American sample. Nor is it possible with certainty to evaluate the differences in construction and variations in the number of vertebrae participating in the several component regions of the pelvis. Because the pelves are so well represented, and because earlier authors have used characteristics of the pelvis in taxonomic determinations, it is appropriate to examine the pelves of two extant edentates. The following digression is included to point up the weakness of dependence on pelvic characters in taxonomy of living edentates, and by analogy, of the extinct glyptodonts.

In a small sample of six skeletal specimens of the nine-banded armadillo, Dasypus novemcinctus, of known sex (USNM Division of Mammals $53321 \delta^{\circ}, 244905 \delta, 249906 \delta^{\circ}, 256760 \%, 256761 \delta^{*}$, 49398 ) , there is significant variation in the iliosacral and ischiosacral unions. In two males (256761 and 53321) there are only two iliosacral vertebrae. In the other two males and in both females there are three iliosacral vertebrae. Apparently as partial compensation in the two spec- imens with only two iliosacrals, the posterior lumbar vertebra participates more strongly in the pelvic structure than does the corresponding vertebra of the specimens with three iliosacrals. Especially in 53321 , this vertebra possesses greatly expanded transverse processes that contact the ilium broadly, allowing participation of this vertebra as an anterior "pseudo-sacral" vertebra.

There is similar variation in the construction of the ischiosacral union in the same sample. In all six specimens there are four ischiosacral vertebrae that participate in this union by fusion of their expanded transverse processes with the ischium. For three of the males (53321, 244905, 244906) the transverse processes of the terminal sacral vertebra are solidly fused both with the ischium and with the transverse process of the adjacent penultimate sacral vertebra. In one specimen (244905) the centrum of the last sacral vertebra is fused to that of the penultimate vertebra; the centrum is unfused in the other two males despite the ankylosis of their transverse processes

In marked contrast, the transverse processes of the other male and the two females (256761, 256760 , and 49398, respectively) are fused only with the ischia and not with the transverse processes of the penultimate sacral vertebra. In all three specimens the last centrum is not fused to the one anterior. Consequently, the terminal sacral vertebra, participating in the ischiosacral union, more closely resembles the anterior caudal vertebra (posterior "pseudo-sacral") than the adjoining sacral vertebrae. Indeed, the fusion of the transverse processes with the ischia is incomplete in 256760 and 256761, in which this contact remains cartilaginous. In the fossil state, without complete vertebral columns for reference, these terminal sacral vertebrae could easily be mistaken for the anterior caudal vertebra, and there would therefore exist an artificial disparity in the ischiosacral count for these specimens.

In all six specimens there are two free vertebrae in the sacral arch, although the participation of the transverse processes of the antepenultimate vertebra is variable, from full participation, to an 
estimated one-quarter participation (i.e., the obturator foramen is more posteriorly situated). Remaining characteristics of the pelvis of $D$. novemcinctus are relatively constant. The pubes are stout in both sexes and they unite at the midline in a strongly ankylosed contact. There is little cvident variation in the compound curvature of the sacrum. In all six specimens the first two caudal vertebrae resemble the "pseudosacral" construction of glyptodonts.

Thus in the nine-banded armadillo, there is considerable variation in the pelvis. None of the variation is attributable either to age or sex; instead, it appears to be simple individual variation, and it evidently bears no taxonomic significance for this species.

Similarly, in two male specimens of the giant armadillo Priodontes giganteus (USNM Division of Mammals 261024, 299630), there is a marked difference in the contribution of the terminal sacral vertebra. In specimen 299630 the transverse processes are fused with the adjoining transverse processes of the penultimate vertebra and with the ischia. In the other specimen the transverse processes are free, remaining unfused with either the ischia or the adjoining transverse processes. This variation cannot be an age-related phenomenon, for the individual with the free posterior sacral vertebra appears to be older than the other. The pelves of these two individuals are otherwise identical.

Thus by analogy with armadillos, it is likely that the amount of intraspecific variation in the glyptodont pelvis is greatcr than Brown (1912) had supposed. Accordingly, the differences in the pelves of the North American representatives are not neccssarily indicative of supraspecific distinction. Variation in vertebral participation in the sacral arch should not bc accorded principal taxonomic significancc, nor should the size of the pubic cross bar be considcred as a primary taxonomic character. Variations in the pelvis are here proposed as no more than species distinctions, for there is no justification for basing gcncric diagnoses on the pelvis. The amended diagnoses rcflect these contentions.
To this point in the discussion, the congeneric status of Boreostracon, Brachyostracon, and Glyptotherium has been mentioned. Glyptotherium Osborn, 1903, has priority, and this is the generic name that is here applied to all known North American glyptodonts.

Xenoglyptodon Meade, 1953, was reduced to synonymy by Melton (1964), who correctly considered the Holloman (Oklahoma) glyptodonts as identical to the Seymour (Texas) representatives but referred the Seymour and Holloman specimens to the South American genus Glyptodon.

The presence of the genus Glyptodon in North America was first proposed by Cope (1888). Hay $(1916,1926)$ and Sellards (1940) followed Cope's assertion, while Brown (1912), Gidley (1926), Simpson (1929b), and Holmes and Simpson (1931), among early North American authors, denied the existence of this genus in the North American fauna. Students of South American glyptodonts, apparently invariably, have denied the existence of Glyptodon in North America, recognizing only Glyptotherium and Boreostracon. Melton's (1964) resurrection of the generic name Glyptodon for the Seymour glyptodonts is therefore questionable from a historic standpoint. More important, however, is the fact that the North American glyptodonts are all closely related, and apparently reprcsent evolution from a single carly Pleistocene immigrant. At least for threc species, Glyptotherium texanum, $G$. arizonae, and $G$. floridanum, an ancestral-descendant relationship can be proposed with substantial basis. The other two species, $G$. cylindricum and $G$. mexicanum, of which the latter is nominally retained, are not as easily placed in the sequence, primarily because they are poorly known. They appear to rcpresent a spccics (or, nominally, two species) contemporaneous with the more northern Late Pleistocene $G$. floridanum, if not actually pertaining to the same specics. Thus the North American glyptodonts are not only closely related, but they also appear to have an isolated history, apparently quite apart from South American relatives. Moreover, the carly origin of the North American lineage (Early Pleistoccne-Blancan Land Mammal Age) coin- 
cides temporally with only one South American species of Glyptodon, G. laevis Burmeister; the remaining South American species are listed by Castellanos (1954) as Middle or Late Pleistocene and, therefore, cannot be considered as ancestral or closely related on temporal grounds. The relationship of the ancestral North American species, Glyptotherium texanum, with the apparently contemporaneous Glyptodon laevis (contemporaneous in the broad sense, and accepting Castellanos' (1954) affirmation of the validity of this species) of South America seems to be no closer than that between $G$. texanum and other South American species of this genus. Nor does there appear to be any closer relationship between the North American species, collectively or individually, with the species of Glyptodon than with other South American species in the subfamily Glyptodontinae.

The preceding comments assume validity of the genus Glyptodon, a matter that in itself, and quite apart from taxonomic problems in North America, deserves special attention. The status of the generic name Glyptodon has been reviewed by Hoffstetter (1955), who discussed the inappropriate circumstances surrounding the origin of this name. The generic name Glyptodon has been applied, classically, to a group for which the original description (Owen, 1838) does not apply, at least in part. Hoffstetter recommended designation of a lectotype corresponding to the rear foot that Owen described and that pertains in actuality to the genus in the classic sense (that is, as has been accepted by subsequent common usage). Whether the recourse Hoffstetter has suggested, which seems altogether reasonable, will gain future acceptance is uncertain. For the present, however, it would be premature to assign North American glyptodonts on the basis of a South American genus of uncertain status. Certainly the group of glyptodonts to which the name Glyptodon has been applied is a unified and characteristic group, and it has been the subject of several taxonomic reevaluations among which that of Castellanos (1954) is pertinent to the taxonomy of North American representatives.
Finally, application of the generic name Glyptodon to North American fossils would suggest a closer relationship than the evidence at hand warrants. The North American glyptodonts, in all respects members of the subfamily Glyptodontinae, are distinct from their South American relatives, and the existing lower level taxonomy should reflect this situation by retention of a separate generic name. The existence of so-called Boreostracon in South America is quite another matter, and there is no reason to deny the possibility of secondary invasion of the North American representatives back into South America.

Although the taxonomy proposed here is a substantial alteration of the previously accepted classification of North American glyptodonts, the changes are supported by a great expansion in the number of specimens, including skulls and dentitions. The upper level classification follows Simpson (1945) and Castellanos (1954).

\section{Order Edentata Cuvier, 1798 \\ Suborder Xenarthra Cope, 1889 \\ Infraorder Cingulata Illiger, 1811 \\ Superfamily Glyptodontoidea Simpson, 1931 \\ Family Glyptodontidae Burmeister, 1879 \\ Subfamily GlyptodontinaE Trouessart, 1898 \\ Genus Glyplotherium Osborn, 1903 \\ Glyptotherium lexanum Osborn, 1903 \\ G. arizonae Gidley, 1926 \\ G. floridanum (Simpson, 1929) \\ G. cylindricum (Brown, 1912) \\ G. mexicanum (Cuatáparo and Ramirez, 1875)}

As acknowledged by Simpson (1945) and Hoffstetter (1958), among others, the family name Glyptodontidae Burmeister, 1879, has gained the advantage of usage over Hoplophoridae Huxley, 1864. Except for the problematical Early Tertiary genus Palaeopeltis Ameghino, 1895, all glyptodonts belong in the family Glyptodontidae. The taxonomic position of Palaeopeltis has not been resolved; some (e.g., Castellanos, 1954) assign this genus to a separate family, while others (e.g., Simpson, 1945) conservatively declare its status to be incertae sedis.

Simpson (1945) recognized four subfamilies of Glyptodontidae, whereas Hoffstetter (1958) rec- 
ognized five by choosing to split off two genera from Simpson's recognized subfamily Propalaeohoplophorinae Castellanos, 1932, to be included in a separate subfamily. The remaining three subfamilies seem to be well established: Hoplophorinae Weber, 1928 (this is Simpson's, 1945, preference; Hoffstetter, 1958, retains the older name Sclerocalyptinae Trouessart, 1898, for the same assemblage); Doedicurinae Trouessart, 1898; and Glyptodontinae Trouessart, 1898.

Brown (1912) believed that his genus Brachyostracon belonged in a family separate from Glyptotherium. Simpson (1945) formalized this belief by placing Brachyostracon in the subfamily Hoplophorinae, and the remaining North American taxa in the subfamily Glyptodontinae. Hoffstetter (1958) recognized the closer relationship between Brachyostracon and the other North American genera, placing it also in the subfamily Glyptodontinae.

Castellanos (1954) divided the subfamily Glyptodontinae into three tribes, according to which the North American genera Glyptotherium and Boreostracon were separated. He apparently also believed that Brachyostracon belonged in a separate subfamily, for he did not include it in the Glyptodontinae (Castellanos, 1953, 1954). According to the determinations of the present investigation, all North American glyptodonts belong in the genus Glyptotherium Osborn, 1903, and the matter of tribal designation deserves reinterpretation.

\section{Subfamily GlyptodontinaE}

Hoffstetter (1958) has provided the most comprehensive review of the characters of this subfamily. The following features are some of the more pertinent ones that distinguish the Glyptodontinae from the other subfamilics: (1) carapace divided into long thoracic region and short lumbosacral region; (2) scutes thick, with simple ornamentation; (3) marginal scutes mostly differentiated into a highly tuberculated construction; (4) caudal armor composed of movable rings, each formed by two or three rows of plates, of which those in the postcrior row are sometimes conical or tuberculated; terminal armor ankylosed into a short tube (Hoffstetter, 1958, stated that the caudal armor consists of only seven individual rings; evidence presented herein indicates that the number of caudal rings is variable); (5) skull large, tall, and abruptly truncated because of shortening of the nasals, premaxillae, and anterior end of mandible; (6) narial aperture trapezoidal and tall; (7) upper profile of the skull straight and inclined forward; (8) zygomatic arch rather weak posteriorly; descending processes massive; (9) postorbital bar incomplete; (10) teeth all trilobed, but anterior ones smaller; (11) osteodentine cores form numerous secondary ramifications, a condition not known in the other subfamilies; (12) humerus lacks the entepicondylar bridge, which is present in the other subfamilies; (13) manus with no more than four digits; pes with five complete digits.

All of the North American glyptodonts examined in the present study conform to Hoffstetter's (1958) characteristics for this subfamily. Some of the features listed below in the diagnosis for Glyptotherium might also pertain to the entire subfamily.

\section{Genus Glyptotherium Osborn}

"Glyptodon" of Cuatáparo and Ramirez, 1875:362.-Cope, 1888:346.-Hay, 1916:107.-Sellards, 1940:1637.-Melton, 1964:131.

Glyplotherium Osborn, 1903:49'2.-Gidley, 1926:96.-Akersten, 1970:13.

Brachyosiracon Brown, 1912:169.

Boreostracon Simpson, 1929b:581.-Lundelius, 197:2:36.

Xenogtyptodon Meade, 1953:455.

Age.-Late Pliocene to Late Pleistocene; Late Blancan through Rancholabrean Land Mammal Ages.

Diagnosis.-Size medium to large; skull short, truncated, dorsal profile flat, anteriorly inclined; nasal aperture trapezoidal; postorbital bar incomplete; digit I, manus, absent, digits II, III, IV large, digit $\mathrm{V}$ reduced; digits $\mathrm{I}$ and $\mathrm{V}$, pes, small, reduced, digits II, III, IV large; humerus lacking cntcpicondylar foramen; caudal vertebrae un- 
fused, each protected by individual, movable rings, except the "sacrocaudals" and the last two or three, which may be fused into a short tube; scutes of distal row of each caudal ring weakly to strongly conical; first caudal ring incomplete; chevron distal articulation with caudal ring of next posterior vertebra; carapace short, arched, usually with posterior recurved outline; cephalic boss may be present on carapace; carapacial scutes firmly articulated, immovable except in anterolateral region; individual scutes polygonal, with rosette sculpturing; central figure larger than, or equal to, size of peripherals; one row peripherals, with occasional intercalations of incomplete second row; central figures weakly convex, flat, or weakly concave; peripheral figures flat; scutes of caudal border weakly to strongly conical; nuchal scutes usually unbossed; scutes of anterolateral region quadrilateral, movable; lateral border scutes variously conical, pendant.

\section{Glyptotherium texanum Osborn}

Glyptotherium texanum Osborn, 1903:492, pl. 43.-Akersten, 1972:13, figs. 8d,e, 9a,b.

Type Specimen.-AMNH 10704 carapace, caudal vertebrae, caudal armor, pelvis, seven chevrons.

Type-Locality.-Llano Estacado, Texas; exact locality uncertain; probably "Blanco Locality," Crosby County, Texas, of Johnston and Savage (1955).

ReferRed Specimens.-The following specimens are referred to G. texanum Osborn.

Type-Locality: AMNH 10705, several scutes (unseen); AMNH 20092, from Crawfish Draw, Blanco Canyon, probably scutes (unseen).

Cita Canyon Locality, Randall County, Texas, Bed no. 4: JWT 1723, tibiofibula; JWT 1712, calcaneum; JWT 2330, fragmentary right and left mandibles, isolated teeth and tooth fragments; JWT 1837, isolated rear upper tooth; JWT 1715 , nearly complete mandible with broken $\mathrm{N}_{\bar{I}-\mathrm{N}_{\overline{8}}}$; JWT 649, 13 articulated scutes, 119 isolated scutes; JWT 2319, 120 isolated scutes;
JWT 2387, 10 articulated scutes; JWT 1907, 9 articulated scutes; JWT 1706, 10 articulated scutes, 10 isolated scutes; JWT 2356, 2408, 2477, 2501, 2578, 22 isolated scutes; JWT 649, isolated rear ungual phalanx.

Red Light Local Fauna, Love Formation, Hudspeth County, Texas: TMM 40961-1, partial carapace and numerous isolated scutes; TMM 40664-245, distal end right humerus; TMM 40664-109, ungual phalanx.

Hudspeth Local Fauna, Camp Rice Formation, Hudspeth County, Texas: TMM 40254-1, 40254-2, 40254-3, 40255-2, isolated scutes.

Tusker Local Fauna, Graham County, Arizona: F:AM 59581, carapace; F:AM 59583, partial skull; F:AM 59584, radius; F:AM 59589, two scutes; F:AM 59599, carapace; F:AM 95737, nearly complete skeleton and carapace; F:AM 59586, astragalus; F:AM 59584, phalanx; F:AM 59585 , radius.

Age._Blancan Land Mammal Age, Late Pliocene-Early Pleistocene.

Diagnosis._Skull small; glenoid fossa smooth; paroccipital processes small; paroccipital canal lacking; basioccipital-basisphenoid contact in vertical plane of posterior nares; basioccipitalbasisphenoid union contiguous, in same plane; inferior border of foramen magnum entire, basioccipital not deeply clefted; squamous occipital smooth and inclination shallow; occipital condyles conical; hypoglossal canal lacking; ventral extremity petromastoid rounded; medial parietal region not elevated; mental foramen in plane of $\mathrm{N}_{\overline{1}}$ midlobe; inferior margin of horizontal ramus of mandible flattened; $\mathrm{N}^{1}$ ovoid; $\mathrm{N}^{\underline{2}}$ trilobate; $\mathrm{N}^{\underline{5}}-\mathrm{N}^{\underline{8}}$ anterior borders flattened; $\mathrm{N}_{\overline{1}}$ elongate, irregularly ovoid, situated on symphyseal curvature; $\mathrm{N}_{\overline{2}}$ trilobate, submolariform; $\mathrm{N}_{\overline{3}}$ submolariform, obliquity of posterior lobe intermediate; $\mathrm{N}_{\overline{4}}$ anterior lobe relatively undeveloped, no anterointernal sulcus; $\mathrm{N}_{5}-\mathrm{N}_{\overline{7}}$ lobes slightly oblique; $\mathrm{N}_{\overline{8}}$ anteromedial and anterolateral faces convex, apex blunt; presacral vertebrae unknown; acromion process of scapula symmetrical; propodials and epipodials small and lacking greatly exaggerated features; humerus lacking supratrochlear 
foramen; articular facets of manus and pes small, curved; five or six vertebrae in lumbar tube; three iliosacral vertebrae; four free vertebrae in sacral arch; one or two ischiosacral vertebrae; pubic crossbar small; ischiac crests posteriorly convergent; compound curve of sacral arch not pronounced; transverse processes of terminal sacral vertebra directed obliquely rearward; anterior surface of ilium strongly concavoconvex; carapace small, symmetrical anteroposteriorly, not highly arched; no cephalic boss on carapace; border scutes not greatly enlarged; scutes small, central figures convex, larger than peripherals, frequent deep hair follicles; posterior border of carapace recurved weakly or not at all; central figures of scutes usually convex, frequently with deep medial depression; caudal and cephalic apertures taper laterally downward, not vertical; scutes of carapace disposed in transverse and oblique rows; posterior border scutes variable from flat to weakly conical; lateral border scutes only slightly enlarged, occasionally "pendant"; nuchal scutes smooth, unbossed; caudal armor consisting of 11 separate rings of scutes, one ring per vertebra, including an incomplete anterior "accessory ring" and a terminal tube formed by either the single terminal ring or by fusion of the last two rings; scutes of caudal armor unbossed, presenting uniformly scalloped distal outline, except dorsal pair of scutes in rings $4-11$, which are conical and raised.

\section{Glyptotherium arizonae Gidley}

Glyptotherium arizonae Gidley, 1926:96, fig. 4, pls. 40-44.

"Glyptotherium" arizonac Gidley.-Simpson, 1929b:582.

Glyptodon petaliferus Cope.-Hay and Cook, 1930:10.

Xenoglyptodon fredertcensis Meade, 1953:455, pl. 1.

Glypiodon fredericensis (Meade)-Mclion, 1964:131, figs. 2-3, pls. $1-3$.

Type Specimens.-USNM 10536 (holotypc), mandible with teeth, complete right front limb, vertebral fragments including broken dorsal tube, carapace portions, isolated scutes from carapace and tail rings, complete right hind limb, incomplete left hind limb; USNM 10537 and 10336 (paratypes), caudal vertebrae and caudal armor, portions of carapace, foot bones, broken teeth.

Type-Locality.- "About three miles east of the Curtis Ranch, in Sec. 25, T. 18 S., R. 21 E., Cochise County, Arizona" (Gidley, 1926).

Referred Specimens. - The following specimens are referred to $G$. arizonae Gidley.

Type-Locality: AMNH 21808, complete carapace and caudal armor, caudal vertebrae with associated chevrons, pelvis, femur; AMNH 21809 , isolated scutes (unseen).

Holloman Gravel Pit near Frederick, Tillman County, Oklahoma: TMM 934-37, fragmentary mandible with two broken teeth, two isolated scutes; an unnumbered carapace in the Stovall Museum, University of Oklahoma.

Seymour Formation, Gilliland Local Fauna, Knox County, Texas: MWU 1209, 1632, 1633, $1667,1668,1798,1799,1861,1862,1980,2307$, 2309-2315, 2317-2322, 2324, 2456, 2558, 2671, 2672, 2674-2676, 2678, 7997, 7998, numerous scutes, mostly isolated; MWU 1668, 2324, caudal vertebrae, MWU 1634, sacral vertebra fragment; MWU 1668, rib fragment, proximal end; LMMP 33520, phalanx; UMMP 33524, tibiofibula; UMMP 46474, isolated tooth; UMMP 46892, 44704-44706, 44708, 44709, 22475, 46230, 46240-46257. 46259-46264, 46267-46311, $46313-46237,46341,46343,46346,46347,46354$, 46363, 46372, 46379, 46643, partial carapaces, caudal rings, isolated scutes; UMMP 44707, caudal vertebra; UMMP 34826, skull, caudal vertebrae, chevron boncs, carapace scutes, caudal rings, atlas, cervical tube; UMMP 3876I, skull, mandible, complete rear foot, both radii, complete left front foot, incomplete right front foot; UMMP 46231, complete left rear limb; UMMP 46232, broken tibiofibula, two isolated scutes, rib; UMMP 46233, distal end of femur; UMMP 46234, fragmentary mandible and metatarsal II; UMMP 46235, tibiofibula distal extremity; UMMP 46236, patella; UMMP 46237, broken mandibles and seven isolated scutes; UMMP 46238, caudal vertebrae; UMMP 46239, terminal caudal vertebra; UMMP 46258, mandible fragments, rib and several isolated scutes; UMMP 
46329, metatarsal III; UMMP 46330, metatarsal III; UMMP 46331, navicular; UMMP 46332 , navicular; UMMP 46333, phalanx I, digit I, manus; UMMP 46334 metatarsal II with sesamoid bone; UMMP 46335, teeth fragments; UMMP 46376, distal end of femur; UMMP 46378, caudal vertebra; UMMP 46644, fragmentary caudal vertebra.

Specimens unseen: Glyptotherium sp. as listed in Lindsay and Tessman (1974) in the Curtis Ranch fauna and equivalent faunules in Cochise County, Arizona.

AGE.-Irvingtonian Land Mammal Age.

Diagnosis. - Size large, skull very large; glenoid fossa with distinct foramen; paroccipital processes large, with deep paroccipital canal; basioccipital-basisphenoid contact posterior to posterior nares; basioccipital-basisphenoid union obtuse, not contiguous in same plane; foramen magnum inferior border entire; basioccipital $Y$ shaped; squamous occipital smooth and inclination shallow; occipital condyles conical; hypoglossal canal lacking; ventral extremity petromastoid flattened; medial parietal region not elevated; mental foramen anterior to $\mathrm{N}_{\bar{I}}$; mandibular symphysis horizontal and flat; inferior margin of horizontal ramus of mandible rounded; posterior margin ascending ramus of mandible not steeply inclined, parallel to anterior margin; $\mathrm{N}^{1}$ ovoid; $\mathrm{N}^{\underline{2}}$ probably trilobate; $\mathrm{N}^{\underline{5}}-\mathrm{N}^{\underline{8}}$ anterior borders flattened; $\mathrm{N}_{\bar{I}}$ molariform, nearly trilobate, situated behind symphyseal curvature; $\mathrm{N}_{\overline{2}}$ trilobate, molariform; $\mathrm{N}_{\overline{3}}$ molariform, posterior lobe convex, markedly oblique, anterior lobe squared; $\mathrm{N}_{\overline{4}}$ fully trilobate, transverse axes of lobes oblique, posterior face concave, no anterointernal sulcus; $\mathrm{N}_{\overline{5}}-\mathrm{N}_{\overline{7}}$ lobes oblique; $\mathrm{N}_{\overline{8}}$ anteromedial and anterolateral faces concave, anterior apex pointed, anterior lobe widest, middle and posterior lobes progressively narrower, posterior face concave, oblique; atlas free; alar processes perpendicular, struts at anterior opening of intervertebral foramina, posterior openings intervertebral foramina widely separated; cervical tube formed by vertebrae nos. 2-7; axis articular facet oriented downward; first thoracic vertebra free, with fused rib; dorsal tube formed by 10 thoracic vertebrae; acromion process of scapula asymmetrical; propodials and epipodials large and massive with exaggerated features; humerus with supratrochlear foramen; articular facets, manus and pes, large and curved; three iliosacral vertebrae, one or two ischiosacral vertebrae; pubic crossbar small; ischiac crests slightly convergent posteriorly; moderate sacral arch compound curve; transverse processes terminal sacral vertebra directed obliquely rearward; anterior surface ilium strongly concavoconvex; carapace large, highly arched, divided into distinct preiliac and postiliac regions; carapace with cephalic boss; scutes large, central figures of scutes slightly greater than half the scute diameter, always slightly larger than peripherals, flat to weakly convex; border of anterior aperture of carapace tapers laterally downward and rearward, posterior aperture vertical; lateral border scutes large, conical; lateral scutes of first interior row with rounded central boss; caudal armor consisting of 11 or 12 rings, including an incomplete anterior "accessory ring" and a terminal tube formed by either the terminal ring or by fusion of the last two rings; dorsal pair of scutes of each ring very conical, other scutes of distal rows also conical and bossed; scutes of anterior rings unbossed.

REMARKs.-Large, isolated scutes from several late Blancan to early Irvingtonian sites in Florida most closely resemble the scutes of $G$. arizonae from Texas and Arizona. We identify these scutes as Glyptotherium sp., cf. G. arizonae Gidley. These specimens and their localities are: Sant a Fe River, Gilchrist County, (UF localities SF 1, 4A, 8A), UF/FSM 10439, 10743, 10428, 10438, 19198, 15122 , isolated scutes, a broken tooth from a baby individual, and two caudal ring scutes; Inglis 1A, Citrus County, UF/FSM 20568, one scute; Reynolds Point, Charlotte Harbor, Charlotte County, UF/FSM 2774, three scutes; UF/FSM 10322, one scute. The age of the Inglis IA fauna is early Irvingtonian Land Mammal Age (Webb, 1974). The Charlotte Harbor and Santa Fe faunas pertain to the late Blancan Land Mammal age (Webb, 1974; MacFadden and Waldrop, 1980). 


\section{Glyptotherium floridanum (Simpson), new combination}

Glyptodon petaliferus Cope, 1888:346 [nomen nudum]; 1889: 662, fig. 2.-Leidy, 1889b:25, pl. 4: fig. 9; pl. 5: figs. 11 12; pl. 6: figs. 1-3.-Hay, 1916:107, pls. 3-5; 1923:381; 1924:2, 4; 1926:2, pl. 1: fig. 1; pl. 2: fig. 3; 1927:286.Sellards, 1940:1637, pl. 2: fig. 3.

Glyplodon floridanus Leidy, 1889a [nomen vanum].-Cope, 1889:662.

Glyptodon rivipacis Hay, 1923:40 [nomen nudum].

Boreostracon floridanus Simpson, 1929b:581, fig. 10.-Holmes and Simpson, 1931:405, figs. 14-21._-Gazin, 1950:399.Lundelius, 1972:36, figs. 28-30, pl. 1

Type Specimens.-AMNH 23547 (holotype), rear portion of carapace, including posterior border; AMNH 23548-23562 (paratypes), topotypical series of carapace portions and isolated scutes.

Type-Locality.-Seminole Field, Pinellas County, Florida (see Simpson, 1929b; Holmes and Simpson, 1931).

Referred Specimens. - The following specimens are referred to $G$. floridanum (Simpson).

Type-Locality: AMNH 23514, skull fragment (unseen); AMNH 23515, two juvenile teeth; AMNH 23586, isolated scutes; AMNH 23590, mandible fragment; AMNH 95726-95728, 14 isolated scutes.

Catalina Gardens locality, Pinellas County, Florida: UF/FGS 6643, completc carapace, pelvis, six anterior caudal vertebrae, fragmentary mandible and five isolated teeth, and isolated scutes.

Melbourne, Brevard County, Florida: USNM 256750 , in "Melbourne 1928" collection, five isolated scutes.

Sarasota, mouth of Hog Creek, Sarasota County, Florida: USNM 11675, 11975, seven isolated scutes; from Sarasota County, localities unknown: UF 1 1495, 3093, isolated scutes; from Sarasota County, localities unknown: UF11495, 3093, isolated scutes; UF/FSM 16830 isolated tooth? $\mathrm{N}^{3}$

Orange County, Florida (exact locality unknown): USNM 11318, nearly complete mandible.

Waccasassa River, Levy County, Florida: UF/ FSM 16379, 18455, two isolated scutes.
Mefford Cave II, Marion County, Florida: UF/ FSM 6525, eight carapacial scutes.

Piney Point, Manatee County, Florida: UF/ FSM 11469, one carapacial scute, near anterior margin.

Tomoka Park, Volusia County, Florida: UF/ FSM 14762, one carapacial scute.

Terry Owen collection, Sarasota County, Florida: UF/FSM 11498, one carapacial scute.

Pinellas County, Florida: Near bridge at Treasure Island fill, St. Petersburg: UF/FSM unnumbered, nine carapacial scutes; R15E, T30S, approximately 35 carapacial scutes; 9th Street South, St. Petersburg, Catalina Gardens: UF/ FSM unnumbered, two scutes.

Indian River County, Winter Beach, Florida: UF/FSM 1677, isolated tooth from young individual, $\mathrm{N}^{4}$.

DeSoto County, Peace River, $1 / 2$ mile north Highway 70, near Arcadia: UF/FSM 19247, carapacial fragment, approximately 25 articulated scutes.

Hendry County, Banana Creek, Caloosatchee River, Florida: USNM 256751, caudal vertebra.

Edisto Beach and Edingsville Beach, Colleton County (formerly Charleston County), South Carolina: ChM-PV 2415, postglenoid cranial fragment; ChM-PV 2417, 2418, 2090, isolated carapacial scutes.

Nueces County, Texas: AMNH 14158, isolated scute, type specimen of Glyplodon petaliferus Cope, 1888.

Wolfe City, Hunt County, Texas: USNM 6071, approximately 80 isolated scutes; two broken cranial fragments with $\mathrm{N}^{2}$ and $\mathrm{N}^{4}$; several isolated teeth; fragments of mandible; cervical tube; fragmentary dorsal tube; pelvic and scapular fragments; six caudal vertebrae; two humeri, fragmentary; two ulnae; radius; femur; patella; tibiofibula; scveral foot bones.

Aransas River near Sinton, San Patricio County, Texas: USNM 11378, 11379, seven scutes; TMM 31141-15, numerous scutes; TMM 31141-19, tibiofibula; TMM 31141-3, -16, -17, -48 , caudal vertebrac.

Ingleside Pit, San Patricio County, Texas: 
TMM 977-3, incomplete carapace and six anterior tail rings; TMM 30967-2088, approximately 50 articulated scutes from posterior region of carapace; TMM 30967-1926, nearly complete pelvis and six caudal vertebrae; TMM 309671814 , left mandible with $\mathrm{N}_{\overline{2}}-\mathrm{N}_{\overline{8}}$.

Bee County, Texas: TMM 31034-30, broken mandible and isolated scutes; TMM 31186-19, isolated tooth.

Hawley, Jones County, Texas: USNM 8644, approximately 15 isolated scutes.

Laubach Cave, Williamson County, Texas: TMM 41343, approximately 80 scutes.

Port Lavaca, Calhoun County, Texas: TMM 41075-14, approximately 25 isolated scutes.

Runnels Pierce Ranch, near Whorton, Matagordo County, Texas: TMM 41530-6, three isolated scutes.

Specimens identified as Glyptotherium sp. cf. $G$. floridanum from Mexico are MWU 2246, four carapacial scutes in articulation and MWU 2247, 2248, isolated carapacial scutes, from Vera Cruz (Dalquest, 1961); and MWU 9732-9740, isolated scutes from the Cedazo local fauna, Aguascalientes (Mooser and Dalquest, 1975). For other records of Mexican glyptodonts, see discussion following the distribution accounts.

Age.-Rancholabrean Land Mammal Age.

Diagnosis.-Size intermediate to large; glenoid fossa with distinct foramen; squamous occipital steeply inclined, with distinct median ridge; occipital condyles cylindrical; hypoglossal canal present, basioccipital-basisphenoid union contiguous, in same plane; foramen magnum inferior margin deeply clefted; ventral extremity petromastoid crested; medial parietal region either elevated or smooth; mental foramen anterior to $\mathrm{N}_{\overline{1}}$; mandibular symphysis rounded and spoutlike; inferior margin of horizontal ramus of mandible flattened; posterior margin ascending ramus of mandible steeply inclined, not parallel to anterior margin; $\mathrm{N}^{\underline{2}}$ trilobate; $\mathrm{N}_{\overline{1}}$ ovoid, peglike, situated behind symphyseal curvature; $\mathrm{N}_{\overline{2}}$ trilobate and submolariform, or bilobate and irregular; $\mathrm{N}_{\overline{3}}$ molariform, posterior lobe convex and perpendicular, anterior lobe not squared; $\mathrm{N}_{\overline{4}}$ fully trilobate, transverse axes of lobes perpendicular, posterior face convex, sulcus on anterointernal face may be present; $\mathrm{N}_{\overline{5}}-\mathrm{N}_{\overline{7}}$ lobes nearly perpendicular; $\mathrm{N}_{\overline{8}}$ anteromedial and anterolateral faces convex, anterior apex blunt, anterior lobe widest, middle and posterior lobes progressively narrower, posterior face weakly concave, slightly oblique; cervical tube formed by vertebrae nos. 2-6; axis articular facet oriented forward and downward; dorsal tube formed by nine thoracic vertebrae, nos. 5-13; propodials and epipodials intermediate in size and in exaggeration of features; humerus lacking supratrochlear foramen; articular facets of manus and pes flattened; eight to nine vertebrae in lumbar tube, three iliosacral vertebrae, three or four free vertebrae in sacral arch; two ischiosacral vertebrae; pubic crossbar small; ischiac crests posteriorly convergent; transverse processes of terminal sacral vertebra perpendicular to midline; anterior face of ilium uniformly concave; carapace large, probably highly arched, divided into distinct preiliac and postiliac regions; carapace with at least some posterior curvature; scutes small in females with marginal sculpturing at suture; scutes large for males, without marginal sculpturing at sutures; central figures of scutes approximately equal in size to peripherals, usually slightly raised and weakly concave; anterior border scutes simple, lateral border scutes conical; posterior border scutes of females with pointed conical bosses; posterior border scutes of males bluntly conical; caudal armor as in $G$. arizonae.

\section{Glyptotherium cylindricum (Brown), new combination}

Brachyostracon cylindricum Brown, 1912:169, figs. 1-4, pls. 1618.

Type Specimen.-AMNH 15548, complete carapace, 20 isolated teeth, atlas, hyoid fragment, rib fragment, chevron, caudal ring fragment.

Type-Localıty.-Near Ameca, Jalisco, Mexico.

Referred Specimens.-Known from type specimen only. 
Age.-Rancholabrean Land Mammal Age.

Diagnosis. - Size large; $\mathrm{N}^{\underline{1}}$ weakly sigmoid; $\mathrm{N}^{\underline{2}}$ irregular, middle lobe internal border undeveloped, anterior lobe pointed at medial apex; $\mathrm{N}^{\underline{5}}$ $\mathrm{N}^{\underline{8}}$ anterior borders rounded, convex; $\mathrm{N}_{2}$ trilobate, submolariform; $\mathrm{N}_{\overline{3}}$ molariform, posterior lobe convex and perpendicular, anterior lobe not squared; $\mathrm{N}_{\overline{5}}-\mathrm{N}_{\overline{7}}$ lobes nearly perpendicular; $\mathrm{N}_{\overline{8}}$ anterolateral and anteromedial faces convex, anterior apex blunt, lobes equally developed, posterior face concave, perpendicular; atlas free, alar processes laterally directed, no struts at anterior opening intervertebral foramina; posterior opening intervertebral foramina near midline; seven to eight vertebrae in lumbar tube; four iliosacral vertebrae; three frec vertebrae in sacral arch; two ischiosacral vertebrae; pubic crossbar stout, united at symphysis; sacral arch compound curve pronounced; ischiac crests parallel; transverse processes of terminal sacral vertebra perpendicular to midline; ilium anterior surface strongly concavoconvex; carapace large, highly arched, divided into distinct preiliac and postiliac regions; carapace with cephalic boss; anterior border scutes weakly bossed, lateral border scutes large, conical; posterior border scutes conical, central figures of scutes slightly greater than half the scute diameter, always slightly larger than peripherals, flat to weakly concave; anterior and posterior apertures vertical in lateral profile.

\section{Glyptotherium mexicanum (Cuatáparo and Ramirez), new combination}

Glyplodon mexicanus Cuatäparo and Ramirez, 1875:362, figs. $1-4$.

Brachyostracon mexicanus (Cuatäparo and Ramirez).-Brown, 1912: 168, pls. 13-15.

Type Specimen._Carapace, skull, sacrum, and isolated teeth (unscen), last known to be houscd in the Mexico National Museum of Natural History; specimen number unknown.

TYPE-Locality.-Drainage canal in the Vallcy of Mexico near Tequixquiac, Mexico.

Referred Specimens.-Known from type specimens only.
AGE.-Rancholabrean, presumably Wisconsin or Sangamon.

Diagnosis. - Carapace large, similar to that of G. cylindricum; anterior teeth trilobate but lobes not expanded.

Status of Glyptotherium mexicanum (Cuatáparo and Ramirez).- The discovery of glyptodonts in North America was reported by two Mexican civil engineers, who believed their specimen pertained to Glyptodon, but represented a distinct species that they named Glyptodon mexicanus (Cuatáparo and Ramirez, 1875). Their description was deficient in several important respects, and Brown (1912) partially amended their description of the carapace. The remaining skeletal parts, reportedly including the skull, mandible, tceth, and sacrum, had already been lost at the time of Brown's study, but Brown did examine the carapace firsthand. Describing carapacial and skeletal remains of another specimen from a different locality as Brachyostracon cylindricus, Brown referred the earlier named species to his genus. He included several photographs of the carapaces of both species. There is no doubt, as Brown asserted, that the two species belong in the same genus, for the carapaces are nearly identical. Brown chose to retain $B$. mexicanus as a valid species, claiming that it differs from $B$. cylindricus in dental and carapacial features. Brachyostracon Brown, 1912, is a junior synonym of Glyptotherium Osborn, 1903. Thus the two Mexican species are Glyptotherium cylindricum (Brown) and G. mexicanum (Cuatáparo and Ramirez). That the former is specifically distinct from the other North American species is well established. Whether $G$. mexicanum is valid, however, is uncertain.

Apparently the type specimen of $G$. mexicanum, including the carapace, has been lost. If the species is valid, as assumed here, it will be necessary for future workers to designate a neotype, provid: ing the type specimens are not located. By our retention of the species it is hoped that future workers will recognize the type specimens if, and when, they should be found. Sinking the species in synonymy, or as a nomen dubium, would likely 
result in its being forgotten. The following discussion outlines the reasoning for its retention.

First, it is inconceivable that the original description of the species is entirely inaccurate. The singular appearance of a glyptodont carapace and skeleton is so unique as to preclude total conjecture, especially by nonpaleontologists at a time (a century ago) when glyptodonts were unknown in North America, and when comparative material was unavailable. Misrepresentation of the skeleton and carapace is understandable, and their inaccuracies are insufficient justification for reducing the status of $G$. mexicanum to nomen dubium. Indeed, their description of the carapace, except for illustrating it in reverse end-toend orientation, seems accurate. Even their measurements for the carapace, borne out by Brown, are reasonable and they correspond closely to the carapace of $G$. cylindricum.

Because at least the description of the carapace was accurate, the remaining portion of their description should also be considered as basically correct even though it may be erroneous in detail or interpretation.

Part of the dubious status of $G$. mexicanum centers around the description of its skull. As Brown (1912) pointed out, the measurements given by Cuatáparo and Ramirez are remarkable, indicating an extremely prolonged skull. Brown compared the shape of the skull as figured in the original description with that of the armadillo genus Eutaetus. This is certainly an appropriate comparison, although comparison with the skull of a chlamythere would have been even more appropriate. It now seems probable that Cuatáparo and Ramirez described a composite of a glyptodont skull, properly belonging with the carapace, and a chlamythere skull, from the same deposit, which may account for much of the confusion regarding this species.

Pointing toward the inclusion of portions of a chlamythere skull are the drawing, several measurements, and part of the description. Comparison of the drawing in restoration (Cuatáparo and Ramirez, 1875, fig. 1) with the illustrations provided by James (1957) for a chlamythere skull reveals a close similarity-especially James' figure 2 is remarkably similar. Even the casque scutes that James illustrated show a close resemblance. The possibility of the presence of a chlamythere skull among the original material of $G$. mexicanum is also indicated by certain measurements, among which the $174 \mathrm{~mm}$ length of the tooth row, listed by the original authors, corresponds closely to the $170 \mathrm{~mm}$ length that James (1957) reported. These figures are approximately equal to the tooth row length of Glyptotherium texanum; they are greater than $G$. floridanum and less than $G$. arizonae (Tables 3-6).

Moreover, the construction of the descending process of the zygomatic arch figured by Cuatáparo and Ramirez for $G$. mexicanum does not correspond with that of any other known glyptodont. As figured, the zygomatic arch of $G$. mexicanum is posteriorly open, rather than complete as in other glyptodonts. The doubly curved descending process in the figured skull bears a scalloped posterior outline, and its basal connection with the horizontal ramus is weak. This shape and construction closely resemble the upper surface of the zygomatic arch in chlamytheres (see James, 1957, fig. 2 for comparison). Hence, there is a distinct possibility that the zygomatic arch of a chlamythere skull (unknown to Cuatáparo and Ramirez) was taken as the descending process of a glyptodont skull.

The evidence outlined above supports the possibility that a chlamythere skull was associated with the glyptodont carapace and was erroneously figured as pertaining to $G$. mexicanum by the original authors. On the other hand, the facts that they list only eight teeth per tooth row (rather than nine, as in chlamytheres), and that they figured and described what are obviously glyptodont, rather than chlamythere, teeth indicate that there was indeed a glyptodont skull or skull fragments in the same collection. Indeed, it is possible that portions of the chlamythere and glyptodont skulls were inadvertently mixed in the restoration, and the original authors, unaware of chlamytheres but knowing of glyptodonts, be- 
lieved that all of these remains belonged to one species.

From another standpoint, the possibility of a chlamythere-glyptodont mixture is indicated by Silva-Barcenas' (1969) listing of the chlamythere Holmesina in the Tequixquiac faunas, at least provisionally demonstrating that such $^{-}$an admixture is possible.

If the skull that the original authors described for $G$. mexicanum actually pertains to a chlamythere, then most of the mystery surrounding the species is removed. The remaining descriptions, concerning the dentition, sacrum, and carapace are reasonable, and the anterior tooth, which Cuatáparo and Ramirez (1875) illustrated in their figure 3 , serves provisionally to distinguish the species. The carapace certainly indicates $G l y p$ totherium. The validity of retention of a species on the basis of an anterior tooth is questionable, but the one figured in the original description is so distinctive as to warrant at least provisional acceptance of the species. The two teeth figured in the original description are more fully discussed in the osteology section following the dentition descriptions.

Finally, there is some indication that the ages of the two Mexican species are different. As indicated in the taxonomies of $G$. mexicanum and $G$. cylindricum, the latter species apparently is of Late Pleistocene age, and the former is somewhat older, perhaps Early Rancholabrean if Silva-Barcenas' determinations are correct, and if the typelocalities are correctly identified.

Therefore, accepting the authenticity of the carapace and dentition of $G$. mexicanum as described by Cuatáparo and Ramirez (1875) and improved upon by Brown (1912), it seems inadvisable to reject the species. Thus, it is here retained on a provisional basis, with the hope that either rediscovery of the original material or future discoveries will resolve the problem.

\section{Distribution}

The geologic and geographic distribution of the five species of Glyptotherium fall into a consist- ent pattern, a circumstance that adds considerable support to the proposed classification. Glyptotherium mexicanum and $G$. cylindricum are known with certainty only from a single locality each, both in central Mexico. On the basis of meager evidence, $G$. cylindricum seems to be of Early Rancholabrean Age, and G. mexicanum of Late Rancholabrean Age. Glyptotherium cylindricum was recovered from near the western coast of Mexico. To the best of our knowledge, however, glyptodonts in the United States are unknown west of central Arizona.

Glyptotherium texanum appears to be restricted to the Late Blancan Land Mammal Age, and is known only from southwestern United States including Texas and Arizona (Figure 2). Glyptotherium arizonae is mostly Irvingtonian in age, and for the most part its geographic distribution is contiguous with that of $G$. texanum, although the tentative records of $G$ lyptotherium sp., cf. G. arizonae from Florida (late Blancan and early Irvingtonian) suggest an eastern distribution as well (Figure 3).

Glyptotherium floridanum is known from a relatively large number of localities mostly in Texas and Florida, on the Atlantic and Gulf Coastal Plains (Figure 4); all are late Pleistocene (Rancholabrean) in age.

Glyptotherium texanum (Figure 2).-The faunas containing $G$. texanum from the Blanco and Cita Canyon localities in Texas have been extensively studied. Evans and Meade (1945), Meade (1945), Johnston and Savage (1955), and Dalquest (1975) have provided comprehensive treatment of these faunas, which represent the classic Blancan Land Mammal Age.

The Hudspeth local fauna (Strain, 1966) and the Red Light local fauna, both in western Texas, are correlatives (Akersten, 1972), and include representative Blancan vertebrates, among which several apparently are restricted to the Blancan. According to the usage adopted by Akersten (1972), these two faunas represent the Early Pleistocenc portion of the Blancan Land Mammal Age.

The Tusker local fauna has not been as exten- 


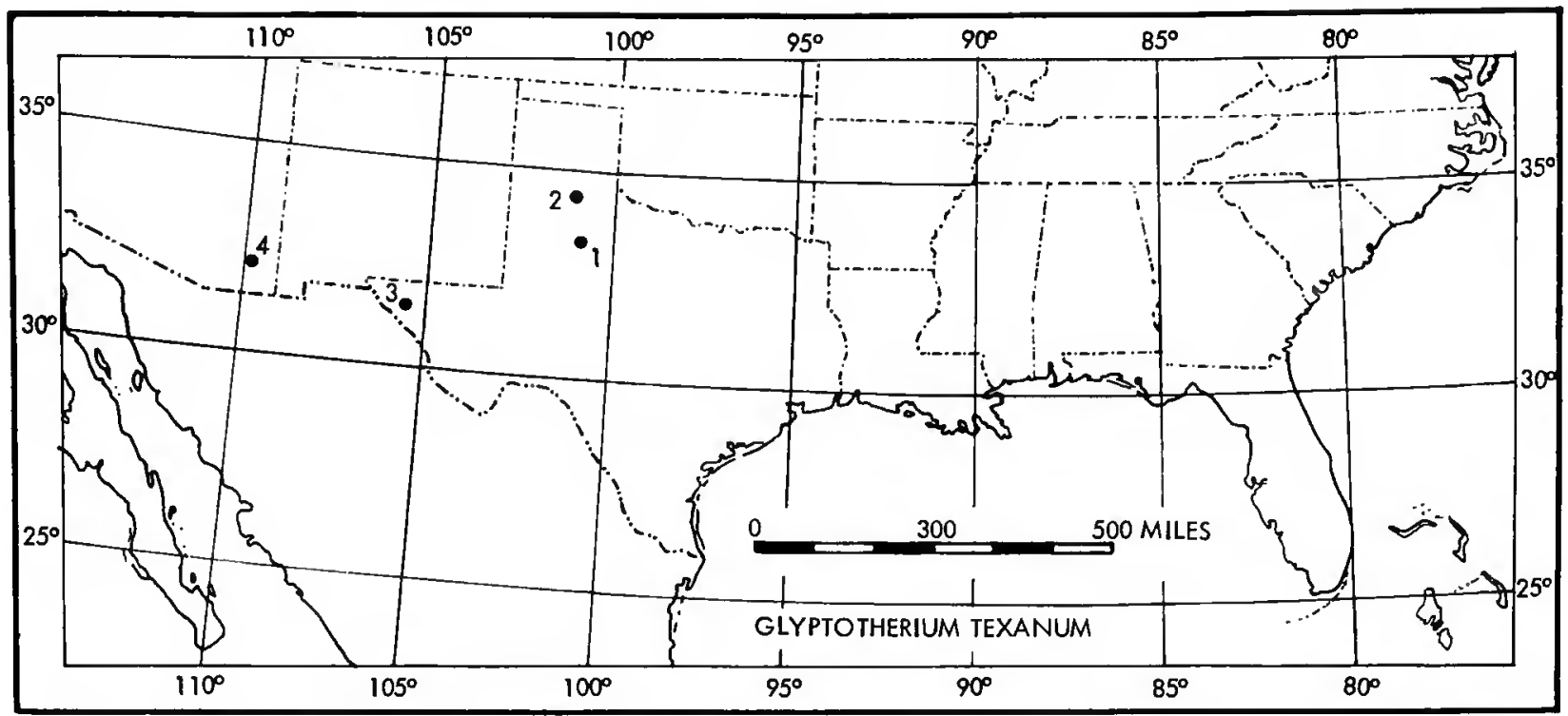

Figure 2.-Occurrences by locality of Glyptotherium texanum. ( 1 = Crosby County, Texas, Blanco Canyon and Crawfish Draw; $2=$ Randall County, Texas, Cita Canyon locality; $3=$ Hudspeth County, Texas, Red Light local fauna and Hudspeth local fauna; 4 = Graham County, Arizona, Tusker local fauna.)

sively studied as the previously mentioned faunas. (This name is applied in the broad sense to include the vertebrate recoveries from a wide geographic area in southeastern Arizona; there have been no fully comprehensive studies of the Tusker faunal horizon localities; glyptodonts support a basic contemporaneity of these localities.) In an unpublished dissertation, however, Wood (1962, Ms.) established an Irvingtonian age on the basis of an extensive fauna that included a glyptodont of undetermined identity. Lance (1960) and Seff (1962, Ms.) have also considered the fauna as Irvingtonian. More recently Downey (1970) agreed with a Middle Pleistocene age determination (presumably Irvingtonian) for the rabbits of the Tusker fauna. Skinner (1942) and Cantwell (1969) have described an antilocaprine and sigmodontid rodents, respectively, from the Tusker fauna, but their data are inconclusive for stratigraphic consideration.

More recently, Lindsay and Tessman (1974) have listed the Tusker fauna as belonging in the Early Blancan Land Mammal Age, by their usage, late Pliocene. The nearby Benson fauna is also listed by these authors as Early Blancan, and may be considered roughly equivalent. The Benson fauna falls well within the Gauss magnetic polarity epoch (greater than $2.43 \mathrm{m.y} . \mathrm{BP}$ ), and has been dated at approximately 3.00 m.y. BP (Lindsay, et al, 1975). According to the occurrence of $G$. texanum in the Arizona Blancan, glyptodonts first appeared in the Tusker fauna, sometime before the end of the Gauss magnetic polar ity epoch (2.43 m.y. BP). The absence of glyptodonts in the Benson fauna might indicate that the Tusker fauna is slightly younger (e.g., between 3.0 and 2.43 m.y. BP); of course sampling error and ecological differences might also account for the lack of Glyptotherium in the Benson fauna.

Lindsay (pers. comm. to Gillette) has expressed doubt that the Tusker fauna is Irvingtonian, for several other reasons. First, there appears not to be as great a faunal separation between the underlying Flat Tire faunal level, which is well established as Blancan, and the Tusker faunal level as has been proposed. Second, an ash that 
occurs between the Tusker and Flat Tire faunal levels has been $\mathrm{K} / \mathrm{Ar}$ dated at $3.2 \times 10^{6}$, well within the Blancan, (Wood, et al., 1941; Evernden, et al., 1964), and placing a lower absolute date on the Tusker fauna. Third, the younger Curtis Ranch fauna (containing Glyptotherium arizonae) is approximately at the base of the Olduvai geomagnetic event of the younger Matayuma magnetic polarity epoch, which Lindsay considers as latest Blancan.

That the glyptodonts in the Tusker fauna are G. texanum is positively indicated by an excellent collection from the Frick Laboratory, American Museum of Natural History, which was made available for the present study. These specimens, including three carapaces and a nearly complete skeleton, were recovered from several localities near Safford, Arizona, by Mr. Ted Galusha. These localities are centered around Dry Mountain, Southern Whitlock Mountains, and Northern Whitlock Mountains, Graham County, Arizona, including the 111 Ranch area from which most of the published Tusker faunal elements were recovered. Whether the horizons that have yielded $G$. texanum are directly correlative with the Tusker faunal horizon (sensu stricto) has not been conclusively established. According to Galusha (pers. comm. to Gillette) the localities from which he recovered the glyptodonts are at least roughly equivalent stratigraphically, and, according to his determination, a Late Blancan age is the most reasonable for the associated (unstudied) faunas.

The type-locality for Glyptotherium texanum is somewhere in the "Blanco Beds" of western Texas, presumably at or near the Mt. Blanco section, which is the type-locality for the Blancan Land Mammal Age. Glyptotherium texanum also occurs in abundance in the ncarby Cita Canyon fauna. The fossils from Mt. Blanco arc younger than those from Cita Canyon. According to Lindsay, et al. (1975) the Cita Canyon fauna is equivalent to the Benson fauna of Arizona (and hence to the Tusker fauna), and corrclates with the Gauss magnetic polarity epoch. The same authors correlate the Mt. Blanco faunas with the lower Matayuma epoch, prior to the Olduvai event.
Therefore, the $G$. lexanum representatives from western Texas represent Middle and Late Blancan faunas.

According to Lindsay, et al. (1975), the Mt. Blanco type section has been dated as between 1.4 and 2.4 m.y. BP by volcanic ash correlation. Hence, the early Plcistocene Blanco fauna of Texas is younger than the Tusker fauna of Arizona, although the difference in age might be no more than 100,000 years. We believe that the Mt. Blanco glyptodonts are somewhat more primitive. Despite the disagreement with the stratigraphic interpretation indicating that the $\mathrm{Mt}$. Blanco fossils are younger, it is nevertheless tenable that the Mt. Blanco glyptodonts exhibit more of the primitive, or ancestral, traits of the species, while the Tusker glyptodonts, although occurring somewhat earlier, revcal more of the advanced traits of the species. It is also possible that sampling error might account for differences between the two populations, or even that reinterpretation is in order.

Lance (1960) regarded the Tusker and Curtis Ranch faunas as roughly equivalent. The latter fauna, containing the descendant species $G$, arizonae, appears on the basis of the glyptodonts, and according to the stratigraphic relationships presented by Lindsay and Tessman (1974) and Lindsay, et al. (1975), to be younger than the Tusker fauna.

Glyptotherium arizonae (Figure 3).-Extensively known from two localities, and poorly known from scveral others, the western geographic distribution of $G$. arizonae overlaps that of $G$. texamum; the spccies is tentatively identified in Florida as well. The occurrence of $G$. arizonae appcars to have followed closcly that of $G$. lexamum; these two specics occur much closer stratigraphically to. cach other than cither does to the remaining North Amcrican specics. Glyptotherium arizonae docs not appcar to have existed contemporancously with $G$. lexanum in any of the known local faunas, although they arc closely related and represent ancestral-descendant species.

The earlicst rccords of $G$. arizonae are the tentative identifications of isolated carapacial scutes 


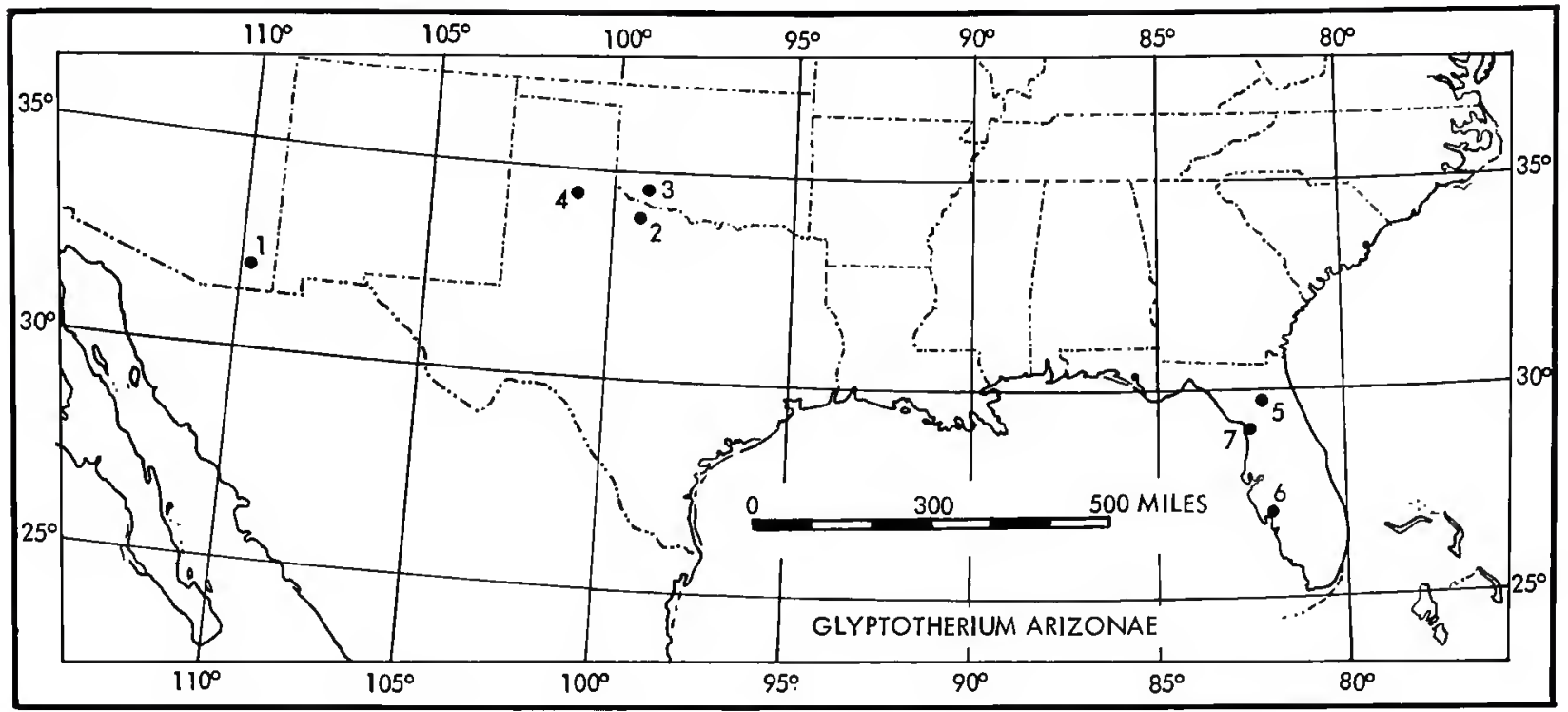

FigURE 3.-Occurrences by locality of Glyplotherium arizonae (localities 1-4) and Glyptotherium sp., cf. G. arizonae (localities 5-7). ( $1=$ Cochise County, Arizona, Curtis Ranch; $2=$ Knox County, Texas, Seymour Formation, Gilliland local fauna; 3 = Tillman County, Oklahoma, Holloman Gravel Pit near Frederick; 4 = Briscoe County, Texas, Rock Creek local fauna; $5=$ Gilchrist County, Florida, Santa Fe River, UF localities SF1, SF4A, SF8A; 6 = Charlotte County, Florida, Reynolds Point; 7 = Citrus County, Florida, UF locality, Inglis 1A.)

and a tooth fragment from localities in the Santa Fe River, Gilchrist County, and Charlotte Harbor, Charlotte County, Florida. The vertebrate faunas from these localities pertain to the Blancan Land Mammal Age, as indicated by the presence of Nanippus phlegon (MacFadden and Waldrop, 1980). Glyptotherium sp., cf. $G$. arizonae is also known from isolated scutes in the fauna from Inglis 1A, Citrus County, Florida. The Inglis 1A fauna is considered earliest Irvingtonian (Webb, 1974 and pers. comm.).

These isolated scutes are problematical for their age and large size; they are all provisionally referred to $G$. arizonae on the basis of sculpturing (eliminating $G$. floridanum and $G$. cylindricum) and size (eliminating $G$. texanum). Presuming the identification of these scutes to be correct, the Santa $\mathrm{Fe}$ and Charlotte Harbor glyptodonts are the earliest occurrence for the species, representing a population roughly contemporaneous with the postulated ancestral species, $G$. texanum.

The other localities that have yielded extensive series of $G$. arizonae remains are far to the west of the Florida sites, in Arizona, Oklahoma, and Texas. The vertebrate fauna from the type-locality of $G$. arizonae (Curtis Ranch locality, Cochise County, Arizona) was preliminarily studied by Gidley (1922, 1926), who did not establish firmly the age of the Curtis Ranch fauna. He believed the Curtis Ranch horizon to be late Pliocene in age, although he did not rule out an early Pleistocene determination. Gidley considered the fauna from the nearby Benson locality (lacking glyptodonts) as somewhat older than that from the Blanco Formation in Texas (classic Blancan, and containing $G$. texanum) and the fauna from the Curtis Ranch locality as somewhat younger (containing $G$. arizonae), although this belief was "not based on very tangible or direct evidence" (Gidley, 1926:83). Gazin (1942) elaborated in an expanded review of the San Pedro Valley faunas but did not substantially alter or improve upon Gidley's contentions. Lance (1960:157) considered the Curtis Ranch fauna to be Middle Pleis- 
tocene, "either late Kansan or early Yarmouthian in terms of the North American glacial chronology." He also considered the Curtis Ranch fauna and the Tusker fauna (containing $G$. texanum) as contemporaneous. As previously discussed, the Tusker fauna is Late Blancan, equivalent to the Benson fauna. The Curtis Ranch fauna according to Lindsay and Tessman (1974) and Lindsay, et al. (1975) belongs in the early Irvingtonian Land Mammal Age, representing the early Matuyama magnetic polarity epoch, and occurring during the Olduvai geomagnetic event (1.86-1.71 m.y. BP). Lammers (1970, abs.) also regarded the fauna as Early Irvingtonian on the basis of biostratigraphic evidence. The work of Lindsay and his collaborators has placed the Curtis Ranch faunas in an absolute chronology, which supports the general concensus of an Early Irvingtonian age; that determination is in turn supported by the glyptodonts, which are indeed younger than those of the faunas equivalent to the Benson. The Curtis Ranch glyptodonts ( $G$. arizonae) are descendant, and advanced, in comparison with their ancestors ( $G$. texanum) in the older faunas.

The glyptodonts recovered from the Seymour formation and belonging in the Gilliland local fauna are proposed here to represent the same species as the Curtis Ranch glyptodonts, $G$. arizonae. The Gilliland local fauna from Knox County, north-central Texas, has classically been considered as belonging in the Kansan glacial age, and because the vertebrates represent a "warm" assemblage, the fauna has been assigned to an interstadial of the Kansan glaciation ( $\mathrm{Hib}$ bard and Dalquest, 1966). This assignment has more recently been altered, however, by the same authors, who stated that the sediments in which the Gilliland local fauna occurs "were laid down prior to the Kansan glaciation .... The warm Gilliland local fauna is post-Blancan and preCudahy fauna in age" (Hibbard and Dalquest, 1973:270, 273). The Gilliland fauna belongs in the Irvingtonian Land Mammal Age, probably earliest Irvingtonian, and perhaps directly cquivalent to the Curtis Ranch fauna. These two faunas have provided the most extensive collec- tion of $G$. arizonae remains, and their near contemporaneity supports the contention that the glyptodonts are the same species.

Hibbard and Dalquest (1966) and Dalquest (1977) regarded the Holloman local fauna (near Frederick, Tillman County, Oklahoma) and the Rock Creek local fauna (Briscoe County, Texas) as contemporaneous with the Gilliland local fauna; both faunas include glyptodonts. It was the glyptodonts from the Holloman locality on which Meade (1953) based the genus Xenoglyptodon. Melton (1964) later correctly assigned the Holloman and Gilliland (Seymour) glyptodonts to the same species. Morphological and stratigraphic evidence indicates that the material identified by Melton as Glyptodon fredericensis (Meade) actually belongs in Glyptotherium arizonae.

The glyptodont remains that Hay (1927) reported for the Rock Creek (Briscoe County, Texas) local fauna (unseen, probably scutes) are probably G. arizonae. This local fauna is correlative with the Gilliland and Holloman local faunas (Hibbard and Dalquest, 1966). Because of this contemporaneity and the proximity of these three localities, it is reasonable to assume that the Rock Creek glyptodonts represent the same species as the better known ones from the other two faunas.

Glyptotherium cylindricum (Figure 4, locality 25).-According to Brown (1912) the type specimen of G. cylindricum was recovered from a richly fossiliferous deposit near the town of Ameca, Jalisco, Mexico.

The Ameca River valley at this point is enclosed by moderately high mountains at the base of which, on either side of the river. Post Tertiary sedinents are exposed in terraces to a height of two hundrcd feet.

The cscarpments, of limited extent, are composed chiefly of volcanic ash, rhyolitic debris and gravel with an admixture of diatomaceous clay having the appearance of a river sediment. Apprarently the outlet of the valley was obstructed during Pleistocene times when a shallow lake was formed over a considerable part of the valley.

Fresh water shells, fish teeth and bones, and turile shells were found in situ in the highest clay strata but vertebrate remains werc chicfly found in the gravels. Many of these remains are identifiable only as to families (Brown, 1912: 167). 


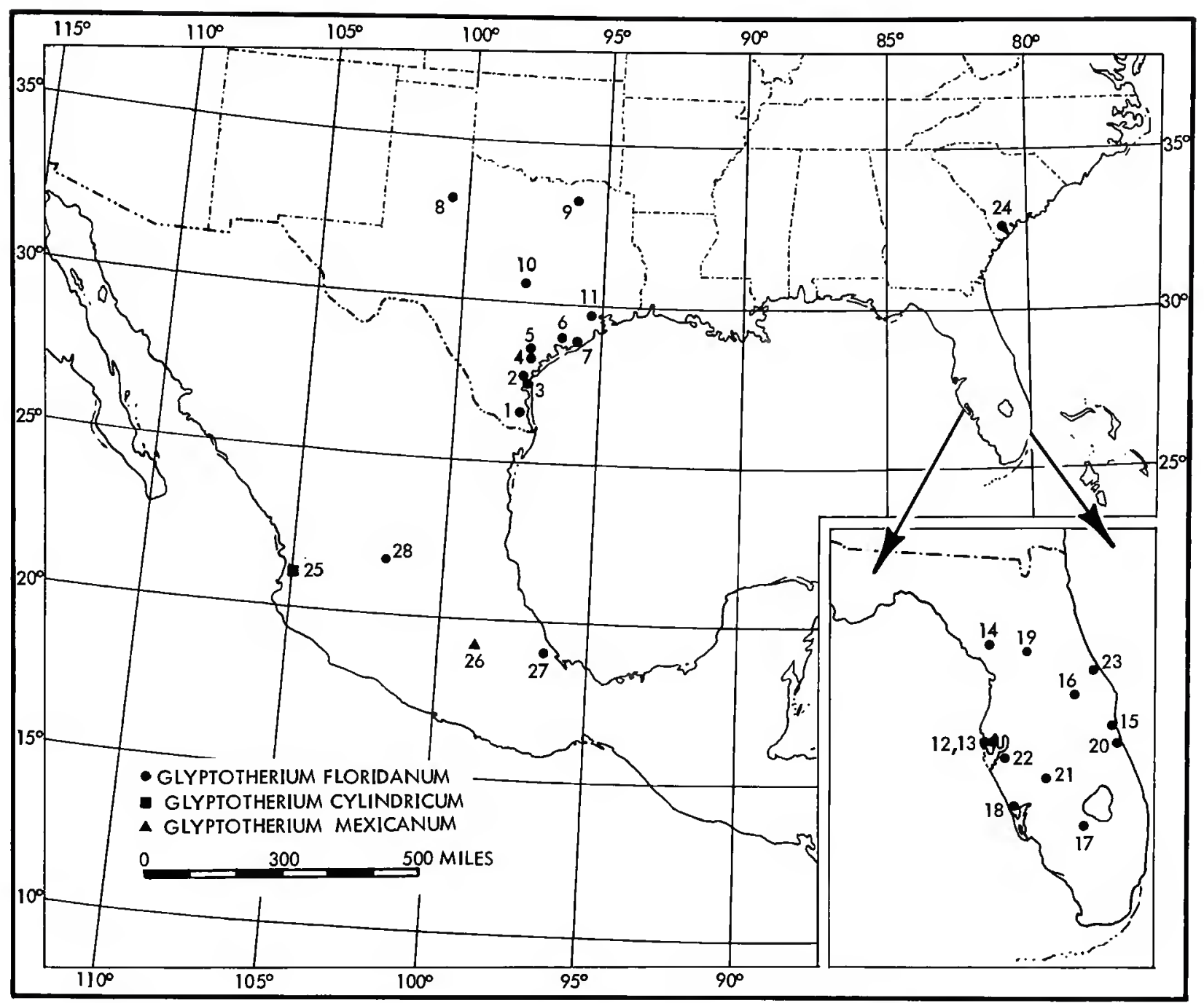

FigURE 4.-Occurrences by locality of Glyptotherium floridanum, G. cylindricum, and G. mexicanum. (G. floridanum, Texas: 1 = Cameron County; 2 = Nueces County, exact locality uncertain; $3=$ San Patricio County, Ingleside local fauna; $4=$ San Patricio County, Sinton near Arkansas River; 5 = Bee County, Berclair Terrace local fauna; $6=$ Calhoun County, Port Lavaca "Eremotherium locality"; 7 = Matagorda County, Pierce Ranch locality; $8=$ Jones County, near Hawley; $9=$ Hunt County near Wolfe City; $10=$ Williamson County, Laubach Cave; $11=$ Harris County, Taylor Bayou local fauna. G. floridanum, Florida: $12=$ Pinellas County, Seminole Field locality; 13 = Pinellas County, Catalina Gardens and other localities; $14=$ Levy County, Waccasassa River; $15=$ Brevard County, Melbourne locality; $16=$ Orange County, exact locality uncertain; $17=$ Hendry County, Caloosahatchee River, Banana Creek; 18 = Sarasota County, several localities; $19=$ Marion County, Mefford Cave II; $20=$ Indian River County, Winter Beach; 21 = DeSoto County, Peace River near Arcadia; $22=$ Manatee County, Piney Point; 23 = Volusia County, Tomoka Park. G. floridanum, South Carolina: 24 $=$ Colleton County (formerly Charleston County), Edisto Beach and Edingsville Beach. $G$. cylindricum: 25 = near Ameca, Jalisco, Mexico. G. mexicanum: 26 = near Tequixquiac, Valley of Mexico. Glyptotherium sp. cf. G. floridanum: $27=$ Vera Cruz, Mexico; $28=$ Aguascalientes, Mexico. For locality information concerning unsubstantiated records of glyptodonts in Mexico, see Alvarez, 1965, and Silva-Barcenas, 1969.) 
Mammals included in Brown's preliminary faunal list are: Sciuridae, Geomyidae, Cricetidae, machaerodont, Equus sp., Elephas columbi, and the glyptodont that he described as Brachyostracon cylindricus (= Glyptotherium cylindricum). The only useful record for stratigraphic purposes is the mammoth, indicating an Irvingtonian or Rancholabrean age.

Silva-Barcenas (1969) listed the following mammals from the same stratigraphic level (Gran Canal) from three other nearby localities in Jalisco: Bison sp.; Camelops sp.; Cervus intertuberculatus; Elephas sp.; Equus sp., cf. E. conversidens; Equus mexicanus; Equus sp., cf. E. mexicanus; Equus sp.; Felis sp.; Holmesina sp.; Mammuthus columbi; Neochoerus sp.; Platygonus sp.; Tetrameryx sp.; and Ursus sp. The presence of Bison sp. indicates a Rancholabrean age. The close similarity of Glyptotherium cylindricum to the Late Pleistocene glyptodonts to the north supports a Rancholabrean age determination for $G$. cylindricum. Silva-Barcenas considered the Gran Canal as pertaining to the Illinoian-Yarmouthian intervals in the glacial chronology. If this determination is correct, then $G$. cylindricum predates the occurrences of $G$. floridanum in Texas and Florida.

Silva-Barcenas also listed several other Mexican localities from which glyptodonts are known. Recognizing several taxa, the only recovery listed as Brachyostracon cylindricus (= Glyptotherium cylindricum) was from the Ameca site, presumably in reference to Brown's (1912) report, although it is not included in the bibliography.

Glyptotherium mexicanum (Figure 4, locality 26).Neither Cuatáparo and Ramirez (1875) nor Brown (1912) provided definite locality information for the occurrence of $G$. mexicanum beyond stating that the specimen was recovered in the Valley of Mexico near Tequixquiac. Neither listed an associated fauna.

Silva-Barcenas (1969) listed several Tequixquiac localities, all of which fall within the Becerra stratigraphic level of Late Pleistocene age. Included in his faunal list in the vicinity of Tequixquiac are Brachyostracon mexicanus (= Glyplotherium mexicanum) from Barranca de Acatlán,
Glyptodon clavipes from Tajo del Desague, and Glyplodon sp. He also listed Glyptodon mexicanus, which Brown (1912) called Brachyostracon mexicanus (= Glyptotherium mexicanum), from the nearby Zumpango de Ocampo locality. It is uncertain which of these listings, if any, refer to the occurrence of the type specimen. According to SilvaBarcenas, all are Late Pleistocene in age. Therefore, a Rancholabrean age seems reasonable for G. mexicanum.

Glyptotherium floridanum (Figure 4, localities 124). - As far as can be determined, all known glyptodonts referable to $G$. floridanum are of Late Pleistocene age, although the time spanned may be as much as 100,000 years or more. Many of the localities that have yielded $G$. floridanum are poorly known both faunally and stratigraphically, but enough is known from the Florida and Texas localities in general to establish a relatively late age for most of the $G$. floridanum records, dating from the early Wisconsin glacial age and therefore representing the late Rancholabrean Land Mammal Age.

Two peculiarities of the geographic distribution of $G$. floridanum are significant: the apparent separation between Florida and Texas, and the near-coastal distribution. The latter characteristic is probably a manifestation of the habitat requirements of glyptodonts, indicating the warm climate and lush vegetation necessary for their existence. The three inland recoveries in Texas (Wolfe City, Hunt County; Laubach Cave, Williamson County; and Jones County) are problematical. They probably indicate the existence of riparian corridors toward the inland areas from the coast, apparently an unconımon situation as indicatcd by the otherwise restriction to nearcoastal areas for this species.

The apparent geographic separation between the Florida (and South Carolina) population and the Tcxas population of $G$. floridanum is probably an artifact of sampling. If Pleistocene faunas were as extensively known along the intervening Gulf Coast (Louisiana, Mississippi, Alabama) as in Texas and Florida, G. floridanum would surely be represented. There are no apparent geographic 
dispersal barriers along the Gulf Coast between Florida and Texas, and there is no substantial reason to postulate one in the past.

Faunal lists for several of the more extensive faunas in Florida were compiled by Simpson (1929a, 1929b) for the Seminole Field, Melbourne, Sarasota, and Peace Creek localities. Gazin (1950) and Ray (1958) elaborated on the Melbourne faunal list, and other authors have provided more limited contributions. Weigel (1962) regarded the extinct fauna from the Vero Beach locality farther south as having lived during the Wisconsin glacial age (from greater than $30,000 \mathrm{BP}$ to $8200 \pm 120 \mathrm{BP}$ ). The Vero Beach fauna (lacking glyptodonts) was considered by Weigel as a correlative of the Melbourne and Seminole Field localities, both of which contain G. floridantw. All of the taxa listed by Simpson (1929a) for the locality at the mouth of Hog Creek at Sarasota, Sarasota County, are present at the Melbourne locality (Simpson, 1929a; Ray, 1958), and a similar statement can be made for the Peace Creek locality, DeSoto County. Thus these four localities in Florida, which have yielded a large share of $G$. floridanum known in that state (Seminole Field, Sarasota, Melbourne, Peace Creek), contain essentially contemporaneous middle to late Wisconsin faunas (Webb, 1974).

No associated fauna has been reported from the Catalina Gardens locality, Pinellas County, which provided the excellent and important $G$. floridanum fossils, described herein for the first time. Because of the close proximity of this locality to the Seminole Field (type) locality, and the certain identification of the glyptodont as $G$. floridanum, this record is here considered to be contemporary with the above-mentioned faunas. Faunas from other Florida localities that have yielded $G$. floridanum are generally poorly known. For example, the locality for USNM 11318, an excellent mandible with most of the teeth (assigned to $G$. floridanum), is known only to be somewhere in Orange County, Florida. Because this specimen is $G$. floridanum, its age is assumed to be equivalent to that for the other faunas, i.e., middle to late Wisconsin.
The beach recoveries of $G$. floridanum from Edisto Island, Colleton County (formerly Charleston County), South Carolina, are the northernmost record for the species. Roth and Laerm (1980) have assembled a preliminary faunal study of the Quaternary reptiles and mammals from the island; chlamythere, Dasypus bellus, Neochoerus pinckneyi, Canis dirus, and Mammuthus sp. are among those mammals consistent with a late Pleistocene age. The glyptodont remains support this age assignment.

In Texas the representatives of $G$. floridanum all appear to be from sediments of Wisconsin glacial age. The fauna from the Ingleside locality, San Patricio County, has been comprehensively reviewed by Lundelius (1972). This locality has yielded the most extensive representation of $G$. floridanum in Texas. According to Lundelius, the Ingleside fauna is best considered as post-Sangamon in age, probably early Wisconsin. He has also indicated (pers. comm.) that an approximate absolute age of $80,000 \mathrm{BP}$ is reasonable, which may indicate that the Ingleside recoveries represent the earliest known occurrence of $G$. floridanum in the United States. Correlation of the Ingleside fauna with the Florida faunas is rendered difficult by the absence of adequate stratigraphic documentation in Florida. Whereas Lundelius (1972: 6) stated that a late Wisconsin age is unlikely for the Ingleside fauna, correlation of the several glyptodont-bearing Florida localities with the Vero Beach locality as reported by Weigel (1962) indicates that $G$. floridanum is likely to have been present in latest Wisconsin time. Further statements regarding the Ingleside correlation with the Florida records of $G$. floridanum must await future investigations. For purposes of this study, the Ingleside fauna is believed to predate, at least partially, the Florida records of $G$. floridanum. That this chronology is correct is suggested by a greater expression of the postulated sexual dimorphism in the Florida representatives, here taken to indicate the culmination of a trend only suggested in the Texas population. Of course this statement rests only on a postulated development, which should not be considered as positively established, 
and is here offered only in the absence of contradictory information. It is not absolute proof of an earlier date for the Ingleside fossils.

Hay (1926) provided a faunal list for the nearby Sinton locality, also in San Patricio County. None of the faunal elements is contradictory to a close correlation with the Ingleside fauna. The Berclair Terrace local fauna, Bee County, Texas, also not far from the Ingleside fauna, was considered by Lundelius (1972) to be probable Wisconsin age. The glyptodonts recovered from these three localities (Ingleside, Sinton, and Bee County) represent the same species, further supporting approximate contemporaneity. No positive statement can be made for the age of the Nueces County Record of $G$. floridanum (Cope, 1888).

The specimen of $G$. floridanum from Cameron County in southern Texas is the southernmost record of the species in the United States. The tentative identifications as Glyptotherium sp., cf. $G$. floridanum for scutes from Vera Cruz and Aguascalientes would be the southernmost records for the species in North America; these were reported by Dalquest (1961) and Mooser and Dalquest (1975) as Brachyostracon mexicanus and Brachyostracon cf. mexicanus, respectively. Mooser and Dalquest (1975) regarded the Aguascalientes fossils from the Cedazo local fauna as Illinoian. We base identification of the glyptodonts as cf. $G$. floridanum in this fauna on scute pattern, scute size, and the presence of large and small adults (male and female) corresponding to the sexual dimorphism postulated for the species in Florida. Because the dimorphism for the Aguascalientes glyptodonts is pronounced, an Illinoian age is inconsistent with our observed increase in the expression of dimorphism from moderate in early Wisconsin to very pronounced in late Wisconsin. An Illinoian age for the fauna would be the earliest occurrence for $G$. floridanum, if our identification is correct, and would necessitate revision of our hypothesis concerning the trend toward increasing sexual dimorphism in the species. Alternatively, the fauna might be younger; the original authors could not positively rule out a
Sangamon age. By our determination the age would be even younger, perhaps middle Wisconsin.

Kaspar and McClure (1976) reported a single scute of Boreostracon sp. in the Taylor Bayou local fauna, Harris County of southeastern Texas. This is the easternmost record of glyptodonts in Texas. The only species assigned to Boreostracon for North American glyptodonts is $B$. floridanus, which we have found invariably to belong to Glyptotherium floridanum, according to our emended diagnosis. The authors regarded the fauna as equivalent to that of Ingleside farther south, which contains abundant $G$. floridanum.

The Port Lavaca, Calhoun County, specimen of $G$. floridanum was associated with an excellent skeleton of Eremotherium, and the site has been radiocarbon dated at roughly $23,000 \mathrm{BP}$ and $28,000 \mathrm{BP}$, both with rather large statist ical errors of approximately 3000 years (Lundelius, pers. comm.). These dates are substantially younger than the assumed age for the Ingleside fauna, and represent a middle Wisconsin age. The Laubach Cave, Williamson County, record is also probably middle to late Wisconsin in age. This recovery, the Jones County, and the Hunt County' records are the only known inland occurrences of $G$. floridanum. The age of the glyptodont from the latter locality is unknown but is presumably also Wisconsin. Other records of $G$. floridanum in Texas are probably also Wisconsin in age.

Therefore, $G$. floridanum inhabited the Texas Gulf Coastal Plain from early to middle Wisconsin time, while circumstantial evidence in Florida indicates the presence of this species at least from middle Wisconsin through late Wisconsin time.

Glyptodonts in Mexico and Central AmerICA.-Besides the type specimens of Glyptotherium cylindricum and $G$. mexicanum, and the specimens tentatively referred to G. floridanum from Vera Cruz and Aguascalientes above, there are several additional records of glyptodonts in Mexico. Hibbard (1955) reported and illustrated scveral scutes from the late Pleistocene Upper Becerra formation from the Valley of Tequixquiac. These he identified as Brachyostracon mexicanus, but he stated 
that scutes from at least one locality more closely resemble those of Boreosiracon floridanus. For the purposes of this study we consider these specimens (unseen by us) tentatively as Glyptotherium sp. indet.

Alvarez (1965) provided synonomies and locality records for Brachyostracon cylindricus (= G. cylindricum), Brachyostracon mexicanus (= G. mexicanum), and Glyptodon sp., which he correctly suggested pertains to Brachyostracon (= Glyptotherium). These records and localities have not been verified except as mentioned in the discussion above.

Silva-Barcenas (1969) also listed various North American glyptodont taxa for several localities in Mexico not previously mentioned. Because he did not conform with established synonymies (he reported both Brachyostracon mexicanus and Glypiodon mexicanus, for example, as well as Glyptodon clavipes which, as far as we can determine is the only such record in North America and for which he made no literature citation), the identities of these specimens cannot be suggested even tentatively. The lack of reported recoveries of Glyptotherium floridanum (= Boreostracon floridanus to Silva-Barcenas) renders his identification suspect, for this species should be present in late Pleistocene deposits of Mexico and Central America.

Other records of Mexican glyptodonts include references by Pichardo (1960). We have not examined these materials. Glyptodonts from Valsequillo, Puebla (fauna currently under study by Russell Graham), possessed scutes far too small and with sculpturing patterns too strikingly different to suppose identity as Glyptotherium. Hence, at least one other genus is present in the North American fauna, as yet unidentified.

This monograph is devoted to all glyptodonts of the United States and to those of Mexico that are important to the taxonomy of Glyptotherium; the only Mexican glyptodonts pertaining to $G$. floridanum of direct interest to this report are the ones reported by Hibbard (1955), Dalquest (1961), and Mooser and Dalquest (1975).

Undoubtedly, still other records of Central American and Mexican glyptodonts have been overlooked. Future discoveries will add substan- tial information to our knowledge of North American glyptodonts south of the United States; it is in this area where remaining secrets of glyptodont taxonomy and evolution are likely to be uncovered.

\section{Osteology}

Previous treatments of the osteology of North American glyptodonts have been limited to descriptions of single individuals, or populations, without extensive comparison to specimens from other localities. The excellent skeletal material from Safford, Arizona, of Glyptotherium texanum, made available for this study by the American Museum of Natural History, forms the basis for this comprehensive review of the comparative osteology of the five species of Glyptotherium.

\section{SkUll}

Skulls of South American glyptodonts have been described by several authors, including Huxley (1865) and Burmeister (1874), both of whom ascertained the general nature of most of the bones of the cranium. Because of the massive, solidly ankylosed nature of the cranial bones in adult specimens, however, only Vinacci Thul (1945) has described completely the individual bones of an entire skull. He described the skull of Glyptodon reticulatus from South America, outlining in rather general fashion the individual bones, where distinguishable, and using a "geographic" approach. His description was not accompanied by figures, and only three gross and imprecise measurements were appended to the text: maximum vertical diameter $191 \mathrm{~mm}$, maximum anteroposterior diameter $302 \mathrm{~mm}$, and maximum transverse diameter $244 \mathrm{~mm}$. Corresponding dimensions for the complete skull (AMNH 95737) of Glyptotherium texanum are $147 \mathrm{~mm}, 248 \mathrm{~mm}$, and $187 \mathrm{~mm}$, respectively. There is a rough proportionality in these gross measurements, the Glyptotherium texanum skull apparently smaller by approximately 25 percent. Measurements of Glyptotherium arizonae closely approximate those pro- 
vided by Vinacci Thul. (These measurements for the Glyptotherium texanum skulls are given only for comparison. Table 1 provides more precisely defined measurements for these and other North American skulls.)

Others who have dealt extensively with glyptodonts (e.g., Burmeister, Lydekker, Clastellanos) have included skulls in their determinations of taxonomic rank. Especially diagnostic is the anterior half of the skull roof, including the frontals, nasals, and premaxillary bones. The configuration of the frontals in their contribution to the upper profile and the shape of the narial aperture have been especially important in South American generic descriptions.

The skulls of Glyptotherium compare favorably with illustrated examples (e.g., Burmeister, Lydekker, Huxley) of the South American genus Glyptodon, in the classical sense (see Hoffstetter, 1955, for an exkellent discussion of the taxonomic status of this meric name). Lydekker's (1894) description wat amplified by Hoffstetter (1958) in a summary of the cranial characteristics of Glyptoddn. The skulls of Glyptotherium resemble those of Glyptodon.

The skull of F:AM 59583 (Glyptotherium texanum, Figures 5-8, Table 1) is complete except for the region anterior to a frontal section through thc anterior borders of the zygomatic arches; the anterior half of the palate is also missing. The upper dentition is fully represented. $\mathrm{N}^{3} \mathrm{~N}^{\underline{y}}$ of both sides are preserved in place in the skull. Fragmentary $\mathrm{N}^{\underline{1}}$ and $\mathrm{N}^{2}$ from both sides, which are isolated from the skull, complete the upper series. Each of the latter four teeth is represented by the crown half of the tooth, including the occlusal surfaces. This individual was probably a young to middleaged adult, for many of the sutures, though strongly united, are discernible.

Except for the right malar bone, the skull of F:AM 95737 (G. texanum, Figure 9) is complete, thus representing the most nearly complete single glyptodont skull in North America, the only one that includes the prezygomatic region. The entire upper dentition is represcnted, although right $\mathrm{N}^{5}$, and $N^{1}, N^{4}$, and $N^{7}$ of the left side are missing.
This skull was associated with the skeletal and carapacial remains, which are undoubtedly from a juvenile individual. Unfortunately the skull is heavily fractured throughout and the sutural contacts are mostly obscured. This broken condition seems to be the result of two disruptive circumstances: the apparent cause of death, and the conditions of preservation.

The latter circumstance likely contributed to most of the broken condition of the skull bones, for there are innumerable small fractures almost "uniformly" covering the skull. Because the braincase and nasal cavity were filled with sediment, however, the fragments were essentially kept in place after fracturing. The fact that many of the fractures are filled with the same matrix that invests the cavities of the skull indicates that the fracturing occurred after burial but before consolidation of the sediment enveloping the skeleton.

That this individual met a violent death is indicated by a pair of elliptical holes almost perfectly centered in the frontal bones (Figure $9 a$ ). The long axes of these holes are situated in the parasagittal plane, evenly placed on either side of the midline. The short axes, which are approximately half the length of the long axes, do not intersect in their medial extensions, because the left hole is slightly more posteriorly situated than the right. Fragments of the skull roof from the region of the injury are preserved within the left hole, solidly held in place by the enveloping matrix, thus indicating that the holes are not a result of extrication or preparation. This contention is confirmed by the preparator, Mr. Gladwyn Sullivan, of the National Museum of Natural History (Smithsonian Institution), whose careful work brought these features to light. Each hole ncasures approximately $20 \mathrm{~mm}$ by $15 \mathrm{~mm}$.

Apparcntly this individual was attacked by a large predator bearing enormous canines, which pierced the skull roof either simultaneously or in consccutive blows, probably resulting in immediate death for the victim. Because this individual was young, the cephalic shield, which was not recovered, apparently was not fully developed, 


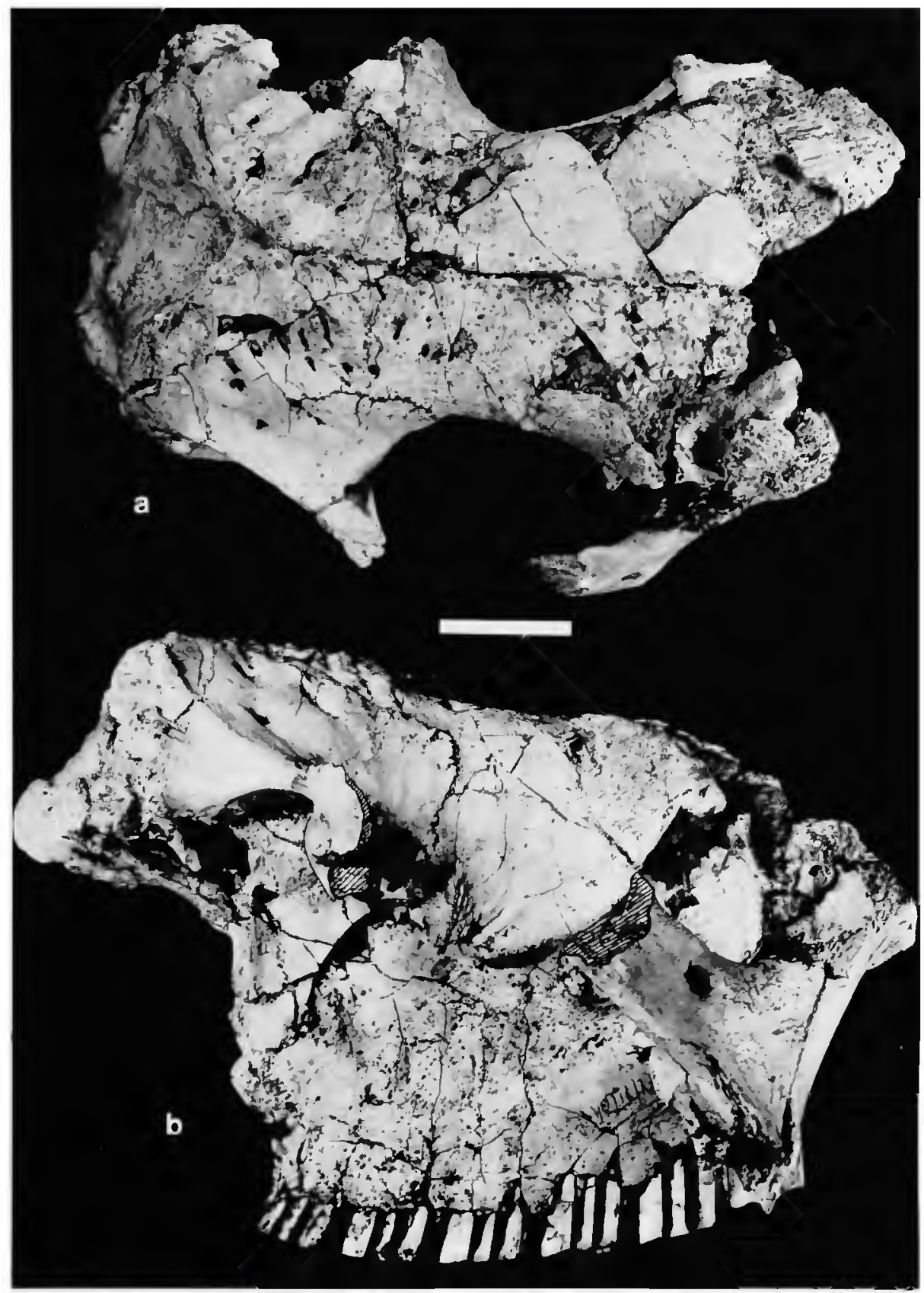

Figure 5.-Skull of Glyptotherium texanum, F:AM 59583: $a$, dorsal; $b$, right side, with centra] zygomatic region broken away. (Bar $=5 \mathrm{~cm}$.)

thus affording poor protection for the skull roof. It appears that the predator, probably a mediumsized cat, attacked from the front, a curious anomaly in view of the preference of most cats for a rear attack. The reason for this assumption is that the rear portion of the skull in glyptodonts was confluent with the anterior notch of the carapace, in lateral aspect forming a continuous concave outline. Thus a rear attack would necessitate at least an estimated $225^{\circ}$ gape, an obvious impos- 

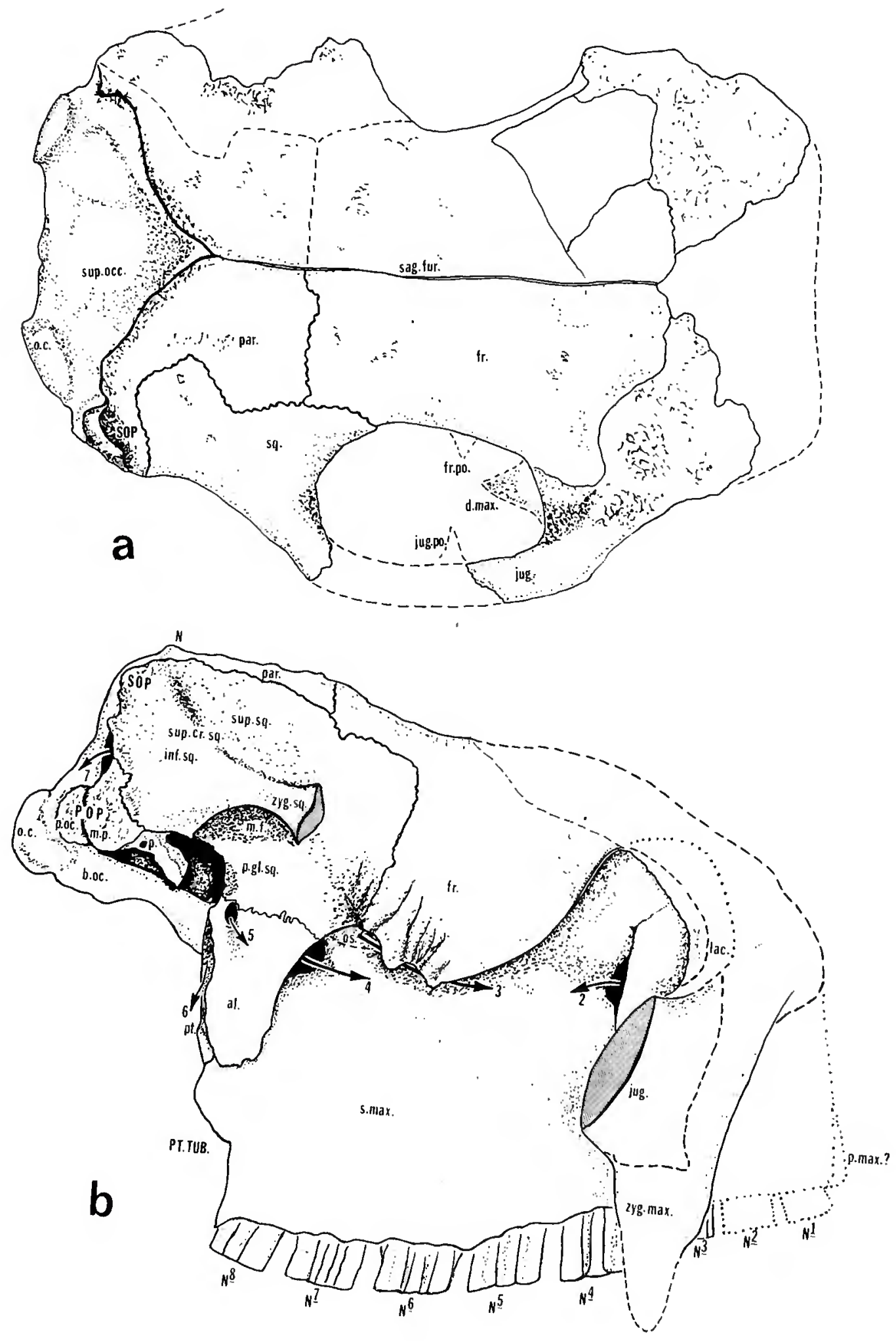
sibility. A front attack, however, seems more likely, owing to the convex outline of the anterior end of the skull.

A final consideration built upon this reasoning concerns the glyptodont's defense. As suggested elsewhere, glyptodonts were probably defenseless except for their armor and had to rely on behavioral mechanisms for protection from predators, either by residing in water like a hippopotamus or by gregarious habits. In either case, it is inconceivable that a predatory cat would simply surprise a juvenile individual by a frontal attack with such a perfectly placed injury. When faced with danger, it seems that a normally healthy individual would at least turn its head from an impending blow, eliminating the possibility of the symmetrically placed holes. It seems more likely that this juvenile was stranded, perhaps in mud, or was otherwise debilitated, unable to avoid an approaching predator. Some authors (e.g., Huxley, 1865; Burmeister, 1874) have entertained the possibility that glyptodonts could retract their head, turtle fashion. Evidence provided by North American fossils neither substan-

Figure 6.-Interpretation of skull of Glyptotherium texanum (F: AM 59583) illustrated in Figure 5: $a$, dorsal, $b$, right lateral, with most of zygoma removed. (Abbreviations as follow: $\mathrm{N}$ $=$ nuchal cres! $; \mathrm{N}^{1}-\mathrm{N}^{\underline{8}}=$ upper tooth row; $\mathrm{POP}=$ paroccipital process; $\mathrm{PT} . \mathrm{TUB} .=$ pterygoid tuberosity; $\mathrm{SOP}=\mathrm{su}$ praoccipital process; al. = alisphenod; b.oc. = basioccipital; d.max. = descending process of zygomatic process of maxilla (= zyg. max.); fr. = frontal; fr.po. = postorbital process of frontal; inf.sq. $=$ inferior region of squamous process of squamosal; jug. = jugal; jug.po. = postorbital process of jugal; lac. = lacrimal (inferred with reference to skull F:AM 95737-see Figure 8); m.f. = mandibular fossa; m.p. = masıoid process of squamosal; o.c. = occipital condyle; par. $=$ parietal; pt. = pterygoid; p.gl.sq. = postglenoid process of squamosal; p.max.? = premaxilla (actual existence uncertain); p.oc. = paroccipital process of squamosal; os. = orbitosphenoid (suture with maxilla shown by dashed line); s.max. $=$ superior process of maxilla; sag.fur. = sagittal furrow; sup.cr.sq. = superior crest of squamosal; sup.occ. = supraoccipital; sup.sq. = superior region of squamous process of squamosal; zyg.max. = zygomatic process of maxilla; zyg.sq. $=$ zygomatic process of squamosal; $\mathrm{p}$. = petromastoid; $2=$ posterior exit of infraorbital canal; $3=$ channel formed by frontosquamosal flange; $4=$ foramen rotundum region; 5 = foramen ovale; $6=$ pterygoid flange; $7=$ petromastoid fenestra.) tiates nor refutes this possibility. If partial retraction was possible, then perhaps this individual was attacked frontally, and the blow penetrated the portion of the skull that remained exposed.

Two skulls of $G$. arizonae provide adequate comparison with those of $G$. texanum. The skull of UMMP 34826 (Figure 10) was briefly described by Melton (1964). It is complete except for the pre-zygomatic region. Another skull from the same locality (UMMP 38761) is badly crushed, and, except for the dentition, offers little information beyond that provided by UMMP 34826 .

Skull fragments of $G$. floridanum from two localities allow tentative comparisons with $G$. texanum and $G$. arizonae. The skull of USNM 6071 (Figure 11), from Texas, was briefly described by Hay (1916). It consists of two fragmentary portions, the posterior dorsal part of the braincase, and the central region including most of the palate, the anterior zygomatic region, and the skull roof. Another skull fragment (ChM 2415, Figure 12), consisting of the postglenoid region, was described by Ray (1965), who was unable to make a generic determination. This specimen compares favorably with USNM 6071 and is tentatively identified herein as $G$. floridanum.

Thus the skull of $G$. floridanum is poorly known. Comparison of associated upper teeth of USNM 6071 with teeth of UF/FGS 6643 from Catalina Gardens, Florida, which is assignable to $G$. floridanum, supports the taxonomy suggested herein for the Florida, South Carolina, and Texas Late Pleistocene representatives.

Cuatáparo and Ramirez (1875) included a largely erroneous description of the skull of Brachyostracon mexicanus (= Glyptotherium mexicanum). As Brown (1912) and Ray (1965) have pointed out, their description and interpretation are highly suspect. Although no further mention will be made of the skull of $G$. mexicanum in the following descriptions, it should be stated that the skull of this species probably differs little from that of the other species of this genus. The present location of the skull is unknown.

The skull of $G$. cylindricum (AMNH 15548) is represented only by a fragment of the posterior extremity of the cranial vault, at the parietal/ 

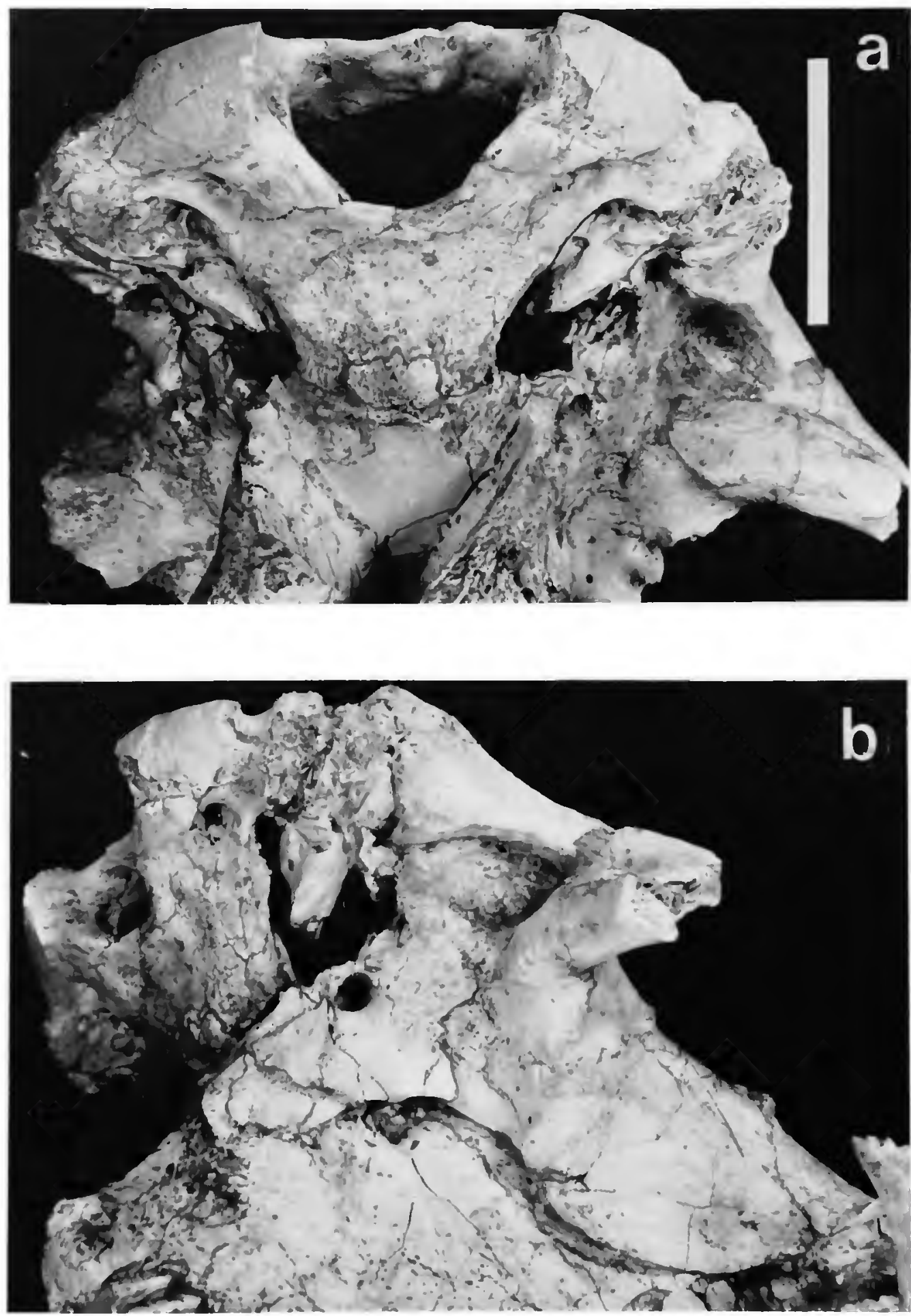

FigURE 7.-Basicranial region of Glyptotherium lexanum (F:AM 59583); $a$, ventral; $b$, ventrolateral. (Bar $=5 \mathrm{~cm}$.) 

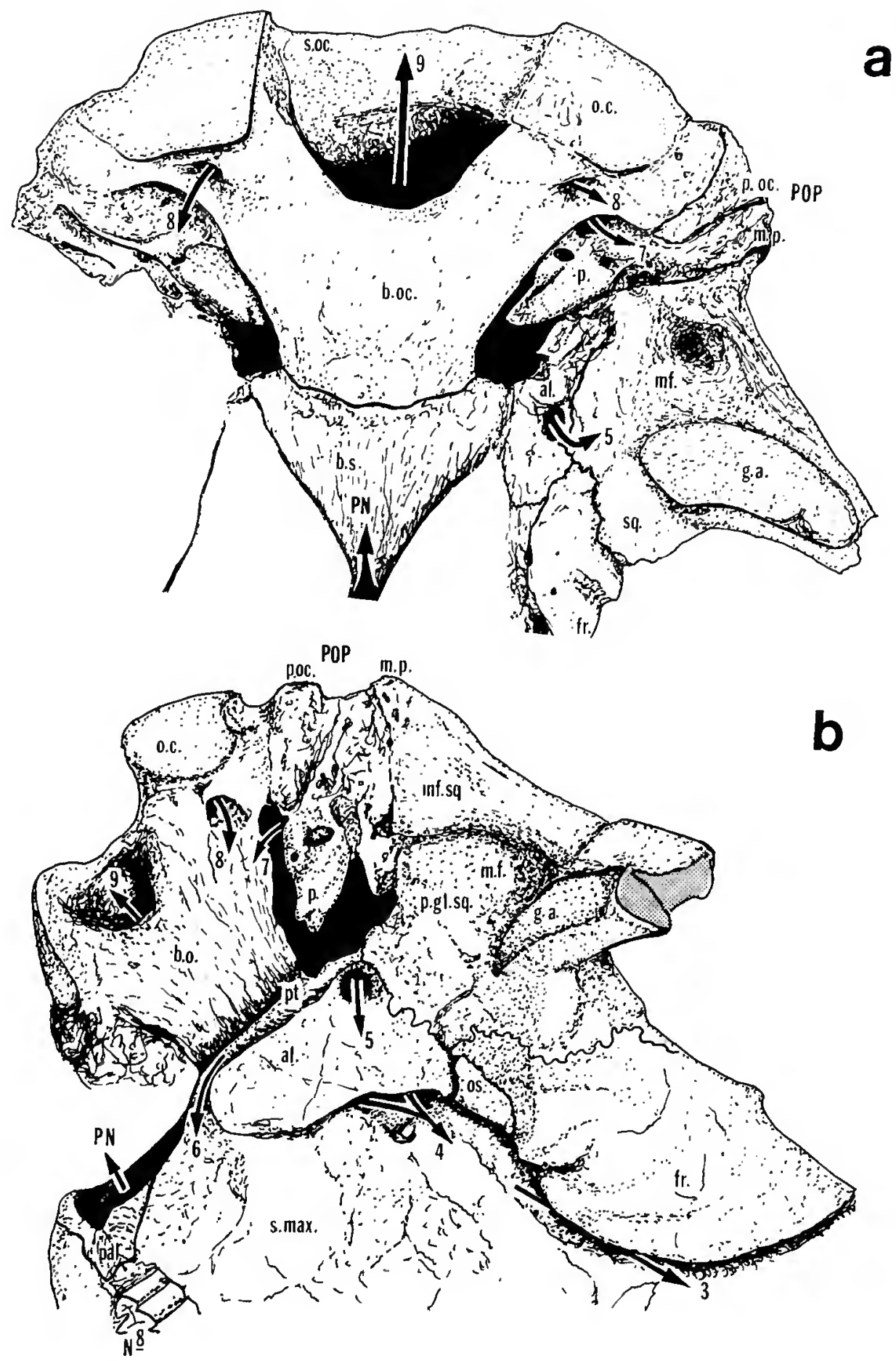

Figure 8.-Glyptotherium texanum (F:AM 59583): $a$, line drawing interpretation of Figure 7a; $b$, line drawing interpretation of Figure 7b. (Abbreviations as in Figure 6, with the following additions: $\mathrm{PN}=$ posterior narial aperture; b.o. and b.oc. = basioccipital; b.s. = basisphenoid; pal. = palatine; g.a. = glenoid articular facet; s.oc. = supraoccipital; $8=$ hypoglossal foramen; $9=$ foramen magnum.) 


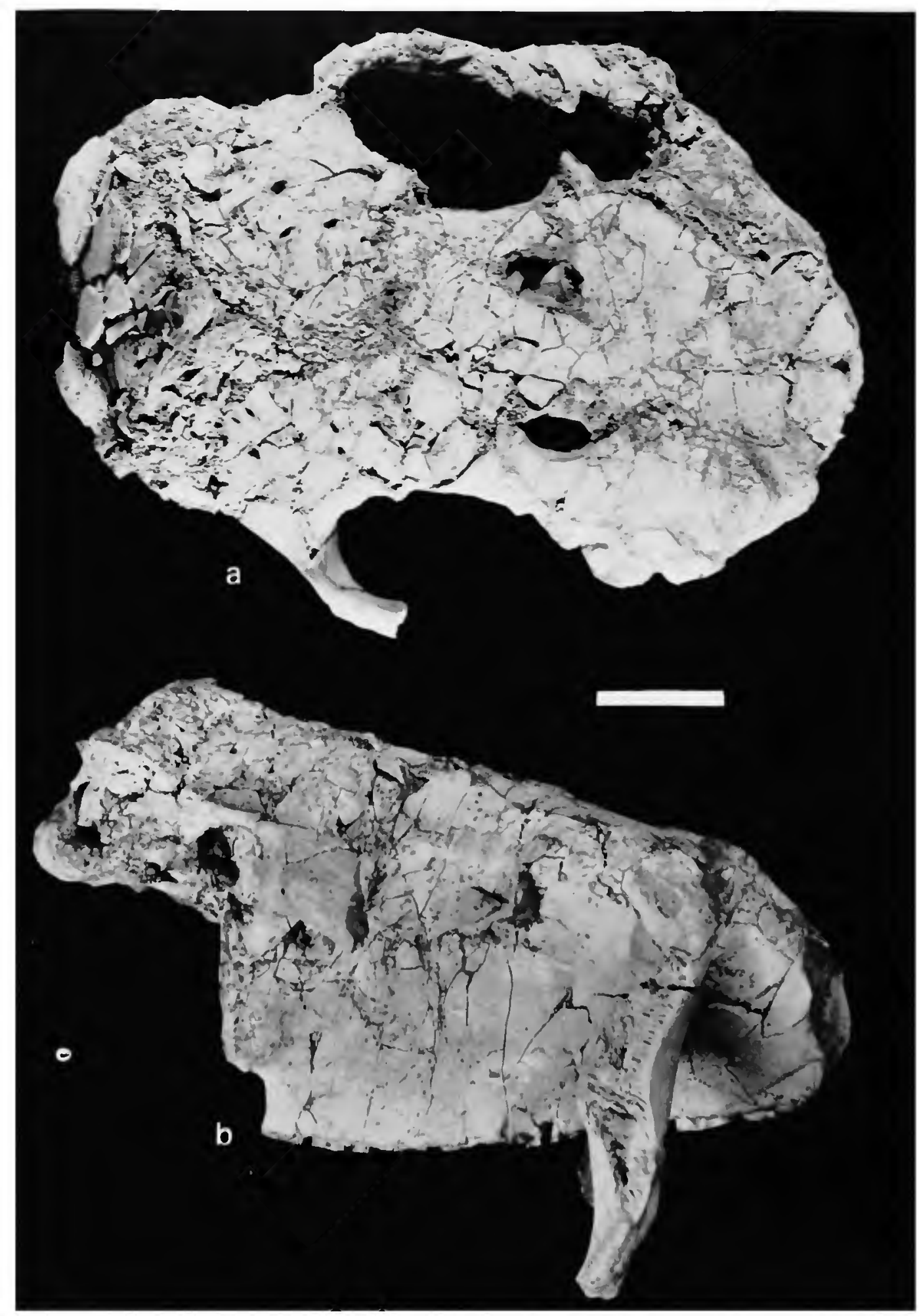

Figure 9.-Skull of Glyptotherium texanum, F:AM 95737, from a juvenile individual: $a$, dorsal, showing a pair of holes presumed to have been the result of an altack by a large predator bearing piercing canines; $b$, lateral. (Bar $=40 \mathrm{~mm}$.) 


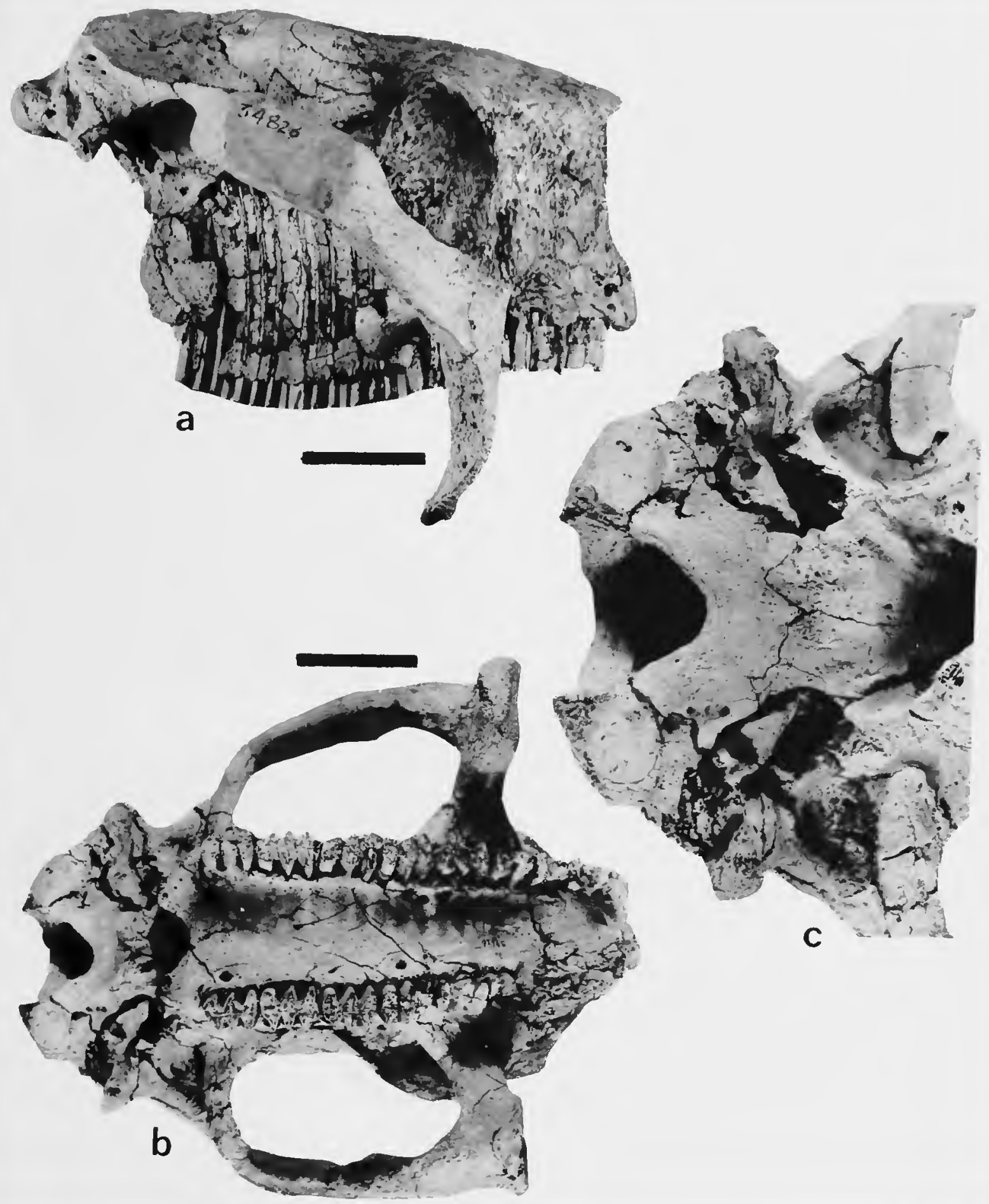

FIGURE 10.-Skull of Glyptotherium arizonae UMMP 34826: $a$, right side, with prezygomatic region restored and incorrectly showing bulged superior profile, which should be straight instead; $b$, ventral, showing complete tooth row; $c$, detail of basicranial region. (Bars $=40 \mathrm{~mm}$.) 

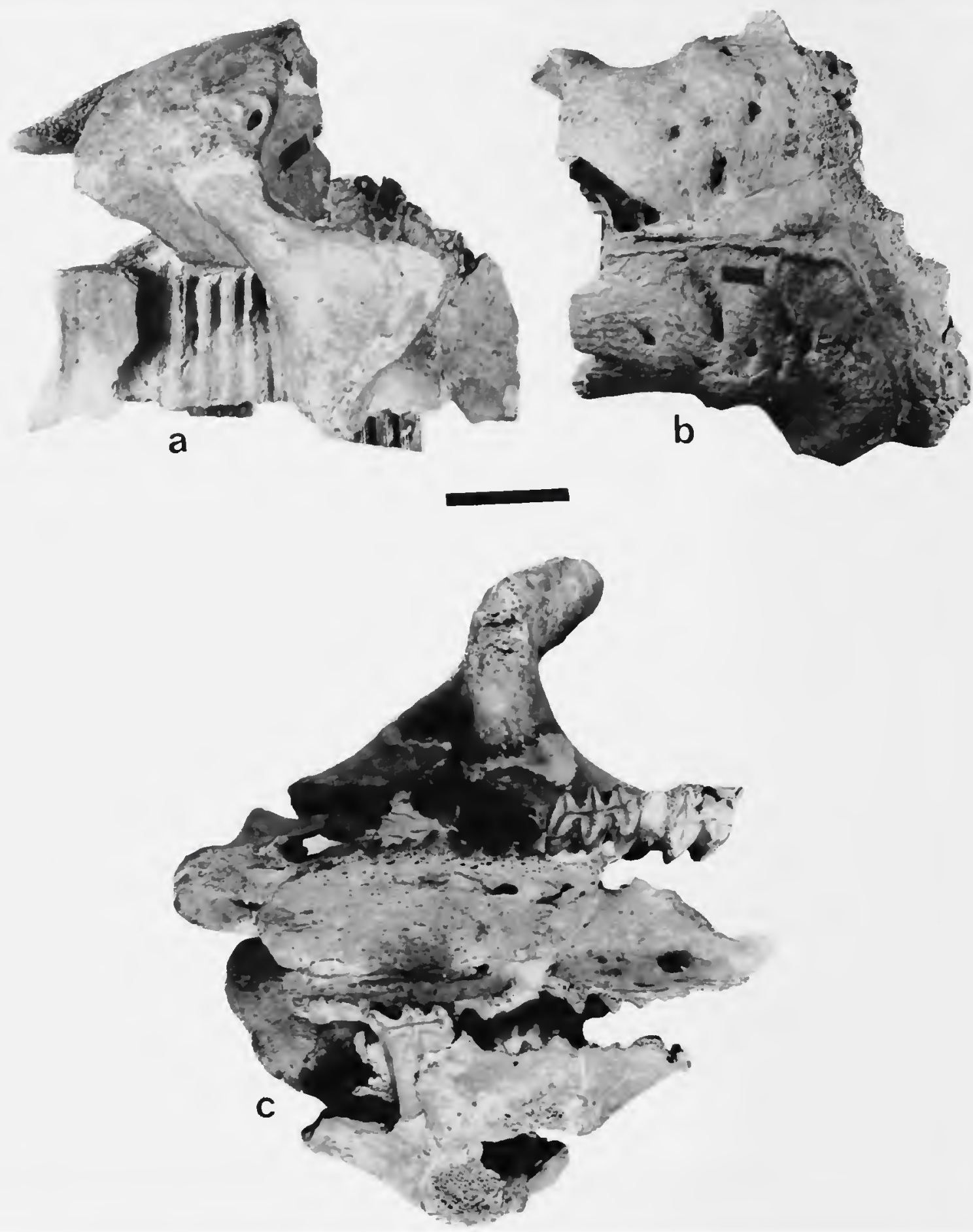

FIGURE 11.-Skull of Glyptotherium floridanum, from the Wolfe City, Hunt County, Texas, locality (USNM 6071): $a, c$, lateral and ventral aspects of cranial fragment from central region of skull, anterior to left; teeth shown in $c$ are right $\mathrm{N}^{2}$ and left $\mathrm{N}^{4} ; b$, cranial fragment from parietal region of skull, dorsal aspect, anterior to left. (Bar $=40 \mathrm{~mm}$.) 


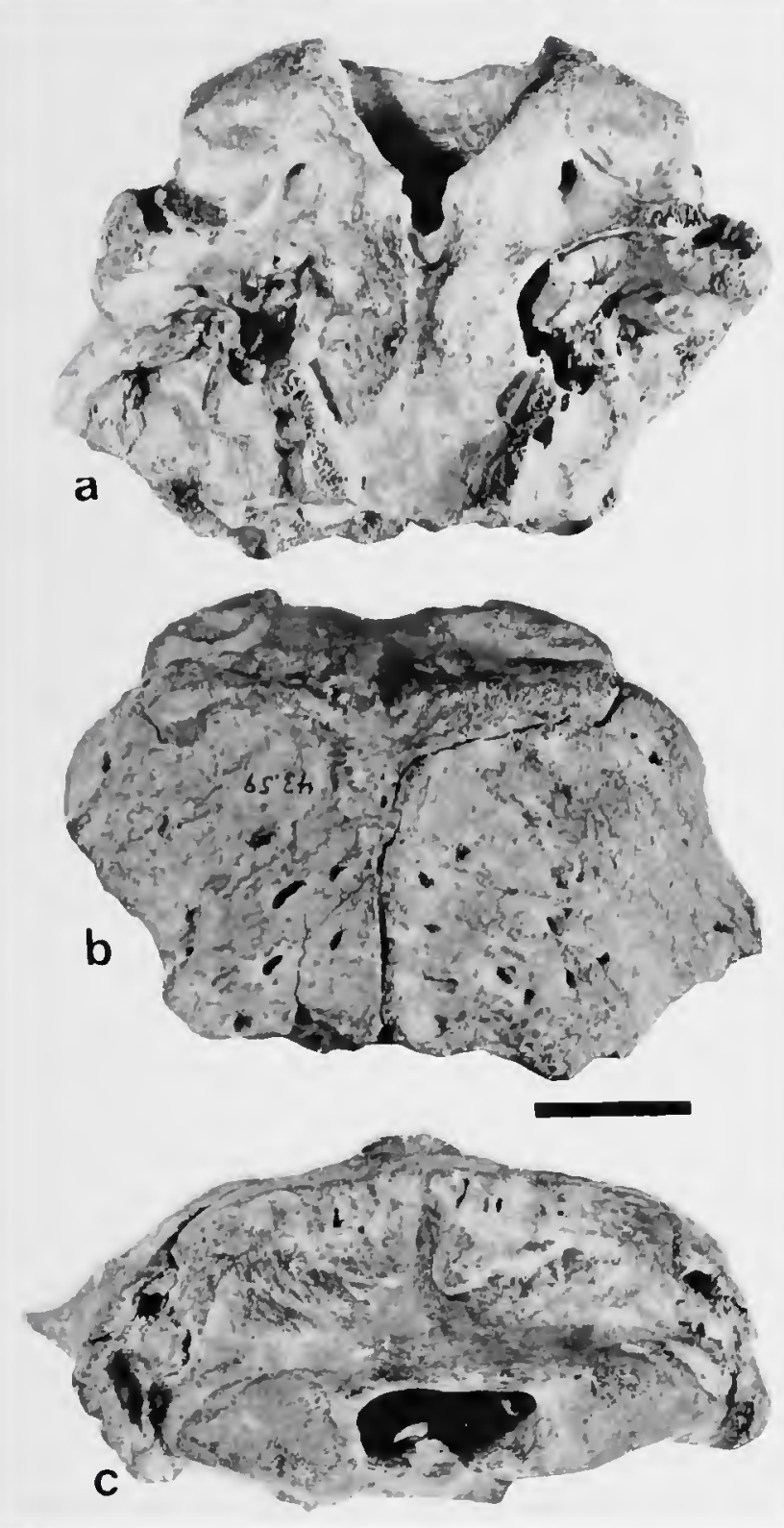

Figure 12.-Skull fragment of Glyptotherium floridanum from coastal South Carolina, postzygomatic region (ChM 2415 $=$ CM 43.59 of Ray, 1965): $a$, ventral, basicranium; $b$, dorsal, parietal region; $c$, postericr, occipital region. (Bar $=40 \mathrm{~mm}$.)

lambdoidal ridge contact. The inner surface of the bone is smoothly convoluted, offering little diagnostic information. The outer surface lacks vascular canals. Associated with this skull is an incomplete hyoid bone, the only one known of a North American glyptodont. It is an elongate, laterally compressed element, with expansions at either end of the constricted shaft. Its length would have exceeded $91 \mathrm{~mm}$.

The following description of the skull of Glyptotherium texanum is based on the two Arizona skulls F:AM 95737 and F:AM 59583 (Figures 5-9). In the former, most sutural contacts are obscured by the fragmented condition of the cranial bones, despite the individual's young age (as determined from the postcranial remains). In the latter skull most sutural contacts are discernible, but they are not sufficiently indicated for complete delimitation of all of the component bones of the skull, especially internally. As far as possible the following descriptions are for individual bones; where contacts are not readily discerned the descriptions resort to a geographic context, adopting the procedure of Vinacci Thul (1945). Following the description of the skull of $G$. texanum are comparative descriptions for $G$. arizonae and $G$. floridanum.

Narial Aperture.-The narial aperture is situated immediately anterior to the first tooth $\left(\mathrm{N}^{1}\right)$. This aperture, which appears to be fully represented in F:AM 95737, bears the shape of an inverted trapezoid, with a concave upper margin. The legs of the trapezoid converge downward, their apex forming an angle of approximately $60^{\circ}$ The sides of the narial apercure are apparently formed by the maxillae, the lower edge by the inferred (reduced) premaxilla, which is missing in these specimens, and the upper edge apparently by the nasals.

Premaxilla.-There is no overt indication of the premaxilla. Its presence in Glyptotherium texanum is inferred by the nature of the inferior (palatine) border of the narial aperture in F:AM 95737. The edge of the bone forming the lower border is somewhat thicker than the bone forming the lateral and superior borders of the nares. Its outline is also irregular, rather more suggestive of sutural contact than of breakage. If indeed there was a premaxilla, it was greatly reduced, for the maxillae as preserved extend nearly to the anterior extremity of the narial aperture, which is formed by the lower edges of the lateral borders. It also appears that the premaxilla was confined 
to the anterior extremity of the palate, either without or with extremely reduced, superior maxillary processes. As Lydekker (1894) pointed out, the bones forming the anterior extremity of the snout are poorly united and are frequently lost. Such appears to be the case in the present instance. Vinacci Thul (1945) found reduced premaxillae in Glyptodon reticulatus and described incisive foramina in his specimen. That incisive foramina were present in Glyptotherium texanum is uncertain, but the symmetry of the anterior edge of the maxillae suggests their presence.

Nasal Septum.- The narial aperture is filled with matrix in F:AM 95737. In F:AM 59583, however, the passage is open. The broken edge of a broken narial septum, formed by the anterior extension of the perpendicular plate of the ethmoid, extends as far forward as $\mathrm{N}^{2}$ in its preserved condition. Its relatively stout construction at the point of breakage indicates that it continued considerably farther forward than its preserved extent, probably to the opening of the narial aperture.

NASAL. - As for the premaxilla, the existence of the nasals is questionable. The upper edge of the narial opening is broken, but its reduced thickness suggests that little is missing. This edge is here interpreted to be formed by the nasals. It is possible, however, that the nasals occupied a more anterior position and that the preserved edge is formed by the frontals. If so, the nasals are extremely reduced, or they may be absent. The interpretation that the nasals are present is not supported by the existence of a nasal-frontal suture. There is, however, an indistinct textural change on the surface of the bone in the frontal plane anterior to the zygomatic roots, suggesting an ankylosed contact, interpreted herein as the nasal-frontal suture. Vinacci Thul recognized nasals in Glyptodon reticulatus. His description corresponds closely to the inferences provided above.

LACRIMAL. - The transverse concavity of the nasofrontal region reaches its greatest depth in the frontal plane through the middle of the roots of the zygomata. In this position, at the superior anterolateral angle of the skull, the nasal and frontal flare laterally upward to contact the expanded and inflated lacrimal bone.

The lacrimals occupy the superior anterolateral corners of the skull, forming the anterodorsal roots of the zygomatic arches. The indistinct frontal-lacrimal contact is situated well within the flattened dorsal region of the skull roof. The lacrimal contacts the zygomatic and nasal processes of the maxilla ventrally and anteriorly, and it contacts the orbital process of the jugal posterolaterally. The nasolacrimal duct is situated on the lateral surface. The surface texture of the lacrimal is finely pitted, in contrast with the smooth and faintly striated texture of the surrounding bones.

Frontal.-The paired frontals occupy the bulk of the upper surface of the cranium. The concavity of the transverse cross section in the anterior region becomes flattened rearward at the position of the postorbital process. From that position rearward the frontals are dorsally flattened and strongly convex laterally. The superior profile of the midline of the frontals, and therefore of most of the upper region of the skull as well, is very weakly concave anteriorly between the zygomatic roots, flat to weakly convex centrally in the plane of the temporal fossae, and again weakly concave on the posterior third extending toward the parietals. The overall lateral profile is almost straight; it tapers anteriorly downward at an angle of approximately $20^{\circ}$ with respect to the palate or tooth row. The construction of the frontals therefore compares favorably with that described by Vinacci Thul (1945) for Glyptodon reticulatus, although the anterior taper is less severe in Glyptotherium texamum. In the anterolateral position on the frontal is a distinct postorbital process, which fails to extend outward to meet its analog on the zygomatic arch. Thus the orbit communicates freely with the temporal fossa, as in all representatives of the Glyptodontinae and Sclerocalyptinae, and unlike the Daedocurinae (Hoffstetter, 1958).

Behind the postorbital process the frontals extend downward, lapping over the maxillae and attaining a fully vertical aspect. This ventrolat- 
eral extension of the frontals, which is apparently unique to glyptodonts, extends downward for approximately the upper third of the vertical diameter of the skull at the temporal opening. The margin of the maxillary process of the frontal is rounded, extending downward from the postorbital process and then upward toward the zygomatic process of the squamosal, in a more or less uniform outline. The flange continues onto the corresponding portion of the squamosal for a short distance before becoming confluent with the zygomatic process. Distinct grooves and ridges mark the posterior half of the frontosquamosal flange. These are oriented in a posteroventralanterodorsal course; the grooves directed slips of the temporalis musculature from the lateral surface of the skull to the coronoid process of the mandible.

The frontal-squamosal suture extends upward from the anterointernal angle of the zygomatic process of the squamosal, curving rearward in a smooth arc on the dorsolateral surface of the skull roof. The suture then becomes straightened in the anteroposterior direction for a short distance before intersecting the frontal-parietal suture in a right angle. The frontal-parietal suture is confined to the dorsal surface of the skull. It is a relatively straight contact, perpendicular to the midline.

The frontals are centrally constricted in the region of the temporal fossae, where the frontosquamosal flange (= maxillary process of the frontal) laps onto the maxilla. The lateral surface of the maxillary process is anteroposteriorly concave. The transverse extent of the border of the frontals is but slightly greater than at the central constriction. The posterior third of each frontal is marked by several large vascular foramina, which penetrate from the external surface inward and rearward. The paired frontals meet in a straight midline contact. At least from the central position, in the plane of the postorbital processes rearward, the suture is open, forming a distinctive groove. This contact was called a sagittal furrow ("surco sagital") by Vinacci Thul (1945). In skull F:AM 95737, the sagittal furrow appears to be open anteriorly and closed from the postorbital plane rearward. Thus it appears that this characteristic may vary with age and/or sex. There is no sagittal crest.

Parietal. - The paired parietals complete the rear portion of the skull roof. The median sagittal furrow continues rearward, terminating at the nuchal crest. The parietals are relatively small and are confined to the dorsal region of the skull. Their external surface is highly irregular, owing to the pits, grooves, and ridges attendant with the cephalic shield that covered these bones.

The frontal-parietal suture is relatively straight and oriented perpendicular to the midline, as already described. The squamosal-parietal suture is a continuation of the squamosal-frontal suture. Rearward, this suture becomes irregular, generally tapering inward toward the occiput. Near the nuchal crest the parietals expand outward in a pair of nuchal wings, which extend to the lateral angles of the nuchal crest. The posterior border of the parietals is situated on the nuchal crest, where it contacts the squamous part of the occipital bone, together forming the broadly $V$-shaped nuchal crest. This description of the parietal corresponds closely with that for Glyptodon reticulatus provided by Vinacci Thul (1945).

Zygomatic ARCH.-The glyptodont skull is notable for the greatly expanded zygoma, which includes a massive descending process arising from the anterolateral angle and extending downward well beyond the level of the tooth row. The development of this process is associated with the horizontal orientation of the masseteric musculature, which originates on the expanded posterior surface of the descending process. (See the discussion of the masticatory apparatus for a more extensive description.) The bones contributing to the zygomatic arch are the lacrimal, maxilla, jugal, and squamosal. The lacrimal was described in the previous section.

Maxilla.-The construction of the maxillae is partly responsible for the singular appearance of the glyptodont skull. For purposes of description, the maxilla can be divided into three portions: the greatly expanded superior maxillary, the pal- 
atal process, and the massive zygomatic process, which contributes the bulk of the anterior root of the descending process of the zygoma.

The zygomatic process arises from the upper two-thirds of the superior maxillary, from the dorsolateral angle of the snout, where it is firmly united with the lacrimal. The anteriormost extent of the zygomatic process lies in the frontal plane between $\mathrm{N}^{1}$ and $\mathrm{N}^{2}$, where it is united with the lacrimal in the dorsolateral position. The enlarged infraorbital canal, which extends rearward, inward, and slightly upward through the zygomatic process, divides the bone into two massive struts. The infraorbital canal is elliptical; its diameter is smaller at its posterior emergence into the orbit.

Nearly all of the anterior surface of the descending process is formed by the maxilla. It descends outward and slightly rearward. The anterior surface in lateral profile is relatively straight, and that of the lower half is curved rearward in a weak convexity. At the level of the tooth row the anterior border of the process is positioned in the plane of the anterior lobe of $\mathrm{N}^{3}$. The inferior extremity is situated in the plane of the anterior lobe of $\mathrm{N}^{4}$ The outer (lateral) border of the descending process is formed by the jugal, which is united with the descending process of the maxilla in a broad vertical contact nearly reaching the terminus of the process. The jugal occupies approximately the lateral one-fourth of the descending process in transverse dimensions, and the upper half of the lateral side in vertical dimensions.

The descending process of the zygomatic arch is anteroposteriorly compressed. The cross section is basically lens-shaped, with the posterior surface somewhat more convex than the anterior. At the base of the zygoma the medial surface is rounded. From the level of the tooth row downward, the inner surface forms a mcdial crest, which continues to the blunt and rugose terminus. The lateral surface of the descending process, the upper half of which is formed by the jugal, is uniformly crested. This construction continues rearward, forming the ventral margin of the horizontal ramus (zygomatic process) of the jugal and the zygomatic process of the squamosal in a continuous crest.

The posterior surface of the descending process of the zygoma is uniformly concave in vertical section, reflecting the lower convexity of the anterior surface. The upper half forms the anterior border of the orbit. The transverse concavity from the orbital region diminishes downward, at the level of the tooth row becoming flattened, obtaining a marked convexity on its lower half.

The superior maxillary is a broad, flattened plate extending from the nares (as here interpreted) rearward to the plane of the glenoid fossa. It is greatly extended inferiorly, in maximum vertical dimension approximately three-fifths the diameter of the maximum anteroposterior length. As previously described, the anterior border of the maxilla appears to form the lateral borders of the nares. (The premaxilla may have contributed short vertical processes at this border.) The prezygomatic portion (narial process) of the maxilla is weakly convex above $\mathrm{N}^{1}$ and $\mathrm{N}^{2}$. In anterior profile the maxillae in this region converge downward in conformation with the construction of the narial aperture. The zygomatic region of the superior maxillary is modified by the root of the zygoma, which occupies all but the lower third of the bone.

Anteriorly, the upper border of the maxilla contacts the lacrimal in an obscure suture extending through the upper portion of the zygoma above the infraorbital canal. Behind the zygomatic root the maxilla contacts the frontal at the posteromedial angle of the orbit. Here the contact forms nearly a right angle. At this position the exposed portion of the maxilla reaches its maximum supcrior extent. From the orbit rearward the actual frontal-maxillary contact is hidden by the descending maxillary process of the frontal (the frontotemporal flange). The frontal-maxillary contact apparently diverges beneath the flange, for at the posterior emergence from beneath this process the maxilla is in contact with the orbitosphenoid, which is wedged between the maxilla and the frontal. At a position directly 
beneath the mandibular facet the border of the maxilla contributes to the large foraminal complex, the bulk of which is formed by the foramen rotundum. Posteriorly the maxilla is overlapped by the sphenopterygoid complex.

The postzygomatic region of the superior maxillary is a smooth, flat plate. It is weakly concave in both the vertical and anteroposterior directions. Superiorly it forms the inner border of the longitudinal groove produced by the maxillary process of the frontal. This groove seems to course rearward and to enter the sphenomaxillary fissure (foramen rotundum region). Presumably, the flange provided protection from the masseteric and temporalis musculature for the blood vessels and nerves, which were transmitted forward from this foraminal complex (i.e., especially the optic nerve, the foramen for which is apparently situated within this foraminal complex). This foraminal complex is more extensively discussed in the description of the alisphenoid.

From the middle of the tooth row rearward, the maxillae taper downward and outward, conforming to the curvature of the alveoli, thus producing the downward divergence (i.e., upward convergence) of the maxillae in frontal section.

The palatal process of the maxilla occupies the entire palatal region. The reduced palatines are confined to the region of the posterior narial aperture. Anteriorly the maxillae apparently are fused with the weak premaxillae, and they appear to form the posterior border of the incisive foramina, as discussed previously. In transverse section the palate is weakly concave anteriorly, with more pronounced concavity rearward. Posteriorly the concavity is very deep owing to the downward extensions of the aveolar processes. In sagittal section the palate is weakly concave for its anterior half, becoming markedly convex posteriorly. This construction conforms closely to the lateral profile of the occlusal surfaces of the tecth.

There is a weak ridge at the midline at the position of $\mathrm{N}^{6}$ to $\mathrm{N}^{\mathrm{z}}$, and anteriorly, between $\mathrm{N}^{2}$ and $\mathrm{N}^{3}$, there is a distinct midline groove. Adjacent to the alveolar processes of each maxilla is a deep longitudinal sulcus. From its broad anterior opening adjacent to $\mathrm{N}^{1}$, the sulcus becomes deepened rearward. Tubercle-like processes on the medial borders nearly encompass the furrows. The left palatine furrow enters the palatine foramen adjacent to the anterior lobe of $\mathrm{N}^{5}$. The right furrow becomes covered by a thin process of bone extending from the posterior lobe of $\mathrm{N}^{4}$ to the anterior lobe of $\mathrm{N}^{5}$. The right palatine foramen opens posterior to this covering, opposite the middle lobe of $\mathrm{N}^{5}$; thus the palatal foramina and the palatal furrows are neither equally constructed nor symmetrically disposed. Ordinarily this construction would receive little attention, for a small amount of asymmetry is expected. However, it is notable that the skull UMMP 34826 (G. arizonae) exhibits an identical construction, except that the left palatine furrow also possesses a bony enclosure anterior to the foramen; the asymmetry in the position of the foramina is identical.

A pair of small, posterior palatine foramina is situated adjacent to the anterior lobe of each $\mathrm{N}^{-}$. The posterointernal border of the terminal alveolar process shares in the formation on each side of a large posterior palatine fissure paralleling the contour of the alveolar bone. The posterior border of each fissure is formed by the palatine bone, which is fused to the maxilla in a solid contact. The posterior palatine fissure was noted by Vinacci Thul (1945), which he identified as the posterior palatine foramen. In contrast, Glyptotherium texanum has well-defined palatal foramina situated anterior to the fissures. The fissures apparently transmitted blood vessels. This construction is probably a consequence of the extremely compressed condition of the posterior part of the skull, providing vascular exit in an otherwise extremely crowded region.

The upper and lower teeth are discussed following the description of the mandible.

Jugal.-In vertical and transverse sections the descending process of the jugal is distinctly concave. By virtue of this concavity, this region is separate from the maxillary part of the process. This roughened surface of the jugal forms the concave posterolateral face of the descending process of the zygoma; it is situated half above 
and half below the tooth row. The maximum dorsoventral diameter is approximately $65 \mathrm{~mm}$ on the preserved zygomatic arch of F:AM 95737; it is approximately $15 \mathrm{~mm}$ wide. This area is a principal region of attachment for the masseteric musculature. (The other primary attachment surface for the masseteric muscles is the tip of the descending process, which is heavily rugose.)

The temporal process of the jugal parallels the midline of the skull. It diminishes in thickness rearward, where it contacts the zygomatic process of the squamosal. The sutural contact is obscured on F:AM 95737, the only one of the pair of Arizona skulls with an intact zygomatic arch. From its contact with the temporal, the jugal is inclined forward and downward with respect to the tooth row, forming an angle of approximately $50^{\circ}$. The temporal process of the jugal is laterally compressed with a lens-shaped cross section. In the region of contact with the squamosal (inferred as the middle of the zygomatic arch), the zygoma is weak and underdeveloped relative to the anterior and posterior regions.

Squamosal. - The squamosal is a large compound bone. The squamous portion and the petromastoid are fully represented in the $G$. texanum specimens. The tympanic bulla is not present. The squamous portion includes four distinct regions: the zygomatic process; the squamous process, occupying the posterior dorsolateral region of the skull; the paroccipital process; and the postglenoid process.

The zygomatic process arises from the lateral extremity of the squamous portion. The free anterior surface of the zygomatic process forms the posterointernal border of the temporal fossa. The weakly crested, lower border of this surface is a continuation of the inferior crest of the zygoma, which is confluent with the frontotemporal flange. The superior crest of the zygomatic process continues rearward and upward, curving medially on the posterior third of the squamosal to become confluent with the nuchal crest. This continuation of the superior crest divides the squamous portion into separate superior and inferior surfaces.
Behind the temporal fossa and situated entirely upon the laterally directed (proximal) portion of the zygomatic process is the glenoid articular facet. This transversely elliptical facet is flat both transversely and dorsoventrally, although on both $G$. texanum skulls the facet is very weakly concave laterally, and weakly convex medially, in transverse section. The facet is confined to the lower half of the posterior surface of the zygomatic process. It is directed rearward and slightly downward and outward. The postglenoid area is an open region from the facet rearward to the paroccipital process. Thus the articular facet for the condyle of the mandible is a flat surface, devoid of confining flanges or processes, with a broad, open postglenoid region.

As indicated above, the squamous region of the squamosal is divided into superior and inferior surfaces by the continuation of the superior crest of the zygomatic process rearward to the nuchal crest. The superior surface is anteroposteriorly convex, with flattening of the profile rearward. The transverse section is anteriorly concave, becoming flattened rearward, with the posterosuperior surface facing dorsolaterally and slightly forward. From its vertical contact at the frontosquamosal flange, the frontal-squamosal suture extends vertically upward, and curves rearward at the dorsolateral angle of the skull roof. From that position, the frontal-squamosal suture continues posteriorly, becoming confluent with the parietal-squamosal suture. The course of this suture is difficult to ascertain posteriorly. It curves inward, where the parietals are transversely constricted, then turns outward and rearward, intersecting the superior crcst of the squamosal and becoming incorporated into the lateral angle of the nuchal ridge, where the squamosal shares in the formation of this crest with the squamous process of the occipital. The posterior half of the superior surface of the squamosal is pierced by several large vascular foramina for the cephalic shield similar to those on the frontals and parietals.

The inferior surface of the squamous process (the region below the superior crest) includes 
an expanded, laterally directed supraoccipital process forming the dorsolateral angle of the nuchal crest. The temporal-occipital contact extends laterally rearward and downward for a short distance. The bone in the region of the temporaloccipital contact is greatly thickened. The temporal-occipital contact diverges, exposing the posterior portion of the petromastoid bone. More laterally and ventrally the squamous portion and the mastoid process reconverge at the position of the paroccipital process, half of which is contributed by the squamosal. The fenestra produced by this separation of the squamosal-occipital contact exposes the posterodorsal region of the petromastoid bone; there is no indication of any bony covering over this opening. From the paroccipital process forward the squamous portion of the temporal diminishes in dorsoventral thickness, its upper and lower borders converging with the zygomatic process above the mandibular fossa. The deeply concave mandibular fossa occupies the open region ventral to the lower squamous portion.

The mandibular fossa is bounded above by the medial projection of the lower squamous bone. The concavity thus formed maintains the shape of a quarter sphere, opening outward, downward, and forward. The anterior boundary is formed by the zygomatic process, the interior surface by the postglenoid process.

The postglenoid process of the squamosal is a flattened, roughened region ventral to the squamous process and posterior and ventral to the zygomatic process. The surface of the bone bears an irregular contour; it generally faces laterally and slightly ventrally. The maxillary-squamosal suture continues inward and rearward from the zygomatic process. At approximately half the distance between the foramen ovale and the zygomatic process the alisphenoid overlaps both the maxilla and the lower border of the squamosal in a forward directed process. The maxillary-squamosal suture there passes beneath the alisphenoid, and its further course is not evident. The postglenoid process contacts the superior border of the alisphenoid in a well-defined suture. This suture passes toward the foramen ovale for a short distance and then turns upward, passing above the foramen. The posterior margin of the postglenoid process is markedly thickened, for open contact (nonsutural) with the anterior region of the petromastoid in two poorly defined, rearward facing concavities. This surface extends upward, outward, and rearward toward the paroccipital process.

The petromastoid includes two distinct regions, the petrous region and the mastoid process, which form the anterolateral portion of the paroccipital process. The mastoid process is heavily pitted and irregular. It is suturally united with the paroccipital process of the squamosal anteriorly, and with the paroccipital process of the occipital posteriorly. The participating bone in both contacts is greatly thickened. Thus the mastoid process occupies an intermediate position between the squamosal and occipital, the respective processes of each forming the compound paroccipital process. Internally, both above and below, the petrous portion is exposed. The upper exposure of the petromastoid (posterolateral fenestra) was described above.

The lower exposure is afforded by the lack of the tympanic bullae in the preserved specimens. The petrous squamosal arises from the anteromedial region of the mastoid process. It projects inward, forward, and slightly downward, partially filling the void between the basioccipital and the postglenoid process of the squamosal. Its shape is pyramidal, suggestive of a doubly convex prism. The external auditory meatus emerges from its ventrolateral surface. A laterally directed channel on the ventral surface of the mastoid process evidently communicated with the meatus by a cartilaginous connection.' The posterior lacerate foramen is bounded anteriorly by the posterior surface of the petromastoid. This elliptical foramen is bounded posteriorly by the basioccipital, and it communicates freely on its medial border with the apparently open basitemporal vacuity. This vacuity is formed by the failure of the petromastoid to enclose the posterolateral region. Its relatively large size is likely 
due to the coalescence of several of the major foramina of the braincase resulting from the crowded condition of the component bones in this region.

Pterygoid-Palatine-Sphenoid Region.Both Vinacci Thul (1945) and Burmeister (1874) described the bones of the basicranium and posterior nares in some detail. Vinacci Thul identified only the palatine and "sphenoids." He accurately described and named the sphenomaxillary fissure, which contains the complex of foramina including the foramen rotundum. He also mentioned a round foramen posterior and lateral to the sphenomaxillary fissure but did not identify it; his description seems to indicate the foramen ovale, as described herein. Burmeister correctly identified these two foramina, and he discussed the palatine-pterygoid complex without reaching a firm conclusion regarding their respective contributions to the posterior narial aperture. He suggested, however, that the pterygoid formed the posterointernal margins of the lateral walls of the narial aperture. Vinacci Thul indicated that the palatines occupied this position instead. This region presents serious difficulties at interpretation in the Arizona skulls because of the strongly fused sutures, and because of the peculiar construction of the alisphenoid, as described below. The following description concurs with Burmeister's suggestions and is at variance with Vinacci Thul's description. It should be pointed out, however, that until the taxonomic identities of the South American and North American genera are more satisfactorily established, the differences noted herein may not indicate erroneous interpretations; instead there may be significant distinctions between taxa, and the one or the other of the skulls described by these two authors might not belong in Glyptodon proper.

The cause for confusion in this region lies in the extreme reduction in the antcroposterior extent of these bones, unlike any other mammal. This reduction is a consequence of the peculiar masticatory apparatus, for which the posterior region of the skull has been foreshortened in order to optimize the effect of the massive masseteric musculature. Accordingly, portions of cach max- illa, palatine, pterygoid, and alisphenoid participate in the formation of the pterygoid processes. These are situated posterior to the last tooth alveolus on each side, at the lateral corners of the vertical posterior narial aperture. Their construction is rather bosslike, each forming a prominent, rounded, and rugose surface at this position, which is essentially in the horizontal plane of the palate. The pterygoid processes taper upward along the margin of the nares, the rugosity and massiveness giving way to the sharp smooth surface of the aperture.

The posterior narial aperture is a vertical, trapezoidal opening. The frontal plane of the aperture lies in the same plane of contact as the basisphenoid-basioccipital surure. (The position of this suture graphically indicates the extreme shortening of the bones in this region.) The upper border of the aperture is formed by the basisphenoid. The superolateral borders of the aperture are formed by the common angle of the alisphenoidpterygoid contact. Inferiorly the pterygoid processes occupy the lateral margins of the nares in a blunt rugose surface. The inferior border of the nares is formed by the palatal (horizontal) processes of the palatines, which are fused at the midline.

Palatine. - The reduced but stout palatines occupy the inferior border of the posterior narial aperture, which is situated immediately behind the last alveolus. Each palatine possesses two processes, the horizontal process and the vertical process. The posterior margin of the horizontal process is free, occupying the inferior border of the narial aperture. Anteriorly the horizontal processes, which fuse at the midline, are firmly united to the palatal processes of the maxillae. The anteroposterior diameter of the horizontal process of the palatines at the midline is only about $1 \mathrm{~cm}$; thus the palatines contribute little to the total length (approximately $18 \mathrm{~cm}$ ) of the base of the palate. The palatine-maxillary suture is a straight transverse contact, and it is limited to the region bchind the frontal plane of the posterior alveoli. The latcral extension of the maxilla-palatine contact is interrupted by the posterior palatine fissure, the posterior margin of which is contributed 
by the palatine. The horizontal process of the palatine contacts the exterior surface of the superior maxillary immediately behind the last alveolus. This short contact terminates laterally in a sharp angle at the intersection with the pterygoid process of the alisphenoid, on the lateral surface of the pterygoid tuberosity.

The posterior border of the lateral portion of the palatine is firmly united with the alisphenoid on the inferior posterolateral surface of the pterygoid tuberosity. This suture continues medially as the pterygoid-palatine contact on the inferior posteromedial surface of the pterygoid tuberosity. The pterygoid-palatine suture extends vertically on the inner surface of the posterior nares as the posterior extremity of the vertical process of the palatine. Superiorly the vertical processes fusc with the basisphenoid in a right angle contact. The vertical process is anteroposteriorly convex in an oblique direction, from anteroventral to posterodorsal. Thus, viewed from the rear, the walls of posterior nares diverge rearward; this divergence is maintained by the pterygoids, which form the posterior margin of the nares. The anterior extent of the palatines cannot be determined. In the region of the anterior apex of the basisphenoid the vertical processes of the palatines nearly come into contact. Their walls diverge inferiorly in this area, thus creating in cross section a trapezoidal outline of the interior surface of the narial aperture in the frontal plane of the apex of the basisphenoid. This cross section becomes reversed posteriorly, owing to the convexity of the vertical processes of the palatines and their consequent oblique posterior divergence. Thus the cross section of the nares at the contact with the pterygoids is an inverted trapezoid. The same cross section, with greater dimensions, obtains at the posterior border of the nares.

Therefore, as interpreted here, the palatine is confined in its horizontal process to the region behind the last alveolus. The vertical process, however, extends forward as the lateral wall of the nares at least to the plane of $\mathrm{N}^{7}$, and perhaps somewhat farther.

Pterygoid.-Occupying the internal posterior extremity of the lateral wall of the nares is the pterygoid. Ventrally, each vertically oriented pterygoid contributes the major portion of the large rugose pterygoid tuberosity. The pterygoid possesses the portion of the tuberosity that includes the greatest development of the tubercle. The inferior and lateral contributions of the palatine and alisphenoid, respectively, participate as adjacent bones, circumscribing in part the tuberosity. The short pterygoid-maxilla suture passes through the lower extremity of the pterygoid tuberosity.

The pterygoid is an elongate, triangular pyramid, apex upward. The basal contact with the maxilla was described above. The three faces of the triangular cross section face anteriorly, posteromedially, and laterally. The anterior side forms the pterygoid-palate contact in a strong suture. The posteromedially facing side forms the posterior extremity of the interior wall of the nares. The posterior margin, which superiorly becomes a sharp crest, is parallel with the palatine-pterygoid suture. Dorsally the pterygoid is united with the horizontal basisphenoid in a right-angle suture. From the upper extremity of the palatine-pterygoid suture the pterygoid-basisphenoid suture extends in an oblique superiorlateral-posterior direction, terminating in the sharp apex of the pyramidal construction of the pterygoid.

The posterolaterally directed face is overlapped superiorly by the alisphenoid (i.e., the pterygoid lies internal and inferior to the alisphenoid). The inferior region is transversely thickened and broadly rounded, forming on its exposed surface the major portion of the pterygoid tubercle, as described above. There is a distinct vertical flange on the lateral surface of the vertical crest of the pterygoid. This flange expands ventrally with the increasing thickness of the bone. This groove appears to have transmitted blood vessels and/or nerves from the basioccipital-temporal fenestra, anterior to the petromastoid, downward to the muscles attaching to the pterygoid tuberosity. Near its superior extremity, the anterior wall of this groove is contributed by a flange of the alisphenoid. The posterolateral surface of the 
pterygoid thus forms the bluntly rugose and greatly thickened posteroinferior terminus of the narial encasement.

This construction of the pterygoid tuberosity, which forms a broad, blunt, rearward-facing surface for muscle attachment, is closely associated with modifications attendant with the development of the descending process of the zygoma and the consequent horizontal direction of the masseteric musculature.

Vinacci Thul's (1945) description of the palatine corresponds closely to that provided here for the pterygoid-palatine complex. Although we have not examined the skull he described, it seems possible that the palatine-pterygoid suture was obscured because of the heavily rugose surface of the pterygoid tuberosity. The palatine and pterygoid together could easily be taken for a single bone, and because of their position (posterior to the maxillae), identification as palatine would be reasonable. The descriptions provided here for Glyptotherium texanum are in close agreement with Burmeister's (1874) suggested identifications of the cranial bones of Glyptodon.

Basisphenoid. - The triangular basisphenoid occupies the roof of the posterior end of the nares and the base of the cranium. Its lateral borders converge anteriorly in an apex, owing to the anterior convergence of the palatines, with which the sides of the basisphenoid are fused in a right angle. Posteriorly the basisphenoid contacts the basioccipital in a strong union. This suture is situated in the vertical plane of the posterior narial aperture. Both bones at this contact are thickened medially, and the thickness decreases laterally, forming a lens-shaped cross section at the suture. The posterolateral apices of the basisphenoid are free, contributing to the bordcr of each basitemporal vacuity.

The lateral borders of the basisphenoid are united posteriorly with the upper extremities of each pterygoid in a short, right angle, sutural contact. The basisphenoid appcars also to contact horizontally the alisphenoid immediately bchind the foramen ovale, although the sutural contact is obscure. The anterior contact with the vomer cannot be ascertained. Presumably this union is situated at the anterior constriction of the superior borders of the palatines.

The narial surface of the basisphenoid is smooth and flat. The basicranial surface is transversely concave and rugose.

Alisphenoid.-As interpreted here, the alisphenoid and orbitosphenoid are separate bones. The alisphenoid occupies the lateral surface of the vertical wall of the posterior nares. The identification of the alisphenoid is founded on the presence of the foramen ovale, which is situated in the posterosuperior position of the bone. The alisphenoid anteriorly contributes the bulk of the sphenomaxillary fissure, the borders of which are in part shared with the superior maxillary and the reduced orbitosphenoid.

From its strong sutural union with the postglenoid process of the temporal, the alisphenoid extends downward in a vertical process, which lies on the lateral surface of the pterygoid. This thickness of the bone diminishes downward, terminating as a thin flange abutting the pterygoid near the superior apex of the posterior extremity of the vertical process of the palatine. The inferior extremity of the alisphenoid contributes the rugose, superior lateral surface of the pterygoid process.

The lateral-facing external surface of the alisphenoid is irregular. Beneath the foramen ovale the external surface is anteroposteriorly concave, apparently providing a broad, downward, and forward-directed groove for the transmission of the maxillary branch of the trigeminal nerve. In vertical section the external face of the alisphenoid is superiorly concave, nearly attaining a horizontal aspect at the temporal suture. The laterally directed inferior surface is flat and rugose.

The posterior margin of the alisphenoid contributes the anterior flange of the vertical pterygoid-alisphenoid groove, as described above. The alisphenoid-pterygoid suture lies within this groove. The suture extends downward and curves anteriorly on the external surface of the pterygoid, where the thin descending process of the alisphe- 
noid laps over the pterygoid. This suture continues forward and upward as the alisphenoid-superior maxillary suture. In this region also, the alisphenoid overlaps the maxillary, so that the maxillary-pterygoid suture is covered by the alisphenoid. The anterior border of the alisphenoid is irregular in shape, passing vertically upward from the rounded lower margin toward the sphenomaxillary fissure, where the alisphenoid is deflected inward as its posterior wall. The sharp anterior margin therefore shields the sphenomaxillary fissure as a sharp flange. Situated on the anterointernal wall of the alisphenoid, within the fissure, is the foramen rotundum. Its elliptical orifice opens downward and forward. The anterior lacerate foramen is situated immediately anterior to the foramen rotundum, within the fissure. Its opening is directed laterally. The walls of the anterior lacerate foramen are formed by the superior maxillary and the alisphenoid. The optic foramen probably also lies within the sphenomaxillary fissure, in the region contributed by the orbitosphenoid.

The sphenomaxillary fissure thus houses the anterior lacerate foramen, the foramen rotundum, and probably the optic foramen. The posterosuperior margin is formed by the alisphenoid flange, the anteroinferior margin by the recessed superior maxillary, and the anterosuperior corner by the orbitosphenoid. The fissure opens laterally downward and forward, providing exit for nerves passing forward beneath the exposed surface of the orbitosphenoid to the groove formed by the maxillary process of the frontal. Thus the optic nerves and the anterior division of the trigeminal are provided considerable protection by the combination of the sphenomaxillary fissure and the maxillary process of the frontal on the side of the face beneath the temporalis musculature.

The alisphenoid is expanded into a short, anteriorly directed flange, overlying the orbitosphenoid from the anterior region of the temporal suture. The orbitosphenoid-alisphenoid contact is hidden by this flange. It should be noted that the bone here identified as the orbitosphenoid may actually be ontogenetically fused with the ali- sphenoid, as the contact between these two presumed, separate bones is obscure. However, the recessed position of the orbitosphenoid (as here described) and its relatively smooth texture distinguish this region from the main body of the alisphenoid. If in fact the two bones are ontogenetically fused, the orbitosphenoid process represents the orbitosphenoid proper. Hence these two bones are here considered as separate entities.

OrbitosPHENOID.-The anterior extension of the thin alisphenoid covers the surface of the orbitosphenoid. In skull F:AM 59583 the alisphenoid processes are broken, exposing the reduced orbitosphenoid. Only the exterior surface of the orbitosphenoid can be described. The orbitosphenoid contribution to the floor of the brain cavity cannot be determined. Lying beneath the alisphenoid flange, which contacts, but does not unite with, the posterior-inferior angle of the frontal behind the maxillary process of the frontal, the orbitosphenoid forms the upper surface of the anterior extension of the sphenomaxillary fissure. It appears to be comprised of two parts, a small horizontal process, continuous with and suturally united to the frontal, and a vertical process, suturally contacting the superior maxillary. The two processes are indistinctly separated by the groove that passes anteriorly from the sphenomaxillary fissure toward the frontomaxillary flange. The orbitosphenoid appears to be confined to the region behind and inferior to the maxillary process of the frontal. Because the latter process overlaps the orbitosphenoid anteriorly, its forward extension cannot be ascertained. It lies internal to the tubercles bordering the frontal flange, and it occupies the intermediate position between the sphenomaxillary fissure and the anteriorly directed groove lying beneath the frontal flange. The orbital foramen is not exposed; presumably it is situated within the sphenomaxillary fissure.

Occipital.-For purposes of description the occipital can be divided into four regions: the squamous region, the paroccipital region, the occipital condyles, and the basioccipital; these welldeveloped regions are solidly fused into the single 
occipital bone to form the large, posterior extremity of the skull.

The thin-boned, dorsal, squamous region is broadly concave in the transverse direction and anteroposteriorly flat. The dorsal surface is distinctly concave along the nuchal crest, where the bone is greatly thickened to meet the parietal and temporal bones. The squamous plate is inclined forward at an estimated angle of $45^{\circ}$ with the posterior palatal region. Thus the squamous occipital attains a significant horizontal component in its attitude, apparently unlike any other terrestrial mammal. In dorsal aspect the squamous region forms a broad, concave plate, fusing anteriorly with the parietals and laterally with the squamous temporals. The apex of the nuchal crest forms approximately a right angle. The posterolateral extensions of the nuchal crest become greatly expanded in the dorsal region of contact with the squamous portions of the squamosals to form the supraoccipital processes. These massive tuberosities form the posterodorsal extremities of the skull. Apparently Melton (1964: 131) was referring to these when he stated that "the external occipital protuberance sits well forward for the attachment of heavy neck muscles," although he may have intended to indicate the apex of the nuchal crest at the juncture with the parietals. In actuality there is no external occipital protuberance, which is usually taken to designate a median tubercle on the squamous occipital, sometimes contiguous with the nuchal crest. Between the supraoccipital processes the squamous occipital is smooth and uniformly concave. The rugose supraoccipital processes are situated above the posterior petromastoid fenestra and form the principal attachment surface for the heavy neck musculature.

Posteriorly the squamous occipital contributes the broad, superior border of the foramen magnum.

The paroccipital region includes that portion of the occipital that is situated posterior and ventral to the supraoccipital process and the occipital contribution to the paroccipital process. This region is separated from the squamous por- tion by a weak external occipital crest, extending obliquely forward from the dorsolateral margin of the foramen magnum. The dorsal portion of the paroccipital region is flat. Its free anterosuperior margin forms the rear border of the posterior petromastoid fenestra. Beneath the fenestra, in the region immediately lateral to the occipital condylc, is the paroccipital process. The mastoid and paroccipital processes of the squamosal contribute the anterior third of the compound paroccipital process. Ventrally the mastoid-paroccipital suture terminates at the lateral extremity of the border of the basioccipital. The paroccipital process is separated from the occipital condyle by a narrow, shallow groove. The external rugose surface of the process lies below the plane of the condyle, and it maintains a similar profile.

The basioccipital is a broad $Y$-shaped region forming the posterior basicranial extremity. Anteriorly the basioccipital is medially united with the basisphenoid in the vertical plane of the posterior narial aperture. As described previously, the bone on both sides of this suture is centrally thickened, diminishing in thickness laterally. The basioccipital in this region is convex on both the internal and external surfaces. Its anterolateral extent is exceeded by the extent of the basisphenoid, forming a notch at this constriction for vascular or nervous passage from the basitemporal vacuity into the nares. The lateral borders of the basioccipital are free, forming the internal margins of the basitcmporal vacuities. These borders are posteriorly divergent in an angle of approximately $60^{\circ}$. The posterior extremity of the basioccipital forms the inferior border of the foramen magnum. A median line connecting the superior and inferior borders of the foramen magnum passes forward and downward, intersecting the median postcrior margin of the palate, and forms approximately a $45^{\circ}$ angle with the palate. Thus the elliptical foramen magnum opens posteriorly downward. This construction is likely attendant with the modifications for the strong neck musculature passing over the occiput to the nuchal crest and the supraoccipital processes. 
Piercing each of the lateral wings of the basioccipital near the occipital condyles are the round hypoglossal foramina. A notch on the posterior extremity of the free lateral border of each wing contributes the posterior margin of the posterior lacerate foramen.

The paired occipital condyles occupy the region lateral to the foramen magnum, the lateral margins of which are formed by the medial borders of the condyles. The transversely elongate condyles are relatively small. Their shape approximates the lower half of a conical section, the base of the cone medial. A pair of small accessory facets projects medially from the ventral border of each condyle; they do not meet at the midline. These facets evidently provided a ventral stop for the atlanto-occipital articulation.

The skull of $G$. arizonae (UMMP 34826, 38761, Figure 10) differs from that of $G$. texanum in several important respects, especially in the postglenoid region. The prezygomatic region is unknown; it is presumably similar to that of $G$. texanum as described above. Except for greater absolute size in all dimensions (Table 1), the preglenoid region of $G$. arizonae closely resembles that of $G$. texanum. The most significant distinctions occur in the basicranial region.

Whereas the bone comprising the upper border of the mandibular fossa is smooth and entire in $G$. texanum, there is a distinct glenoid foramen in G. arizonae. This foramen is apparently not a blind passage, but provides exit from the cranial cavity to the glenoid fossa for nerves and blood vessels to the muscles of the temporal-mandibular capsule. We have been unable to establish the proper homology of this foramen. Its apparent absence in $G$. texanum may be due to the preservation in the skulls of this species.

The foramen ovale and the sphenomaxillary fissure appear to be identical in these two species. The paroccipital processes exhibit a much greater development in $G$. arizonae than in $G$. texanum, although in the skulls of the latter species the processes are partially broken and their full extent is therefore indeterminate.

A distinction in the paroccipital region of $G$. arizonae is the presence of a deep canal behind the paroccipital process. This canal passes downward and inward from the region of the posterior "fenestra" of the petromastoid toward the region of the (missing) tympanic bulla. In actuality, the posterior "fenestra" region of $G$. arizonae is covered by a thin sheet of bone from the mastoid process of the temporal bone, uniting with the mastoid process of the occipital on the inner surface of this channel. There is no indication of this covering over the posterior fenestra in the skulls of $G$. texanum, nor is there any indication of a canal in this position.

Another important distinction occurs in the construction of the basioccipital region. Whereas the basioccipital-basisphenoid contact lies in the plane of the posterior nares in $G$. texanum, this union appears to occur more posteriorly in $G$. arizonae. Moreover, the external surfaces of these two bones meet in a poorly defined obtuse angle in $G$. arizonae, rather than being nearly contiguous as in $G$. texanum. The median inferior margin of the foramen magnum extends farther forward in $G$. arizonae, imparting a more deeply clefted $\mathrm{Y}$ shaped basioccipital.

Another distinction characterizing $G$. arizonae is the presence of a deep concave pit on the anterior border of the ventral extremity of the occipital condyle. The hypoglossal foramen is situated within this recess. Concomitantly, the occipital condyle is more extensively developed and the separation of the articular region from the nonarticular surface is more well defined. There is a similar depression above each occipital condyle on the squamous occipital. These recesses presumably allowed greater vertical motion at the atlanto-occipital joint.

Because of the fragmentary nature of the skull material assigned to $G$. floridanum, fewer distinctions can be determined for this species. The cranial fragments of USNM 6071 (Figure 11) indicate no obvious differences in the palatal and central cranial regions. The basicranial region in this specimen indicates a closer resemblance to $G$. arizonae in the possession of the problematical glenoid foramen. The well-preserved postglenoid 
region of ChM 2415 (Figure 12), which overlaps only slightly in its preserved parts with USNM 6071 , presents several important distinctions that presumably serve to fix the characters of $G$. floridanum (assuming that the assignments of USNM 6071 and ChM 2415 to the same taxon as the remaining Florida and Texas $G$. floridanum material is correct).

The squamous occipital of ChM 2415 bears a median longitudinal ridge from the apex of the nuchal crest to the foramen magnum. This ridge distinctly separates the squamous occipital into right and left halves. There is no corresponding ridge in either $G$. texanum or $G$. arizonae. Also, the squamous occipital is more steeply inclined with respect to the cranial roof, forming an angle of approximately $65^{\circ}$

The occipital condyles are more nearly cylindrical in comparison with the cone-shaped condyles of $G$. texanum and $G$. arizonae. The inferior and superior recesses bounding the condyles are intermediate in development between the deep recesses of $G$. arizonae and the flat surfaces of $G$. texanum. The external-medial extremity of the hypoglossal foramen extends as a short open canal in $G$. floridanum; there is no canal-like exterior construction in either $G$. texanum or $G$ arizonae. The basioccipital-basisphenoid contact more closely resembles the flattened contact of $G$. texanum. There is a pronounced cleft in the median ventral border of the foramen magnum, contrasting with the smooth contour in the other two species. A final noteworthy distinction of ChM 2415 is a pronounced downward extension of the ventral extremity of the petromastoid, producing a distinctive crest at the terminal apex. This region is flattened in $G$. arizonae and smoothly rounded in $G$. texanum.

As Ray (1965) pointed out, ChM 2415 differs from USNM 6071 in the construction of the medial parietal region. This region is elevated in ChM 2415 and is flattened in USNM 6071 and in $G$. texanum and $G$. arizonae. Future recoveries may substantiate this distinction between ChM 2415 and USNM 6071, necessitating reevaluation of the taxonomy as here proposed. Three scutes associated with ChM 2415 (ChM 2090, 2417, and 2418 ) indicate a close resemblance to both $G$. arizonae scutes and $G$. floridanum scutes from other localities. This provisional assignment of the South Carolina material to $G$. floridanum is supported also on geographic grounds, for $G$. arizonae and $G$. texanum are not certainly known from eastern United States, although isolated Florida material, mostly scutes, indicates the early presence of glyptodonts, probably $G$. arizonae, in that state. The associated vertebrate fauna for the Edisto Island cranium appears to be entirely late Pleistocene (Roth and Laerm, 1980), consistent with our assignment to $G$. floridanum.

Mandible (Table 2).-Mandibles of various North American glyptodonts have been described by Gidley (1926), Holmes and Simpson (1931), Meade (1953), Melton (1964), and Lundelius (1972). Except for the very fragmentary mandibular remains of UF/FGS 6643 from the Catalina Gardens site in Florida and a nearly complete hitherto unreported mandible from Orange County, Florida (USNM 11318), there is no new material for study. However, there have been several erroneous statements and consequent misinterpretations concerning the mandible of North Anerican representatives. Only Lundelius (1972) has attempted a comprehensive review, and his determinations were incomplete for lack of comparative materials. A primary misconception centers around Melton's (1964) erroneous assignment of the root end of $\mathrm{N}^{8}$, which had fallen from its alveolus and was cemented to the mandible, as the occlusal surface of $\mathrm{N}_{\bar{\beta}}$ in the Seymour $G$. arizonae. This situation is more fully treated in the description of the dentition, which follows this section. Another problem centers around Gidley's (1926) and Melton's (1964) failures to describe more thoroughly the mandibles of USNM 10536 and UMMP 38761, respectively, from the Curtis Ranch and Seymour faunas. A number of features considered by Lundelius (1972) as distinctive for Boreostracon floridanus (= G. floridanum) are actually present in the Arizona and Texas mandibles, and though distinctive, the differences are not as great as previously supposed. 
Descriptions of mandibles of the South American genus Glyptodon (in the classic sense, see Hoffstetter, 1955) indicate a close resemblance with the North American Glyptotherium. Because of the need for a modern comprehensive study of South American glyptodonts, and for other more problematical reasons as discussed in the taxonomy section, the similarity of mandibular characters between the North and South American representatives should not be so construed as to indicate generic identity. Hence, comparisons of mandibular characters, like comparisons of other features, are here intended to indicate only the close similarity.

Only the mandible of $G$. arizonae is completely known. USNM 10536 (Figure 13) is an entire mandible, with a full set of teeth. UMMP 38761 (Figure 14), in separate right and left sides, com- prises a nearly complete composite mandible. Comparisons of the mandibles of these two specimens indicate their close relationship and provide partial foundation for the determination of specific identity between the Curtis Ranch and Seymour representatives. The mandible (TMM 934-37) from the Holloman gravel pit, Oklahoma, originally accorded generic distinction by Meade (1953) as Xenoglyptodon fredericensis, and later recognized as identical with the Seymour glyptodonts by Melton (1964) is a partial right mandible with portions of the horizontal and ascending rami, including $\mathrm{N}_{\overline{6}}$ and $\mathrm{N}_{\overline{7}}$ with missing crowns, and partial alveoli for $\mathrm{N}_{\overline{4}}, \mathrm{~N}_{\overline{5}}$, and $\mathrm{N}_{\overline{8}}$. Two scutes were associated with this mandible, and they exhibit no important distinction from the Seymour representatives. The present study agrees with Melton's (1964) contention that Xen-

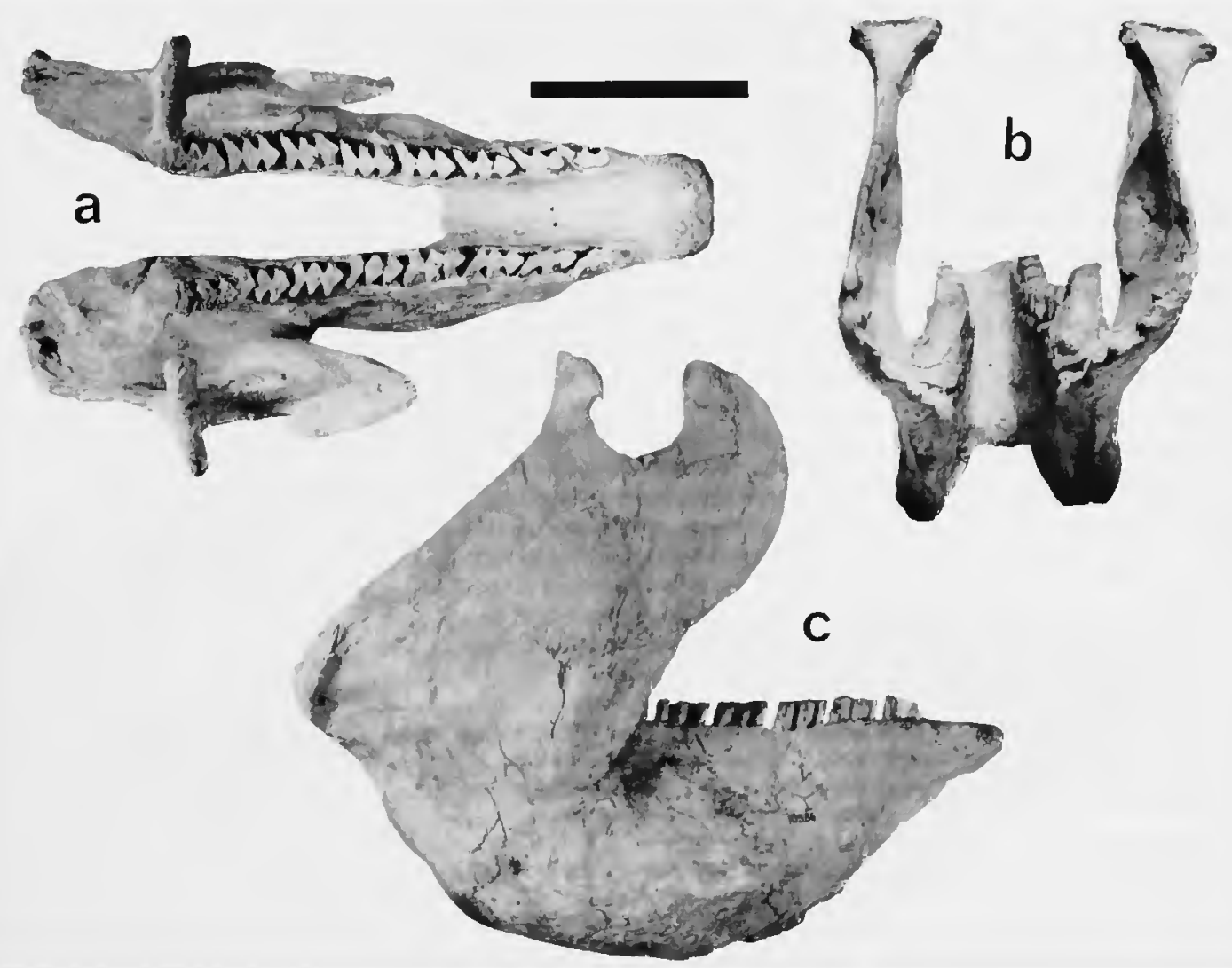

FIGURE 13.-Mandible of Glyptotherium arizonae from the Curtis Ranch fauna, Arizona (USNM 10536): $a$, dorsal; $b$, posterior; $c$, right side. (Bar $=10 \mathrm{~cm} ; c$ slightly larger.) 


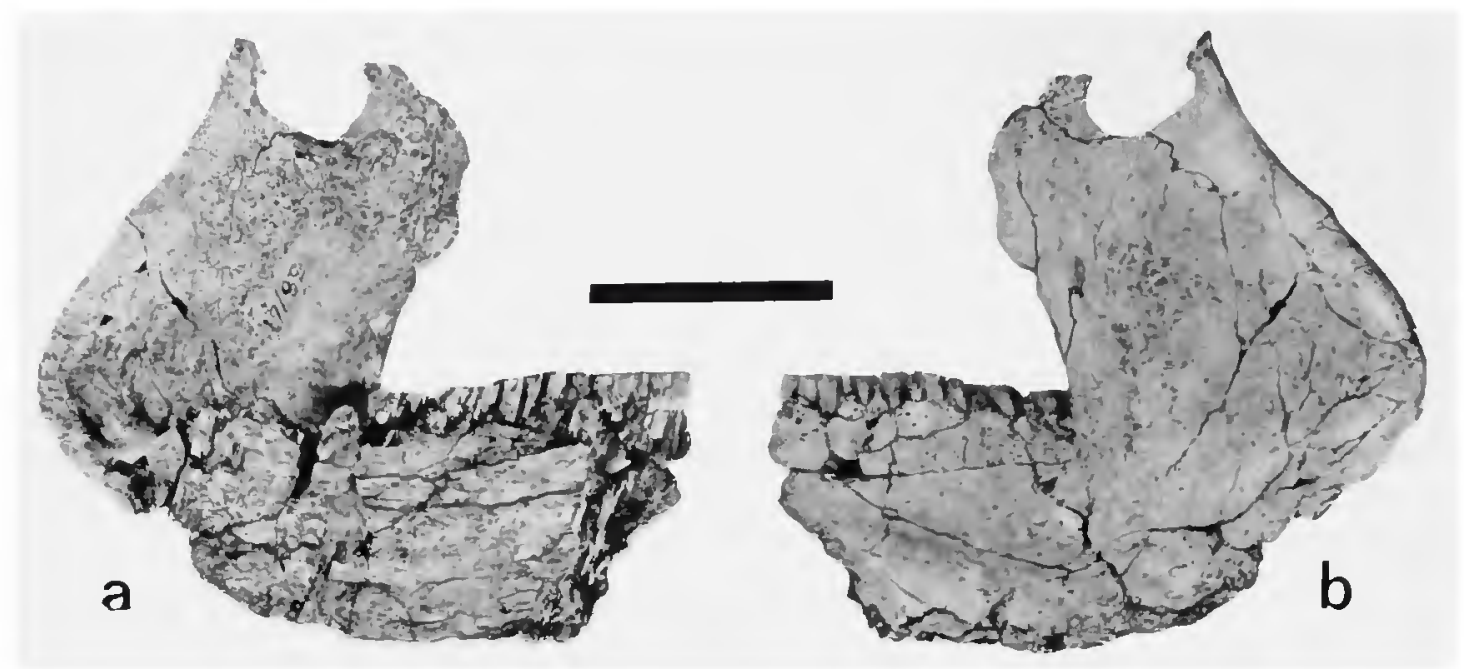

Figure 14.-Left mandible of Glyptotherium arizonae from the Seymour formation, Gilliland local fauna, Texas (UMMP 38761): $a$, medial; $b$, lateral. (Bar $=10 \mathrm{~cm}$.)

oglyptodon fredericensis (Meade, 1953) is synonymous with the Seymour glyptodonts, which are here considered as Glyptotherium arizonae.

The mandible of $G$. floridanum has been described by Holmes and Simpson (1931), and more recently by Lundelius (1972), on the basis of a nearly complete left mandible, missing only $\mathrm{N}_{\overline{\mathrm{I}}}$, the anterior extremity of the symphyseal ramus, the margin of the posterior angle, and the condyle (TMM 30967-1814, Figure 16). Mandibular fragments and fragmentary isolated teeth referable to G. floridanum are known from several other Texas localities, including sites in Bee, Goliad, and Hunt counties (TMM 31034-30, Figure 15b;31186-19; and USNM 6071, respectively); and one from Orange County. Florida (USNM 11318, Figure 17).

The only known mandibular specimens of $G$. texanum are right and left jaw fragments with associated fragmentary $\mathrm{N}_{\overline{1}}, \mathrm{~N}_{\overline{2}}, \mathrm{~N}_{\overline{4}}-\mathrm{N}_{\overline{8}}$ (JWT 2330) and a partial left mandible with broken $\mathrm{N}_{\overline{1}}-\mathrm{N}_{\overline{8}}$ (JWT 1715, Figurc 15a) from the Cita Canyon Blanco beds.

The mandible of $G$. cylindricum is unknown; however, the completc lower dentition is known for this species (AMNH 15548). Comparing these teeth with those of the other North American

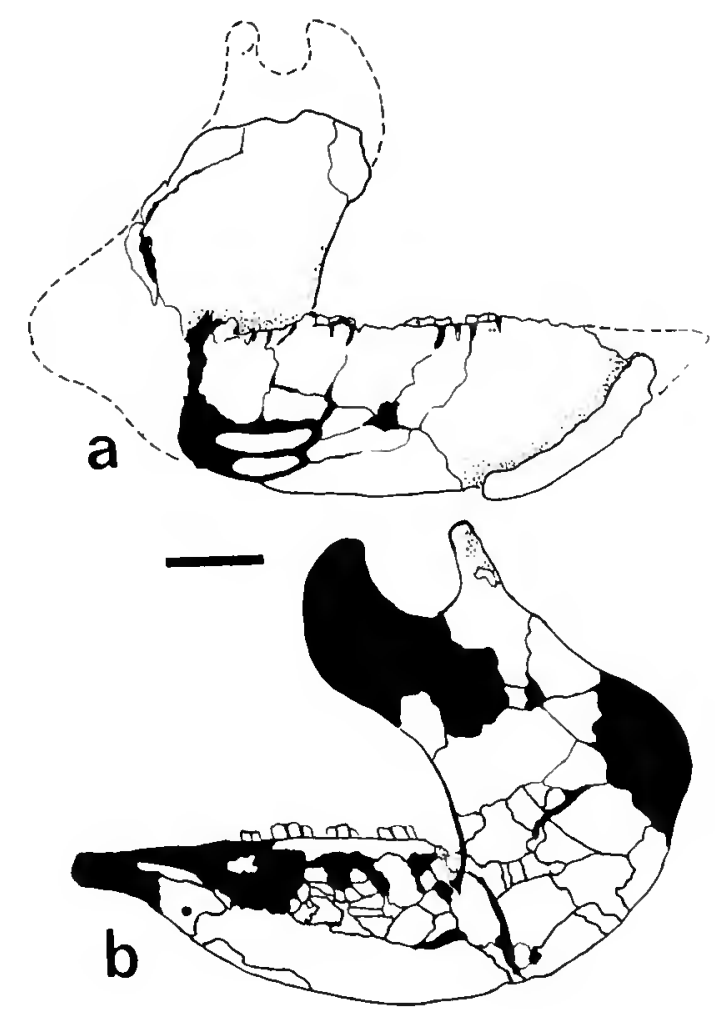

Fisilre 15.-Left mandible: $a$, Glyptotherium texanum (JWT 1715), medial side, reconstructed outline hypothetical; $b, G$. floridanum from Texas (TMM 31034-30). (Bar $=40 \mathrm{~mm}$.) 


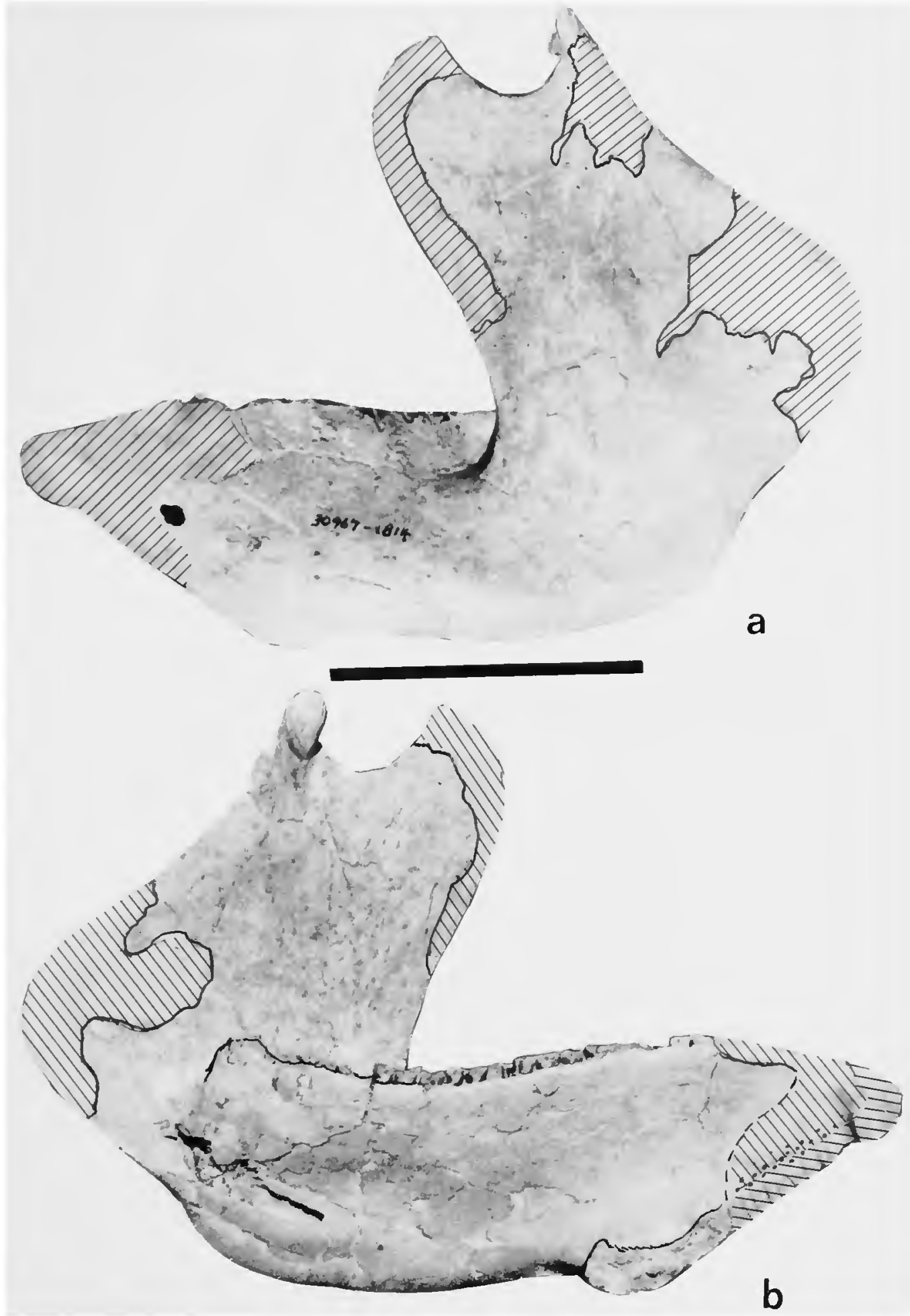

FIgURE 16.-Left mandible of Glyptotherium floridanum from Texas (TMM 30967-1814): a, lateral; $b$, medial. (Reconstructed portions crosshatched; bar $=10 \mathrm{~cm}$.) 

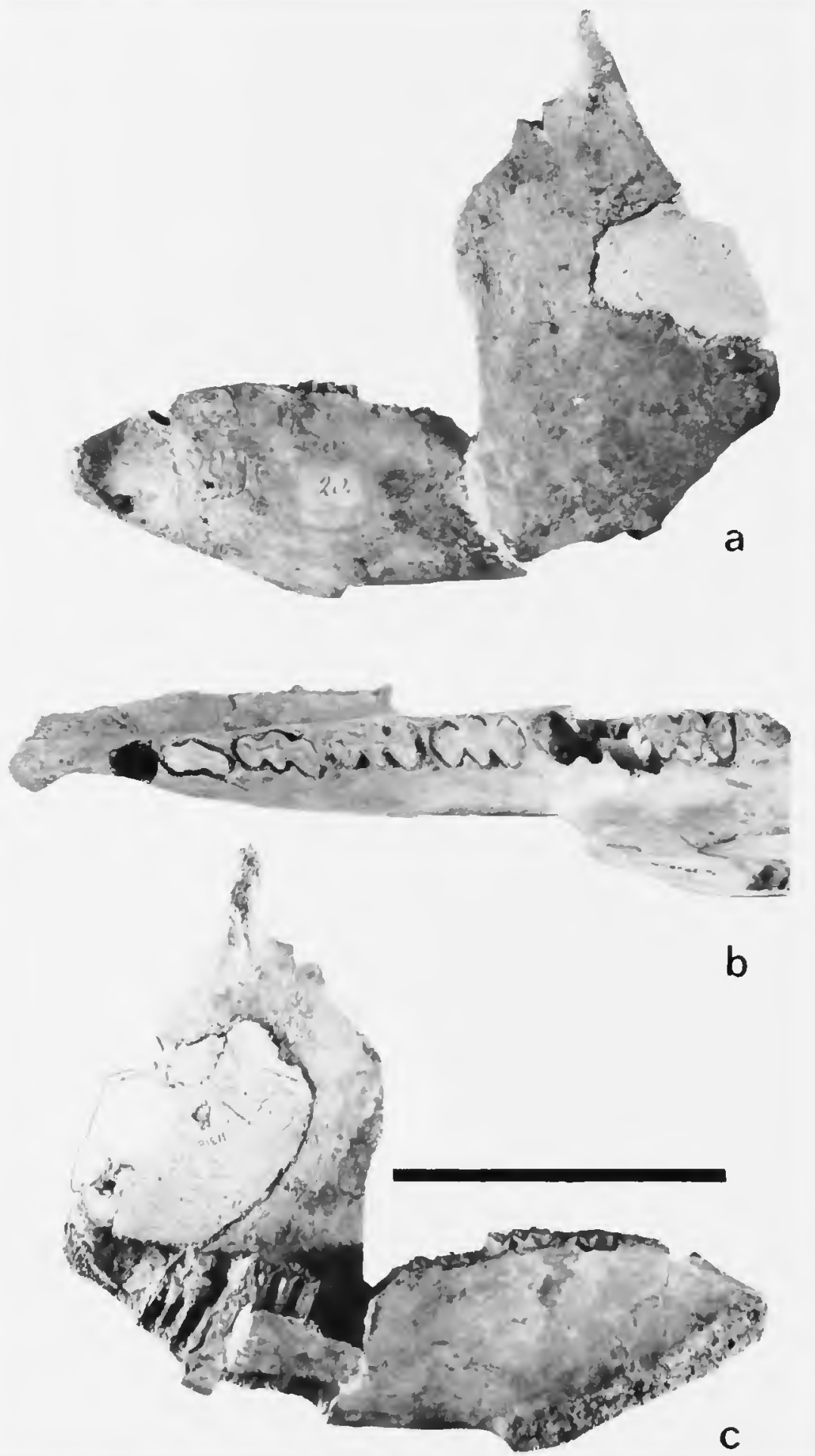

Figure 17, - Left mandible of Glyptuthernum flundanum from Florida (USNM 11318): a, lateral; $b$, dorsal, slightly enlarged; $c$ medial. (Bar $=10 \mathrm{~cm}$.) 
species, it appears that the mandible is probably not significantly different.

The mandible of Glyptotherium is characterized by its extremely massive build associated with lengthening tooth row, open rooted teeth, and the unique masticatory apparatus involving the horizontal disposition of the masseteric musculature. The two sides are solidly ankylosed at the symphysis. The horizontal and ascending rami are subequal in bulk. The condyle is situated well above the tooth row, fully twice the height of the occlusal surfaces from the lower margin of the horizontal ramus. The coronoid process and the posterior angle of the jaw are well developed, and the symphysis bears a spoutlike construction presumably for the long tongue.

Lundelius (1972) and Holmes and Simpson (1931) described the postdental canal for Boreostracon floridanus (= Glyptotherium floridanum) mandibles. Neither Gidley (1926) nor Melton (1964) mentioned the presence of the postdental canal in their descriptions of Glyptotherium arizonae and Glyptodon fredericensis ( $=G$. arizonae), respectively. The postdental canal is indeed present in $G$. arizonae, and it is not significantly different from that of $G$. floridanum. The postdental canal is situated behind the last alveolus, extending "downward and inward and emerg(ing) on the inner side of the mandible where it forms a semicircular groove about $4 \mathrm{~mm}$ across and half as deep" in the Texas G. floridanum (Lundelius, 1972:36). Correct dimensions of $13 \times 7 \mathrm{~mm}$ for the postdental canal were given by Holmes and Simpson (1931) for the Florida representative. In both, the canal emerges on the inner side of the jaw as the true dental canal, as observed by Lundelius (1972). It branches below the last tooth. The postdental canal and the dental canal are similar in the Florida and Texas representatives of $G$. floridanum. As Lundelius (1972:37) observed, "The development of the post-dental canal allows the formation of a buttress at the posterior end of the tooth row without crowding the nerves and blood vessels of the mandible between the posterior end of the tooth row and the posterior end of the jaw."
The strut forming the postdental canal is broken on mandibles of $G$. arizonae (USNM 10536, Figure 13; and UMMP 38761, Figure 14). Its presence is indicated, however, by the broken nature of the bones in this region and by the rearward continuation of the dental canal from the inner surface of the mandible. Thus, although not previously recognized, $G$. arizonae possesses a dental canal and a postdental canal as well. The construction is similar in all respects to that of $G$. floridanum. The dental canal in USNM 10536 is particularly well preserved and is relatively undamaged anterior to the broken strut. The open canal becomes covered below the seventh tooth. It passes anteriorly into the horizontal ramus. Below the last tooth it issues several smaller foramina, which pass inward to the alveolus.

The dental and postdental canals are unknown for $G$. texanum owing to the fragmentary condition of available specimens. It can probably be safely assumed that this species is not very different from $G$. arizonae or $G$. floridanum in this character.

On a provisional basis, the position of the mental foramen may be used to differentiate between species of Glyptotherium. In G. texanum (WT 1715) the mental foramen is opposite the midlobe of $\mathrm{N}_{\mathrm{I}}$. It is more anteriorly placed in $G$. arizonae (USNM 10536) and G. floridanum (USNM 11318). In the Texas representative of the latter species (TMM 30967-1814), the symphyseal region that includes the mental foramen, as indicated by the Florida specimen, is missing. What appears to be a mental foramen in the Texas specimen, located at the edge of the anterior breakage, is probably one of the accessory foramina situated posterior to the mental foramen beneath the second tooth.

The upper margin of the rounded symphyseal region is level with the alveoli in $G$. arizonae. This profile is unknown for G. texanum; it was probably similar to $G$. arizonae. In $G$. floridanum, the upper margin of the symphysis curves downward anterior to $\mathrm{N}_{\bar{I}}$ in a rounded anterior profile. This condition is well indicated in USNM 11318, the only $G$. floridanum mandible with a fully intact symphyseal region. It is puzzling that the recon- 
struction of TMM 30964-1814 includes a similar profile, for the Florida mandible has never been reported. The reconstruction of the Seymour mandible, however, is essentially correct, assuming the identity of the Texas and Florida specimens. Hence, there is a fundamental difference between $G$. arizonae, with a flat anterior profile, and $G$. floridanum, with a conspicuous, downturned curvature in the symphyseal region of the mandible.

The upper surface of the symphysis is heavily rugose, and it protrudes beyond the anterior profile of the skull in a spoutlike construction. This surface probably provided attachment for strong lip musculature. In lateral profile the symphysis in all three species tapers upward in a relatively straight line. The symphyseal inclination is much steeper in $G$. arizonae than in G. floridanum.

For all three species ( $G$. texanum, $G$. arizonae, $G$. floridanum), the posterior extremity of the symphysis occurs in the plane of the anterior lobe of $\mathrm{N}_{\overline{4}}$, and the ascending ramus emerges opposite $\mathrm{N}_{\overline{6}}$. The condyle is situated directly above the last tooth in $G$. arizonae and $G$. floridanum, and probably in $G$. texanum as well.

Apparently the only useful taxonomic characters of the mandible, other than the dentition and the anterior profile of the symphysis, are the shape of the lower margin of the horizontal ramus and the outlinc of the borders of the ascending ramus.

In $G$. arizonae the lower margin of the horizontal ramus is broadly rounded. Its maximum depth occurs in the vertical plane passing through $\mathrm{N}_{\overline{7}}$ and the coronoid proccss. From this position antcriorly and posteriorly the lower margin curves upward and docs not parallel the tooth row. Both USNM 10536 and UMMP 38761 exhibit this shape, although the curvature is slightly morc pronounced in the formcr specimen. In marked contrast, both $G$. texanum (Figurc 15) and $G$. floridanum (Figures 15b, 16, 17) possess a lower margin that is nearly parallel to the tooth row.

Mcade (1953) based the diagnosis of Xenoglyptodon fredericensis in part on the inclination of the anterior border of the ascending ramus of TMM
934-37. Melton (1964), in establishing the synonymy of Xenoglyptodon with the Seymour glyptodonts, did not discuss this characteristic. Indeed, the mandiblc of TMM 934-37, from the Holloman fauna, does seem to have a more nearly vertically oriented anterior border than either the Seymour or Curtis Ranch mandibles. However, the broken condition of the Holloman specimen and the absence of the upper half of the ascending ramus render comparison of this feature partially inconclusive. The emergence of the anterior border from the side of the tooth row is indeed vertical. Above the level of the tooth row, the anterior border is broken away and appears to have been waterworn and abraded. As Melton (1964) determined, the Holloman and Seymour glyptodont mandibular characters are nearly identical, on the basis of the dentition and shape of the horizontal ramus, but definite conclusions regarding the inclination of the ascending rami must await future discoveries from the Holloman locality. On the basis of the similarity in dentition and construction of the scutes, we agree with Melton's (1964) contentions regarding the identity of the Holloman glyptodont.

In all of the remaining specimens, the anterior border of the ascending ramus is uniformly inclined forward at an angle of approximately $60^{\circ}$ to the occlusal surfacc of the tooth row, with increasing inclination above the tooth row, before becoming broadly rounded, leading upivard to the angle of the coronoid process. The anteriormost cxtent of the anterior border occurs in the vertical plane of the rear lobc of $\mathrm{N}_{4}$.

The postcrior margin of the ascending ramus is morc steeply inclincd, forming an angle of approximately $40^{\circ}$ with the occlusal surface of the tooth row in $G$. floridamum, as discussed by Lundelius (1972), and approximately $50^{\circ}$ in $G$. arizonae. Thus the anterior and posterior margins of the ascending ramus are more nearly parallel in C. arizonae than in G. floridanum. The slope of the postcrior margin is indeterminate for $G$. texanum.

The lower cxtent of the posterior margin of the asccnding ramus forms a greatly expanded pos- 
terior extremity of the mandible, which functionally replaces the underdeveloped angular process as a primary region of muscle attachment. The posteriormost extremity occurs approximately at the level of the occlusal surface of the tooth row in $G$. arizonae and $G$. floridanum. This construction seemingly distinguishes the North American glyptodonts from South American representatives, for which the posterior extremity is situated rather above the level of the tooth row, as observed by Holmes and Simpson (1931).

The inner surface of the lower half of the posterior margin of the ascending ramus is marked by distinct grooves for channeling the slips of the masseteric muscles. The outer surface is thickened into a massive boss for muscle attachment.

The condyles are situated well above the tooth row, reaching a height level with the coronoid process. The coronoid fossa is semicircular and relatively shallow. The condyles are transversely elongate and convex dorsoventrally. They are directed forward and slightly upward, occluding loosely with the glenoid articular facets of the skull. There are no confining flanges on the condylar process. The transverse elongation of the condyles indicates a relative freedom of transverse motion in the occlusal action, and the weak construction and anterior direction of the articulation indicate a general lack of vertical stresses at the temporomandibular joint. This construction is more fully treated in the discussion of the functional anatomy of the masticatory apparatus.

Complete descriptions of the upper and lower dentitions are provided in the following sections.

Dentition.-The teeth of all North American species show a close correspondence in occlusal patterns, differing in minor details and in size. Complete upper dentitions (Figure 18) are known for $G$. texanum and $G$. arizonae; a nearly complete upper series, lacking only $\mathrm{N}^{4}$, is known for $G$. clylindricum; and isolated upper teeth are known for both the Texas and Florida representatives of G. floridanum. A complete lower series is known only for $G$. arizonae, although nearly complete series are known for the other species (Figure 19).
Occlusal surfaces of individual teeth are horizontally flat (see schematic illustration in Figure 95); lower occlusal surfaces are directed upward and somewhat medially; upper occlusal surfaces are directed downward and somewhat outward. Unfortunately, there are no complete mandibleskull associations. It appears, however, that all teeth of each series are in full contact when in occlusion. The composite occlusal surface of the lower tooth row is flat along the anterior twothirds and distinctly concave along the posterior third. The composite occlusal surface of the upper tooth row is correspondingly convex posteriorly and flattened anteriorly. There are eight teeth in both the upper and lower tooth rows. As in other edentates, it is impossible to determine the dental formula. All teeth are distinctly molariform with a basic trilobate, prismatic construction. The two anterior teeth, in both the upper and lower series, are smaller and less distinctly molariform than the more posterior teeth, but their construction is otherwise similar, and they doubtless functioned similarly, as the anterior members of the grinding mill. The teeth are confined to the parallel portions of the palate and mandible, respectively; there are no teeth on the rounded symphyseal process, and there is no indication of upper teeth in the standard incisor position. Thus, glyptodonts lack incisiform and caniniform teeth, and they therefore lacked any dental participation in food procurement.

There is no evidence of the eruption sequences, nor is there any indication that glyptodonts possessed separate milk and permanent series. There are available for study three teeth from young individuals (F:AM 23515 and UF/FSM 10623) in which the apex is but slightly worn. From the little worn occlusal surfaces on these teeth, the alveolar portion rapidly increases in diameter and the trilobate construction appears only a short distance from the apex. The bases on all three are broken away. Apparently these teeth simply increased in diameter toward the pulp cavity, eventually attaining full adult proportions through growth and attrition. There is no indication that these are milk teeth, for they are but miniature 
versions of adult teeth. Flower (1868) established the existence of tooth replacement in armadillos. Hoffstetter (1958) suggested polyodonty as a possible explanation for edentate departures from normal mammalian dental formulae. Polyodonty, in the way of suppression of replacement teeth and multiplication of existing tooth germs, is a convenient, though undemonstrable, explanation for the existence of near perfect homodonty in glyptodonts.

Except for the reduced anterior two teeth in both the upper and lower series, individual teeth are three-lobed. The lobate construction is formed by two pairs of opposing longitudinal grooves on each side of the tooth; anterior teeth are progressively less deeply grooved. The teeth are all open rooted, and the pulp cavities remained unclosed throughout life. Except for alveolar thinning of the outer osteodentine ridge, the prismatic teeth of adults are uniform in thickness and construction from the occlusal facet to the pulp cavity. There is no substantial increase in circumference toward the pulp cavity in adult teeth. The outer shapes of the teeth are generally maintained from the occlusal surface downward, although slight variation can be perceived with advancing age, especially with regard to the posterior surface of uppers. Because of the uniformity of individual teeth and the lack of pulp cavity closure, it is impossible to determine relative ages of adult individuals on the basis of dentition alone.

In typical edentate fashion, glyptodont teeth entirely lack enamel. Compensatory elaboration of the osteodentine ridges provides an effective grinding mill, allowing for feeding habits associated with the ever-growing teeth. A thin outer osteodentine rim completely encloses the inner dentine-like core. Additional osteodentine tracts are situated in the center of each tooth, with branches penetrating into the lobes from a main stem. Elaboration of the interior osteodentine tracts in North American glyptodonts is limited to minor secondary branching.

The outer and interior osteodentine ridges stand up in relief above the dentine core. Attrition facets indicate a principal fore-and-aft mastica- tory motion, with secondary lateral motion (Figure 95). This is consistent with the nature of construction of the mandible and its glenoid articulation.

Development of the three-lobed construction of each tooth lengthens the tooth row to the extent that its length is fully three-quarters of the total length of the skull. This extreme proportion, the deep and massive construction of the mandible, and the brachycephaly of the basicranium distinguish the glyptodont skull as unmistakably unique. Perhaps the closest comparison of glyptodont teeth with those of modern mammals is with certain rodents, notably microtines and capybaras. Thus the trilobate construction, the corresponding elongation of the tooth row, and the elaboration of the osteodentine tracts can be viewed as an alternative to enamel.

The following descriptions of individual teeth utilize Hoffstetter's (1958) means of designation: $\mathrm{N}^{1}$ is the anteriormost upper tooth, $\mathrm{N}^{2}$ the next, to $\mathrm{N}^{8}$, the last upper tooth. Similarly, $\mathrm{N}_{\overline{1}}$ is the first lower tooth, $\mathrm{N}_{\overline{2}}$ the second, to $\mathrm{N}_{\overline{8}}$.

Lundelius (1972) questioned Brown's (1912) designations for the positions of the isolated teeth associated with the type specimen of Brachyostracon cylindricus $(=G$. cylindricum). Lundelius suggested that the teeth Brown designated as $\mathrm{N}_{\overline{1}}$ and $\mathrm{N}_{\overline{2}}$ are more like $\mathrm{N}^{1}$ and $\mathrm{N}^{2}$ and that Brown's $\mathrm{N}^{2}, \mathrm{~N}^{3}, \mathrm{~N}^{4}$ are more like $\mathrm{N}_{\overline{2}}, \mathrm{~N}_{\overline{3}}, \mathrm{~N}_{\overline{4}}$ in other glyptodonts. Lundelius further suggested that if his contention regarding the positions of the teeth were correct, then "the lower dentition of Brachyostracon cylindricus is very much like that of Glyptotherium "In actuality, Brown's designations were more erroneous than simple transposition of uppers for lowers and vice versa, as indicated in the following discussion and the accompanying charts.

Proper assignments for the upper dentition of G. cylindricum and Brown's original designations are as follows (* figured in Brown, 1912:170, fig. 1 , upper series; ${ }^{* *}$ same, lower series):
Actual position

$N^{1}($ left)

$\mathrm{N}^{2}$ (left)
Brown's (1912) designation

$\mathrm{N}_{\overline{\mathrm{i}}}$ (right) ${ }^{* *}$ $\mathrm{N}_{\overline{2}}$ (right) ${ }^{* *}$ 


\begin{tabular}{|c|c|}
\hline $\mathrm{N}^{3}$ (lefi) & $\mathrm{N}^{4}(\mathrm{left})^{*}$ \\
\hline $\mathrm{N}^{3}$ (right) & $\mathrm{N}^{4}$ (right) \\
\hline \multicolumn{2}{|c|}{ ( $\mathrm{N}^{4} \mathrm{not}$ present in collection) } \\
\hline $\mathrm{N}^{5}$ (left) & same* \\
\hline $\mathrm{N}^{5}$ (right) & $\mathrm{N}^{\underline{6}}$ (right) \\
\hline $\mathrm{N}^{\underline{6}}$ (left) & same* \\
\hline $\mathrm{N}^{\underline{6}}$ (right) & $\mathrm{N}^{5}$ (right) \\
\hline $\mathrm{N}^{?}$ (left) & same* \\
\hline $\mathrm{N}^{8}$ (left) & same* \\
\hline $\mathrm{N}^{\mathrm{g}}$ (right) & same* \\
\hline
\end{tabular}

Thus, as shown in this chart for the upper dentition, Lundelius was correct in suggesting that Brown was mistaken in the assignment of $\mathrm{N}_{\overline{1}}$ and $N_{\overline{2}}$ (right) and that these were instead the first two teeth of the left upper series, respectively. The tooth Brown identified and figured as $\mathrm{N}^{4}$ (left) is actually $\mathrm{N}^{\underline{3}}$ (left). Similarly, the tooth identified (and unfigured) in the collection as $\mathrm{N}^{4}$ (right) is actually $\mathrm{N}^{3}$ (right). There are no $\mathrm{N}^{4}$ 's represented in the collection; i.e., the teeth Brown identified as $\mathrm{N}^{4}$ are actually $\mathrm{N}^{3}$. Brown's figured designations for $\mathrm{N}^{\underline{5}}-\mathrm{N}^{\underline{8}}$ (left) were correct, although his designated labels for $\mathrm{N}^{5}$ and $\mathrm{N}^{6}$ (right), in the collection and unfigured, were apparently a transposition from the actual order.

Proper assignments for the lower dentition of G. cylindrium and Brown's original designations are as follows (* figured in Brown, 1912:170, figure 1, upper series; ${ }^{* *}$ same, lower series):

\section{Aclual position}

Brown's (1912) designation

$\begin{array}{ll}\left(N_{\overline{1}} \text { not present in collection) }\right. & \\ N_{\overline{2}} \text { (right) } & \mathrm{N}^{\underline{2}} \text { (left)* } \\ N_{\overline{3}} \text { (right) } & \mathrm{N}^{\underline{3}} \text { (left) }^{*} \\ \left(\mathrm{~N}_{\overline{4}} \text { not present in collection) }\right. & \\ N_{\overline{5}} \text { (left) } & \text { same** } \\ N_{\overline{6}} \text { (left) } & \text { same** } \\ N_{\overline{6}} \text { (right) } & \text { same } \\ N_{\overline{7}} \text { (left) } & \text { same** } \\ N_{\overline{7}} \text { (right) } & \text { same } \\ N_{\overline{8}} \text { (left) } & \text { same** } \\ N_{\overline{8}} \text { (right) } & \text { same }\end{array}$

As shown in this chart for the lower dentition, Brown's designations of $\mathrm{N}^{2}$ and $\mathrm{N}^{3}$ are actually $\mathrm{N}_{\overline{2}}$ and $\mathrm{N}_{\overline{3}}$, respectively. $\mathrm{N}_{\overline{1}}$ and $\mathrm{N}_{\overline{4}}$ are not represented in the collection, and $\mathrm{N}_{\overline{5}}, \mathrm{~N}_{\overline{6}}, \mathrm{~N}_{\overline{7}}$, and $\mathrm{N}_{\overline{8}}$ were correctly identified and figured by Brown.

The present assignments of these isolated teeth of $G$. cylindricum are based on direct comparison with teeth of known position in the species $G$. arizonae, $G$. texanum, and $G$. floridanum. Melton's (1964) assignments of the lower teeth of UMMP 38761 ( $G$. arizonae) were erroneous. The tooth Melton considered as $N_{\overline{8}}$ was an upper, from the rear of the associated skull, which was cemented to the rear border of the posterior alveolus of the mandible. This tooth and the cementing matrix were not removed from the lower jaw until the present study revealed this situation. Thus, the occlusal surface Melton identified and figured as $\mathrm{N}_{\overline{8}}$ was actually the unclosed alveolar end of $\mathrm{N}^{\underline{8}}$, and the teeth he identified as $N_{\overline{5}}, N_{\overline{6}}$, and $N_{\overline{7}}$ were actually $\mathrm{N}_{\overline{6}}, \mathrm{~N}_{\overline{7}}$, and $\mathrm{N}_{\overline{8}}$, respectively, from the right mandible. Only the posterior lobe of $\mathrm{N}_{\overline{5}}$ is present on the right mandible; $\mathrm{N}_{\overline{5}}$ is broken and its nature is indeterminate on the left mandible. Measurements provided in Table 8 are composite for the lower series, from the crowns of the left $\mathrm{N}_{\overline{2}}-\mathrm{N}_{\overline{4}}$, and $\mathrm{N}_{\overline{6}}-\mathrm{N}_{\overline{8}}$ for the right side. $\mathrm{N}_{\overline{1}}$ is not present, nor is $\mathrm{N}_{\overline{5}}$ adequately preserved for measurement.

Melton's (1964) assignments for the upper series of UMMP 38761 were correct. His illustrations and discussions of $\mathrm{N}^{2}$ and $\mathrm{N}^{3}$ were incorrect, however. As discussed in more detail below, it appears that $\mathrm{N}^{2}$ is probably trilobed (similar to those of F:AM 95737 and USNM 6071, and distinct from that of AMNH 15548), rather than bilobed, as Melton suggested. Similarly, $\mathrm{N}^{3}$ is less symmetrical than Melton indicated, having relatively underdeveloped buccal portions of the anterior and posterior lobes, respectively. Moreover, the lingual portion of the anterior lobe is more obliquely oriented, rather than perpendicular to the long axis of the tooth row.

$\mathrm{N}^{2}$ and $\mathrm{N}^{3}$ therefore exhibit less departure from other North American glyptodonts than is indicated in Melton's descriptions. It must be stated that our reinterpretation would not have been possible prior to the availability of the excellent comparative material used in the present study.

Upper Dentition (Figure 18, Tables 3-6).- $\mathrm{N}^{1}$ is submolariform, having a simple peglike, prismatic ovoid construction. $\mathrm{N}^{2}$ is intermediate be- 


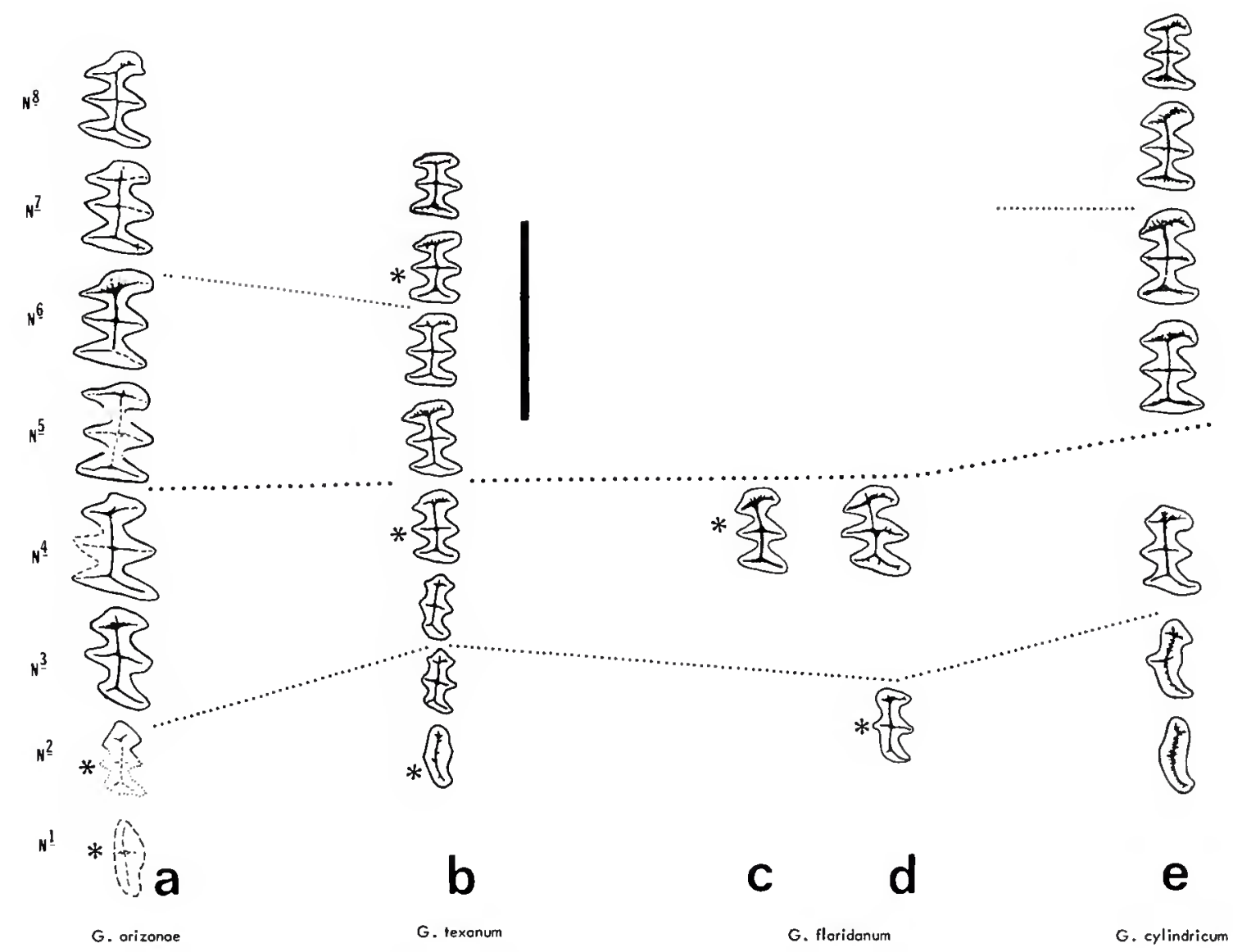

Figure 18.- Upper teeth of North American glyptodonts, occlusal surfaces, left side (asterisk $=$ reversed pattern, taken from corresponding tooth of right side): $a$, UMMP $34826: \mathrm{N}^{1}, \mathrm{~N}^{5}{ }^{\mathrm{k}}$ : UMMP 38761: $\mathrm{N}^{3}, \mathrm{~N}^{4} ; b, \mathrm{~F}: \mathrm{AM}$ 95737; $c$, UF/FGS 6643; $d$, USNM 6071;, AMNH 15548; relative sizes of individual teeth are accurate, but lengths of tooth rows are adjusted for comparison. (Bar $=5 \mathrm{~cm}$.)

tween the submolariform $\mathrm{N}^{1}$ and the nearly completely molariform $\mathrm{N}^{3} \cdot \mathrm{N}^{4}-\mathrm{N}^{8}$ are completcly molariform, having rather symmetrical development of the inner and outer portions of each lobe. Occlusal surfaces of the anterior tceth are paralle! to the planc of the palate. Posteriorly this oricntation is relinquished for progressively more outward-facing occlusal surfaces.

From the occlusal surface, the alveolar portion of $\mathrm{N}^{1}$ curves outward and slightly rearward toward the pulp cavity. The occlusal surface is inclined outward with respect to the cross-sectional plane of the tooth. $\mathrm{N}^{2}$ and $\mathrm{N}^{3}$ are similarly constructed, lacking the posterior component of the alveolar curvature, and with progressive loss of the outward curvature and outward orientation of the wear facet. The outward curvature of the alveolar portion is lost in $\mathrm{N}^{5}$, which is nearly straight. The occlusal surface is inclined forward with respect to the cross-sectional plane in $\mathrm{N}^{3}-\mathrm{N}^{5}$. It is perpendicular in $\mathrm{N}^{6}$ and inclined rearward in $\mathrm{N}^{\underline{7}}$ and $\mathrm{N}^{\underline{z}}$. The latter two teeth, especially $\mathrm{N}^{\underline{8}}$, possess pronounced rcarward curvature of the alveolar portion. The height of the teeth (pulp cavity to occlusal surface) increases gradually to $\mathrm{N}^{6}$ and decreases dramatically from $\mathrm{N}^{6}$ to $\mathrm{N}^{8}$; the height of $\mathrm{N}^{\underline{y}}$ is only about 70 percent of the height of $\mathrm{N}^{6}$ (approximatcly $101 \mathrm{~mm}$ and $70 \mathrm{~mm}$, re- 
spectively) for AMNH 15548. $\mathrm{N}^{8}$ is approximately the same length as $\mathrm{N}^{1}$

The first two uppers, $\mathrm{N}^{\underline{1}}$ and $\mathrm{N}^{\underline{2}}$, are the most distinctive teeth of $G$. cylindricum. $\mathrm{N}^{1}$ is irregularly ovoid, elongated in the anteroposterior direction. The external face of the tooth is convex. The rear half of the internal face is also convex, and the anterior half is recurved in a concave outline, producing an overall weakly sigmoid occlusal pattern. This contrasts with the more pronounced convexity of the internal face in $G$. arizonae and $G$. Otexanum. In the latter two species, $N^{1}$ is more nearly oval, with a less pronounced anterior concavity on the internal face. The osteodentine pattern in all is weakly sigmoid, with a pair of short branches issuing from the center. In $G$. texanum and $G$. cylindricum, the osteodentine tract issues short spinose branches along its main branch. The nature of the osteodentine tract in $G$. arizonae is indeterminate; presumably it possessed similar branching. $\mathrm{N}^{\underline{1}}$ is unknown for $G$. floridanum.

The $\mathrm{N}^{2}$ occlusal pattern of $G$. cylindricum exhibits the most distinctive differences from known $\mathrm{N}^{2}$ 's of other species. The tooth here assigned as $\mathrm{N}^{2}$ for G. cylindricum (Brown's $\mathrm{N}_{\overline{2}}$ ) appears to be properly designated as an upper tooth because the occlusal pattern, the development of the lobes, and the curvature of the tooth are all inconsistent with any tooth of the lower series. Furthermore, the assignments of the distinctive first two lowers are made with confidence, and these positions represent the only possible alternatives that the tooth here designated as $\mathrm{N}^{2}$ could possibly occupy. This tooth is identified as the second in the upper series because of the intermediate development of the lobes with respect to $\mathrm{N}^{\underline{1}}$ and $\mathrm{N}^{\underline{3}}$, and also because of the intermediate, and closely fitting, curvature and asymmetry of the alveolar portion of the tooth.

More specifically, this $\mathrm{N}^{2}$ exhibits no lingual (inner) development of the middle lobe, nor is there any indication of the development of this lobe with age. Instead, in this position, the occlusal pattern is only slightly convex. The outer portion of the middle lobe displays approximately the same configuration as in the other North American species. The anterior lobe appears to be slightly more pointed on the medial apex, and the lingual (inner) portion of the lobe is weakly developed. This is the most distinctive tooth of $G$. cylindricum and it serves to distinguish this species.

$\mathrm{N}^{2}$ of $G$. texanum and $G$. floridanum is trilobate, with a nearly symmetrical middle lobe due to the presence of two well-developed grooves on the internal face, producing a more typical, trilobate occlusal pattern. The external sides of the anterior and posterior lobes are underdeveloped relative to the internal sides. Although nearly as long anteroposteriorly as the succeeding teeth, $\mathrm{N}^{2}$ is transversely smaller; it is intermediate in size between $\mathrm{N}^{1}$ and $\mathrm{N}^{3}$.

Because of the broken condition of both $\mathrm{N}^{2}$ 's of UMMP 34826, the exact configuration of this tooth in $G$. arizonae cannot be determined with certainty. The posterolateral face is flattened, and there is a distinct posterior apex. A portion of right $\mathrm{N}^{2}$ below the missing crown indicates that there was a constriction both externally and internally, producing a posterior lobe. This portion of the tooth more closely resembles that of $G$. texanum. Although Melton (1964) asserted that $\mathrm{N}^{2}$ of this specimen possessed anterior and posterior lobes, and lacked a center lobe, the construction anterior to the posterior lobe cannot be determined with confidence. Because of the closer similarity of the remaining teeth with $G$. texanum, it is likely that $\mathrm{N}^{2}$ of $G$. arizonae is trilobate rather than either bilobate, as Melton suggested, or irregular as in G. cylindricum. The assumption of a trilobate construction should not be accepted as fact, however, since in G. floridanum, which exhibits occlusal patterns otherwise almost identical with G. cylindricum, $\mathrm{N}^{2}$ is more similar to that of G. texanum and quite distinct from $\mathrm{N}^{2}$ of $G$. cylindricum. Hence, resemblances of anterior teeth between species are not necessarily consistent with resemblances of posterior teeth.

Osteodentine branches penetrate both the middle and posterior lobes with perpendicular rami in $G$. texanum and $G$. floridanum. A perpendicular ramus extends only externally into the medioex- 
ternal lobe in G. cylindricum; this branch does not cross the main tract toward the internal face of the tooth. The anterior extremity of the osteodentine tract curves medially into the anterointernal lobe, giving off a short branch toward the underdeveloped anteroexternal lobe as an unequal bifurcation. There is no anterior bifurcation in $G$. cylindricum. There is weak spinose elaboration of the osteodentine tract in G. cylindricum, G. texanum, and $G$. floridanum. Osteodentine patterns cannot be determined for $G$ arizonae.

$\mathrm{N}^{3}$ is indistinguishable among the three species for which it is known. The assignment of $\mathrm{N}^{3}$ from the isolated teeth of $G$. cylindricum is based on direct comparison with this tooth in $G$. texanum and $G$. arizonae, to both of which it is identical. There is an obvious disparity in the teeth in the $\mathrm{N}^{3}$ position between the two Seymour $G$. arizonae skulls. The fragments of teeth replaced into the position of $\mathrm{N}^{3}$ in UMMP 34826 appear not to be $\mathrm{N}^{3}$, nor does the shape of right $\mathrm{N}^{3}$ match that of left $\mathrm{N}^{3}$. Actual $\mathrm{N}^{3}$ is present and unbroken in UMMP 38761, and it is from this specimen that the $\mathrm{N}^{3}$ characteristics of $G$. arizonae are derived. The tooth figured and described by Melton (1964) as $\mathrm{N}^{3}$ was the tooth for which the crown was improperly placed in this position in UMMP 34826. This tooth is probably $\mathrm{N}^{4}$ or $\mathrm{N}^{5}$.

$\mathrm{N}^{3}$ is present in the skulls of $G$. texanum. It is not known for $G$. floridanum; however, the alveolus for $\mathrm{N}^{3}$ in the skull of USNM 6071 indicates close correspondence of the shape of this tooth with those of the other species, especially with regard to the shape and disposition of the anterior lobe and the relative latcral extents of the lobes.

The anterior border of the alveolus of $\mathrm{N}^{3}$ is situated opposite the anterior border of the root of the zygomatic proccss of the maxillary. This is the first fully molariform, trilobate tooth of the upper scries. Each lobe is distinctly wider transversely than the poorly devcloped lobes of $\mathrm{N}^{2}$ and somewhat less expandcd than those of $\mathrm{N}^{4} . \mathrm{N}^{3}$ is characterized by its distinct asymmetry in comparison with the more posterior teeth. The anterior lobe is broadly rounded and convex. Its external side is relatively lcss expanded than the medial. The transverse axis of the anterior lobe is somewhat obliquely oriented with respect to the middle and posterior lobes and to the long axis of the tooth row. The middle lobe is the most widely expanded. It extends farther laterally, but not as far medially in comparison with the anterior and posterior lobes. The posterointernal face of the posterior lobe is broadly convex. The posteroexternal face bears a shallow sulcus, producing a weak concavity in the occlusal pattern at this position. The characteristic asymmetry of this tooth is produced primarily by the oblique disposition of the anterior lobe and the unequal transverse development of the lobes with respect to each other.

$\mathrm{N}^{4}$ is the first tooth to possess equal external and internal devclopment of the lobes. The transverse axes of the anterior and posterior lobes are laterally convergent. The anterior face is slightly convex to straight. The middle lobe possesses equal development of both sides, thus distinguishing this tooth from $\mathrm{N}^{\underline{3}}$ The rear lobe is posterointernally convex. There is a characteristic shallow sulcus on the posteroexternal face, rendering a morc pointed external apex for the posterior lobe. Besides the oblique orientation of the anterior and posterior lobes with respect to each other and the equal development of the middle lobe, $\mathrm{N}^{4}$ can be distinguished from the adjacent $\mathrm{N}^{3}$ by its lack of outward curvature in the alveolar portion. $\mathrm{N}^{4}$ is virtually identical in G. texanum, $G$. arizonae, and G. floridanum. It is notable that the $\mathrm{N}^{4}$ of UF/FGS 6643 ( $G$. floridanum) is identical to that of the Texas representative, USNM 607l. $\mathrm{N}^{4}$ is unknown for G. cylindricum; presumably it was sinilar. Osteodentine rami extend into each lobe, and there is an indistinct branching of the ramus in the posterior lobc.

The posterior teeth of the upper series, $\mathrm{N}^{5}-\mathrm{N}^{8}$, have nearly identical patterns, and they are identical in size, except for the only known $\mathrm{N}^{8}$ of $G$. cylindricum (AMNH 15548), which is distinctly smaller than the preceding teeth. This disparity is probably due to the relatively late eruption of $\mathrm{N}^{8}$, however, as indicated by a full millimeter increase in length from the occlusal surface (19 
$\mathrm{mm}$ ) to the pulp cavity $(20 \mathrm{~mm})$ over a relatively short, tooth height diameter. Thus, it is likely that $\mathrm{N}^{8}$ of $G$. cylindricum in the full adult condition approximated the size of the preceding teeth. Accordingly, this noted size difference in $\mathrm{N}^{\underline{8}}$ of $G$. cylindricum is of little diagnostic valve.

Isolated posterior upper teeth are difficult to position correctly. It is possible, however, to place a complete series in proper order on the basis of the curvature of the alveolar portions that grade uniformly from the outward curvature, without any rearward curvature in $\mathrm{N}^{\underline{5}}$, to strong rearward curvature, without any outward curvature in $\mathrm{N}^{\underline{8}}$, and on the orientation of the occlusal surfaces with respect to the cross-sectional plane of the teeth, which increase in posterior inclination rearward from the nearly perpendicular orientation of $\mathrm{N}^{6} ; \mathrm{N}^{5}$ occlusal surface is directed somewhat laterally.

The occlusal patterns of $\mathrm{N}^{\underline{5}}-\mathrm{N}^{8}$ exhibit a uniform development of the lobes. The anterior borders are broadly convex to nearly straight. $G$. arizonae and $G$. texanum have relatively flattened anterior borders, in contrast to the more rounded anterior borders of $G$. cylindricum. A similar distinction is evident for the posterior lobes of the lower dentitions of these species. The posterointernal angle is rounded, and the posteroexternal angle is pointed, owing to the presence of a distinct sulcus on the posteroexternal face of each tooth. The laterally convergent transverse axes of the anterior and posterior lobes are slightly offset from a perpendicular orientation with the long axis of the tooth row. Osteodentine branches penetrate into each lobe, and there is minor secondary branching. The osteodentine ridges are marked by short spinose accessory ridges to varying degrees. $\mathrm{N}^{5}$ to $\mathrm{N}^{8}$ are unknown for $G$. floridanum; presumably these teeth more closely resemble those of $G$. cylindricum than either $G$. texanum or $G$. arizonae, as discussed above.

A single upper molar, probably $\mathrm{N}^{7}$ or one adjacent, is known from the Cita Canyon Blanco Beds (JWT 1837). This tooth most closely resembles that of $G$. texanum from Arizona in having a relatively shallow posterointernal sulcus on the posterior face and in having relatively blunt apices of the lobes. This specimen is referable to $G$. lexanum on the basis of the more nearly complete lower dentition.

Lower Dentition (Figure 19, Tables 7-10).The first lower tooth, though distinctly less molariform than the succeeding teeth, is nevertheless rather more elaborate than the corresponding upper tooth, at least in $G$. texanum and $G$. arizonae. The succeeding teeth are increasingly more molariform and exhibit increasing definition of the trilobate construction. $\mathrm{N}_{\overline{4}}-\mathrm{N}_{\overline{8}}$ are fully molariform and completely trilobate; the last five teeth are so similar that occlusal patterns alone are insufficient for determining proper position in the series. The dispositions of the occlusal surfaces and the direction of alveolar curvature exhibit a development complementary to the upper teeth, so that these features provide reasonably confident determination of proper positions of isolated teeth.

The alveolar portion of $N_{\overline{1}}$ curves strongly inward and rearward, and the occlusal surface is directed inward with respect to the horizontal cross section of the tooth. Alveolar portions of $\mathrm{N}_{\overline{2}}-$ $\mathrm{N}_{\overline{4}}$ are similarly constructed, but with decreasing curvature, and the inward direction of the occlusal surfaces diminishes rearward. There is no inward curvature in the alveolar portion of $\mathrm{N}_{5}$; it is nearly straight. Its occlusal surface is directed rearward with respect to the cross section. Alveolar portions of $N_{\overline{6}}-N_{\overline{8}}$ exhibit increasing rearward curvature. The occlusal surface of $\mathrm{N}_{\overline{7}}$ is directed rearward, but not as distinctly as $\mathrm{N}_{\overline{6}}$. The occlusal surface of $\mathrm{N}_{\overline{8}}$ is perpendicular to the cross section.

The occlusal pattern and the mandibular position of $\mathrm{N}_{\bar{I}}$ are diagnostic. In $G$. texanum (Figure 19) $N_{\bar{I}}$ is elongate and irregularly ovoid, with a convex inner face and a pair of shallow grooves on the outer face suggesting a tripartite division. On the posteroexternal face there is a shallow concavity, producing an elongate posterior region. In the fragmented specimen JWT 1715, the only $G$. texanum mandible with anterior teeth, it appears that $\mathrm{N}_{\bar{I}}$ is situated near the beginning of the curvature of the symphyseal ramus. Accord- 


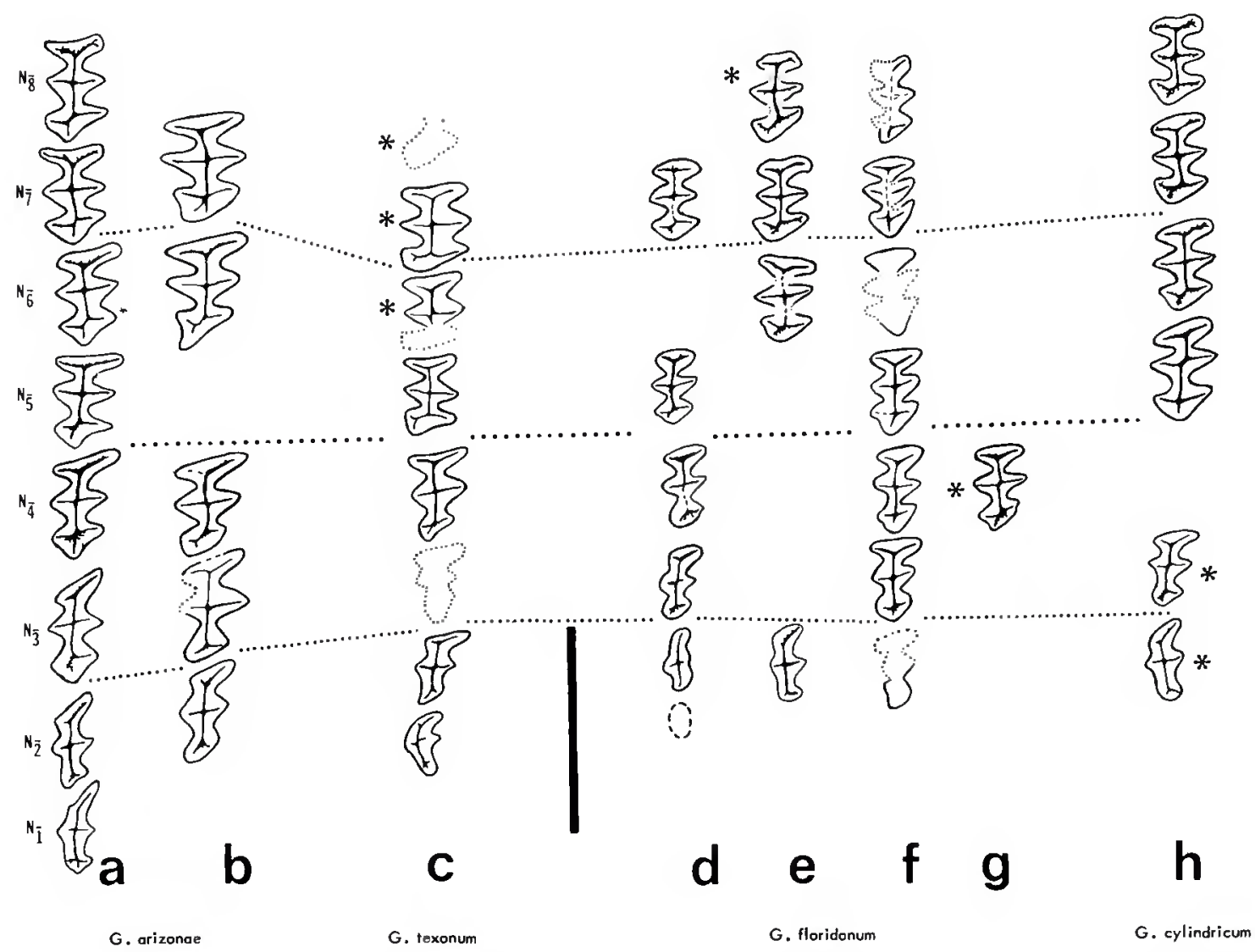

Figure 19.-Lower teeth of North American glyptodonts, occlusal surfaces, left side (asterisk $=$ reversed pattern, taken from corresponding tooth of right side): $a$, USNM 10536; $b$, UMMP 38761; c, JWT 2330; $d$, USNM 11318; $е$, UF/FGS 6643; $\int$, TMM 30967-1814; $g$, USNM 6071; $h$, AMNH 11548; relative sizes of individual teeth are accurate, but lengths of tooth rows are adjusted for comparison. (Bar $=5 \mathrm{~cm}$.)

ingly, the long axis of the tooth is obliquely oriented with respect to the anteroposterior axis of the tooth row.

$\mathrm{N}_{\bar{I}}$ is unknown for $G$. floridanum, but mandible USNM 11318 (Figure 17) includes the alveolus for this tooth, indicating a considerable reduction in size. This tooth was apparently an ovoid, peglike tooth, with a convex inner surface and two weak grooves on the outer surface, representing the vestige of the former three-parted division. The alveolus is situated well behind the symphyseal curvature.

Quite in contrast, $\mathrm{N}_{\bar{I}}$ of $G$. arizonae is strikingly molariform. The occlusal surface is more nearly trilobate. The anterior lobe is relatively under- developed, without medial expansion and only slight lateral expansion. The outer portion of the middle lobe is well defined; the inner portion is less well developed, but is nevertheless distinct. The posterior lobe is obliquely oriented, extending posteroexternally into an elongate lobe. The posterointernal apex of the posterior lobe is poorly developed, and there is a shallow sulcus on the anteroexternal face. The alveolus for $N_{\overline{1}}$ is situated posterior to the symphyseal curvature, as in G. floridanum.

In $G$. arizonae, the osteodentine core issues rami in both directions at the middle lobe; it bifurcates posteriorly into a short internal and a long external branch; anteriorly the core bifurcates into 
two short rami in the anterior lobe. Secondary spinose branching, though poorly developed, is distinguishable. The nature of the osteodentine core is indeterminate in the available specimens of $G$. texanum.

$\mathrm{N}_{\overline{2}}$ is apparently a highly variable tooth. It is distinguishable from $N_{\bar{I}}$ and $N_{\overline{3}}$ by its intermediate molariform construction and alveolar curvature. The anterior and posterior lobes are well defined relative to $N_{\overline{1}}$, but their transverse development is less than in $\mathrm{N}_{\overline{3}}$, especially with respect to the inner apices of the anterior and posterior lobes.

In $G$. texanum the anterointernal surface of $\mathrm{N}_{\overline{2}}$ is straight, nearly like that of $\mathrm{N}_{\bar{I}}$ of $G$. arizonae. The apices of the middle lobe in G. texanum are well defined, and the posterior lobe is well developed, with prolongation of the posteroexternal lobe and corresponding obliquity in its orientation. The posterior surface is convex, becoming somewhat more flattened with age.

In $G$. arizonae, $\mathrm{N}_{\overline{2}}$ is distinctly more molariform in the elongation of the lobes and in the pronounced oblique disposition of the posterior lobe, which distinguishes it from the other species. $\mathrm{N}_{\overline{2}}$ of the Seymour glyptodont is identical to that of the Curt is Ranch glyptodont, USNM 10536 (type specimen), supporting the asserted identity of the glyptodonts from these two localities as $G$. arizonae.

A broken $\mathrm{N}_{\overline{2}}$ in the mandible of TMM $30967-$ 1814 (Ingleside, Texas, respresentative) and a complete $\mathrm{N}_{\overline{2}}$ in USNM 11318 (Orange County, Florida, specimen), both representing $G$. floridanum, are strikingly different. An isolated $\mathrm{N}_{\overline{2}}$ from the Catalina Gardens, Florida, locality (UF/ FGS 6643) more closely resembles the Texas specimen than the one from nearby Orange County. The tooth here identified as $\mathrm{N}_{\overline{2}}$ for $G$. cylindricum is identical to the one from Catalina Gardens. Although it is possible that the isolated teeth here regarded as $\mathrm{N}_{\overline{2}}$ for the Catalina Gardens and $G$. cylindricum specimens are actually $\mathrm{N}_{\bar{I}}$ (thus resembling $G$. arizonae), the present assignment seems most likely because $N_{\overline{3}}$ of USNM 11318 is identical to the tooth assigned as $\mathrm{N}_{\overline{3}}$ of $\mathrm{AMNH}_{15548}$ (these represent different species, but the closer resemblance of the other teeth of $G$. cylindricum with $G$. floridanum rather than $G$. arizonae supports this contention); the tooth identified as $\mathrm{N}_{\overline{2}}$ for AMNH 15548, because of the alveolar curvature and the orientation of the occlusal facet, certainly bclongs in the position immediately anterior to the tooth identified as $\mathrm{N}_{\overline{3}}$. By indirect comparison, the tooth identified with confidence as $\mathrm{N}_{\overline{2}}$ for G. cylindricum is identical to one of the teeth of the Catalina Gardens specimen of $G$. floridanum, and this tooth is therefore assigned as $\mathrm{N}_{\overline{2}}$. Thus, by reason of inference, $\mathrm{N}_{\overline{2}}$ of $G$. cylindricum is identical to $\mathrm{N}_{\overline{2}}$ of one specimen of $G$. floridanum. Both of these seem to resemble closely $\mathrm{N}_{\overline{2}}$ of the Ingleside glyptodont (TMM 30967-1814), and all three of these differ considerably from $\mathrm{N}_{\overline{2}}$ of the other Florida representative, USNM 11318, despite the close similarity of $\mathrm{N}_{\overline{3}}$ and the succeeding teeth in all four. (It is also notable that USNM 11318 most closely resembles known $G$. floridanum mandibles and teeth on a quantitative basis, indicating that if this specimen represents a separate species, it is not one of the others and is most closely related to $G$. floridanum; see Tables 2 and 10.)

Therefore, $\mathrm{N}_{2}$ of $G$. cylindricum and of the $\mathrm{Ca}$ talina Gardens (Florida) and Ingleside (Texas) representatives bears a distinct trilobate construction, and, compared with the teeth of $G$. arizonae and $G$. texanum, it more closely resembles $\mathrm{N}_{\overline{1}}$. Thus $\mathrm{N}_{\overline{2}}$ is less distinctly molariform in these specimens than in either $G$. arizonae or $G$. texanum. The anterointernal border is straight, without medial development of the anterior lobe. The lateral portion of the anterior lobe is slightly expanded, while both portions of the middle lobe are well expanded. The rear lobe is expanded posterolaterally, with only slight medial development. The posterior lobe is obliquely oriented with respect to the long axis of the tooth. This description is also accurate for the G. cylindricum and Catalina Gardens specimens, which are identical. It is accurate for the Ingleside specimen, at least for the anterior and middle lobes. The Ingleside $\mathrm{N}_{\overline{2}}$ appears to differ from $\mathrm{N}_{\overline{2}}$ of USNM 11318 in much 
the same fashion as AMNH 15548 (G. cylindricum) and UF/FGS 6643 (Catalina Gardens).

In USNM 11318, here tentatively identified as G. floridanum, $\mathrm{N}_{\overline{2}}$ is even less molariform. Its construction resembles that of $\mathrm{N}_{\overline{2}}$ in $G$. cylindricum in the reduction of the external portion of the middle lobe. (The assignments for the upper teeth in $G$. cylindricum are made with confidence so that this is a case of a parallel trend in reduction of anterior teeth, rather than suggestive of an incorrect assignment for the tooth here identified as $\mathrm{N}^{2}$ for $G$. cylindricum.) Identification of USNM 11318 as $G$. floridanum is based on the posterior teeth. Thus $\mathrm{N}_{\overline{2}}$ in USNM 11318 represents a variation within the species and is not sufficient evidence alone to warrant the establishment of a new species. Only future discoveries will resolve this problematical situation. This tooth bears a sigmoid occlusal pattern, formed by prolongation, without expansion, of the anterointernal and posteroexternal lobes. The posterointernal face is a smoothly convex, tapering surface from the weak expansion of the middle lobe; i.e., there is no internal development of the posterior lobe. The outer portion of the middle lobe is reduced to a faintly convex surface connecting the weak lateral expansions of the anterior and posterior lobes.

The osteodentine core in all $\mathrm{N}_{\overline{2}}$ 's represented issues transverse rami into the middle and posterior lobes and anteriorly the core issues a branch into the anterolateral lobe (except in USNM 11318 , which has no anterolateral lobe). There is minor secondary spinose branching at least in $G$. cylindricum, $G$ arizonae, and the problematical $G$. floridanum specimen-and probably in the others as well.

Thus, in conclusion for this tooth, $\mathrm{N}_{\overline{2}}$ is apparently the most highly variable tooth in the lower series. It is distinctly trilobate and molariform in $G$. arizonae, somewhat less so in $G$. texanum, and variously developed in $G$. floridanum and $G$. cylindricum.

$\mathrm{N}_{\overline{3}}$ occlusal pattern is distinctive for $G$. texanum and $G$. arizonae, and it is identical in $G$. cylindricum and $G$. floridanum. In $G$. texanum, $\mathrm{N}_{\widehat{3}}$ is distinctly less molariform than $\mathrm{N}_{\overline{4}}$; indeed, its development more closely approximates $\mathrm{N}_{\overline{2}}$ of the other species. The anteroexternal and posterointernal lobes are poorly developed. The disposition of the posterior lobe is somewhat oblique, rather intermediate between the markedly oblique orientation in $G$. arizonae and the nearly perpendicular orientation in G. floridanum.

$\mathrm{N}_{\overline{3}}$ of $G$. arizonae and $G$. floridanum/G. cylindricum more closely resemble each other than either resembles that of $G$. texanum. In $G$. arizonae the transverse development of the anterior lobe nearly equals that of the middle and posterior lobes. The anterior lobe obtains a rather squared outline produced by weak concavities on the anteromedial and anterolateral surfaces, as shown in USNM 10536. The middle lobe is set almost perpendicular to the tooth row, and the convex posterior lobe is markedly oblique, with prolongation of the posteroexternal lobe. The posterointernal apex is sharp. The anteromedial and anterolateral surfaces are more rounded in UMMP 38761; this difference is attributable to geographic or temporal variation of the species. The relative development and oblique disposition of the lobes of $\mathrm{N}_{\overline{3}}$ in UMMP 38761 are identical to those of the Curtis Ranch representative.

$\mathrm{N}_{\overline{3}}$ of the Ingleside representative of $G$. floridanum (TMM 30967-1814) is identical to the teeth assigned as $\mathrm{N}_{\overline{3}}$ for $G$. cylindricum and the Orange County (Florida) representative of $G$. floridanum (USNM 11318). The anterior lobe is less distinctly squared in $G$. floridanum and $G$. cylindricum. The anteroexternal face is convex, rather than concave. The transverse axes of all three lobes are nearly parallel, and their orientation is almost perpendicular to the tooth row. The postcrior face is broadly convex, the posteroexternal lobe is only weakly prolonged, and the posterointernal apex is not sharply pointed.

Ostcodentine rami extend transversely into each lobe from the central core. Secondary spinose branching appears to be limited to the anterior lobe.

$\mathrm{N}_{\overline{4}}$ is the first completely molariform tooth in the lower series of $G$. arizonae and $G$. floridanum, possessing a transverse development of the ante- 
rior lobe equal to that of the middle and posterior lobes. $\mathrm{N}_{\overline{4}}$ of $G$. texanum differs considerably in its relatively shorter transverse development of the anterior lobe. In fact, $\mathrm{N}_{\overline{4}}$ of $G$. texanum (WT 1715) possesses an occlusal pattern that closely resembles $\mathrm{N}_{\overline{3}}$ of $G$. floridanum, although there is a deep sulcus on the anterointernal face. In $G$. texanum the lobes are nearly perpendicular to the long axis of the tooth row, and the anterior lobe is relatively underdeveloped. $\mathrm{N}_{\overline{4}}$ of $G$. texanum differs from $\mathrm{N}_{\overline{3}}$ of $G$. floridanum in possessing a weakly concave posterior face.

$\mathrm{N}_{\overline{4}}$ of $G$. arizonae and $G$. floridanum is fully trilobed. As in $\mathrm{N}_{\overline{3}}$, the anteromedial and anterolateral surfaces are concave in USNM 10536, and they are convex in UMMP 38761. In the latter specimen also, the transverse extent of the anterior lobe is rather less than that of the middle and posterior lobes, thus contrasting with USNM 10536. In both specimens of $G$. arizonae, however, the transverse axes of the lobes are obliquely oriented. The posterior face of USNM 10536 is concave; it is broadly convex in UMMP 38761. These differences between the Gurtis Ranch and Seymour representatives are likely attributable to variation. $\mathrm{N}_{4}$ 's of the specimens from these two localities more closely resemble each other than either resembles $\mathrm{N}_{\overline{4}}$ of $G$. floridanum.

In $G$. floridanum, $\mathrm{N}_{\overline{4}}$ is also fully trilobate, although the anterior lobe is slightly shorter than the middle and posterior lobes, as in the Seymour $G$. arizonae. The lobes are more nearly perpendicular to the long axis of the tooth row, and the posterior face is distinctly convex. There is a wide range of variation in the development of the sulcus on the anterointernal face-from deep in USNM 6071, to shallow in TMM 30967-1814, to entirely absent in USNM 11318. There is no corresponding sulcus in either $G$. texanum or $G$. arizonae. In all three species osteodentine rami extend into each lobe. Secondary spinose branching is apparently limited to the anterior lobe.

$\mathrm{N}_{\overline{4}}$ is unknown for $G$. cylindricum. Within each species the occlusal patterns of $N_{\overline{5}}, N_{\overline{6}}$, and $N_{\overline{7}}$ are almost identical. These teeth can be serially distinguished in isolation by the orientation of the occlusal surfaces with the cross-sectional plane of the tooth: relatively steeply inclined, facing rearward in $\mathrm{N}_{\overline{5}}$, with diminishing inclination rearward; $N_{\overline{7}}$ is approximately perpendicular. These teeth are sufficiently different between species to warrant separate descriptions, but the similarities are by far greater than the distinctions.

In all four species the lobes are equally developed in the transverse dimension, and the transverse axes are more or less perpendicular to the long axis of the tooth row. There is a distinctive flattening of the anterointernal face, uniformly developed on all three teeth for each species. This flattening produces an anterior apex in the occlusal pattern. The anteromedial surfaces of $\mathrm{N}_{\overline{5}}-\mathrm{N}_{\overline{7}}$ are concave in $G$. arizonae, flattened $\left(\mathrm{N}_{\overline{5}}, \mathrm{~N}_{\overline{7}}\right)$ to weakly concave $\left(\mathrm{N}_{\overline{6}}\right)$ in $G$. cylindricum, concave $\left(\mathrm{N}_{\overline{5}}, \mathrm{~N}_{\overline{6}}\right)$ to flat $\left(\mathrm{N}_{\overline{7}}\right)$ in $G$. floridanum, and all flattened in $G$. texanum. A similar variability occurs for the anterolateral surfaces: all concave in G. arizonae and G. texanum, all straight in $G$. cylindricum, and convex to straight in $G$. floridanum.

The development of the middle lobes of $\mathrm{N}_{\overline{5}}-\mathrm{N}_{\overline{7}}$ is identical in all four species. The posterior lobes exhibit a variability comparable to that of the anterior lobes. The posterior lobes are concave and slightly oblique $\left(\mathrm{N}_{\overline{5}}, \mathrm{~N}_{\overline{6}}\right)$ to perpendicular $\left(\mathrm{N}_{\overline{7}}\right)$ to the long axis in $G$. arizonae and $G$. texanum, flat $\left(\mathrm{N}_{\overline{5}}, \mathrm{~N}_{\overline{6}}\right)$ to weakly convex $\left(\mathrm{N}_{\overline{7}}\right)$ in $G$. cylindricum, convex in the Texas and Orange County, Florida, G. floridanum (TMM 30967-1814 and USNM 11318, respectively), and flattened ( $\mathrm{N}_{\overline{6}}$, $\left.\mathrm{N}_{\overline{7}}\right)$ in the Florida Catalina Gardens $G$. floridanum ( $\mathrm{N}_{\overline{5}}$ not known). In $G$. cylindricum and $G$. floridanum the orientation of the lobes is more nearly perpendicular to the long axis of the tooth row.

Osteodentine rami extend into each lobe. There is limited spinose secondary branching along the transverse rami, especially in the anterior and posterior lobes.

$\mathrm{N}_{\overline{8}}$ can be distinguished from the more anterior teeth by its perpendicular occlusal surface with respect to the cross section of the tooth, by the posteriorly diminishing medial extent of the lobes, and by the distinctive concavity on the posterior face of the tooth. 
The anteromedial and anterolateral faces are concave in $G$. arizonae, producing an occlusal pattern similar to the anterior teeth for this lobe, with a relatively pointed anterior apex. These faces are convex in the other three species, and the anterior apex is rather more blunt in the occlusal pattern.

In $G$. arizonae and $G$. floridanum the middle and posterior lobes are progressively shorter in the transverse dimension. In $G$. cylindricum the three lobes attain nearly equal development, and there is no rearward taper. The symmetrical middle lobes are otherwise similar in these three species. (The posterior two-thirds of $\mathrm{N}_{\overline{8}}$ for $G$. texanum is unknown.)

The posterior face exhibits a deep concavity in $G$. arizonae and $G$. cylindricum. In the latter species the posterior lobe is perpendicular to the long axis, whereas in $G$. arizonae it is somewhat oblique. The posterior surface of $\mathrm{N}_{\overline{8}}$ of $G$. floridanum possesses a weak concavity; in occlusal outline this concavity is barely evident. The posterior lobe is slightly oblique, as in $G$. arizonae.

In all three species the posteroexternal apex is flattened, another feature distinguishing $\mathrm{N}_{\overline{8}}$ from the more anterior teeth in the lower series, in which this apex is generally pointed or broadly rounded.

Dentition of G. mexicanum.-As discussed under "Systematics," the description provided by Cuatáparo and Ramirez (1875) for the dentition of $G$. mexicanum serves to fix provisionally the character of the species. That the specimens they described belong in Glyptotherium is well established by the characters of the carapace, as described elsewherc. According to their observations the tooth lengths vary from $21 \mathrm{~mm}$ anteriorly to $25 \mathrm{~mm}$ posteriorly; hence the teeth are somewhat longer than those of $G$. cylindricum. The lower tooth row measures $174 \mathrm{~mm}$ in total length, an intermediate sizc in comparison with the other species. The authors figured occlusal views of two teeth, an anterior one and a posterior one, without designating their positions or whether they are uppers or lowers.

The drawing of the posterior tooth closcly re- sembles $\mathrm{N}_{\overline{8}}$ of $G$. cylindricum. If this is indeed the correct position, the anterior face is decidedly more concave in $G$. mexicanum; otherwise $\mathrm{N}_{\overline{8}}$ is virtually identical in these two species. The figure reveals that there is distinct but minimal secondary spinose branching of the osteodentine core.

The anterior tooth as figured by Cuatáparo and Ramircz is unlike any teeth of the other species. If indeed it is an $\mathrm{N}_{\bar{I}}$ or $\mathrm{N}^{1}, G$. mexicanum possesses the most molariform anterior teeth of the genus. The tooth as figured is anteroposteriorly elongate and straight, rather than sigmoid or peglike as in other species, and it is distinctly trilobate. The three lobes are not greatly expanded transversely, and there is an unusual apex at either extremity. If the drawing is accurate, this tooth is sufficiently distinctive to indicate the validity of the species. Brown (1912) considered the highly molariform teeth of $G$. mexicanum as one of the principal features distinguishing this species, and we concur.

\section{Presacral Axial Skeleton}

The axial skeleton of glyptodonts exhibits a degree of fusion unparalleled among mammals. Summarizing the general scheme of the axial construction for all glyptodonts, Hoffstettcr (1958) stated that: the atlas is free, and usually the axis and the next three or four ccrvical vertebrae are united into a single element, the cervical tube; the sixth cervical is free; the posterior cervical and first two thoracic vertebrae are united into a single elemcnt (occasionally referred to as the "trivertebral" bone); and the remaining thoracics, usually numbering ten, are united into a compound dorsal tube. Because of the highly fused condition of these vertcbrac, determinations of vertebral count are difficult and are necessarily interpretive. Criteria for deternination of vertebral count and the proper determination of individual elcments in the following descriptions are (1) the presence of neural foramina emerging laterally between fused transverse processes of adjoining vertcbrac, analogous to the condition exhibited by armadillos; and (2) the presence of rib facets or of an ankylosed first rib to distinguish 
thoracic vertebrae from cervical vertebrae in the cervicothoracic region. To the extent that these criteria are valid, rudimentary and incomplete comparisons between three North American taxa are possible.

The presacral vertebrae are unknown for $G$. texanum. Only the atlas is known for $G$. cylindricum; it exhibits minor differences from the atlas of $G$. arizonae. In the latter species, the atlas is free; the cervical tube is formed by the fused axis and the remaining cervical vertebrae (i.e., nos. 2-7); there is a free anterior thoracic vertebra bearing an ankylosed, immovable rib; the second rib articulates more or less freely with the second thoracic vertebra. The remaining vertebrae participating in the anterior dorsal elements, presumably corresponding to the so-called "trivertebral" element of South American glyptodonts, is unknown for G. arizonae. The dorsal tube is formed by at least 10 ankylosed thoracic vertebrae.

The atlas of $G$. floridanum is unknown. The cervical tube consists of only five vertebrae, nos. 2-6. The sixth cervical and first thoracic vertebrae are unknown. Presumably they were fused, and together supported the first rib in an immovable union, as in $G$. arizonae. The trivertebral element contains three dorsal vertebrae, presumably thoracic vertebrae nos. 2-4. The dorsal tube includes nine thoracic vertebrae, nos. 5-13.

Although there is little new material to report for the presacral axial skeleton of North American representatives, previous descriptions have been incomplete. The following descriptions are an attempt to consider more thoroughly this largely unknown and poorly understood region of the glyptodont skeleton.

Brown (1912) described briefly the atlas of AMNH 15548 (G. cylindricum); this is the only known presacral vertebra for the species. Hay (1916) described the cervical tube, the trivertebral, and the broken dorsal tube of USNM 6071 (G. floridanum). Melton (1964) summarily described the atlas, the cervical tube, and, according to his determination, the fused last cervical and first thoracic vertebrae (here considered as the free first thoracic) of UMMP 34826 ( $G$. arizonae).
Atlas (Table 11).- The atlas of $G$. arizonae (Figure 20) is the only free cervical vertebra. It is short and complex, with a concave posterior facet and a more deeply concave anterior facet. The dimensions are shortest in the anteroposterior direction, intermediate dorsoventrally, and most greatly elongated in the transverse direction. The alar processes extend upward from the anterodorsal angle of the atlas. They are obliquely compressed in the anterolateral-posteromedial plane. The posterolateral face is concave, the anteromedial face roughened and irregular. The intervertebral foramina pass obliquely forward

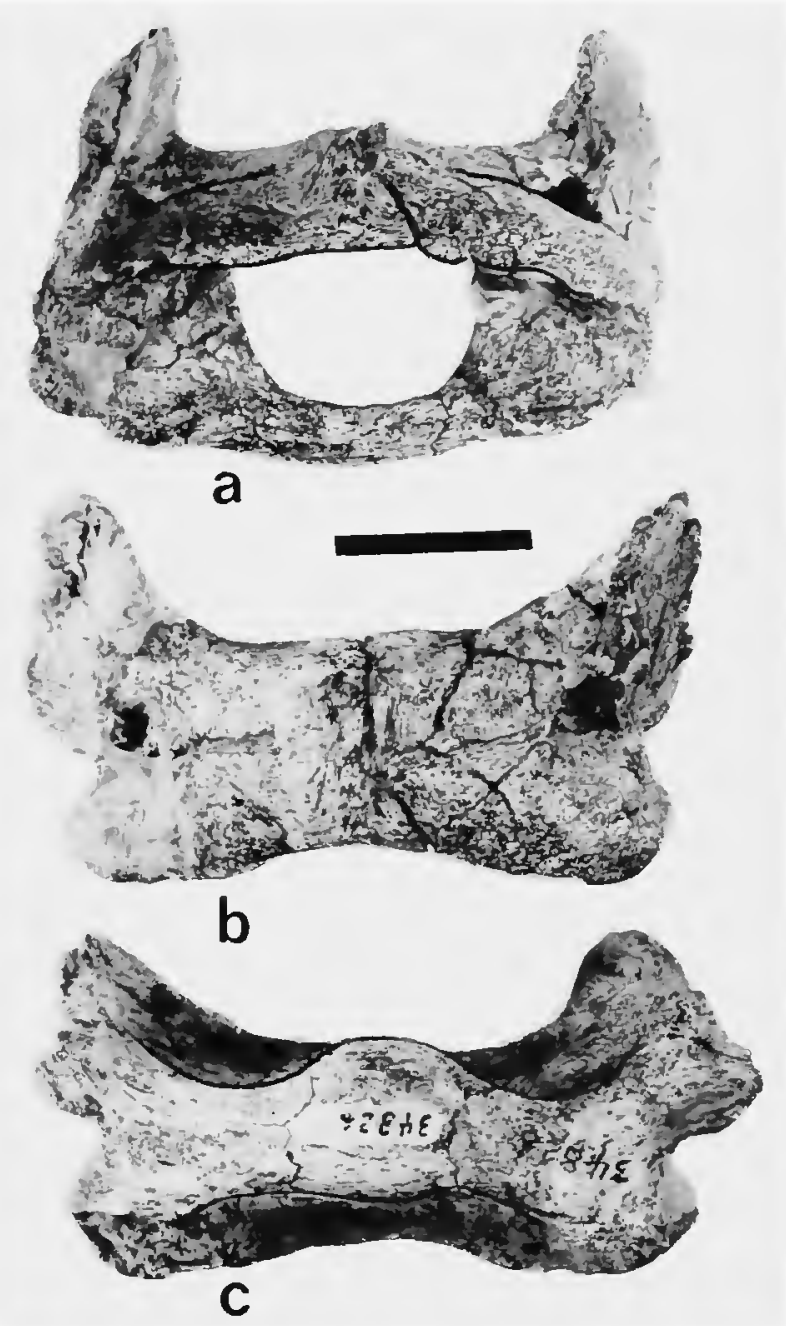

Figure 20.-Atlas of Glyptotherium arizonae (UMMP 34826): $a$, anterior; $b$, dorsal; $c$, ventral. (Bar $=40 \mathrm{~mm}$.) 
and downward from a central position immediately above the articular facets for the axis. These foramina emerge laterally and somewhat posteriorly with respect to the alar foramina on the dorsal arch. The alar foramina are more complex, coursing forward and mesially inward. These foramina emerge on the dorsal arch directly anterior to the alar processes, where a pair of thin anteroposteriorly oriented struts flanks the upper borders of the foramina. A mesially directed groove passes from the small opening formed by the medial strut of the alar foramen, and it terminates at the raised dorsal tuberosity. Another groove passes from the same opening forward and medially to the anterior border of the dorsal arch. These grooves presumably mark the position of vascular (nerves or blood) channels to the dorsal surface of the neck and rear portion of the head.

The dorsal and ventral arches are convex, the dorsal rather more massive than the ventral. The ventral tuberosity is an expansion of the ventral arch for the support and articulation of the odontoid process of the axis. The paired articular facets for the axis are confined to the posterior face of the atlas. They are weakly concave in both the transverse and dorsoventral directions. They are directed mesially and slightly rearward. These facets are confluent with the expanded facet for the odontoid process, which is confined to the upper face of the ventral arch. It is weakly concave and faces upward and very slightly rearward.

The occipital facet is deeply concave dorsoventrally and concave transversely to a lesser degree. The dorsoventral chord of each half of the facet covers approximately $180^{\circ}$. The paired halves of the occipital facet flare outward and forward, forming a continuous marginal flange. Thus, the primary motion at the occiput-atlas joint is dorsoventral; lateral motion was limited by the relatively flattened concavity in the transverse plane. The deep dorsoventral concavity indicates considerable dorsoventral motion of the hcad, from horizontal downward through an arc of approximately $40^{\circ}$. The dorsal arch prohibits upward motion beyond horizontal, while the anterior border of the odontoid expansion of the ventral arch functions as the ventral stop.

The atlas of $G$. cylindricum (Figure 21) differs little from that of $G$. arizonae. The alar processes are more laterally directed than the near-perpendicular orientation in $G$. arizonae. There are no struts bordering the anterior opening of the intervertebral foramina, and there is no mesially directed groove passing toward the dorsal tuberosity. The intervertebral foramina emerge posteriorly much nearer the midline in $G$. cylindricum. The occipital facet is rather less concave, and the odontoid facet faces entirely upward. In the atlas of AMNH 15548 there is considerable evidence of an arthritic condition at the occipital joint. The anterior extremity of the odontoid process and the inner margins of the occipital facets are marked by roughened, apparently pathologic, tubercles.

It is difficult to estimate the degree of transverse motion at the occipital joint. The atlas moves freely in the transverse direction over the occipital condyles through a half arc of approximately $15^{\circ}$. Because the atlas is so shortened (the anterior and posterior articular facets are so close that they nearly contact internally), this figure seems extreme and a $10^{\circ}$ half arc is probably more reasonable.

The notion at the atlas-axis joint is more limited. The convexity of the odontoid process allowed a small degree of dorsoventral motion. The relatively flattened articular facets permitted a greater transverse motion than in the anterior joint, the half arc apparcntly as great as $15^{\circ}$. Thus, the compound motion of the atlas, in functioning as the principal cervical articulation, is linited.

Cervical Tube (Table 12).-In G. arizonae the ccrvical tube (Figure 22) is formed by the fused axis and cervical vertebrac 3-7 (i.e., the cervical tube includes cervical vertebrae $2-7$ ). This statement is contrary to Melton's (1964) assertion that the tube includes only cervical vertebrae nos. 2 6 , and that no. 7 is fused with the first thoracic. The neural arches and the extremities of the 

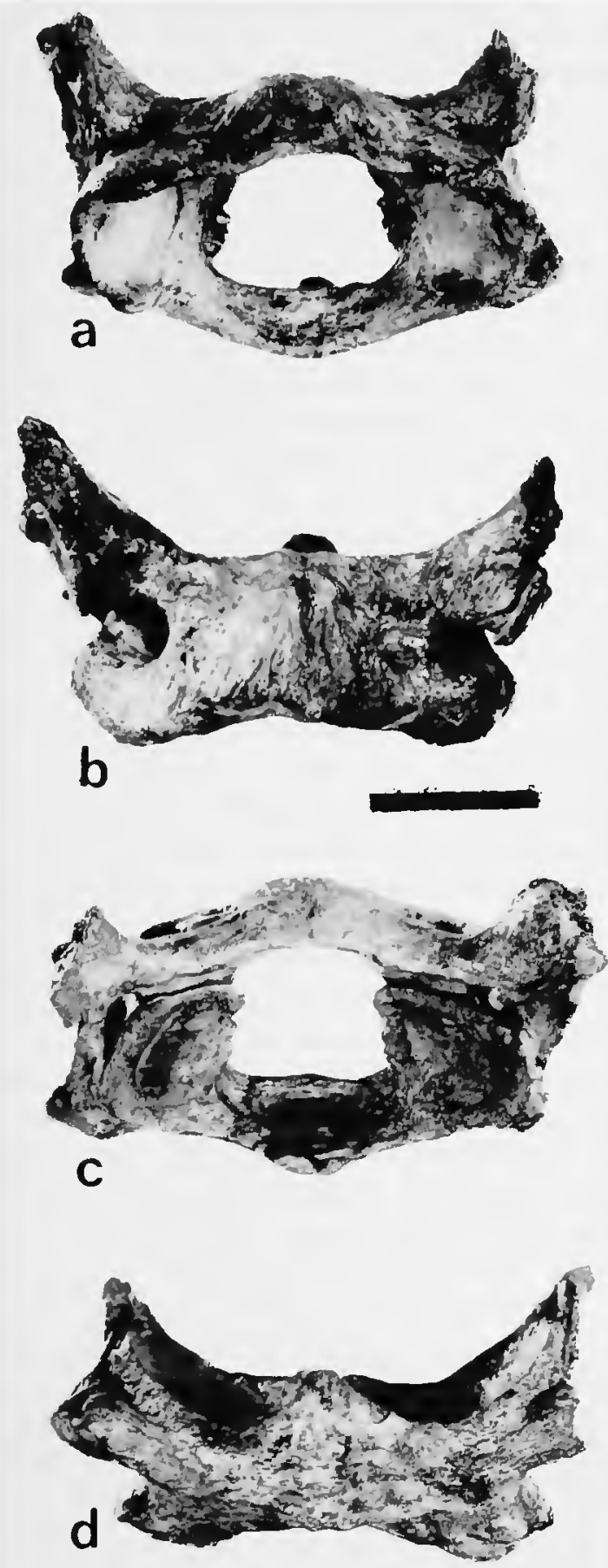

FIGURE 21.-Atlas of Glyptotherium cylindricum (AMNH 15548): $a$, anterior; $b$, dorsal; $c$, posterior; $d$, ventral. (Bar $=$ $40 \mathrm{~mm}$.)

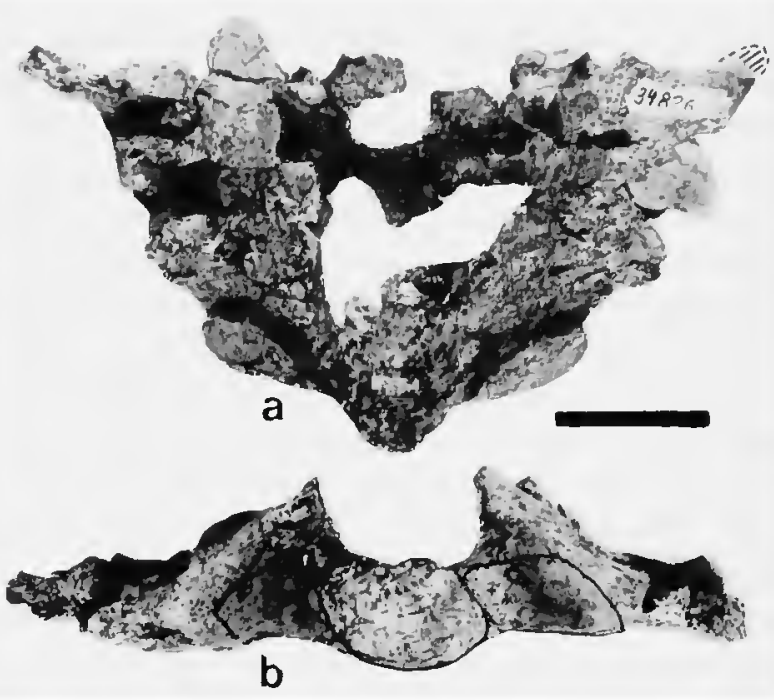

Figure 22.-Cervical tube of Glyptotherium arizonae (UMMP 34826): $a$, dorsal; $b$, anterior. (Solid line delimits articular surfaces as preserved; bar $=40 \mathrm{~mm}$.)

transverse processes of the cervical vertebrae are absent. The neural tube is apparently closed above, as in $G$. floridanum, and it probably possessed short, fused neural spines. The convex odontoid process forms the anterior extremity. It is ovoid, and directed downward and somewhat forward, situated forward of the plane of articulation of the lateral facets of the axis. The transverse processes appear to increase in width rearward, reaching maximum transverse dimensions at the last vertebra of the tube, this dimension exceeding that of the anteroposterior length. The vertebrae are solidly fused along the ventral arches, forming a flattened and transversely concave lower surface. The only means of distinguishing individual vertebrae in this specimen is by counting neural foramina. Externally there are five neural foramina, each presumably situated between transverse processes of the vertebrae, thereby indicating six cervicals. The anteriormost foramen, situated immediately posterior to the articular facet of the axis, merges internally with the second neural foramen. Thus the first and second neural foramina share a common internal opening for the neural canal, and there are only four internal neural foramina. 
There are three posterior articular facets on each side of the cervical tube for contact with the first thoracic vertebra and its fused rib. The lateralmost facet is situated on the posterior face of the last transverse process. It is concave and is directed posteriorly, receiving the corresponding facet of the rib of the first thoracic vertebra. The facet is transversely elongate, at least three times longer than high; its lateral extent cannot be determined from this specimen. In addition to this laterally situated facet for reception of the modified head of the rib, there are two mesial facets, one above the other, for the articulation between the centra of the last cervical and the first thoracic vertebrae. These facets are separated from each other by the large neural foramen that passes laterally and somewhat downward between the cervical and thoracic articulations. The lower facet is also separated from the lateral rib articular facet by the same obliquely directed neural foramen. On the left side, there is a large and distinct anteroposteriorly directed foramen situated in the angle between the three articular facets. This foramen communicates anteriorly with the adjoining neural foramen as a posterior bifurcation of that canal. This foramen is entirely absent on the right side; there is a continuous bony cover in the corresponding position.

The lower of the internal facets is transversely elongate and concave. It is situated on a necklike protuberance formed by the neural foramen along its upper and lateral borders. It is directed posteriorly and somewhat inward and upward. The upper process is a posterior extension of the dorsolateral neural arch. It is situated directly above the lower facet, its lower surface forming the upper border of the neural canal at the cervicothoracic joint. The articular facet faces downward and posteriorly, receiving the opposing anterior xenarthral process of the thoracic vertebra.

The cervical tube of $G$. floridanum (Figure 23) appears to be considerably different. Although the broken condition of the posterior extremity of USNM 6071 precludes full comparison with UMMP 34826, it is sufficiently well preserved to afford positive species distinction. The cervical tube of $G$. floridanum is formed by only five vertebrae, rather than six. This determination is founded on the presence of four external neural foramina. As in G. arizonae, the first two foramina merge mesially and share a common internal opening for the neural canal. In USNM 6071 the two anterior neural foramina bifurcate, sending separate dorsal branches upward and rearward to emerge above the lateral openings of the main foramina. The corresponding region in LMMP 34826 is broken. Hence the first two interior foramina (coalesced nos. 1 and 2, and no. 3) communicate with distinct dorsal branches passing upward and rearward from the neural canal.

The determination of five vertebrae in cervical tube USNM 6071 is contrary to Hay's (1916)

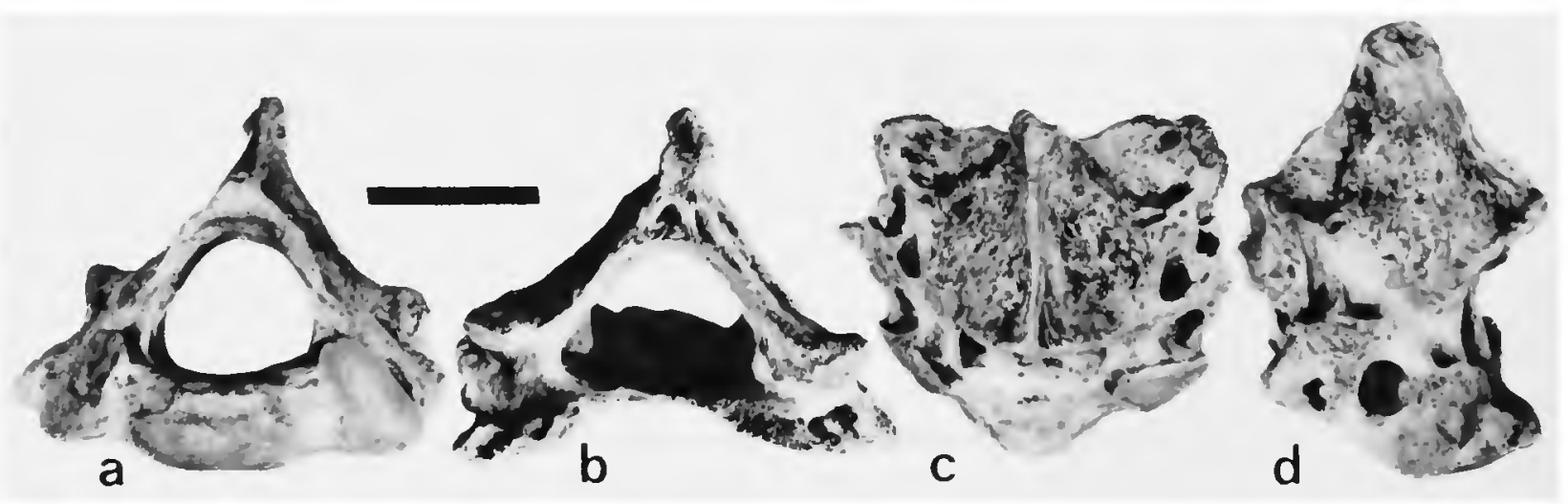

Figure 23.-Cervical tube of Glyplotherium floridanum (USNM 6071): $a$, anterior; $b$, posterior; $c$, ventral; $d$, left side. (Bar $=40 \mathrm{~mm}$.) 
assertion that there are four (cervical nos. 2-5). Hay apparently counted only the interior openings of the foramina into the neural canal. The determination presented here, that the vertebrae are nos. 2-6, is made in a fashion analogous to that for the $G$. arizonae specimens, in which the cervical tube and anterior thoracic vertebrae are present, allowing more confident analysis. The posterior cervical (no. 7) and the anterior thoracic vertebrae are not preserved for USNM 6071, or for any other $G$. floridanum specimens, necessitating this determination of vertebral count by analogy.

The dorsal arches of the cervical vertebrae of USNM 6071 are solidly fused, forming a medial crest that increases in height rearward, reaching maximum elevation in the plane of the posterior extremity of the tube. The neural canal is nearly circular above and laterally, and it is flattened inferiorly.

The anterior articular facets for the atlas are distinctive. The odontoid facet is inclined at approximately $45^{\circ}$, thus facing forward as much as downward. This contrasts to the mostly downward direction in $G$. arizonae. Accordingly, the odontoid facet of the atlas of $G$. floridanum (which is unknown) is probably also distinctive in possessing a marked rearward-facing component in its orientation.

The posterior region of USNM 6071 is incompletely preserved. The lateral rib facet is missing on both sides. The partially represented centrum facets are separated by the large neural foramen as in $G$. arizonae. The lower facet is directed rearward and outward, rather than somewhat inward and upward. The upper facet faces posteriorly downward and outward, contrasting to the orientation of this facet in $G$. arizonae.

Anterior Thoracic Vertebra.-Only the left half of the first thoracic vertebra and the basal portion of the neural arch of the second are known for G. arizonae (UMMP 34826, Figure 24). Most of the first rib is preserved. Its head portion is solidly fused with the first thoracic vertebra. Anterior and posterior articular facets indicate that the first thoracic vertebra was free. However, it appears that the neural arch of the second thoracic may have been immovably united with that of the first; the broken condition of the bone precludes certain determination of this contact, and what appears to be a broken contact might well be a relatively immobile articular surface instead. A small, concave, posteriorly directed facet on the first thoracic vertebra indicates an articular contact with the head of the second rib.

The anterior articulations correspond to the posterior facets of the cervical tube. The lower and inner facet is the smaller; it is situated on a prominent, knoblike, anteriorly projected tubercle. The continuation of the neural foramen produces a narrowed constriction posterior to the facet, effectively forming a distinct neck upon which the centrum facet is situated. Above the centrum facet, and separated from it by the neural foramen, is the anterior xenarthral process for articulation with the posterior process of the cervical tube. A flat, upwardly directed articular facet is situated on the upper surface of the process.

The rib facet is much larger than either of the internal facets. It is convex and transversely elongate, and it is directed anteriorly and somewhat laterally. The head of the rib is solidly fused with the ventrolateral angle of the vertebra, obscuring the limits of these two bones. The shaft of the rib is expanded and flattened downward and forward, forming a large, flat, vertically oriented plate. A distinct tubercle ("unciform process"?) marks the upper (inner) border in a position midway between the head of the rib and the midline of the body, giving a doubly concave, scalloped outline to the upper border of the rib. The lower border along the expanded plate is broken, and the distal end of the rib is absent, obscuring the nature of the construction of the sternum.

Because of the solid fusion of this rib with the vertebra, it is certain that the vertebra is the first thoracic and that this vertebra is apparently free. This contradicts Melton's (1964) conclusion that the seventh cervical was fused with the first thoracic and that the rib was fused primarily with 


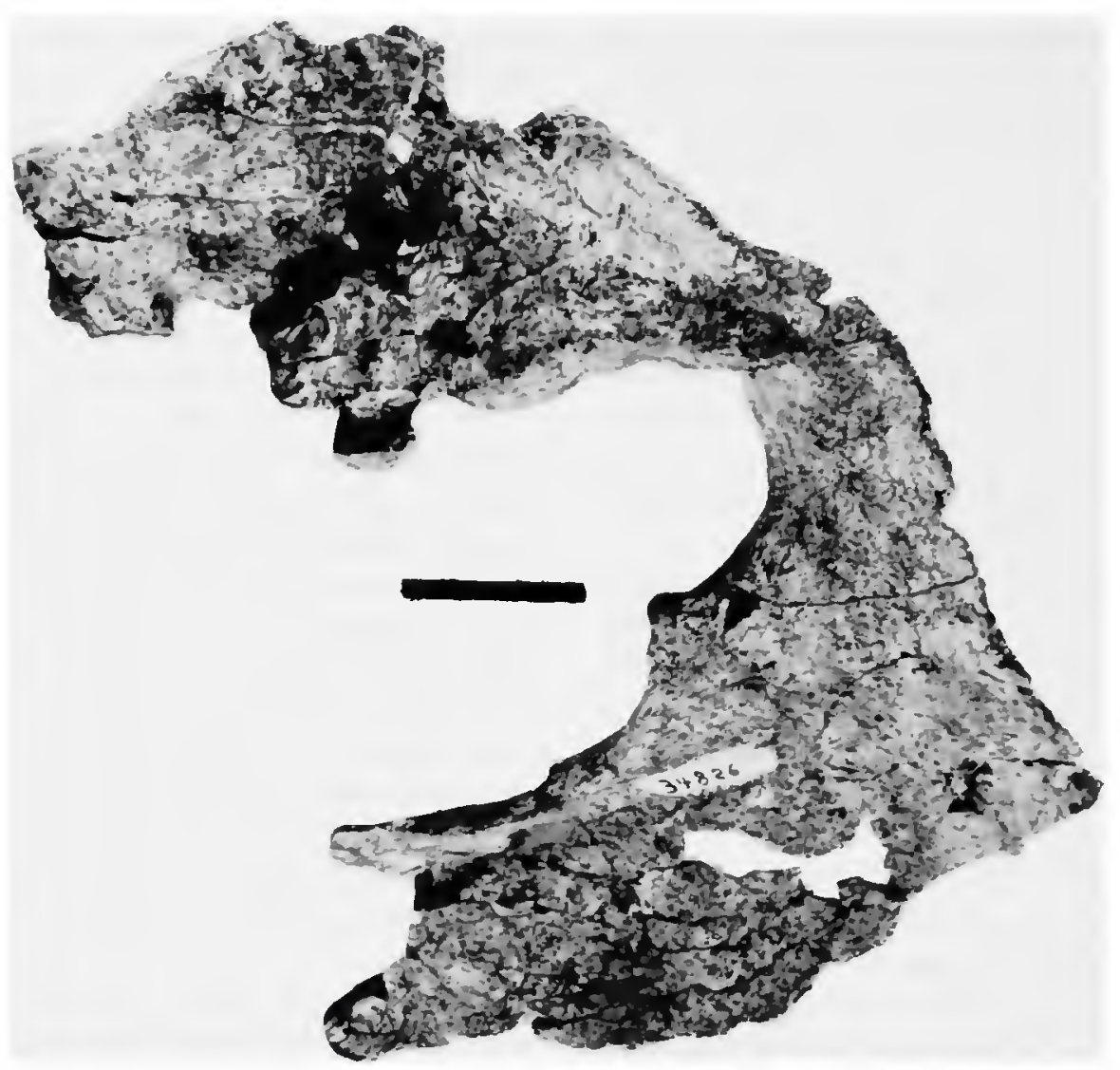

Figure 24.-First thoracic vertebra with fused right rib of Glyptotherium arizonae (UMMP 34826 ), oblique posteroventral aspect. (Bar $=40 \mathrm{~mm}$.)

the thoracic and in part with the cervical. To the contrary, there seems to be no indication of two vertebrae in the region of fusion of the rib. This conclusion, that the vertebra is the first thoracic, rather than last cervical, is consistent with the conclusion regarding the number of cervicals incorporated into the cervical tube of this species.

Measurements for thoracic vertebra 1 (free anterior thoracic with fused rib) of UMMP 34826 , for the left side, are as follows: anteroposterior diameter between rib articular facets, $47 \mathrm{~mm}$; transverse diameter anterior rib facet, $40 \mathrm{~mm}$; transverse diameter lateral extremity anterior rib facet to internal extremity centrum facet, approximately $62 \mathrm{~mm}$.

The anterior vertebral count for $G$. arizonae is as follows: one free atlas; fused cervical tube consisting of the axis and five cervical vertebrae; one free thoracic with a single fused rib; and an indeterminate number of vertebrae in the remaining thoracic series.

The anterior thoracic vertebra and the last cervical are unknown for $G$. floridanum. The prescnce of a free rib articular surface on the anteriormost vertcbra of the trivertebral element of USNM 6071 indicates that the first thoracic vertebra is indeed missing and is not incorporated in to the trivertebral element. The presence of an immovable first rib, fused to the first thoracic vertebra, is apparently a characteristic common to most late Cenozoic glyptodonts. This fact, plus the similarity between the trivertebral elements betwcen $G$. arizonae and $G$. floridanum, insofar as known, indicates that the first thoracic vertebra 
is indeed absent in USNM 6071. The lack of the seventh cervical vertebra in USNM 6071 is also problematical. Either there was reduction in the number of cervical vertebrae, or there was a free terminal cervical and a free anterior thoracic, or the last cervical and first thoracic were united into a single element, together supporting the first rib. The latter suggestion is the most probable, since in glyptodonts there is considerable variation in this region but apparently never any reduction in the cervical count.

These elements are unknown for the other North American species. This presumed distinction between $G$. arizonae (a free first thoracic) and $G$. floridanum (probably fused last cervical and first thoracic) may prove to be important in further elucidation of evolutionary relationships of North American glyptodonts.

"Trivertebral" Element.-The so-called "trivertebral" element of South American glyptodonts has usually been considered as consisting of the last cervical vertebra and the first two thoracics (Hoffstetter, 1958). Apparently these homologies were first established by Huxley (1865), who stated that the anteriormost rib articular fossa on the trivertebral element is clearly formed by the last cervical and first thoracic. This identification assumed that the actual first rib articulated at this position. Huxley unfortunately had no complete anterior vertebral series to examine, and apparently he was not aware of the vertebra anterior to the trivertebral, which bears a fused rib, here identified as the first thoracic. Apparently, Burmeister (1874) also missed this important feature. Although it is possible that there is here a fundamental distinction between the North and South American taxa, it is more likely that the homologies for the participating vertebrae of the trivertebral were erroneous, as first suggested by Huxley, and that these homologies have remained unchallenged. At least among the North American representatives, insofar as known, the trivertebral is formed by the second, third, and fourth thoracic vertebrae.

A complete trivertebral element is known for G. floridanum (USNM 6071). This specimen was described by Hay (1916) as the seventh cervical and first two thoracics, following the South American supposition of homologies. Except for the fragment of the anterior vertebra of the trivertebral element associated with the free first thoracic vertebra of UMMP 34826 ( $G$. arizonae) discussed above, the trivertebral element is unknown for the remaining North American taxa. However, at least for $G$. arizonae, the trivertebral was probably not significantly different, for the anterior articular facets of the trivertebral of USNM 6071 exhibit a construction complementary to the posterior facets of the first thoracic vertebra of UMMP 34826; thus, at least the articulations are similar, and probably the entire elements as well.

The trivertebral element of USNM 6071 ( $G$. floridanum, Figure 25) is shorter in the anteroposterior dimension, longest in the transverse dimension as the following measurements indicate: maximum transverse diameter between articular facets for anterior ribs, $128 \mathrm{~mm}$; maximum transverse diameter between articular facets for posterior ribs, approximately $137 \mathrm{~mm}$; maximum slightly oblique dorsoventral diameter from transverse tangent connecting lower edge of posterior articular facets to upper extremity dorsal spine, $75 \mathrm{~mm}$; maximum anteroposterior diameter between vertebral articular facets, left side, $66 \mathrm{~mm}$ and right side, $65 \mathrm{~mm}$; minimum anteroposterior inside diameter between neural foramina, left side, $27 \mathrm{~mm}$ and right side, $19 \mathrm{~mm}$; maximum dorsoventral diameter neural canal, $24 \mathrm{~mm}$; maximum transverse diameter neural canal, $42 \mathrm{~mm}$.

That there are indeed three vertebrae is indicated by the presence on each side of two neural foramina passing laterally downward and forward. Each foramen bifurcates internally, sending a separate dorsal canal to the upper surface of the transverse process and a ventral canal to the lateral extremity. Above each ventral foramen is a complex rib articular facet, with a separation between the head and tubercle portions. The upper (head) portions of the facets occupy the lateral extremity of the fused transverse process. Each is elongate and concave in the anteroposterior direction. The anterior head facet is more 


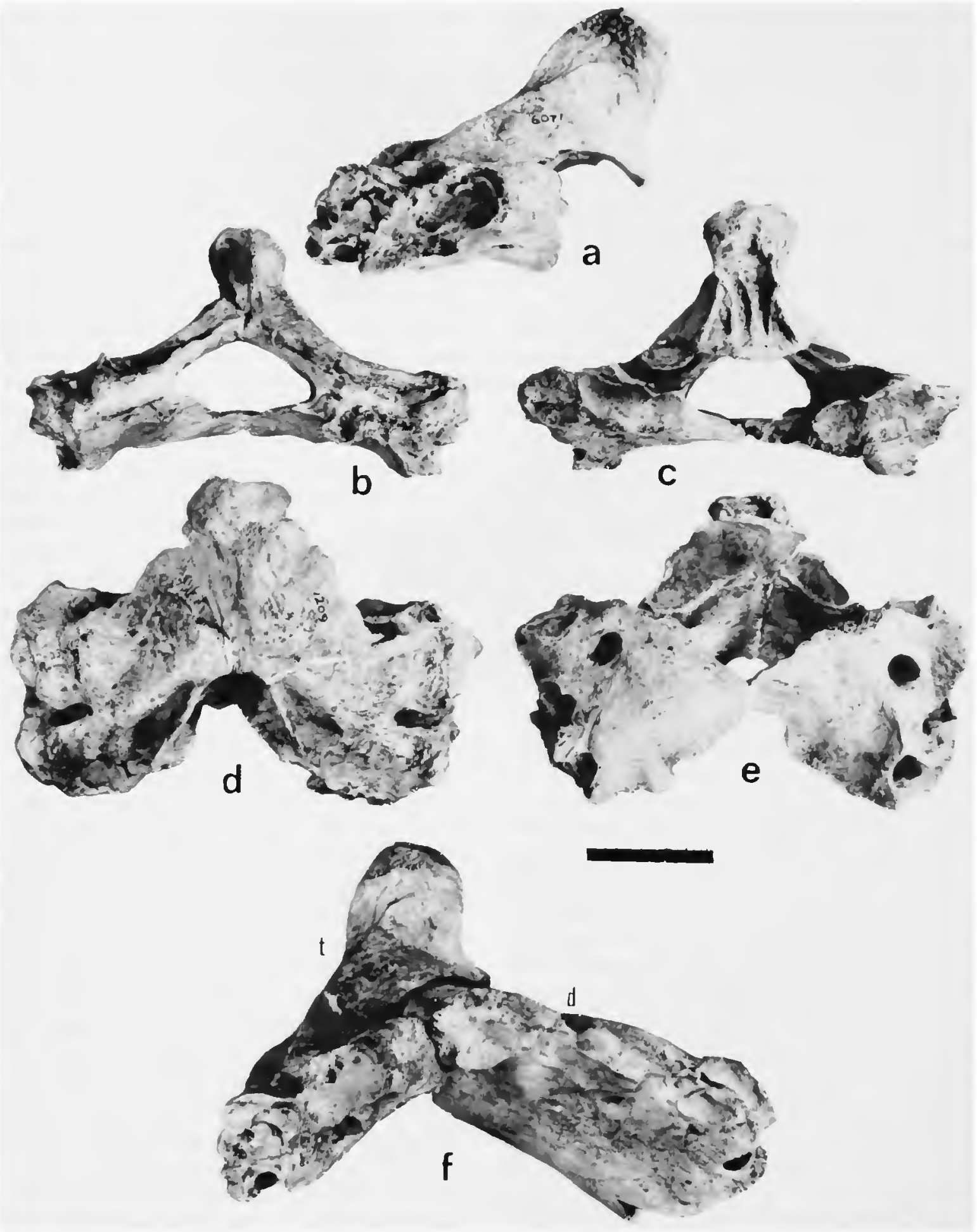

FIgURE 25.- "Trivertebral" element of Glyptotherium floridanum (USNM 6071): $a$, left side; $b$, anterior; $c$, posterior; $d$, dorsal; $\ell$, ventral; $f$, trivertebral element $(t=$ trivertebral element, $\mathrm{d}=$ dorsal tube). (Bar $=40 \mathrm{~mm}$.) 
roughened and irregular, indicating less mobility than the posterior facet, which is relatively smoother. The head facets are circumscribed by small tubercles for muscle attachment, and they are penetrated near their superior margin by several vascular foramina.

The four smaller tubercle facets are situated beneath the head facets. They are concave and slightly oval in shape. One tubercle facet is located anterior to the first neural foramen. It articulates with the corresponding facet on the first rib, which is (presumably) united to the first thoracic vertebra. Another tubercle facet, for the second rib, is situated posterior to the first neural foramen and directly beneath the anterior head facet on this bone. A third tubercle facet is located external and slightly anterior to the posterior foramen. It contacts the posterior head facet. A fourth tubercle facet, for the first rib of the adjoining dorsal tube, is situated on the posterior surface of the transverse process. It is located internally with respect to the other rib facets on the trivertebral element, and, unlike the other laterally directed tubercle facets, the fourth facet faces downward and rearward.

The anterior articular surface for the first thoracic vertebra is poorly delimited. This rugose region is marked by a number of small tuberclelike processes, and there is no distinct articular region, indicating that the mobility in the articulation between the first thoracic vertebra and the trivertebral element, although free, is relatively minor. This contrasts with the posterior articulation with the dorsal tube, for which there are three well-developed facets on the trivertebral element. The two lateral facets are transversely elongate and irregularly concave. They are oriented rearward and somewhat medially and upward. The transverse and dorsoventral diameters are approximately $42 \mathrm{~mm}$ and $19 \mathrm{~mm}$, respectively. The upper facet, situated directly beneath the dorsal spine and confined to the inferior surface of the neural arch, faces entirely downward. Viewed inferiorly, this facet is seen to occupy approximately half of the inferior surface of the neural arch. It is crescentic in shape and transversely elongate. This facet is concave an- teroposteriorly and flat transversely. Its contact with the central facet of the dorsal tube indicates a motion between these two elements that is confined to the vertical plane. The construction of this articulation precludes any torsional or lateral motion.

The dorsal spine is apparently formed by the fused neural arches of the middle and posterior vertebrae. It is inclined steeply rearward, its anterior border forming an angle of approximately $45^{\circ}$ with respect to the horizontal axis of the bone. Its superior extremity, terminating in a stout, blunt tuberosity, is situated immediately above the central facet for the dorsal tube. This construction surely bolsters the articulation with the dorsal tube and indicates the principal importance of this articular contact.

The neural canal is short. It is superiorly arched in a rounded profile, and it is inferiorly flattened. Its anterior opening is posteriorly inclined in roughly the same outline as that of the dorsal spine, so that the superior extremity of the anterior opening lies well posterior to the inferior margin.

The ventral surface of the trivertebral element is smooth and unmarked by tubercles or foramina. The posterior surface of the dorsal spine is deeply marked by three vertical ridges and four vertical grooves. This roughened region apparently provided an enlarged surface for attachment of the dorsal vertebral musculature connecting the trivertebral element with the dorsal tube; this is another indication of the importance of the trivertebral-dorsal tube articulation. This articulation can pass through an arc of at least $60^{\circ}$, although this figure is probably excessive by $15^{\circ}-20^{\circ}$ over that possible in the living state. Nevertheless, a vertical articulation of at least $40^{\circ}$ is a considerable arc for a single contact.

Dorsal Tube.-Fragmentary dorsal tubes are known for G. floridanum and G. arizonae. Represented by three broken portions, the dorsal tube of G. floridanum (USNM 6071, Figures 25f, 26) appears to include only nine vertebrae, here identified as thoracic vertebrae nos. 5-13. This determination is contrary to Hay's (1916) assertion that there are 10 vertebrae represented in this 


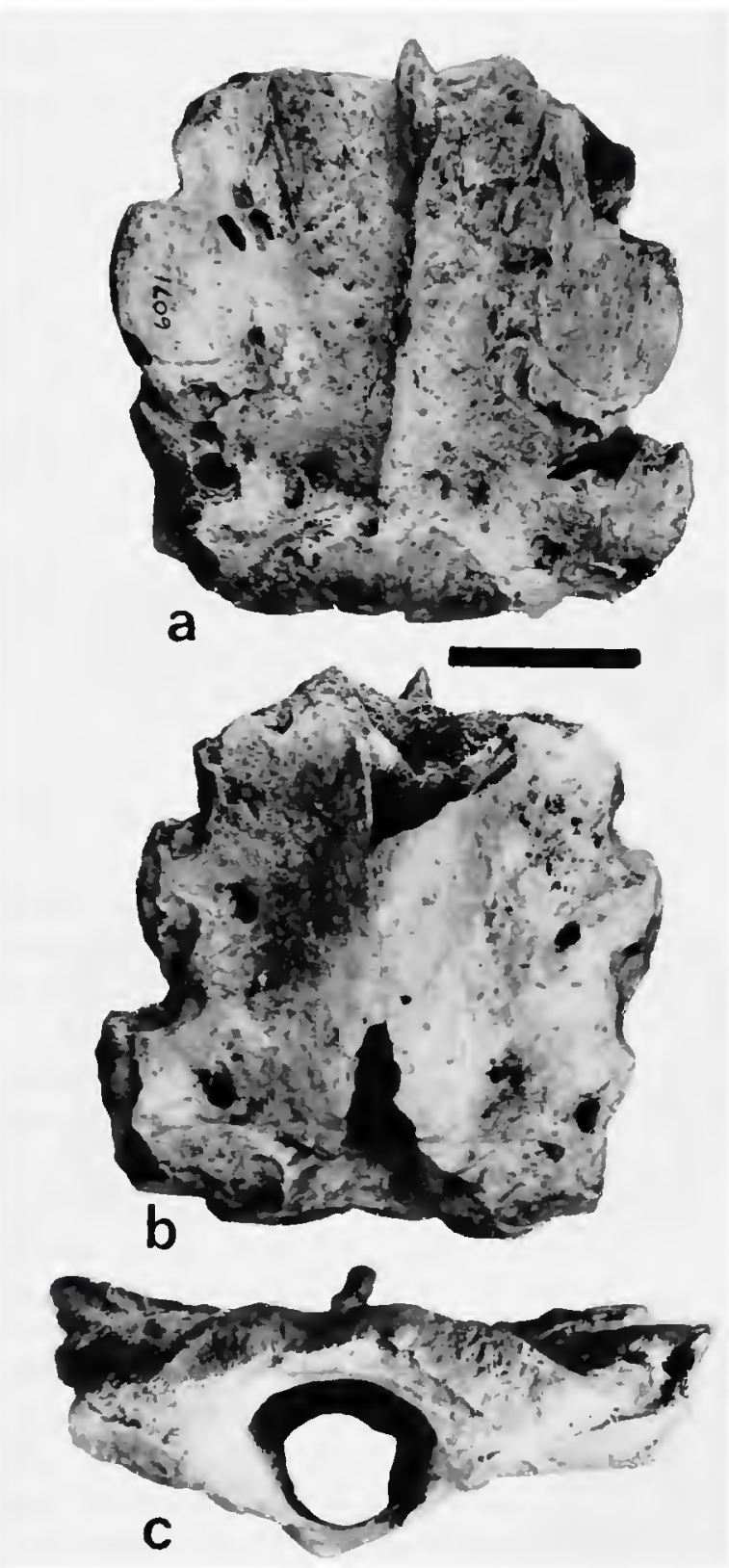

FIGURE 26.-Dorsal tube of Glyptotherium flondanum (USNM 6071), approximately anterior third: $a$, dorsal; $b$, ventral; $c$, anterior. (Bar $=40 \mathrm{~mm}$.)

specimen. The count of nine vertebrae in the dorsal tube, rather than 10 , and of a total thoracic series of 13 rather than 12 , indicate a contrast from the usual conditions of 10 vertebrae in the dorsal arch and a total of 12 thoracic vertebrae for South American glyptodonts (Hoffstetter, 1958).

The three broken portions of USNM 6071 apparently include nearly the entire dorsal tube. The anterior fragment includes the first three vertebrae and a fragment of the fourth (nos. 5-8) of the dorsal tube. The middle fragment anteriorly includes the posterior portion of a vertebra, here identified as the rear section of thoracic vertebra no. 8; three complete vertebrae, nos. 911 ; and the anterior section of thoracic vertebra no. 12 , here interpreted as the penultimate vertebra. The posterior fragment includes the rear section of the penultimate vertebra and the complete terminal vertebra, here interpreted as thoracic vertebrae nos. 12 and 13 , respectively. Although the three fragments cannot be reunited into a single element, there appears to be no entirely missing vertebra. Despite Hay's (1916) assertion that one vertebra is missing, at the breakage between the anterior and middle fragments, there is no compelling justification for this assumption. Indeed the curvature and continuity of the entire dorsal tube is well maintained without (imaginary) supposition of a missing vertebra. Moreover, a supposition of 10 vertebrae in the dorsal tube, bringing the count up to that for most South American representatives, would add another vertebra to the total thoracic count of 14 for $G$. floridanum, an even more drastic departure from the usual count of 12 in South American forms. Thus the three fragments of USNM 6071 are here assumed to include at least portions of all of the vertebrae incorporated into the dorsal tube of $G$. floridanum, representing thoracic vertebrae 5-13. Except for the number of vertebrae, the dorsal tube of $G$. floridanum does not appear to differ significantly from that of either $G$. arizonae, described below, or Glyptodon asper, as figured by Burmeister (1874, pl. 30), and noted by Hay (1916).

The anterior articulation with the trivertebral clement is accomplished by a distinct crescentic zygapophyseal facet and a pair of lateral facets. The dorsal zygapophyseal facet is convex both transversely and anteroposteriorly and is directed 
forward and upward, fitting neatly into the corresponding facet of the trivertebral element. The lateral facets, situated ventrally on the transverse processes of the anterior vertebra, are semicylindrical (to borrow from Hay's, 1916, apt description) for articulation with the correspondingly concave lateral facets of the trivertebral element in a tight contact.

The low and irregular dorsal spine is preserved posteriorly only to the thoracic vertebra 9. Although broken above 10-12, the process appears to have been weak and its vertical extent insignificant. Above the terminal vertebra the spine is reduced and forms only a prominent median ridge, which does not extend vertically as far as the transverse processes.

The transverse processes are completely preserved for the first three vertebrae of the dorsal tube. The transverse processes appear to taper gradually rearward from their maximum expansion at thoracic vertebra 6 (second from front), as indicated by the progressively more medial disposition of the neural foramina. Posteriorly the ventral surface of the coalesced transverse process becomes deflected laterally and compressed, at the terminal vertebra attaining a transverse extent apparently only slightly greater than that of the neural canal. The neural foramina internally bifurcate, as in the preceding vertebrae, sending separate dorsal and lateral branches to the exterior. The dorsal openings, on the upper surface of the transverse process, are smaller and less conspicuous than the round lateral foramina, anteriorly emerging from the ventral surface of the transverse process, posteriorly becoming more laterally situated and nearer the neural canal.

The neural canal increases in depth rearward, changing gradually from a nearly circular shape anteriorly to an oblate and deepened shape at the posterior terminus. As Hay (1916) pointed out, the floor of the neural canal is approximately 1 mm thick at the anterior extremity and approximately $5 \mathrm{~mm}$ thick at the posterior end.

Anteriorly the ventral surface is smooth and broadly convex in the transverse direction. The ventral surface in the middle region is missing.
Posteriorly, the ventral surface is strongly convex in the transverse direction, conforming to the interior shape of the neural canal. In the anteroposterior direction the ventral surface maintains a relatively small compound curve, with an increasing curvature in the concavity toward the rear.

Concave facets for the heads of ribs $4-6$ are situated ventrally on the transverse processes. They are elliptical and are directed outward and slightly forward. The head facet for rib 4 is located somewhat lateral and ventral with respect to the next two facets, which are situated progressively more superiorly and medially, in conformation with the corresponding change in the transverse process.

The tubercle facet for rib 4 is located on the corresponding region of the trivertebral element, as described above. Tubercular facets for the fifth and sixth ribs are situated in the shallow recesses separating the respective transverse processes. These two concave facets are somewhat smaller than the head facets; they are located anterior to, and somewhat above, their respective head facets. They are directed downward and posteriorly. The remaining rib facets are missing.

The posterior articular surface for contact with the sacrolumbar tube is formed by a pair of lateral wing-shaped facets and a pair of dorsal postzygapophyseal facets. These are separated by deep recesses for the corresponding prezygapophyseal facets of the lumbar tube. The small zygapophyseal facets of the dorsal tube are flattened and directed downward and outward and slightly rearward. The rearward-directed lateral facets, situated on the terminus of the only slightly expanded transverse processes, are rough and irregular, indicating a loose, primarily ligamentous connection at this contact.

Measurements for the dorsal tube of USNM 6071 , insofar as the broken condition permits, are as follows: estimated anteroposterior diameter, $370 \pm 10 \mathrm{~mm}$; maximum transverse diameter at anterior extremity, $110 \mathrm{~mm}$; maximum transverse diameter at posterior extremity, $46 \mathrm{~mm}$; maximum transverse diameter neural canal anterior 
extremity, $30 \mathrm{~mm}$; maximum transverse diameter neural canal posterior extremity, $22 \mathrm{~mm}$; maximum dorsoventral diameter neural canal anterior extremity, approximately $23 \mathrm{~mm}$; maximum dorsoventral diameter neural canal posterior extremity, $36 \mathrm{~mm}$; maximum transverse diameter prezygapophyseal facet (anterior extremity), $67 \mathrm{~mm}$.

As Hay (1916) pointed out, there are several differences between USNM 6071 and the dorsal tube figured by Burmeister (1874, pl. 30) for Glyptodon asper, among which smaller size for the North American species is perhaps the most significant. Because Burmeister provided no comparable measurements, and since his illustrations are somewhat idealized for his plate 30, figure 1, further comparison here, on the basis of his account, is not justified.

Gidley (1926) mentioned the recovery of the dorsal tube of USNM 10536, stating that it includes 10 fused vertebrae. He did not compare it with USNM 6071, however, in deference to a comparison with the South American genera Panochthus, Glyptodon, and Hoplophorus (with 10, 11, and 12 vertebrae in the dorsal tube, respectively, according to Burmeister (1874)). The count of 10 vertebrae appears to be correct, and we accept this number because the specimen has deteriorated somewhat from Gidley's time and is now in two broken portions that cannot be matched along a common breakage. The count of 10 vertebrae in the dorsal tube of $G$. arizonae differs by one from that assumed for $G$. floridanum, as discussed above. However, due to the fact that the count for the latter species is not established with certainty, distinction between these two species on the basis of the number of vertebrae in the dorsal tube is unjustified.

The anterior eight vertebrae of the dorsal tube of $G$. arizonae (USNM 10536, Figure 27) can be examined only from the ventral surface. The last two vertebrae, although broken, are free from their plaster encasement. The anterior articular facets closely resemble those of USNM 6071. The dorsal facet, although partially hidden, appears to possess a convex crescentic construction as in G. floridanum. The lateral facets differ only in being slightly elevated above the surface of the surrounding bone, with a better demarcation of the articular margin.

The centra of the first five vertebrae are present, and they retain discrete separation from adjacent centra. In lateral silhouette, the ventral outline is wcakly scalloped, owing to slight thickening of each centrum at the contact with the adjoining centra. The centra are not preserved for USNM 6071, precluding comparison with $G$. floridanum.

Although somewhat damaged, the posterior

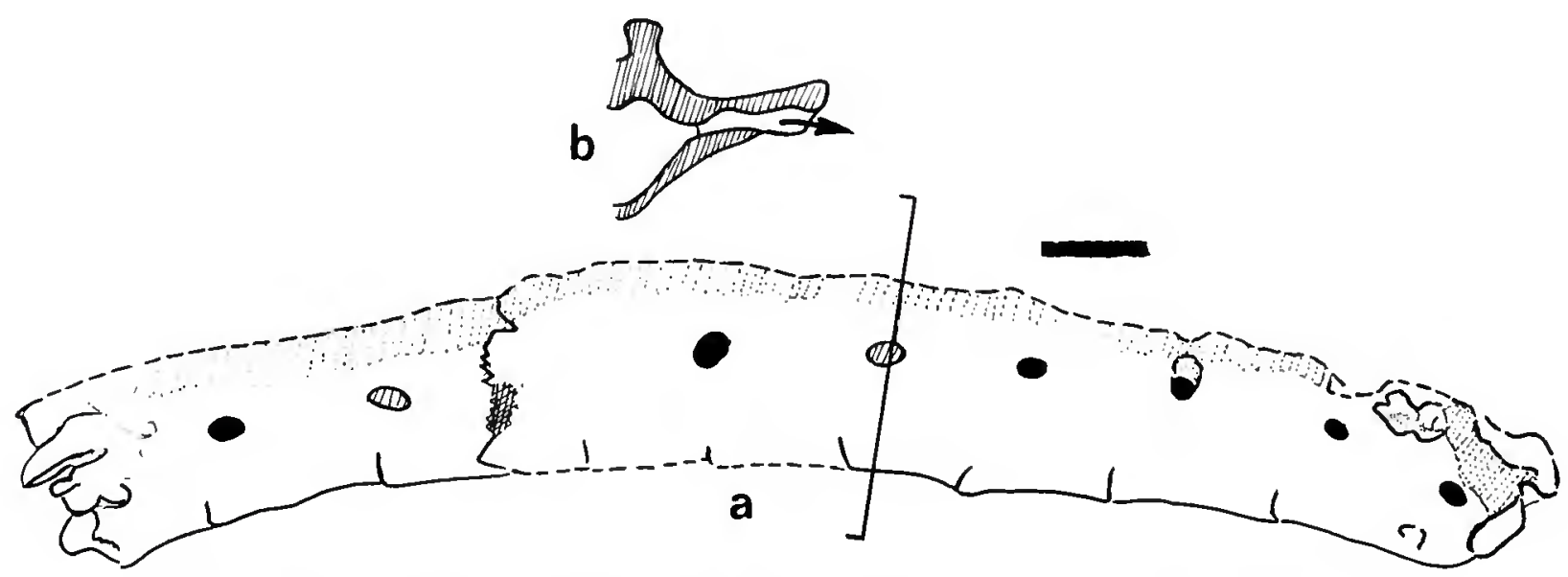

FIGURE 27. - Schematic interpretation of dorsal tube of Glyptotherium arizonae (USNM 10536): $a$, right side, anterior to right; $b$, cross section through section line in $a$. (Bar $=40 \mathrm{~mm}$.) 
lumbar articular region is sufficiently well preserved to indicate near identity with that of $G$. floridanum. The only apparent difference is that the vertical height of the dorsal tube at its posterior extremity is rather larger in $G$. arizonae. Its broken condition does not allow accurate measurement.

The only notable difference between these two dorsal tubes lies in the nature of the fused transverse processes in the middle region of the bone. In $G$. floridanum the transverse processes, as viewed from below, emerge from the centrum with a distinct vertical orientation, whereas the ventral surface is more flattened in $G$. arizonae. Accordingly, the positions of emergence of the ventral rami of the neural foramina reflect this difference. In $G$. floridanum they emerge from the nearly vertical wall of the transverse processes near the centra. In $G$. arizonae these foramina are situated more laterally, where the ventral surface is not so steeply inclined. Another difference, though certainly not of taxonomic value, is that the anterior neural foramina are much larger in $G$. arizonae. The posterior foramina are approximately equal.

Because of the broken condition of dorsal tube USNM 10536 no accurate measurements are possible. Its proportions and size closely resemble those of USNM 6071. If future discoveries substantiate the existence of 10 vertebrae in the dorsal tube of $G$. floridanum, rather than nine as proposed here, there will be no definitive distinction in this element between these two species.

Riss.-Except for the first rib, which is fused to the first thoracic vertebra, ribs of North American glyptodonts are mostly unknown. A single fragment, representing the proximal extremity of a rib of $G$. arizonae (MU 1668), possesses a distinctly flattened shaft in the typical glyptodont fashion. It bears two articular facets. Measurements for this fragment are as follows: transverse diameter between facets, $74 \mathrm{~mm}$; dorsoventral and transverse diameters of shaft distal to proximal expansion, $33 \mathrm{~mm}$ and $19 \mathrm{~mm}$, respectively. Because of the similarity of Glyptotherium with South American representatives, the ribs and sternum are here assumed to be similar, as tentatively indicated by rib 1 and the free rib fragment discussed above.

\section{Front LimB}

The elements of the front limb are somewhat less massive than those of the hind limb. Although it exhibits a measure of specialization in the loss of the first digit, the extreme reduction of the fifth digit, and the reduction of the trapezium and trapezoid, the front limb nevertheless retains mostly a primitive construction correlated with the animal's massive build: the scapula is an extremely broad plate, providing a large area for muscle attachment; there is no indication of a clavicle; the humerus is pillar-like; the radius length is only half that of the humerus, a proportion indicating the extreme graviportal mechanics manifest in the front limb; the ulna shares equally with the radius the transfer of weight to the carpus; the carpal bones are unfused, with the nominal exception of disease conditions; there is a full battery of digital sesamoids, a large palmar sesamoid, and a well-developed pisiform; the metacarpals and phalanges are stout and relatively simple. The construction of the manus is suggestive of an elephant-like padded foot. There appears to have been little capacity for digging, despite others' statements to the contrary.

Only Burmeister (1874) and Vinacci Thul (1943) have discussed in detail the osteology of the front limb of glyptodonts. Vinacci Thul (1943) provided an excellent description of the manus of Glyptodon, establishing that the missing digit is the first, rather than the fifth as asserted by Burmeister (1874) and others. Unfortunately, Vinacci Thul provided only one illustration and no measurements to accompany his description.

The front limb of the North American glyptodonts closely resembles that of Glyptodon, although all of the South American species seem to be sufficiently distinct from North American representatives to preclude any assumption of identity.

Scapula (Table 13). - The broadly rounded scapula of Glyptotherium provides a widely ex- 
panded surface for muscular attachment. The straight scapular spine, increasing in height ventrally, expands into a broad curved acromion. The acromion process curves ventromedially beyond the plane of the glenoid cavity. The spine divides the scapula into a smaller cranial supraspinous fossa, and a larger caudal infraspinous fossa. The caudal border is relatively straight to its confluence with the neck. The thickness of the bone is expanded along this border. Although the scapular cartilage was apparently not extensive in F:AM 95737 ( $G$. texanum, Figure 28), the broadly rounded vertebral border is incomplete along the margin because of the incomplete ossification of the scapular margin in this subadult individual. The caudal angle is sharp and well defined. The cranial border is poorly preserved. It appears to have been confluent with the vertebral border, with no obvious cranial angle. If visually projected the vertebral border describes

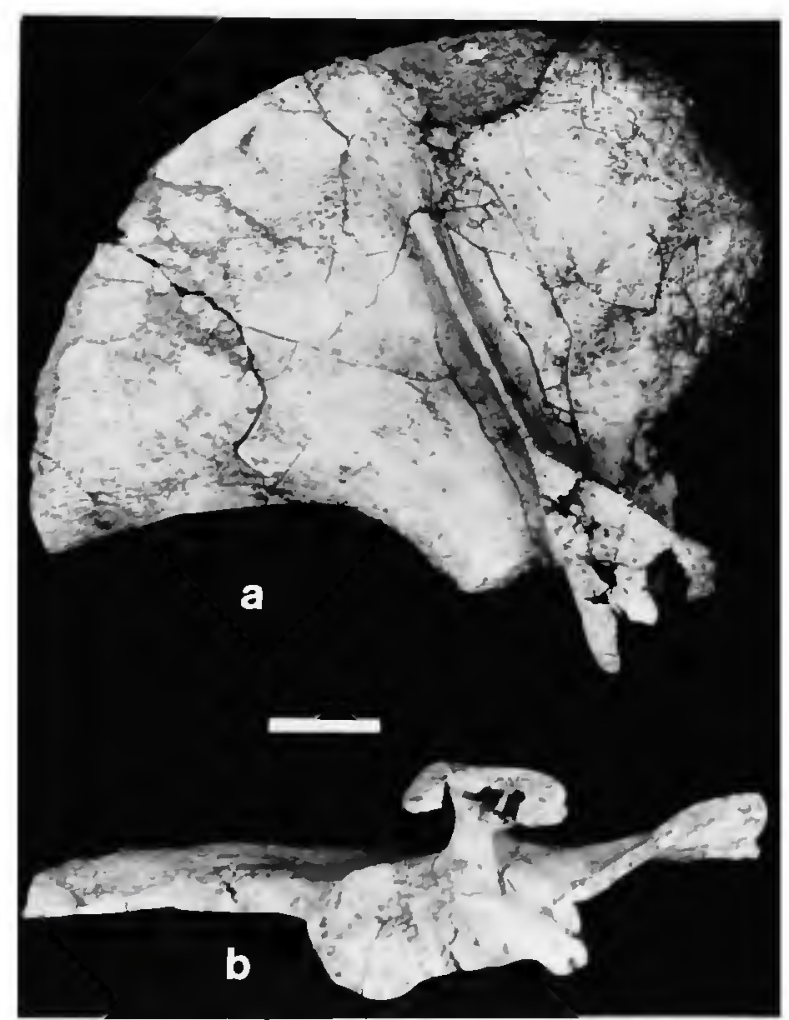

IGURE 28.-Right scapula of Glyptotherium texanum (F:AM 95737): $a$, lateral; $b$, ventral. (Bar $=40 \mathrm{~mm}$.) the greater portion of a nearly complete irregular semicircle. The infraspinous fossa is smooth and relatively flat, with the cranial border slightly inflected laterally.

The entire medial surface is smoothly concave. The subscapular fossa is relatively smooth, with a dorsoventral furrow extending from near the vertebral border toward the neck of the scapula in the position opposite the scapular spine on the outer surface. The bone is extremely thin over the entire surface of the fossa except in the strengthened region of the scapular spine. The bone in the neck region thickens toward the glenoid cavity and the coracoid process. The latter, broken in F:AM 95737, projects anteromedially from the glenoid border.

The glenoid cavity is broadly and irregularly ovoid, the broadest expansion occurring at the posterior border of the articular surface. The glenoid fossa is shallowly concave in both the transverse and anteroposterior directions. It is directed perpendicular to the surface of the expanded portion of the scapula.

The scapula of $G$. arizonae (USNM 10536, Figure $32 a$ ) is considerably larger and more massive. The caudal angle is decidedly more acute, and the surface of the infraspinous fossa bears several large prominences. As in G. texanum, the cranial border is broadly rounded, but the caudal border is more deeply concave owing to the acute caudal angle. The acromion process is less symmetrical in lateral aspect, with a considerably greater cranial development and little caudal development of the curved extremity. The scapular spine is curved rather than straight.

As Gidley (1926) pointed out, the scapula of USNM 10536 resembles that of the South American genus Glyptodon, although it differs considerably in the anteroposterior extent, in the broadly rounded superior scapular border, and in the shapes of the external fossae. The scapula of $F$ : AM 95737 differs much in the same way and is more similar to USNM 10536 than to the South American forms. Thus the scapula of each species resembles the other more closely than either resembles that of South American species, so far as known. 
Humerus (Table 14). - The humerus of Glyptotherium is a stout, pillar-like bone with a massive greater tuberosity. Only the right humerus of $F$ : AM 95737, a juvenile, is represented in North American collections for $G$. texanum; the nature of the epiphyseal contacts indicates that growth was nearly complete at the time of death. The humerus of $G$. texanum is considerably smaller than that of $G$. arizonae, even allowing for additional length in the full adult condition. The humerus of $G$. floridanum is known only for the distal extremity, and it is unknown for $G$. cylindricum.

In $G$. texanum (Figure 29) the hemispherical head presents a well-defined articular surface. In proximal view the head is slightly elongate in the anterolateral direction, with a right angle formed by the convergent margins of the head along the indistinct neck between the head and the tuberosities. The greater tuberosity extends nearly as far proximally as the head, forming a massive lateral tubercle. The lesser tuberosity, forming the anteromedial eminence of the proximal end, is separated from the greater tuberosity by a shallow bicipital groove. With the head, the rugose tuberosities comprise the proximal expansion, the maximum diameter of which is approximately twice the minimum diameter of the shaft at its midpoint.

The ridge of the greater tuberosity is rounded and poorly defined, intersecting the deltoid ridge approximately one-third the distance along the shaft from the proximal extremity. The anconeal crest and the deltoid ridge form the posterior border of the well-developed deltoid tuberosity. The lateral border of the deltoid tuberosity on F:AM 95737 is somewhat damaged; there was apparently a subdued flange along the course of the deltoid tuberosity in this position. The deltoid tuberosity is directed anterolaterally and forms an isosceles triangle in lateral aspect, with the distal apex positioned at the junction of the deltoid tuberosity and the ridge of the greater tuberosity.

The ridge of the lesser tuberosity is not as well developed. At a point on the medial surface opposite the apex of the deltoid tuberosity, a projection of the ridge as a low eminence marks its distal extremity. The teres tuberosity on the posterior surface of the shaft is poorly developed.

In cross section, the shaft at its midpoint forms a nearly equilateral triangle, with rounded apices. The posterior apex is formed by the confluence of the subdued ridge of the teres tuberosity with the proximal portion of the supinator ridge; the anterior apex is formed by the confluence of the medial supracondylar ridge as it crosses over the anterior border in line with the distal portion of the deltoid tuberosity; and a posteromedial apex is formed as the proximal extension of the posterior border of the medial supracondylar ridge.

The lateral supracondylar ridge forms an expanded supinator plate, extending in a spiral course from a posterior position near midshaft to a lateral position at its confluence with the lateral epicondyle. The supinator ridge thickens distally, forming a smooth concave anterior surface as the distolateral border of the musculospiral groove. The posterior surface of the lateral supracondylar ridge is flattened. The medial epicondyle forms an expanded surface on the distomedial extremity. Its rugose surface is penetrated by three small foramina.

The lateral epicondyle is continuous with the supinator ridge and it is not greatly expanded. Its surface is directed anterolaterally. The coronoid and radial fossae are confluent, forming a single shallow excavation with a triangular outline. The olecranon fossa is more deeply excavated, forming a semicircular anterior boundary. The anterior boundary is the steepest, nearly at a right angle with the shaft. There is no supratrochlear foramen piercing the bony septum.

The trochlear facet is directed obliquely in a distolateral direction. The capitular facet is broader and provides a greater radius of articulation. The intercondylar groove is shallow.

The most prominent features of the humerus of $G$. texanum are the expanded deltoid tuberosity and the broadened supinator plate. Although not greatly expanded at either extremity, there is sufficient development to deduce strong musculature in the upper limb. The long axis of the humerus is directed from the most proximal articulating surface of the head through the center 


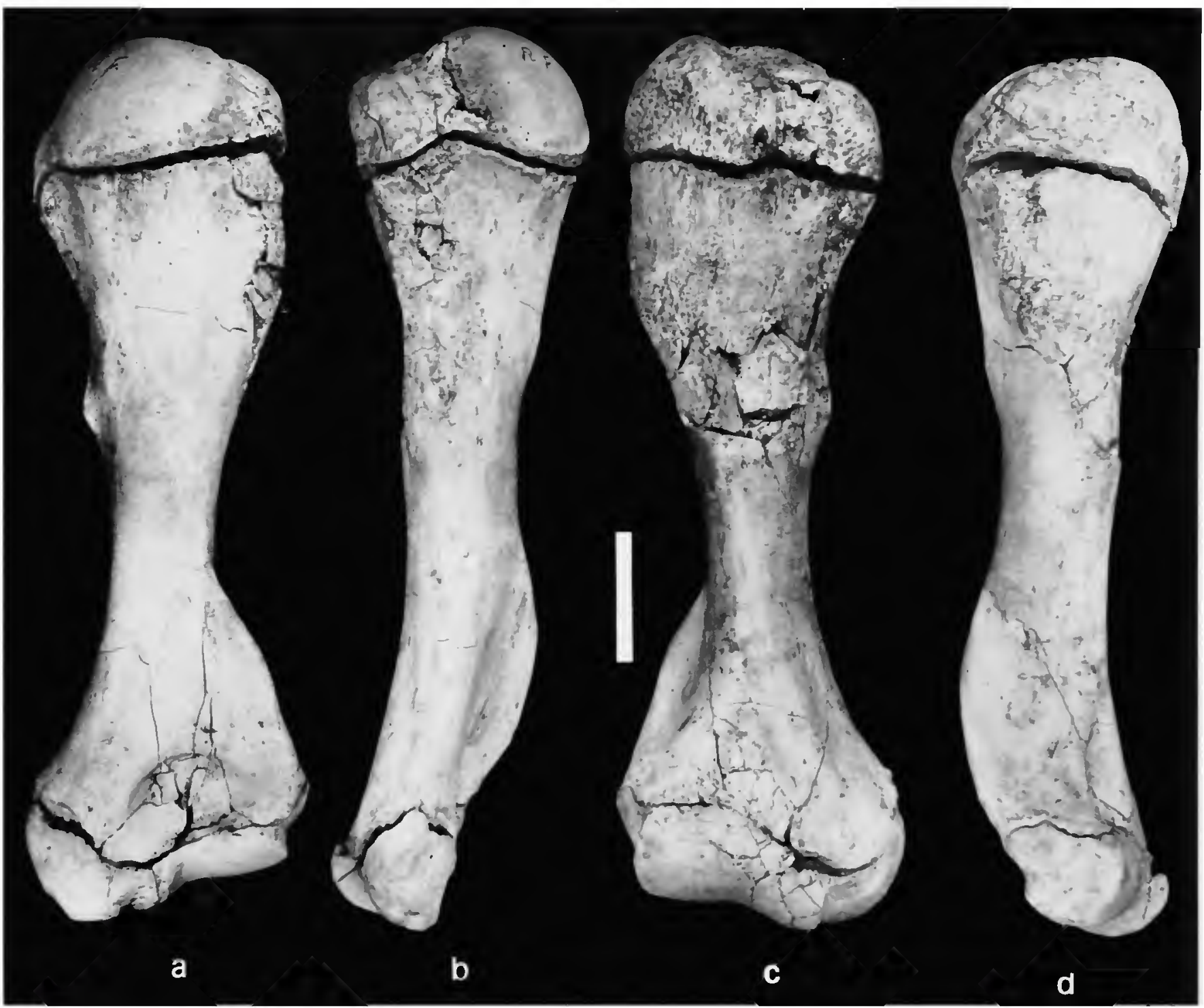

Figure 29.-Right humerus of Glyptotherium texanum (F:AM 95737): $a$, posterior; $b$, medial; $c$, anterior; $d$, lateral. (Bar $=40 \mathrm{~mm}$.)

of the shaft to the trochlear facet which is located in a central position on the distal extremity.

The humerus of $G$. arizonae (Figure $32 b$ ) apparently differs considerably from that of $G$. texanum. Besides being much larger and considerably more massive, the humerus of $G$. arizonae presents a tremendous exaggeration of features related to regions of muscle attachment. A prominent dis- tinction often mentioned in the literature is the presence of a supratrochlear foramen. This characteristic, however, actually seems to bear diagnostic value only as a specific distinction. Until a series of glyptodont humeri is evaluated for ontogenetic variation, this characteristic should be used only as a provisional distinction, as indicated herein. Because the only complete humerus of $G$. 
texanum available for comparison (F:AM 95737, above) is from a juvenile individual, the following full description of the humerus of $G$. arizonae is included. Because of the age disparity the differences may be more apparent than real, but until new specimens of both species are recovered, separate descriptions are warranted. Indeed, the distal end of the right humerus of $G$. texanum (TMM 40664-245) from the Red Light local fauna is more nearly like that of $G$. arizonae (USNM 10536), as pointed out by Akersten (1972). It lacks a supratrochlear foramen.

In G. arizonae (USNM 10536, Figure 32b) as in $G$. texanum, the head presents a broad articulating surface, expanding beyond the thickness of the shaft at the epiphysis. The greater and lesser tuberosities extend nearly to the most proximal extremity of the head and are separated from it by an indistinct neck. The intertubercular groove (bicipital groove) is distinct only between the tuberosities, where it forms a narrow furrow. The crests of both tuberosities are pronounced. The crest of the lesser tuberosity extends along the medial surface to midshaft. The crest of the greater tuberosity, in cranial aspect, forms a broad surface for muscle attachment, curving downward across the anterior surface to intersect the lateral margin of the deltoid tuberosity at approximately one-third the distance from the head along the shaft. The surface between the crest of the greater tuberosity and the deltoid ridge is concave, elongated parallel to the sagittal plane. The deltoid tuberosity presents a rugose triangular surface in lateral aspect, with the distal apex located at the intersection of the crest of the greater tuberosity with the deltoid ridge on an elevated surface. The caudal margin of the deltoid ridge is inflected, forming a prominent flange. This deltoid flange extends from a point near the head anteromedially across the proximal portion of the shaft, forming the anterior boundary of the musculospiral groove, which wraps around the lateral border of the shaft to an anterior position on the distal end. The inner surface of the musculospiral groove is formed by the well-developed supinator ridge that originates on the posterior surface of the shaft at its midpoint, in direct line with the proximal extension of the lateral supracondylar ridge.

The cross-sectional aspect of the shaft at its midpoint is a slightly eccentric ellipse, with the primary axis extending from the craniomedial border to the caudolateral border. This cross section obtains for only a short distance along the middle portion of the shaft, giving way to irregular outlines at either extremity.

The trochlear and capitular facets are circular in outline in lateral aspect, forming an arc of approximately $300^{\circ}$. The trochlear facet forms the distal extremity. The medial epicondyle is expanded and bears two distinct notches for muscle insertions, one on the anterior surface, the other on the anteroproximal surface.

The coronoid fossa is deeply excavated, with the medial and lateral supracondylar ridges forming prominent borders on either side of the triangular fossa. The coronoid fossa undercuts the medial ridge. The bony septum in the coronoid fossa is extremely thin and is perforated in the central position by the supratrochlear foramen. From the lateral supracondylar ridge issues a prominent flange, the supinator ridge, concave on its cranial surface. The supinator ridge extends along the lateral surface of the lateral supracondylar ridge, forming the distal boundary for the musculospiral groove. The lateral epicondyle is directed distolaterally, forming a broadly obtuse angle with the supinator ridge. The olecranon fossa is roughly elliptical in shape, with the major axis directed at an angle from proximolateral to distomedial. The fossa is deeply excavated; on the medial boundary the excavation undercuts the medial supracondylar ridge.

Only the distal ends of the humeri of $G$. floridanum are known (USNM 6071, Figure 32e,f). Their size and shape more closely approximate that of $G$. arizonae than $G$. texanum. There is no supratrochlear foramen, although this may not be an important distinction, as indicated above. This character is here utilized only as a provisional species distinction. The coronoid and olecranon fossae are small and not deeply excavated, 
rather intermediate in form between those of $G$. arizonae and G. texanum.

UlNA (Table 15). - The ulna of G. texanum (F: AM 95737, Figure 30) is essentially a straight, laterally compressed rectangular prism, rounded on the posterior margin of the olecranon process. The rugose epiphysis of the olecranon constitutes the proximal extremity, with only slight expansion from the shaft. The shaft is but slightly expanded transversely at either extremity; the narrowest portion of the shaft occurs immediately below the semilunar notch. Distal to the semilunar notch, the narrowed anterior margin of the shaft is bowed medially. The rounded posterior border is nearly straight, tapering from a broadened proximal surface to a narrowed ridge on the distal end. In lateral aspect also, the posterior margin is nearly straight, with a gentle curvature at the proximal extreme in contour with the rounded olecranon process. The coronoid process on the medial side of the semilunar notch provides an oblique surface for articulation with the trochlear facet of the humerus. Lateral to the coronoid process are two distinct facets: the flattened radial notch, directed anteriorly, for reception of the radius; and the capitular facet, forming the lateral surface of the semilunar notch for reception of the capitulum of the humerus.

The distal extremity is not greatly expanded. Two facets provide the articular surface for the carpals. The larger facet is lateral (anterior in anatomical position) and provides the articular surface for the cuneiform. This semicircular facet is flattened in the cross-sectional plane and forms

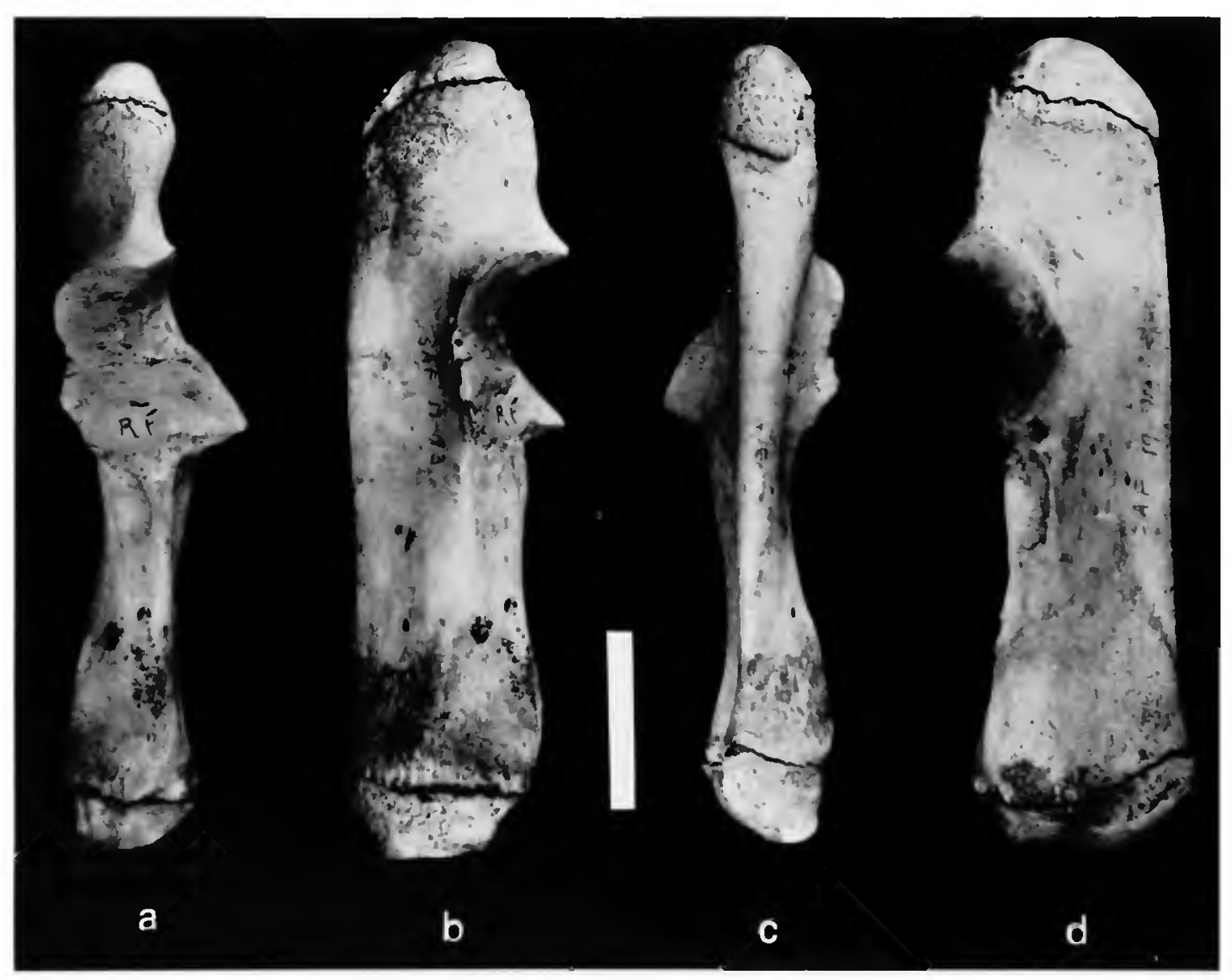

FigURE 30.-Right ulna of Gtyptotherium texanum (F:AM 95737): $a$, anterior; $b$, lateral; $c$, posterior; $d$, medial. (Bar $=40 \mathrm{~mm}$.) 
the distal extremity of the ulna. The facet for articulation with the pisiform is medial and posterior to the cuneiform facet (laterally in anatomical position), directed distomedially (distolaterally in anatomical position). The surface of the pisiform facet is oblate and convex, fitting loosely into the anterolateral articular surface of the pisiform.

The only remaining prominent feature of the ulna is a pronounced trough, with a roughened surface distal to the coronoid process of the semilunar notch and situated on the anteromedial side of the shaft.

Except for greater size, the ulnae of $G$. floridanum (Figure 32c) and G. arizonae (Figure 32d) differ only in the more greatly exaggerated features, a condition that might be attributed to the age disparity represented by the available specimens of these two species (USNM 6071, 10536, respectively).

Radius (Table 16).-The radius of $G$. texanum (F:AM 95737, 59585, Figure 31) is short and stout, with both extremities expanded from the narrow shaft; the distal extremity of the shaft is the larger. The length of the radius is approximately half that of the humerus. The radius crosses the anterior surface of the ulna at a low angle, permitting only a slight degree of rotational motion in the forearm. The glenoid cavity of the radius presents an expanded articular surface for the reception of the broad capitulum of the humerus. Proximal articulation with the ulna is limited to the flattened posterior face on the epiphysis. There is no radial tuberosity. The interosseous space between the radius and the ulna extends from the anterior epiphysis of the radius distally to the point of articulation with the ulna at the distal end of the shaft of the radius. This concave ulnar facet, on the posterior border of the radius, includes only a small portion of the epiphysis. It is situated opposite the convex anterior radial facet of the ulna, on which the articulation is equally divided between the shaft and the epiphysis.

The radius is approximately equidimensional at midshaft. In lateral view the radius is straight. In anterior view the shaft of the radius is directed obliquely with respect to the articular facets. The rugose styloid process is the most prominent feature on the distal extremity. The dorsal tubercle, although not as prominent as the styloid process, extends laterally to form a rounded rugose knob on the anterolateral surface of the distal extremity. The distal articular surface consists of a single concave facet for the reception of the lunar and trapezoid bones of the wrist. This surface is directed posteriorly at approximately $45^{\circ}$ with the cross-sectional axis of the shaft.

As for the ulna, the radius of $G$. arizonae (USNM 6701, 10536, UMMP 38761, Figure 32c) differs only in being larger and possessing rather exaggerated features, especially those related to muscle attachment. The apparent size disparity, as in the ulna, may be due to the differences in age between the juvenile specimen of $G$. texanum and the older individuals of $G$. arizonae; thus there are no apparent diagnostic distinctions in the radii of these two species. The radius of $G$. floridanum (USNM 6071, Figure 32d) appears to bear no distinctive differences from that of $G$. arizonae, and it differs from G. texanum much in the same way.

Carpus. - The carpal bones are arranged in two rows, four bones in each row. The proximal row includes the pisiform, and three tightly abutted elements, the cuneiform, lunar, and scaphoid. Together, the last three bones form a broad convex proximal articulation with the radius and ulna. Distally, these elements articulate with the bones of the distal row in a construction permitting limited fore-and-aft motion. Transverse motion at the intercarpal joint was almost totally prohibited by the interlocking construction of the distal series, both with each other and with the proximal articulations from above.

The distal series includes the trapezium, trapezoid, magnum, and unciform. The trapezium is considerably reduced relative to the other carpals; the trapezoid is also reduced, but to a lesser degree; the magnum and unciform are large. The distal carpals articulate with the metacarpals distally, also in a construction permitting limited fore-and-aft motion and little transverse motion.

The carpals of the North American representatives closely resemble the description of those of 


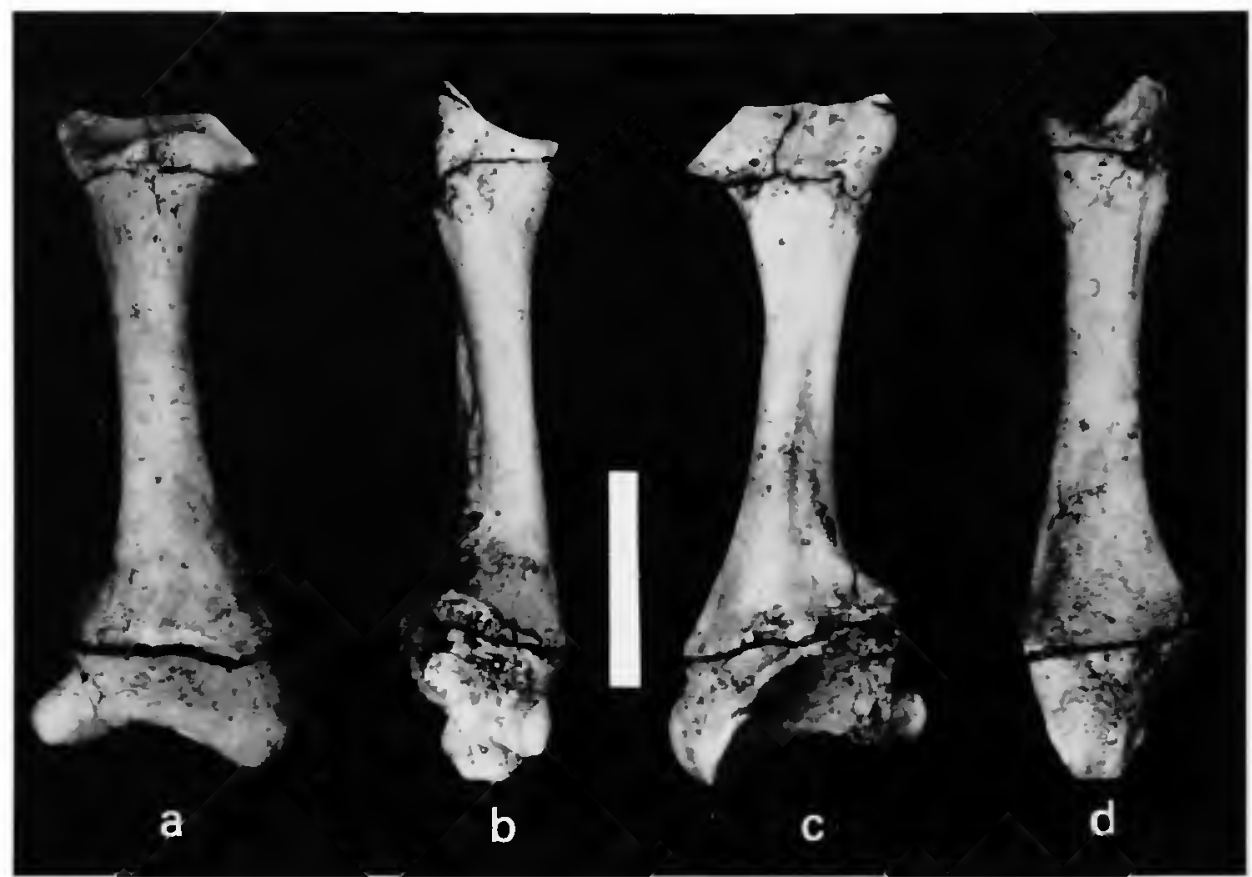

FIGURE 31.-Right radius of Gtyptotherium lexanum (F:AM 95737): $a$, anterior; $b$, lateral; $c$, posterior; $d$, medial. (Bar $=40 \mathrm{~mm}$.)

Glyptodon by Vinacci Thul (1943). The resemblance is so close, in fact, that there is little doubt that the. South American Glyptodon is a close relative of the North American genus. Unfortunately only a single illustration of the front foot, in complete articulation, was included with his description, and he provided no measurements. At least proportionally the carpals of Glyptodon, as described by Vinacci Thul, appear to be very similar, if not identical, to those of Glyptotherium.

A pertinent statement by Vinacci Thul (1943) concerning the trapezium and trapezoid is that these two bones are sometimes fused. His statement is unclear as to whether the fusion occurs occasionally in Glyptodon, or whether it is characteristic for certain taxa (i.e., certain species of Glyptodon, or other non-Glyptodon taxa). We suspect his intention was that this fusion is a manifestation of ontogenetic variability within the genus and that fusion of these two reduccd boncs is not significant as a diagnostic character. The rcasons for this deduction are more fully discussed in the descriptions of the carpal and metacarpal elements of $G$. arizonae, in which there is considerable evidence of pathologic conditions, in at least one instance including fusion of two bones owing to an arthritic condition.

Nearly complete carpal series are known for $G$. texanum and $G$. arizonae.

Pisiform (Table 17).- The pisiform is situated lateral to the proximal series of carpals. Geometrically the pisiform of G. texanum (F:AM 95737, Figure 41 ) is a distorted tetrahedron, with two articular and two nonarticular surfaces. Its concave proximal articular facet receives the lateral facet of the ulna. On the anteromedial surface, at right angles with the proximal facet, is the articular surfacc for the reception of the corresponding surface of the cuneiforn. The distopalmar surface is concave and rugose. The anterolateral surface is similarly rugose, forming an oblique angle with each of the articulating surfaces and an acute angle with the distopalmar surface.

The pisiform of $G$. arizonae (USNM 10536, 

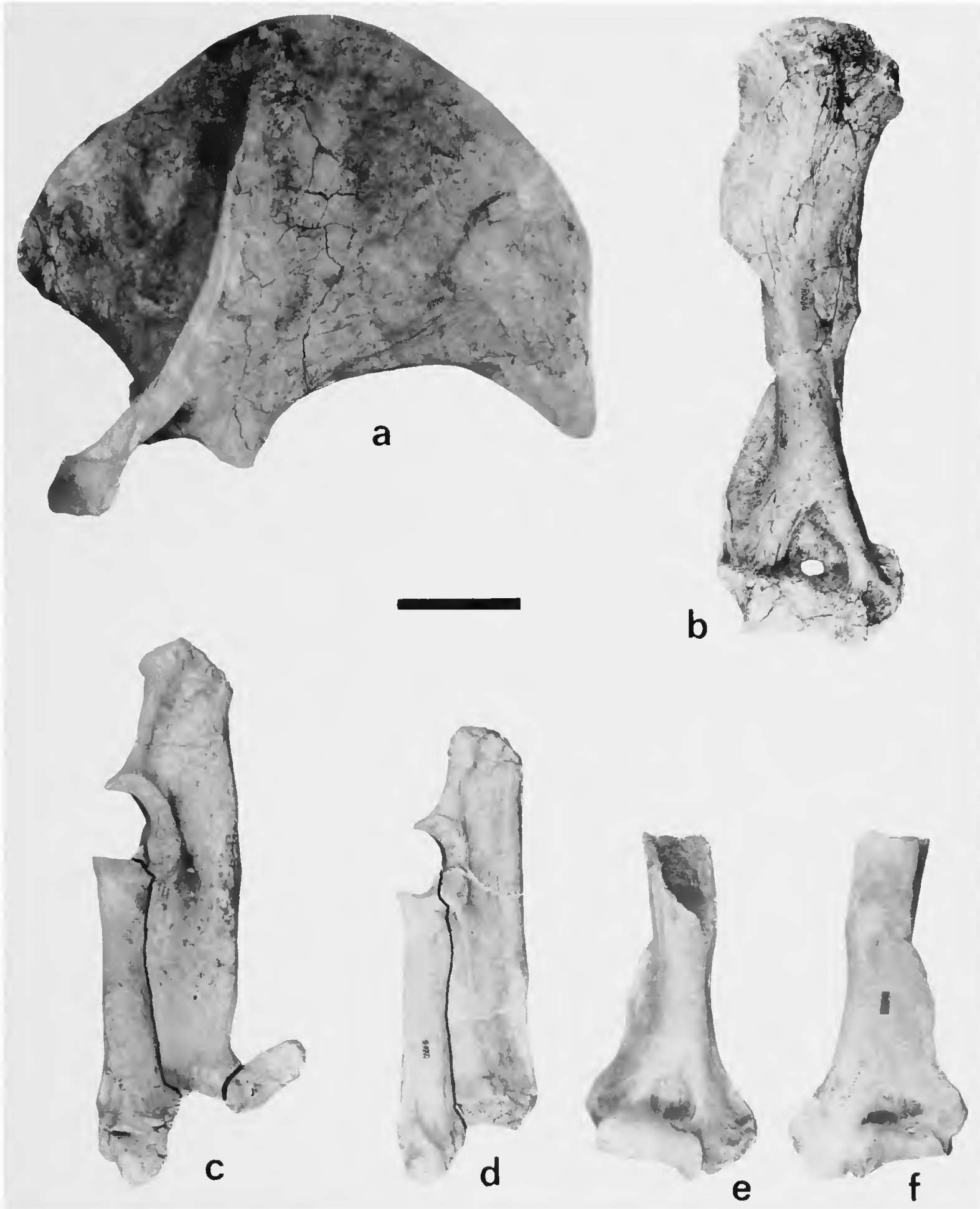

FiguRe 32.-Glyptotherium arizonae (USNM 10536): $a$, left scapula, lateral; $b$, right humerus, anterior; $c$, right radius-ulna-pisiform in articulation, medial. Glyptotherium floridanum (USNM $6071): d$, right radius-ulna in articulation, medial; $e$, anterior; $f$, posterior of distal extremity of right humerus. (Bar $=40 \mathrm{~mm}$.) 
Figure $32 c$ ) is proportionately longer in the proximodistal plane. Otherwise it is identical to that of $G$. texanum.

Vinacci Thul (1943) aptly compared the shape of the pisiform of Glyptodon to that of a human external ear or pinna. A similar comparison can be made for the pisiform of both of these North American species.

Cuneiform (Table 18). - The cuneiform of $G$. texanum (F:AM 95737, Figure 41) is a transversely elongated concavoconvex disc. The proximal articular surface for reception of the ulna is convex in the plane of elongation and slightly concave in the plantar-palmar plane, with the anterior border forming a raised lip. The proximal surface bears a rugose nonarticular region on the lateral margin, the lateral extremity of which forms an eminence, providing a laterally directed convex articular surface for reception of metacarpal $\mathrm{V}$. This is the only articulation for the reduced fifth digit, with loss of unciform contact, a modification indicative of the digit's vestigial character.

The anterior (plantar) surface is convex in proximal view, concave in lateral aspect, providing a groove for the reception of a strong plantar tendon crossing from the medial surface of the carpal series to the reduced fifth digit. The medial surface of the cuneiform is convex, articulating laterally with the corresponding articular surface of the lunar. The posterior (palmar) surface is slightly convex, articulating with the pisiform.

The distal articular surface is concave, repeating in parallel the convexity of the proximal surface. The distal articulation with the unciform occupies the entire distal surface except for the lateral region distal to the lateral knob. Herc, lateral to the articular surface for the unciform and directed slightly antcriorly, is a facet for articulation with metacarpal IV. The cuneiform, thereforc, articulates not only with the unciform, which in turn articulates with metacarpal IV, but also with the proximolateral surface of the fourth metacarpal. In this respect, the transfer of weight directly to the fourth metacarpal from the cunciform is a reflection of the reduction of the fifth digit, with its concomitant loss of articulation with the unciform and reduction in size of the latter bone. This arrangement in the carpal series thus exhibits specialization for increased efficiency in weight support by the elimination of a portion of an articular surface between the cuneiform and the unciform and by the sharing of weight transfer to the metacarpal IV by these two bones of the carpal series.

The cuneiform of $G$. arizonae (USNM 10536, Figure 42, UMMP 3876l, Figure 43), besides being half again larger, differs principally in the nature of the articular facets. The proximal articular facet is less rounded on the anterior margin and extends nearly to the lateral metacarpal facet. The latter is flattened, rather than convex, and is situated on the lateral margin of the bone instead of occupying a knoblike projection. The distal articular surface is more deeply excavated. The medial articular facet (lunar facet) is somewhat more extensive in $G$. arizonae, and it is essentially flattened. The most significant difference is the relatively poor development of the pisiform facet.

Lunar (Table 19).--Largest of the proximal carpal series, the lunar of $G$. texanum (Figure 41) occupies a central position, receiving the bulk of weight transfer from the radius. It is elongated anteroposteriorly and bears four articular facets: a proximal facet for articulation with the radius; a distal facet for articulation with the magnum; and a medial and a lateral facet for articulation with the adjacent proximal carpals. The medial and lateral articular facets are both concave in the anteroposterior direction and in the proximodistal plane. The result of these concavities on either side is a constriction, centrally located in proximal aspect. From this vantage, the expanded anteroproximal articular surface is broadly rounded and in contour with the corresponding articular surfaces of the adjacent cuneiform and scaphoid. This facet receives the lateral and postcrior portion of the concave articular surface of the radius. The nonarticular rear portion of the proximal surface is concave, extending to a proximal posterior flange, which serves as a heel by prohibiting the transfer of weight to the posterior border of the lunar.

The distal facet, articulating with the magnum, 
is concave in its entirety, except for the anterior surface, which is recurved, forming a convex facet. Like the proximal surface, the distal facet is constricted in the middle, expanding toward the posterior and anterior borders. The posterior surface of the lunar is directed perpendicular to the long axis of the arm, in a palmar direction. Along with the posterior portion of the proximal surface, this rear expansion forms the prominent heel.

The lunar of $G$. arizonae (Figure 42) differs only in its larger size and a proportionally greater transverse extent of the proximal articular facet. The lateral border of this facet protrudes in an extension above the plane of contact formed by the abutting surfaces of the lunar and cuneiform. The distal articular facet (magnum facet) is somewhat more deeply excavated in $G$. arizonae. These differences are attributable to variation and are not diagnostic.

ScapHoId (Table 20). - The scaphoid completes the proximal carpal series, occupying the medial position and receiving the articular surface of the radius. The anterior (plantar) twothirds of the scaphoid of $G$. texanum (Figure 41 ) is wedge-shaped, with three symmetrically disposed facets, and a fourth, located on the anterolateral surface, which interrupts the symmetry. The proximal surface bears a convex facet for reception of the medial surface of the radius. The broad convexity of this articular facet is in contour with the corresponding articular surfaces of the lunar and cuneiform. On the rear portion of the proximal surface is a raised nonarticular boss, occupying approximately the posterior third of the bone. This boss forms a heel similar to that of the lunar and is confluent with it. The lateral surface of the scaphoid is convex, articulating with the concave medial surface of the lunar. The distal surface of the scaphoid is directed medially and bears three concave articular surfaces. The medial articular surface receives the reduced trapezium; the middle articular surface, occupying half the distal facet, receives the convex surface of the trapezoid; and the distolateral facet articulates with the posteromedial surface of a projection of the magnum.
The scaphoid of $G$. arizonae (Figure 42) differs only in the nature of the posterior tubercle. Whereas this tubercle is knoblike in $G$. texanum, it is tapered in $G$. arizonae and extends proportionally farther posteriorly from the border of the proximal facet.

Trapezium (Table 21).-Together with the trapezoid, the trapezium carries most of the weight from the scaphoid, with which it articulates. The trapezium of G. texanum (Figure 41) is a small, reduced bone, the medial member of the distal carpal series. It is wedge-shaped, firmly articulating on its lateral surface with the trapezoid and with the proximomedial articular surface of metacarpal II. The facets for these two articulations are separated by a subdued ridge on the lateral surface. The convex proximal articular surface meets the scaphoid on its distomedial margin. The trapezium, with its dual articulation between the trapezoid and metacarpal II, is firmly locked into position on the medial side of the wrist, and although reduced in size, it is an important element. In $G$. texanum the size of the trapezium is subequal to that of the trapezoid.

In the Arizona representative of $G$. arizonae (USNM 10536, Figure 42) the trapezium is similar to that of $G$. texanum; although considerably larger absolutely, it is nevertheless subequal with the trapezoid. The broken and fragmentary trapezium of the Texas G. arizonae (UMMP 38761, Figure 43), however, is considerably smaller than the trapezoid, although its construction appears to be similar.

The reduced trapezium and trapezoid are together approximately equal in size to the remaining distal carpals. Vinacci Thul (1943) indicated that there is some variability in the trapeziumtrapezoid construction, including occasional fusion. Whether his statement was intended for only the genus Glyptodon is unclear. Comparing species of the North American Glyptotherium, it appears that there is indeed a high degree of variability within a single genus. Because of the reduction in these two bones, especially in the trapezium, the difference in size between the Arizona (Curtis Ranch) and Texas (Seymour) representatives of $G$. arizonae is not here considered diagnostic. 
Trapezold (Table 22). - The trapezoid of $G$. texanum (Figure 4l), like the trapezium, is wedgeshaped and reduced. It is situated within a trough of the proximal surface of metacarpal II, with which it articulates on its laterally convex, anteroposteriorly concave distal surface. The proximal articulation with the scaphoid firmly locks the distal carpal series on the inside. On the lateral border the trapezoid is nonarticular but meets the interlocking wedge projection of the magnum, where the latter articulates with the scaphoid. The anterior (plantar) surface is broadly expanded from the distal articular concavity.

The trapezoid of the Arizona $G$. arizonae (Figure 42 ) is characterized by its proportionately greater transverse diameter; otherwise it is similar to that of $G$. texanum.

The trapezoid of the Texas Seymour $G$. arizonae (Figure 43) is considerably different from either of the preceding. Rather than being reduced in size, the trapezoid approximates the size of the unciform and magnum. Thus, in the Seymour representative, there are three primary distal carpals and a reduced (almost vestigial) trapezium. The trapezoid in proximal aspect is triangular with rounded and irregular sides; the apices are posterior, anterolateral, and anteromedial. The proximal (scaphoid) facet is transversely convex and fan-shaped. With respect to the long axis of metacarpal II the proximal facet is directed posteroproximally and somewhat laterally. The proximal (scaphoid) and distal (metacarpal) facets are posteriorly convergent, the minimum proximodistal diameter occurring at the posterior apex, the maximum at the anterior border. The minimum transverse diameter occurs along the anterior border.

The distal (metacarpal) articular facet is deeply concave in the transverse direction and concave in an elongate sulcus in the anteroposterior direction. The facet bccomes transversely convex near the lateral border, to conform with the corresponding facet of the metacarpal. Beyond the medial extremity of the distal facet there is a massive tubercle-like extension. This process oc- cupies the anteromedial extremity of the element, the position vacated by the reduction of the trapezium; it extends medially over the anteromedial tubercle of metacarpal II, fully extending (in articular position) to the level of the medial borders of the scaphoid and metacarpal II, respectively. Thus, the trapezoid of the Seymour $G$. arizonae is considerably larger than in the Arizona representatives of both $G$. arizonae and $G$. texanum, occupying the entire proximal surface of the metacarpal. There is no indication of pathologic irregularity, nor is there any indication of articulation with the reduced trapezium.

As discussed for the trapezium, these differences in the trapezoid are seemingly unimportant as taxonomic characters. Because of the loss of digit I, it might be expected that the medial carpals would exhibit more structural variation than do the other carpals. Since the other carpals of the Seymour glyptodont are virtually identical with the Arizona representative, the disparities in the trapezoid-trapezium complex could be attributed to variation.

Magnum (Table 23). - In proximal view, the magnum of G. texanum (Figure 41) is rectangular, with the articular facets for the lunar and scaphoid occupying the entire proximal surface. The lunar facet is sigmoid in the anteroposterior direction, concave and depressed anteriorly, convex and raised posteriorly. This facet receives the corresponding distal surface of the lunar. The distal articular facet of the magnum articulates with the proximal trough of the metacarpal III. The facet is concave, with an anteroposterior ridge separating the medial and lateral portions of the facet, these portions articulating with the lateral shoulders of the trough of the metacarpal.

The medial border bears two articular facets, a proximonedial articulation with the distolateral process of the scaphoid and a distomedial articulation for the proximolateral surface of the metacarpal II. The facet for this metacarpal is concave and directed more distally than medially, serving to distribute weight from the center of the carpal series toward the medial digit.

The lateral surface is flat, abutting with the 
corresponding surface of the unciform. The articulation is parallel to the long axis of the forearm and serves further to interlock the carpal series, rather than for weight transfer. The anterior (plantar) surface is rugose and is nonarticular.

The magnum of $G$. arizonae (Figure 42) bears little distinction from that of $G$. texanum other than greater size. It does, however, possess a scaphoid facet, a feature that is partially missing in the $G$. texanum specimen as preserved. This facet is concave and is directed posteromedially, receiving the corresponding facet of the scaphoid,

UnCIFORM (Table 24).-The wedge-shaped unciform of $G$. texanum (Figure 41) articulates exclusively with the cuneiform on its proximal surface, which is convex and directed laterally at approximately $45^{\circ}$. This articular surface is confluent with the proximolateral (cuneiform) facet of metacarpal IV Thus the unciform shares with the distal surface of the cuneiform the articulation with metacarpal IV. The distal articulation with the medial two-thirds of the proximal facet of the metacarpal is perpendicular to the long axis of the digit. The proximal and distal articulations intersect on the lateral surface, owing to the oblique orientation of the proximal facet. The distal articular surface is saddle-shaped, receiving the central portion of the fourth metacarpal. On the distomedial surface of the unciform is an additional facet for the reception of the anterolateral projection of the third metacarpal. This articulation serves to transfer considerable force from the ulna through the cuneiform and unciform to the middle digit. This articulation is parallel to the oblique proximal facet of the unciform and is so arranged as further to lock the carpal series.

The unciform of $G$. arizonae (Figure 42) is distinctive in having a proportionately greater anteroposterior extent, producing a subrectangular proximal outline. The bulk of this extension involves the relatively greater development of the posterior region, forming a tubercle-like construction on the posterior border in contrast to the attenuated posterior region in $G$. texanum. The distolateral articular facet (for metacarpal IV) is less deeply excavated, and the anterior margin of the proximal articular facet is less distinct in $G$. arizonae.

Metacarpals. - There are three functional, weight-bearing metacarpals (numbers II, III, and IV) and one reduced nonweight-supporting lateral metacarpal (number V). Metacarpal I is absent, as is digit I. Metacarpal $\mathrm{V}$ and digit $\mathrm{V}$ are greatly reduced; these elements present the greatest variability in the forefoot of North American glyptodonts.

Metacarpal II is by far the largest, with progressive decrease in size to metacarpal V All are basically rectangular prisms in form. Proximal interlocking contacts with each other and with the carpals preclude extensive carpal-metacarpal mobility.

Vinacci Thul's (1943) descriptions of the metacarpals of Glyptodon indicate close similarity with those of the North American representatives and could serve as proxy for the descriptions provided here. For completeness, however, the metacarpals of the North American genera are described in full detail. The accompanying measurements (lacking in Vinacci Thul's description) should provide a better foundation for future comparisons with South American taxa.

Metacarpal II (Table 25).-The proximodistally elongate metacarpal II of $G$. texanum (Figure 33) bears four proximal articular facets: two on the proximal extremity, and one on each side in the anteroproximal position. In anterior view the outline of the proximal end is rendered asymmetrical by the proximally raised facet articulating with the medial distal surface of the magnum. This articular surface is laterally flattened and anteroposteriorly sigmoid, strongly convex anteriorly and weakly concave on the posterior curvature. It terminates in a weak posterior flange. This facet is bordered medially by a shallowly grooved trochlear facet for articulation with the distal concavity of the trapezoid. This facet, which extends neither anteriorly nor posteriorly as far as the magnum facet, receives the entire distal surface of the trapezoid. The posterodistal tubercle of the trapezoid fits snugly into a circular 


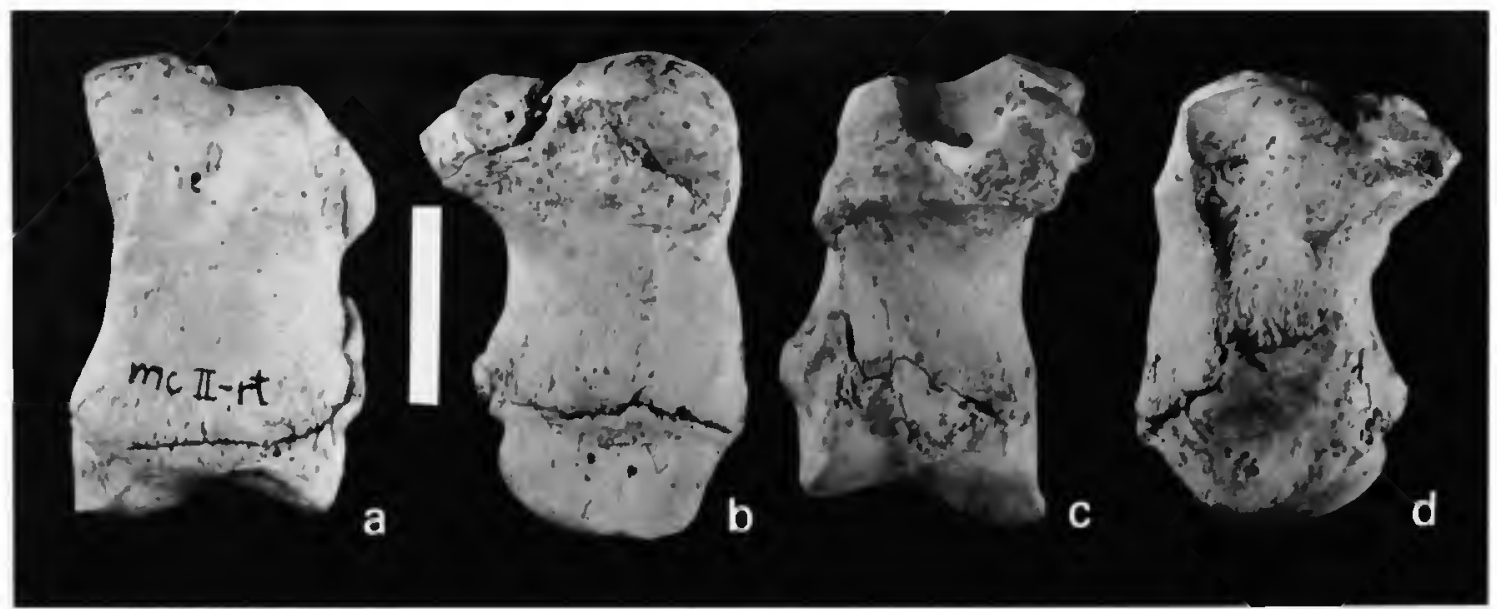

Figure 33.-Right metacarpal II of Glyplotherium texanum (F:AM 95737): $a$, anterior; $b$, lateral; $c$, posterior; $d$, medial. $(\mathrm{Bar}=20 \mathrm{~mm}$.)

depression on the posterior border of the articular facet of the metacarpal. Posteriorly beyond this concavity is an expanded nonarticular region extending to the posterior border of the shaft, which it intersects in an acute angle; this border in posterior (palmar) view is directed obliquely downward toward the medial side.

Viewed laterally, the shaft on its proximal extension is expanded along its posterior border and flattened on its anterior margin. On the proximal end of the lateral surface of the shaft is a small distolaterally directed facet for articulation with a proximomedial facet of the third metacarpal. Similarly, there is a vertical facet on the proximal end of the medial surface of the shaft for articulation with the terminal portion of the distolateral facet of the trapezoid. Posterior and distal to this facet is a pronounced tubercle. A proximodistal furrow extends along the medial surface of the shaft, distal to the trapezoid facet and anterior to the tubercle, toward the distal epiphysis.

The distal articulation with the first phalanx is saddle-shaped, elongate in the anteroposterior plane. The lateral surface, with a longer radius of curvature, extends farther distally than the medial, and the central groove is offset slightly toward the medial side. The central furrow terminates anteriorly in a slight depression, for the reception of a heel-like prominence on the anterior end of the carina of the first phalanx.

A pair of facets for the two proximal sesamoid bones of digit II is situated on the epiphysis near the distal end of the shaft on its posterior surface. The larger facet, articulating with a large sesamoid, is centrally located; the smaller facet is nearer the lateral border and appears as an inconspicuous notch on the posterodistal extremity of the lateral trochlear facet. Vinacci Thul (1943) did not recognize these sesamoid facets. Descriptions of these sesamoid bones follow the description of digit II.

Metacarpal II of $G$. arizonae (Figure 42) is considerably more robust, especially in the transverse and anteroposterior dimensions. Another distinction is the relatively deeper excavation of the shaft on its medial surface distal to the trapezoid facet.

A feature not related to ontogenetic differences is the greater proximodistal extent of the articular facet for metacarpal III on the lateral side of the shaft. This facet extends fully half the length of the shaft in $G$. arizonae, whereas in $G$. texanum, the iacet extends barely one-fourth the shaft length. In addition, this facet in $G$. arizonae is vertically situated, whereas in $G$. texanum it is oblique, directed somewhat distally as well as laterally.

Metacarpal III (Table 26).--Metacarpal III, 
G. texanum (Figure 34), like metacarpal II, is a modified rectangular prism. In block proportions the third metacarpal is nearly equidimensional, only slightly longer in the proximodistal plane than in the transverse and anteroposterior planes. It can be further distinguished from the metacarpal II by the greater development of the lateral metacarpal articular facet, which is restricted to the anterior half of the lateral side and extends to a point past midshaft, and by the lack of a depression posterior to the articular facet on the proximal extremity.

The principal carpal articulation is with the magnum; the facet for the magnum is saddleshaped, transversely concave and anteroposteriorly convex. This articular surface extends the full length of the anteroposterior dimension and occupies nearly the entire proximal surface except for the anterolateral corner. The posterior surface of the proximal articular facet projects somewhat beyond the shaft.

Two facets provide lateral articulation with metacarpal IV and the unciform, respectively. The anterolaterally directed unciform facet is situated on the proximal anterolateral corner. Its facet forms an obtuse angle, with the proximal saddle articulation with the magnum, and an acute angle, with the more laterally situated facet for metacarpal IV. The metacarpal IV articular facet presents a curved surface, directed distoposterolaterally above and laterally below in its distal portion. This facet occupies the anterior proxi- molateral quarter of the lateral side of the metacarpal.

A small medial facet provides an articular surface for metacarpal II. This facet is situated on the anteroproximal corner of the lateral face of the epiphysis and is directed medially and slightly posteriorly.

The distal articular facet is broader and more extensive than the proximal facet. It is saddleshaped, with a shallow valley located between slightly elevated ridges on the sides. This facet is rather more flattened than rounded, and in proximal view the shape is more nearly symmetrical than for metacarpal II, and the medial articular flange only slightly less expansive and elevated than the lateral. A poorly developed anterior heel provides a weak stop for hyperextension of the digit. A posterior central prominence with a pair of flanking sesamoids buttresses the posterior border of the distal facet. The sesamoids are situated on either side of the posterior articular prominence, fitting neatly into posteriorly directed facets in this position.

The shaft of the metacarpal III is equidimensional, with slight expansion at the epiphyses. A marked tendinal sulcus on the medial surface extends along the shaft, terminating at the distal epiphysis.

Metacarpal III of $G$. arizonae (Figure 42) is distinctly more robust. In block proportions this element is roughly cuboid, rather than resembling a rectangular prism. There are two other differ-

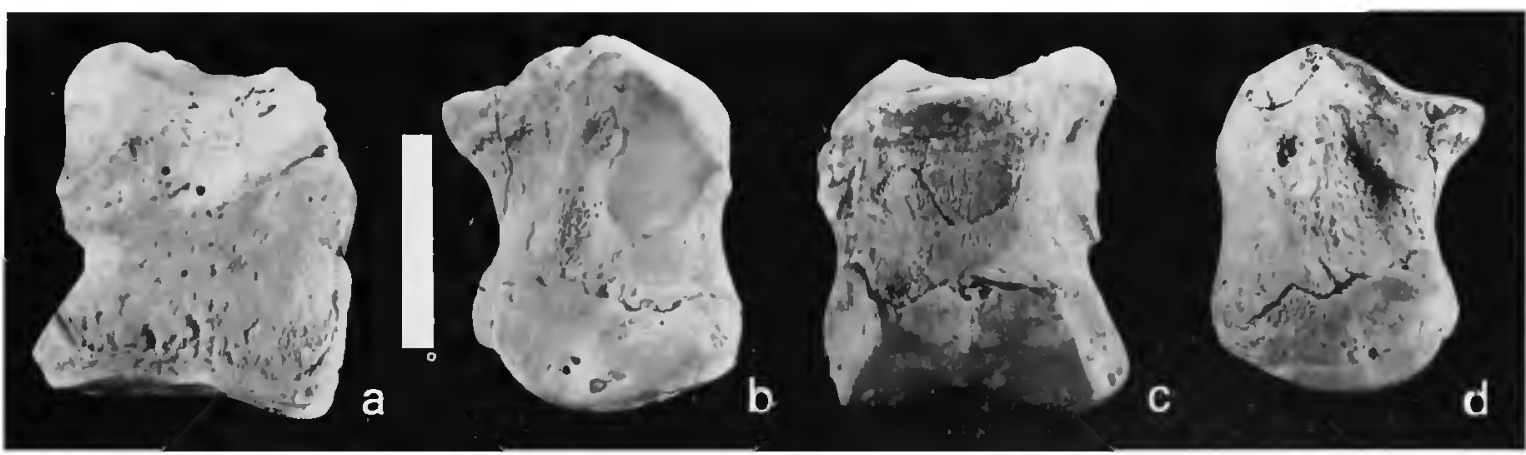

Figure 34.-Right metacarpal III of Glyptotherium texanum (F:AM 95737): $a$, anterior; $b$, lateral; $c$, posterior; $d$, medial. (Bar $=20 \mathrm{~mm}$.) 
ences in the available specimens (which are not attributable to proportionality or age): the unciform articular facet in $G$. arizonae is shallowly concave in contrast to the slight convexity in $G$. texanum, and similarly, the metacarpal IV articular facet is somewhat less concave, and it has a greater anteroposterior diameter, comprising roughly two-thirds the diameter of the shaft.

Metacarpal IV (Table 27).-Metacarpal IV of $G$. texanum (Figure 35 ) is by far the smallest of the three functional anterior metapodials, its length approximately half that of the third metacarpal and less than half that of the second. Its transverse and anteroposterior diameters are only slightly compressed relative to the other metacarpals.

The proximal articular facet of metacarpal IV is convex and elongated in the anteroposterior direction, for reception of the concave saddleshaped facet of the unciform. This facet is directed somewhat laterally, producing a central peak, evident especially in anterior aspect; from this peak the superior surface of the convexity of the facet extends anterolaterally, intersecting the common border of this facet with the lateral facet for the cuneiform. The anterior border of the proximal facet is directed anteroproximally, while the posterior border is slightly upturned, oriented in a proximal direction.

The slightly convex cunciform facet is located on the proximal anterior portion of the lateral face of the shaft, and it is confluent with the lateral facet of the unciform, which together receive the distal facet of the cuneiform.
A convex facet for articulation with metacarpal III on the medial surface in an anteroproximal position receives the laterally directed anteroproximally concave facet of metacarpal III, serving as a locking mechanism as well as transferring weight toward the more lateral digit.

The distal articular facet is flattened, with only a slight anterior-posterior curvature, fitting loosely into the concave proximal facet of the first phalanx. A tubercle located in a central position on the posterior border of the facet is the only irregularity on the distal surface. Posterior to this prominence is an irregular, triangular-shaped nonarticular region. Relative to the proximal articulation, the distal facet is oriented in a slightly posterior direction, so that in lateral or medial aspect the outline is wedge-shaped, the apex of which is formed by extension of the proximal and distal facets along the nonarticular surfaces to their posterior intersection.

The shaft of the fourth metacarpal is longest on the flattened anterior surface. A prominent tubercle is located on the posterior surface, and an elongatcd onc is situated parallel to the distal articular facet on the latcral surface.

Metacarpal IV of $G$. arizonae (Figure 42) closely resembles that of $G$. texanum. It is proportionately longer in the transverse and anteroposterior directions, imparting a relatively more robust character. The articular facets differ from those of $G$. texanum only in being relatively more extensive in the transverse and anteroposterior planes.

In marked contrast, metacarpal IV of $G$. floridanum (Figure 44c) presents several distinctions.

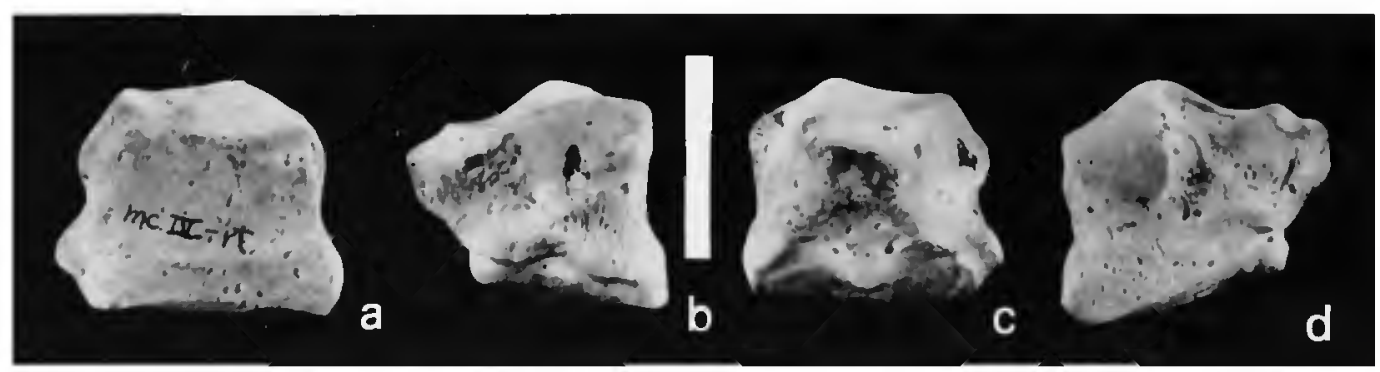

Figure 35.-Right metacarpal IV of Gtyplotherium texanum (F:AM 95737): $a$, anterior; $b$, lateral; $c$, posterior; $d$, medial. (Bar $=20 \mathrm{~mm}$.) 
This element is more nearly a modified rectangular prism, the posterior region not tapering rearward. The posterior portion of the proximal articular facet is flattened and directed posterolaterally. The medial facet for articulation with metacarpal III is flattened and vertically oriented. The distal articular facet is even more distinctive. Whereas in $G$. texanum and $G$. arizonae the distal facet is weakly convex, in $G$. floridanum it is anteriorly flattened and posteriorly concave, with a distinct separation between the lateral and medial portions of the posterior region. Moreover, the posterocentral prominence is absent; in its place there is a simple elevated region at the juncture of the two portions of the posterior part of the facet. Also, the orientation of the distal facet is nearly parallel to the proximal facet, rather than posteriorly convergent.

Metacarpal V (Table 28).- The extreme reduction of the digit $\mathrm{V}$ of Glyptotherium is reflected by the small metacarpal. Despite its extreme reduction, however, this bone nevertheless dwarfs the first phalanx. The distal articular facet of the metacarpal V of $G$. lexanum (Figure 39) is flat, its shape in distal aspect is roughly circular, and it occupies only the anterior two-thirds of the distal extremity. The concave proximal articular facet articulates with the convex prominence projecting from the lateral surface of the cuneiform and is elongate in the anteroposterior direction. The lateral articulation with the cuneiform imparts an oblique orientation of digit $\mathrm{V}$ with respect to the other digits. The lateral projection of the digit and the lack of interlocking contacts of metacarpal $\mathrm{V}$, as in the other metacarpals, indicate the lack of importance of the lateral digit in weight transfer during locomotion.

Although Melton (1964) reported the recovery of metacarpal $\mathrm{V}$ for the Seymour glyptodont $(G$. arizonae), this element was not located. The only remaining metacarpal $\mathrm{V}$ of $G$. arizonae (USNM 10536) available for study is abnormally coossified, as described in the following section.

Coossified Metacarpal V, Phalanx I, Digit $\mathrm{V}$, MaNus.-The fusion of the fifth metacarpal with the first phalanx, digit V, of USNM 10536
(G. arizonae, Figure 42), can be explained either as representing the natural ontogenetic coalescence of these two elements or the fusion at this relatively immobile joint due to an age-related abnormality. The relative proportions of this element approximate the combined proportions of these two elements of $G$. texanum. The nonarticular surfaces, primarily on the shaft, are heavily rugose, and there is at least the hint of a separation between the two presumed fused bones represented by a groove at the posteromedial position on the shaft. Because of the close correspondence with the combined proportions of the fifth metacarpal and first phalanx of $G$. texanum, and because of the groove suggesting the actual separation of these two elements, it appears that the bone was formed by fusion of the two elements rather than by the loss of one and corresponding increase in size and proportions of the other.

Whether the fusion is representative of intraor interspecific variation or is representative of an osteological abnormality related to old age is problematical. It seems most parsimonious to attribute this fusion to old age for two reasons: (1) there is a very close similarity with $G$. texanum of all the other bones of the forefoot, with little, if any, reduction, and no fusion of any of the elements; and (2) several of the other phalanges of the manus of USNM 10536 are suggestive of osteological disease or abnormality (e.g., phalanx I, digit III). In another specimen of $G$. arizonae (UMMP 38761), there is also considerable degeneration of the bones of the feet, as already mentioned. Although it is possible to attribute the coossification of these two elements to injury, it seems more likely to be a condition of old age, perhaps arthritis.

Unlike the concave proximal articular facet of metacarpal $\mathrm{V}$ of $G$. texanum, the proximal facet of this bone is flat, as is the lateral facet of the cuneiform with which it articulates. Also, unlike the concave distal articular facet of the first phalanx of $G$. lexanum, the distal articular facet of this bone is convex. Similarly, this facet articulates with the shallow, concave, proximal facet of the terminal phalanx in marked contrast to the dis- 
tinctly convex facet of the ungual phalanx, digit $\mathrm{V}$, of $G$. texanum. Because of these seemingly distinct differences between the articular facets of the phalanges of $G$. arizonae and $G$. texanum, the conclusion drawn above that the fusion of the two elements of USNM 10536 was due primarily to an age-related abnormality must not be accepted with finality. Recovery of additional specimens may alter this conclusion. The remaining features of the fused metacarpal V-first phalanx of USNM 10536 correspond to those of these two elements in combination of $G$. texanum. Measurements for this coossified element are as follows: maximum proximodistal diameter, $26 \mathrm{~mm}$; maximum anteroposterior diameter, $23 \mathrm{~mm}$; maximum transverse diameter, $19 \mathrm{~mm}$.

Digit II, Manus._-Digit I, manus, is lacking in North American representatives. Vinacci Thul (1943) established the existence of digit $\mathrm{V}$ in Glyplodon reticulalus, correcting earlier statements (e.g., Burmeister, 1874) to the effect that digit V was the missing toe. Burmeister, among others, had erroneously identified the elements of digit $\mathrm{V}$ as belonging to digit I. Thus the North American glyptodonts are similar to $G$. reticulatus in lacking digit I; digit II is the medial member of the manus. It consists of three phalanges and three associated sesamoid bones (Figure 36). Digits II and III are subequal in size; digit II is slightly longer and relatively more slender; digit III is slightly shorter and relatively more robust. Digit IV is smaller, but nevertheless stout and important as the lateralmost fully functional digit. Digit $V$ is extremely reduced. Digit II is directed somewhat medially with respect to the midline of the forelimb. The phalanges display asymmetry associated with the position of the digit. Phalanges I and II are short and robust. The ungual phalanx is elongate and was covered by an ungual sheath over most of its surface.

Phalanx I, Digit II, Manus (Table 29).-The first phalanx of the second digit, manus, of $G$. texanum (Figure 36), is a distorted concavoconvex disc. Two anteroposterior proximal facets receive

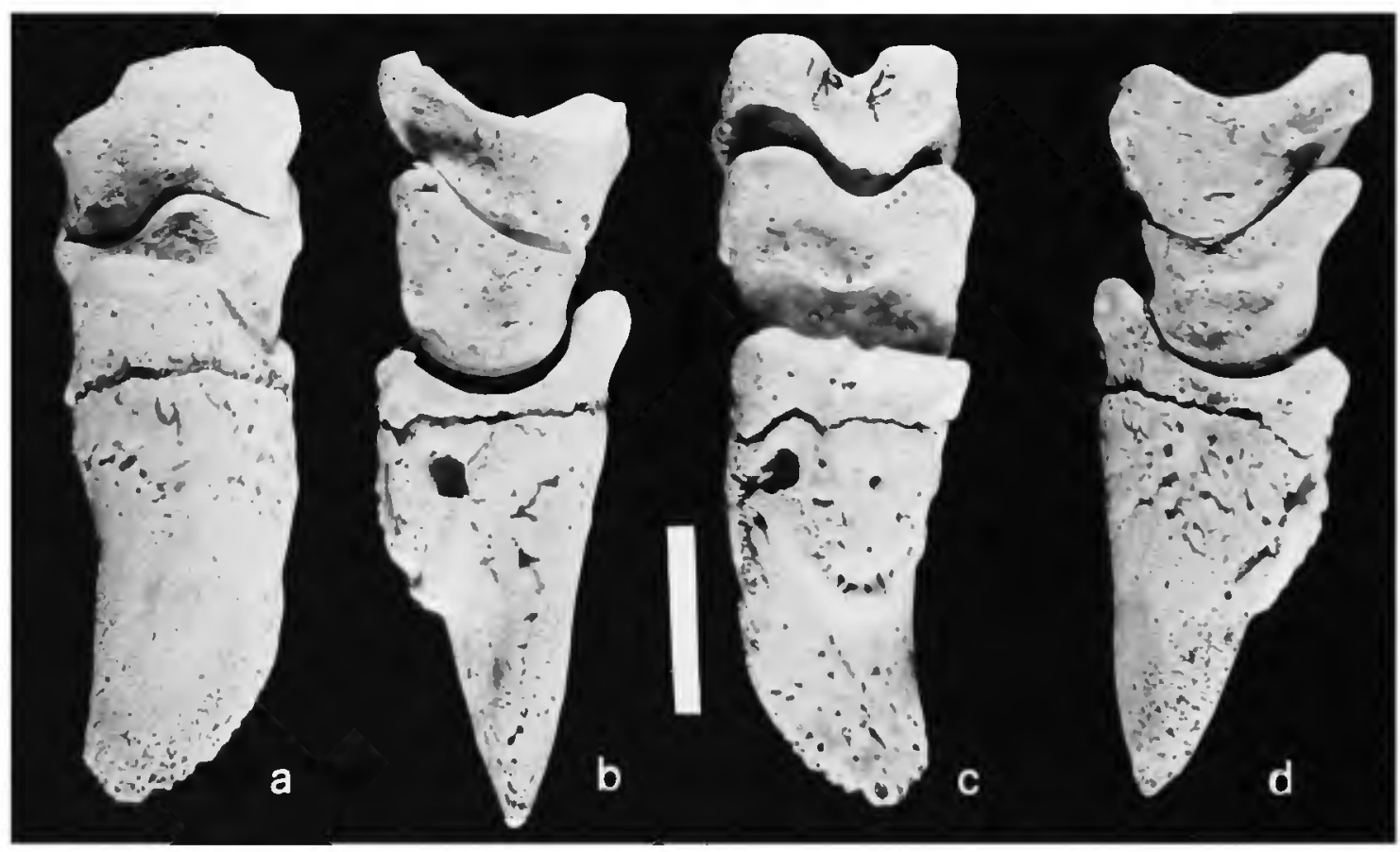

Figure 36.-Right digil II, manus, of Gtyptotherium texanum (F:AM 95737): $a$, anterior; $b$, lateral; $c$, posterior; $d$, medial. (Bar $=20 \mathrm{~mm}$.) 
the distal trochlear facet of the metacarpal. Both facets are deeply concave, the lateral deeper than the medial. These proximal facets are separated by a flattened interarticular carina. Both proximal facets are buttressed by posterior projections extending beyond the terminus of the central interarticular carina. The medial facet is directed slightly outward, its deepest recess situated posterior to the transverse midline. On its anterior extension the medial facet is confluent with an anteromedial prominence, which extends proximally to the level of the posterior lip of the facet. This anteromedial facet forms a heellike articular prominence for articulation with the anterior depression of the central furrow of the metacarpal II.

The lateral facet is deeper than the medial and extends farther anteriorly, where at its terminus is its deepest depression. This facet is directed parallel to the long axis of the digit and receives the larger lateral facet of the trochlea of the metacarpal II.

The distal articular surface is formed by a pair of confluent convex articular facets, together presenting in distal aspect a dumbbell outline, with the medial facet somewhat smaller than the lateral, and with only a slight anteroposterior central constriction. The lateral facet is the larger; it is directed parallel to the long axis of the digit. The medial facet is directed distolaterally, its medial border forming a distinct lip with the nonarticular medial side. The rockers of the distal extremity occupy only the anterior half of the surface. A pair of nonarticular projections extend posteriorly from the facets in a broadly confluent fashion, forming the undersurface of the buttress for the proximal articulations. The distal surface of these buttresses is directed posteroproximally, resulting in a lateral view of the phalanx, which is deeper anteriorly and tapers rearward posterior to the concavoconvex depression.

The two posterior projections each bear a facet for the sesamoids, which are situated on the posterior surface of the joint between the metacarpal II and the first phalanx. The lateral projection bears the larger sesamoid facet, which is directed proximomedially. The medial eminence bears a smaller facet for the medial sesamoid, which is the smaller of the two at this joint. This facet is directed proximolaterally. Between the two posterior projections is a deep concavity, the center of which is penetrated by several small foramina.

A prominent tuberosity on the anterior surface is situated in line with a proximodistal plane, passing through the proximal carina and the distal groove, and at a position level with the anterior border of the lateral facet.

Another tuberosity is situated on the medial side, extending from near the anterior border to the posterior extension of the medial prominence.

Except for its larger size, phalanx I, digit II, manus of G. arizonae (Figure 42) is similar in all respects.

Phalanx II, Digit II, Manus (Table 29). - The second phalanx of the digit II, manus, of $G$. texanum (Figure 36), repeats the form of the first phalanx. It is slightly smaller than the first phalanx, especially in lateral aspect, in which the two posterior prominences do not project as far posteriorly. The articular facets on both extremities differ from those of the first phalanx only in presenting a slightly shorter radius of curvature and in covering a smaller surface area. The region corresponding to that forming the anterior prominence of the proximal articulation of the first phalanx is subdued in phalanx II. Combined with the shorter radius of curvature of the distal rockers, the subdued anterior prominence on the proximal facet allows for a somewhat greater freedom of movement over the surface of the distal rockers of the first phalanx. The facets for the first phalanx/second phalanx articulation are proximodistally flattened, however, prohibiting a large degree of rotation in this joint. The distal articular surface of the second phalanx is saddleshaped and presents a greater freedom of rotation in articulation with the terminal phalanx; the pair of symmetrically disposed facets, in lateral view, turns through nearly $180^{\circ}$, whereas the distal facet of the first phalanx is distinctly more flattened and less extensive.

In addition, the second phalanx is distinct from 
the first in possessing three large foramina on the anterior nonarticular surface; by comparison, the foramina on the first phalanx are much smaller.

The posterior surface receives a large sesamoid, which is situated at the joint with the ungual phalanx. The distal articulation allows considerable motion in this joint, indicating a relatively large freedom of rotation for the terminal phalanx. The large sesamoid is testament to the larger freedom of motion. It is this joint at which the greatest freedom of movement in the digit occurs. Indeed, there was enough flexibility for the terminal phalanx at maximum extension to abut with the first phalanx, at which position further hyperextension was prohibited. Small wear facets on the tip of an anterior prominence on the proximal facet of the ungual phalanx and on the anterior border of the lateral facet of the first phalanx indicate that this articulation acted as a lock to prohibit further movement of the ungual phalanx over the surface of the second phalanx at hyperextension.

Phalanx II, digit II, manus, of $G$. arizonae and $G$. floridanum, differ in several respects. In $G$. floridanum (Figure 44d), the proximolateral articular facet is deeply excavated, the distal articular facet is a nearly perfect cylindrical section, and the marginal borders of the distal trochlea are nearly parallel, rather than anteriorly convergent.

Phalanx II, digit II, manus, of $G$. arizonae (Figure 42), has a distinctly greater elevation of the medial portion of the proximal articular facet. This elevation is less pronounced in $G$. texanum, and it is essentially absent in $G$. floridanum.

In one specimen of $G$. arizonae (UMMP 38761, Figure 43), an extension of the posterior tubercle appears to be the fused sesamoids, ankylosed to the phalanx in their appropriate positions and with each other. This construction is a manifestation of the degenerate condition in the front foot of this individual, owing to an apparent arthritic malady. Other elements of this foot are even more severely affected.

Ungual Phalanx, Digit II, Manus (Table 30). - The terminal phalanx of digit II, manus, of G. texanum (Figure 36 ), is proximodistally clon- gate, ventrally flattened, and dorsally arched in the transverse plane. Two proximal facets articulate with the corresponding pair of rockers of the second phalanx. These facets are separated by a subdued carina. Both facets are roughly triangular in proximal aspect, the outer margins tapering anteriorly toward the prominent anterior tubercle. The taper is more pronounced on the margin of the medial facet, imparting an asymmetrical proximal aspect. Both facets are decply concave in lateral aspect, comprising a chord of approximately $120^{\circ}$, the anterior extremity of each facet reaching a higher (more proximal) position than the posterior border. The anterior tubercle bears a small foramen, situated on the inner surface of the tubercle at the terminus of the carina.

A pair of sesamoid articular facets is located on the posteroproximal border. These articulate with the large single sesamoid at the terminal joint on the palmar (posterior) surface. These facets are directed posteroproximally and are separated by a distinct tendinal groove, a furrow that is mirrored on the articular surface of the sesamoid. A deep foramen is situated within the groove, and another is locatcd on the border of the groove and the articular facet. A third foramen pierces the medial sesamoid articular facet near its distal border.

The free end of the phalanx was covered in life by a horny sheath, apparently more hooflike than clawlike. This sheath covered the entire phalanx distal to the epiphysis except for the subungual region. That the sheath was hooflike is indicated by the flattened ventral (subungual) region of the bone and the highly arched dorsal region. The sheath conformed to the surface of the bone, and at the distal end it terminated bluntly; the sheath did not extend far beyond the distal tip of the bone.

In F:AM 95737, the juvenile individual, the subungual base is roughly semicircular in outline, although there is the hint of an apex near the distal border. Its margins are not well defined, in contrast to the extensions of the subungual base into a short hood process in older individuals. 
Two large subungual foramina are situated on the medial and lateral borders of the subungual base, respectively. The axis passing through the centers of these foramina is roughly parallel to the transverse axis of the proximal articular facets. Both penetrate deeply into the bone toward the center.

The claw process bears numerous vascular foramina piercing the otherwise smooth outer surface. In cross section the claw process is halfellipsoid, with the long axis passing from dorsolateral to anteromedial. In lateral aspect the phalanx is wedge-shaped, forming a nearly perfect isosceles triangle distal to the epiphysis. Viewed dorsally, the lateral and medial borders both curve toward the lateral side. The medial border has a shorter radius of curvature, producing a terminal apex in direct line with the lateral border of the proximal articular facet.

The terminal phalanx of the digit II, manus, of G. arizonae (Figure 42), differs in few details other than its larger size. The subungual hood in the adult specimens is more well developed, extending as a projection around the circumference of the subungual base and barely extending on the lateral surface to the anterior tubercle. The single characteristic distinguishing $G$. arizonae is the positioning of the subungual foramina. The axis passing through the centers of these foramina is obliquely situated with respect to the transverse axis of the articular facet. These two axes, if extended, are medially convergent.

Ungual phalanx, digit II, manus, of $G$. floridanum (Figure 44f), is similar in most respects to G. arizonae (Figure 43), although its proportions are less robust. The subungual foramina are obliquely situated. The articular facet is not extensive, the chord representing approximately $90^{\circ}$. The shorter anteroposterior extent of the articular facet is due primarily to a relatively underdeveloped anterior tubercle.

Sesamoid Bones, Digit II, Manus.-Vinacci Thul (1943) did not recognize or describe any digital sesamoids in the manus of Glyptodon reticulatus. Burmeister (1874) found only one digital sesamoid bone in the manus of Glyptodon asper and three in Doedicurus. There are three sesamoids each on digits II and III in Glyptotherium, a proximal pair at the metacarpal-phalanx joint and a single distal one at the terminal joint; one sesamoid only on digit IV; and one sesamoid bone on digit $\mathrm{V}$. Thus there are eight digital sesamoids in the manus of the North American representatives. These bones are subject to considerable pathologic degeneration and/or fusion, as noted earlier, and in the respective descriptions of the individual elements.

The proximal pair of sesamoids of digit II, manus, in G. texanum (Figure 41), are both irregular in shape, approximating a distorted sphere in configuration. The medial sesamoid is the larger, approximately twice the size of the lateral. Both articulate with distinct sesamoid facets on the palmar surfaces of the metacarpal and phalanx at the joint. The medial sesamoid is centered approximately in line with the middle furrow of the metacarpal and the carina of the phalanx. The lateral sesamoid is situated in line with the lateral rocker of the metacarpal.

The proximal sesamoids, digit II, manus, of $G$. arizonae (Figure 42), are distinctly more robust. They are subequal in size, the medial only slightly larger than the lateral. The medial sesamoid bone more closely approximates equidimensional proportions than the lateral sesamoid, which is rather elongate.

The distal sesamoid, digit II, manus, of $G$. texanum (Figure 41), is three times as large as the medial sesamoid bone of the proximal pair. It is transversely elongate and tapers posteriorly from the dorsoventral and mediolateral surfaces to form a broad arc in palmar aspect. Two distinct articular facets meet at a right angle on the anteroproximal (proximoplantar) border. The larger anterior facet articulates with the ungual phalanx, the smaller plantar (dorsal) facet with the second phalanx. A distinct tendinal groove is centrally situated at the juncture between the facets, separating the plantar (dorsal) facet into a pair of smaller facets.

The distal sesamoid of $G$. arizonae (Figure 42) is similar to that of $G$. texanum. The single distin- 
guishing feature is the development on the nonarticular surface opposite the ungual facet of a distinct broad sulcus that extends anteroposteriorly, with raised margins on the lateral and medial borders.

Measurements for all of the sesamoid bones of the manus are provided in Table 37

Digit III, Manus.-Digit III is the central member of the three functional digits of the manus. It consists of three phalanges and three sesamoid bones. The phalanges are more symmetrical than those of the adjacent digits, and they are larger and more robust. The middle digit is slightly shorter than digit II, but it is distinctly more robust, participating as the strongest weight-bearing member of the front foot. Phalanges I and II are short and robust, as in the adjacent digits, and the ungual phalanx was covered almost entirely by an ungual sheath.

Phalanx I, Digit III, Manus (Table 31).Phalanx I, digit III, manus, of G. texanum (Figure 37 ), is compressed in the proximodistal plane to the extent that it is an irregular concavoconvex disc, with proximal concave and distal convex articular facets. Two posterior projections provide the rear buttress for the posterior extension of the proximal facet. This concave articular surface is divided in the sagittal plane by an unobtrusive raised area. On each side of this central rise the articular facets are shallowly excavated, receiving the two weakly developed distal rockers of metacarpal III. This facet is broadest in the transverse dimension near the anterior border; tapering posteriorly, its narrowest transverse diameter occurs at the posterior extremity. The anterior border of the proximal facet is slightly recurved, forming a heel to interlock with the metacarpal for limiting hyperextension.

The distal articular facet is convex and covers a less extensive area than the proximal facet. It is divided by a shallow central furrow, along which the articular surface is constricted anterolaterally, producing an hourglass shape in distal view, the lateral facet slightly larger than the medial. Neither facet extends posteriorly to include the distal surface of the posterior tubercles. The curvature

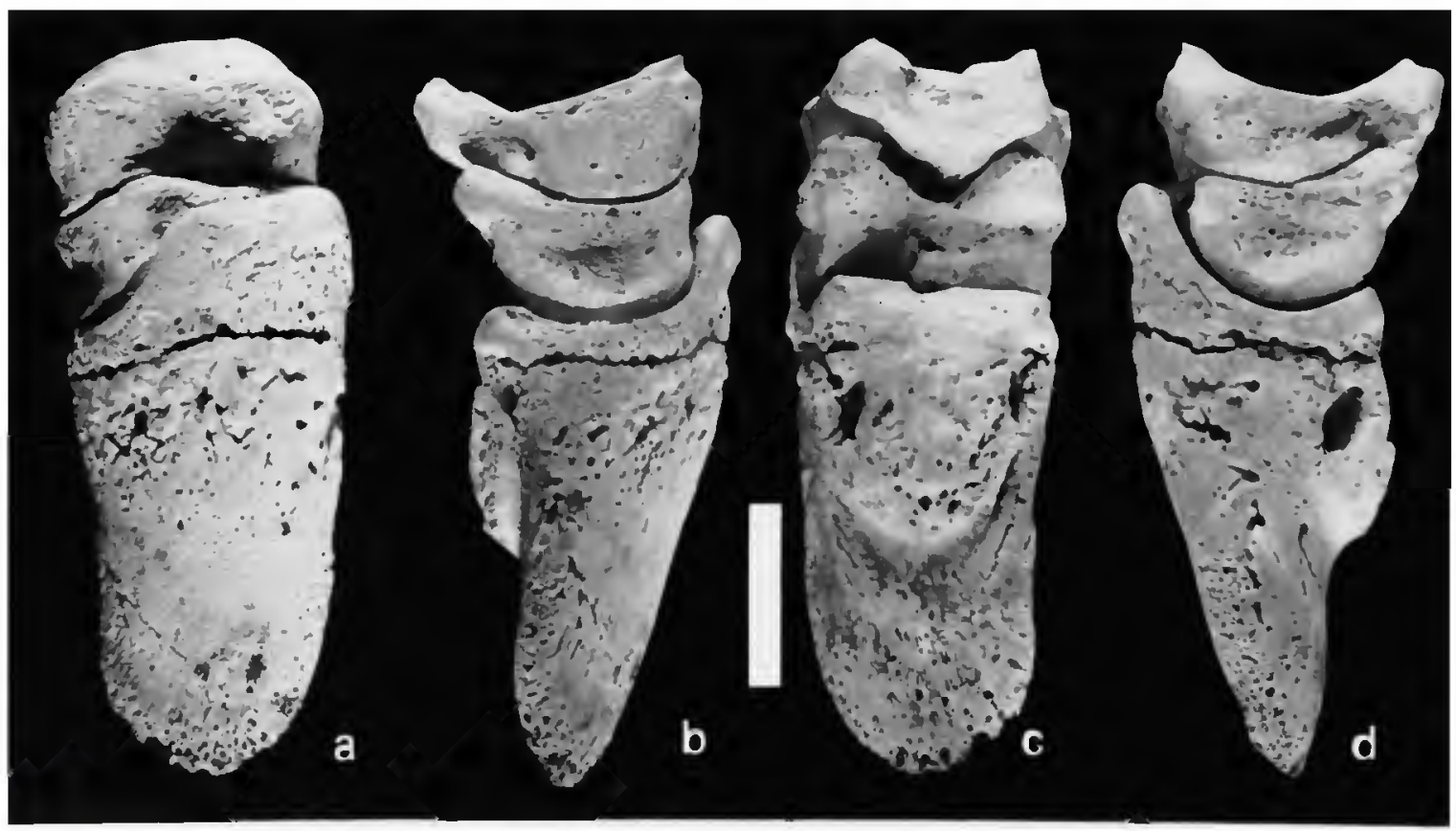

FIGURE 37.-Right digit III, manus, of Glyplotherium lexanum (F:AM 95737): $a$, anterior; $b$, lateral; $c$, posterior; $d$, medial. (Bar $=20 \mathrm{~mm}$.) 
of the distal facet is more flattened than that of the proximal facet. The distal facet is directed at an angle somewhat posterior to the direction of the proximal facet. A large medial tubercle and a small lateral one are situated on the anterior facet in the same sagittal planes as the medial and lateral pairs of articular facets.

Each of the posterior tubercles bears a posteroproximal facet for the reception of a sesamoid in the metacarpal-phalanx joint.

Except for size differences in the adult specimens of $G$. arizonae (Figure 42) compared with the juvenile specimen of $G$. texanum, phalanx I, digit III, manus, is similar in all respects. USNM 10536 bears extremely rugose nonarticular surfaces, and the articular facets are rough and heavily worn. The distorted and misshapen posterior tubercles in this specimen indicate a pathological condition, probably an arthritic malady.

Phalanx II, Digit III, Manus (Table 31).Phalanx II, digit 1II, manus, of $G$. texanum (Figure 37 ), is a smaller version of the first phalanx, with several distinguishing features. The proximal articular surface is more symmetrical in shape and the medial and lateral portions are separated by a deeper excavation between the posterior tubercles. A small constriction on the anterior border of the facet contrasts with the straight margin on the corresponding facet of the first phalanx.

The distal articular surface has a shorter radius of curvature, and the central constriction is more pronounced. In sagittal section this facet resembles a symmetrically disposed half hourglass figure, in contrast with the flattened aspect of this facet on the first phalanx. The medial portion of the distal facet on the second phalanx is slightly more flattened than the lateral, and it extends to a more proximal position at its anterior terminus, producing a slight asymmetry in the hourglass shape.

Like the first phalanx, the second is proximodistally compressed; its proximodistal dimension approximates that of the first phalanx. There are no tubercles on the anterior face, nor are there any sesamoid articular facets on the posterior tubercles.
The second phalanx, digit III, manus, of $G$. arizonae (Figurc 42), is distinct only in that the proximal and distal facets are separated into medial and lateral portions by poorly defined nonarticular antcroposterior furrows. Because the articular facets are otherwise identical in shape and proportions to the juvenile $G$. texanum, this separation in to lateral and medial regions in the adult appcars to be due simply to ontogenetic differences.

Ungual Phalanx, Digit III, Manus (Table 32). - The ungual phalanx, digit III, of $G$. texanum (Figure 37), is the largest terminal element in the manus, its length nearly double that of the ungual phalanx of digit IV and exceeding that of digit II by more than 10 percent. The ungual phalanx of the third digit can be distinguished from that of digit II by its flattened and more symmetrical cross section and by its nearly symmetrical anterior outline. Except for its larger size, this element is similar to the third phalanx, digit IV, in shape and cross-sectional and anterior aspects. A primary distinction, however, between the ungual phalanges of digits III and IV is the rotation of the proximal articular trough for reception of the second phalanx. In digit III this medial rotation of the articular facet of the ungual phalanx is not as pronounced, so that in anterior aspect the outline of the proximal end produces only a downward-directed slope toward the lateral margin from the anteroproximal border, rather than a distinct trough with a raised margin on the lateral side as in the ungual phalanx of the digit IV

The proximal articulation consists of two confluent concave facets separated by an indistinct ridge. Both facets describe an arc of approximately $120^{\circ}$, with most of the curvature anterior to the midline. The posterior terminus of the articular facets does not extend beyond the level of the subungual process, while the anterior extension continues proximally, resulting in a posterior orientation for the facets at their anterior border. The medial facet extends farther proximally than the lateral; the latter possesses a greater transverse diameter. A plane passing 
through the low median ridge projects through the anterior face of the claw process near the medial border, indicating a rotational motion in the anteroposterior plane, which is oblique to the transverse axis of the roughly symmetrical claw process.

The claw process includes all of the distal portion of the phalanx except for the semicircular prominence on the proximal end of the posterior face formed by the subungual process. The proximal borders of the claw process are indistinct in F:AM 95737, presumably because of the young age of the individual. The cross section is an anteroposteriorly compressed and roughly symmetrical lens shape. On the posterior face the medial border is flattened near the proximal end. The two subungual foramina, located on either side of the subungual process, pass deeply into the bone in a distal direction toward the midline. The diameter of the lateral foramen is approximately half that of the medial, a feature serving to further distinguish the ungual phalanx of digit III from those of the adjacent digits, in which the diameters of the subungual foramina are approximately equal.

Articular facets for the large posterior sesamoid on the joint between the second and third phalanges are located on the posterior border of each proximal articular facet. These two sesamoid facets are continuous with the proximal articular facet, forming a rounded, convex terminus for the posterior border of the larger facet.

Ungual phalanx, digit III, manus, of $G$. arizonae (Figure 42), exhibits a massive development in adult individuals, especially with respect to the overgrowth of the subungual hood, which extends on the medial side to the anteromedial corner of the proximal extremity and on the lateral side only to the margin. Thus the sheath covered the entire anterior surface and the greatest portion of the other surfaces as well. By inference, the same statement can be made for the adults of $G$. texanum.

The shape and proportions of $G$. arizonae closely approximate those of $G$. texanum. The flattened medial surface of the claw process is rather pro- nounced, and the anterior proximal tubercle is divided by a shallow groove, producing a larger medial prominence and a smaller lateral one. The articular facets are weakly divided by an indistinct nonarticular area.

The ungual phalanx, digit III, manus, of $G$. floridanum (Figure $44 \mathrm{~g}$ ), exhibits a somewhat greater departure from the features of $G$. texanum, especially with respect to the articular facet. As in the ungual phalanx of the second digit, the articular facet is less extensive and rather flattened, again primarily due to the relatively underdeveloped anterior proximal tubercle.

Sesamold Bones, Digit III, Manus.-Three sesamoid bones are located on the palmar surface of the third digit: two small ones at the metacarpal-phalanx joint and a large one at the terminal joint.

Of the proximal pair of sesamoids in $G$. texanum (Figure 41), the medial is slightly larger than the lateral. Both are irregularly spherical in shape, with two poorly developed, flattened, articular surfaces, a metacarpal facet, and a first phalanx facet. Only the lateral of the proximal pair of sesarnoids is known for $G$. arizonae (USNM 10536, Figure 42). As in G. texanum, this element is irregularly spherical in shape, somewhat elongated in the transverse direction. The articular facet for the first phalanx is likewise transversely elongated, and its surface is weakly sigmoid in the transverse plane.

The large distal sesamoid of $G$. texanum (Figure 41 ), located at the terminal joint, is approximately four times larger than the proximal ones. Its shape is more well defined, transversely elongate with a distinct second phalanx articular facet on its proximal surface along the anterior border, and two somewhat less distinct terminal phalanx articular facets on the anterior face. Compared with the terminal sesamoid of digit II, this element is slightly narrower and the proximal articular facet is narrower and more elongate in the transverse plane. A minor difference between these elements occurs in the shape of the proximal articular facet: broadly convex in the sesamoid of digit II, more distinctly divided into three sepa- 
rate portions in the terminal sesamoid of digit III. The distal sesamoid bone of $G$. arizonae (Figure 42) closely resembles that of $G$. texanum. The only marked distinction is the exaggeration of the tendinal sulcus on the nonarticular surface opposite the articular facet for the ungual phalanx.

Digit IV, Manus.-The annular digit is the most lateral of the three functional weight-bearing digits of the manus (Figure 38). Digit $\mathrm{V}$, located lateral to the fourth, is reduced in size and length and is essentially vestigial. The fourth digit is directed laterally from the midline and participates as the lateral member of the manus. The lateral orientation, approximately $45^{\circ}$ from the medial digit, is achieved through distortion of the unciform in the distal carpal series. The distal articular facet of the unciform, articulating with the fourth metacarpal, is rotated laterally, so that with respect to a sagittal plane passing through the proximal facet, the distal facet is directed distolaterally and is restricted to the lateral half of the element.

The fourth digit is the smallest of the three functional toes of the manus; each phalanx is somewhat reduced in size. There is only one known sesamoid, a large palmar one at the terminal joint. No proximal sesamoids at the metacarpal-phalanx joint were recovered with F:AM 95737, the only known North American specimen with associated sesamoids, nor are there any facets indicating their existence. It is possible, however, that these sesamoids were unossified at the time of death for this juvenile individual and would have ossified at a later age.

Phalanx I, Digit IV, Manus (Table 33).Phalanx I, digit IV, manus, of $G$. texanum (Figure 38 ), is extremely compressed in the proximodistal direction. The proximal articular facet is bilaterally symmetrical about the sagittal plane. Its slightly concave surface is turned up on the straight anterior border and to a lesser extent on the rounded lateral borders. A deeply penetrating, tendinal sulcus interrupts the posterior margin.

The distal articular facet is the complement of the proximal, its convex surface offset slightly toward the medial margin. This surface is somewhat asymmetrical, with a subdued central sulcus located medial to the midsagittal plane. The medial margin forms an acute angle with the shaft, while the lateral margin of the facet forms a broadly obtuse angle with the lateral surface of the shaft. Unlike the proximal articular surface, the distal facet does not extend posteriorly to include the entire region beneath the two posterior tubercles formed by the posterior tendinal sulcus.

There is little shaft on the first phalanx, its proximodistal length being so compressed that its shape is that of a concavoconvex discoid with a broadly oblate outline. A tubercle is situated laterally on the shaft, the only notable feature on the nonarticular surface of this element. There are no evident sesamoid articular surfaces.

Phalanx I, digit IV, manus, of $G$. arizonae (Figure 42), bears no significant distinction from that of $G$. texanum. In USNM 10536, the posterior tubercles are distorted and suggestive of disease, as in phalanx I, digit III.

Phalanx II, Digit IV, Manus (Table 33).Phalanx II, digit IV, manus, of $G$. texanum (Figure 38 ), is not as extensively compressed in the proximodistal direction as phalanx I. Its articular facets display a shorter radius of curvature, allowing for greater rotational motion than in the metacarpal-phalanx joint. In proximal aspect the concave articular facet is butterfly-shaped, with the medial expansion rather narrower than the lateral. The lateral portion of the proximal facet terminates anteriorly at the highest point on the anterior border.

The distal articular facet is trochlear, with the medial facet separated from the lateral facet by a shallow constriction. Both portions of the facet possess a tighter radius of curvature than the corresponding surface of the first phalanx. The medial portion is longer and narrower than the lateral in the anteroposterior direction. The lateral portion of the facet is transversely wider and is rendered somewhat asymmetrical by having a broader surface on the posterior margin than on the antcrior. The medial portion of the facet is 


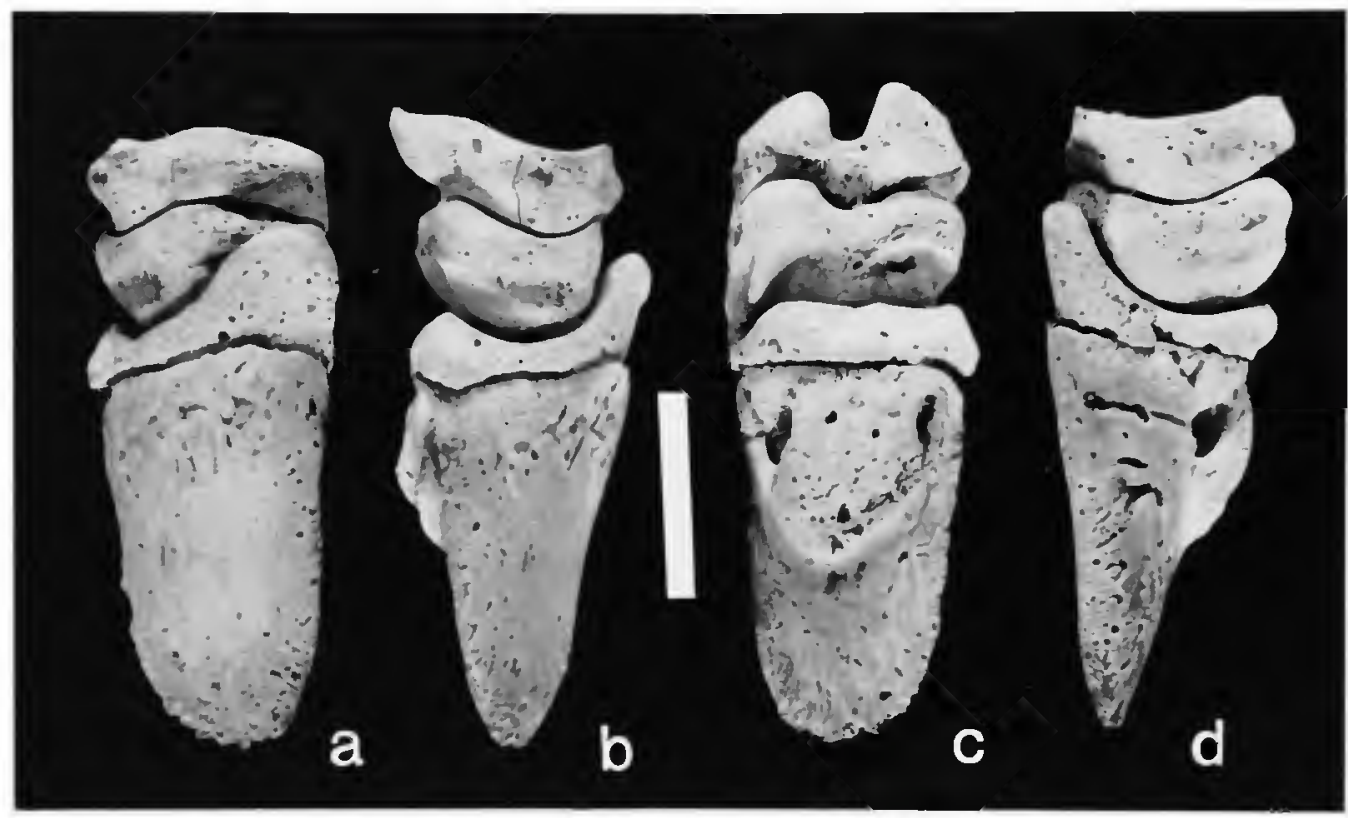

Figure 38.-Right digit IV, manus, of Gtyptotherium texanum (F:AM 95737): $a$, anterior: $b$, lateral; $c$, posterior; $d$, medial. (Bar $=20 \mathrm{~mm}$.)

directed laterally, departing farther than the medially directed lateral facet from the normal sagittal orientation, thus imparting a marked asymmetrical outline in anterior aspect. The central sulcus is situated in a position medial to the sagittal plane.

The shaft is extremely compressed, as in the first phalanx; no prominent tubercles mark its nonarticular surface.

The posterior margins of the two portions of the distal facet articulate with a large sesamoid on the palmar surface of the terminal joint. This articulation is confluent with that for the terminal phalanx.

Except for greater size and more extensive rugosity, in the adult specimens compared with the juvenile of $G$. texanum, this element of $G$. arizonae (Figure 42) is similar in all respects.

Ungual Phalanx, Digit IV, Manus (Table 34).-Ungual phalanx, digit IV, of G. texanum (Figure 38), is the most asymmetrical phalanx of the digit. It is the smallest of the three functional terminal phalanges and its cross-sectional aspect exhibits the farthest departure from bilateral symmetry as a reflection of the lateral orientation of the digit with respect to the midline of the front limb.

The proximal articular facet is deeply concave in the anteroposterior direction, forming a right triangle in proximal view, with legs of equal dimension formed by the medial and posterior borders, and the hypotenuse by the anterolateral margin. This is the cross-sectional aspect as well, which obtains for the length of the element, becoming more rounded and anteroposteriorly compressed toward the free end

The free end of the terminal phalanx, like that of the other ungual phalanges, was encased by a horny sheath, except for the raised subungual region in the posterior proximal position. As with the other terminal phalanges of the juvenile specince F:AM 95737, the proximal borders of the claw process arc indistinct, presumably because of the young age. Two large subungual foramina penetrate the bone on the medial and lateral sides, respectively, of the subungual process. The anterolateral surface is flattened, forming a sharp anglc with the posterior border and a somewhat more rounded angle with the medial border.

The articular motion of the ungual phalanx is 


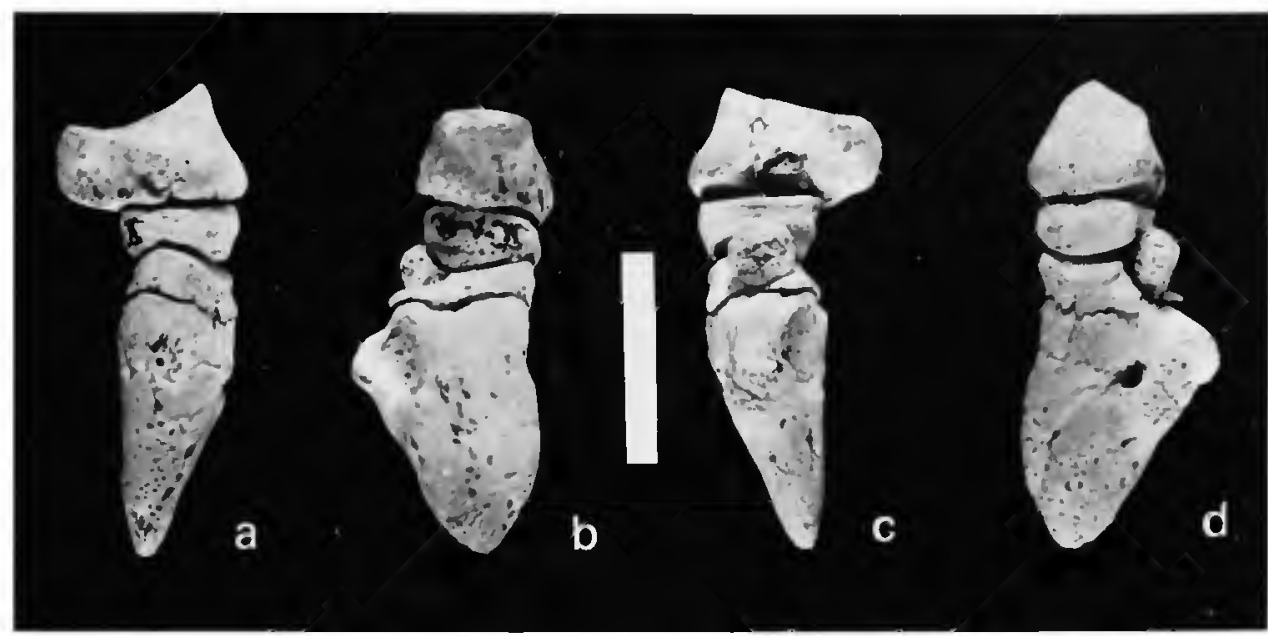

FigURE 39.-Righı digit V, manus, and metacarpal V of Glyptotherium texanum (F:AM 95737): $a$, anterior; $b$, lateral; $c$, posterior; $d$, medial. (Bar $=20 \mathrm{~mm}$.)

in the sagittal plane passing through the proximal facet and the raised anterior tubercle. The leading edge of the phalanx is the anteromedial border, in keeping with the lateral position of the digit.

A sesamoid articular facet is situated on the posteroproximal surface, forming an angle at the common border with the proximal facet.

The terminal phalanx, digit IV, manus, of $G$. floridanum (Figure $44 h$ ), differs in several important features. As with the other ungual phalanges of this species, the proximal articular surface is more extensive in the transverse direction; the maximum transverse diameter occurs through the central low point of the facet rather than through the sesamoid facet on the posteroproximal border. Moreover, the radius of curvature of this facet is longer, producing a more flattened articular surface. The reduced curvature of the proximal facet is accentuated by the relatively underdeveloped anterior tubercle. The proximal facet is more distinctly divided into lateral and medial portions, and the outer shape of the proximal facet is less triangular and somewhat suggestive of a figure eight (8) shape.

The most distinguishing feature in $G$. floridanum is the lesser degree of axial rotation of the articular facet. Whereas in $G$. texanum the rotation of the ungual phalanx formed an angle of roughly $45^{\circ}$ with respect to the flattened anterolateral outer

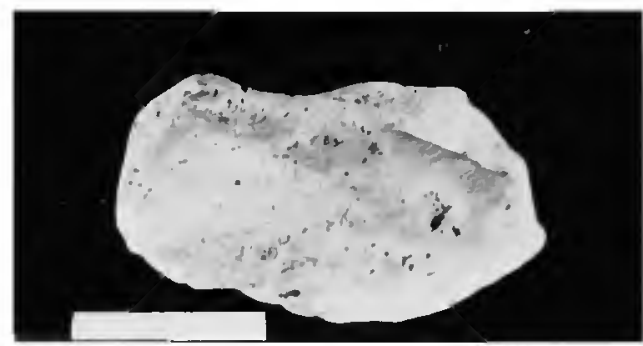

FIGURE 40.-Right palmar sesamoid of Glyptotherium texanum (F:AM 95737): plantar surface. (Bar $=20 \mathrm{~mm}$.)

surface of the claw process, in $G$. floridanum this rotation is less acute, forming an angle of roughly $60^{\circ}$.

The subungual hood of the adult specimen of USNM 6071 (G. floridanum) is more well defined than that of the juvenile specimen of $G$. texanum, extending to the anteromedial and lateral corners of the proximal end. The subungual base is relatively larger. The lateral subungual foramen is distinctly smaller than the medial in contrast to those of $G$. texanum, which are approximately equal in dimensions. The posterior (palmar) surface of the claw process is transversely concave rather than convex.

The phalanx is unknown for either the Seymour or the Curtis Ranch representatives of $G$. arizonae.

Sesamoid Bone, Digit IV, Manus (Table 


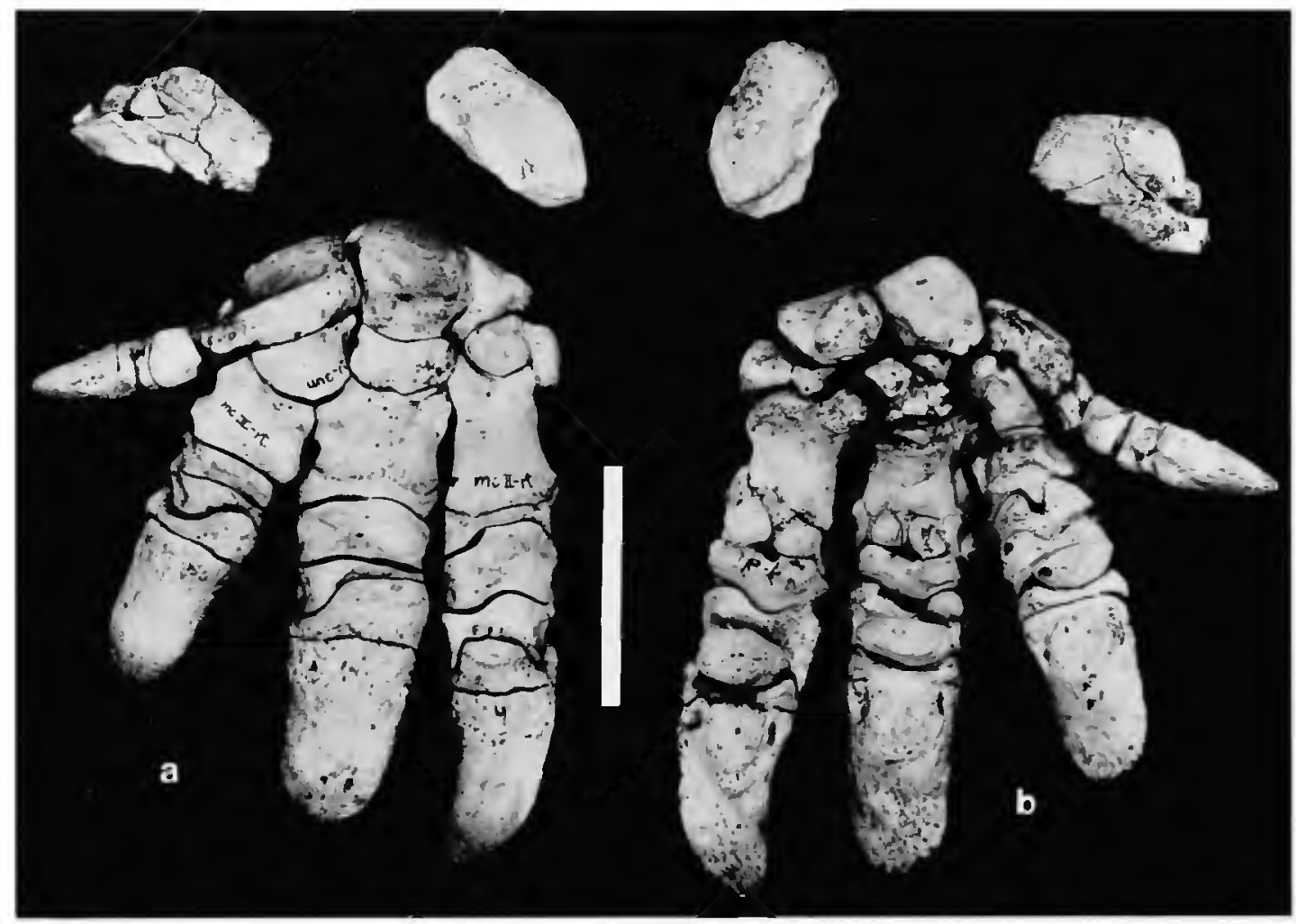

Figure 41.-Articulated right manus of Glyplotherium texanum (F:AM 95737): a, anterior, with pisiform above (left), and palmar sesamoid above (right); $b$, posterior, including digital sesamoid bones, with palmar sesamoid above (left) and pisiform above (right). (Bar $=5 \mathrm{~cm}$.)
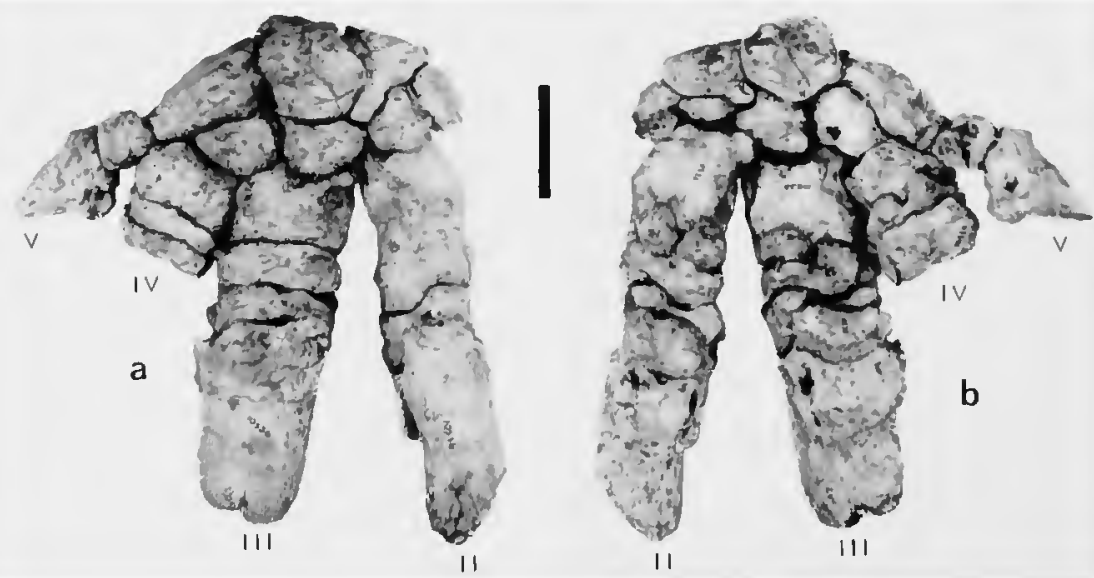

FIGURE 42.-Articulated right manus of Glyptotherium arizonae (USNM 10536): $a$, anterior; $b$, posterior. (Bar $=40 \mathrm{~mm}$.) 
37). - There is no indication of proximal sesamoids at the metacarpal-phalanx joint, digit IV, manus in known specimens of Glyptotherium. The single large sesamoid at the terminal joint of digit IV in G. texanum (Figure 41 ) is the smallest of the terminal sesamoid bones. Like the others, it is transversely elongate, with articular facets for the second and ungual phalanges meeting at approximately a right angle on the anteroproximal border. This bone is the least distinctive of the terminal digital sesamoids of the manus.

This element was not recovered with any other specimens.

Digit V, Manus.-As discussed in the description of digit II, manus, digit $\mathrm{V}$ was not universally recognized in the South American genus Glyptodon until Vinacci Thul (1943) established its existence. Some earlier authors (e.g., Burmeister, 1874) had erroneously assigned the bones of digit $\mathrm{V}$ to digit $\mathrm{I}$ and claimed that digit $\mathrm{V}$ was absent. Like the South American Glyptodon, the North American representatives have a well-defined digit $\mathrm{V}$, but it is very reduced and may be considered as functionally vestigial.

In Glyptotherium, digit V (Figure 39) consists of only two phalanges and a sesamoid bone at the terminal joint. This determination is at variance with Vinacci Thul's (1943) contention that Glyptodon reticulatus has three phalanges. He maintained that phalanges I and II were lost in his specimen and that the two elements he described were metacarpal $\mathrm{V}$ and phalanx III. His justification for the belief that $G$. reticulatus has three phalanges was not stated, although it is possible that he based his statement on knowledge of other specimens. In the particular specimen he described, there were indeed only two elements in this digit (including the metacarpal); his textual descriptions and the figure of both the metacarpal and the terminal phalanx indicate close similarity to phalanges I and II described here for North American representatives. It therefore appears possible that $G$. reticulatus has only two phalanges in digit $\mathrm{V}$ and that Vinacci Thul's statement to the contrary for $G$. reticulatus was erroneous. This assumed difference between the North American glyptodonts and their close South American relative is therefore only provisionally important as a taxonomic distinction.

Digit $\mathrm{V}$ articulates with metacarpal $\mathrm{V}$ on the lateral edge of the foot and is directed laterally with respect to the long axis of the foot.

Phalanx I, Digit V, Manus (Table 35).-Phalanx I, digit V, manus, of G. texanum (Figure 39), is the smallest element of the forefoot except for the sesamoid bones. Its proximal aspect is semicircular, rounded along the anterior border. The flattened proximal articular facet bears the same shape, occupying the entire proximal extremity. The distal articular facet is transversely concave, and in distal aspect it is likewise semicircular. The distal facet articulates with the convex facet of the second (terminal) phalanx; a small spherical sesamoid bone is situated at the posterior border of the terminal joint.

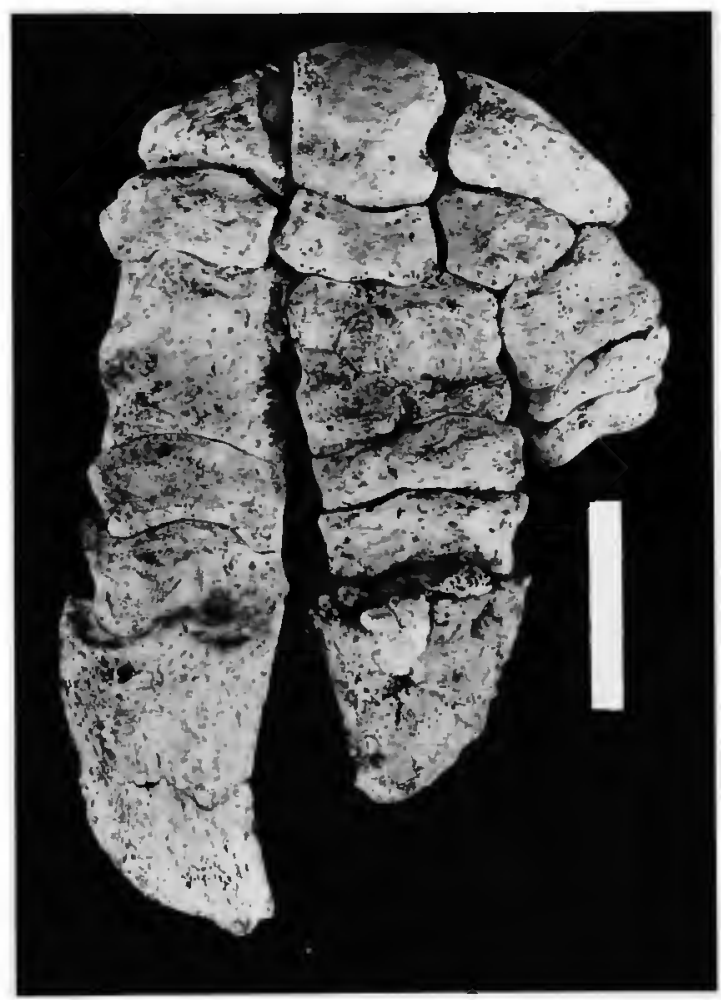

Figure 43.-Articulated left manus of Glyptotherium arizonae (UMMP 38761), with digits I and II and phalanges I and II of digit IV, anterior. (Bar $=40 \mathrm{~mm}$.) 
There is no indication of fusion between the first and second phalanges of this digit. There is no middle phalanx and no indication of its incorporation by fusion into either of the other phalanges.

Description of the abnormal coossification of phalanx I with metacarpal $\mathrm{V}$ in one specimen of $G$. arizonae was discussed above. It does not appear that phalanx I, digit $\mathrm{V}$, of $G$. arizonae, differs significantly from that of $G$. lexanum.

Phalanx II (Ungual Phalanx), Digit V, Manus (Table 36).- The ungual phalanx of the

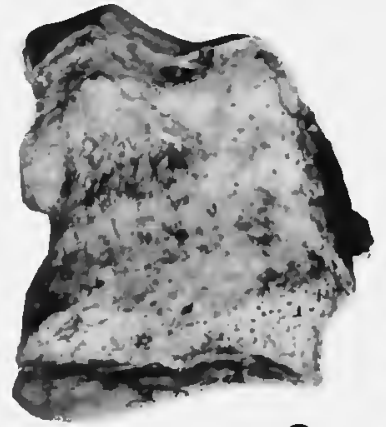

a
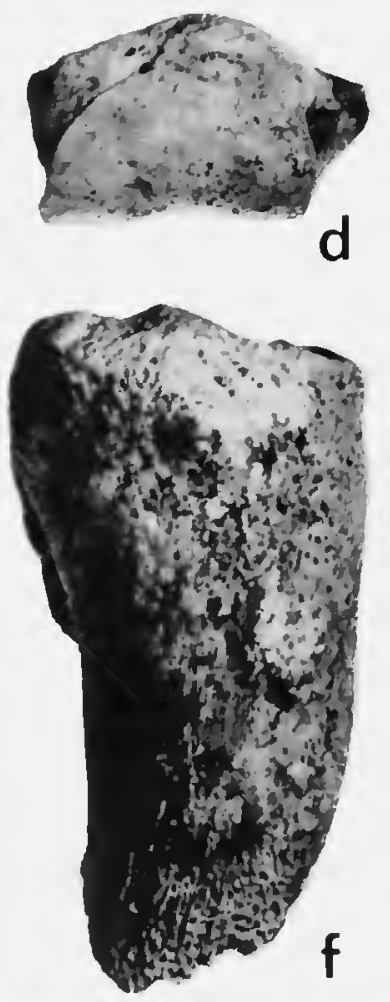
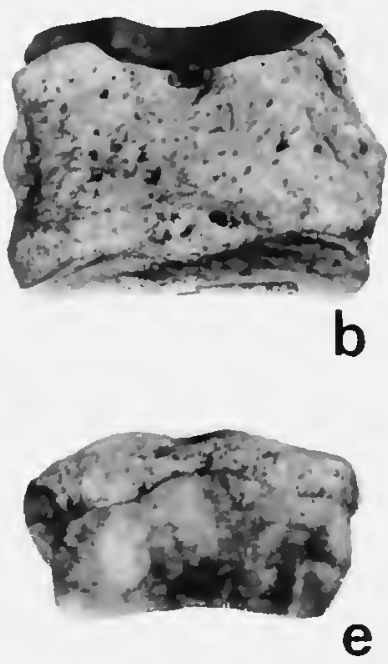

e

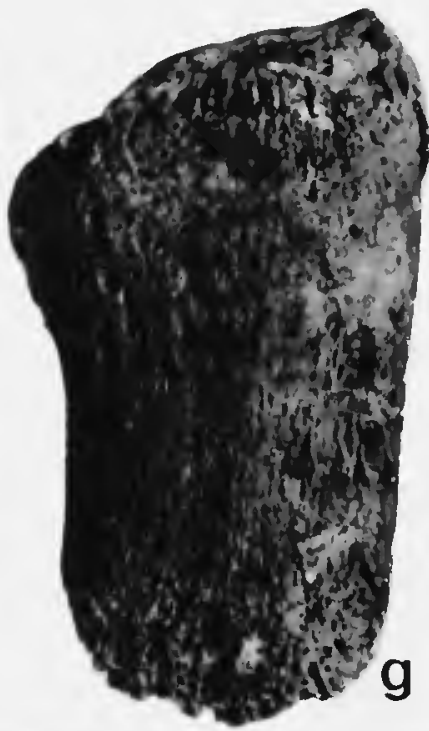

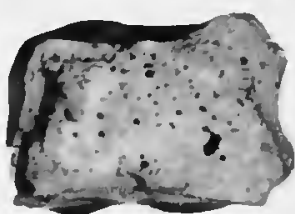

C
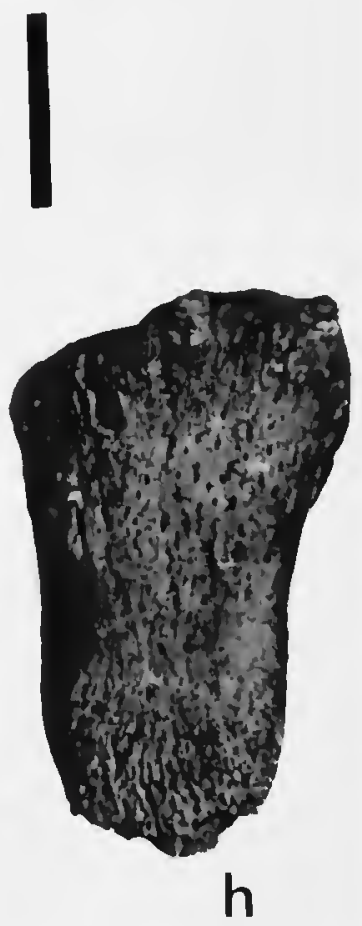

Figure 44.-Isolated elements of manus of Glyptothenum floridanum (USNM 6071), anterior aspects: $a$, right metacarpal II; $b$, right metacarpal III; $c$, left metacarpal IV; $d$, second phalanx of digit II, right; $e$, second phalanx of digit III, right; $f$, ungual phalanx of digit II, right; $g$, ungual phalanx of digit III, right; $h$, ungual phalanx of digit IV, right. (Bar $=20 \mathrm{~mm}$.) 
digit V, manus, of G. texanum (Figure 39), is transversely compressed and proximodistally elongate. The small proximal articular facet is convex in the transverse direction and semicircular in proximal view. The precise limits of the subungual base are indistinguishable from the claw process. Two subungual foramina penetrate deeply into the subungual base; the lateral foramen is slightly larger than the medial. In lateral and medial views the portion of the bone distal to the epiphysis bears the shape of an isoceles triangle, the apex at the terminus of the claw process. The smooth surface of the claw process is distinct from the pitted surface of the subungual base, indicating that the free end was encased in a horny sheath.

A distinct posteroproximal tubercle is situated between the subungual foramina as an eminence projecting from the subungual base. It bears a flattened surface of insertion at its extremity for the tendon of the digit.

The second (terminal) phalanx of the fifth digit, manus, of $G$. arizonae (Figure 42), differs in several important respects. First, as discussed previously (under the heading "Coossified Metacarpal V, Phalanx I, Digit V, Manus"), the proximal articular facet is weakly concave in the anteroposterior direction, rather than transversely convex. Another important distinction is the disposition of the subungual base. In USNM 10536, the subungual base is situated entirely at the posteroproximal position of the medial surface of the transversely compressed claw process. Accordingly, the "lateral" subungual foramen is situated
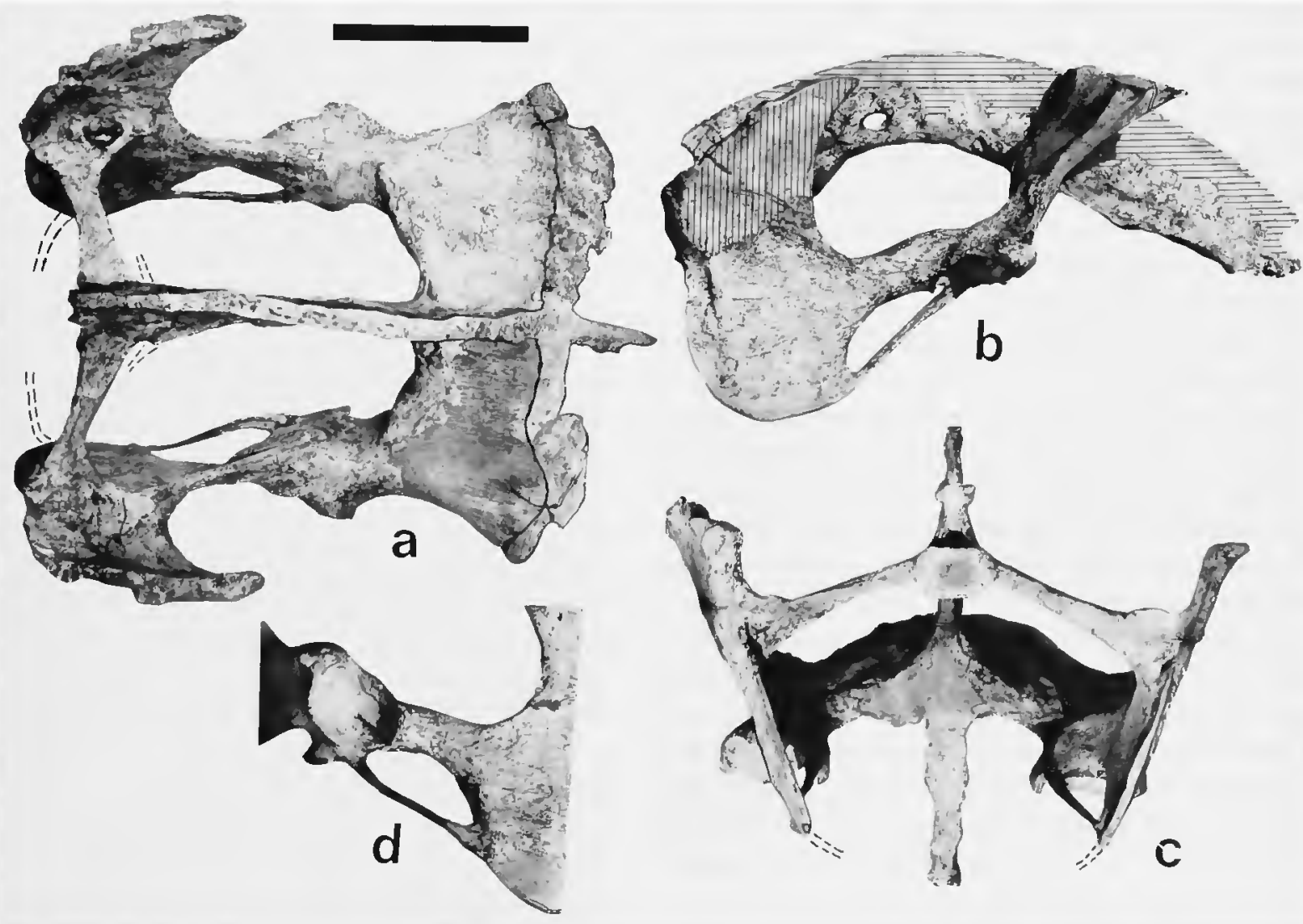

FigURE 45.-Pelvis of Glyptotherium texanum (AMNH 10704): $a$, dorsal; $b$, right side (reconstructed portions halched); $c$, posterior; $d$, detail of acetabular region, ventral sightly enlarged. (Bar $=$ $20 \mathrm{~cm}$.) 
in direct line with the posterior margin, and the "medial" foramen is located at the proximocentral position on the medial side. Thus the terminal phalanx, digit $\mathrm{V}$, of $G$. arizonae, bears a distinct asymmetry in marked contrast to the symmetrical disposition of the subungual features of $G$. texanum.

Sesamoid Bone, Digit V, Manus (Table 37).The single sesamoid of digit $\mathrm{V}$, manus, of $G$. texanum (Figure 41), is the smallest sesamoid bone of the forefoot. It is approximately spherical in shape and occupies a position on the posterior border of the proximal extremity of the terminal phalanx, at the terminal joint.

The sesamoid of the digit $\mathrm{V}$, manus, of $G$. arizonae (Figure 42), contrasts with that of $G$. texanum in its tetrahedral shape. There are two articular facets. One is a large, slightly concave surface, which articulates and rests on a weakly convex surface posterior to the proximal articular facet of the terminal phalanx. The other facet is smaller, meeting the larger facet at approximately a right angle. The smaller facet is transversely concave and elongate and articulates at the proximodistal surface of the fused metacarpal $\mathrm{V}$, first phalanx. There are two nonarticular surfaces; one is a triangular-shaped surface on the lateral side, the other an irregular surface at the proximoposterior position.

Palmar Sesamoid, Manus.-In addition to the digital sesamoid bones, there is a large palmar sesamoid in the front foot. In bulk this element approximates that of metacarpals I and II and is thus a prominent bone of the manus. In both $G$. texanum (Figures 40,41) and $G$. arizonae, the palmar sesamoid is a nondescript, irregularly elongate bone. The surfaces are generally extremely rugose, although the sides are rather smooth, and in several regions there are distinct striations. Length-width-height measurements are $62 \mathrm{~mm}$, $38 \mathrm{~mm}$, and $21 \mathrm{~mm}$ for G. arizonae (USNM 10536) and $44 \mathrm{~mm}, 24 \mathrm{~mm}$, and $22 \mathrm{~mm}$ for $G$. texanum (F:AM 95737), respectively.

\section{Pelvis}

The glyptodont pelvis is remarkable for the degree of fusion of its component bones. United into a single structure are the lumbar vertebrae, the sacral vertebrae, and the paired ilia, ischia, and pubes. The axial component includes two primary contributions, the lumbar tube, consisting of five to nine fused vertebrae (in North American glyptodonts); and the sacral tube, which includes eight or nine vertebrae of which three or four are united with the ilia and one or two with the ischia. The lumbar tube is solidly ankylosed to the sacral tube. Fusion is so extensive in the axial portion of the glyptodont pelvis that accurate determination of vertebral counts is nearly impossible for the lumbar tube and the free sacral vertebrae ("free" in the sense that they are not united with the appendicular skeleton; they are serially ankylosed in the sacral arch and are therefore not "free" in the sense of maintaining discrete separation from the serially adjacent vertebrae).

The appendicular portion of the pelvis includes the greatly expanded ilia and ischia and the relatively small pubes, which in at least one North American species ( $G$. cylindricum) are fused at the midline in a solid union. For the remaining species, for which the extremities of the pubes are not preserved, there was probably cartilaginous or ligamentous contact, if not actual fusion, at the midline. Because of the small sample of pelves known for North American glyptodonts, it cannot be determined whether there is sexual dimorphism in the construction of the pelvis. Brown's (1912) classification was weighted heavily toward the construction of the pelvis, in part separating the two families Glyptodontidae and Sclerocalyptidae on the basis of differences in the pubes. As discussed below, the distinctions in the pelves cannot be relicd upon to exhibit a constant set of characters, and in the present state of knowledge taxonomic determination therefore must not rely heavily on the nature of the pelvis.

Nearly complete pelves are known for all four North American specics. Osborn (1903) merely mentioned the recovery of the pelvis of $\mathrm{AMNH}$ 10704 ( $G$. texanum type specimen), without description or illustration. Brown (1912) compared this specimen with the one he described and figured for AMNH 15548 (G. cylindricum type 
specimen), concluding that the differences in these two pelves, among other distinctions, indicate generic (and familial) separation. Another pelvis of $G$. texanum (F:AM 95737), from Arizona, is reported here for the first time.

Hay (1916) described fragmentary portions of the pelvis of USNM 6071 ( $G$. floridanum), including an acetabulum and the ischiosacral vertebrae. Lundelius (1972) reported a nearly complete pelvis of $G$. floridanum from the Ingleside locality. These two pelves from the Texas population of the species are apparently identical. A hitherto unreported pelvis, UF/FGS 6643, from the Catalina Gardens, Florida, locality, permits comparison between the Florida and Texas representatives.

A nearly complete pelvis of $G$. arizonae, associated with a carapace and a femur, is also described herein for the first time. Although this specimen was collected many years ago, around 1925, it has been entirely overlooked except for Gidley's (1926) mention of its recovery. It was recovered from the Curtis Ranch locality, Arizona, from which the type specimen (USNM 10536) of the species was obtained. Thus this pelvis adds to the osteology of this species, for which the entire skeleton, except for some of the thoracic vertebrae, is known.

The number of vertebrae participating in the various regions of the axial skeleton can be tabulated as follows.

$$
\begin{array}{cccc}
G . & G . & G . & G . \\
\text { texanum } & \text { arizonae } & \text { cylindricum } & \text { floridanum }
\end{array}
$$

1. Number of ver- $5-6 \quad-\quad$ 7-8 $8-9$ tebrae in lumbar tube

\section{Number of il-} 3 3 4 3 iosacral vertebrae

3. Number of ver4

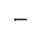
3 3 or 4 tebrae in sacral arch

4. Number of is1 or 21 or 2 2 2 chiosacral vertebrae

The significance of these counts is more fully discussed under "Systematics," where a detailed comparison with armadillo pelves is advanced to account at least in part for these variations in vertebral count. Variation in the construction of the components of the armadillo pelvis is considered in the same discussion, and an evaluation and emended diagnoses for the pelves of the North American representatives are there provided.

Pelvis of Glyptotherium texanum (Table 38).The pelvis of the type specimen of $G$. texanum (AMNH 10704, Figures 45, 46) has not been fully described, despite its early recovery near the turn of the century. The addition of the pelvis of the subadult individual F:AM 95737 (Figure 47) serves further to fix the characters of Glyptotherium and allows positive identification of the Arizona Blancan glyptodonts as $G$. texanum.

Osborn (1903) merely mentioned the pelvis recovered with the carapace AMNH 10704. Brown (1912), comparing this pelvis with AMNH 15548 , stated that in $G$. texanum there are 16 vertebrae in the sacrolumbar tube. Our determination of 13 or 14 vertebrae in the enire arch is based on the apparent presence of five or six discrete neural arches in the lumbar tube and four free vertebrae in the sacral arch. As Brown (1912) stated, there are three iliosacral and one ischiosacral vertebrae; thus, there are 13 or 14 vertebrae in the pelvis, rather than 16 as Brown assumed.

Brown (1912) also thought that the penultimate vertebra lacks transverse processes. In actuality the tip of each process is broken close to the centrum so that its lateral extent cannot be determined. They appear to have been very short, and, as Brown assumed, they apparently did not participate in the ischiac support. In contrast, the transverse processes of the penultimate vertebra of F:AM 95737 (Figure 48) extend to the ischium. Relative to the transverse processes of the terminal vertebra, however, they are small and if broken away, their lateral extent could not be determined with certainty on the basis of their dimensions at the centrum. Therefore, in F:AM 95737 there are two ischiosacral vertebrae, whereas in AMNH 10704 there appears to be only one, 


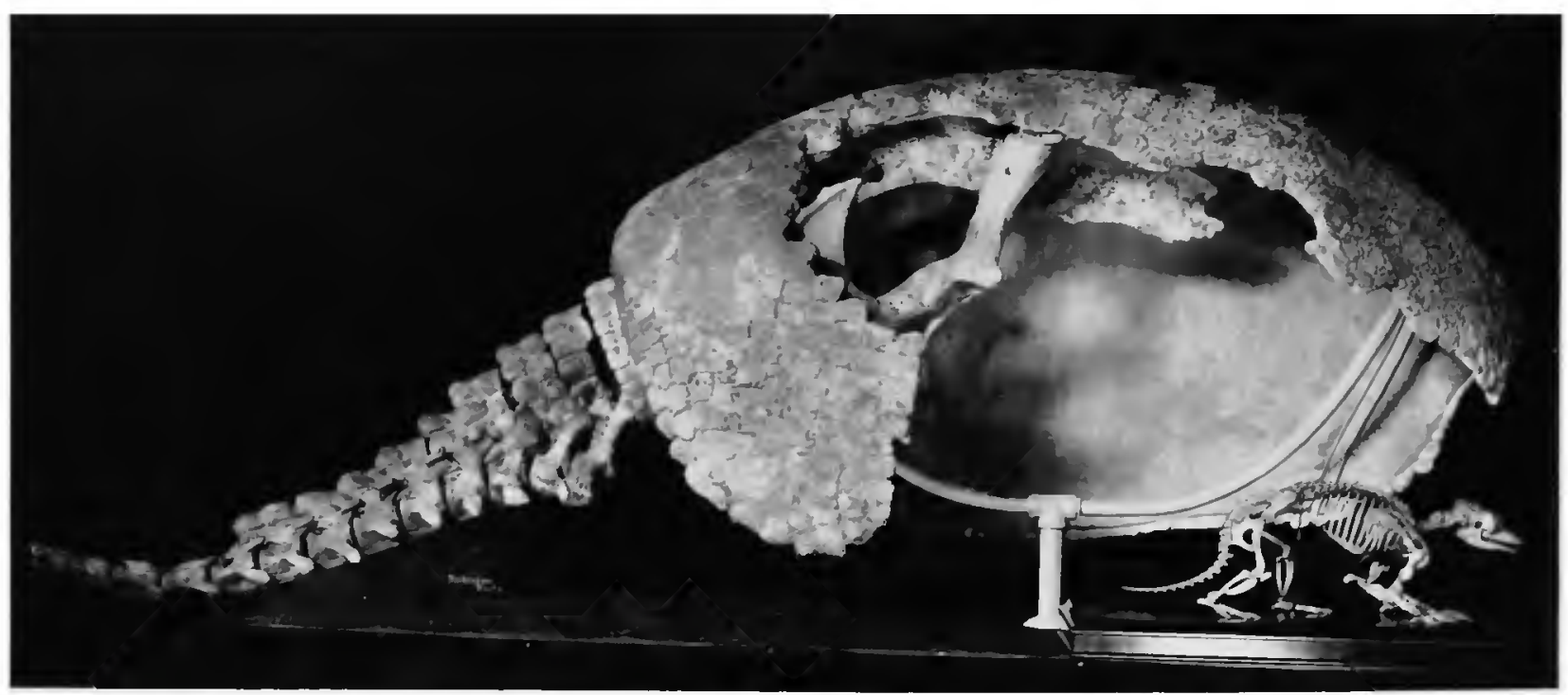

Figure 46.-Pelvis and carapace of Glyplotherium lexanum (AMNH 10704), right side. (Photo courtesy American Museum of Natural History.)

although the possibility of participation by the penultimate vertebra cannot be discounted.

Brown (1912) also assumed that in $G$. texanum there is no pubic crossbar because the preserved proximal portion of the pubes of AMNH 10704 is extremely reduced. The distal region is missing in this specimen, however, so that just as "there is no indication of a crossbar," as Brown asserted, neither is there any indication, other than the reduced size of the pubes, of the absence of a crossbar. That there may have been a crossbar is indicated in F:AM 95737 (Figure 48), in which the pubes are also reduced, but their distal extremities are preserved, and they were apparently united at the midline in a cartilaginous connection. With maturity from this subadult condition, it is likely that the pubes would have bccome ankylosed despite the small size of these bones. Hence, at least in the Arizona rcpresentative, and probably in the Texas representative, the pubes apparently were united in a wcak contact.

As Brown (1912) asserted, in $G$. lexanum thcre is a uniform height of the ncural arches for the entire length of the sacrolumbar tubc, with consequent uniformity in the compound curve for the sacrolumbar arch. The height of the neural spines at the anterior iliosacral vertebra is approximately $130 \mathrm{~mm}$. This same height occurs for the spine of the terminal sacral vertebra, while the minimum height, located at the midpoint of the sacral arch, is an estimated $110 \mathrm{~mm}$. Because the sacral arch and the lumbar vertebrae are not fully represented in F:AM 95737, no new insight into this seemingly important character can be established. However, it does appear that in the Arizona specimen the neural arches were relatively low throughout, for the vertebral height at the iliac union $(130 \mathrm{~mm})$ is approximately the same as in the terminal vertebra $(140 \mathrm{~mm})$. The curvature of the sacrolumbar tube therefore appears to distinguish $G$. texanum from $G$. cylindricum. As discussed below, however, the compound curve of the pelvis of $G$. cylindricum is not as pronounced as Brown stated, and it is likely that the differences are not worthy of more than specific distinction.

For purposes of comparison with other species, and because the pelves AMNH 10704 and F:AM 95737 are representative of the type-species of Glyptotherium, the following description of the pelvis of $G$. texanum goes into considerable detail. It is a fortunatc circumstance to have two nearly 
complete pelves of the same species from different localities, one from a subadult individual (F:AM 95737), the other from a mature adult (AMNH 10704), allowing for an assessment of intraspecific and ontogenetic variation. The pelvis of the subadult individual seems to be the least developed skeletal region, indicating, as expected, that fusion and termination of growth in the glyptodont pelvis occurred relatively late. The lack of fusion of the pelvic bones permits rather precise delimitation of the component bones in this region; hitherto, descriptions of glyptodont pelves have been for completely fused (i.e., adult) specimens only.

The lumbar tube, incorporating five or six vertebrae as the preiliac axial component of the pelvis, is complete in AMNH 10704. Only portions of the three lumbar vertebrae immediately preceding the iliosacrals are preserved for $\mathrm{F}: \mathrm{AM}$ 95737. The articular facets for the thoracic tube are diminutive. They are but slightly expanded beyond the thickness of the lumbar tube. Because of breakage, the development of the prezygapophyseal facets cannot be accurately determined. They appear not to have been very large, however, indicating a close similarity in the thoracolumbar articulation with that known for $G$. arizonae. The height of the fused neural crests of the lumbar tube appears to be relatively uniform for both specimens, and this height is approximately continuous rearward for the length of the sacrolumbar tube. There is no indication of carapacial contact.

The iliosacral vertebrae, numbering three in both specimens, are united with the body of the ilium by fusion of their neural arches and their transverse processes in a continuous ankylosed contact. Whereas the two neural foramina are present in the younger individual, they are obscured in the adult condition. The neural arch of

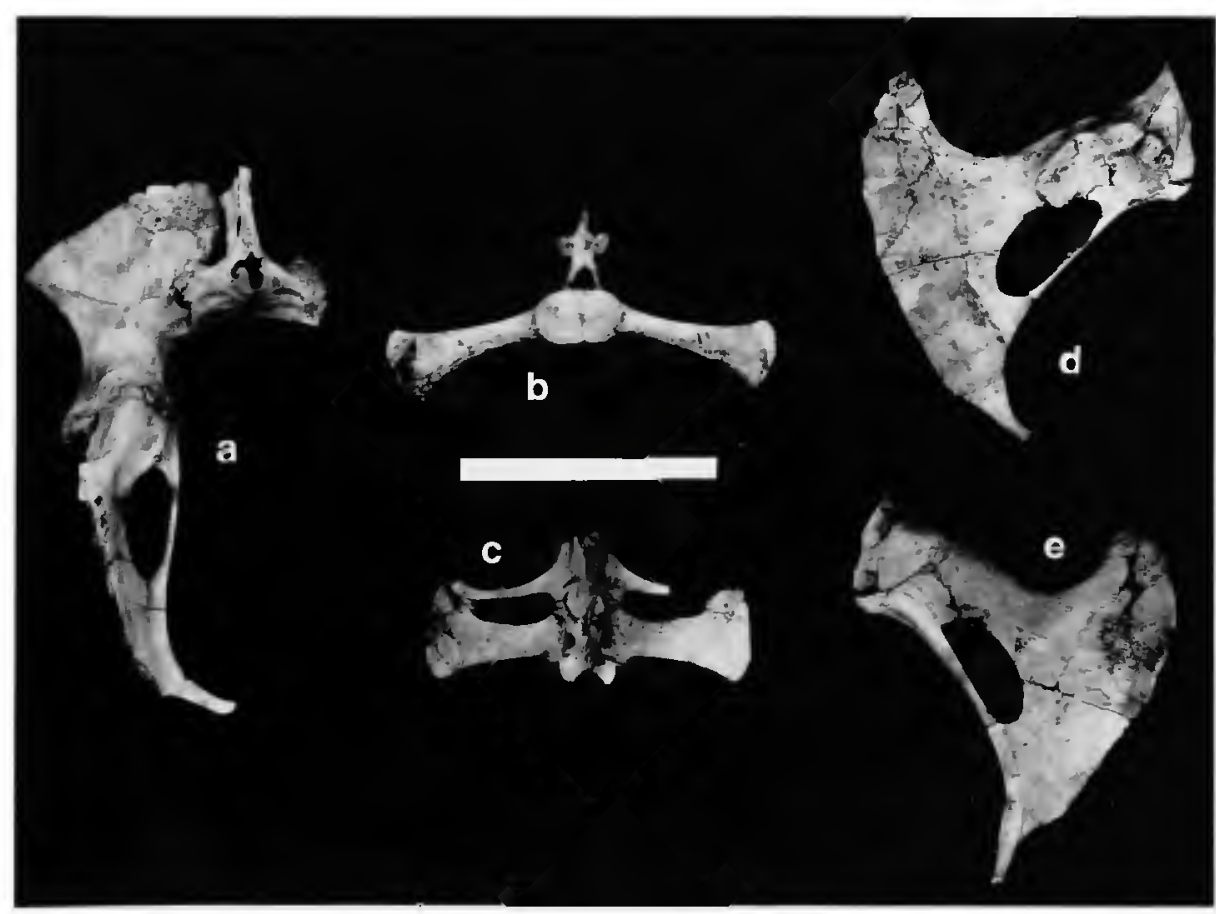

Figure 47.-Pelvis of Glyptotherium texanum (F:AM 95737): $a$, left side of pelvis showing unfused contact (juvenile) of ilium with iliosacral vertebrae and incomplete pubic crossbar; $b$, posterior aspect, $c$, dorsal aspect of ishiosacral vertebrae; $d$, ventrolateral aspect, $e$, ventromedial aspect of the right ischium and pubis. (Bar $=20 \mathrm{~cm}$.) 
the middle iliosacral vertebra is the dominant element in the union of the neural arches with the ilium. With respect to the vertical contacts between neural spines, which are unfused in the young individual, the iliac-vertebral contact is inclined anteriorly from below upward, crossing the neural spines in a slightly oblique angle.

There are four free vertebrae in the sacral arch in the adult specimen, as indicated in part by the neural canals. The neural spines are relatively uniform in height; they were apparently united with the carapace in a ligamentous connection. A uniform transverse diameter of the neural crest is maintained from the iliac region to the posterior extremity of the sacral arch.

The ischiosacral vertebrae, numbering two in the subadult specimen (Figure 47) and apparently only one in the adult, are united with the ischiac plates by fusion of their extended transverse processes with the posteromedial surface of each ischium in a horizontal contact. The shaft of the transverse process of the terminal vertebra of each specimen is stout and thickened. It is dorsoventrally compressed and anteroposteriorly elongate. These processes pass slightly downward and rearward from the centrum. The penultimate vertebra in both specimens bears transverse processes. In the adult these are broken and their lateral extent cannot be determined. The only positive statement that can be made concerning the penultimate transverse processes of $\mathrm{AMNH}$ 10704 is that they were small in this individual, but perhaps no smaller than in F:AM 95737, in which they extend to the ischium. In the latter specimen, the transverse processes of the penultimate vertebra parallel the posterior ones, but they are considerably smaller and their participation in the ischiosacral contact is minor. They do not contact the posterior transverse processes, although it is possible that there would have been contact and subsequent fusion with growth.

The centrum and neural arch of the terminal vertebra of AMNH 10704 are fused. In the subadult condition (F:AM 95737), however, the terminal vertebra is unfused, contacting the penultimate vertebra dorsally in a xenarthral artic- ulation and sharing with it a common centrum disc. Certainly the centrum contact, and probably the xenarthral articulation, would have fused with growth, rendering a construction similar to that of the adult specimen.

Articulation with the first caudal vertebra is achieved through a broad centrum contact and a well-developed xenarthral contact. The centrum facet is transversely elongate and concave. The paired xenarthral facets are convex and are directed downward and outward in typical zygapophyseal fashion.

In AMNH 10704, at the posterior angle formed by the contact of the transverse process of the terminal vertebra with the ischium, there is a weak, downward-directed concavity for reception of the lateral extremity of the transverse process of the first caudal vertebra. This weak lateral contact at the sacrocaudal union reflects a relative lack of importance of the first caudal vertebra in the structure of the pelvis as a "pseudo-sacral" vertebra. This region is underdeveloped in the younger individual, F:AM 95737. The transverse processes of the anterior caudal vertebra exhibit no indication of contact at the lateral ischiac angle. With growth, however, there probably would have been contact, with the development of a shallow articular concavity as in the adult condition, in contrast to the deep concavity in other taxa.

The massive ilium of $G$. texanum is inclined anteriorly with respect to the cross-sectional axis of the body. The ilium is fused to the iliosacral vertebrac along its medial border. It is greatly expanded transversely and dorsoventrally to conform to the undersurface of the carapace. In the adult condition, the crests of the ilia became fused with the carapace; in the subadult condition, the ilia were apparently united by ligamentous or cartilaginous connection. The ilium presents two surfaces and three borders: a concavoconvex anterior (cranial) surface, and an opposing posterior (caudal) surface; the medial border, including the greater sciatic notch; the expanded superior border (iliac crest); and the ventrolateral border. At its ventral extremity the ilium contributes to the 
acetabulum where it is united with the ischium and pubis. For purposes of description, the ilium can be divided into the expanded superior region, or "wing," and the narrower inferior region, the "body."

The anterior surface of the expanded wing is medially convex and laterally concave. The posterior surface of the wing reflects the curvature of the anterior surface: medially concave and laterally convex, although these inflections are less pronounced. The wing is an anteroposteriorly compressed plate, gradually increasing in thickness from the body toward the iliac crest, attaining maximum thickness at its ventrolateral angle. The rugose iliac crest is arcuate. In the adult condition the transverse curvature of the crest becomes more nearly flattened (Figure 47) in comparison with the subadult curvature, which is very rounded (Figure 45). Accordingly, the lateral angle of the iliac crest in the adult stage is elevated nearly to the height of the iliosacral region, whereas in the younger condition the lateral angle is decidedly lower.

On the continuous medial border of the body and wing, there is a marked thickening and expansion of the bone for contact and subsequent fusion with the united transverse processes of the iliosacral vertebrae. This contact is unfused in the subadult condition; in the adult stage there is complete fusion, obscuring these contacts. Beneath the region of contact with the iliosacral vertebrae, the medial border of the body is deeply concave, forming the greater sciatic notch.

The body, or shaft, of the ilium is uniformly convex on the anterior surface. It is flat on the posterior surface, with a weakly developed concave inflection on the medial border in the region of the greater sciatic notch. The lateral border of the ilium forms a uniformly concave arc in profile. At the inferior extremity of the medial border there is a prominent iliopubic tuberosity.

The lower extremity of the ilium is united on its flat anteromedial surface anteriorly with the pubis and posteriorly with the ischium; it is united at its posterolateral surface exclusively with the ischium. The lateral surface of the ace- tabular ramus of the ilium is free, occupying the anterior portion of the acetabular circumference. The inferior epiphysis of the ilium forms the acetabular angle, and the anterior two-thirds of the articular surface of the acetabulum is contributed by the ilium, as indicated in the subadult specimen.

The ischium is a broadly expanded plate, approximating the ilium in size and surface area. It is transversely compressed and anteroposteriorly expanded. The ischiac plate is situated at approximately a right angle with respect to the wing of the ilium. The ischium consists of two regions: the narrow acetabular ramus anteriorly and the greatly expanded body forming the flat ischiac plate posteriorly. The lateral, slightly posteriorly directed surface is the outer face of the ischiac plate. The inner, slightly anteriorly directed surface is weakly concave. In the subadult specimen F:AM 95737, a rough and broken region occupying the middle third of the medial surface near the posterior border marks the surface with which the ischiosacral vertebrae unite. The articulation in this subadult condition was cartilaginous. In the adult specimen AMNH 10704, this contact is solidly fused.

The ischiac crest is broad and uniformly arched, conforming to the undersurface of the carapace in the anteroposterior direction. There was a marked upward expansion of the crest with growth, as the bulk of the body and the carapace expanded. Accordingly, in the adult condition, the crest is less curved and is more nearly horizontal than in the juvenile stage. In addition, there appears to have been posterior expansion of the ischiac plate with growth, more clearly separating the crest from the free posterior border. The crest intersects the deeply concave anterior border in an acute angle. The anterior border is a continuation of the superior border of the acetabular ramus.

The posteroinferior region of the ischium distal to the obturator foramen is fused with the pubis. Although the contact is not readily distinguishable even for the younger individual, it appears to have been adjacent to the distinctly thickened 
region. The entire body of the ischium is situated in a single plane. The greatest thickness of the ischiac plate is at the superior angle, with diminishing thickness toward the pubis.

The continuous dorsal and anterior border of the ischium (lesser sciatic notch) is straight along the shaft, forming a deeply concave arch in the expansion toward the ischiac crest. The shaft connecting the acetabular ramus with the body is flat on both sides and thicker in cross section along the lesser sciatic notch than along the border of the obturator foramen.

Uniting with the ilium at its upper extremity and with the pubis on its anteromedial surface, the acetabular ramus contributes the posterior third of the acetabulum. In cross section the ramus is three-sided, presenting flattened anterolateral and posteromedial nonarticular surfaces and the concave articular surface of the acetabulum.

The acetabulum is formed by the fused acetabular rami of the ilium, ischium, and pubis. The latter bone is excluded from the articular surface, to which the ilium contributes the superior and lateral two-thirds and the ischium the posterior third. The deep cup-shaped acetabulum is slightly elongate in the anterolateral/posteromedial direction. The inner circumference of the acetabulum is interrupted by the medial acetabular fossa, which penetrates toward the center from the acetabular margin on the ischial surface. This nonarticular sulcus is marked by a shallow furrow bordering the iliac portion of the acetabulum. Another fossa, usually termed the external acetabular fossa, penetrates inward from the outer margin.

The long slender pubis of $G$. texanum occupies the lower position in its participation in the ischiopubic plate. From the acetabular ramus, the pubis initially extends downward and outward, situated in direct line with the medial border of the ilium. Distally the pubis curves toward the midline, in the subadult condition apparently uniting with its partner in a cartilaginous connection. The distal extremity is broken in the adult specimen (AMNH 10704), and the actual- ity of a midline fusion cannot be firmly established. Because of the close similarity with F:AM 95737 in the proximal portions of the pubis, it appears likely that there was indeed a complete pubic crossbar in adults. The pubis is divided into the acetabular ramus, the middle body or shaft, and the symphyseal ramus.

The acetabular ramus is an expansion that unites with the ilium and the ischium. From the acetabulum to the body of the pubis, the acetabular ramus is expanded transversely, and, to a lesser extent, anteroposteriorly for participation in the acetabulum, although it is excluded from the actual articular surface. The thin, compressed body forms the medioventral border of the obturator foramen. The symphyseal ramus in F:AM 95737 extends in a broad arc toward the midline of the body to meet its opposite. The symphyseal terminus of the pubis extends as a short, thin rod, the flattened rugose terminus indicating a cartilaginous continuation. This region is missing in the adult AMNH 10704, and a pubic crossbar is not included in the restoration. Because of its close similarity to the juvenile specimen, there is no reason to believe that the crossbar was absent. It is only missing from the specimen, and it is probable that it was simply a small, reduced bone (as in the younger individual) in the adult condition, fusing at the midline. A similar argument is advanced below for the pelves of $G$. floridanum and $G$. arizonae. The pubis of $G$. cylindricum is massive and unites at the midline in a strongly ankylosed contact.

In the region of ischiopubic fusion the pubis presents a flat posteromedially directed surface as a continuation of the anteromedial surface of the body. Beyond the region of the ischiopubic fusion the crossbar becomes roundcd.

Thus the pelves F:AM 95737 and AMNH 10704 arc qualitatively similar. As indicated in Table 38, quantitative measurements are remarkably close between these two specimens, the only important differences being in the smaller pubis in the younger individual - a distinction attributable to age. Moreover, these specimens more closely resemble each other, both qualitatively 
and quantitatively, than either resembles other specimens. It is partly on the basis of this comparison that these specimens, one from Texas, the other from Arizona, are referred to the same species, despite their geographic separation. These matters are discussed in greater detail elsewhere.

In addition to those dimensions presented in Table 38, several other potentially useful measurements for the type specimen (AMNH 10704) of $G$. texanum are: transverse diameter between anterosuperior angles of ischiac crests, measured in a straight line through neural arch, $500 \mathrm{~mm}$; transverse diameter between posterosuperior angles of ischiac crests, measured in a straight line, $360 \mathrm{~mm}$; transverse diameter sacrocaudal facet, $58 \mathrm{~mm}$; inferior-superior diameter, sacrocaudal facet, $39 \mathrm{~mm}$; approximate height (inferior-su-

$$
\begin{aligned}
& \text { G. arizonae } \\
& \text { G. cylindricum } \\
& \frac{190}{200}=0.86 \\
& \frac{160}{180}=
\end{aligned}
$$

perior diameter) iliac crest from posterior border of acetabulum, $300 \mathrm{~mm}$; transverse inside diameter between acetabula, $220 \mathrm{~mm}$. A notable characteristic is the posterior convergence of the ischiac crests, an important feature distinguishing $G$. texanum from $G$. arizonae and $G$. cylindricum, as discussed below and under "Systematics".

Pelvis of Glyptotherium arizonae (Table 38).The pelvis of $G$. arizonae is known from a single specimen only (AMNH 21808, Figure 48), collected from the type-locality for the species, Curtis Ranch, Arizona. The only mention of this important specimen in print was Gidley's (1926) remark that the pubes appeared to be reduced. The pelvis is partially fused to the carapace. The crests of both ischiac plates are missing, as are the distal extremities of the pubes. The number of vertebrae in the lumbar tube is indeterminate. There are three iliosacral vertebrae, an indeterminate number in the sacral arch, and either one or two ischiosacral vertebrae.

The transverse processes of the three iliosacral vertebrae are solidly fused with the ilium, as in $G$. texanum. The transverse processes of the penultimate sacral vertebra are broken. It cannot be determined whether these processes were free or laterally fused, either to the transverse processes of the last sacral, as in G. cylindricum, or directly to the ischium, as in $G$. texanum and $G$. floridanum. There is no obvious point of breakage on either the ischium or the last transverse process, suggesting that the penultimate vertebra did not participate in ischiac support.

The neural crests are very high, exceeding those of $G$. texanum by a factor of approximately 1.5 (attributable to allometric size differences; see Table 38) and approximating those of G. cylindricum. For comparison, height measurements at the anterior iliosacral vertebra, at the posterior iliosacral vertebra, at the midsacral arch, and at the ischiosacral vertebra for AMNH 21808 ( $G$. arizonae) and AMNH 15548 (G. cylindricum), respectively, are as follows:

$0.88 ; \quad \frac{120}{130}=0.92 ; \quad \frac{170}{150}=1.13$

Thus, the compound curvature of the sacral arch of $G$. arizonae, as reflected in these measurements, is less than in G. cylindricum, for which the sacral arch diminishes in height rearward more drastically.

Although the ischiac crests are broken away in AMNH 21808, they appear to be slightly convergent posteriorly but not as pronounced as in $G$. texanum. The transverse process of the ischiosacral vertebra is directed slightly rearward, so that a line connecting the angles formed by the ischium/ transverse process contact passes somewhat posterior to the caudal articular facet. This orientation is similar to that in G. texanum and distinct from that in $G$. cylindricum and $G$. floridanum.

The distal ends of the pubes are broken. Despite their reconstruction to the contrary, they were probably centrally united at the midline, as assumed for $G$. texanum. Indeed, the shafts of the pubes of this specimen are intermediate in size between those of AMNH 10704 ( $G$. texanum type) and AMNH 15548 (G. cylindricum type), as indicated in Table 38. Thus the fact that the pubes are even larger than in $G$. texanum, for which there is evidence of a crossbar, is indirect evidence that 


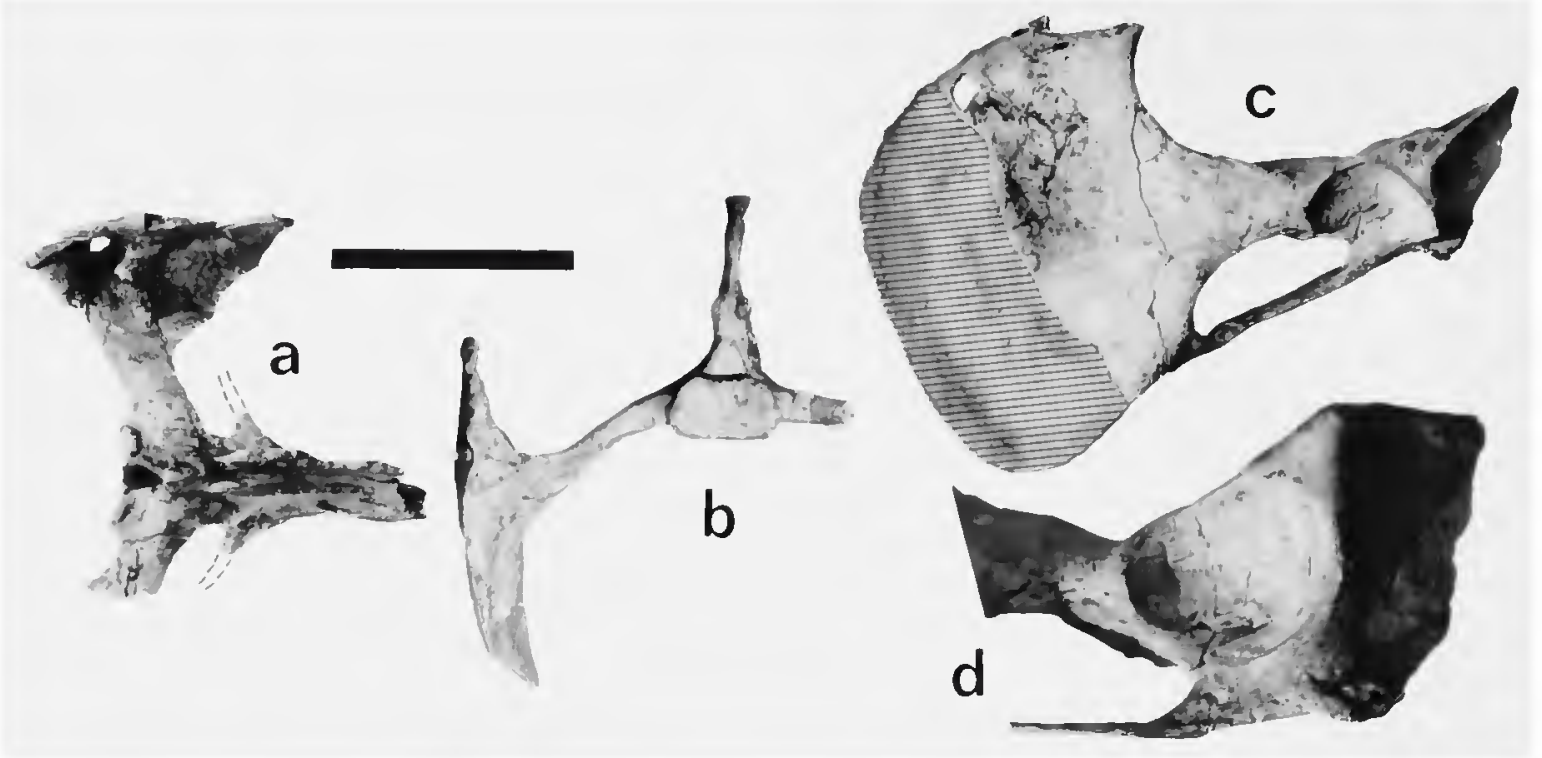

Figure 48.-Pelvis of Glyptotherium anzonae (AMNH 21808): $a$, posterior region showing sacral arch, including ischiosacral vertebrae and superior crest of ischium; $b$, same, posterior; $c$, acetabulum, ischiac plate, and pubis, ventrolateral; (reconstructed portions hatched) $d$, enlarged detail of acetabulum. (Bar $=20 \mathrm{~cm}$.)

G. arizonae possessed a crossbar also. In addition, the shape and contribution of the pubes more closely resemble those of $G$. cylindricum, adding further support for the assumption of a crossbar.

The anterior surface of the ilium is concave in the inferior-superior direction; transversely, it is deeply concave for the medial two-thirds, and the lateral third is strongly convex. There is a subdued, but nevertheless distinct, vertical ridge on the crest of the convex anterior surface, separating the inner concave region from the outer convex region. This ridge is not present on the available ilia of $G$. texanum. The posterior surface of the ilium is distinctive for its flat inner third; the outer two-thirds is concave, corresponding to the convexity of the anterior surface. These two regions are separated by a vertical crest, similar to the one on the anterior surface.

The articulation with the transverse process of the first caudal vertebra is formed by a deep concavity at the juncture of the transverse process with the ischium. This downward-directed concavity is formed by a posterior extension of the crest of the ischium, which "over-rides" the transverse process. It undoubtedly received the extremity of the transverse process of the first caudal vertebra. This participation by the first caudal vertebra in the sacrocaudal complex as a "pseudosacral" is the most highly developed among North American representatives.

Pelvis of Glyptotherium cylindricum (Table 38).The pelvis of the type specimen of $G$. cylindricum (AMNH 15548, Figure 49d) was originally described by Brown (1912). He accurately reported a vertebral count of seven (but there may be eight) vertebrae in the lumbar tube, four iliosacral vertebrae, three free vertebrae in the sacral arch, and two ischiosacral vertebrac; total 16 (possibly 17) vertebrae in the pelvis. The number of iliosacral vertebrae is indicated by the presence of four stout transverse processes on the inferior arch, which are solidly fused with the ilia.

The transverse processes of the two ischiosacral vertebrae are fused into a single shaft midway between the ischia and the centra. The transverse processes of the anterior ischiosacral vertebra (i.e., 
penultimate sacral vertebra) are slender in comparison with the posterior transverse processes. The transverse processes of the terminal vertebra are massive; they are directed laterally and slightly downward from the centra, as in other representatives. Their rearward extension lies only slightly posterior to the plane of the sacrocaudal articular facet. This orientation is intermediate between the greater posterior component of $G$. texanum and $G$. arizonae and the perpendicular orientation in $G$. floridanum.

As Brown noted, the compound curve of the neural spines of the sacral arch decreases rearward with respect to the centra. The heights of anterior neural spines measured from the lower margin of the centrum are as follows: ischiosacral spine, $150 \mathrm{~mm}$; midsacral arch, $130 \mathrm{~mm}$; posterior iliosacral spine, $180 \mathrm{~mm}$; anterior iliosacral spine, $220 \mathrm{~mm}$. Thus the height of the anterior neural spines is greater than the minimum height at midsacral arch by a factor of 1.5, rather than a factor of 2 as stated by Brown (1912); and the anterior height is greater than that of the ischiosacral vertebra by a factor of approximately 1.3.

As Brown (1912) indicated, the pubis is massive in comparison with the other North American representatives. It is solidly fused at the symphysis, where its cross-sectional shape is elliptical. Anteroposterior and dorsoventral dimensions at the pubic symphysis are 29 and $38 \mathrm{~mm}$, respectively. These dimensions are significantly greater than those of the pubic shafts (Table 38), which, although considerably larger than those of the other specimens, are not as different as Brown (1912) inferred. Brown considered the nature of the pubes as one of the principal distinguishing features of this specimen for his proposed taxonomy. He was apparently correct in assuming that this construction of the pubes is taxonomically significant, but similarities of the remaining skeletal elements to other North American species indicate a much closer relationship than the familial separation that Brown proposed.

The ilia differ slightly from those known for $G$. arizonae in being more deeply.concave on the anterior surface and rather flattened on the pos- terior surface. The crests of the ischia are parallel, as in $G$. floridanum and in contrast to $G$. texanum and $G$. arizonae.

Only the fused centra, numbering seven or eight, are present. The neural spines are broken away, so that it cannot be determined whether the spines were fused with the carapace. The undersurface of the scutes along the arch of the carapace exhibits somewhat more rugosity than the adjoining scutes, but there is no indication of ankylosis with the lumbar tube. The connection was probably ligamental.

There are prominent articular facets at the angles formed by the transverse processes of the ischiosacral vertebra and the ischiac plate for reception of the transverse processes of the first caudal vertebra. These facets are oval and weakly concave and are directed inward and rearward.

In summary for $G$. cylindricum, the pelvis is distinctive in possessing four iliosacral vertebrae, in the massive pubes with a strong crossbar, and the flattened posterior surface of the ilium. Its remaining characteristics are variously similar to those of the remaining North American species, notably in the orientation of the ischiac crests, the orientation of the transverse process of the terminal sacral vertebra, the height and curvature of the neural spines, the fusion of the transverse processes of the ischiosacral vertebrae with each other, and the general overall construction.

Pelvis of Glyptotherium floridanum (Table 38). The pelvis of $G$. floridanum is known from several specimens, including a nearly complete one from the Texas Ingleside locality (TMM 30967-1926, Figure $49 a, b, c)$, which was described by Lundelius (1972); fragmentary remains from Hunt County, Texas (USNM 6071), which were described by Hay (1916); and undescribed remains, comprising a nearly complete composite pelvis, from the Catalina Gardens locality in Florida (UF/FGS 6643). These remains allow positive comparison between the Texas and Florida representatives, in part forming the basis for establishing the taxonomic identity of these two populations. Unfortunately, no pelvic remains are associated with the type specimen. 


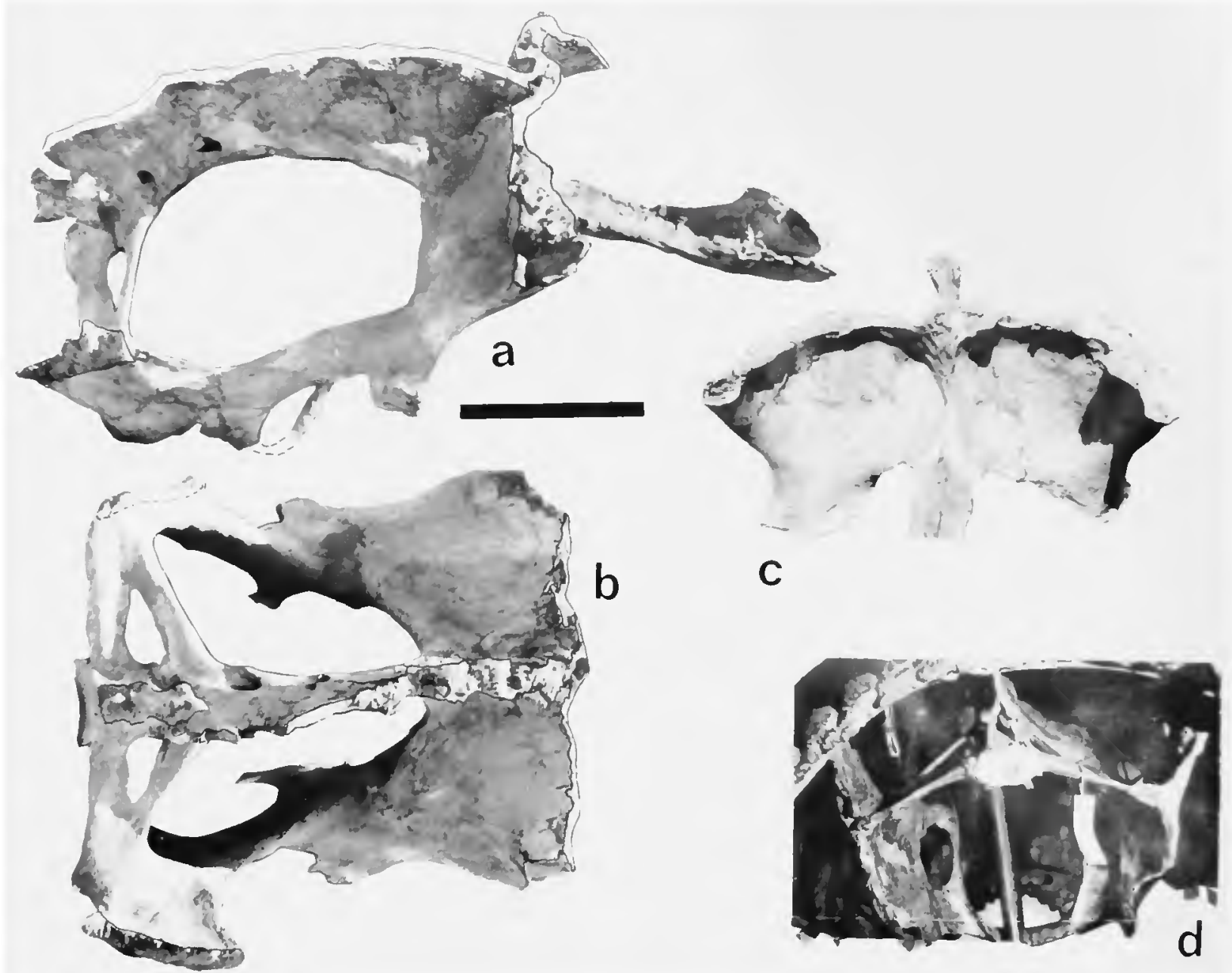

FIGURE 49.-Pelvis of Glyptotherium floridanum (TMM 30967-1926): a, dorsolateral, including lumbar tube; $b$, dorsal; $c$, anterior of ilia; $d$, posterior aspect of pelvis of Glyptotherium cr/tundricum $(\mathrm{AMNH} 15548) .(\mathrm{Bar}=20 \mathrm{~cm}$.)

The lumbar tube, as preserved in the Ingleside specimen, indicates no appreciable difference from that known for the other species. Because it is nearly complete, however, it adds to the knowledge of this element in several regards. The paired haemal arches are serially fused, forming a continuous haemal concavity from approximately the midposition of the tube rearward. The dorsal spines, although broken, are thin and solidly fused. The centra of the lumbar tube are fused into a straight, unarched unit.

There are three iliosacral vertebrae in the Flor- ida specimen; the number of iliosacrals is indeterminate for the Ingleside specimen. The construction of this region in the latter, however, closely resembles that of the Florida pelvis, rather than the region of the four iliosacral vertebrae in G. cylindricum, so it is likely that there are only three in TMM 30967-1926. In both the Florida and Texas specimens, this region otherwise presents no outstanding features.

Only a fragment of the sacral arch of USNM 6071 is preserved. Hay (1916) stated that this fragment represents the fourth and fifth sacral 
vertebrae, which is a reasonable identification. Complete sacral arches are present for both TMM 30967-1926 and UF/FGS 6643. In the former specimen, the number of free vertebrae in the sacral arch is obscured by the high degree of fusion. There are at least three free sacrals, and probably four, in the Florida pelvis.

Ischiosacral vertebrae are preserved for all three representatives, although they are complete only in TMM 30967-1926. In this specimen the last two sacral vertebrae participate in ischiac support by their transverse processes. The processes of the terminal vertebra are much larger than those of the penultimate vertebra. The processes are fused to each other from slightly beyond their midpoint, as in $G$. cylindricum. The antepenultimate centrum in the Ingleside specimen possesses transverse processes that overlap the anterolateral angles of the centrum of the first ischiosacral vertebra. These are fused with the centrum, although this fusion appears to have occurred at a relatively late age. The centra of the two ischiosacral vertebrae are incompletely fused, similarly exhibiting a relatively late fusion.

The transverse processes of the anterior ischiosacral vertebra of UF/FGS 6643 are broken. They are relatively small, as in the Ingleside specimen, and their proximal orientation is similar, indicating that they fused with the posterior transverse process before contacting the ischium.

The last sacral vertebra (presumably sacral vertebra 8 , as identified by Hay, 1916) of USNM 6071 is preserved as a separate element of the sacrolumbar series. The region on this specimen that Hay (1916) identified as "the hinder part of the seventh sacral" is actually the anterior part of the last centrum, for which the dorsal arches are broken. The lateral extremities of the transverse processes of the penultimate (seventh) sacral vertebra are present as fused additions to the larger transverse processes of the terminal vertebra. Thus, in USNM 6071, as in TMM 30967-1926 and as inferred for UF/FGS 6643, the transverse processes of the two ischiosacral vertebrae are fused from their midpoints outward.

Another characteristic of the ischiosacral ver- tebrae indicating the close relationship between these three specimens is the perpendicular orientation of the transverse processes. Thus the ischiosacral vertebrae of $G$. floridanum are similar to those of $G$. cylindricum in the midpoint fusion of the transverse processes and their perpendicular orientation.

The anterior surface of the ilium of G. floridanum, as indicated by both the Florida and Ingleside specimens, is distinctive in being almost uniformly concave in the transverse direction, rather than concavoconvex as in the other species. The only convexity occurs near the lateral margin, where the body is rounded and thickened. There is otherwise no lateral convexity on the anterior surface. The posterior surface is weakly convex to nearly flat, with only a slight medial concavity.

The crest of the ischium is missing for the Florida specimen; the ischium of the Ingleside representative is complete. The crests of the ischia are strongly convergent posteriorly. The ischium otherwise exhibits no peculiarities affording distinction from that of the other species.

Lundelius (1972) suggested that the reduced pubes of TMM 30967-1926, for which the distal extremities are not preserved, probably indicate that there was no crossbar in this specimen. Although the distal extremity of the pubis of the Florida specimen is also missing, enough is present to indicate the likelihood of a crossbar. The shaft of this pubis is preserved, including the entire region of fusion with the ischium. It is broken beyond the ischiac contact; the breakage indicates that the pubes extended medially, maintaining approximately the same thickness toward the midline. Whether there was actual fusion or a persistent cartilaginous or ligamentous connection cannot be determined, but at least some connection is certain, for it is unlikely that the pubes would extend medially and terminate as blunt processes without distal support or connection. The similarity of the Ingleside pubes with those of the Florida representative suggests that there was indeed a crossbar, the relatively reduced size of the pubes notwithstanding. 


\section{Hind LimB}

The bones of the hind limb of Glyptotherium are notable for their even more massive construction in comparison with their counterparts in the front limb. The femoral length exceeds that of the humerus by a factor of approximately 1.25. The tibiofibula is a single fused element, and although only approximately half the length of the femur, it is a massive bone reflecting the graviportal nature of the rear leg. The tarsals and metatarsals are large and extremely compressed, unlike those of any other mammal. There are five symmetrically disposed, complete digits on the hind foot.

As in the front limb, there is a full battery of digital sesamoids, and there is no indication of fusion or loss of individual bones. The patella is so constructed as to form a "patellar lock" allowing full extension at the femoral-tibial joint in the "resting" (probably related to feeding habits, i.e., grazing or browsing) position.

Although the hind limb of South American glyptodonts is fairly well known, there have been few comprehensive accounts other than Burmeister's (1874). As for the front limb, the hind limb of Glyptotherium compares closely with that of the South American Glyptodon, in the classic sense.

Femur (Table 39).- The femur of $G$. texanum (Figure 50) is distinctive for its almost perfectly straight, columnar construction. In block proportions it is a rectangular prism, the transverse breadth somewhat greater than half the length. The massive greater trochanter extends proximally as far as the head in this species, and in gross proportions it is approximately equal in size. The trochanteric fossa is shallow and smooth. The short neck is unconstricted in the transverse plane and only slightly constricted in the anteroposterior plane.

The underdeveloped lesser tuberosity extends as a rugose surface from the medial side of the head to midshaft, occupying the proximal half of the medial angle. A trochanteric ridge on the posteroproximal surface of the shaft is wanting. The proximal two-thirds of the posterior surface of the shaft is distinctly flattened; the distal third is gently rounded on the medial side and slightly concave on the expansion for the lateral epicondyle. The anterior surface of the shaft is irregularly rounded in cross section. In sagittal section the anteroproximal surface is weakly concave, expanding in thickness toward the head and the greater trochanter; the middle third is flattened; and the distal third is gently concave, expanding toward the trochlea and the lateral epicondyle. In anterior aspect, the narrowest constriction of the shaft occurs near the middle, with marked expansion toward the extremities. The expansion of the shaft for the lateral supracondylar crest presents a broad transverse inflection on the anterior surface.

The central longitudinal axis (sagittal plane) of the femur passes through the trochanteric fossa, centrally through the narrowest constriction at midshaft, and emerges in the plane passing through the lateral ridge of the distal trochlea. The massive lateral supracondylar crest is heavily rugose and presents a deeply pitted and flattened lateral surface. It occupies the entire distal third of the lateral angle of the shaft as a continuation of the obliquely oriented lateral epicondyle. The medial epicondyle is represented by an inconspicuous tuberosity on the medial angle.

The distal articular surfaces are represented by the trochlea and the medial and lateral condyles. The trochlea is situated medially with respect to the long axis of the femur. Although the angle of the medial ridge is broken away, the trochlea appears to have been approximately symmetrical, with the anteroposterior extent of the lateral ridge slightly greater than that of the medial ridge. The trochlea is notable for its relatively short anteroposterior diameter.

The obliquity of the distal articulation is accentuated by the tremendous difference in size between the condyles: the medial condyle is at least twice as large as the lateral one. The medial condyle is round in medial aspect, extending from a relatively flat surface at the distal extremity to assumc a posterior and somewhat proximal orientation at its upper extremity. It is markedly elongate in the plane of articulation. The smaller 


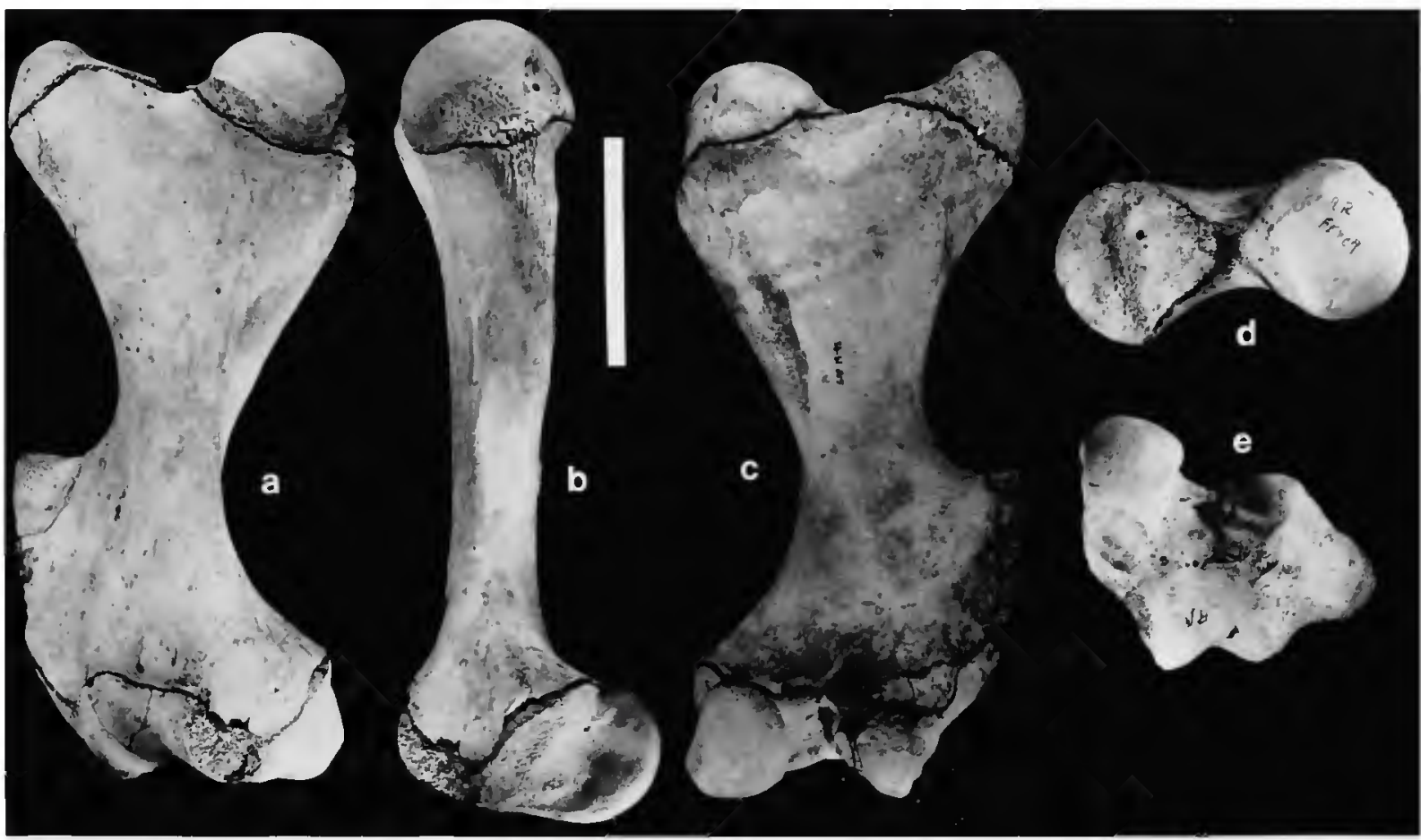

Figure 50.-Femur of Glyplotherium texanum (F:AM 95737): $a$, anterior; $b$, medial; $c$, posterior; $d$, proximal extremity; $e$, distal extremity. (Bar $=10 \mathrm{~cm}$.)

lateral condyle is separated from the medial condyle by a deeply excavated intercondyloid fossa. The lateral condyle is convex, and its boundaries are approximately triangular in shape.

The femora of $G$. arizonae and $G$. floridanum differ in minor details, mostly related to size differences. Although future recoveries will perhaps fill in the existing gaps, the femora of these two species are sufficiently distinct to allow separate comparisons with $G$. texanum, and with each other, as follows.

Melton (1964) noted the excessive length of the femur of UMMP 46231, implying taxonomic distinction from the Curtis Ranch glyptodont. As indicated under "Systematics," however, the dimensions of this specimen are not significantly different from those of USNM 10536 and AMNH 21808. Despite the small sample size, however, the three femora known from the Seymour fauna indicate a slightly greater size than the two known from the Curtis Ranch fauna (USNM 10536 and
AMNH 21808). This larger size in the Seymour representatives might indicate an actual size difference between the two populations of $G$. arizonae, or it might be variation attributable to the small sample size. Because these differences seem to indicate a continuum, rather than a well-marked separation, there is no foundation in these small samples for taxonomic distinction between these two populations.

On the other hand, the obvious size difference between these femora and the ones known for $G$. texanum is substantial. The femur of $G$. arizonae (Figure $51 a, b$ ), in addition to its larger size, differs from $G$. texanum in a number of relatively minor features. The plane of elongation of the head of the femur in G. arizonae is oriented approximately perpendicular to the transverse axis of the proximal extremity. If projected, this plane intersects the distal extremity through the medial facet of the trochlea approximately through its plane of elongation. In contrast, the plane of elongation of 

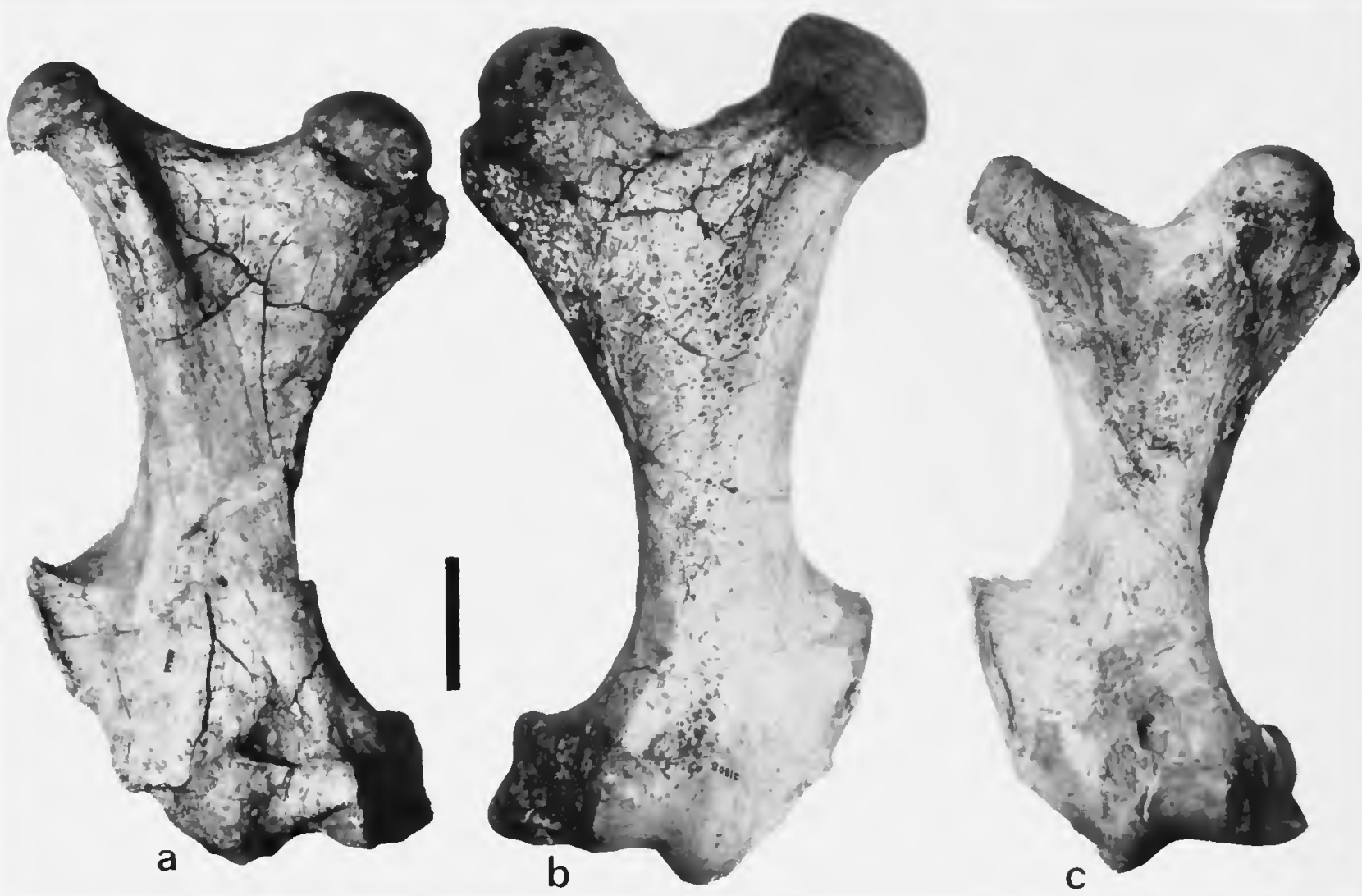

Figure 51.-Femur: $a$, right, Giyptotherium anzonae from Curtis Ranch, Arizona (USNM 10536), anterior; $b$, left, $G$. arizonae (AMNH 21808) from same locality, anterior (greater trochanter restored): $c$, right, G. Rondanum (USNM 6071), anterior. (Bar $=80 \mathrm{~mm}$.)

the femoral head in $G$. texanum is oblique with respect to the transverse axis of the proximal extremity, and in projection, this plane intersects the medial condyle in an oblique angle with respect to its plane of elongation. Moreover, the femoral head in $G$. arizonae is situated on a definite neck, which exhibits a greater degree of expansion from the shaft, especially on the anterior surface.

Another distinction of $G$. arizonae is the massive development of the greater trochanter. It cxhibits a relatively greater expansion from the shaft than does that of $G$. texanum, and it is elevated somewhat beyond the level of the head. Pronounced anterolateral and proximal crests of the greatcr trochanter are separated by a distinct concavity, whereas this region in $G$. texanum presents a uniformly convex surface, without noticeable development of these crests.
Remaining distinctions between the femora of $G$. texanum and $G$. arizonae are attributable to size and age differences in the available specimens. For example, there is a deeply excavated triangular supratrochlear fossa in the $G$. arizonae adult specimens; this region is unexcavated in the juvenile (F:AM 95737) representative of $G$. texanum.

The femur of $G$. floridanum (Figure 51c), represented by a complete specimen from Hunt County, Texas, and a portion of the femoral head from the Catalina Gardens, Florida locality (UF/ FGS 6643), is somewhat intermediate with respect to the femora described above. It is smaller than those known for $G$. arizonae and larger than the ones known for $G$. texanum. The construction of the proximal extremity is similar to that of $G$. texanum, although the head is more elongate in the Catalina Gardens specimen. Similarly, there 
is no development of the anterolateral and proximal crests of the greater trochanter, as in $G$. texanum, and in contrast with $G$. arizonae.

There is a shallow supratrochlear fossa in $G$. floridanum. A single feature distinguishing the femur of this species is the construction of the proximolateral surface of the shaft, which expands for the greater trochanter. Whereas in $G$. arizonae and $G$. texanum there is a distinct crest demarcating the anterior and lateral surfaces, this region is broadly rounded and convex in $G$. floridanum. Furthermore, this region is distinctly rugose, including the anteriorly oriented region that replaces the lateral crest.

In summary for the femur, there are only minor differences among the three North American species for which it is known. The distinctions are likely attributable more to ontogenetic variation than is here recognized and, accordingly, should not receive significant taxonomic consideration, despite others' (e.g. Hay, 1916; Melton, 1964) opinions to the contrary.

Patella (Table 40).- The patella of Glyptotherium (Figure 52) is known for three species, including the juvenile specimen of $G$. texanum $(F$ : AM 95737) and adult specimens of $G$. arizonae (USNM 10536) and $G$. floridanum (USNM 6071). Except for size differences the patella is identical for all three species.

The patella is elongate in the proximodistal plane. In transverse section the outline describes a broad sector of a circle, with the apex situated at the central crest of the articular facet. The proximodistal diameter is the longest; the transverse diameter is intermediate; and the anteroposterior diameter (craniocaudal diameter) is the

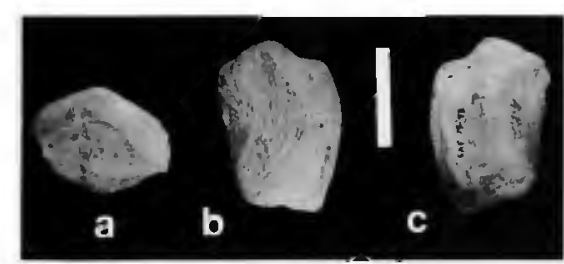

Figure 52.-Patella of Glyptotherium texanum (F:AM 95737): $a$, proximal extremity; $b$, outer surface; $c$, inner surface. (Bar $=40 \mathrm{~mm}$.) shortest. The latter dimension is greatest near the proximal border, and least at the distal extremity.

The striated outer (cranial) nonarticular surface is roughly cylindrical in shape, with the lateral region somewhat flattened, especially near the proximal extremity. In the proximocentral position there is a distinct tuberosity for insertion of the quadriceps musculature.

The articular facet is confined to the posterior (caudal) surface. It is separated from the striated and rugose anterior surface by a distinct nonarticular and nonrugose depressed region circumscribing the articular surface and bearing vascular foramina of variable size. The articular facet conforms loosely to the trochlea of the femur, articulating with it tangentially. A rounded, central crest, directed proximodistally, separates the flattened medial region of the facet from the concave lateral portion. The proximolateral and distomedial borders extend as flared, concave surfaces to form the proximal and distal extremities of the facet, respectively, imparting a distinct asymmetrical shape to the articular surface.

The blunt distal apex fits loosely over the anteroproximal surface of the tibiofibula in extension. Hyperextension is prevented partly by the patella, which by the flared proximolateral surface forms a "stopping" device or "patellar lock" at the position of near-maximum extension (i.e., the femoral-tibial contact is straight at maximum extension and allows a resting position for this articulation in the erect, standing posture).

The patellae of $G$. arizonae and $G$. texanum are identical in all features except for size. The patella of $G$. floridanum (USNM 6071) differs in possessing more deeply grooved striae on the cranial surface, especially on the distal half of the bone. The articular facet is relatively broader and more nearly rectangular, the proximolateral and distomedial flared extensions projecting less than in the other two species. The articular surface of the patella of $G$. floridanum is flattened; the transverse concavities are not as deeply excavated as in $G$. texanum and $G$. arizonae.

Trbiofibula (Table 41). - The tibia and fibula are ankylosed into a single, stout element, typical of glyptodonts. As a unit the tibiofibula is a 
cylindrical body, its length approximately half that of the femur. The length of the "cylinder" is somewhat less than twice the diameter at either extremity. The proximal and distal extremities are nearly equal in outside dimensions, and they are only moderately expanded beyond the diameter of the "shaft" of the tibiofibular cylinder. The shaft obtains a narrow anterior aperture formed by the interosseous space that expands posteriorly. The tibial shaft is more massive than the fibular shaft, although the latter was important in weight support.

The separate identities of the proximal and distal epiphyseal plates are lost in the subadult stage, with the tibial and fibular epiphyses fused with each other but not with the diaphyses. In this young condition, the diaphyses are not in proximal contact, the complete bridge being formed by the epiphysis. Examination of the tibiofibulae of older individuals reveals that there is little, if any, subsequent fusion of the proximal extremities of the diaphyses with advancing age.

In $G$. texanum (Figure 53) the proximal extremity is divided into tibial and fibular articular facets by a distinct nonarticular intercondyloid fossa. The tibial facet, for reception of the medial condyle of the femur, covers approximately twice the surface area of the fibular facet. Except for a weakly convex anterior margin, the tibial facet is uniformly concave. The facet is situated in a posterior position, flaring weakly beyond the extent of the shaft on the posterior and medial margins.

The entire anterior region of the proximal epiphysis is nonarticular. The caudal and cranial intercondylar fossae are contiguous as a single obliquely directed sulcus. The anterior terminus of the intercondylar sulcus intersects with the more vertically oriented tibial tuberosity, representing the most distal extension of the epiphysis. The tibial tuberosity overlies the anterolateral extremity of the proximal end of the tibial shaft.

The fibular facet, which receives the lateral condyle of the femur, presents the shape of an equilateral triangle in proximal aspect, with apices at the anterior, posteromedial, and posterolateral positions. The facet is saddle-shaped, anteroposteriorly convex, and transversely concave. The medial extremity of the facet forms a prominent intercondyloid eminence, situated on the border of the facet with the intercondylar sulcus. A smaller intercondylar eminence is situated on the anterolateral margin of the tibial facet, anterior and slightly medial to the larger fibular eminence.

The shaft of the tibia is transversely compressed, and it is considerably deeper in the anteroposterior direction at the proximal end than at the distal terminus of the shaft. The tibial crest

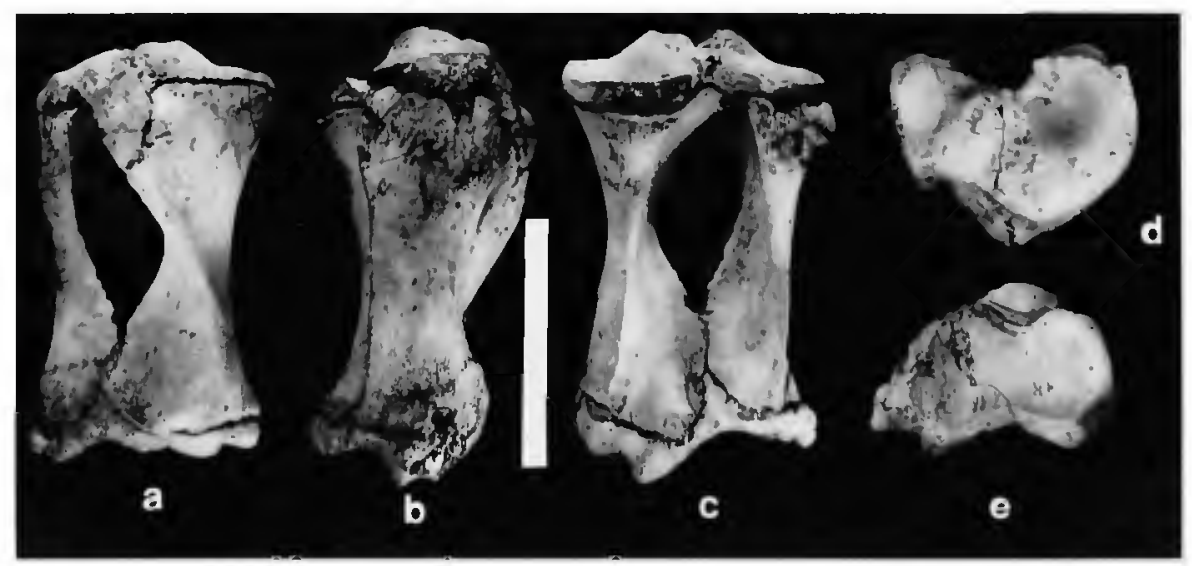

FIGURE 53.-Right tibiofibula of Glyplotherium texanum (F:AM 95737): $a$, anterior; $b$, lateral; $c$, posterior; $d$, proximal exiremity; $\ell$, distal extremity. $(B a r=10 \mathrm{~cm}$.) 
extends obliquely from its anteroproximal confluence with the tibial tuberosity to a distomedial position on the anterior surface of the shaft. The minimum transverse diameter occurs at approximately midshaft. The medial surface (i.e., outside surface) is broadly convex at its proximal extremity, becoming flattened at midshaft and remaining flat to the constricted distal extremity. The lateral surface (i.e., interosseous surface) of the shaft is uniformly concave in the proximodistal plane and irregularly concave in cross section. The cross section of the distal extremity is approximately triangular, with apices formed anteromedially by the tibial crest, posteriorly by the vertical posterior crest of the shaft, and anterolaterally by the fibular process. The fibular process of the tibia extends from midshaft to fuse with the corresponding tibial process of the fibula at the distal extremity. The anterior surfaces of these processes are confluent, together forming the expansive attachment surface for the massive tibialis musculature for lateral rotation and flexion of the tarsus.

The shaft of the fibula, although somewhat less massive than the tibial shaft, is nevertheless a well developed and integral part of the tibiofibula. Like the shaft of the tibia, this bone is markedly compressed in the transverse direction. There is little expansion at the proximal extremity, where the shaft contacts the epiphysis. A lateral tuberosity is situated on the proximal third of the shaft. The tibial process is the distal extension of the nearly straight anterior fibular crest and the medial expansion of the distal extremity of the shaft. As described above, this anterior surface of the shaft is confluent with the corresponding surface of the tibia, forming the distinctive muscular groove. The posterior crest of the fibular shaft is gently sigmoid in posterior aspect. The medial surface (interosseous surface) of the fibular shaft is anteriorly concave and posteriorly convex. The lateral surface (outside surface of the tibiofibula) of the shaft is somewhat flattened at its proximal end, strongly convex at midshaft, and divided into flat lateral and anterior surfaces at the distal extremity by the lateral malleolus. The distal extremity of the fibular shaft is distinctly expanded for fusion with the distal epiphysis and with the fibular process of the tibia.

The distal epiphysis is subequally divided into tibial and fibular portions with indistinct boundaries. Unlike its proximal counterpart, the distal epiphysis does not contact the diaphyses of the tibia and fibula as a discoid surface of fusion. Instead, the shape of the epiphyseal plate reflects approximately the sculpturing of the articular facets. The medial malleolus of the tibiofibula occupies the entire medial surface of the epiphysis and extends proximally onto the distolateral surface of the tibia. A prominent posterior malleolus is situated in direct line with the shaft of the tibia. This posterior tuberosity is separated from the medial malleolus by an obliquely oriented sulcus, extending from the lateral (interosseous) surface of the tibial shaft, downward over the posteromedial surface of the epiphysis, as a small muscular groove.

The lateral malleolus forms a somewhat more rugose prominence, located on the anterolateral surface of the epiphysis and extending proximally to form the distolateral angle of the fibular shaft.

The articular facet receives the trochlear facet of the astragalus. The shape of the distal articular facet in distal aspect is that of an hourglass, with a somewhat greater anterolateral expanse of the fibular portion. The facet is comprised of two parallel grooves, the smaller tibial (medial) groove and the larger and deeper fibular (lateral) groove. The fibular groove is deeper and its transverse concavity is rather more pronounced. The rotational axes of these facets are parallel, and the rotational motion imparted to the astragalus is obliquely oriented, anteromedial to posterolateral. Surrounding the entire articular facet, except for the medial malleolus groove, is a continuous rugose nonarticular border, encasing the articular facet on the margin.

The only known tibiofibula of a full adult individual of $G$. texanum (JWT 1723), from the Cita Canyon fauna, is smaller than those known for $G$. floridanum and $G$. arizonae.

The tibiofibula of $G$. arizonae (Figure 54) is 


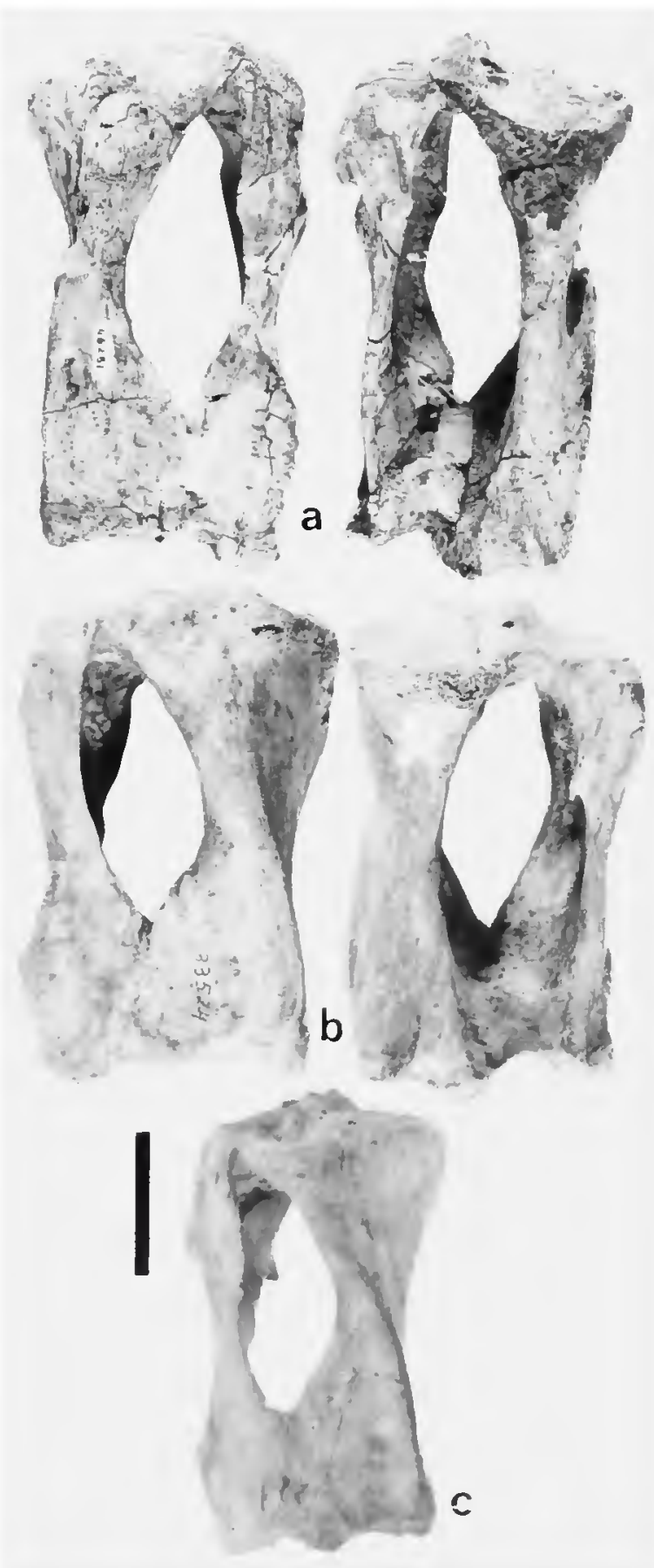

Figure 54.-Tibiofibula of 3 representalives of Glyptotherium arizonae, showing intraspecific variation: $a$, left tibiofibula with long and slender proportions (UMMP 46231) from the Gilliland local fauna, Seymour Formation, Texas: $b$, right tibiofibula with short and robust proportions (UMMP known from several specimens. Melton (1964) noted the somewhat greater lengths of the tibiofibulae of the Seymour glyptodonts in comparison with the Curtis Ranch specimen. (Specimens 46231 and 33524 in Melton's (1964) table III should be reversed so as to be placed above their proper measurements.) In actuality, there is overlap in these measurements when taken between articular surfaces rather than including the proximal and distal tuberosities.

The tibiofibula of $G$. arizonae differs from that of $G$. texanum primarily in features related to the size. Muscle attachment surfaces are distinctly more prominent and rugose. The tibial tuberosity and the malleoli are heavily rugose, the malleolar groove is more sharply defined, and the articular facets are deep and well defined. The interosseous surfaces of the tibial and fibular shafts bear a number of prominent ridges and grooves, and the bone is deeply pitted and rugose. A feature on USNM 10536 related to the exaggeration of the malleoli is a peculiar scoop-shaped sulcus issuing from the lateral tuberosity of the fibula on the proximoposterior surface of the shaft. This obliquely oriented sulcus is formed by the flared transverse expansion of the bone surrounding the origin surface for $m$. flexor digitalis longus in this position. From this origin, the muscle passed obliquely downward over the malleolar groove of the posterodistal surface of the tibia.

A distinction of the tibiofibula of $G$. arizonae not related to age or size is the presence in USNM 10536 of a pair of deep excavations situated between the lateral margin of the distal articular facet and the flattened distal surface of the lateral malleolus. Both are subrectangular in shape, and the posterior one is the larger. They penetrate obliquely into the lateral malleolus, and they are separated by a bony strut connecting the lateral malleolus and the margin of the distal facet.

33524 ), also from the Gilliland local fauna; $c$, right tibiofibula with proportions similar to $a$, but of slightly shorter total length, from the Curtis Ranch local fauna, Arizona (USNM 10536); left, anterior and risht, posterior aspects in $a$ and $b ; c$ is anterior. (Bar $=40 \mathrm{~mm}$.) 
The four available tibiofibulae of $G$. arizonae are variable in the orientation of the muscular groove. In UMMP 46232 and USNM 10536 the muscular groove is less obliquely disposed than in UMMP 46231 and UMMP 33524. Apparently the more slender proportions and the lesser obliquity of the muscular groove are correlative, perhaps indicating sexual dimorphism. The fifth tibiofibula, MU 2670, is not sufficiently complete to provide an adequate comparison.

The tibiofibula of $G$. floridanum (Figure 55) is known from only two specimens, both from Texas (TMM 31141-19 and USNM 6071). These two bones closely resemble the slender pair of $G$. arizonae tibiofibulae discussed above. They are slender and their muscular groove is less oblique than in the more robust specimens. Distinctive features of $G$. floridanum occur in the articular facets. The tibial (medial) portion of the proximal facet is somewhat elongate in the anteroposterior plane, rather than being a nearly circular depression as in $G$. arizonae and $G$. texanum. The distinctive distal articular facet is more asymmetrical at the central constriction between the medial and lateral facets.

Tarsal Series. - The tarsal series (Figures 56 62; and in articulation, Figures 74, 75) consists of seven separate elements: the proximally situated calcaneum and astragalus; the intermediate na-

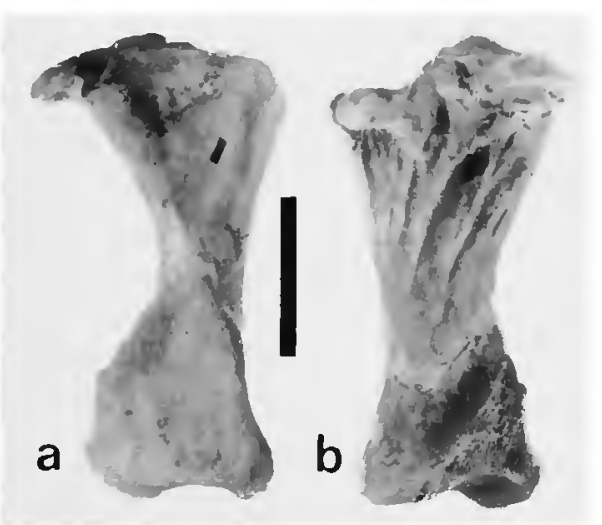

FIgURE 55.-Right fragmentary tibiofibula of Glyptotherium floridanum (USNM 6071): $a$, anterior, with most of fibular portion broken away; $b$, medial (inner surface) of tibia. (Bar $=40 \mathrm{~mm}$.) vicular and cuboid; and distally, the three cuneiforms. Articulation of the tarsus is a complex system of buttress and support.

The proximal trochlear facet of the astragalus is the primary fore-and-aft articulation of the tarsus. The torsion produced by the outward rotation of the tibiofibula at this joint is succeeded by an additional displacement of the rotational axis at the astragalus-navicular joint. The latter joint completes the serial torsion of the axes of rotation of the rear leg, resulting in a nearly transverse rotation at this intertarsal joint, the most distal primary articulation of the rear leg.

The astragalar-calcaneum articulation is a rotational buttress in the dorsoventral plane, supporting the transversely directed astragalar-navicular articulation. The latter joint is the major intertarsal articulation for weight transfer. An additional, but restricted, articulation in weight transfer is accomplished through the calcanealcuboid joint. The three complete and separate cuneiforms are tightly situated beneath the compressed and greatly expanded navicular. The laterally situated cuboid lies adjacent to the ectocuneiform and navicular, equaling their proximodistal thickness. Thus the distal extension of the cuboid occupies a lateral position equivalent to that of the cuneiforms; i.e., it functions as a separate fourth "distal" tarsal. The distal tarsals (cuneiforms and cuboid) form a tightly arranged series of functionally immobile elements of the tarsus. The flattened distal articular facets of the distal tarsals provide little rotational mobility at the tarsus-metatarsus joints.

Astragalus (Table 42). - The astragalus presents a trochlear facet on the proximal and anterior surface for articulation with the tibiofibula, two posterior articular facets for the calcaneum, and an anterodistal articular facet for the navicular. The tibiofibular/astragalus articulation is directed obliquely with respect to the sagittal plane of the proximal articular facet of the tibiofibula. This obliquity, measuring approximately $30^{\circ}$ inward, is imparted mainly by the torsion of the tibiofibula.

In the astragalus of $G$. texanum (Figure 56), the 


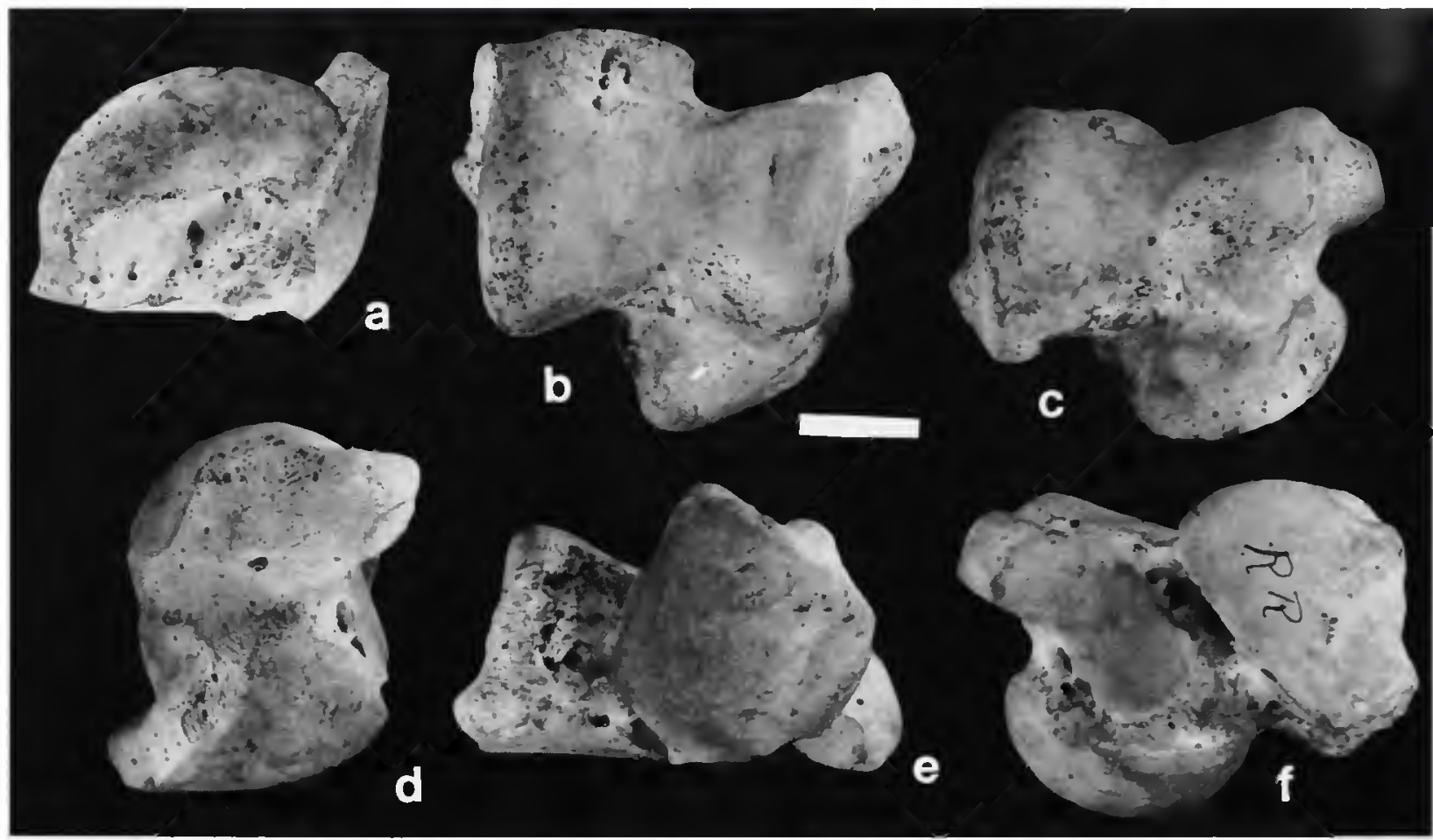

Figure 56.-Right astragalus of Glyptotherium texanum (F:AM 95737): $a$, medial; $b$, proximal; $c$. anteroproximal; $d$, lateral; $e$, distal; $f$, posterior. (Bar $=20 \mathrm{~mm}$.)

lateral (fibular) rocker of the trochlear facet is somewhat larger and more elevated than the medial (tibial) rocker. In anterior profile, the lateral rocker is more deeply convex than the medial, and the trough of the trochlea is situated closer to the lateral rocker. Thus the concavity of the anterior profile of the trochlea is asymmetrical, somewhat steeper on the lateral side than on the medial. This configuration conforms to the deeper fibular facet, and the shallower tibial facet of the distal articulation of the tibiofibula. In addition, the lateral (fibular) rocker of the astragalus covers a longer chord, although the radius of curvature of each rocker is approximately equal. The chord of the lateral rocker traverses nearly a semicircle, the main addition relative to the opposing rocker being in the anterior extent. The medial (tibial) rocker is bordered on its posteromedial corner by a pronounced eminence, the medial calcaneal tuberosity, and on its anterior border by a sulcus separating the articular surface from the navicular tuberosity.

The posterior surface bears two facets for articulation with the calcaneum. The lateral calcaneal facet is flat and irregular in outline, suggesting a distorted ovoid shape, with the blunt end of the oval dirceted upward. This facet occupies the entire lateral half of the posterior surface of the astragalus. It is separated from the medial calcaneal facet by a decp, obliquely directed, interarticular fossa. A small, laterally directed eminence, the lateral calcaneal tuberosity, projects from the anterolateral border of this facet, beyond the vertical plane of the lateral surface of the fibular (lateral) rocker of the trochlea.

The medial calcaneal articular facet (sustentacular facet) is subrectangular in outline, nearly twice as long as wide. The long axis is situated obliquely, in the distolateral/proximomedial plane. The distal half of this facet is flat, its 
surface lying in a plane, which is oblique with respect to the adjacent lateral calcaneal facet, and directed slightly proximally and medially away from it. The proximal half of the sustentacular facet is concave, flaring upward to terminate immediately beneath the medial calcaneal tuberosity. This facet is uniformly flat in its transverse plane (short axis of the rectangular outline).

The facet for articulation with the navicular occupies most of the distal extremity, as an anterodistal condyloid surface projecting from a short, indistinct neck. The navicular facet is strongly convex in the transverse direction and only slightly convex anteroposteriorly. In distal aspect its outline is nearly the shape of a quartercircle, the apex forming rather less than a right angle and situated at the proximal extremity of the facet. Immediately above the apex lies the navicular tuberosity. The long axis of the nearly cylindrical surface of the navicular facet is directed obliquely with respect to the rotational axis of the trochlear facet, increasing the torsion of the lower limb at this joint. Thus, the additive effect of torsion at the tibiofibular/astragalar and the astragalar/navicular joints produces a rotational axis at the distal joint, which is nearly perpendicular to the femoral/tibiofibular joint. This perpendicular rotational motion of the primary tarsal joint with respect to the rotational motion of the knee is probably a consequence of the immobility of the pelvis during locomotion.

The navicular articular facet is the only distal articulation of the astragalus. There is no cuboid articulation, nor are there any articulations with the distal tarsal elements.

As indicated in separate adult (F:AM 59586) and juvenile astragali (F:AM 95737) of $G$. texanum, there is modification with increasing age, despite only a slight increase in size. There is not only a relatively greater development of the tuberosities, but also there is a peculiar modification of the sustentacular facet in the adult stage. In F:AM 59586, the sustentacular facet is evidently separated into two portions: a flat posterior surface, and a rounded posteromedial surface, oc- cupying the same position as the concave upper extremity of this facet in the younger individual. There is a suggestion of the incipient development of a similar separation between these two portions of the facet in the left astragalus of F:AM 95737, whereas the facet is continuous for the right astragalus.

Except for their greater size, the known astragali of $G$. arizonae are identical in all respects to those known for $G$. texanum. As shown in Table 42 , there is a pronounced size difference between UMMP 46231 and UMMP 38761, both from the same locality. Although both are adults, the navicular and calcaneal tuberosities of the latter are very underdeveloped with respect to those of the former specimen. The sustentacular facet is continuous in $G$. arizonae.

The astragalus of $G$. floridanum, known from a single specimen only (USNM 6071), is intermediate in size between $G$. texanum and $G$. arizonae. It is distinct in possessing a more nearly symmetrical trochlear facet, in which the trochlear groove is very shallow. The rockers are nearly identical in anterior profile, although the medial (tibial) rocker is less extensive anteroposteriorly, as in the other species. In addition, the calcaneal facet is more nearly equidimensional, rather than elongate. The anterior extremity of the navicular facet and the posterior extremity of the sustentacular facet are broken in this specimen. These facets do not differ significantly from those of the other species.

Calcaneum (Table 43).-The calcaneum of $G$. texanum (Figure 57) bears three articular facets, two for the astragalus and one for the cuboid. The transversely compressed calcaneal process (tuber calcis) is rectangular in lateral aspect, its proximodistal length approximately twice the height, and with a slight constriction at the neck. In superior aspect the same constriction is evident on the medial surface of the neck, but the lateral surface instead bears only an elongate dorsolateral concavity, with an indistinct lateral crest forming the lateral profile. The free end (distal extremity of the calcaneal process) in the subadult condition is formed by the unfused epiphysis, 


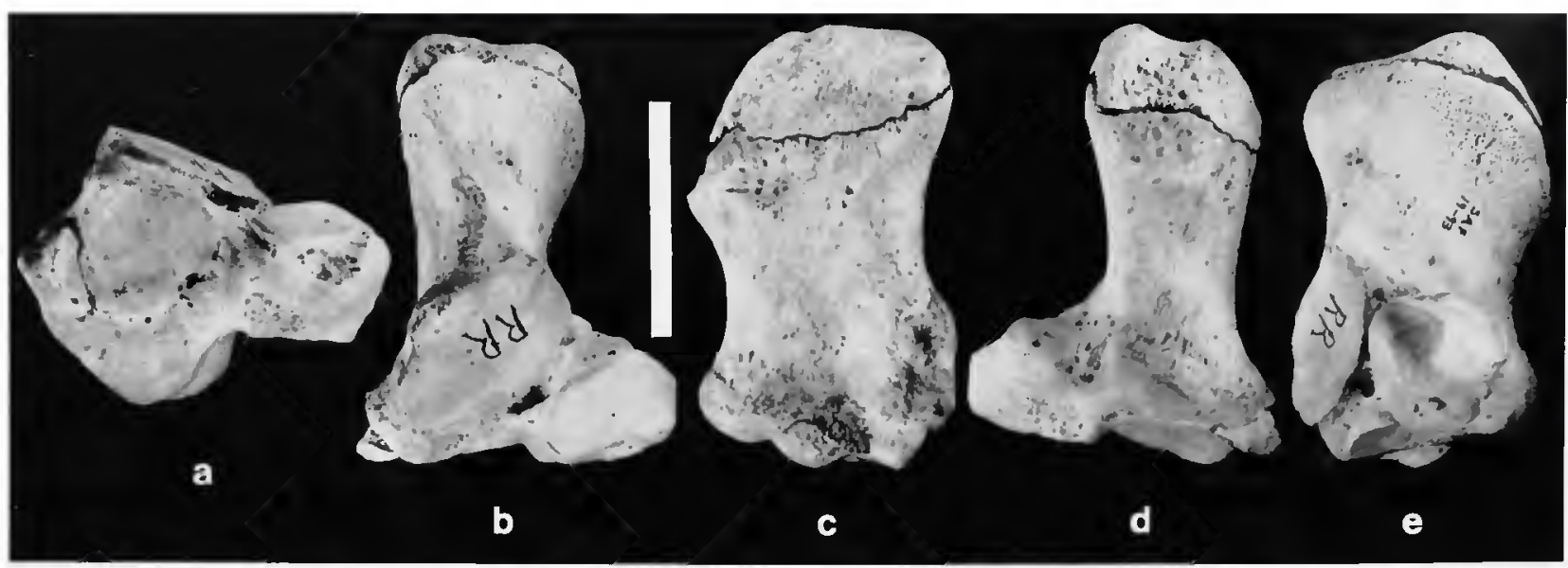

Figure 57.-Right calcaneum of Glyptotherium texanum (F:AM 95737): a, distal extremity; $b$, anterior; $c$, lateral; $d$, posterior; $e$, medial. (Bar $=5 \mathrm{~cm}$.)

which joins the neck at an oblique proximolateral/distomedial angle.

The flat and ovoid lateral astragalar facet is directed proximomedially with respect to the superior crest of the calcaneal process. It is separated from the proximomedially situated sustentacular facet by a deep sulcus and from the cuboid facet only by a shallow interarticular region.

The sustentaculum projects proximomedially, forming a massive tuberosity, upon which is located the sustentacular facet for articulation with the medial (sustentacular) facet of the astragalus. This facet reflects its partner on the astragalus. The subrectangular outline is rendered asymmetrical by a proximal extension of the upper convex portion, increasing the width of the outline of this facet at the superior extremity. The long axis of this facet is oriented in the proximolateral/distomedial direction, forming an oblique angle with respect to the lateral astragalar facet. The proxi$\mathrm{mal}$ and inferior flat surface is dirccted proximally and slightly laterally. The upper portion of this facet is uniformly convex about the long axis of the facet, its chord traversing nearly a scmicircle. The extremity of this facet occupies the medial surface of the sustentaculum. The entirc facet is uniformly flat in the short-axis dircction. The inferior portion of the sustentaculum fits snugly into the depression between the bifurcate posteromedial tubercles of the navicular, inhibiting extension at this joint in the tarsal series.

The cuboid facet forms the lateral side of the proximal end of the calcaneum. It is slightly concave, nearly ovoid in shape, and proximally directed. A small lateral tubercle projects from the margin of this facet to form the lateral extremity of the proximal end, and a large inferior tubercle forms the lower extremity. The latter tuberosity occupies a position above the superior depression of the posterior tubercle of the cuboid, producing a locking mechanism, which aids in inhibiting extension of the calcaneal-astragalus/ cuboid joint.

The calcaneum of $G$. arizonae (Figure 75) differs from that of $G$. texanum principally in features rclated to its greater size. In place of the dorsolateral concavity on the neck of the calcaneal process of $G$. texanum, there is a deeply excavated sulcus. This proximodistal excavation occupies the superior half of the lateral surface of the calcancal process. The inferior border of this groove is formed by a distinct lateral crest, curving proximally upward to participate as the border of the lateral tubercle. The furrow emerges proximally between the astragalus facet and the lateral tubercle at the dorsolateral angle of the 
proximal extremity of the calcaneum. Although this furrow may simply reflect allometric changes resulting as a consequence of the achievement of larger size in the calcaneum of $G$. arizonae, this character seems to distinguish the species, for it is similarly developed in all three calcanea recognized as $G$. arizonae (USNM 10536, UMMP 4623 1, UMMP 38761), and it is not present in $G$. floridanum, for which the size of the calcaneum approaches that of $G$. arizonae. The sustentacular facet is contiguous in two of the $G$. arizonae specimens (USNM 10536 and UMMP 38761), and it appears to be separated into two portions by a weak angle in the other (UMMP 46231). The remaining characteristics of the calcaneum of $G$. arizonae are related to the larger size in this species, including elaboration of tuberosities and exaggeration of muscle attachment surfaces.

The calcaneum of $G$. floridanum is known only for one individual, USNM 6071, for which both were recovered; one is nearly complete, the other is fragmentary. The size approximates that of $G$. arizonae. The distal extremity of the calcaneal process of $G$. floridanum bears a prominent downward-directed tubercle on its inferior angle. Relative to the "horizontal axis," this tubercle extends below the level of the proximal extremity of the calcaneum. Moreover, a vertical groove marks the rounded extremity of the free end, passing over the posterior tubercle on its medial side, in contrast with the rounded and rugose free extremities in $G$. arizonae and $G$. texanum. The neck of the calcaneal process is smooth and unexcavated, as in G. texanum, although there is a weak concavity. The astragalar facet is less elongate and the cuboid facet is more deeply concave than in either $G$. arizonae or $G$. texanum.

Navicular (Table 44). - The greatly expanded navicular of $G$. texanum (Figure 58) presents a single, broad cotyloid facet for articultion with the astragalus. In proximal aspect the shape of this facet is irregularly ovoid, and elongate in the transverse plane. The facet is concave in this direction, and only slightly concave anteroposteriorly, imparting a close resemblance to a portion of the inner surface of a cylinder.

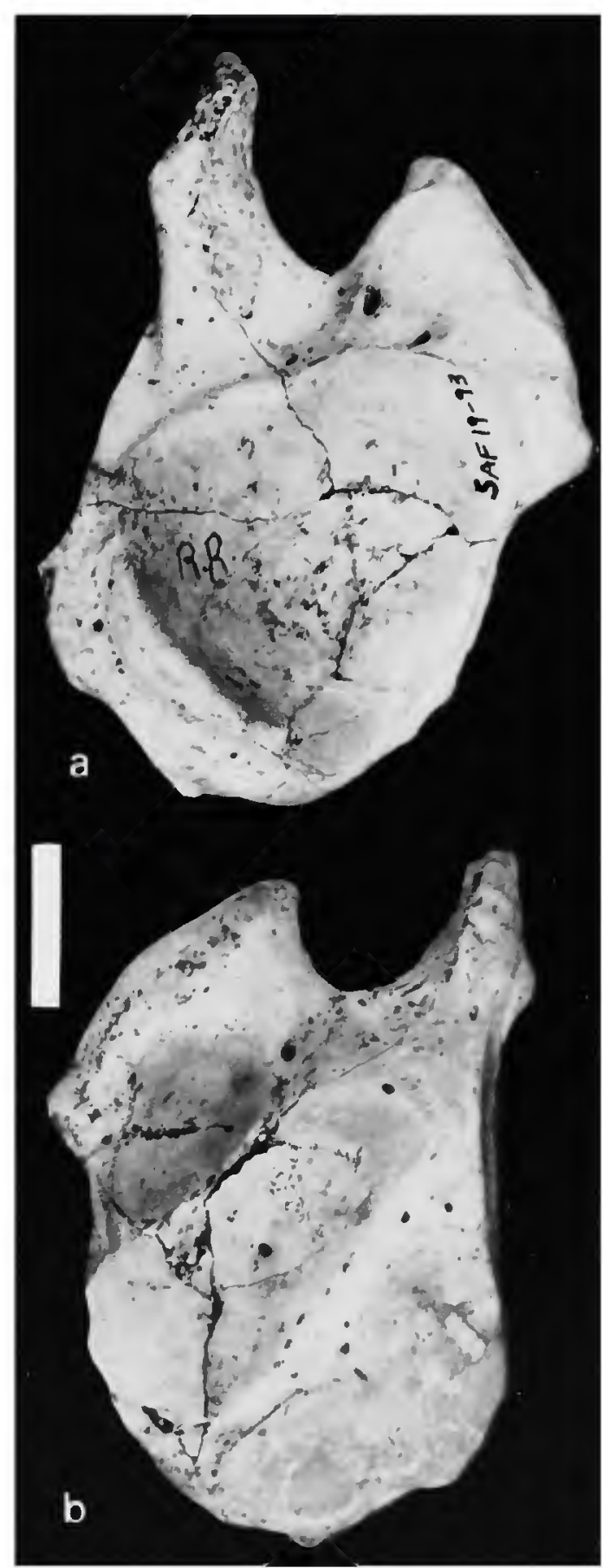

Figure 58.-Right navicular of Glyptotherium texanum (F:AM 95737): a, proximal; $b$, distal. $($ Bar $=20 \mathrm{~mm}$.) 
Two massive posterior tuberosities characterize the navicular. The outer (lateral) tuberosity is pointed, laterally compressed, and curved upward and medially, projecting farther from the articular facet than the medial tuberosity. The inner (medial) tuberosity is a blunt fusiform process extending posterolaterally as a greatly thickened surface for muscle attachment. On the undersurface of the "neck" of this tuberosity is the articular facet for the internal cuneiform. In articulation, the sustentaculum of the calcaneum fits snugly between these tuberosities.

The distal facets of the navicular, one for each of the three cuneiform bones, are situated directly beneath the proximal facet. The lateral facet for the external cuneiform is the largest. It is triangular and flattened, conforming exactly to the proximal facet of the external cuneiform. There was little, if any, mobility at this joint. The shape of this facet closely resembles a right triangle with rounded apices, with the hypotenuse formed by the internal, anteroposteriorly directed border facing the middle cuneiform. The rear portion of the facet grades imperceptibly into the distinct interarticular region separating this facet from that for the middle cuneiform. The lateral margin of the facet forms a common angle with the laterally directed facet for the cuboid.

The articular facet for the middle cuneiform is trapezoidal and elongate in the anteroposterior direction. It is distally directed, oblique with respect to the somewhat laterally directed facet for the external and internal cuneiforms. The facet is situated in the plane of elongation of the lateral posterior tuberosity. The surface is irregular, but mostly flattened, and slightly concave transversely. This is by far the longest of the distal facets; its greatest transverse diameter is slightly greater than that of the internal cuneiform facet. The lateral border of the middle cuneiform facet is slightly elevated above the interarticular region, separating it from the lateral cuneiform facet. The medial border contacts along its middle half the lateral border of the internal cuneiform facet.

The facet for articulation with the internal cuneiform is the smallest of the distal facets of the navicular. It is ovoid, slightly concave, and directed distomedially. It is located in direct line with the medial extremity of the proximal facet, occupying the central part of the "neck" portion of the distal surface of the medial tuberosity.

There is, in addition, an elongate, laterally directed facet for articulation with the cuboid. This flattened facet occupies the lateral margin of the navicular. Continuing above the posterior extremity of the facet is the flattened lateral tuberosity, the lateral surface of which is situated in the same plane as the cuboid facet. The net result of the three flat, distal articular facets produces in gross proportions a convex surface parallel to the upper concavity of the proximal facet. Thus, the overall configuration of the navicular is that of a concavoconvex discoid, with two posterior tuberosities. The maximum thickness of the disc is between the posterior border of the proximal facet and the posterior margin of the distal middle cuneiform articular facet. The shortest proximodistal diameter is at the anterior border of the same two facets.

The navicular of $G$. arizonae is identical in most respects to that of $G$. texanum, except for its larger size and the corresponding accentuation of the articular facets and tuberosities. The proximal articular facet in $G$. arizonae is distinctly more concave in the anteroposterior direction, especially near its posterolateral margin, where the facet is inflected upward. This articulation is more nearly cotyloid than the cylindrical surface of the proximal facet of $G$. texanum. Similarly, the distal facets, especially the facet for the internal cuneiforn, are markedly more concave in the transverse direction. The inferior border of the lateral posterior tuberosity is medially inflected, providing a distinct channel beneath which the strong tarsal musculature passed. This inflection is only incipiently developed in G. texanum. With this posterodistal inflection of the lateral tuberosity, the lateral profile of the navicular of $G$. arizonae is squared at this angle, rather than rounded.

The navicular is unknown for $G$. floridanum and G. cylindricum. 
Curord (Table 45).- The cuboid of $G$. texanum (Figure 59) is an irregular bone, presenting three articular facets and a posterior tuberosity. It is anteroposteriorly elongate, in length nearly twice the subequal transverse and proximodistal dimensions. The cuboid functions as the posterolateral element of the distal tarsal series and as a lateral buttress adjacent to the navicular. The elongate facet for articulation with the navicular is flattened and triangular in shape. It occupies approximately half of the anteromedial surface of the cuboid, conforming exactly to the opposing facet of the navicular. It is bounded on all sides by distinct interarticular regions, a deeply excavated inferior interarticular region separating this facet from the metatarsal facet.

The anterolateral facet of the cuboid articulates with the distolateral facet of the calcaneum. It is flattened, with convex upper and lateral borders, fitting loosely into the opposing facet of the calcaneum. Although this joint was undoubtedly important in weight transfer, it appears to have been more important as a lever for transmission of calcaneal exertions through the tarsus to the metatarsus and digits. This facet faces outward and upward and is separated from the other cuboid facets by shallow interarticular regions.

The flat distal articular facet is slightly convex in the anteroposterior direction. Marginal projections of this facet produce a weakly constricted "neck," upon which the facet is situated. A small flat facet, located on the anteromedial portion of this "neck," is continuous with the distal facet as a transverse articulation with the metatarsal.

The posterior tuberosity extends rearward to conform with the shape of the lateral tuberosity of the navicular. It presents a flat triangular extremity facing posteriorly and occupying the posterolateral position of the distal tarsal series. It is separated from the more anteriorly placed calcaneal and distal articular facets by a distinct neck. The neck of the posterior tuberosity is constricted on its outer surface and bears on its inner surface the elongate navicular articular facet.

The cuboid of $G$. arizonae differs from that of $G$. texanum mainly in size and the accentuation of the articular facets and tuberosities. The only notable distinction is the squared, rather than triangular, shape of the posterior tuberosity in $G$. arizonae. The undersurface of the neck of the tuberosity is clearly divided into two regions: a deep anterior

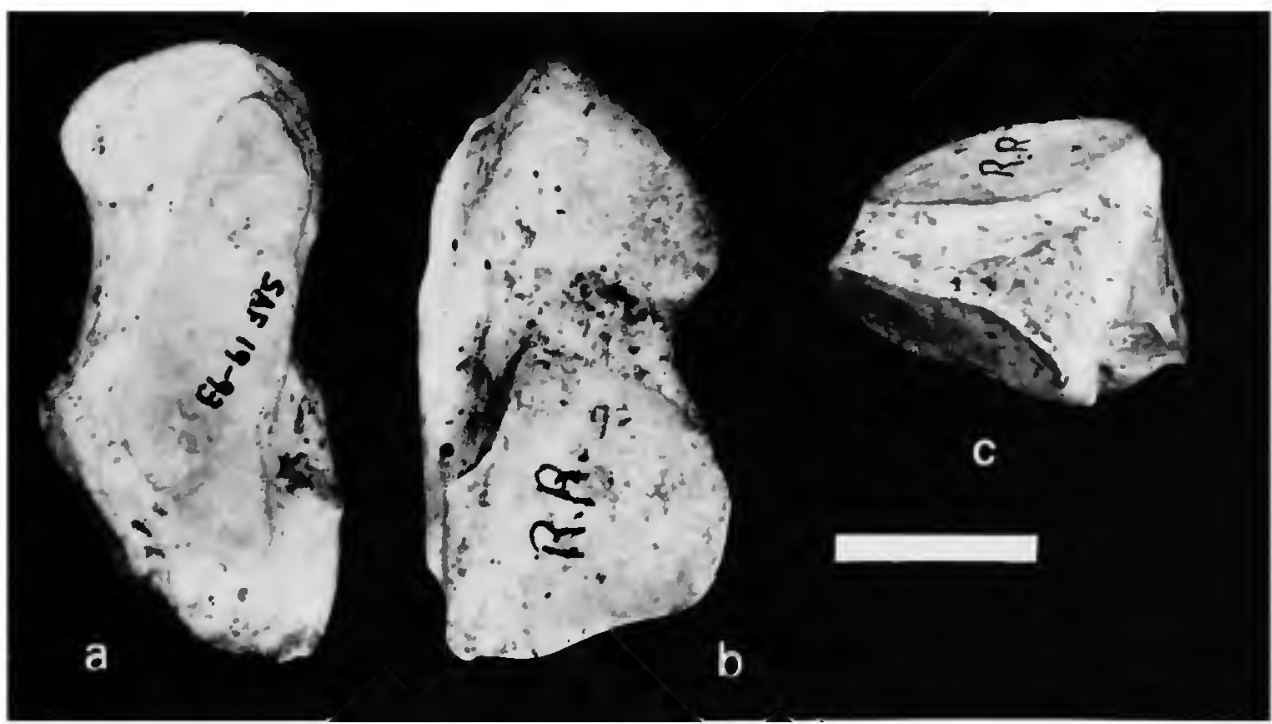

Figure 59.-Right cuboid of Glyptotherium texanum (F:AM 95737): $a$, distal; $b$, proximal; $c$, anterior. (Bar $=20 \mathrm{~mm}$.) 
sulcus passing transversely just posterior to the distal articular facet, and a posterior roughened portion behind the sulcus.

In USNM 10536, the articular facet for the navicular is heavily rugose and tuberculated due to degenerative arthritis (or some similar condition) in this individual. Moreover, this condition indicates that little mobility was obtained through the cuboid-navicular articulation. The arthritic condition is so extensive at this joint that possibly there could have occurred a solid fusion of the cuboid with the navicular with advanced age.

External Cunelform (Table 46).-The external cuneiform of $G$. texanum (Figure 60) represents an asymmetrical section of a discoid, with the apex in the posterior position. The chord covers approximately $60^{\circ}$, the internal leg of the proximal (and distal) profile is deeply concave, and the outer leg is nearly straight. The proximal and distal facets, for articulation with the navicular and metatarsals, respectively, are parallel and nearly identical. Both are flat and nearly triangular with equidimensional proportions, having a convex anterior outline, a concave posteromedial border, and an irregularly shaped posterolateral border. The proximal facet is slightly concave and is gradually elevated toward the anterolateral angle, there producing the greatest proximodistal dimension of the bone. The posterior apex of the distal facet is somewhat more extensive than the proximal, and it projects farther rearward, resulting in a downward taper of the interarticular surface between these apices at the posterior extremity.

Two small laterally directed facets for the cuboid continue around the lateral angle from the proximal and distal facets. There is a distinct anterolateral tubercle and a shallow transverse sulcus on the nonarticular anterior face. A posteromedially directed semicircular facet meets the distal facet at a right angle on the internal border of the external cuneiform. This facet occupies the anterior extremity of the internal border for articulation with the opposing facet of metatarsal II.

The external cuneiform of $G$. arizonae bears all the characters of that of $G$. texanum, with several

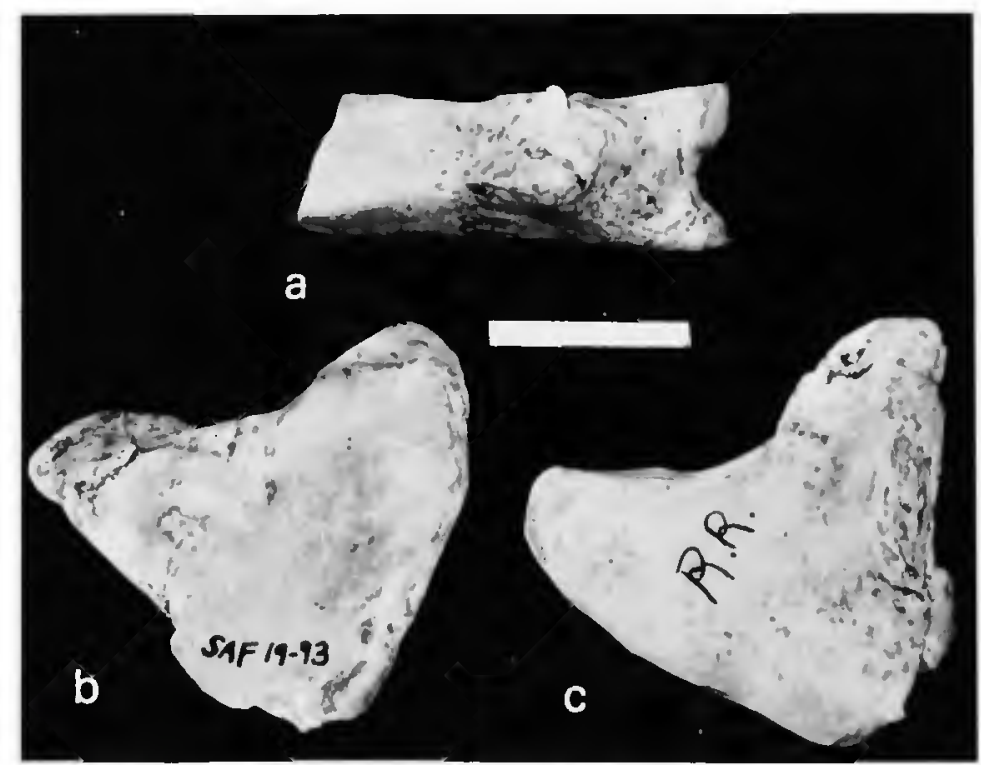

FigURE 60.-Right ectocuneiform of Glyptotherium texanum (F: AM 95737): $a$, anterior; $b$, proximal; $c$, distal. (Bar $=20$ $\mathrm{mm}$.) 
notable additions. The distal facet is slightly concave in the transverse direction and slightly convex anteroposteriorly. A nearly straight extension of the proximal surface over the concavity of the internal border produces a cup-shaped interarticular region for reception of the proximolatcral angle of the second metatarsal. The lateral and medial facets for articulation with the cuboid and second metatarsal, respectively, are less well developed, although the surfaces of these posterolateral and posteromedial borders are more heavily rugose. The anterolateral tubercle on the anterior border is more massively developed, and the anterior border of the distal facet projects as an anterior flange, accentuating the transverse sulcus on the anterior border. The external cuneiforms of the Seymour glyptodonts are identical in size and construction to the Curtis Ranch specimen.

This element is unknown for $G$. floridanum.

Middle Cuneiform (Table 47).-The middle cuneiform of $G$. texanum (Figure 61 ) is an anteroposteriorly elongate bone, bearing a flat proximal facet for the navicular and a concave distal facet for metatarsal II. The posterior half of the bone is flat, with parallel upper and lower facets. The distal concavity produces increasing proximodistal thickness anteriorly. The lower facet is directed distally on its posterior half, becom.ng more medially directed toward the anterior face. This produces a quadrilateral anterior aspect with three right angles and a lower oblique side forming an acute distomedial angle and an obtuse distolateral angle. Hence, the greatest proximodistal diameter occurs at the anteromedial angle. The proximal facet conforms with the opposing facet of the navicular, the distal facet with the proximal facet of metatarsal II. There was little mobility at either joint. Distinct vertical interarticular regions separate the proximal and distal facets around the circumference of the bone.

The middle cuneiform of $G$. arizonae is similar to that of $G$. texanum, the only obvious differences apparently related to size. The proximal facet does not cover the entire upper surface posteriorly; instead, a prominent, transversely elon-

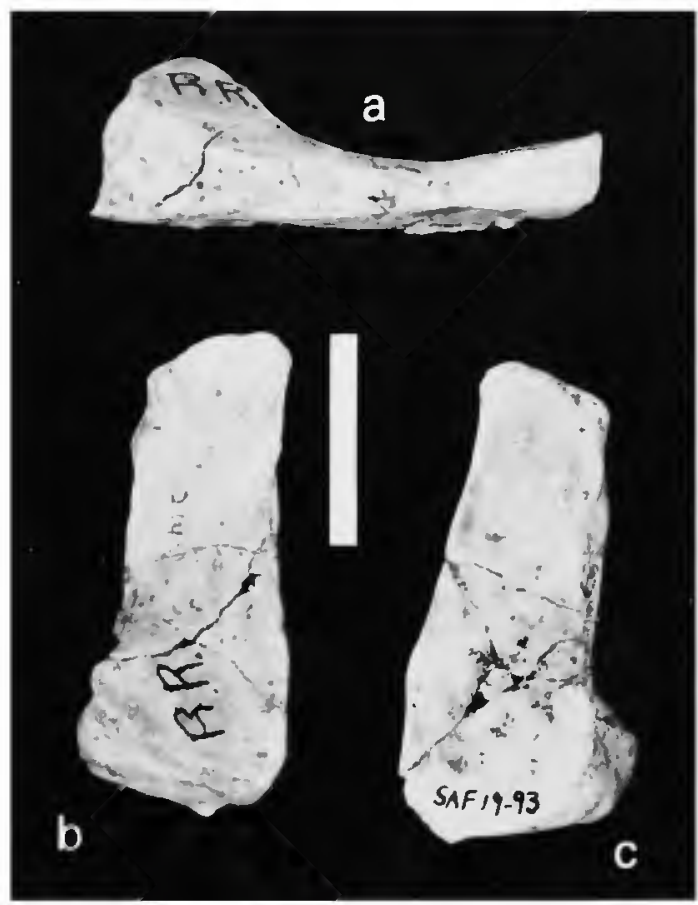

Figure 61.-Right middle cuneiform of Glyptotherium lexanum (F:AM 95737): $a$, medial; $b$, distal; $c$, proximal. (Bar $=20$ mm.)

gate, posterior tubercle projects from the posterior face beyond the extent of the articular facets. Similarly on the anterior face, a distinct tubercle marks the anteromedial angle. The distal articular facet is relatively less concave. The margins of both articular facets are irregular, rather than straight, and the medial margin of the distal facet is distinctly concave in outline. A notable distinction of USNM 10536 is a deep groove on the anterior face that extends downward and presumably marks the position of a strong tarsal-metatarsal tendon. This sulcus is absent in UMMP 46231 and UMMP 38761.

Internal Cuneiform (Table 48). - The internal cuneiform of $G$. texanum (Figure 62) is the smallest of the distal tarsals. It occupies the distomedial position of the tarsus, providing the only articulation for the first metatarsal. The internal cuneiform is directed medially and distally from the proximomedial surface of the navicular. The articular surface for the navicular is oval and 


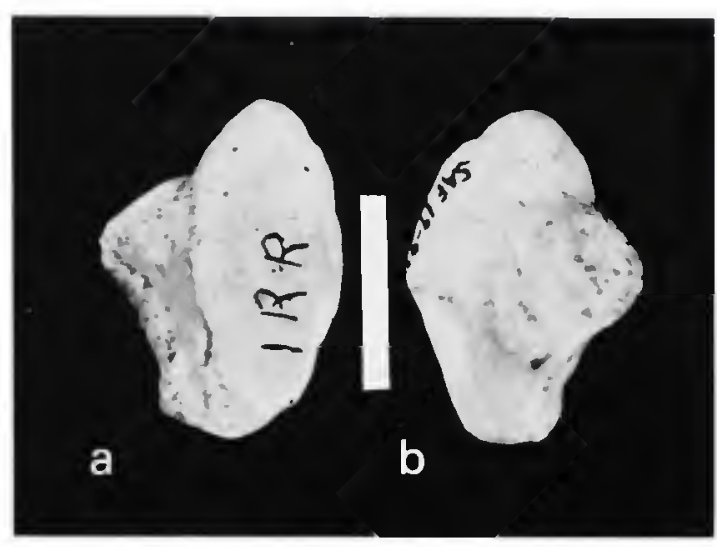

FIGURE 62.-Right entocuneiform of Glyptotherium texanum (F: AM 95737): $a$, proximal; $b$, distal. (Bar $=20 \mathrm{~mm}$.)

slightly convex. It covers nearly the entire convex proximal surface of the bone. There was little mobility at this joint, and little weight was transmitted to the first digit. A small, distomedially directed, convex distal facet for metatarsal I is oriented obliquely with respect to the proximal facet. These facets are posteriorly convergent in an acute angle of approximately $45^{\circ}$. A distinct posterior tubercle projects beyond the extent of the proximal facet, and a small elongate tubercle on the medial side projects downward from the border of the proximal facet.

The internal cuneiform of $G$. arizonae is identical in all respects except for larger size.

Metatarsals. - The five metatarsals articulate with the distal tarsal bones in flat contacts. Metatarsals I, II, and part of III articulate with the cuneiforms; part of metatarsal IV and all of $\mathrm{V}$ articulate with the cuboid. There is a unique system of overlap between adjacent metatarsals involving II-V. In each there is a proximolateral extension, which is supported beneath by a proximomedial facet of the laterally adjacent metatarsal. This arrangement interlocks the metatarsals at their proximal extremities, limiting movement, and serving to distribute weight toward the lateral digit. It is by this mechanism that the symmetrical disposition of the digits and consequently their nearly perfect symmetry in function are achieved.

The middle metatarsal is the largest. Meta- tarsals II and IV are intermediate in size, and I and $\mathrm{V}$ are the smallest. They are arranged in a near-perfect semicircle. All are stout elements approaching cubic proportions; i.e., the proximodistal diameters are only slightly greater than the transverse and anteroposterior diameters.

Each of the three middle metatarsals possesses a pair of large plantar sesamoid bones. The two outer metatarsals each possess only a single sesamoid bone, considerably smaller than the internal sesamoids.

All of the metatarsals are known for $G$. lexanum and $G$. arizonae, and III and IV are known for $G$. floridanum. They exhibit a close resemblance to those described by Burmeister (1874) for Glyplodon.

Melton (1964) was the first to attempt an enumeration of the elements of the pes, although he did not compare the pes of the Seymour glyptodont with that known for the Curtis Ranch representative, which was briefly described and figured by Gidley (1926). Describing the Seymour specimens, Melton (1964:137-138) stated:

There are 39 bones in each of the complete left feet: 7 tarsals, 5 metatarsals, 15 phalanges, and 12 sesmoids [sic]. Burmeister lists 14 phalanges and 10 sesmoids [sic] for G/y $p$ todon asper. He found no $2 \mathrm{~d}$ phalanx and no distal sesmoids [sic] on digil I. In both of the feet recovered, digit I had 2 phalanges and 2 distal sesmoids [sic].

In - stuality, Burmeister found two phalanges for digit $\mathbf{I}$, accounting for the phalangeal count of 14. Moreover, there are 14, rather than 15, phalanges in the Seymour pes. The count of 14 phalanges accounts for only two phalanges in digit I. The two sesamoid bones Melton identified as "distal" for digit I are in actuality single proximal and distal elements, one articulating at the metatarsal-phalanx joint, the other at the terminal joint. The correct sesamoid count for $G$. arizonae and $G$. lexanum is 13 , rather than 12 as Melton asserted.

Thus there is a closer similarity with the South American genus than Melton recognized, for the counts for the various elements of the pes are identical. Burmeister's (1874) descriptions and figures do indeed indicate a close resemblance.

Neither Melton (1964) nor Gidley (1926) de- 
scribed the metatarsals, although both provided illustrations.

Metatarsal I (Table 49).- - The first metatarsal of $G$. texanum (Figure 63) is a small, stout element bearing two articular facets. In proximal view its shape is oval, rounded posteriorly and rather more pointed anteriorly. The proximal facet is shallowly concave, for reception of the distal facet of the internal cuneiform.

The distal facet of metatarsal I is anteroposteriorly elongate, extending farther anteriorly than the proximal facet, producing a tapered anterior border in lateral and medial aspects. The distal facet is convex in the anteroposterior direction and weakly concave in the transverse direction. The articular facets are basically parallel, but the distal facet is laterally offset so that its medial border lies almost directly beneath the center of the proximal facet. The distal facet articulates on its anterior two-thirds with the first phalanx, digit $\mathrm{I}$, and on its posterior third with a stout single sesamoid bone, which projects posteriorly from the long axis of the digit. The posterior border of the distal facet extends a short distance beyond the interarticular "neck" as a small flange along the posterodistal margin. Small proximal and distal tubercles are present on the medial surface of the interarticular area; a slightly raised tubercle is situated along the anterior margin; and a prominent bosslike tubercle is located $o$, the posterolateral angle of the shaft.

Metatarsal I of $G$. arizonae is distinct in having a greater definition of the boundary between the phalangeal and sesamoid portions of the distal articular facet. The articular surface for the phalanx is anteroposteriorly flat and transversely concave. The rear portion of this facet, for articulation with the sesamoid, is convex anteroposteriorly and transversely flattened. A distinct boundary delimits these portions of the distal facet.

The marginal tubercles are distinctly more well developed. A large medial groove and a smaller lateral groove mark the lower surface of the body of the bone, immediately above the margins of the distal facet. The tubercles project over these tendinal grooves, accentuating their depth.

Sesamoid Bone, Metatarsal I (Table 54).One plantar sesamoid is situated at each of the joints of the first digit, rear foot of $G$. texanum. The more proximal digital sesamoid, located at the metatarsal-phalanx joint, is approximately twice as long as the distal one. It articulates primarily with the posterior portion of the distal facet of the metatarsal in a slightly dorsally directed facet; it articulates secondarily below with the rear down-turned portion of the proximal facet of the first phalanx in a small lower facet. This articular facet of the sesamoid is flat and situated at nearly a right angle with respect to the long axis of the element; the lower portion is downward-directed to meet the phalanx. This sesamoid bone extends in the plantar direction as a somewhat transversely flattened cylinder with a rounded, knoblike and medially inturned free end. It is heavily rugose on the nonarticular surfaces.

The metatarsal sesamoid of $G$. arizonae is larger, more transversely compressed, and more heavily

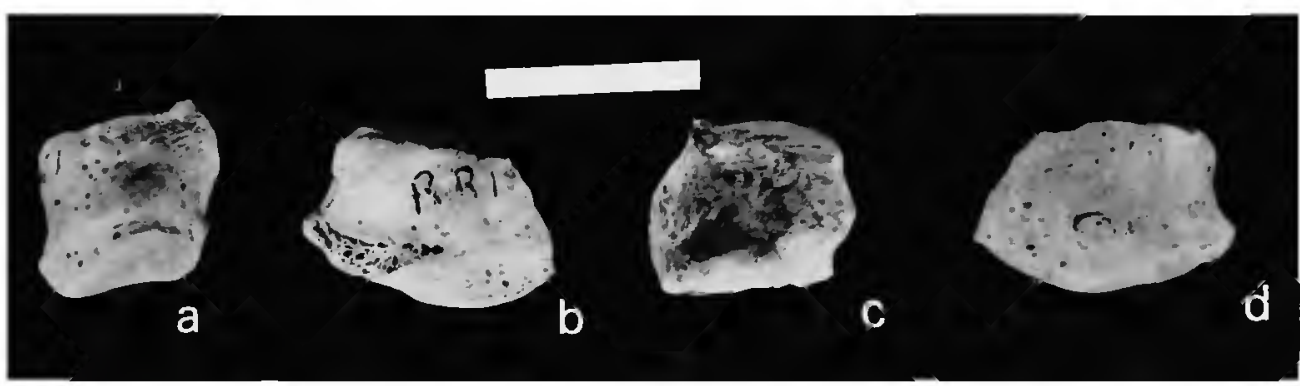

Figure 63.-Right metatarsal I of Glyptotherium texanum (F:AM 95737): $a$, anterior; $b$, lateral; $c$, posterior; $d$, medial. (Bar $=20 \mathrm{~mm}$.) 
rugose than the same element in $G$. texanum. The articular facets are more transversely expanded and somewhat more dorsally directed. These differences are within the expected range of ontogenetic variation. The element is otherwise identical in these two species.

This metatarsal sesamoid in UMMP 46231 exhibits considerable degeneration of the bone, as do the remaining bones of the digit, as a manifestation of the apparent arthritic malady suffered by this individual.

Metatarsal II (Table 50).- The second metatarsal in $G$. lexanum (Figure 64) is a complexly modified rectangular prism, only slightly longer in the proximodistal dimension than in the subequal dorsoplantar and mediolateral dimensions. It bears proximal and distal facets for articulation with the middle cuneiform and first phalanx of the second digit, respectively. There is an additional pair of proximal articular facets, a lateral one for vertical contact with the external cuneiform, and a distally directed one beneath the large ectocuneiform process on the proximolateral angle for articulation with metatarsal III. There are also two plantar-distal articular facets for the pair of sesamoids located at the metatarsal-pha$\operatorname{lan} x$ joint of this digit. Proximal articulation of this bone includes contact with three other elements, the middle and external cuneiforms and the third metatarsal. The net effect of this articulation is a strong lateral buttress preventing outward rotation laterally beyond the long axis of the digit. Because of the tight-fitting contact with the adjacent tarsals and metatarsals, there appears to have been little proximal motion for the second metatarsal.

Metatarsal II bears a saddle-shaped proximal articular facet, convex in the dorsoplantar direction, and transverscly concave, with the posterior extension becoming transversely flattened. This facet extends laterally beyond the lateral surface of the body covering the upper surface of the ectocuneiform process. The proximal articular facet conforms exactly with the opposing facet of the middle cuneiform.

The ectocuneiform tubercle is a squared extension of the proximolateral angle, with flat articular surfaces on its upper side, as the extension of the proximal articular facet, and on its lateral and lower sides to interlock with the ectocuneiform and metatarsal III, respectively. The ectocuneiform facet occupies the entire lateral extremity of the ectocuneiform process. It is rectangular and flat, facing laterally and slightly outward. The long axis of the rectangle is directed downward at approximately $45^{\circ}$ with respect to the long axis of digit II. The undersurface of the ectocuneiform process, for articulation with metatarsal III, is semicircular and flat, forming an external right angle with the ectocuneiform facet. Its surface is parallel with the upper anterior surface of the proximal facet, facing in the distal

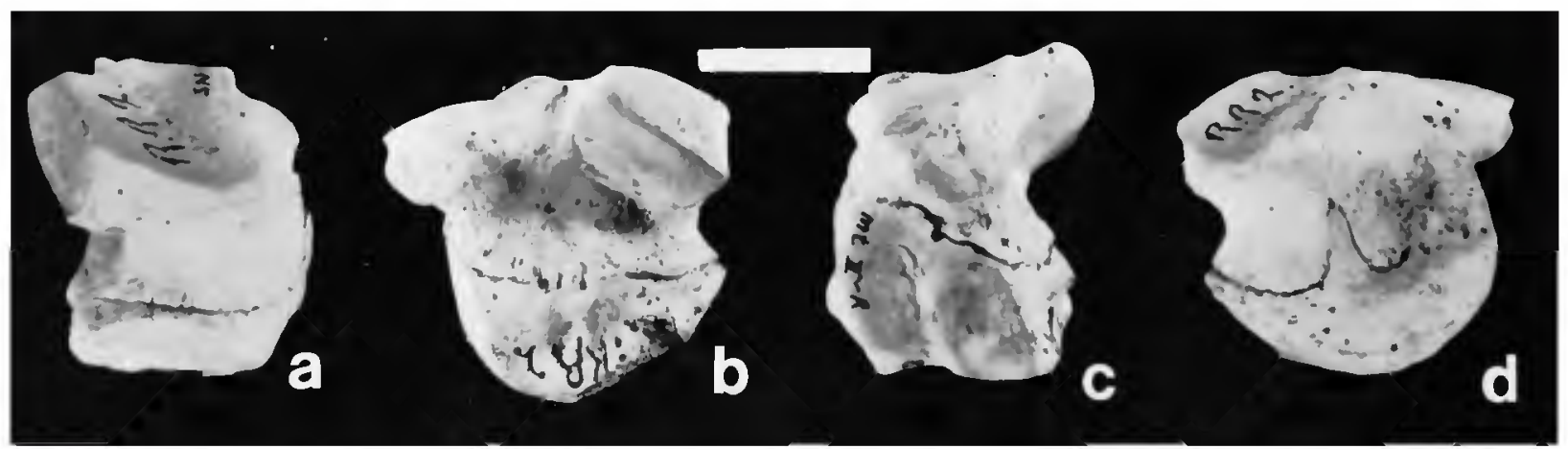

Figure 64.-Right metatarsal II of Glyplotherium texanum (F:AM 95737): $a$, anterior; $b$, lateral; $c$, posterior; $d$, medial. (Bar $=20 \mathrm{~mm}$.) 
and plantar direction, and slightly laterally. The ectocuneiform process occupies the anterior half of the proximolateral extremity of the bone.

The shaft, or body, of metatarsal II bears four modified surfaces. The lateral and medial surfaces are irregularly concave. The anterior surface, between the proximal and distal articular facets, is weakly concave, and the posterior surface is occupied almost entirely by the sesamoid facets. Only a small blunt tubercle underlying the posterior extension of the proximal facet represents the nonarticular portion of the rear surface of the body.

The sesamoid facets are posterior continuations of the distal articular facet. They are proximodistally elongate, the larger medial one extending farther proximally, and the smaller lateral one extending farther distally. They are transversely concave and are separated by an indistinct ridge, which is a continuation of the flattened lateral portion of the distal facet.

The distal articular facet, for the first phalanx, digit II, is saddle-shaped, convex in the dorsoplantar direction, and transversely concave. It narrows gradually anteriorly, reaching a rounded anterior extremity, which is directed as much dorsally as distally. The lateral fourth of the facet is transversely flat, indistinctly separated from the medial concave portion by a weak angle, and extends somewhat farther in the distal direction.

The second metatarsal of $G$. arizonae exhibits minor modifications of the features described for G. texanum. The proximolateral angle of the ectocuneiform process is marked by a deep dorsoplantar sulcus separating the proximal facet from the laterally directed ectocuneiform facet. Moreover, the ectocuneiform facet is convex, rather than flat, in the direction of its long axis. The most distinctive character of metatarsal II of $G$. arizonae is the relatively short ectocuneiform process, in absolute comparison approximately equidimensional with that of $G$. texanum, despite the otherwise pronounced difference in size between these two elements. The transverse concavity of the proximal facet is less pronounced, while the articular facet for the medial sesamoid is more deeply excavated and considerably larger than the facet for the lateral sesamoid.

Sesamold Bones, Metatarsal II (Table 54).The two plantar sesamoids of the second metatarsal articulate exclusively with this element. They are both transversely compressed and irregular in shape. The medial sesamoid is nearly twice as large as the lateral one and has a considerably wider articular surface. The articular facets are concave in the sagittal direction and transversely convex, conforming with the opposing facets of the metatarsal. The free ends of both sesamoids terminate in a blunt, knoblike extension that is curved laterally, imparting a convex medial and concave lateral surface for each bone.

Except for the much larger absolute size in $G$. arizonae these bones are identical to those of $G$. texanum.

Metatarsal III (Table 51).- The third metatarsal of $G$. texanum (Figure 65) is the largest and stoutest of the metatarsal series. It presents primary proximal and distal articular facets, a pair of secondary facets for interlocking with the adjacent metatarsals, and two posterior facets for the plantar sesamoids.

The nearly flat, slightly convex, proximal articular facet meets the corresponding facet of the middle cuneiform in a broad and expanded contact. The anterior (dorsal) margin of this facet is rounded. The medial border, which forms a common angle with the facet for metatarsal II, is straight and directed laterally and rearward from the anteromedial corner of the anterior arch. The lateral border, forming an acute common angle with the facet for metatarsal IV, is nearly straight, and it is parallel with the sagittal plane. The posterior portion of this facet includes a squared extension covering the posterior tubercle. The proximal facet is directed anteriorly with respect to the distal articular facet, and these two facets are anteriorly convergent in an acute angle of approximately $45^{\circ}$. The lateral portion extends over the lateral metatarsal process, the undersurface of which is occupied by a convex articular facet. This facet narrows from before rearward and is oriented distolaterally. It interlocks in a 


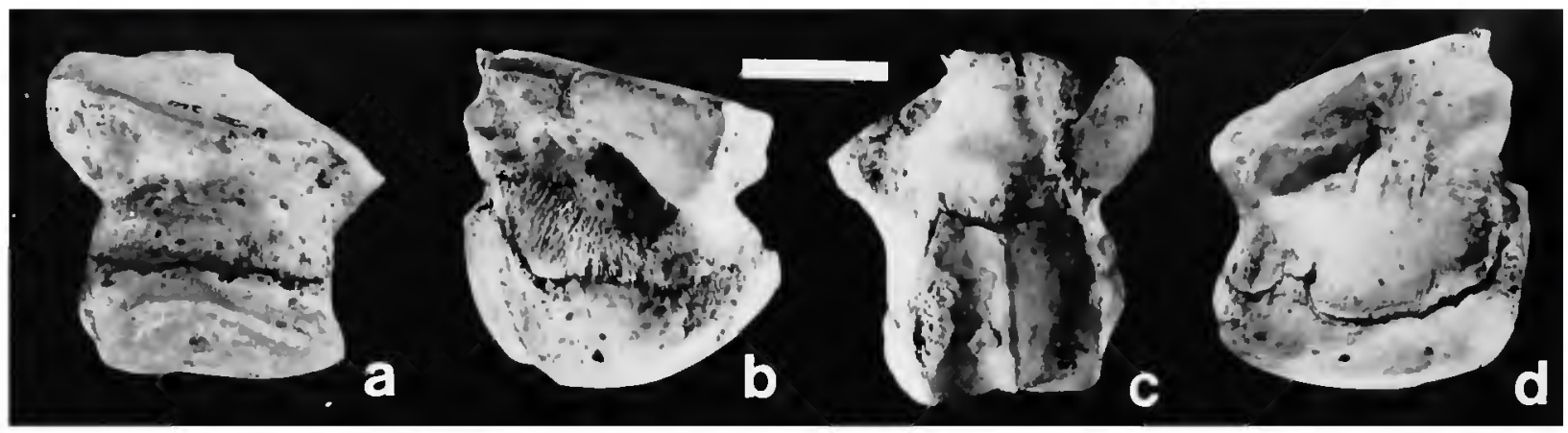

Figure 65.-Right metatarsal III of Glyptotherium texanum (F:AM 95737): $a$, anterior; $b$, lateral; $c$, posterior; $d$, medial. (Bar $=20 \mathrm{~mm}$.

tight articulation with the medial concave portion of the proximal facet of metatarsal IV.

The medial metatarsal process is less extensive. Upon its upper surface is situated the facet for metatarsal II, which exhibits a flattened, foursided shape, the two external corners forming right angles, and the two internal corners formed by the obliquely directed common border with the middle cuneiform facet. This metatarsal facet is directed anteriorly with respect to the sagittal plane and somewhat medially away from the cuneiform facet.

The distal articular facet is anteroposteriorly convex and weakly concave in the transverse direction. From the rounded anterior border the facet narrows posteriorly. Its posterior border joins the posterior sesamoid facets in a rounded, indistinct angle. A pair of small nutritive foramina is situated within the poorly defined central furrow of the facet, at the junction with the medial ridge of the sesamoid facets.

The sesamoid facets are proximodistally elongate and convex, and each is concave in the transverse direction. They are separated by a sharp median longitudinal ridge, and they are equally developed. These sesamoid facets occupy the distal two-thirds of the posterior surfacc of the bone. Immediately above these facets is the posterior tubercle.

The four-sided shaft of metatarsal III is irregular. The medial and lateral sides are posteriorly convergent; the expanded anterior surface is proximodistally concave and transversely convex; and the posterior surface is occupied primarily by the sesamoid facets and the posterior tubercle. A less prominent tubercle is situated near the lateral margin of the anterior surface, immediately beneath the proximal facet.

Metatarsal III of $G$. arizonae (Figure 75) differs in possessing weakly concave, rather than flat, proximal articular facets (cuneiform and metatarsal II facets), and the distal articular surface is deeply excavated in its posterocentral position, in place of the median furrow of $G$. texanum. The tubercles are more pronounced, and medial and lateral excavations on the surface of the shaft accentuate the greater size.

Metatarsal III of $G$. floridanum (Figure 73a) is intermediate in size. It most closely resembles that of $G$. arizonae. It differs from $G$. texanum in possessing the same additional features as those described for $G$. arizonae, but it also exhibits several important distinctions separating it from both species. The boundary between the proximal articular facet and the medial facet for articulation with metatarsal II is more sharply defined. The concavity of the proximal facet is as pronounced as in $G$. arizonae, but its direction is more anteriorly oriented. The articular facet for metatarsal II is more distinctly concave, and that for metatarsal IV lacks the proximodistal convexity of the other two species. The sesamoid articular facets are relatively less elongate than in $G$. arizonae. The distal articular facet entirely lacks the 
central nonarticular depression of $G$. arizonae, which is incipiently developed in $G$. texanum.

Sesamoid Bones, Metatarsal III (Table 54).-The two plantar sesamoids of metatarsal III in $G$. arizonae and $G$. texanum are symmetrically disposed, mirror-image equivalents. They are in proximal contact along the median ridge of the sesamoid facet of the metatarsal. These are by far the largest of the proximal digital sesamoids of the rear foot, a condition indicating the primary importance of digit III in weight support. These transversely compressed sesamoids each present lateral and medial surfaces and three borders: the concave articular facet, the upper scalloped, doubly concave proximal (with respect to the proximal orientation of the metatarsal) border, and a lower uniformly curved border connecting the distal end of the facet with the upper border. Thus, in lateral aspect, the shape is that of a halfcrescent. The external (parasagittal) surface is weakly concave, while the internal surface (facing the sagittal plane of the metatarsal) is proximally flattened and rugose and is concave in a longitudinal furrow near the free border. This concavity is mirrored in the opposing sesamoid, producing a proximodistal tendinal channel, which is anteriorly and marginally bordered by the sesamoids and open to the rear. The upper margin of the free end forms a right angle with the upper end of the articular facet and an acute angle with the broadly curved lower margin. The bone is thickened along the lower margin and along the articular facet. The articular surface is proximodistally (with respect to this orientation of the metatarsal) concave and transversely convex.

Except for larger size and exaggeration of features in $G$. arizonae, these bones are identical in both species.

Metatarsal IV (Table 52). - The fourth metatarsal of $G$. texanum (Figure 66) is approximately the same size or slightly smaller than metatarsal II, as a reflection of the basic symmetry of the rear foot. It possesses three proximal articular facets: a primary one for articulation with the cuboid and the lateral angle of the external cuneiform, and a pair of marginal ones for articu- lation with the adjacent metatarsals. There is an expanded distal facet for articulation with phalanx I and a two-parted sesamoid facet for the two plantar sesamoids. The shape of metatarsal IV is irregular. Its maximum proximodistal dimension approximately equals the anteroposterior (dorsoplantar) dimension, and both exceed slightly the maximum transverse diameter.

The proximal facet, for articulation with the cuboid and the ectocuneiform, bears no evidence of the relative importance of these two proximal articulations. They are situated in the same plane, and metatarsal IV evidently moved freely in the transverse direction across their contact. The facet bears the shape of a parallelogram, with straight marginal sides nearly twice the length of the convex anterior and posterior borders. The anterior and posterior borders are directed generally anteriorly and medially from the lateral angles. This outline is interrupted along the posterior half of the medial border, which is irregular. The anterior half of the same border forms a common angle with the facet for metatarsal III. Similarly, the anterior half of the lateral border of the proximal facet forms a common angle with the facet for metatarsal $V$. The posterior half of the proximal facet is a rearward extension beyond the level of the shaft. It is buttressed beneath by the blunt posterior tubercle. The proximal facet is weakly concave in both the transverse and anteroposterior directions, with its central concavity directed from the posterolateral angle forward and downward, reaching a low point at the anteromedial angle.

The facet for metatarsal III occupies the anteroproximal third of the medial surface of the shaft. It is transversely concave and is directed medially upward and forward, receiving the corresponding facet of metatarsal III in a curved contact. Its medial margin is rounded and extends as a flared process in a medial flange. The anterior apex forms the distal extremity of the facet, and it is separated from the distal articular facet by a narrow interarticular region on the anteromedial angle of the shaft.

The lateral facet for metatarsal $\mathrm{V}$ is triangular 


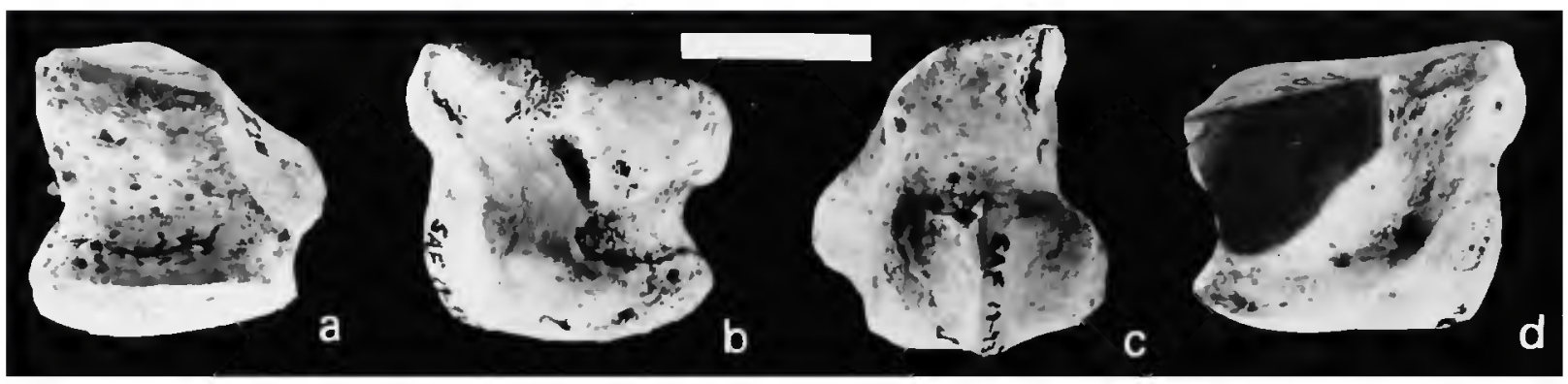

FIGURE 66.-Right metatarsal IV of Glyptotherium texanum (F:AM 95737): $a$, anterior; $b$, lateral; $c$, posterior; $d$, medial. (Bar $=20 \mathrm{~mm}$.)

and weakly convex in the proximodistal direction. Its orientation is roughly parallel to the sagittal plane.

The distal articular surface, for phalanx $\mathrm{I}$, is a four-sided facet, convex in both the anteroposterior and transverse directions and occupying the entire distal surface of the bone. The straight medial border is nearly twice as long as the lateral border. Hence, the broadly rounded anterior margin reaches its anterior extremity at the rounded anteromedial apex, from which it tapers laterally and rearward, forming a rounded anterolateral angle with the lateral margin. The marginal borders are posteriorly convergent. They meet the posterior sesamoid facets at the posterodistal angle, the border with the shorter medial facet extending farther posteriorly than that for the lateral facet. The intersesamoid crest of the sesamoid facet continues as a weak ridge on the posterocentral surface of the distal facet.

Both sesamoid facets are proximodistally elongate, parallel to the sagittal plane, and concave in the transverse direction. They unite at the crest of the intersesamoid ridge, which is situated approximately in the sagittal plane. They are approximately equal in length, but the lateral one is distinctly wider transversely. Together they occupy the distal half of the posterior surface of the shaft.

The nonarticular regions of the shaft are irregular and pitted. There are shallow lateral and medial excavations, and therc are modestly de- veloped anteroproximal, posteroproximal, and posteromedial tubercles.

Metatarsal IV of G. arizonae (Figure 75) is similar in most respects to that of $G$. texanum. It is considerably larger, but all proportions are approximately the same except for those in the transverse dimensions, which are somewhat longer. The distal articular facet is rather more flattened, and it bears in the central position a nonarticular excavation. The facet for metatarsal $\mathrm{V}$ is rectangular, rather than triangular, but its situation and disposition are otherwise identical. The tubercles and excavations are more pronounced, in keeping with the larger size in this species.

In UMMP 46231, there is a large foramen in the shaft on the posterior surface immediately above the sesamoid facets, and directed anteriorly and upward. There are, in addition, two deep foramina on the anterolateral surface of the shaft above the distal facet, penetrating deeply inward. These are likely pathologic, as in other elements in this specimen. There is a similar condition on the ungual phalanx.

Metatarsal IV of $G$. floridanum (Figure $73 b$ ) is intermediate in size. Despite the fact that it is smaller than that of $G$. arizonae, it is more transversely expanded, and the proximal articular facet is disproportionately wider. Its most significant character is in the nature of the sesamoid articular facets, which, rather than parallel to the sagittal plane, are directed distally inward, form- 
ing an oblique angle with the distal articular facet. The crest separating these two facets is similarly oriented. Moreover, the shapes of these facets are less symmetrical, and there are three massive foramina situated on the shaft at their proximal border, where only small foramina are situated in the other two species.

Sesamoid Bones, Metatarsal IV (Table 54).-The lateral sesamoid of metatarsal IV in $G$. arizonae and $G$. texanum is considerably larger than the medial. Both sesamoids are transversely compressed, and they present articular facets that are proximodistally concave and transversely convex, these conforming exactly with the sesamoid facets of the metatarsal. The articular facet of the lateral sesamoid is approximately twice the width of that of the medial, although it is only slightly longer in the proximodistal direction. The free end of each sesamoid forms a posteroproximal apex situated above the upper level of the articular facet. The plantar border of the lateral sesamoid is thickened, forming an expanded convex free end, while that of the smaller medial sesamoid forms a more compressed, relatively sharp plantar angle. The inner surface of each is partly concave, together in opposition forming the tendinal channel, as in the other metatarsal sesamoids. The outer surfaces are irregular. Except for the marked size difference, these elements are identical in the two species for which they are known.

Metatarsal V (Table 53). - The fifth metatarsal occupies the lateral position of the metatarsus. It articulates proximally with the lateral half of the cuboid, proximomedially with the fourth metatarsal in a flat contact, and distally with phalanx I, digit V. It possesses an articular surface for the single metatarsal sesamoid, which also contacts phalanx I. In $G$. texanum, metatarsal $\mathrm{V}$ (Figure 67) is approximately the size of metatarsal I. It is distinguished from the medial metatarsal by the articular facet on the shaft for metatarsal IV; metatarsal I lacks articulation with the adjacent metatarsal. Metatarsal $\mathrm{V}$ is further distinguished by the two concave primary articular facets, rather than one convex and the other concave. It is anteroposteriorly elongate and irregular in shape.

The proximal articular facet is a uniform concave half ellipse, with the straight border on the medial side, and the rounded outer margin extending from the anteromedial angle to the posteromedial angle, conforming with the outer portion of the opposing facet of the cuboid. The posteromedial angle is upturned and forms a small pointed prominence. The facet for contact with metatarsal IV is triangular, with a straight proximodistal margin on the anteromedial corner of the bone, an upper anteroposterior margin forming a common angle with the proximal facet, and a diagonal extending downward and forward from a position near the proximomedial tubercle of the proximal facet. The anteroproximal angle is approximately $90^{\circ}$. This facet is directed medially and slightly proximally with respect to the proximal facet.

The distal articular facet is rather less concave than the proximal one. It is oval in shape, with the medial margin somewhat straightened. The posterior border is upturned for the plantar sesamoid, forming a poorly defined knoblike facet. The distal facet is directed somewhat laterally with respect to the proximal facet, their respective concavities convergent posterolaterally. The maximum proximodistal diameter occurs at the anteromedial angle.

The medial surface of the shaft is flattened, and the remaining outer border is rounded. A blunt tubercle occupies the posterolateral position.

Metatarsal V in G. arizonae (Figure 75) is proportionally similar to that of $G$. texanum. The proximal articular facet is identical. The metatarsal facet differs in having rounded margins, with a distally directed apex. It contacts the proximal facet over a relatively shorter distance because of its rounded anterior margin. The distal articular facet is more transversely expanded, and its concavity is irregular. There is a mediocentral depression on the distal facet, lacking in $G$. texanum. The sesamoid facet is more well defined. It 


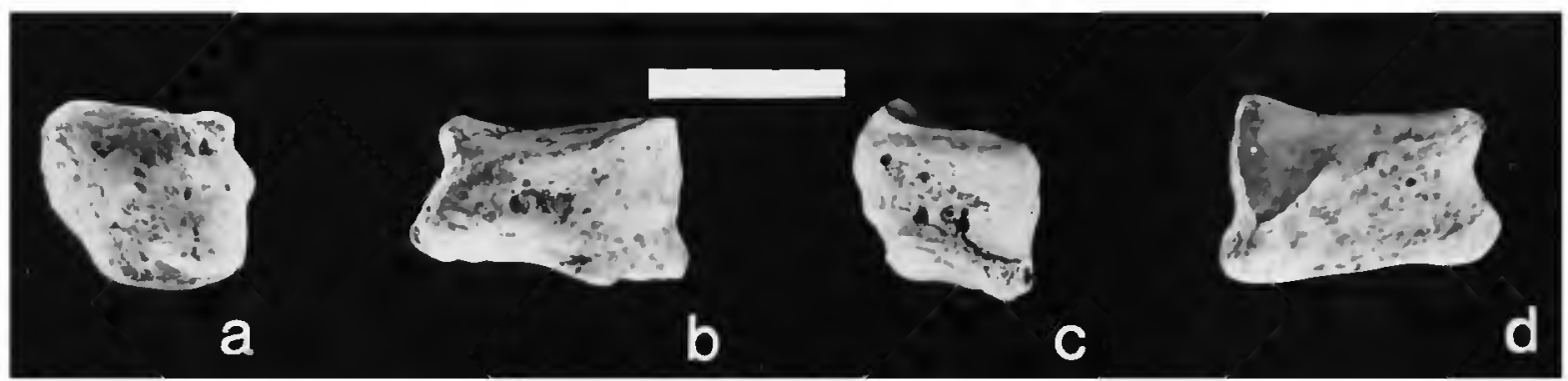

Figure 67.-Right metatarsal V of Glyptotherium lexanum (F:AM 95737): $a$, anterior; $b$, lateral; $c$, posterior; $d$, medial. (Bar $=20 \mathrm{~mm}$.)

is convex and extends posteriorly as a prominent tubercle. The posterolateral tubercle is extremely well developed, extending far beyond the margins of the articular facets. The surface of the shaft is rugose and pitted.

Sesamoid Bone, Metatarsal V (Table 54).The single plantar sesamoid associated with metatarsal $\mathrm{V}$ in $G$. texanum is a small, irregular element. In F:AM 95737, the one associated with left metatarsal $\mathrm{V}$ is rather more flattened and somewhat larger than the one for the right metatarsal. The latter is a somewhat compressed spheroid, devoid of articular facets, thus accounting for the indistinct sesamoid articular region of the metatarsal. In contrast, the left sesamoid, metatarsal $\mathrm{V}$, in this specimen, possesses a flattened articular facet and contacts the more well-defined articular region of the corresponding metatarsal. It is situated at the posteroproximal extremity of the first phalanx and contacts the phalanx and the large sesamoid of phalanx II.

The sesamoid bone for metatarsal $\mathrm{V}$ is not known for either the Curtis Ranch or Seymour representatives of $G$. arizonae, in part explaining the disparity in sesamoid counts betwcen Melton's (1964) determination and that proposed here. Although, of course, the existence of a sesamoid bone for this metatarsal is questionable until one is found, in all three otherwise complete specimens, USNM 10536, UMMP 38761, UMMP 46231, including metatarsal $\mathrm{V}$ and the complete digit for each, there is an appropriate space for a sesamoid comparable to that for F:
AM 95737 (G. texanum). In USNM 10536 there is a single sesamoid facet on metatarsal $\mathrm{V}$ in the appropriate position, providing evidence of one sesamoid, rather than two or none. In all three $G$. arizonae specimens the lateral posterior tubercle of phalanx I is greatly overdeveloped, and the medial tubercle virtually lacking, as in $G$. texanum. Thus a sesamoid bone was likely situated in the space between the metatarsal and phalanx II, occupying the space left vacant by the reduction of the medial posterior tubercle of phalanx $I$.

Digit I, PEs. - The first digit of the rear foot includes two phalanges and two plantar sesamoid bones, one at each of the two joints. The first phalanx is smaller than either the first metatarsal or the terminal (ungual) phalanx. The proximal sesamoid, situated at the metatarsal-phalanx joint, as described above, is more than two times longer than the distal sesamoid, located at the terminal joint. This digit projects downward and medially from the center of the tarsus. This orientation is effected primarily by the medial rotation of the distal facet of the internal cuneiform. The succecding articular facets are oriented obliquely with respect to the transverse axis of the digit, so that in anterior view the articular surfaces are directed laterally downward. Hence, the transverse motion in the joints of this digit is functionally as important as the fore-and-aft motion.

Digit I exhibits modifications commensurate with its position as the medial member of a series of the five symmetrically disposed digits arranged 
in a semicircle. Progressive modifications for this position, beginning with the internal cuneiform, culminate in the terminal phalanx, which is so rotated that its flattened outer (dorsal) surface is medially directed with respect to the body of the animal. Similarly, the ontogenetically lateral border of the compressed ungual phalanx occupies anatomically the anteriormost position. The following descriptions for this digit are based on the ontogenetic reference, i.e., dorsal-anterior, plantar-posterior, keeping in mind that the dorsal surface is medially directed (outward with respect to the foot) and the plantar surface is laterally directed (inward with respect to the foot).

It is impossible to determine with confidence whether an isolated rear ungual phalanx belongs to the first digit on one side (for example digit I, right), or to the fifth digit of the other side (digit $\mathrm{V}$, left). The reason for this difficulty is that the outer and inner ungual phalanges of each rear foot are virtual mirror images, a consequence of the marked bilateral symmetry of the rear foot.

Digit I is known only for $G$. texanum (Figure 68) and G. arizonae (Figure 75).

Phalanx I, Digit I, Pes (Table 55). - The first phalanx of digit $\mathrm{I}$, pes, of $G$. texanum, is a proximodistally compressed element, bearing proximal and distal articular facets, each with posteriorly directed extensions for contact with plantar digital sesamoids. Both articular facets present the shape of a half ellipsoid with rounded anterior apices, the proximal more elongated than the distal. The proximal facet is concave in the anteroposterior direction, transversely flat anteriorly, and weakly convex near its posterior border. A smaller lateral and a larger medial extension of the proximal facet provide posteroproximally directed articular surfaces for the single digital sesamoid at the phalanx-metatarsal joint. A prominent posteromedial tubercle is situated beneath the proximal facet, and a smaller lateral tubercle is situated on the posterolateral angle.

The distal articular facet is anteroposteriorly convex and transversely concave. It is laterally convergent in an acute angle with the proximal facet, and it is laterally offset so that its lateral border projects beyond the lateral extent of the proximal facet. The posterior border of the distal facet is upturned to form a large articular surface for the distal sesamoid.

The only notable distinctions of this element in $G$. arizonae are the transverse, rather than flat, concavity of the proximal facet and the more proximal orientation of the sesamoid portions of this same facet. The posterior tubercles are more massively developed, and the region separating them is more deeply excavated. These differences are attributable to ontogenetic variation with increasing size and are not taxonomically useful.

In UMMP 46231 there is considerable degeneration of the bone in both phalanges of this digit. In phalanx I this obvious pathologic abnormality includes a tremendous enlargement of the posterior foramen.

Phalanx II, Digit I, Pes (Table 55).-The terminal phalanx of the first digit, pes, in $G$. texanum (Figure 68), is a triangular, dorsoventrally compressed element. An ungual sheath enveloped the entire bone except for the small subungual base. The proximal articular facet is transversely elongate. It faces laterally and posteriorly, in anatomical position assuming a nearly vertical orientation. The weakly concave facet is dorsally and laterally elevated, reaching an apex at the posterolateral angle, from which occurs the greatest proximodistal diameter. The flattened dorsal surface of the ungual phalan $x$ is rotated medially with respect to the long axis of the digit, and the lateral angle represents the leading edge of the bone in fore-and-aft motion. Loose articulation with the first phalanx occurred over a broad area, indicating considerable mobility at this joint.

The subungual base in the juvenile specimen F:AM 95737 occupies the proximal half of the posterior surface of the claw process. Its rounded outline continues medially and laterally, merging gradually with the proximomedial and proximolateral angles. Two subungual foramina, a large lateral one and a smaller medial one, penetrate deeply into the plantar surface. The claw process is weakly convex on its dorsal surface in both the transverse and proximodistal directions and more 


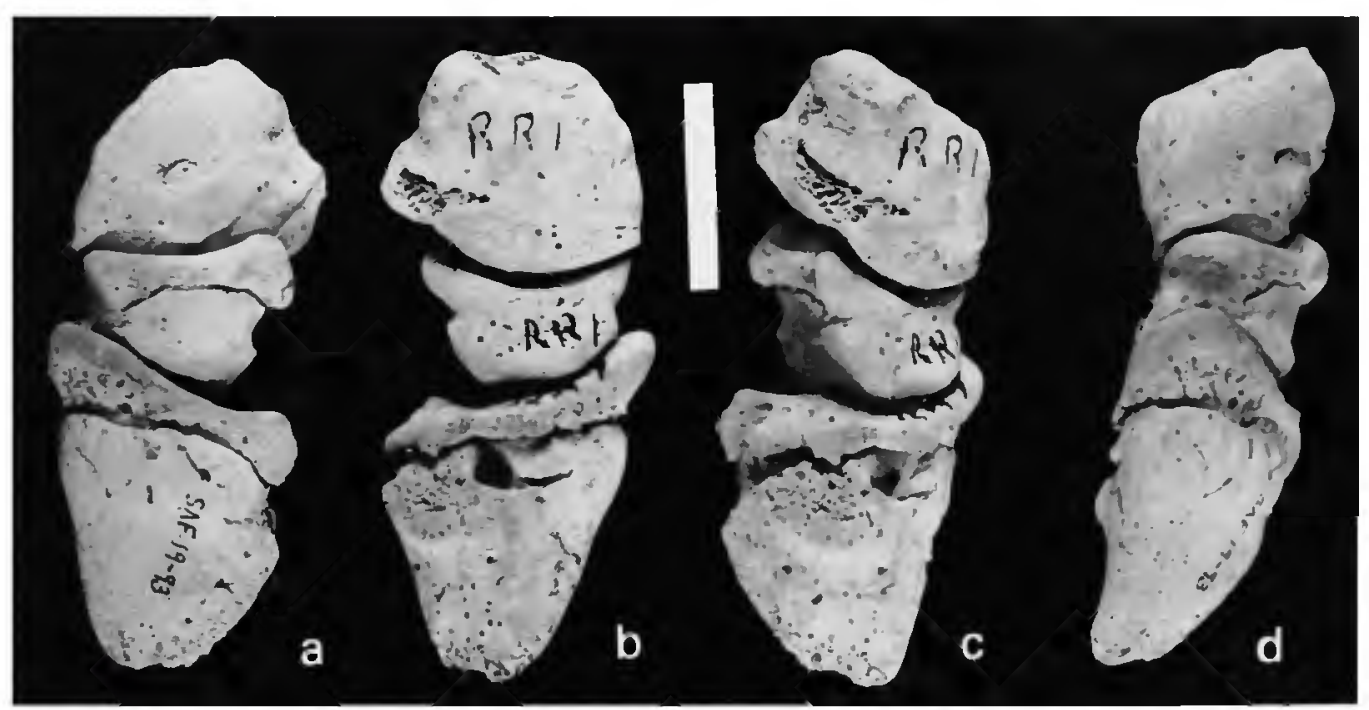

FIGURE 68.-Digit I, right pes, with metatarsal I, of Glyptotherium texanum (F:AM 95737): a, medial, or plantar face of digit with respect to axial plane of foot; $b$, lateral, or palmar face of digit with respect to axial plane of foot; $c$, posterior, or trailing edge of digit wih respect to axial plane of foot; $d$, anterior, or leading edge of digit with respect to axial plane of foot. (Bar $=20$ $\mathrm{mm}$.)

strongly convex on its posterior surface. The triangular claw process terminates in an indistinct apex.

Ungual phalanx, digit I, pes, of $G$ arizonae (Figure 75), is greatly expanded, especially in the transverse direction, in comparison with that of G. texanum. The articular facet occupies relatively less surface area. Its surface is laterally flattened and medially upturned in a small concavity. The subungual hood is proximally expanded and heavily rugose, completely surrounding the proximal facet. Accordingly, the subungual foramina are situated well within the region of the subungual hood on the proximal surface, rather than on the border of the hood with the claw process. The subungual hood extends as a well-defined flange over the claw process in the adult condition, clearly demarcating the proximal limits of the ungual sheath. It is broadly arched on the plantar surface of the bone, continuing upward to terminate on the medial and lateral angles. The subungual hood did not extend onto the dorsal surface. The ungual sheath apparently covered the entire dorsal surface except for the extremely rugose proximal extremity. The subungual hood was probably similarly developed in the adult condition for $G$. texanum.

As described in the general discussion of digit I, pes, this bone bears an exact reverse identity (mirror image identity), with the terminal phalanx of digit $V$ on the same side of the body. Hence, it is identical to the ungual phalanx of digit $V$ of the opposite foot. Therefore, caution must be cmployed before determining that a given isolated rear ungual phalanx belongs to either the outer of one side or the inner digit of the other side.

Distal Sesamoid Bone, Digit I, Pes (Table 64).-The distal sesamoid in $G$. lexanum, located at the first phalanx-terminal phalanx joint, is a modified sphere with a flattened articular surface for contact with both phalanges, primarily the first. It is also flattencd on $j$ ts lower surface, forming with the articular facet a right angle. It is rugose and pitted, presenting a transverse diameter nearly equal to that of the proximal sesamoid and a long-axis diameter only approximately half that of the upper sesamoid. 
This element is embedded in the plaster mount for USNM 10536 (G. arizonae). In both UMMP 38761 and UMMP 4623I, the distal sesamoids are identical to that of $G$. texanum in all respects except for their larger size.

Digit II, Pes.-As the inner of the three primary weight-bearing digits of the rear foot, digit II includes the full complement of three phalanges, and along with the metatarsal, three plantar digital sesamoids, two proximal ones articulating with the metatarsal, described above, and a distal one at the terminal joint. The articulations are generally flat and broad, with close contact and little mobility, except at the terminal joint, which has considerable fore-and-aft and transverse motion. The proximal and middle phalanges are compressed and discoid, the proximal one somewhat larger than the middle one. The latter phalanx is wedge-shaped, its articular facets anteriorly convergent. The medially and distally directed outer (dorsal) surface of the ungual phalanx is obliquely oriented at approximately $45^{\circ}$ with respect to the sagittal and transverse planes. Its proximal and distal length approximates the combined lengths of the two preceding phalanges. All three phalanges are rounded medially and anteriorly and flattened laterally, fitting snugly against the opposing surfaces of the middle digit. The sesamoids are stout.

Like the relationship between digit I and digit $\mathrm{V}$, the second digit bears a close reverse symmetrical identity with the fourth. The resemblance is especially marked for the terminal phalanges, which are indistinguishable in isolation as being from digit II on one side or from digit IV from the opposite limb. This situation is analogous to that for the outer digits as discussed above.

Digit II, pes, is known only for G. texanum (Figure 69) and G. arizonae (Figure 75).

Phalanx I, Digit II, Pes (Table 56). - The first phalanx of digit II, pes, of G. texanum (Figure 69), is a modified and greatly compressed planoconcave discoid, with subequal transverse and anteroposterior (dorsoplantar) dimensions. In proximal and distal aspects the outline is anteroposteriorly elongate, with a broadly curved medial border, a rounded anterolateral apex, and a nearly straight lateral border. The two posterior tubercles are relatively small, and the intervening groove is narrow. The medial tubercle is rather more blunt and expanded than the lateral one. The proximal articular facet is concave in the anteroposterior direction and flat in the transverse plane. The dorsal border is elevated as the anterior extension of the concave facet, producing in this position the greatest proximodistal diameter. The proximal facet is indistinctly separated into a narrower lateral portion and a broader medial portion. The nearly flat distal articular facet is weakly concave in all directions, thus producing at its center the minimum proximodistal diameter. From this central position, a shallow and poorly defined nonarticular sulcus extends rearward to the posterior border. Thus the distal facet is posteriorly divided into medial and lateral winged portions. A prominent transversely expanded tubercle marks the proximal half of the anterior (dorsal) surface of the compressed shaft.

Phalanx I, digit II, pes, of G. arizonae (Figure 75), differs in the relative proportions, being especially elongate in the transverse dimension. It is so greatly expanded in the transverse dimension, relative to the anteroposterior and proximodistal dimensions, that it is transversely elongate, rather than anteroposteriorly, as in G. texanum. This marked expansion may be regarded as the allometric product of increased size, for this bone is otherwise very similar to that of $G$. texanum except for the elaboration of features related to ontogenetic change: the anterior tubercle and the two posterior tubercles are more pronounced; the articular facets are more well defined; and the shaft is relatively more rugose and pitted in the larger species.

Phalanx II, Digrt II, Pes (Table 56). - The second phalanx of digit II, pes, in G. texanum (Figure 69), like the first phalanx, is a modified plano-concave discoid, but the plantar articular facet is the proximal one, and the concave facet is the distal one. It is smaller than the first phalanx, and in articulation it represents a wedgeshaped element separating the first phalanx from 


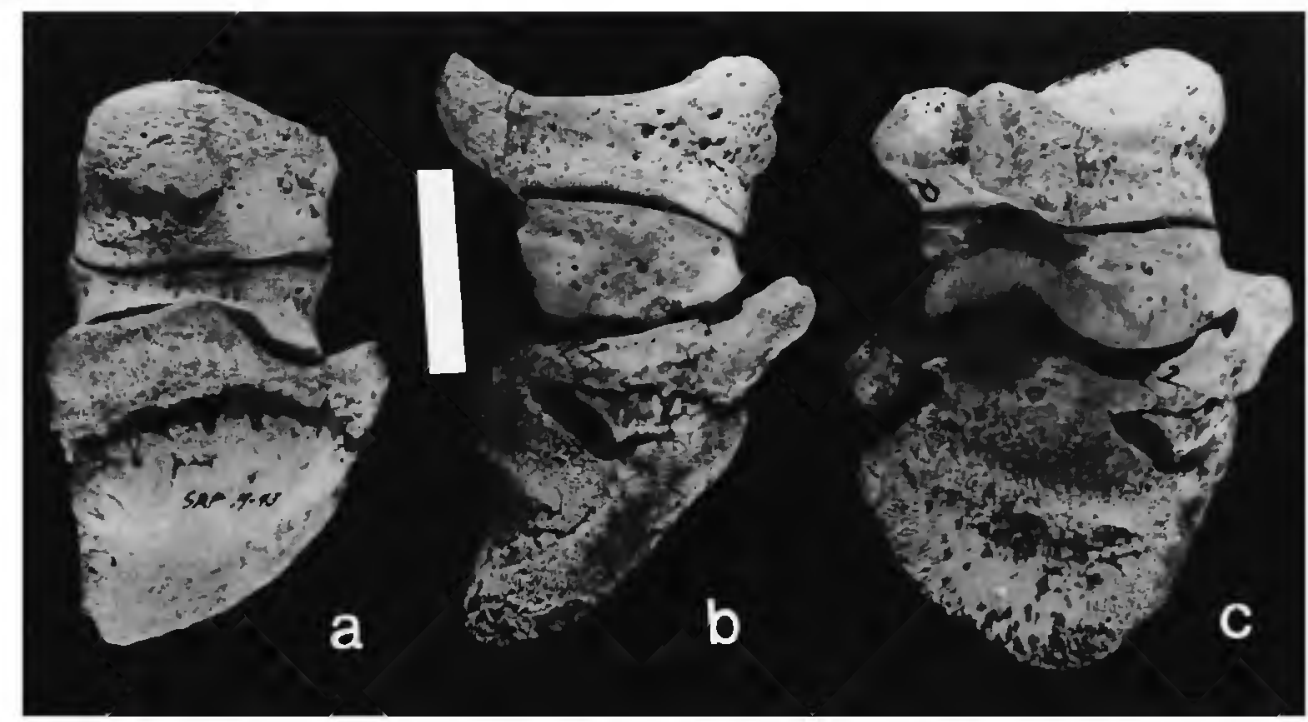

FIGURE 69.-Digit II, right pes, of Glyptotherium lexanum (F:AM 95737): a, anterior; $b$, lateral; $c$, slightly oblique posterior. (Bar $=20 \mathrm{~mm}$.)

the third. Its transverse diameter is slightly greater than the anteroposterior diameter, and the proximodistal diameter is approximately half of both. The flattened proximal facet presents two poorly defined portions: a smaller medial side, facing slightly away from center in the medial direction, and a larger lateral portion. The proximal facet extends rearward to the medial and lateral angles over the subdued posterior tubercles. In proximal aspect the medial border is broadly curved, and the anterior border is nearly straight, as is the lateral border. The distal articular facet is directed somewhat anteriorly (dorsally) with respect to the proximal facet, imparting the wedge-like construction of the phalanx. It is transversely concave and weakly convex in the anteroposterior direction. The anterior border nearly meets the anterior extremity of the proximal facet. There is a gradual increase in proximodistal thickness rearward. The distal facet is confluent with the concave articular facet for the distal digital sesamoid. This latter facet occupies all of the posterior surface of the shaft except for a narrow interarticular region separating the sesamoid facet from the posterior border of the proximal facet.
The second phalanx, digit II, pes, in $G$. arizonae (Figure 75), although much larger, is proportionally equivalent to that of $G$. texanum. It differs in details of the articular facets and in having medial and lateral tubercles on the shaft. The proximal articular facet is uniformly flat and not divided into two portions. There is a central constriction on the anterior face of the shaft that modifies the proximal facet into a wing-shaped surface, with concave anterior and post erior borders. The distal articular facet is divided into lateral and medial flattened portions, each facing inward, by a longitudinal nonarticular furrow, corresponding to the central concavity of this facet in $G$. texanum. This furrow continues rearward, meeting a similar groove on the posterior surface of the shaft, which divides the sesamoid facet into medial and lateral portions. The posterior tubercles are correspondingly more pronounced.

Phalanx III, Digit II, Pes (Table 57). - The terminal phalanx of the second digit, pes, bears a reverse symmetrical identity with the terminal phalanx of digit IV. Hence, it is impossible to distinguish between terminal phalanx, digit II, and terminal phalanx, digit IV, of the opposite limb, as explained previously. 
This bone in G. texanum (Figure 70) is a triangular, wedge-shaped element, expanded in the proximodistal and transverse directions and compressed in the anteroposterior (dorsoplantar) direction. It was entirely encased in an ungual sheath except for the region of the subungual base on the plantar surface. The proximal articular facet forms an acute angle (approximately $45^{\circ}$ ) with the dorsal surface, producing a triangular outline in lateral and medial aspects. The proximal facet is ovoid, with a straight posterior border. It is slightly convex in the transverse direction, and there is an indistinct division into medial and lateral portions. The facet extends to the anteromedial angle, but its remaining borders are flanked by nonarticular regions. The anterolateral tubercle extends in the plane of the facet as a prominent process. In anterior view, this tubercle forms the expanded lateral portion of the proximal extremity above the epiphysis.

The subungual base presents the shape of a half ellipsoid, with the subungual foramina occupying the medial and lateral borders. These foramina are slightly elliptical and symmetrically disposed on the plantar surface of the bone. The lateral foramen is slightly larger than the medial, and both nearly contact the border of the proximal facet. The free end of the phalanx is triangular, with equidimensional, rounded sides. The anterior surface is broadly and uniformly convex, the posterior surface irregularly convex and somewhat flattened near its lateral margin. The terminal apex is situated directly in line with the center of the proximal facet. The surface of the free end is distinctly smoother and less rugose than the subungual base and the nonarticular regions of the proximal extremity.

The terminal phalanx, digit II, pes, of $G$. arizonae (Figure 75), differs from that of $G$. texanum in its relatively greater transverse expansion and in details of the articular facet and the free end. The proximal facet is distinctly divided into two portions, a medial concave one, and a lateral flattened and somewhat elevated portion. The division of these two portions of the facet is accentuated by anterior and posterior constric- tions of the outline of the facet, imparting an overall bilobate shape to the articular surface. This construction corresponds to the similar modifications of the second phalanx.

The subungual foramina are situated well within the margins of the subungual base, and both border the proximal facet. They are approximately equal in size. The free end is more elongate in the proximodistal direction and suggests the shape of a trapezoid on edge (base of the trapezoid is the lateral border of the bone). The lateral, proximal, and medial borders are straight, rather than rounded, and the roughened terminus is weakly arched. The distal extremity of the phalanx occurs at the distolateral angle. The expanded posterior surface of the free end is weakly concave in the transverse plane, and the lateral portion of the posterior surface is distinctly flattened.

Although these distinctions are in part attributable to ontogenetic changes, the differences between these two species seem to be consistent.

Distal Sesamoid Bone, Digit II, Pes (Table 64).-The transversely elongate distal sesamoid bone in $G$. texanum articulates exclusively with the second phalanx at the terminal joint. Its articular facet conforms exactly with the sesamoid facet of phalanx II. Its surface is rectangular, with rounded corners, and its transverse dimension is approximately twice that of the proximodistal diameter. From a crest offset slightly medially from center, the facet is laterally concave and medially flattened. The former portion is oriented somewhat laterally, the latter somewhat medially. The proximodistal diameter of this sesamoid in articular position is approximately the same as that of the phalanx. The plantar surface is weakly divided into two proximodistally directed tendinal grooves, and it extends distally to form a small median distal tubercle.

This bone is similar in G. arizonae. Its articular facet is divided into two portions by a deep furrow, corresponding to the division of the sesamoid facet of phalanx II. This sesamoid is more heavily rugose and more deeply excavated than in G. texanum. 
Digit III, Pes. - The middle digit is the largest of the hind foot, and each of the three phalanges are respectively the largest of the pes. Digit III is bilaterally symmetrical, with a broadly rounded anterior border and flattened lateral and medial borders. As the largest weight-bearing digit it articulates with the metatarsus as the central, anteriorly directed, elcment of the foot. Phalanx I is discoid, and phalanx II is wedge-shaped. The ungual phalanx is a stout, symmetrical terminus, buttressed by a large plantar sesamoid on the posterior surface of the phalanx II. The total length of digit III is only slightly greater than that of metatarsal III, with which it articulates. In anterior aspect the articular facets are elevated slightly toward the lateral side, with respect to the sagittal plane, thereby permitting determination of right or left for an isolated phalanx of this digit.

Complete middle digits, including the sesamoid, are known for $G$. lexanum (Figure 70) and $G$. arizonae (Figure 75). The first and ungual phalanges are known for $G$. floridanum.

Phalanx I, Digit III, Pes (Table 58).-The first phalanx of the middle digit in $G$. texanum (Figure 70) is a doubly concave discoid, somewhat elongate in the anteroposterior direction. This element displays almost perfect bilateral symme- try except for the rather greater development on the anterolateral surface of the anterolateral tubercle. The posterior tubercles are blunt and rounded and set close together; they are separated by a relatively small intertubercular groove. The proximal articular facet is transversely flat, anteroposteriorly concave, reaching maximum elevation at the anterior margin. In proximal aspect this facet is ovoid, with gradual narrowing rearward from the expanded anterior border. The facet extends onto the proximal surface of the posterior tubercles.

The distal articular facet is more nearly circular and does not include the lower surface of the posterior tubercles. Its concavity is less pronounced. An indistinct nonarticular region in the central position of this uniformly concave surface affords identification as the distal facet. The articular facets are posteriorly convergent, but the angle so formed is very acute. Besides the anterolateral and the two posterior tubercles, there is an elongate tubercle on the lateral surface of the shaft. The nonarticular shaft is otherwise mildly rugose and pitted by nutritive foramina.

The only important distinction in phalanx I of $G$. arizonae (Figure 75) and $G$. lexanum is the better definition of the central nonarticular region of the distal facet. This region is somewhat de-

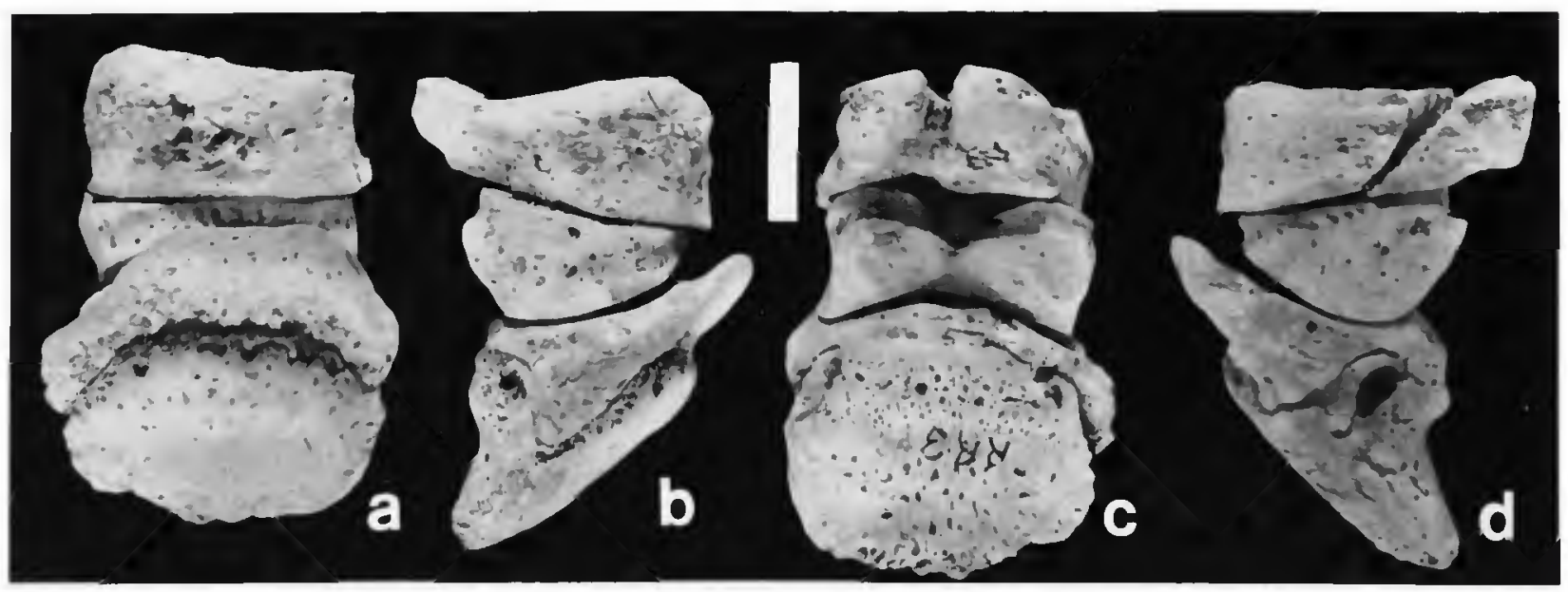

FigURE 70.-Digil III, right pes, of Glyptotherium texanum (F:AM 95737): $a$, anterior; $b$, lateral; $c$, posterior; $d$, medial. (Bar $=20 \mathrm{~mm}$.) 
pressed and extends rearward to the posterior border of the bone in both species. The distal facet in $G$. floridanum is distinctly more concave than in either of the other species. The transverse dimension is disproportionately larger in $G$. anzonae, in accordance with expected ontogenetic changes due to the larger size in this species. The phalanx in $G$. floridanum, intermediate in size between $G$. arizonae and $G$. texanum, is also intermediate in the transverse expansion.

Phalanx II, Digit III, Pes (Table 58).-The second phalanx of the middle digit in $G$. texanum is a wedge-shaped element, triangular in lateral and medial aspects. The proximal articular facet is flat, with only a subtle indication of convexity, thus conforming closely with the concavity of the opposing facet of phalanx I. The proximal facet is nearly rectangular in shape, with rounded anterior corners and rounded posterior extensions at the posterior angles. The intertubercular groove (tendinal groove) is widely expanded and relatively shallow.

The distal articular facet is transversely concave and anteroposteriorly convex. The phalanx exhibits equal medial and lateral proximodistal diameters at the posteromarginal angles of the facet. The minimum diameter occurs in the central position of the distal facet. The distal articular surface is directed anteriorly at approximately $30^{\circ}$; thus its anterior convergence with the proximal facet imparts the wedge-shaped character of this element. The distal facet nearly contacts the proximal one on its anterior border, with only a very narrow interarticular region separating the two facets on the anterior border.

The two-parted sesamoid facet is transversely concave, the marginal expanded portions directed posteriorly and inward. The two portions are continuous across a narrow constricted connection in line with the central concavity of the distal facet. The sesamoid facet meets the distal facet in a rounded angle. It is separated from the proximal facet by a narrow interarticular region. The posterior tubercles of the proximal phalanx are replaced by the expanded portions of the sesamoid facet. Indistinct tubercles are situated on the medial and lateral nonarticular surfaces of the shaft, which is otherwise mildly rugose and pitted with nutritive foramina.

The second phalanx of digit III, pes, of $G$. arizonae, is similar in most respects. The differences are primarily in degree of elaboration. Both the proximal and distal articular facets are indistinctly divided into medial and lateral sides by a shallow nonarticular depression. The medial and lateral sides of the distal facet are more nearly flat, rather than concave, and the sesamoid facets are somewhat more flat tened. The latter are completely separated by the tendinal groove. The medial portion of the proximal surface of USNM 10536 exhibits a degree of degeneration and exostosis, presumably due to the degenerative arthritic condition as noted for some of the other phalanges.

Phalanx III, Digit III, Pes (Table 59).-The terminal phalanx of digit III in G. texanum is the only bilaterally symmetrical ungual phalanx of the rear foot. The only apparent departure from this symmetry occurs with the subungual foramina, of which the medial is rather larger than the lateral, thus permitting identification of right or left for an isolated specimen. The overall shape of this bone is a broad oval in anterior aspect, while the lateral and medial aspects present a modified triangular outline, with two concave short sides formed by the articular facet and the distal end of the posterior surface, respectively, and a longer convex side formed by the dorsal surface. The articular facet is transversely convex and weakly concave in the anteroposterior direction. It is oval and somewhat longer transversely. The facet is bounded on all sides by a nonarticular border, especially on the anterior margin, which is extended in the same plane as the facet as a broad, flattened anterior tubercle. The proximal third of the dorsal surface is a flattened, crescent-shaped region, which, in the juvenile (as indicated in F:AM 95737), remained unsheathed. The dorsal surface of the free end is elevated above this proximal crescent, and the two portions are clearly demarcated.

The subungual base is transversely elongate 
and poorly separated from the ungual process, from which it stands as an elevated process. The symmetrically disposed subungual foramina, of which the medial is larger than the lateral, are situated on the border of the subungual base and the ungual process. They do not contact the articular facet.

The uniformly convex dorsal surface of the ungual process is nearly circular in outline. The plantar surface is transversely convex to a somewhat greater degree, and it is proximodistally concave for the elevation of the subungual base. The articular face is situated at approximately $45^{\circ}$ with respect to the dorsal border. In articulation this orientation produces an anterior surface for the ungual phalanx, which is directed as much downward as forward, with the articular facet maintaining the standard orientation and the plantar surface of the free end remaining in the plane of the posterior (plantar) surfaces of the more proximal phalanges.

The terminal phalanx of $G$. arizonae differs primarily in its larger size, especially in the transverse dimensions, and by the exaggeration of the same features possessed by the smaller species. The proximal nonarticular portion of the dorsal surface is fused with the free end, the junction being indicated only by an obscure boundary reflected by the nature of the pitted surfaces. The dorsal surface of the ungual process thus includes all of the anterior surface and was entirely encased in the ungual sheath. In anterior (dorsal) aspect the shape is more rectangular, with a somewhat greater expansion in the transverse plane. The articular facet is divided into medial and lateral portions by a median ridge. These are anteroposteriorly flattened, rather than concave, and transversely each faces outward to the same degree as the marginal portions of the facet of $G$. texanum. The subungual base is relatively more greatly expanded, incorporating within its bounds the subungual foramina. The subungual hood is well developed and extends on the margins upward to terminate on the proximomarginal angles. The plantar surface of the ungual process is centrally concave in the transverse di- rection. It is flattened on the margins, conforming with the corresponding surfaces of the adjacent ungual phalanges. The distal terminus is straight rather than rounded. The anterior tubercle is relatively less pronounced.

In UMMP 46231, this phalanx is rendered almost fragmentary by the presumed arthritic degeneration in this individual's foot. The claw process is greatly reduced and certainly pathologic.

Although the ungual phalanx, digit III, of $G$. floridanum (Figure 73e), resembles most closely the ungual phalanx of $G$. arizonae, it differs in several important details. Rather than presenting in overall outline a convex shape, the two portions of the articular facet are weakly concave, and their posterior border is nearly straight. The subungual foramina are relatively smaller than in either of the other species, and there are three large foramina situated in a row along the posterior margin of the articular facet. These are lacking in $G$. texanum and $G$. arizonae, both of which possess smaller, irregularly spaced foramina in this position. The posterior concavity of the ungual process is more deeply excavated than in $G$. arizonae, and the flattened margins are less well developed.

Distal Sesamoid Bone, Digit III, Pes (Table 64). - The distal sesamoid of the middle digit, pes, in $G$. texanum, articulates exclusively with phalanx II on its plantar surface at the terminal joint. The sesamoid bone is transversely elongate, approximately as long in this dimension as the phalanges. It possesses an elongate articular facet, occupying the full length of the bone, and a generally rounded, fusiform nonarticular surface, tapering gradually toward the rounded margins.

The articular facet conforms with the opposing facet of the phalanx. The facet is transversely elongate and faces anteriorly and proximally. The lower margin of the facet is straight, the upper is centrally constricted to produce the bilobate construction. The "wings" of the facet are directed somewhat outward with respect to the sagittal plane, and they are weakly concave in the transverse direction. Projecting proximally and poste- 
riorly is a blunt tubercle on the free margin of this sesamoid. The plantar surface is rounded and smooth, and the lower surface possesses several nutritive foramina set within a shallow, transverse excavation.

The distal sesamoid bone of digit III in $G$. arizonae is similar to that of $G$. texanum, except that the articular facet is separated into two distinct lobes by an intervening groove. The two portions of the facet are relatively more extensive in the proximodistal direction.

Digit IV, PEs.-The fourth digit of the rear foot is the lateralmost of the three primary weight-bearing toes. Because phalanx $\mathrm{I}$ is relatively short, digit IV is in total length somewhat shorter than digit II, and both are considerably shorter than digit III. The fourth digit, along with its metatarsal, includes the full complement of metatarsal and three phalanges plus one distal and two proximal sesamoid bones. The digit is medially flattened and broadly arched on the continuous anterolateral outer surface. The proximal and middle phalanges are extremely compressed, and the ungual phalanx is stout and pointed on its distomedial apex.

Complete fourth digits are known for $G$. texanum (Figure 71) and $G$. arizonae (Figure 75), and the ungual phalanx is known for $G$. floridanum (Figure $73 d)$.
Phalanx I, Digit IV, Pes (Table 60). - The proximal phalanx of the fourth digit, pes, in $G$. texanum, is easily distinguished from phalanx I, digit II, by its nearly uniform proximodistal thickness; its maximum proximodistal diameter is nearly equal to the minimum diameter of phalanx I, digit II. The proximal articular facet is weakly concave and extends onto the upper surfaces of the posterior tubercles. The margins of the facets parallel the surface of the shaft. The medial margin is straight, and the anterior and lateral margins form a broad continuous arc. The distal articular facet is nearly flat, and it possesses at its center a shallow excavation, which opens posteriorly as a nonarticular surface, separating posteriorly the medial and lateral portions of the distal facet. The distal articular surface coalesces gradually with the nonarticular lower surface of the posterior tubercles. The lateral tubercle is blunt and broad; the medial tubercle is narrow and more pointed. The intertubercular groove is constricted and narrow.

Phalanx I, digit IV, pes, in $G$. arizonae, is similar in most respects to that of $G$. texanum. The concavity of the proximal facet is rather more pronounced, especially near the medial border, and the nonarticular central depression of the distal facet is more deeply excavated. The posterior tubercles are larger, and the intertubercular

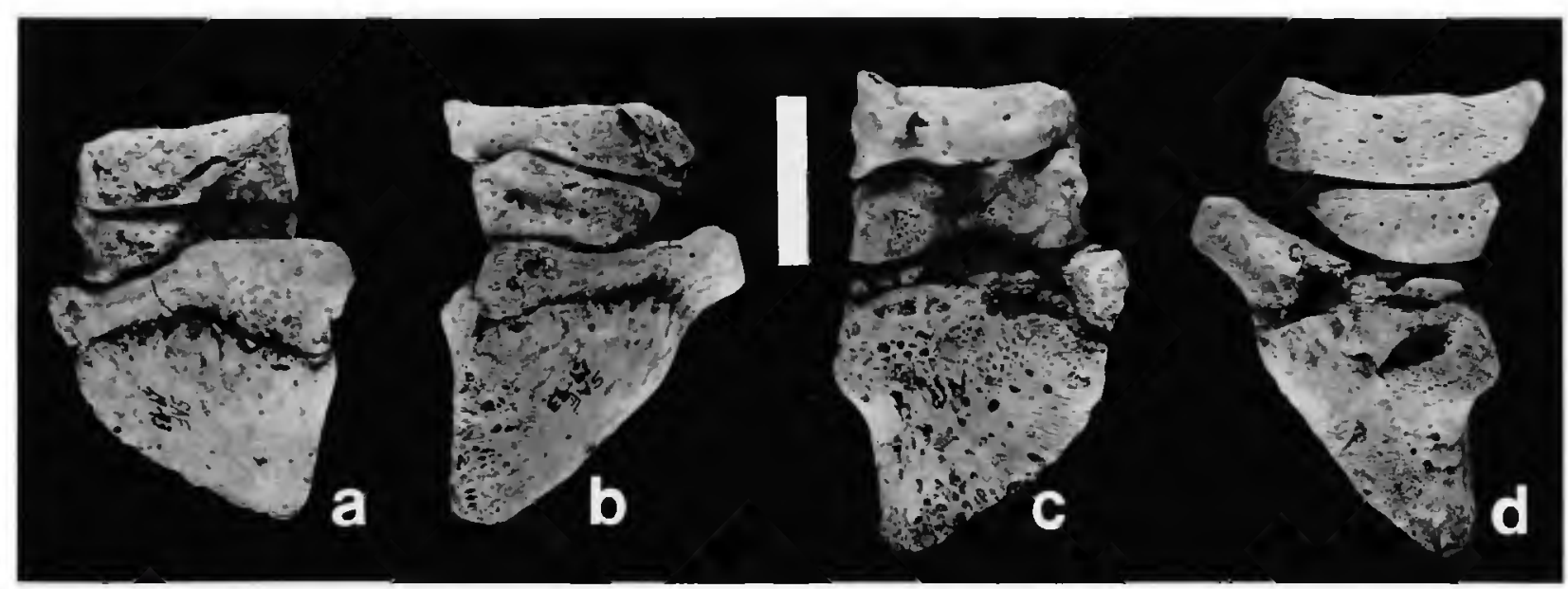

Figure 71.-Digit IV, right pes, of Glyptotherium texanum (F:AM 95737): a, anterior; b, lateral; $c$, posterior; $d$, medial. (Bar $=20 \mathrm{~mm}$.) 
groove is more widely expanded. The body is heavily rugose and deeply pitted, and the anteromedial tubercle is well developed. In overall comparison, phalanx I of $G$. arizonae exhibits a proportionally greater development in the transverse dimensions, probably in simple accordance with the larger size in this species.

Phalanx II, Digit IV, Pes (Table 60).-The second phalanx of digit IV, pes, in G. texanum, is somewhat smaller than phalanx I. It can be distinguished from phalanx II, digit II, by its flattened proximal facet, the lesser development of the sesamoid facet, the lesser degree of concavity of the distal facet, and its more nearly symmetrical shape. It is a wedge-shaped element, the proximal and distal articular facets anteriorly convergent in an acute angle. The proximal articular facet is flat and uccupies the entire proximal surface, including the upper surface of the widely expanded posterior tubercles. The intertubercular groove is broad and widely expanded to the rear. The distal articular facet is weakly concave in the transverse direction and slightly convex anteroposteriorly. It is directed somewhat anteriorly with respect to the proximal facet. The proximal and distal facets nearly come into contact on the anterior border of the bone. The marginal and anterior borders of the phalanx are rounded, and the posterior tubercles are blunt and rounded. The sesamoid articular facet is centrally constricted, producing medial and lateral, downward- and inward-directed flattened portions.

Phalanx II in G. arizonae is similar in most respects to that of $G$. texanum. Like the other phalanges, it is proportionally wider in the transverse dimensions, and the angle formed by the convergent proximal and distal articular facets is less acute. The proximal facet is divided into medial and lateral halves by an interarticular depression. The distal facet is similarly divided and the sides are flattened and inward-directed. The sesamoid facet is two-parted also, with the central constriction separating completely the two sides.

Phalanx III, Digit IV, Pes (Table 61). - The description for the terminal phalanx, digit IV, pes, of $G$. texanum, is exactly the same as that for the ungual phalanx of digit II, pes. By merely interchanging "medial" and "lateral," that description fully applies in every detail to ungual phalanx IV. There are no differences in size, proportions, or detail.

As for $G$. texanum, the terminal phalanx of the fourth digit, pes, of $G$. arizonae, bears a reverse identity with phalanx III, digit II. It possesses only two distinctions: its transverse dimensions are smaller, and the anterior margin of the articular facet is smoothly rounded rather than centrally constricted. Otherwise, these two elements are identical, and by merely interchanging medial and lateral, the description for this element is the same as for its symmetrical equivalent. The comparisons between the two species are also the same as for digit II. (See "Phalanx III, Digit II, Pes.")

In UMMP 46231, the ungual phalanx exhibits considerable pathologic erosion of the terminal border of the claw process. There is also erosion of the proximolateral tubercle, resulting in a pronounced sulcus between the anterolateral angle and the anterolateral corner of the articular facet. A similar condition, but less pronounced, is evident in UMMP 38761.

The terminal phalanx of digit IV in G. floridanum bears a close similarity in size and proportions to that of $G$. arizonae. Because the ungual phalanx for digit II is unknown for $G$. floridanum, a comparison between these two digits is not possible. There are only two minor distinctions characterizing this element of $G$. floridanum. The medial subungual foramen is smaller than the lateral one, rather than being equal in size. The articular facet is distinctly more flattened, with only a slight transverse convexity, and its shape is almost perfectly ellipsoidal.

Distal Sesamoid Bone, Digit IV, Pes (Table 64). - The distal sesamoid bone, digit IV, pes, of both $G$. texanum and $G$. arizonae, articulates exclusively with the middle phalanx at the terminal joint. It closely resembles the distal sesamoid of digit II, although it is somewhat smaller in all 
dimensions. The articular facet is two-parted and elongate transversely. The upper margin is constricted, and the lower is straight. The bone is fusiform in shape. There are several large foramina on the lower surface near the region of constriction of the articular facet. Posterior to these is situated a blunt plantar tubercle occupying the posterior position. The only difference between the two species is that the sesamoid of $G$. arizonae is considerably larger and more rugose.

Digit V, Pes.-The lateral digit of the rear foot contains three phalanges and two sesamoid bones. It occupies the lateral extremity of the semicircle formed by the digits, in a position fully opposite the first digit. The proximal and middle phalanges are wedge-shaped in opposite directions, together in articulation forming a more or less complete discoid. In this fashion, digit $\mathrm{V}$ displays a remarkable convergence with digit I, in which there are only two phalanges, the proximal and the ungual, rather than three. Digit $\mathrm{V}$ is medially flattened, and laterally and anteriorly rounded. Its outer surface is convex in the proximodistal direction. Like the first digit, its mobility and capacity for weight support are limited.

Complete fifth digits are known for $G$. texanum (Figure 72) and G. arizonae (Figure 75), and the ungual phalanx is known for $G$. floridanum.

Phalanx I, Digit V, Pes (Table 62). - The first phalanx, digit $\mathrm{V}$, pes, of $G$. texanum, is the most extremely compressed bone of the rear foot. The proximal facet is anteriorly flat and posteriorly convex, curving downward to contact the distal facet in a common angle at the posterior border. The distal articular facet bears an irregular, anteroposteriorly directed groove. The nonarticular surface of the shaft is reduced, forming a narrow irregular surface on the lateral and medial borders. The articulation of phalanx $I$ is advanced forward in such a way that its anterior margin contacts the anterior tubercle of the ungual phalanx in the fully extended position of the digit, thus bypassing the middle phalanx, due to its anterior wedge-shaped construction. The first phalanx therefore participates as the anterior portion of the doubly wedged discoid, formed by the proximal and middle phalanges in articulation.

Except for larger size and greater rugosity, this element is identical in G. arizonae. In UMMP 46231 there is a deep foramen on the posterior surface, owing to the pathologic condition in this specimen.

Phalanx II, Digit V, Pes (Table 62).-The second phalanx completes the double-wedge construction in the fifth digit. In $G$. texamum, the primary facets taper anteriorly, and their anterior borders are virtually in contact in a sharp angle. The facets are faintly divided into two regions by

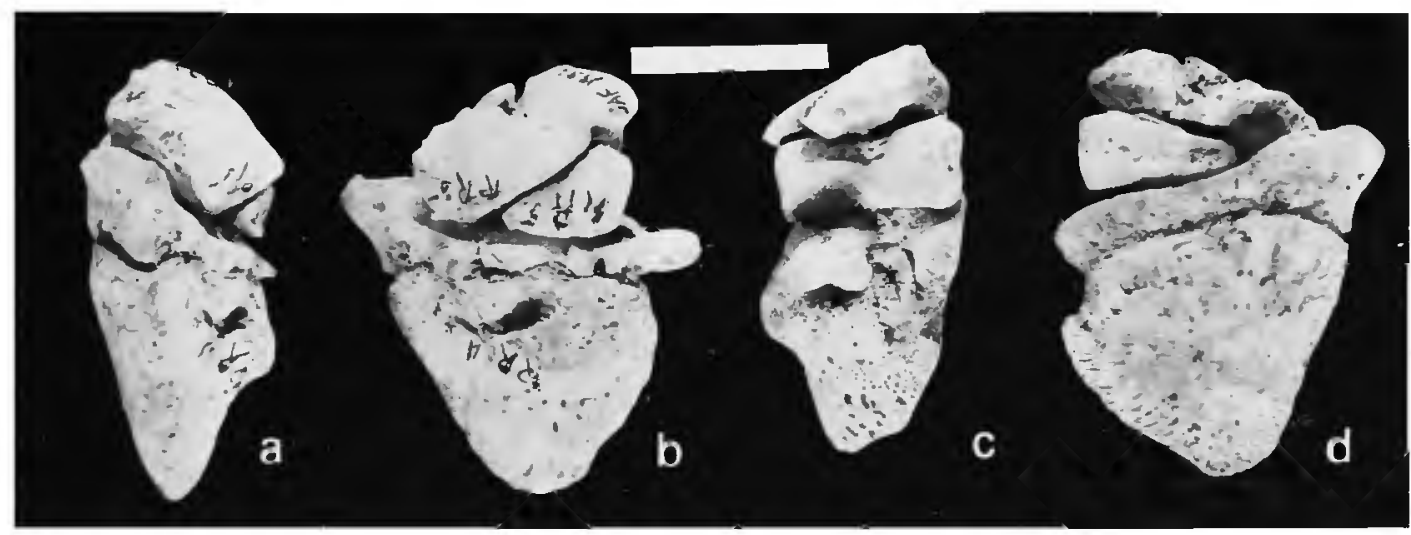

Ficure 72,-Digit V, right pes, of Glyptotherium texanum (F:AM 95737): a, anterior or leading edge of digit with respect to axial plane of foot; $b$, medial or palmar face; $c$, posterior or Irailing edge of digit wilh respect to axial plane of foot; $d$, lateral or plantar face. (Bar $=20 \mathrm{~mm}$.) 

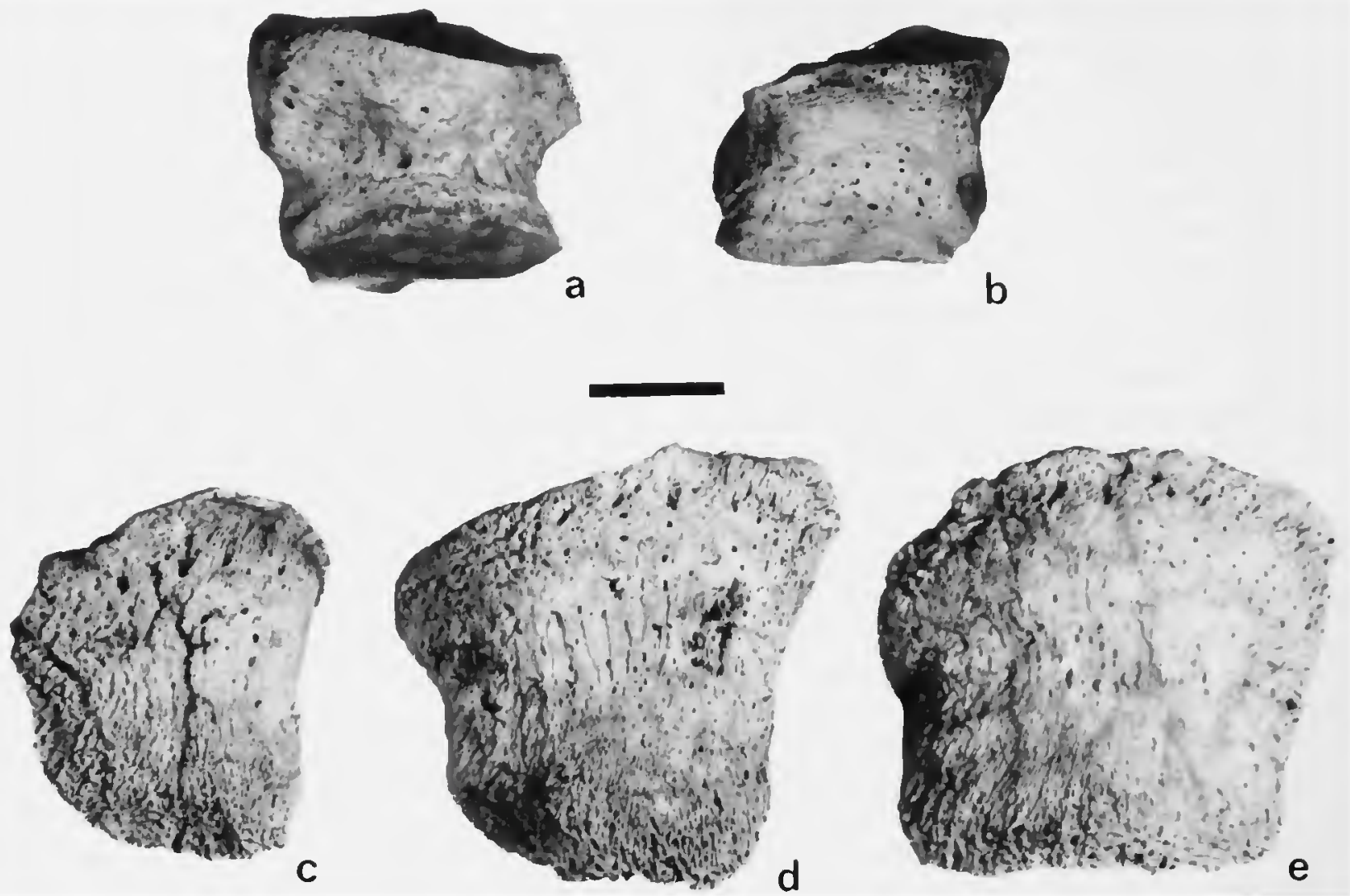

Figure 73.-Isolated bones of pes of Glyptotherium floridanum (USNM 6071): $a$, right metatarsal III, anterior; $b$, left metatarsal IV, anterior; $c$, ungual phalanx, right digit I, anterior; $d$, ungual phalanx, right digit IV, anterior; e, ungual phalanx, right digit III, anterior. (Bar $=20 \mathrm{~mm}$.)

a weak central constriction. The two portions of the proximal facet are each weakly concave, while the distal facet is uniformly concave in the transverse plane. The expanded posterior surface is occupied almost entirely by the sesamoid facet, which is confluent with the distal facet in a blunt angle. In lateral or medial aspect this wedgeshaped phalanx suggests a $30^{\circ}-60^{\circ}$-right triangle, the hypotenuse formed by the proximal facet, the $30^{\circ}$ angle by the anterior border. The anterior border reaches the midpoint only beneath the proximal phalanx, thus allowing partial contact between phalanges I and III.

Phalanx II, digit V, in $G$. arizonae, is similar in most respects. The only distinctions other than larger absolute size are the separation of the sesamoid facet into lateral and medial halves and the greater relative thickness at the posterior border imparting a nearly equidimensional wedge shape in lateral outline.

Phalanx III, Digit V, Pes (Table 63).-The ungual phalanx of digit $\mathrm{V}$, pes, in $G$. texanum, is nearly a symmetrical equivalent of the terminal phalanx of the first digit. The only perceptible difference is that in the fifth digit the terminal phalanx is somewhat broader transversely. As for the ungual phalanges of digits II and IV, by interchanging "medial" and "lateral" the description for terminal phalanx, digit 1 , applies in every detail to terminal phalanx, digit $\mathrm{V}$

Similarly, the terminal phalanx of digit $\mathrm{V}$, pes, in $G$. arizonae, is the symmetrical equivalent of the ungual phalanx, digit I. Unlike $G$. texanum, the transverse dimensions are approximately equal in 
these two elements. The proximal facet is somewhat smaller, and the medial subungual foramen is relatively larger than the lateral in digit $\mathrm{V}$. Otherwise, by interchanging "medial" and "lateral" the description for the ungual phalanx of digit I, pes, applies in every detail to that of digit V. (See "Phalanx II, Digit I, Pes.")

In UMMP 46231 there is considerable degeneration of the free border of the claw process and obviously pathologic enlargement of the lateral subungual foramen with concomitant exostosis of the ungual hood in the region surrounding this foramen. Similar conditions on phalanges I and
II are further evidence of this apparently arthritic pathologic condition.

The ungual phalanx, digit $\mathrm{V}$, pes, in $G$. floridanum, closely resembles that of $G$. arizonae in size and construction. Rather than convex, however, the articular facet is flat, and the medial extremity of the subungual hood is not as extensive as in $G$. arizonae. Also, the subungual foramina are approximately equal in size.

Distal Sesamoid Bone, Digit V, Pes (Table 64).- The distal sesamoid bone, situated in the plantar space between phalanges I and III and articulating with phalanx II, is a proximodistally

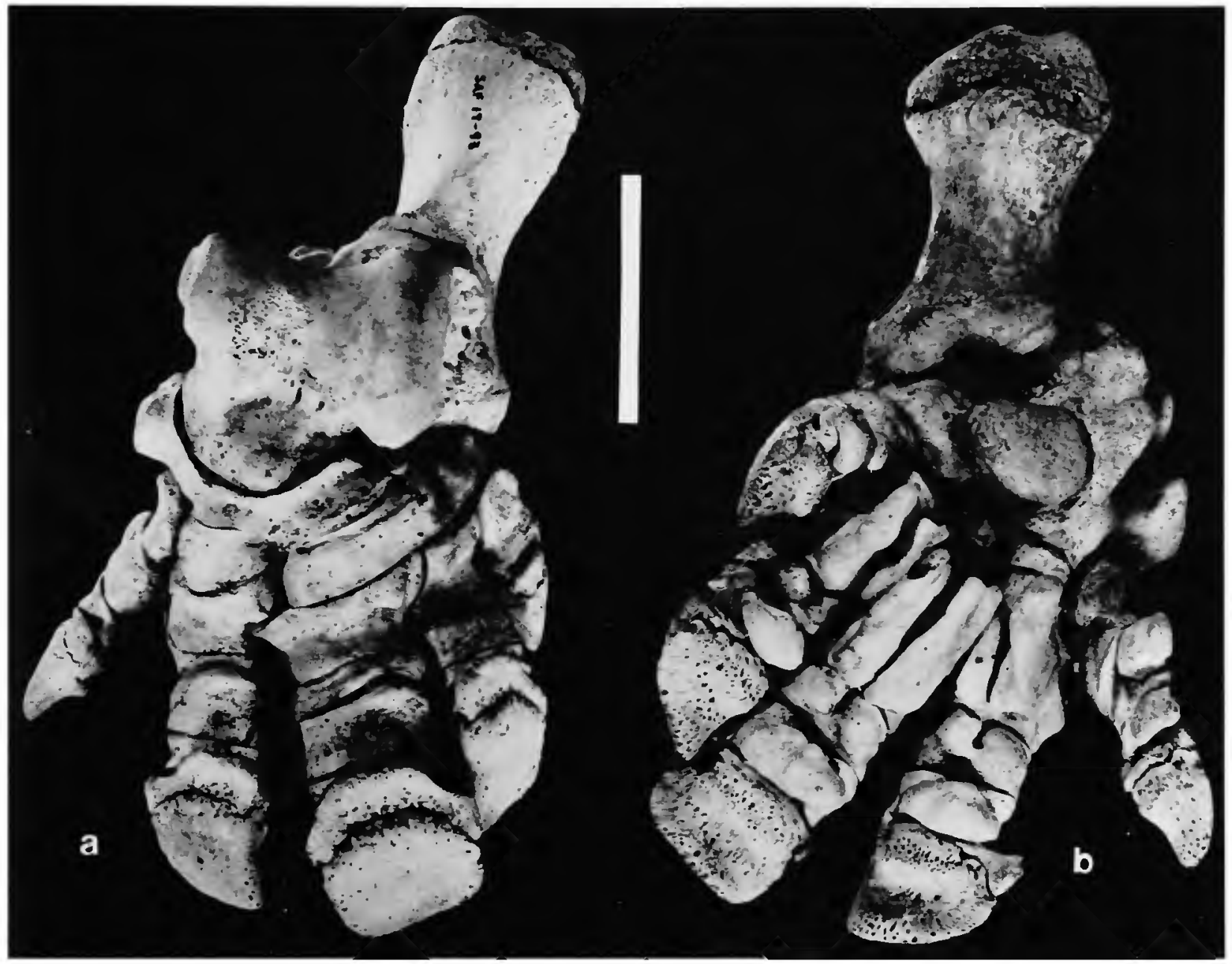

Figure 74.-Articulated right pes of Glyptotherium texanum (F:AM 95737): $a$, anterior; $b$, posterior, with digital sesamoid bones. $(\mathrm{Bar}=5 \mathrm{~cm}$.) 


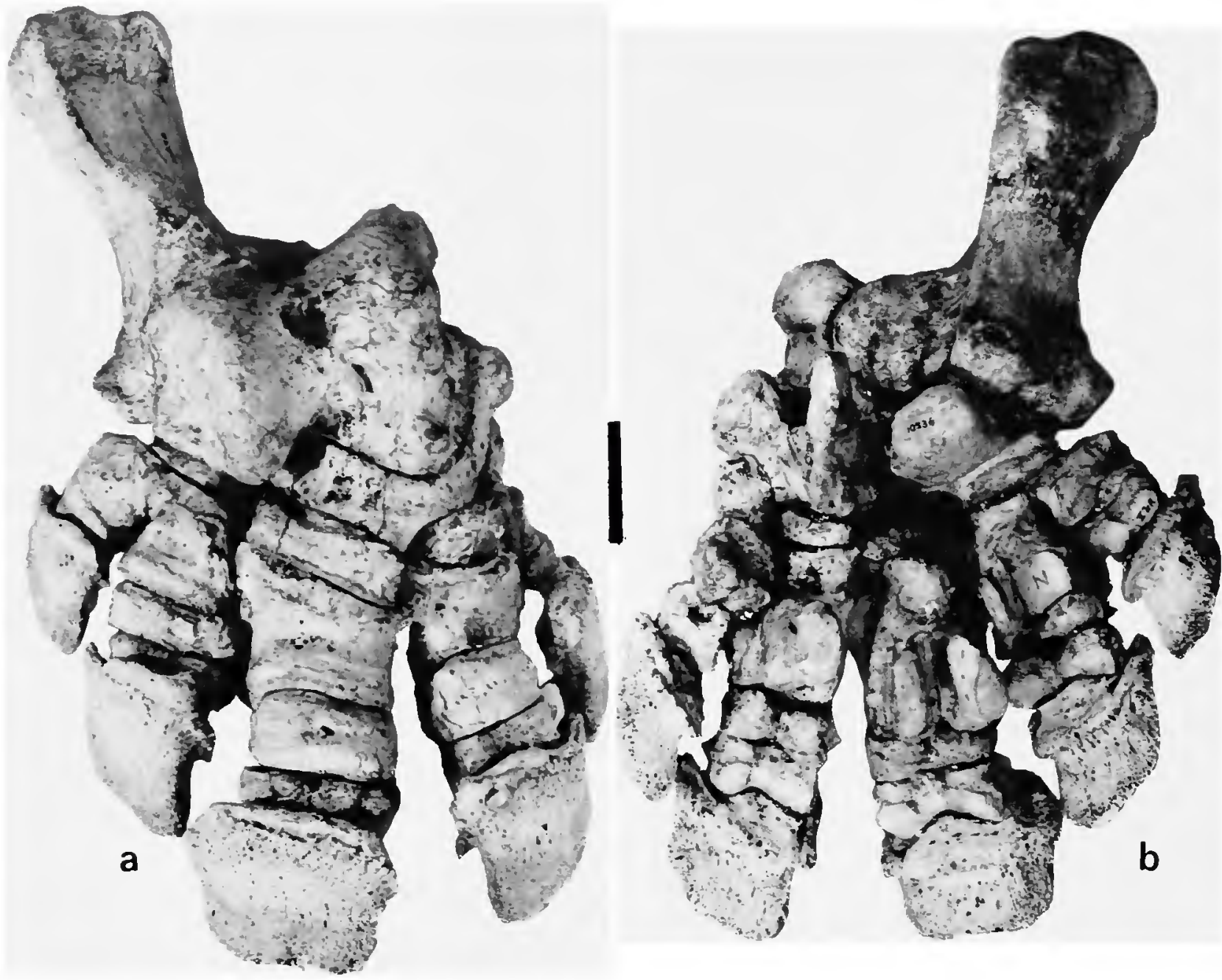

Figure 75.-Articulated right pes of Glyptolherium arizonae (USNM 10536): $a$, anterior; $b$, posterior. (Bar $=20 \mathrm{~mm}$.)

compressed, transversely elongate element. Its size and shape are similar to that in digit I. Its elongate articular surface is faintly divided into two weakly concave portions.

The distal sesamoid bone in $G$. arizonae is similar, except that its articular facet is almost completely separated into halves. Except for its larger size and greater development of rugosity on the nonarticular surface, it is identical to that of $G$. texanum.

\section{Caudal Vertebrae}

Osborn (1903) described the caudal vertebrae of the type specimen of G. texanum (AMNH 10704,
Figure 47, Table 65), which included one sacrocaudal vertebra, 13 free caudal vertebrae, and an imperfectly developed 14 th terminal vertebra.

Of these vertebrae the posterior ten as appears from measurement and from the deflected transverse processes, were fitted within the tail sheath, there being thus a vertebra for each ring, while the anterior three articulated with the peculiar sacrocaudal vertebrae, in which the greatly elongated transverse processes or ribs extend outward to coosify with the posterior plates of the ischia. The first free caudal has a transverse diameter of $302 \mathrm{~mm}$., and distinct lateral articulations as facets of the posterior borders of the last sacrocaudal and of the ischium; the neural laminae are elevated, the pre- and post-zygapophyses are elevated and vertically placed; the neural spine is low; caudals 2 and 3 were also well within the carapace, with transversely ex- 
tended spines; in caudals 4-11 the transverse processes are deflected, downwardly and forwardly directed; the neural arches, zygapophyses and spines diminish in distinctness. Caudals 12-13 lack all processes. A single chevron, of the narrow type .. was found with the specimen; it measures $130 \mathrm{~mm}$. vertically. Six stout chevrons with shallow, obtusely forked inferior processes, anteroposteriorly expanded dislally, are placed beneath caudals 5-11 (Osborn, 1903:493494).

Therefore, Osborn identified a total of 15 caudal vertebrae, including the sacrocaudal vertebra and the imperfect terminal one. There are eight rings of caudal armor and the terminal cone for the type specimen. As described below, the Arizona specimen F:AM 95737 also possesses eight caudal rings and a terminal cone, but the vertebral count is different, with one sacrocaudal vertebra, 11 rather than 13 complete free caudals, and an incomplete terminal vertebra, for a total of 13 caudals instead of 15 as in the type specimen.

In the Arizona specimen (Figure 76, Table 66) the last three caudal vertebrae lay within the terminal cone, and all but the first two vertebrae were protected by complete caudal rings. The second vertebra was protected by the incomplete accessory ring, and the first caudal vertebra (the sacrocaudal vertebra) had no armor protection and lay well within the posterior aperture of the carapace. The difference in total counts between the Arizona and Texas representatives occurs in the "pseudosacrals," of which there are three in the type specimen and only one in the Arizona specimen. This interpretation also explains why the two specimens have the same number of caudal rings, for only the last of the three pseudosacrals in the type specimen would have armor protection in the incomplete accessory ring, the succeeding eight vertebrae with complete rings, and the last three set within the terminal tube.

The fact that the caudal rings are identical in number and morphology between the Texas and Arizona specimens is by far the more important consideration taxonomically; the disparity in vertebral count is attributable to variation, a matter which is discussed at length for modern armadillos in our introductory remarks under "Systematics."
Osborn (1903) measured the caudal rings in articulation at $620 \mathrm{~mm}$ for the type specimen. In F:AM 95737, for which the caudal armor is identical to that of the type specimen, the length of caudal vertebrae nos. 3-13 (the vertebrae that received the protection of complete rings) is also $620 \mathrm{~mm}$. This measurement must correspond closely to the length of the caudal armor (not presently in articulation, therefore unmeasurable) for F:AM 95737. Hence, by indirect comparison, lengths of the caudal armor and of the last 11 vertebrae for both the type specimen and the Arizona representative are identical.

In F:AM 95737 the sacrocaudal vertebra possesses expanded extremities of the transverse processes for cartilaginous (subadult individual) contact with the ischiac plates. This contact would have ankylosed in the adult condition, incorporating the sacrocaudal vertebra as a strong participant in the sacrum. There is no associated chevron with vertebra no. 1 , and there is no indication that it received protection of any dermal armor.

The second caudal vertebra has expanded transverse processes for contact with the extremities of the sacrocaudal vertebra. Its transverse processes are not as stout as in either the sacrocaudal vertebra or in the succeeding vertebrae. The neural spine is tall, and the lateral processes of the metapophyses are likewise elevated for contact with the accessory ring of armor, which did not extend laterally to contact the transverse processes.

Vertebrae 3-10 bear downturned processes at the extremities of the transverse processes for articulation with the inner surface of the caudal rings. In the Arizona subadult individual these processes are underdeveloped and at the time of death were united with the dermal armor only by cartilaginous contact. The xenarthral processes for vertebrae 3-7 are strong and well developed. Diminishing in all dimensions rearward, the posterior xenarthral processes, although present, are unimportant in vertebrae $6-7$, and from vertebra 8 rearward, the posterior region is absent entirely. The anterior xenarthral processes also diminish in importance rearward, reduced to insignificant 


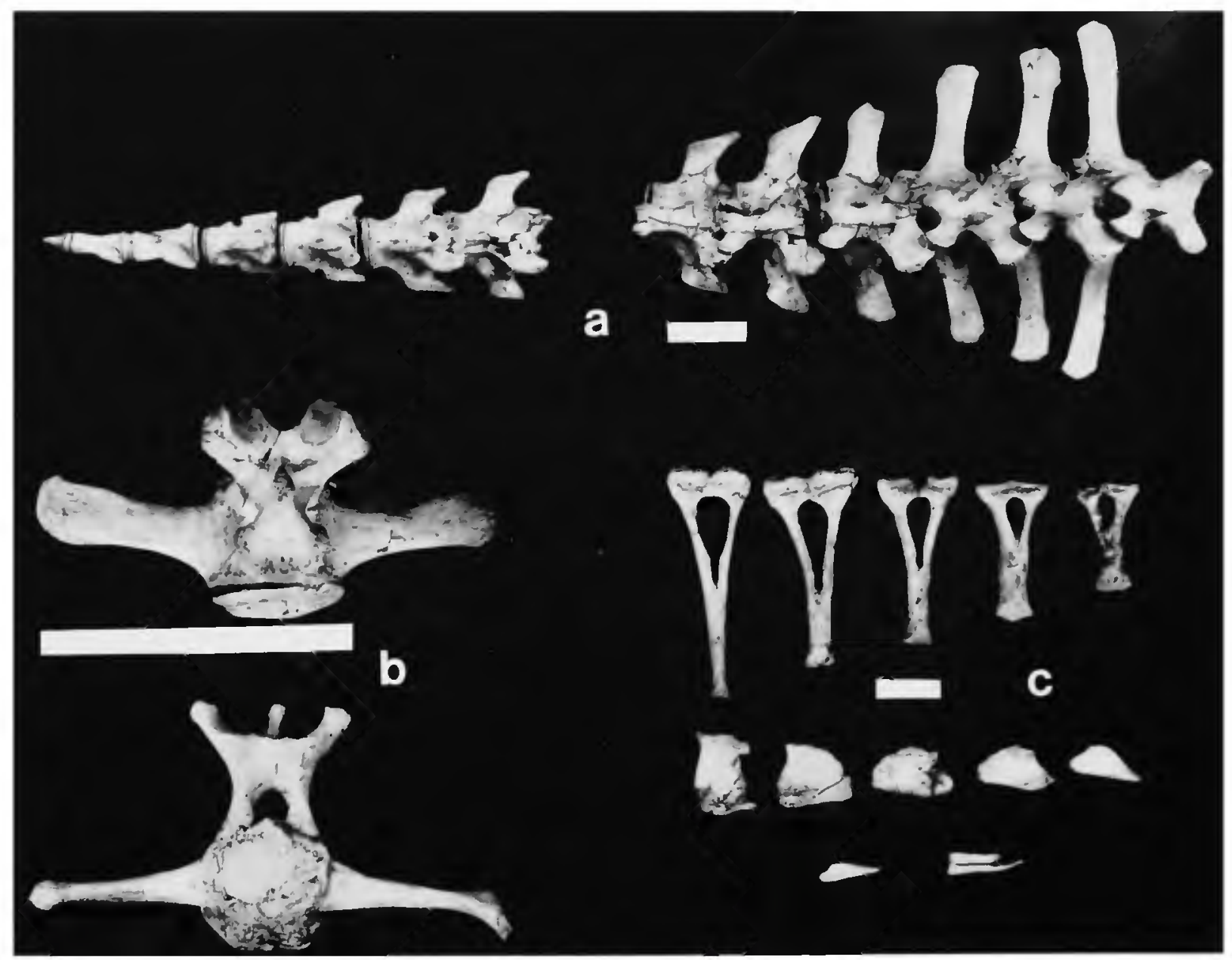

FIGURE, 76.-Caudal vertebrae of Glyptotherium texanum (F:AM 95737): a, articulated caudal series, dorsal; $b$, detail of representative vertebra, caudal vertebra 3 (dorsal aspect upper, and anterior aspect lower); $c$, chevron bones (upper row, 1-5, posterior aspect; middle row, 6-10, left side; lower row, 11 , left, left side, and 12, right; all dorsal). (Bars $=50 \mathrm{~mm}$.)

tubercles on vertebra 9 and absent on the last two vertebrae (12-13).

The last three caudal vertebrac (11-13) are fused by union of their intercentral discs. Vertebra 13 terminates in a blunt point and is therefore incomplete. These three vertebrae are $120 \mathrm{~mm}$ long, corresponding to the internal length of the terminal caudal tube.

Osborn described seven chevron bones for the type specimen. There are "a single chevron of the narrow type," measuring $130 \mathrm{~mm}$ vertically and "six stout chevrons with shallow, obtusely forked inferior processes, anteroposteriorly expanded distally ... beneath caudals 5-11" (Osborn, 1903: 493-494). In the Arizona specimen, F:AM 95737, there is a full set of 11 chevrons (Figure 76), of which the anterior one is long and narrow and measures $113 \mathrm{~mm}$. They diminish in length rearward, becoming stouter, and possessing blunt, bifurcate inferior extremities for contact with the caudal rings. The first two are long and slender, the next two are intermediate, and the last seven are short and stout. The last four are wedgeshaped and small. There is also a pair of (pre- 
sumed) ossified tendons associated with the terminal vertebra and found within the terminal tube. The principal proximal articulation of the first chevron was with the lower posterior surface of the centrum of caudal vertebra 2 , and its distal contact was with the caudal ring that encircled the third caudal vertebra. The succeeding chevrons articulated similarly, so that each chevron articulated proximally with a vertebra and distally with the caudal ring of the next posterior vertebra. The articular facets are two-parted and narrow, relative to those in other species.

The total length of caudal vertebrae F:AM 95737 in articulation (including the sacrocaudal vertebra) is approximately $750 \mathrm{~mm}$. Because there are two additional anterior vertebrae in the type specimen AMNH 10704, the length (which as stated above is identical for the last 11 vertebrae to that of the Arizona specimen) including the sacrocaudal is probably near $900 \mathrm{~mm}$ total. Melton's (1964) erroneous statement that the tail of the type specimen of $G$. texanum measures only $620 \mathrm{~mm}$ was apparently based on the serial length of the caudal rings of this specimen, as provided by Osborn (1903). The probable 900-mm length in $G$. texanum (maximum estimate) compares favorably with the lower extreme in lengths observed for $G$. arizonae.

Gidley (1926) gave an accurate count of 12 caudal vertebrae for paratype USNM 10537 (Figure $77 b$ ) of $G$. arizonae (Table 67). It appears, however, that there may have been 13 and that half of the 12th and all of the 13th are missing. This condition is indicated by the construction of vertebrae 10-12. The 10th vertebra was free, and was encased by the last complete caudal ring. The last two, 11 and 12, are fused and lay within the terminal tube. Their combined length is 115 $\mathrm{mm}$. Apparently the terminal tube and the last caudal ring were fused in this individual, so that vertebrae 10-12 lay within the terminal tube, although vertebra 10 seems to have been unfused. Vertebrae 3-9 were encased by complete caudal rings. Vertebra 2 supported the first, or "accessory" caudal ring, and 1 lacked dermal armor.

The caudal vertebrae of AMNH 21808 (Figure
$77 a$ ), from the type-locality, are identical in number and construction to those of the type specimen. The caudal vertebrae of the Seymour representative, UMMP 34826, are similar to those from the type-locality, but there are 13, rather than 12, in the caudal series. Although it was proposed above that the Arizona representatives perhaps had 13 caudal vertebrae rather than 12 , there nevertheless appears to be an actual disparity in the vertebral counts as indicated by the caudal ring counts from these two localities. In addition, UMMP 34826 appears to have rather large caudal vertebrae. For example, vertebra 6 in this specimen measures $92 \mathrm{~mm}$ centrum length and $171 \mathrm{~mm}$ transverse diameter between angles of transverse processes; corresponding measurements for vertebra 6 in USNM 10537 are $82 \mathrm{~mm}$ and $136 \mathrm{~mm}$, respectively, while those of the next anterior vertebra $(5: 81 \mathrm{~mm}$ and $167 \mathrm{~mm}$, respectively) more nearly approximate the dimensions of the sixth in the Seymour representative. It must be remembered, however, that UMMP 34826 is a large individual compared with others in the same population.

The difference in vertebral counts appears to reside in the number of pseudosacrals, similar to the variation noted for $G$. texanum. In the Seymour representative there are three pseudosacrals, whereas in the Curtis Ranch specimens there are only two. Whether this variation is attributable to sexual dimorphism is unclear, but that is a possibility. In all three specimens, caudal vertebra no. 1 possesses expanded lateral extremities of the transverse processes, with upturned facets for contact with the ischiac plates. However, the contact appears to have been an articular one rather than eventual ankylosis as in $G$. texanum. Thus the first caudal vertebra of $G$. arizonae participates more as a pseudosacral than as a sacrocaudal vertebra (by comparison with $G$. texanum), for the transverse processes are not immovably united with the ischia. The ischiac facets are dorsal expansions, facing upward and slightly outward and forward. The roughened surface indicates a general lack of mobility at this joint, but there is no indication of fusion. The transverse processes are also ex- 

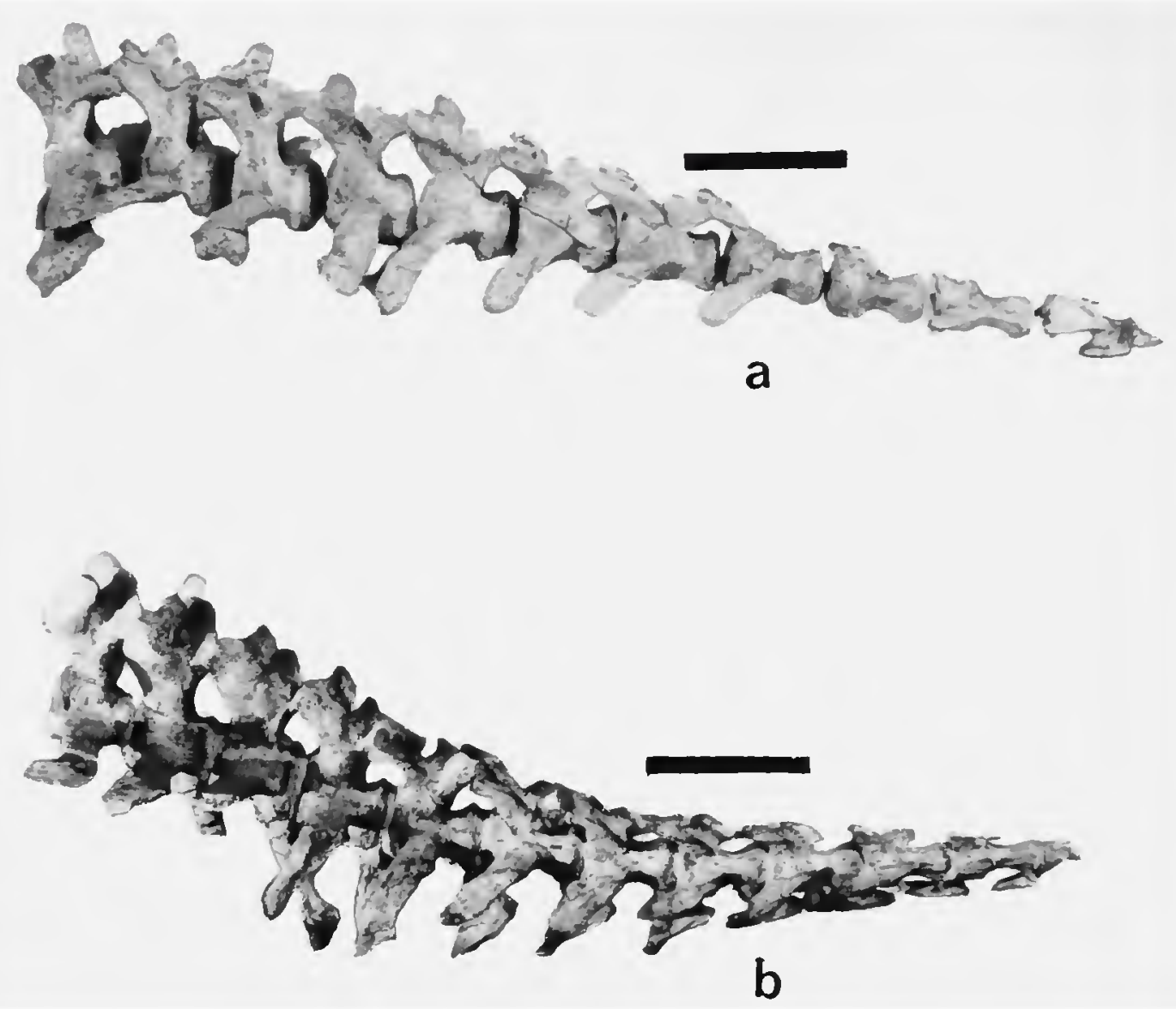

Figure 77.-Caudal vertebrae of Glyptotherium arizonae: $a, \mathrm{AMNH} 21808$, without chevron bones, left side; $b$, USNM 10537, with chevron bones in articulation, but partially obscured by: transverse processes, left side; both specimens from the Curtis Ranch locality, Arizona. (Bar = $15 \mathrm{~cm}$.)

panded rearward in the same horizontal plane, nearly overlapping similar expansions of the next vertebra.

The transverse processes of vertebra 2 in both Arizona specimens and of vertebrae 2 and 3 in the Seymour specimen are also horizontally expanded for participation in the pelvic construction as pseudosacrals. In all three specimens, a narrow chevron arises by principal articulation from the posterior extremity of vertebra 2 and articulates distally with the first complete caudal ring (which encases vertebra 3). Therefore, vertebra 2 supported the incomplete "accessory" caudal ring, which partially encased caudal vertebra 2 .
Succeeding chevrons are increasingly more elongate and stout. Except for the first chevron they are markedly bifurcate at their distal extremities, quite in contrast to the blunt or weakly bifurcate condition in $G$. texanum. Beginning with vertebra 3 in the Arizona specimens and vertebra 4 in the Seymour specimens, the transverse processes bear strongly downturned, forwarddirected processes for internal contact with their respective caudal rings. These processes are stouter and more massive than in $G$. texanum. They diminish in proportions rearward, becoming vestigial on the vertebrae set within the terminal tube. The metapophyses and xenarthral articulations are similar to those of $G$. texanum, 
differing only in size. The remaining features of the caudal vertebrae of $G$. arizonae are similar to those of $G$. texanum. The greatest difference in the caudal vertebrae between $G$. texanum and $G$. arizonae is the distinctly greater size in the latter species.

Melton (1964) stated that the length of the caudal series in UMMP 34826 is $1102 \mathrm{~mm}$. Because the specimen is now disarticulated, his determination cannot be checked. Assuming that his measurement is correct, the tail of the Seymour specimen is considerably longer than that of the Arizona specimens, which measure approximately $900 \mathrm{~mm}$. The difference in length is attributable to the different vertebral counts and is not taxonomically significant; however, it may be indicative of a trend toward larger size, although lack of adequate samples of $G$. arizonae precludes certain determination of this matter.

A single chevron bone (Figure 78) is the only element of the caudal series known for G. cylindricum. It is large, corresponding in size and shape to the anterior two chevrons in $G$. arizonae. It is "of the narrow type," to borrow Osborn's (1903) parlance, and its distal extremity is apparently not bifurcate, indicating that it is probably chevron 1. Its articular facet is extremely rugose and marked with tubercles, indicating a pathological (arthritic?) condition. Its proximodistal length of $145 \mathrm{~mm}$ compares favorably with the lengths of the anterior two chevrons in $G$. arizonae. It exhibits no substantial distinction from chevron no. 1 of USNM 10537.

Only fragmentary caudal vertebrae are known for $G$. floridanum (Table 68), all of which are from the Texas population. Lundelius (1972) described caudal vertebrae nos. 1-6 for the Ingleside representative, associated with as many caudal rings. Hay (1916) briefly described six caudal vertebrae from the Hunt County locality (USNM 6071); these are from the basal region of the tail, as Hay stated, and represent the last six vertebrae that possessed complete caudal rings, exclusive of the vertebrae incorporated into the terminal tube. Because the number of caudal vertebrae is unknown for $G$. floridanum, the exact serial positions of these six vertebrae are uncertain. They proba-

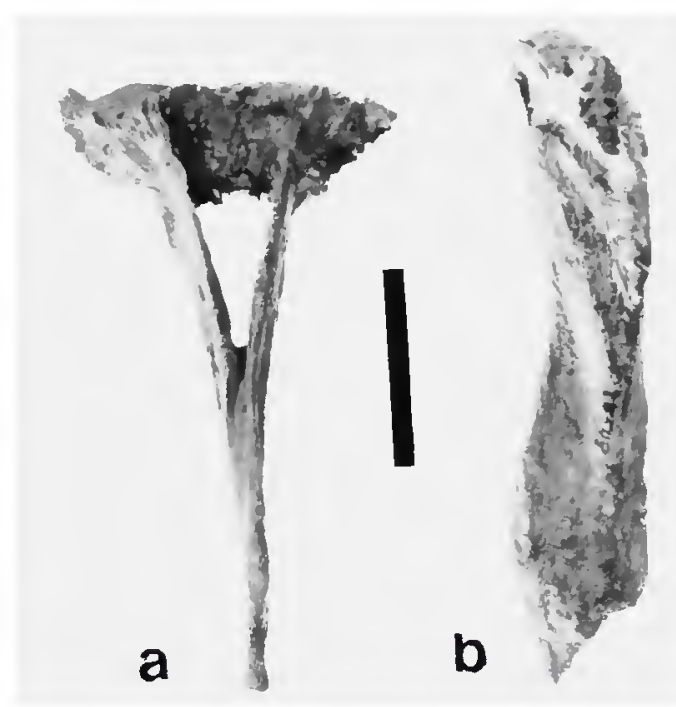

FIGURE 78.-Isolated chevron bone of Glyptotherium cylindricum (AMNH 15548): $a$, anterior; $b$, right side. $(B a r=20 \mathrm{~mm}$.)

bly represent positions 5-10, although these assignments might be wrong by one position in either direction. If they represent caudal vertebrae $5-10$, then the first 10 caudal vertebrae are known for $G$. floridanum in composite sequence between the Ingleside and Hunt County specimens.

The anterior six caudal vertebrae from Ingleside are similar in all respects to those of $G$. arizonae. Vertebrae 1-3 bear greatly expanded transverse processes, the first joining with the ischiac plates and 2 and 3 participating as pseudosacrals. Apparently the first participated in the pelvis as a sacrocaudal, for the transverse processes are expanded for contact. Vertebrae 36 possess downturned lateral processes for articulation with the caudal rings. Thus the caudal armor probably began with vertebra 2 , with an incomplete accessory ring, and ring 2 encased vertebra 3 , which is the first to provide lateral support for a complete ring. As Lundelius stated, the downturned processes posteriorly increase in their anterior orientation.

Chevron bones for vertebrae 2-6 are identical to those of $G$. arizonae. The chevron for vertebra no. 2 distally supported the caudal ring encasing vertebra 3 , further supporting the sequence proposed above. 
The six vertebrae from the Wolfe City specimen (USNM 6071), here assigned position 5-10, nearly complete the caudal series for $G$. floridanum. Although measurements for the first two (5 and 6 as here assigned) do not correspond exactly with 5 and 6 of the Ingleside specimen, the assignments nevertheless appear to be reasonable. Downturned lateral processes are present on 6 and 7 , but their extremities are broken. Lateral processes are broken on the other vertebrae. Metapophyses are preserved only for 6; they are large and expanded, as typical for the genus. Metapophyses and transverse processes are vestigial on vertebra 10. The diameter of the centrum of 10 suggests that two additional vertebrae completed the caudal series and that these fit within the terminal tube (unknown for this species). If the counts suggested here are correct, there are probably 12 caudal vertebrae in $G$. floridanum. The important matter is not the number of vertebrae, but the fact that the last several are free and unfused. By inference, therefore, the terminal caudal armor (unknown) was composed of typical caudal rings for each vertebra except the last two (presumably), which were protected by the terminal tube.

The caudal vertebrac of $G$. floridanum therefore appear not to differ in any substantial manner from those of $G$. arizonae. Lundelius (1972) considered the participation of three vertebrae in the pelvic complex as an indication of distinction from the older Seymour representatives. Actually there are three pseudosacral vertebrae in the Seymour $G$. arizonae and only two in the Gurtis Ranch representative, a disparity that we attribute to variation. A similar disparity exists for the representatives of $G$. texanum, indicating that the number of pseudosacrals is not taxonomically significant and may represent sexual dimorphism.

In summary for $G$. floridanum, caudal vertebrae, insofar as they are known, are not distinguishable from those of $G$. arizonae; a similar conclusion is reached for the caudal armor.

\section{Carapace}

The dermal armor ("coat of mail" of other authors) is the single most outstanding character- istic of glyptodonts. The armor largely consists of coalesced, tightly sutured individual scutes. The scutes covering the trunk region of the body are polygonal, usually six- or four-sided, and they are so united as to inhibit trunk mobility. The structure so formed is the carapace, analogous to the turtle carapace and more closely resembling it than the mobile carapace of the related armadillos. In Glyptotherium there are approximately 1600 scutes in the carapace, each firmly united with the next except toward the margins of the carapace, where the quadrilateral shapes of the scutes allowed limited mobility. The carapace covers the entire trunk region except for the ventral surface of the body, providing nearly impenetrable protection from predators. In adults the scutes are thick, lateral ones measuring up to $60 \mathrm{~mm}$ or more in thickness, interior scutes $30 \mathrm{~mm}$ or more, and, compared with armadillo scutes, they are relatively porous and light.

The disposition of the component scutes of the carapace into rows was established early in the ontogenetic development of the individual. Maximum transverse dimensions of the component scutes were achieved upon attainment of full scute-to-scute contact, with subsequent growth possibly limited to increasing the thickness of each scutc

Holmes and Simpson (1931) adequately treated the microstructure of the carapacial scutes of North American representatives. For the purposes of this study, no additional information has been gathercd, and their discussion appears to be entirely accurate. Carapacial scutes exhibit a relatively uniform construction, variable only in quantitative and geometric details. The undersurface of a scute is typically weakly concave, with scveral largc vascular foramina penetrating to the interior. Except for ankylosed attachment in the pelvic region, the scutes generally occupied a dermal position, so that the undersurfaces are generally smooth, or, in some instances, weakly striated as an apparent indication of attachment by connective tissue.

In Boreastracon $\mid=$ Glyptotherium], like most glyptodonts, the scutes are much more porous and lighter relative to their size than in the armadillos. The inner lable is reduced to a 
thin periosteal layer of interwoven fiber groups, between which pass numerous canals. The latter become larger in passing outward and communicate with the sinuses of the cancellous central layers. Canals and sinuses are surrounded by lamellar bone. The outer table is fairly thick, but it, also, is not sharply distinguished from the trabecular part, and it contains numerous vascular canals. The vertical sutural surfaces are not so dense as in armadillos, and the scutes articulate by long spicules of bone, with prominent radial haversian systems. Spicules of adjacent scutes interlock somewhat as do the bristles of two brushes pressed together (Holmes and Simpson, 1931:417).

In life the scutes were covered externally by scales, similar to those of armadillos. Glyptodont scutes are readily distinguished, however, by the fact that each scute was covered by several scales arranged in a generally symmetrical pattern, rather than being covered entirely by a single scale as in armadillos. Grooves on the external surfaces of the scutes mark the scale patterns; this sculpturing has been extensively relied upon for taxonomic determinations. For a typical hexagonal scute of Glyptotherium from the middle region of the carapace, there is usually a central scale and several peripheral scales symmetrically arranged around the center one, producing a characteristic rosette pattern for each scute, resembling that of the South American genus Glyptodon.

In Glyptotherium the rosette pattern is diagnostic. The central figure is usually equal in size or somewhat larger than the peripherals for interior scutes, with increasing importance of the central figure in the scutes nearer the margins of the carapace. There is only a single row of peripheral figures, varying from seven to 13 in number, surrounding the central figure. The peripheral figures are usually confined to one scute, although they occasionally overlap across sutural contacts. In $G$. texanum the central figures are larger than the peripherals, and they are convex and slightly raised above the level of the flattened peripheral figures. In G. arizonae and G. cylindricum the central figures are relatively smaller, usually not much greater than half the scute diameter, but always at least slightly larger than the peripherals and generally flat to weakly convex. In $G$. floridanum the central figures are approximately equal in size to the peripherals, and they are usually slightly raised and weakly concave.

Surface texture of the scutes is punctate, owing to numerous vascular channels that lay beneath the scales for communication with the dermis and epidermis. These pass into the interior of the scute and communicate with the cancellous central layer.

Also penetrating the external surface of the scutes are variable numbers of larger hair follicles issuing from within the circular grooves at the boundary of the central figure. Typically, one follicle is set at the intersection of a radial groove, with the circular groove on the anterior side of the scute. Dorsal and anterior scutes possess as many as five large follicles; the frequency diminishes laterally and rearward so that away from the dorsal region follicles are less numerous or absent. That these large pits lodged hairs, rather than blood vessels, was argued convincingly by Holmes and Simpson (1931).

Scute thickness increases toward the margins, and the peripheral figures predominate. The border scutes are variously modified into large conical projections, effectively protecting the undersurface of the body.

Besides the carapace, numerous ossicles invested the skin of the legs and undersurface of the body. This condition is indicated by a large number of small isolated ossicles associated with the limb elements of carapace F:AM 95737.

The North American species are known from complete or nearly complete carapaces, and the addition of several unreported specimens provides important information regarding variation and species characteristics. Carapacial features of North American species, though distinctive, are not as different as previous authors have believed.

Besides the carapace, dermal armor covered the head, in a cephalic shield, and the tail, in a series of movable rings of decreasing size. The head shield, composed of many so-called "casque" scutes, is not sufficiently well represented for any North American species to warrant detailed description. These scutes protected the dorsal surface of the skull (but they did not afford complete protection; see description of the skull); their position is indicated on the frontal and 
parietal bones by numerous vascular foramina. Apparently the cephalic shield abutted against the cephalic boss of the carapace, protecting the neck.

The tail of Glyptotherium was protected by rings of armor, one ring per vertcbra, composed of double or triple rows of fused scutes. Except in $G$. texanum, for which the rings are smooth, the distal row of all the rings beyond the first two bore large conical bosses. The terminal ring is usually composed of the coalesced rings of the last two vertebrae.

Measurements for the carapace are provided in Table 69.

Carapace of G. texanum.-Osborn (1903) established the genus and species Glyptotherium texanum primarily on the basis of carapace AMNH 10704. Although brief, his description was sufficiently complete to provide a foundation for the genus. The addition of three nearly complete carapaces and the recoveries of carapace fragments in southwestern Texas substantially improve the state of knowledge for the carapace of this species.

The carapace of the type specimen AMNH 10704 (Figures 47, 79) is considerably smaller than the known complete carapaces of other spccies; it measures $145 \mathrm{~cm}$ in length and an estimated $186 \mathrm{~cm}$ maximum half-circumference (marginal scute to marginal scute). The length/ width ratio (actually length/half-circumference ratio) is approximately 0.79 . The scutes in this carapace are mostly unfused but all are fully developed, and thus the carapace belongs to a nearly mature adult of maximum size. The unfused condition might also indicate a limited mobility in the carapace, even in the adult. This carapace is complete on the left side, and the cephalic and caudal aperturcs are fully represented, allowing a complete description.

In lateral aspect the shape of the dorsal arch of the carapace is broadly clliptical, with near symmetry between the anterior and posterior regions. The posterior rows of scutes at the caudal notch are not recurved upward, nor is there a prominent division of the carapace into preiliac and postiliac
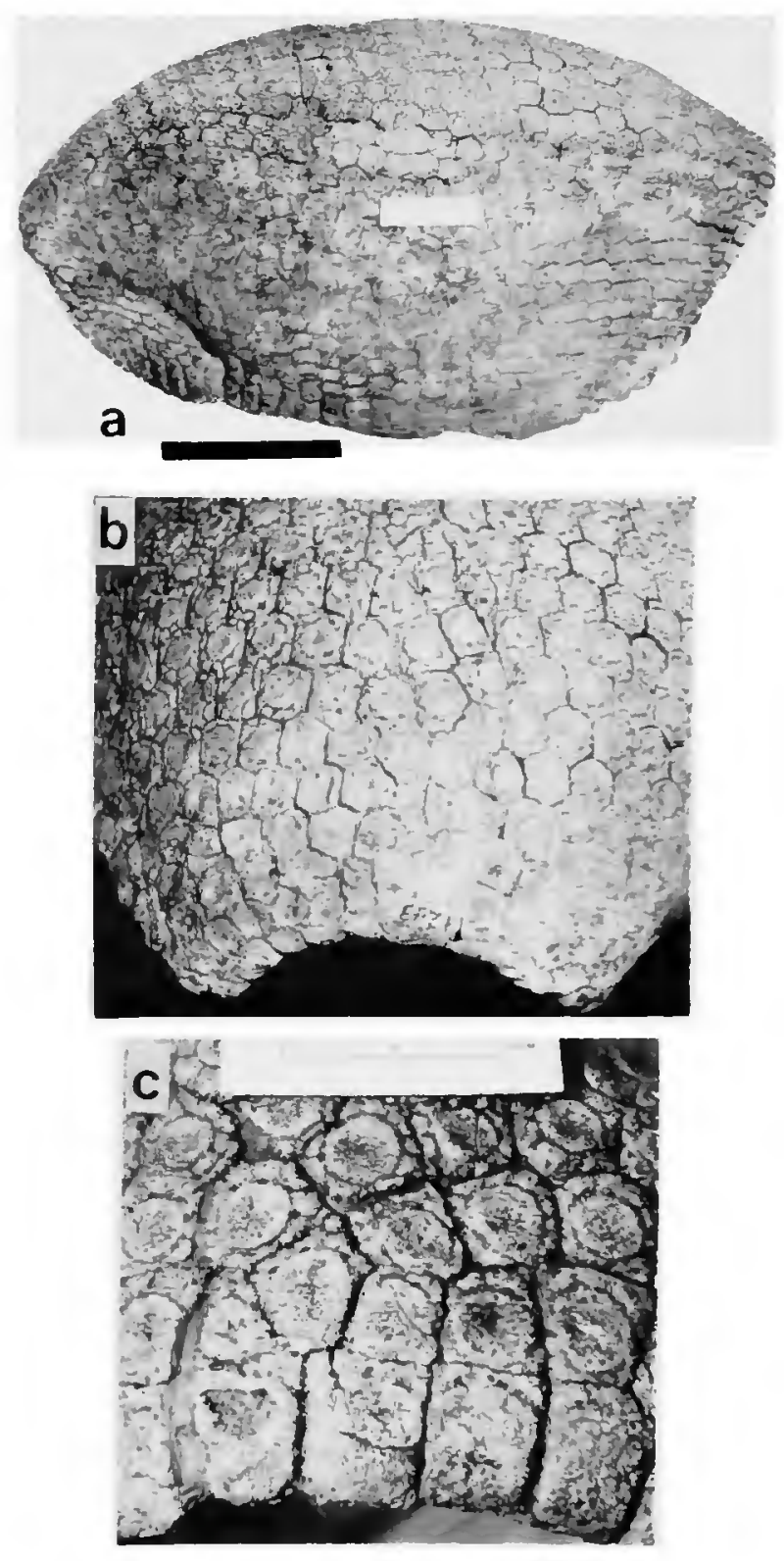

Figure 79.-Carapace of lype specimen of Clyptotherium texanum (AMNH 10704): $a$, left side anterior to left; $b$, detail of nuchal notch, dorsal; $c$, detail of caudal notch, dorsal. (Bar $=20 \mathrm{~cm}$.)

regions. The maximum height occurs at the center of the carapace, and it is not as highly arched as in the other species.

Because this free-mount is somewhat distorted as restored, comparisons between the caudal and 
cephalic apertures must be inferred. As in other glyptodonts, the posterior aperture is much the larger, measuring an estimated $60 \pm 20 \mathrm{~cm}$; the anterior aperture is only half as wide. The posterior aperture is distinctive in the lack of vertical outline in lateral aspect: the outline of the border scutes continues posteriorly from the posterolateral angle upward to the posterior notch. Thus the posterior extremity of the carapace is the posterocentral border scute. The shape of the anterior aperture is similar, tapering upward, forward, and medially from the anterolateral angle.

The border scutes of the anterior aperture are quadrilateral, uniformly simple, and unbossed. They are fused along their lateral borders to the adjacent border scutes. Together, they form a smooth anterior outline. Sculpturing is indistinct; dermal scales individually covered each scute entirely, except, in a few instances, along the interior suture. The anterior border scutes are small relative to interior scutes. There is no apparent indication of a cephalic boss at the anterior notch as in $G$. cylindricum. The position of the center of the anterior notch is not distinguishable, for all the scutes along the anterior border are identical.

Border scutes at the anterolateral angle become irregularly conical, but they remain small and quadrilateral. A few of the border scutes rearward from the anterolateral angle become "pendant," i.e., sutural contacts with adjacent border scutes are open, producing a scalloped outline for a short distance. From there (approximately 10 scutes from the anterolateral angle) the border scutes increase in size rearward; they are quadrilateral and unbossed along the lateral margin. Anterior to the poorly defined posterolateral angle, the border scutes again become conical, pointing downward and rearward. The scutes are generally three-sided, with a rounded or pointed free margin and a blunt apex formed by the sutures for the interior scutes of the first row. Rearward from the posterolateral angle the border scutes are again unbossed, but they become increasingly larger toward the posterior notch. They are generally five-sided, with rounded outer margins and internal apices for the sutural contacts with the interior scutes. Only the two scutes at the posterior notch are conical, and these are very low, poorly defined cones. These quadrilateral scutes are the largest of the border scutes, measuring approximately $45 \mathrm{~mm}$ in the transverse (side-to-side) diameter and $55 \mathrm{~mm}$ in the exterior-interior diameter.

Most of the interior scutes are disposed into distinct rows allowed by the hexagonal shape of the scutes. Rows are distinguishable in three directions. The primary direction is transverse, parallel to the anterior and posterior apertures. The other two directions are oblique, offset at $30^{\circ}$ in either direction from the sagittal plane. Laterally, the scutes become quadrilateral and the row directions are transverse (parallel to the anterior and posterior apertures) and sagittal (parallel to the lateral margin). Thus, it appears that as much as the lower half of the side of the carapace retained at least limited mobility, permitted by the quadrilateral scutes. These scutes appear to be joined rather loosely, in the same fashion as the scutes of the anterolateral region.

Sculpturing of the interior scutes is uniformly punctate. Near the border row, the round central figures occupy nearly all of the external surface, and peripheral figures are absent or indistinct. Interiorly the central figures become smaller, but they are always greater than half the diameter of the scute. Also, the central figures are never equaled, or nearly equaled, in size by the peripheral figures as in the other species.

The circular and radial grooves are generally shallow, and on some scutes these grooves are rather poorly defined. There are usually eight (less frequently six, seven, nine, 10,11) peripheral figures in a single row around the central figure. The central figure is everywhere convex along its outer margin, and about half are excavated in a shallow depression, usually to a level slightly lower than the depth of the radial grooves. The other half are flat to slightly convex in the center. Similarly, the peripheral figures are generally convex. Maximum side-to-side diameters of the scutes vary between $40-45 \mathrm{~mm}$, in this respect 
somewhat smaller than in the other species.

Large, deep hair follicles occur generally in the anterior half of the circular groove; they vary in number from one to five per scute. These are most frequent in the anterodorsal scutes, where there was a central tract of stiff hairs along the midline of the body. Although the follicles are present posteriorly along the dorsal arch, their density decreases rearward. Laterally, the scutes are mostly devoid of the hair follicles.

Identical in size to the carapace of the type specimen of $G$. texanum (see Table 69), carapace F:AM 59599 (Figure 80) bears little obvious distinction and without doubt belongs in the same species. It is unfortunately not associated with any noncarapacial remains. As in carapace AMNH 10704, the scutes are mostly unfused, but they are fully developed and represent a mature adult individual.

This nearly complete carapace from Arizona is important for the construction of its caudal aperture, exemplifying the posterior upturned curvature in lateral silhouette. The lateral outline does not exhibit the broadly elliptical and nearly symmetrical silhouette of the type specimen. Instead, beginning approximately four rows internal to the caudal notch, the scutes near the posterior border are upturned to produce a recurved outline. The outline does not achieve a horizontal attitude, however, so that the up- turned profile is not as pronounced as in the other species. The existence of this character in a carapace that is otherwise identical to the type specimen emphasizes the intraspecific variability in carapacial features.

The appearance of this recurved outline in the Arizona $G$. texanum might indicate an intermediate condition in the trend toward $G$. arizonae. We suggest an ancestral-descendant relationship betwecn the Blancan $G$. texanum, of Texas and Arizona, and the Arizona Curtis Ranch $G$ arizonae, in which this outline is more pronounced, among other changes in carapacial features.

The remaining characteristics of carapace F:AM 59599 are otherwise identical to those of AMNH 10704, and it differs from the other species in much the same fashion. This carapace is not highly arched, and there is no prominent preiliac and postiliac division. With only minor exception, details of the scutes in F:AM 59599 are identical to those of AMNH 10704. The posterior border scutes are all flat, however, without the pair of weakly conical scutes at the posterior notch. As in the type specimen, the quadrilateral shape of the scutes becomes prominent approximately midway between the dorsal arch and the lateral margin, and there appears to have been considerable mobility in the anterolateral region. There is a lower frequency of the deep depressions in the central figures; only about one-

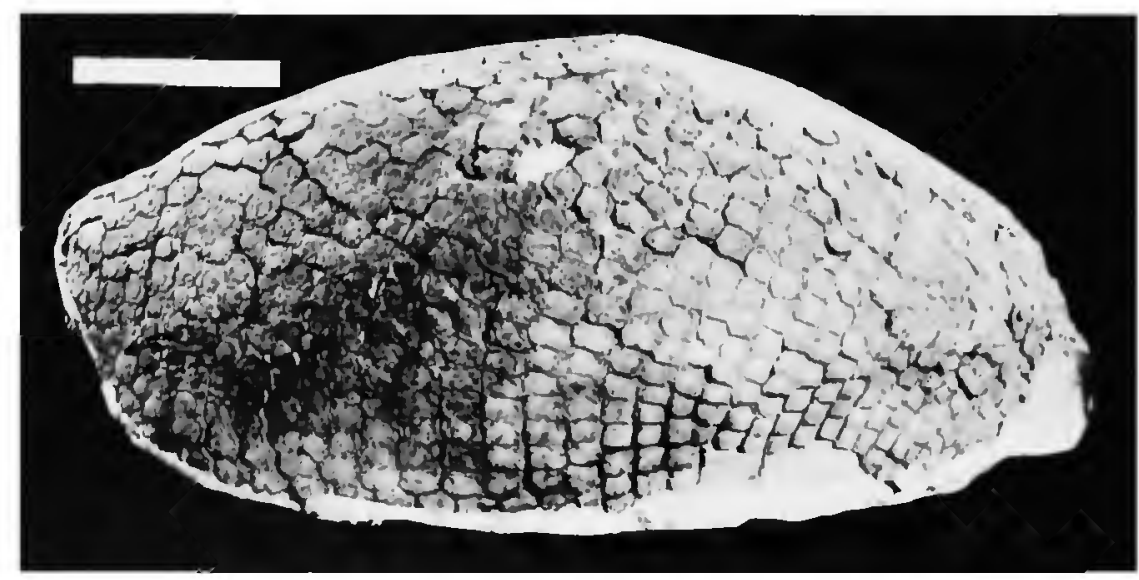

Figure 80.-Carapace of Glyptotherium texanum (F:AM 59599), righi side, showing weakly recurved oulline of posterior dorsal silhouelle. (Bar $=20 \mathrm{~cm}$.) 


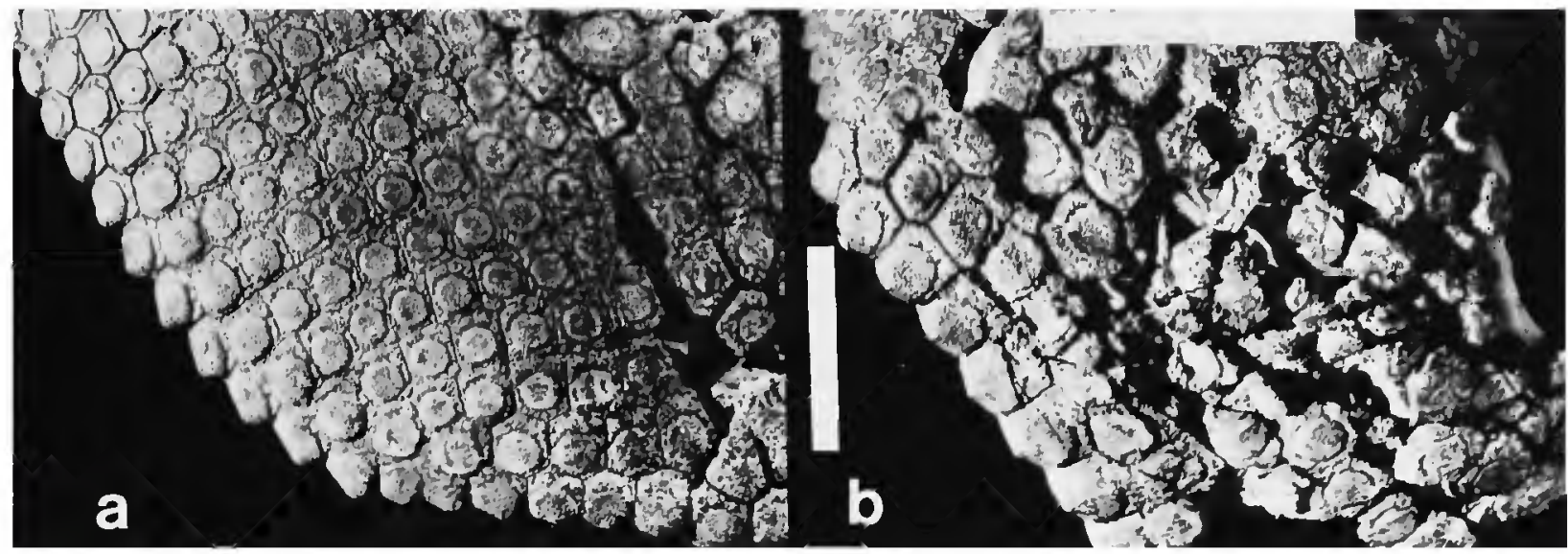

Figure 81.-Carapace of juvenile Glyptotherium texanum (F:AM 95737): a, region of posterolateral angle, left side; $b$, region of caudal notch, showing weakly conical border scutes of caudal aperture. $(\mathrm{Bar}=10 \mathrm{~cm}$.)

fourth of the scutes are so depressed. The largest scutes are barely $50 \mathrm{~mm}$ in side-to-side diameter; most measure 40-45 mm. The external surfaces of the scutes are not as markedly convex as in AMNH 10704; most are flat, or weakly convex.

The complete carapace of the subadult individual F:AM 95737 (Figure 81) provides additional information on ontogenetic variation in $G$. lexanum. This carapace, recovered not far from the preceding one, is from the Safford area, Arizona, and is associated with an essentially complete skeleton. Because of the immaturity of this individual, the component scutes of the carapace had not all achieved full articulation with the adjacent scutes. Consequently this carapace cannot be restored in a free mount; instead, it is separated into six sections. The scutes of the rear half of this carapace are solidly fused, while those of the anterior half are mostly in loose contact, indicating that the rear scutes became fused ontogenetically sooner than the anterior scutes. Because it is in sections, overall measurements for this carapace cannot be made. It does not appear to be much smaller than F:AM 59599, however, indicating that it is nearly of maximum size.

The anterior border scutes are small and simple, forming a smooth anterior border. The lateral border scutes are also small, increasing in size rearward and becoming conical toward the pos- terolateral angle. Unlike the previous carapace, the scutes of the caudal aperture are all weakly conical, with gentle concave outlines leading to the apices of the cones. They are not highly elevated, but they are prominent features of the posterior region. Sculpturing is uniformly punctate. Central figures are all much larger than the peripherals, and they are only slightly depressed in the middle. It appears that the development of deep depressions is an age-related phenomenon. Central areas are slightly raised above the level of the peripheral areas, and they are in places weakly convex. Also like the previous specimen, large hair follicles are common, especially anteriorly and dorsally.

Another Safford area specimen, F:AM 59581 (Figure 82), is represented by approximately onethird of the carapace, mostly from the anterior and dorsal regions. This was a mature individual, as indicated by the uniform development of the scutes, although the sutural contacts are largely unfused. All of the central areas are depressed, some very deeply. There are generally five large hair follicles, each situated in the circular groove at the juncture with the anterior radial grooves. The scutes of the anterior notch are smooth and relatively unsculptured.

The three glyptodont scutes (not seen) reported by Wood (1962) from the Safford area, and which 


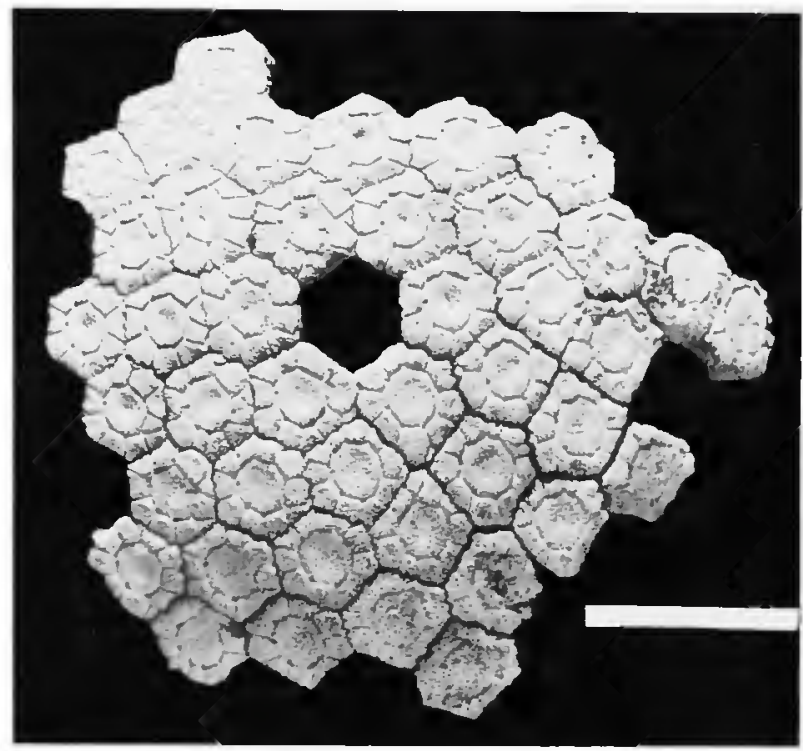

Figure 82.-Carapace fragment of Glyptotherium texanum (F: AM 59581), posterodorsal region near iliac attachment. (Bar $=10 \mathrm{~cm}$.)

he placed in the Tusker local fauna, are probably also $G$. texanum.

Akersten (1972) reported isolated scutes and approximately one-third of a carapace of $G$. texanum in the Red Light local fauna from western Texas. This carapace remains unprepared, and no information, other than that which Akersten has provided, can be derived from the specimen in its present condition. The species assignment appears to be correct, on the basis of a combination of features, including the size and construction of interior and marginal scutes, the disposition and shape of the border scutes of the anterior aperture, the pronounced disposition of the dorsal scutes into rows, and the nature of the sculpturing of the scutes. This carapace appears to be identical to those described above; it is important for extending the geographic range of the species.

A few isolated scutes (TMM 40254-1, 40254-2, 40254-3, 40255-2) in the Hudspeth local fauna, a direct correlative with the nearby Red Light local fauna, were identified only to genus by Strain (1966). These are probably also G. texanum and add no new information concerning the features of the carapace.
Reported recoveries of scutes of $G$. texanum in the "Texas Blanco Beds," in addition to that for the type specimen, include Johnston (1944), Meade (1945), and Johnston and Savage (1955). These exhibit no important properties distinguishing them from any of the carapacial material described above for the species. Most numerous are those from the Cita Canyon locality, as reported in detail by Johnston (1944) and mentioned by Johnston and Savage (1955). These scutes (JWT 649, 1706, 1907, 2319, 2356, 2387, $2408,2477,2501,2578$ ), some of which are in articulation, are the only large series of $G$. texanum scutes, other than those in the carapace of $\mathrm{AMNH}$ 10704, from the vicinity of the type specimen.

Carapace of G. arizonae.-Gidley (1926) briefly described the composite carapace consisting of paratypes USNM 10336 and USNM 10537, which he chose for his diagnosis in deference to the more fragmentary carapacial remains of the type specimen (USNM 10536) of $G$. arizonae. The carapace of the type specimen is identical to the portions of the two paratypes in the mounted specimen (see Gidley, 1926. pl. 40; also Figure 83, herein) so that his description for the type material remains accurate. However, Gidley's figure of the carapace is misleading in that the posterodorsal region is restored and many of the anterodorsal scutes have been merely set in plaster, and they are not in articulation. Although this latter condition is not evident in the figure, the restoration of the posterior region of the carapace may be incorrect. Because these individuals were identical in size, a detailed description of this compositc carapace is justified as accurately representing the fragmentary carapace of the type specimen.

Gidley (1926) mentioned the recovery of another carapace from the same locality (Curtis Ranch, Arizona), which was sent to the American Muscum of Natural History. At the time of his description of $G$. arizonae this carapace (AMNH 21808, Figure 84) had not been prepared, and Gidley kncw little of its characteristics. It appears from the American Muscum specimen that the posterior restoration in USNM 10537/10336 in- 
correctly indicates a smoothly rounded, convex lateral outline, similar to that in the type specimen of $G$. texanum. Although it is possible that this restoration is accurate and that both the convex and recurved outlines occurred in this population, it is more likely that the lateral profile of the posterior region was recurved as in AMNH 21808.

Most of the scutes in USNM 10537/10336 that are in true articulation are solidly fused. This condition may be partially attributable to the old age of these individuals, which is indicated in the noncarapacial elements of the skeletons. The fusion of scutes is in places so extensive as to obscure the boundaries between scutes, and their sculpturing is correspondingly indistinct.

Compared with AMNH 21808 (described below), carapace USNM $10537 / 10336$ is shorter anteroposteriorly by $15 \mathrm{~cm}$, and the count of 16 marginal scutes for the caudal aperture is half that for the undescribed specimen (Table 69). In this composite carapace, the anteroposterior length and the maximum half-circumference are $175 \mathrm{~cm}$ and $215 \mathrm{~cm}$, respectively, giving a lengthwidth ratio of approximately 0.81 .

As restored, the lateral outline of carapace
USNM $10537 / 10336$ is nearly uniformly ellipsoidal, with a somewhat more pronounced anterior curvature. The restoration of the posterodorsal scutes begins from the region of iliac attachment, precluding positive determination of the postcrior curvature, and also precluding determination of whether there was a definite preiliac and postiliac division in the curvature.

The cephalic aperture is somewhat smaller than the caudal aperture in transverse dimensions, and the caudal aperture reaches a much higher maximum elevation. Whereas the outline in lateral aspect of the curvature of the marginal scutes leading to the anterior notch continues anteriorly and upward, the outline of the posterior notch turns abruptly upward at the posterolateral angle, producing a vertical posterior outline for the carapace.

The scutes of the outer row of the cephalic aperture are small and quadrilateral, laterally becoming larger and conical. The scutes of the second row are considerably larger and project anteriorly ahead of the scutes of the first row. None of these scutes are conical. In the lower fourth of the anterior half of the carapace (i.e., in

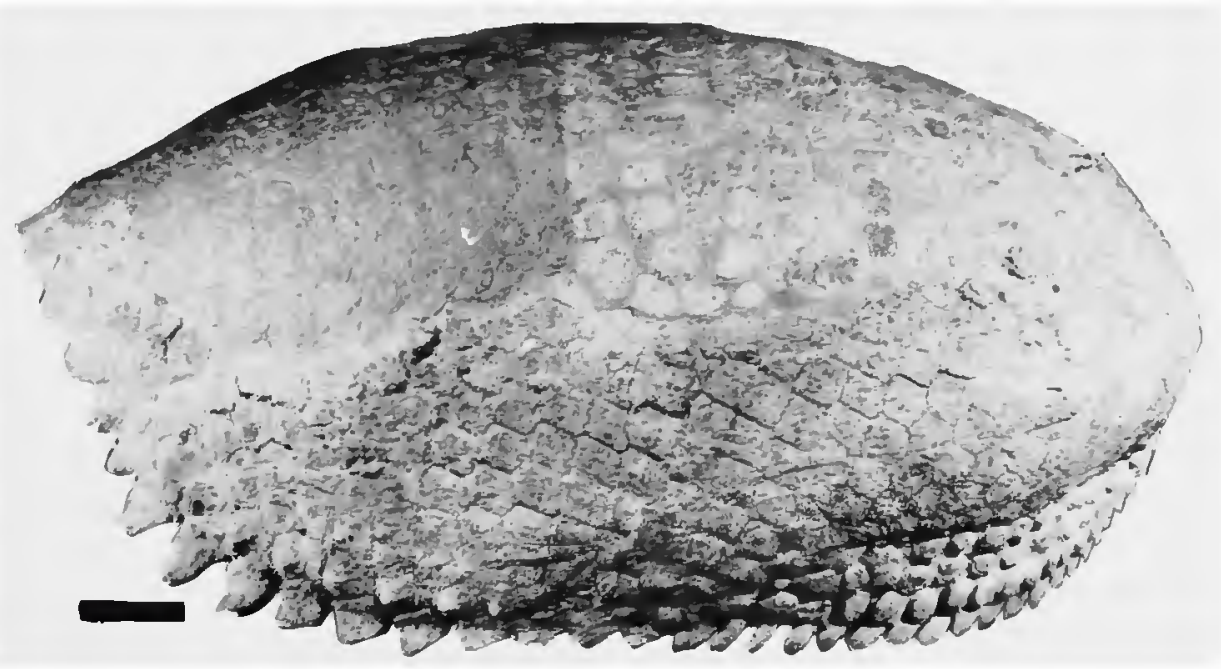

FIGURE 83.-Composite carapace of paralype of Glyptotherium arizonae (USNM 10336/10537), right side; scutes of entire lower half and all border scules in proper articulation; scutes of anterior half of upper region improperly articulated jigsaw fashion and set in plaster; posterior half of upper region entirely restored (figures carved in plaster) except for border scutes; dorsal outline is probably inaccurate. (Bar $=10 \mathrm{~cm}$.) 
the region of the poorly defined anterolateral angle and rearward), the scutes are generally quadrilateral and unfused, attaining an imbricated construction. The marginal scutes in this region arc not significantly larger than the interior scutes, but they are variously conical to pendant (i.e., free, or open, contacts with the adjacent marginal scutes). The region of imbrication includes only about four rows of scutes, tapering rearward to terminate at approximately the midcarapace position. Marginal scutes in the posterior half are large and conical, with increasing size rearward. The conical projections are directed downward and rearward. The marginals of the posterior notch are similarly conical, and they project rearward. The largest marginal scutes occur at the posterolateral angle, and their conical projections are somewhat recurved. These measure approximately $65 \mathrm{~mm}$ transversely, and the diameter from the interior border to the extremity of the conical projection is approximately $80 \mathrm{~mm}$, of which all but $20 \mathrm{~mm}$ is occupied by the projection. The scutes of the second row, from the midpoint of the lateral margin to the posterolateral angle, bear a smaller, but nevertheless prominent, outward-projecting boss. Sculpturing of the lateral scutes is variously absent or limited to near the sutural contacts in indistinct patterns.

The interior scutes are polygonal, tending toward a six-sided ideal shape, although few of the scutes exhibit symmetrical hexagon proportions. Interior scutes are large and thick, averaging approximately $50 \mathrm{~mm}$ side-to-side diameter. As Gidley (1926) stated, the central figures are larger than the peripherals, and they measure approximately half the scute diameter. Peripheral figures are considerably smaller and they are generally indistinct, owing to these individuals' advanced age. The number of peripheral figures varies from six to 11 or 12 , with eight the most common. The central figures generally are depressed, as Gidley (1926) observed, except near the marginal areas of the carapace. The outer surfaces of the scutes are flat, rugose, and pitted.

A predominant characteristic of this composite carapace is its dorsally depressed cross section. Anteriorly the dorsal region is broad and almost flat, tapering rearward and becoming more rounded at the caudal aperture. Whether this shape is an accurate restoration is problematical, but it appears to be correct.

Other portions of these two specimens (USNM 10537, 10336) and of the type carapace (USNM 10536) exhibit no outstanding differences from this composite mount. All three are large, adult individuals. Marginal scutes are prominently conical, interior scutes sculptured as described above. Unfort unately, these remaining fragments are not sufficiently complete to indicate the shape of the posterior border.

Because carapace AMNH 21808 is more nearly complete and its composition less obscured by extensive fusion, a more detailed description is provided below.

Carapace AMNH 21808 (Figure 84), from the type locality of $G$. arizonae, was collected in 1924 , and except for oblique reference to this specimen by Gidley (1926) and an apparent reference to it by Simpson (1929), this carapace has been ignored. As restored in free mount, this large carapace is unnaturally flattened transversely, so that end views are somewhat distorted. The proper shape would be rather more rounded than flattened. Accordingly, the maximum transverse half-circumference (from side to side) would be increased by an estimated $30+\mathrm{cm}$. Allowing for this alteration, the transverse half-circumference measures approximately $260 \mathrm{~cm}$; and the anteroposterior length, which appears properly restored, measures $190 \mathrm{~cm}$. Thus, the length-width ratio is approximately 0.73 , intermediate between the same ratio for carapace USNM 10537/10336, as described above, and for carapace AMNH 15548 , the type spceimen for $G$. cylindricum, described below.

In lateral aspect, the carapace is uniformly arched in an ellipsoidal outline from the anterior notch for approximately the anterior two-thirds of the curvature, reaching maximum height at the position of the iliac attachment, approximately $120 \mathrm{~cm}$ from the anterior notch. From the 


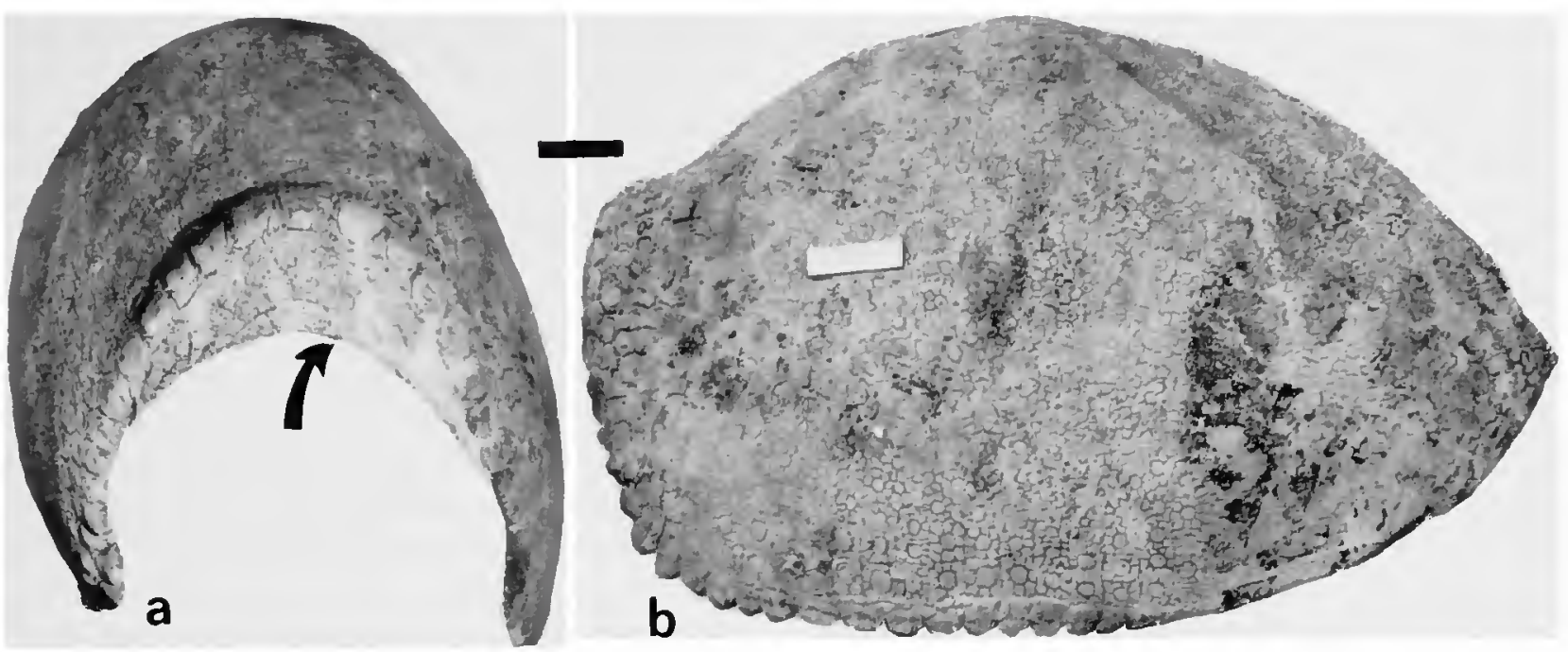

Figure 84.-Carapace of Glyplotherium arizonae (AMNH 21808) from type-locality: a, posterior aspect showing caudal notch and caudal bridge (arrow); $b$, right side, showing recurved posterior outline of dorsal border. $(\mathrm{Bar}=10 \mathrm{~cm}$.)

iliac position rearward, the lateral outline curves more steeply downward, and then beginning approximately three scute rows inward from the posterior notch, the outline becomes recurved upward, reaching a horizontal attitude at the posterior border. Thus the carapace is divided into distinct anterior (preiliac) and posterior (postiliac) regions, occupying approximately twothirds and one-third of the curvature, respectively.

The anterior aperture is distinctly smaller than the posterior one, measuring an estimated $30 \mathrm{~cm}$ transverse diameter. In contrast with the posterior aperture, the border scutes of the anterior aperture continue in a smooth curvature from the lateral scutes (rather than abruptly becoming vertical in lateral aspect) upward and forward. Hence, the anteriormost point of the carapace is at the anterior notch.

The posterior aperture is roughly twice as large as the anterior opening, measuring an estimated $60 \pm 10 \mathrm{~cm}$. The serial arrangement of the border scutes of the caudal aperture becomes nearly vertical in a relatively sharp angle at the posterolateral extremity of the carapace. The border scutes continue vertically upward in a smooth radius of curvature, forming in posterior aspect a semicircular caudal opening.

Beneath the border scutes forming the caudal arch is a massive bridge of bone, not represented in USNM 10537/10336, which is solidly ankylosed to the border scutes (Figure 84a). This bridge appears to be formed by the fusion of two transversely directed arches of bone. The bridge tapers laterally, terminating approximately midway down the caudal aperture. The bone is externally sculptured in an irregular pattern and, at least along the tapered lateral extremities, appears to have been formed by coalesced scutes. There are a few irregularly placed hair follicles. The inner surface of this bridge parallels the outer surface, attaching to the undersurface of the border scutes of the caudal aperture in a right angle. By analogy with AMNH 15548 (G. cylindricum, with a similar bridge), for which the tail is unknown (but in which the exact spatial position of the sacrum and thus the sacrocaudal vertebra articular facet is indicated), at least two, and perhaps three, caudal vertebrae were situated beneath the carapace and were afforded protection by the caudal bridge. This observation further documents Melton's (1964) suggestion con- 
cerning the position of the anteriormost caudal ring in $G$. arizonae. The bridge probably provided considerablc surface area for origin of the caudal musculature.

On all marginal scutes, the dermal scale covered all but the interiormost position. The scute occupying the antcrior notch is unbossed and is uniformly rounded inward. The adjacent border scutes are weakly bossed. Situated within the interior angle between the nuchal scute and the adjacent border scutes are a pair of enlarged, heavily bossed and projecting scutes, which form an anterior extremity composed of five symmetrically arranged scutes. The upper outline of these five scutes is roughly squared and was likely confluent with the scutes covering the skull roof in the living animal.

The scutes interior to this flat compound boss and the adjacent border scutes are unbossed, conforming with the surface of the interior scutes of the carapace. The remaining border scutes of the anterior aperture are small and unbossed. The dermal scales covered each scute entirely.

Beginning at the poorly defined anterolateral angle of the margin of the carapace, the border scutes become gradually more conical. The bosses thus formed increase in size rearward, becoming markedly elongate, externointernally compressed, and forming a scalloped outline in lateral aspect. The scute with the greatest elongation occurs 18 scute positions from the posterior notch or approximately six scute positions anterior to the posterolateral angle. From this scute rearward, the border scutes become conical, the boss reaching maximum development at the posterolateral angle. Conical bosses of the caudal aperture occur only on the two latcral scutcs of cach side at the extrcmity of the opening, adjacent to the postcrolateral anglc. The remaining 10 scutes on each side increase in size toward the caudal notch, becoming rounded and extremely large (largest scutes of the carapace) at the posterior notch. Sculpturing, indicating the boundaries of the dermal scales, remains confined to the area near the interior border of cach scute. Wedged betwecn the large posterior border scutes arc smaller ac- cessory scutes, completing the outline of the caudal aperture and forming the connection for the ankylosis of the caudal bridge. Several of the large posterior border scutes are centrally depressed in a deep and smooth excavation occupying most of the central region.

The posterior border scutes are pentagonal, with a rounded or conical outer margin and an interior apex forming the suture for the apices of the scutes of the sccond row. The lateral border scutes anteriorly become increasingly more uniformly quadrilateral, facilitating the imbrication of the scutes in the anterolateral region of the carapace.

As restored, apparently correctly, the border scutes of this carapace along the anterolateral margin turn beneath the remaining outer border of the carapace, downward and inward. (A similar construction is indicated in USNM 10537/ 10336.) Thus, the circumferential arc of the carapace near the anterior extremity covers nearly $270^{\circ}$, this extent decreasing gradually rearward to become approximately semicircular at the posterior aperture. Besides the border row of scutes, there are two rows of interior scutes forming the "undercurvcd" anterolateral region of the carapacc. The interior rows taper rearward to approximately the midcarapace position, where the undercurved region gives way to the downwarddirccted lateral scutes. These undercurved scutes appear to have maintained some mobility. The fourth row of scutes forms a sharp angle, occupying the actual anterolatcral extremity of the carapace. This row continues rearward, posteriorly becoming the first row interior to the border scutes. Sculpturing of the undercurved scutes is irrcgular. Radial grooves are variously indistinct or absent, and the central figure occupies nearly the cntirc scute. The central figure is generally convex and punctate; a few of the scutes include hair follicles, and one scute exhibits a central cxcavation. The scutes forming the anterolateral angle of the carapace are generally quadrilateral, with rounded (convex) interior borders; they all appear to have been solidly ankylosed with the interior scutes. Sculpturing on these scutes is in- 
distinct, the dermal scales apparently occupying the entire external surfaces.

The four-sided scutes of the posterolateral portion of the carapace are arranged in anteroposterior and vertical rows. Dorsally and anteriorly the rows become obscure and the scutes become generally six-sided (but frequently five and sevensided) in the more dorsal regions of the carapace. Along the first row of interior scutes, posterolaterally and posteriorly, the central figures are large (occupying at least 80 percent of the scute surface), generally circular, and convex. The number of peripheral figures varies from seven to 12 , and the radial groove in some scutes is indistinct. The external surface of the scutes is generally punctate, and the central regions are not elevated above the level of the peripheral figures, a condition characterizing all the interior scutes except for those of the anterolateral angle and of the anterior cephalic boss.

Interior scutes are generally six-sided, and any disposition into rows is obscured by the complex pattern of the sculpturing. Interiorly the central figures become smaller, but their diameters are never less than half the diameter of the scutes, and they are never smaller than the peripheral figures, although in some scutes the peripheral figures and the central figure occupy approximately the same amount of surface area. The central figures of perhaps one-fourth of the scutes are excavated, forming generally shallow central depressions, and a few are rather deeply depressed. Large hair follicles are generally wanting; this individual (which is probably very mature to old age) was mostly devoid of pelage in the carapacial region.

The central figures of the interior scutes are generally circular. The shapes of the peripheral figures are more variable, although they are usually five- to six-sided and bilaterally symmetrical about the radius of the scute. The number of peripherals varies from seven to 13 , the lower counts being more common. The radial grooves are rarely continuous across the sutures. Occasionally an accessory peripheral figure occupies the space between two peripherals, usually in the apex regions, where the scutes are irregular in shape. Otherwise, there are seldom more than two peripheral figures separating adjacent central figures. The surface texture of the interior scutes is punctate, although some are rather smooth with only a few indistinct small foramina. Sideto-side dimensions of the scutes are generally 45$55 \mathrm{~mm}$. A few are slightly larger, and some are slightly smaller.

Compared with carapace USNM 10537/ 10336, this carapace differs considerably in shape and construction. Among the most notable distinctions are the recurved posterior outline, the cephalic boss, and the caudal bridge, none of which are present in the composite carapace that Gidley (1926) described and figured as the paratypes for $G$. arizonae, but which are present in carapace AMNH 15548 (G. cylindricum). Therefore, while the differences between $G$. texanum and $G$. arizonae are valid distinctions, there is much less difference between these two species and $G$. cylindricum than has previously been supposed. Moreover, there are no features in the carapace of $G$. arizonae that are not derivable, in a simple ancestor-descendant relationship, from $G$. texanum.

From the Curtis Ranch locality, St. David Formation, Lammers (1970:32) reported a few additional carapacial scutes (not seen), including some from "portions of the carapace apron," presumably referring to the scutes of the anterolateral region. Besides the two carapaces described above, this is the only additional glyptodont material collected from the Curtis Ranch site.

Carapacial remains from the Seymour Formation, northern Texas, are referable to $G$. arizonae on the basis of sculpturing and overall construction. Partial carapaces and isolated scutes from the Seymour fauna represent a large number of individuals, perhaps as many as 80 or more, according to Melton (1964). Particularly pertinent are Melton's remarks concerning the recurved outline of the posterior region of the carapace, and the measurement for the maximum width of carapace UMMP 46320, which exceeds 
$214 \mathrm{~cm}$. Both of these characteristics indicate a close affinity with AMNH 21808 and the composite type carapace USNM 10537/10336. The details of the sculpturing of the scutes and their arrangement and disposition, which Melton accurately described, confirm the close similarity to Curtis Ranch specimens. Undescribed specimens in the Midwestern University collection, recovered subsequent to Melton's study, do not add any significant information. The noncarapacial osteology also indicates the identity of the Seymour representatives with those from the Curtis Ranch locality.

The only remaining carapacial material pertaining to $G$. arizonae is from the Holloman gravel pit, near Frederick, Tillman County, Oklahoma. A fragmentary mandible and two associated marginal scutes from this locality were the material upon which Meade (1953) founded Xenoglyptodon fredericensis, and upon which Melton (1964) subsequently claimed synonymy with the Seymour representatives. These two marginal scutes (TMM 934-37) are from the midlateral border, and they are identical to corresponding scutes in the better known carapaces of $G$. arizonae.

An improperly restored carapace in the Stovall Museum of Paleontology, University of Oklahoma, has been mentioned by several authors, including Meade (1953) and Simpson (1929b). Apparently only Simpson had the opportunity for direct observation, and referring to the $\mathrm{Hol}$ loman specimen in his description of Boreostracon floridanus, he stated in a footnote; "Through the kindness of $\mathrm{C}$. N. Gould I have been able to examine parts of this important find. The plates do not agree with those of any other North American specimen known to me, and probably represent an undescribed species" (Simpson, 1929b: 582 ). The restoration of this unnumbered carapace (Figure 85 ) is similar to that for the type specimen of $G$. texanum. The scutes were improperly articulated in the restoration, randomly set in plaster, jigsaw fashion, with no proper alignment or positioning of the scutes. The scutes are all large (up to $55 \mathrm{~mm}$ in diameter), with a large central figure occupying more than half the exterior surface; the central figures are flat to weakly concave, and occasionally deeply concave; there are generally seven to 10 peripheral figures, with shallow grooves delimiting them from the central figure, and there are variable numbers of relatively small hair follicles. These scutes do not differ from those known with more certainty as pertaining to $G$. arizonae. The similarity of these scutes with those of known $G$. arizonae specimens, the similarity of the mandible from the same locality, and the general acceptance of near contemporaneity of the Holloman fauna with the Seymour fauna (Meade, 1953; Melton, 1964; Dalquest, 1977; and Hibbard, pers. comm.) are sufficient grounds for assuming specific identity of the glyptodonts from these two localities.

Hay (1927) reported unidentified glyptodont remains (unseen, probably scutes) from Rock Creek, Briscoe County. On the basis of the biostratigraphic equivalence of the Rock Creek fauna with the Gilliland and Holloman faunas (Hibbard and Dalquest, 1966), this occurrence is probably $G$. arizonae. Lundelius $(1967,1972)$ has reported glyptodont remains that he assumed to be Late Pleistocene in age from Shafter Lake, Andrews County, which lies on the southeastern edge of the Great Plains to the south of the Blanco Beds. These scutes (unexamined), on geographic grounds perhaps represent $G$. arizonae, for such an inland and western recovery of Late Pleistocene glyptodonts is inprobable.

Finally, a small collection of isolated scutes from three localities along the Santa Fe River, Gilchrist County, Florida (Figure 86); four scutes from Charlotte Harbor, Charlotte County, Florida; and one scute from the Inglis 1A locality, Citrus County, Florida, represent the possible occurrencc of $G$. arizonae in eastern United States. Thesc scutes are not associated with any noncarapacial remains cxccpt for an isolated tooth from a baby individual from the Santa Fe River, which is without diagnostic value. These scutes are identified as Glyptotherium sp., cf. G. arizonae on the basis of their size and the nature of the external sculpturing. They are larger than scutes of $G$. texanum. The central figures of representative in- 


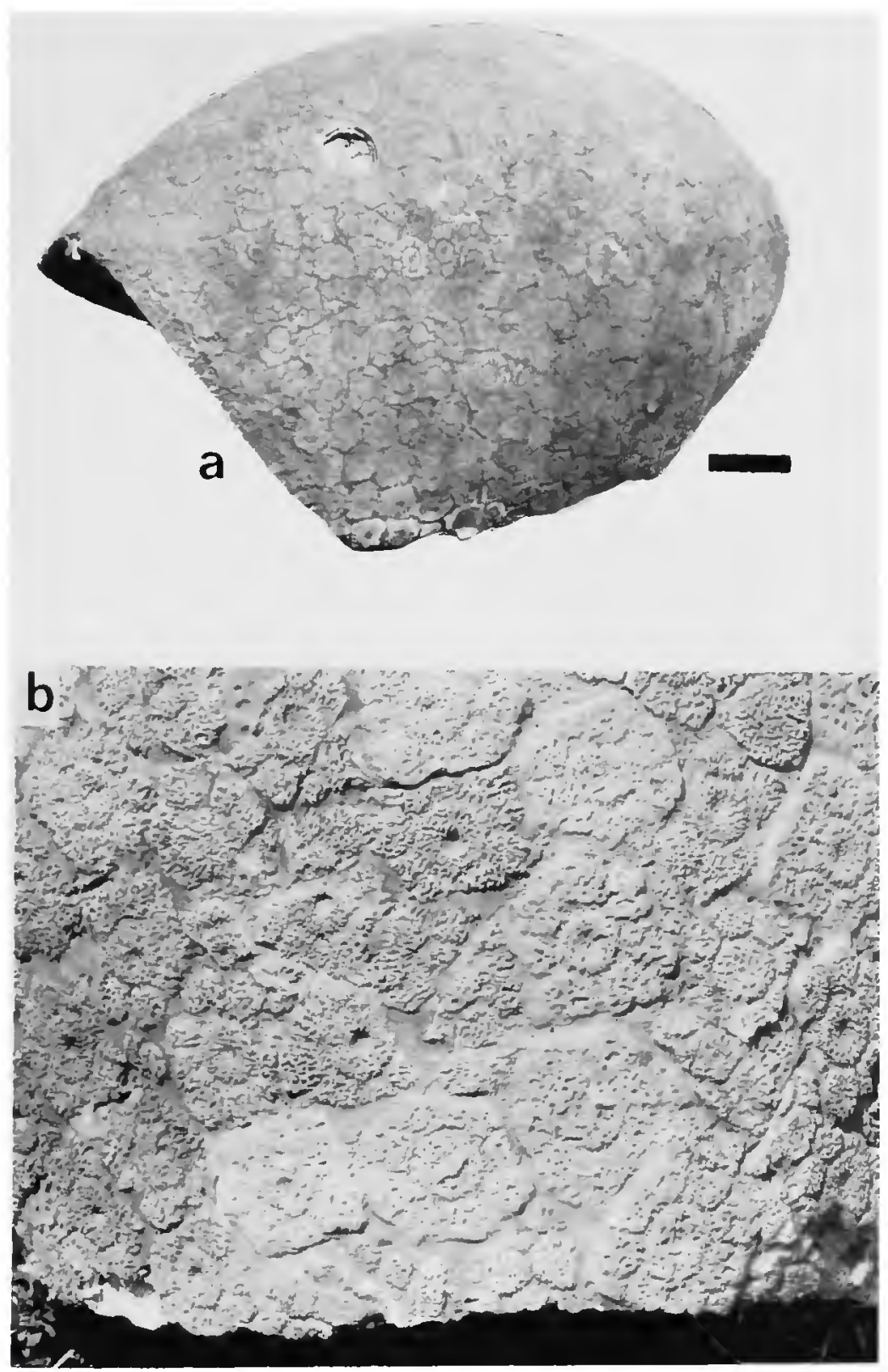

FIGURE 85.-Improperly reconstructed carapace of Glyptotherium arizonae from the Holloman locality, Oklahoma, unnumbered specimen, Stovall Museum, University of Oklahoma: $a$, postero(?)-lateral aspect of right(?) side; $b$, detail of carapace showing jigsaw fashion reconstruction. $($ Bar $=10 \mathrm{~cm}$.)

terior scutes are considerably larger than the peripheral figures, excluding G. floridanum, and the central figures are weakly convex; external figures for two of the scutes bear deep central excavations as in G. arizonae, G. texanum, and $G$. cylindricum. The closest resemblance is to G. arizonae and $G$. cylindricum; the latter species is omitted on geographic grounds. For discussion of the age and associated faunas for these Florida specimens, see "Remarks" under the taxonomic treat- 


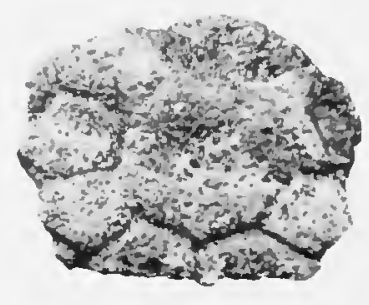

a

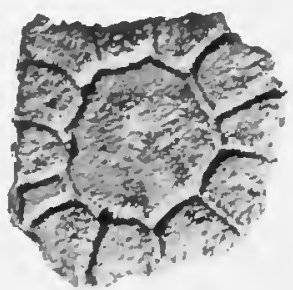

C

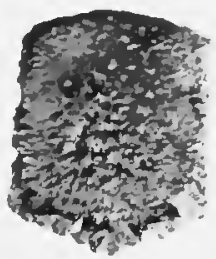

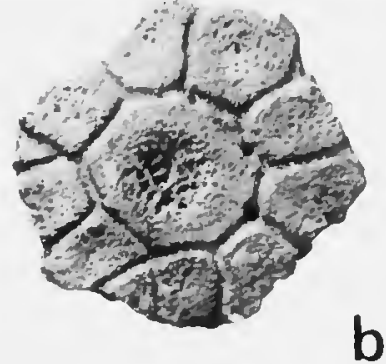
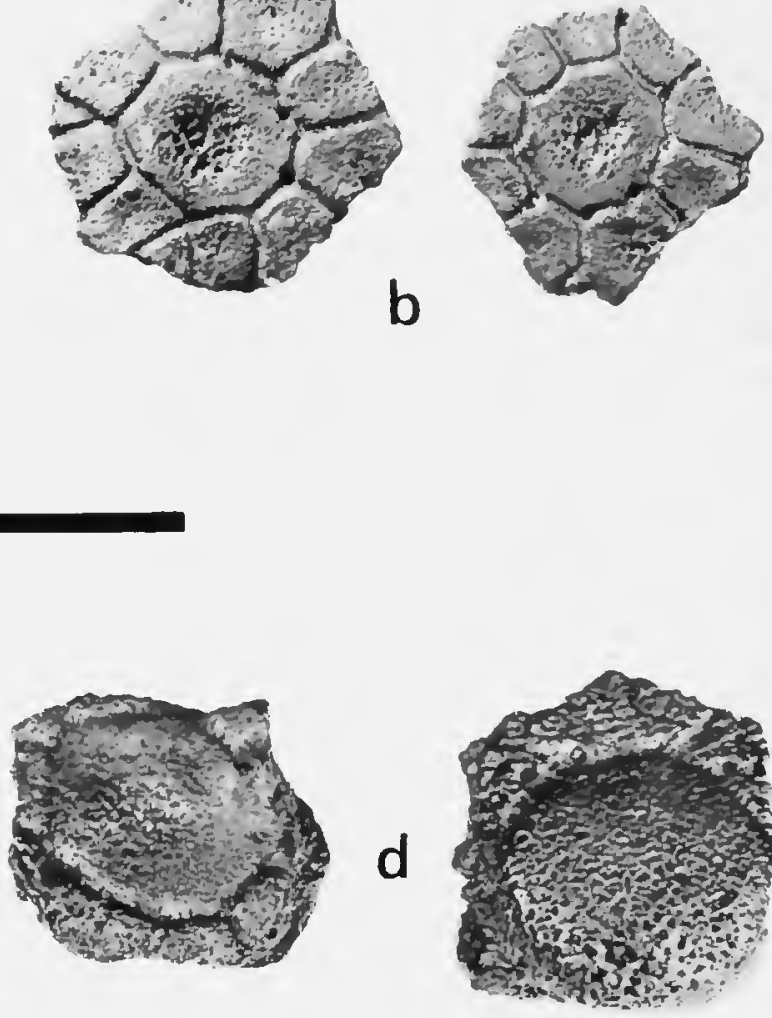

FigURE 86.-Isolated scutes of Glyptotherium sp. cf. G. arizonae from Florida: $a$, interior carapacial scute UF/FSM 10438; $b$, two interior carapacial scutes UF/FSM 10743; $c$, isolated scutes UF/ FSM 10428 (upper left, interior scute from near lateral or posterior border; upper right, interior carapacial scute; lower left, scute from distal row of first or second caudal ring; lower right, scute from proximal row of second or third caudal ring); $d$, UF/FSM isolated scutes (left, interior carapacial scute near margin of carapace; right, border scute from caudal aperture; all from Sante Fe River, UF site 1). (Bar $=10 \mathrm{~cm}$.)

ment for $G$, arizonae and the distribution account for the species.

CARAPACE of $G$. cylindricum and $G$. mexicanum.Brown (1912) accurately described the carapace of AMNH 15548 (Figure 87), designating it the type carapace for the genus Brachyostracon. At the time there appeared to be a significant difference between this carapace and that of Glyptotherium texanum, which had been established by Osborn a decade earlier. Direct comparison of these two specimens reveals no less distinction now than when Brown described this carapace, but the addition of the several other specimens of North American glyptodonts indicates a much closer relationship than the distant one Brown proposed. As discussed elsewhere, AMNH 15548, here designated Glyptotherium cylindricum, is distinct from other North American specimens primarily 
in the characters of the pelvis, although even in this part of the skeleton the differences are not as great as Brown perceived. Other regions of the body, so far as known, indicate a rather close relationship with other North American species. The dentition, although distinctive, is assuredly similar; and the carapace, previously considered to be highly characteristic and in itself partially indicative of a distant relationship with other North American representatives, is actually quite similar to carapace AMNH 21808 (G. arizonae), verifying the expected close relationship inferred by comparison of dentitions and pelves. Carapace AMNH 15548 is described below, following a short digression on the carapace of $G$. mexicanum.
Brown briefly considered the description of Glyptodon mexicanus (= Glyptotherium mexicanum) by Cuatáparo and Ramirez (1875). As Brown pointed out, their description, although largely deficient and at least in part incorrect, is nevertheless substantial enough to warrant at least nominal retention of the species. Fortunately, Brown was privileged to examine the carapace; subsequent to his study the carapace was lost along with the remainder of the two type specimens, and the whereabouts of these fossils remains unknown. Cuatáparo and Ramirez mistakenly reversed the carapace end for end in their description and in their figure. Brown (1912), recognizing this error and having examined the carapace

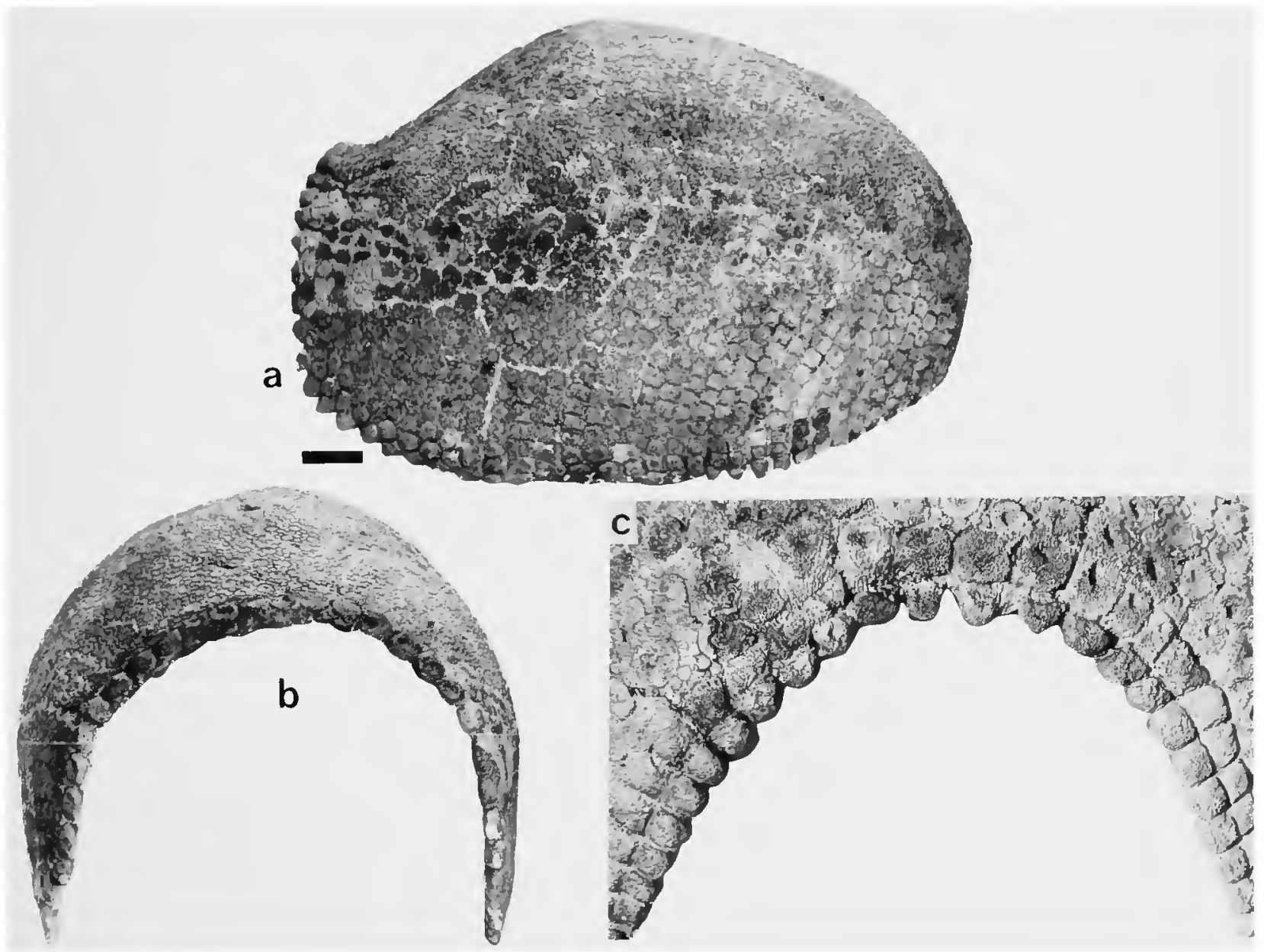

FIGURE 87.-Carapace of Glyptotherium cylindricum (AMNH 15548): $a$, right side; $b$, caudal notch; $c$, detail of anterior aperture. $($ Bar $=10 \mathrm{~cm}$.) 
firsthand, provided a brief description and three useful photographs of the type specimen of $G$. mexicanum. These two descriptions together comprise the only accurate information regarding this carapace, and the verification of its characters in Brown's photographs (pls. 13-15) justify an extracted amplification.

Measurements for this carapace (unnumbered, reported to be preserved in the Mexican National Museum of Natural History prior to its disappearance) are $183 \mathrm{~cm}$ length and $240 \mathrm{~cm}$ width, as given by the original authors, and providing a length-width ratio of 0.76 . These measurements, if correct, are nearly identical to those for the type carapace of $G$. cylindricum (AMNH 15548). Near the posterior border the scutes are recurved upward in a fashion identical to that in AMNH 21808 (G. arizonae) and AMNH 15548 (G. cylindricum.) The caudal aperture in lateral aspect achieves a near vertical outline, and the cephalic aperture is much smaller. There is apparently a preiliac and postiliac division of the carapace in lateral aspect, comprising roughly two-thirds and one-third of the dorsal arch, respectively. The marginal scutes are conical and some are pendant. They increase in size rearward. Border scutes of the anterior notch are simple and unbossed; those of the posterior notch are very large and conical. Along the lateral margin the scutes of the first interior row bear knoblike bosses, identical to those in $G$. cylindricum and $G$. arizonae. There appear to be 24 marginal scutes along the posterior border, 14 along the anterior border, and a total count of 48 along the right side, from the anterior notch to the posterior notch. These counts do not differ greatly from those of either $G$. arizonae or $G$. cylindricum. It cannot be determined whether there is an anterolateral region of imbricated scutes; according to Brown's photographs the anterolateral scutes are firmly united and continuous with those of the dorsal region. Sizes of the scutes, as given by Cuatáparo and Ramirez, and as shown in Brown's photographs, correspond closely to the sizes in G. cylindricum and G. arizonae. Central figures are generally large, never smaller than half the scute diameter, and there are frequent deep recessions in the central figure similar to those of the other two species under comparison. Peripheral figures vary in number from eight to 12 , according to the original authors; this determination is borne out by inspection of Brown's photographs.

According to Brown, this carapace is distinguishable from that of $G$. cylindricum in several characters: larger central figures; transverse rows of scutes not continued far beyond border and more firmly united; border scutes larger and more pendant. These differences are attributable to variation and are insufficient as diagnostic features. There appears to be no reason to assume taxonomic distinction on the basis of these two carapaces. As discussed in the taxonomy section, however, it is appropriate nominally to retain $G$. mexicanum, primarily on the basis of the dentition.

The carapace of $G$. cylindricum, as originally described by Brown (1912), remains the most well-preserved and most perfectly restored one in North America. That it differs little from the carapace of $G$. mexicanum was admitted by Brown, but he nevertheless chose to consider the distinctions as diagnostic. Carapace AMNH 15548 is large, measuring $170 \mathrm{~cm}$ anteroposteriorly and $248 \mathrm{~cm}$ in the transverse (half-circumference) dimension, with a length-width ratio of 0.68 , which is slightly less than that estimated for AMNH 21808 (0.73), and somewhat greater than that for either USNM $10537 / 10336(0.81)$ or the $G$. mexicanum type specimen (0.76), all of which are similar in carapacial features to AMNH 15548. This range in the length-width ratios, from 0.68 to 0.81 , is attributable to variation within the genus. Therefore, the relative length-width proportions should not be used as taxonomic criteria on the spccics level, although these proportions collectively may be indicative of generic characterization. Moreover, the 0.79 and 0.75 lengthwidth ratios of the two mounted carapaces of $G$. texanum, discussed above, are not as radically different from that of $G$. cylindricum as Brown supposed.

In lateral aspect the shape compares favorably with AMNH 21808. The anterior dorsal arch is 
ellipsoidal, reaching a maximum elevation at the position of the iliac attachment approximately $105 \mathrm{~cm}$ from the nuchal border. From that point (approximately two-thirds the anteroposterior length from the anterior border) rearward, the carapace curves more steeply downward, becoming recurved upward at the posterior aperture beginning at approximately the second interior row of scutes from the posterior border. The outline in lateral aspect curves upward somewhat beyond horizontal at the posterior border. Thus, as in AMNH 21808, the carapace is divided into distinct anterior (preiliac) and posterior (postiliac) regions, occupying approximately twothirds $(105 / 170)$ and one-third $(65 / 170)$ of the curvature, respectively.

The anterior aperture measures approximately $45 \mathrm{~cm}$. This figure is considerably larger than the $30 \mathrm{~cm}$ estimate for AMNH 21808, although the figure for the latter could well be larger because of distortion in the free mount. Thus, the lateral extent of the anterior opening, the outline of which is almost vertical, is more easily identified than in AMNH 21808, and the anteriormost point of the carapace, although it is the nuchal scute, does not project far beyond the border scutes of the anterior opening, thus distinguishing $G$. cylindricum from $G$. arizonae. The anterior aperture includes 26 border scutes between the anterolateral angles, approximately the same as that derived for $G$. mexicanum.

The posterior aperture is much larger, measuring an estimated $70 \mathrm{~cm}$ in transverse diameter. This measurement compares favorably with that of $G$. arizonae, and, similarly, it is roughly twice as large in transverse diameter as the anterior opening. The serial arrangement of the border scutes of the caudal aperture becomes vertical, beginning in a relatively sharp angle at the posterolateral position. As in AMNH 21808, the posterior border scutes continue vertically upward to a uniform curvature, forming a semicircular outline in posterior aspect.

The massive posterodorsal bridge located in the dorsal region within the caudal aperture of AMNH 21808 is represented in this specimen by only a few ankylosed scutes occupying the ventral margins of some of the scutes of the caudal border. These are largest in the central position; laterally the bridge is represented by smaller accessory scutes solidly fused to several of the dorsolateral border scutes. For this reason, and because of the nature of the external sculpturing of the scutes in this specimen, we believe that this individual was an adult, and not an old-age representative as in AMNH 21808; hence the presence and relative development of the caudal bridge are not diagnostic.

Associated with this carapace, and in proper restoration in the free mount, is the complete pelvis. Iliac scars on the undersurface of the carapace mark the attachment of the iliac crests to the external armor. The sacrum is therefore in proper position as restored. The sacrocaudal articulation lies some $22 \mathrm{~cm}$ inside the posterior notch. This figure corresponds closely with the anteroposterior diameter of the first three caudal vertebrae of AMNH 21808 (no caudal vertebrae are associated with carapace AMNH 15548), tentatively indicating by analogy that probably three caudal vertebrae were situated beneath the posterior aperture, and corroborating Melton's (1964) suggestion that the first three caudal vertebrae probably lay interior to the caudal border.

The border scutes of the anterior aperture are uniformly bossed in blunt projections dorsally; laterally these projections expand to fuse with the adjacent scutes. None of the border scutes of the anterior opening are large. The four scutes of the first interior row at the anterior notch extend somewhat beyond the border scutes, and their anterior margins form a transversely straight outline and anteroposteriorly a sharp convex surface. Thus, as in the similar bossed structure of AMNH 21808 , it appears that the casque scutes of the rear portion of the skull fit snugly against this projection, similarly protecting the short neck from exposure. The remaining border scutes of the anterior aperture laterally become more solidly ankylosed along their free lateral borders. The open external boundaries in this specimen, as compared with the closed borders in AMNH 
21808, may be simply an age-related factor, and therefore should not be accorded any taxonomic significance. These small anterior scutes were covered entirely by their dermal scales; hence these scutes are devoid of sculpturing. None possess hair follicles, and they are uniformly punctate.

Beginning at the relatively well-defined anterolateral angle, the border scutes become increasingly more pointed and conical. The lateral scutes on the anterior half of the carapace margin are noticeably "villiform," i.e., their boundaries with adjacent border scutes are deeply excavated, producing the pendant scutes of the anterior portion of the margin as described by Brown (1912) for this specimen. As for the anterior border scutes, these excavations (i.e., the pendant scutes) might well be present because of the relatively younger age in comparison with AMNH 21808 and the type specimen of $G$. mexicanum.

The posterior lateral border scutes increase in transverse (border scute suture to border scute suture) dimension. At approximately midposition, the border scutes are elongate and bossed. Posteriorly the scutes become more conical, reaching a well-defined, cone-shaped, external construction at the posterolateral angle. These coneshaped scutes project downward and posteriorly, increasingly more so rearward. The largest conical scutes are the four situated in the posterolateral angle. Like the other border scutes, each of the lateral border scutes was covered by a single dermal scale. There is no sculpturing or radial grooves, except along the interior borders of the scutes near the interior sutures.

The border scutes of the posterior aperture are uniformly large and most bear prominent conical bosses occupying nearly their cntire external surface. Nine of the 27 scutcs of the postcrior apcrture bear deep depressions in place of the apices of the cones, and several of these are punctuatcd by a single large foramen. These large foramina appcar to terminate blindly without entering into the internal portion of the scutes. The posterior border scutes are pentagonal, with conical outcr margins and interior apices forming the suture for the corresponding apices of the scutes of the first interior row.
The interior lateral scutes become increasingly more quadrilateral anteriorly. At least four longitudinal rows of anterolateral scutes are discernible. The imbricated and apparently loose fit of these scutes indicate limited mobility of the carapace in this region. In contrast with $\mathrm{AMNH}$ 21808, these scutes are not underturned; instead, they are vertically oriented, their external faces directed outward and anteriorly.

The first row of scutes internal to the anterior border is anteroposteriorly complete. At least four additional transversely oriented rows occur posterior to the first interior row, the dorsal extent of the rows diminishing rearward. Here, also, the scutes are generally quadrilateral, as a continuation of the apparently flexible construction of the anterolateral region of the carapace. Additional transverse rows of scutes along the margin are discernible, but none extend farther upward than the sixth or seventh scute from the border. There are also at least faintly recognizable longitudinal rows, parallel to the row of lateral border scutes. Thus, the margins of this carapace were flexible not only at the anterolateral angle, but also to a lesser degree, along the lateral regions as well. Central figures on the scutes near the margins are uniformly large, and the peripherals are poorly defined and small. The size of the central figures decreases interiorly, and the peripheral figures become more prominent. In the midregions of the carapace, the central figures are approximately the same size as the peripherals, but never smaller. A number of the central figures (at least half) are weakly concave; a smaller number, perhaps onefourth, are deeply depresscd in the midregion of the central figure. The interior scutes are gencrally six-sided; occasional five-, six-, eight-, nine-, and 10-sided scutcs occur but with lesser frequency with incrcasing number. The scutes are unifornly punctatc. There are no smooth-surfaccd scutes, quitc in contrast to the large number of smooth scutes in AMNH 21808. This possibly agc-related difference in surface texture perhaps corresponds to the greater number of hair follicles in AMNH 15548, although in this specimen also, there are only a few.

The central figures of all the interior scutes are 
flat or depressed, as described above. They are never convex and elevated above the level of the peripheral scutes as in G. texanum. The number of peripheral figures of the interior scutes varies from six to 10 , with eight the most frequent. Sideto-side diameter of the interior scutes falls consistently between 45 and $50 \mathrm{~cm}$, averaging slightly smaller than in AMNH 21808, and the diameters seem to be less variable.

In summary for the carapace of G. cylindricum, there is only a single characteristic that separates it from that of $G$. arizonae--the lateral outline of the anterior aperture; and there is apparently no clear distinction from the carapace of $G$. mexicanum. The vertical outline of the cephalic aperture in $G$. cylindricum might also be attributable to variation, indicating no valid species distinction in the carapaces of these three species. The carapace of both $G$. cylindricum and G. mexicanum therefore differs from that of $G$. texanum in exactly the same fashion as does G. arizonae.

Carapace of $G$. floridanum.-The carapace of G. floridanum is known from several localities in Florida and Texas. It is ironic that this species, which is known from by far the greatest number of localities, is not represented by a single complete carapace adequately preserved for mounting. It was primarily on the basis of a large series of scutes and partial carapaces that Simpson (1929b) established Boreostracon floridanus. As demonstrated below, this material belongs in Glyptotherium, but the carapacial characters are sufficiently well established in the type series to retain the specific assignment. Unfortunately, the Seminole Field type specimens were not associated with any noncarapacial elements, save for a fragmentary mandible, two teeth from an infant, and one adult tooth (the latter from nearby Sarasota, in a private collection). Hence, the relationship of this material to other Late Pleistocene glyptodonts in Florida can be established only on carapacial comparisons and biostratigraphic correlation; therefore, comparison of noncarapacial remains can be made only on an inferential basis. Because Simpson's designation sufficiently defined the characters of the species, his assignment is here retained. The possibility of more than one
Late Pleistocene species in Florida cannot be ruled out a priori, however, although this presumption is here maintained for lack of evidence to the contrary. Moreover, chlamytheres, a group of giant dasypodid edentates comparable in part to glyptodonts, often occur in the same fauna. Although glyptodonts and chlamytheres are likely not ecologic equivalents, they are probably ecologically "analogous," and the likelihood of a third ecological "analog" among glyptodonts seems remote. Therefore, despite the unfortunate lack of noncarapacial remains in the type material of $G$. floridanum, comparison on the basis of carapacial features, as described below, is an adequate means of specific identification for Florida glyptodonts.

Furthermore, identification of Texas representatives of this species must rest ultimately on comparisons with the type specimens from Seminole Field, although comparison with noncarapacial remains of other Florida fossils that are circumstantially identified as $G$. floridanum (on the undesirable basis of carapacial features) must also be considered. It is this latter consideration upon which the Texas Late Pleistocene glyptodonts are referred to the same species as the Florida glyptodonts, in agreement with Lundelius' (1972) conclusions founded primarily on carapacial resemblance.

It should be pointed out, however, that despite the apparent resemblance in carapacial features between the Florida and Texas representatives, there is inconclusive evidence that there may be two species, for the mandibular and dental characters are not identical. Therefore, the Florida population would retain the species designation G. floridanum, while the Texas population would represent an unnamed species, unless the resurrection of the species $G$. petaliferus (Cope, 1888) were to be argued as valid, a matter that Simpson (1929b) partially resolved by declaring Glyptodon petaliferus Cope a nomen nudem. However, Simpson did not designate another species name for the Texas glyptodonts, which he considered specifically distinct from the Florida representatives. At present, the problem is only hypothetical, for there is no compelling reason to consider the two 
populations as different species, and, regardless of inconclusive evidence indicating a specific distinction, the carapacial characters of the representatives from both states are identical.

The carapacial fragments recovered from the Seminole Field locality (type-locality for G. floridanum) apparently can be separated into two distinctive groups, those bearing the characters described by Simpson (1929b) and Holmes and Simpson (1931) for the types, and those closely resembling the carapace of $G$. arizonae and $G$. cylindricum. These are here assumed to represent sexual dimorphism for the following reasons: (1) they are associated in the same lots, and there is no reason to assume that they were recovered from separate strata; (2) as discussed above, there is no compelling justification to assume two glyptodont species in the same fauna; (3) a similar dimorphism occurs in the Texas population, thus providing further evidence for rejecting a twospecies hypothesis, since sympatry should not be expected to occur over such a great distance; and (4) there is a general consistency, rather than separation into discrete groups, in the noncarapacial remains, an unlikely circumstance in the case of sympatric species, i.e., if there are two species recognizable according to carapacial features, they should also be recognizable according to noncarapacial features, and this is not the case in either the Texas or the Florida populations.

Thus, there appears to be sexual dimorphism in carapacial features of $G$. floridanum. That this variation is attributable to sexual dimorphism rather than ontogenetic variation is indicated by the more or less discrete separation into one or the other of the two groups, without intermediate conditions, and by the representation of carapaces from mature adults that fall into only one or the other of the two groups. By analogy with other mammals, the carapaces with small scutes, indicative of smaller individuals, are identified as female and the larger ones as male.

Most of the carapacial remains that Simpson described and figured as the type and referred specimens from the Seminole Field locality belong in the female group. These include the hol- otype (AMNH 23547) and most of the designated paratypes (AMNH 23548-23562), although an isolated scute (AMNH 23550) in this series, which Simpson called "an unusually large scute" (Holmes and Simpson, 1931:412), belongs to a male. Accordingly, Simpson's description of the species applies largely to the female characters, among which relatively small size and maintenance of open sculpturing along the scute sutures are most prominent. Simpson apparently considered the female carapacial fragments as representing immature individuals. This contention is here rejected because there is full scute-to-scute contact with firmly united, although largely unclosed, sutures. This is an indication of maturity, and except for possible increase in thickness, there is no reason to assume these scutes would have become significantly larger with age. Furthermore, the recovery of a large number of immature individuals at the same stage of development, without size gradient, seems improbable. Simpson's general description of the scutes for the species, here considered as pertaining to the females, cannot be improved upon.

The central scutes of this species show a typical pattern which is variously modified in the more marginal regions. These scutes are generally hexagonal, although they may be very irregular and with four to eight sides. The inner surface is concave, with numerous vascular foramina . The dorsal surface is divided by grooves into a nearly circular central area and number of snaller marginal areas, corresponding the overlying scales. The area of the primary scale is here uruly central, generally somewhat depressed in the center, and strongly punctate [vascular foramina]. The marginal areas, which are not always well differentiated from each other, also have vascular openings and are especially marked by a number of irregular radiating vascular grooves. On cach plate these areas are generally six to nine in number, and in this central region they generally were separated by narginal grooves [along the sutures] from their neighbors on the next plate follicles, usially two to four in number oceur only between a primary scale and the surrounding intercalary scales and tend to occur only on the anterior and lateral margins of the primary scale.

Toward the borders the central or primary scale area becomes relatively larger and, especially anterolaterally, may touch the posterior margin of the scute Hair follicles are soniewhat less numerous laterally, usually only one or two on each scute, occasionally none at all. 
Along the borders of the carapace the scutes are regularly arranged in transverse rows. In the more central part traces of regularity are discernible, but the segmented arrangement is masked by interpolation of accessory rows and individual scules

Normally the scutes are united by open sutures, crossed by numerous long interlocking spicules of bone which hold the scutes firmly logether

All of the scutes of the marginal row were covered by a single scale each. Those of the nuchal border, or anterior notch were without bosses, and the first two rows, at least, of this part were somewhat movable against each other

The lateral borders are formed by projecting boss-like scules which are firmly united with each other and the apices of which point backward, downward, and slightly outward. The scutes of the posterior border bear low pointed bosses (Holmes and Simpson, 1931:408-410).

In addition, there is one important feature not indicated by Simpson. In the type specimen AMNH 23547 (Figure 88), which is from the posterior notch, there is the indication of a recurved posterior outline similar to that in the other species and comparable to the weak curvature found in $G$. texanum. Because the curvature is weak and the series consists of only a small region of the carapace, the recurved outline is not immediately evident but is nevertheless present. The similarity of these carapacial features with those of other species referred to Glyptotherium is evident from Simpson's description and from the recognition of the posterior recurved outline. Fea-

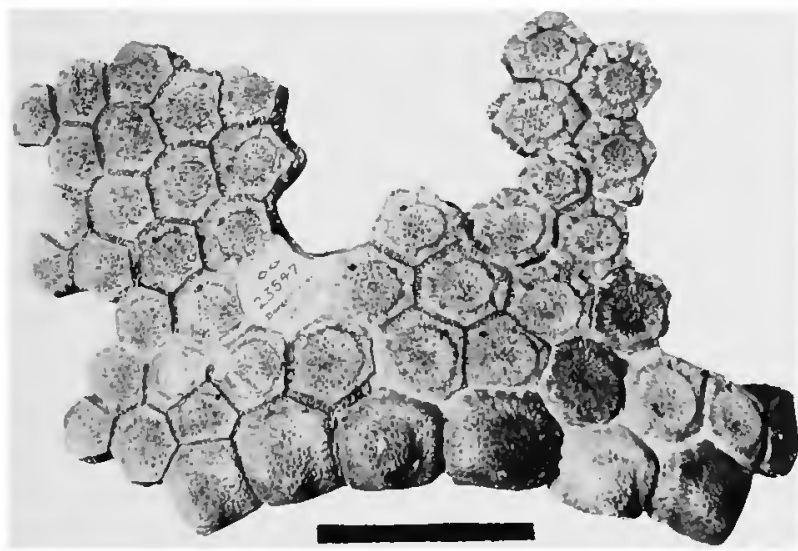

FIGURE 88.-Carapace fragment of Gtyptotherium floridanum holotype (AMNH 23547) from dorsal region of caudal border. $($ Bar $=10 \mathrm{~cm}$.) tures characterizing the species are (1) the relatively small size of the central figures of interior scutes, diameters approximately half the scute diameter, and not significantly larger than peripheral figures; and (2) the maintenance of open sutural contacts in the group herc identified as female. The central figures are weakly concave and raised slightly above the level of the peripheral figures, and the surface of the scutes is gencrally punctate. The number of peripherals varies between six and nine, and for the interior scutes, they are nearly as large as the central figures. For the females, the scutes are relatively small. Interior scutes of the type specimen AMNH 23547 measure approximately $30 \mathrm{~mm}$ transverse diameter between parallel sides and $20 \mathrm{~mm}$ thickness. Measurements on the largest typical scute of the posterior border (third from left) are $42 \mathrm{~mm}$ transverse diameter, $40 \mathrm{~mm}$ from free edge to interior sutural apex, and $29 \mathrm{~mm}$ maximum thickness measured through the external boss.

A statistical analysis of isolated, individual scutes would be falacious because it cannot be determined how many are from separate individuals. There is, however, a distinct bimodal separation in scute size in the Seminole Field specimens. The smaller ones, as described above, are attributed to female individuals. Larger ones, with slightly different sculpturing, are attributable to males. None of the larger ones are in serial articulation. Another characteristic that seems to be limited to the female specimens is the pointed construction of the bosses on the posterior border scutes.

Scutes attributable to males are characteristically larger, and apparently there is no open groove marking the boundaries between scutes, the sutures closing to the level of the peripheral figures. Therefore, the sculpturing delimiting the peripheral figures is continuous across sutural contacts rather than generally separated by the open marginal groove as in the females. A typical border scute from the posterior notch (AMNH 95728, Figure 89) measures $59 \mathrm{~mm}$ transverse diameter, $57 \mathrm{~mm}$ diameter from the free edge to the interior sutural apex, and $44 \mathrm{~mm}$ maximum 
thickness through the external boss. The latter figure does not adequately represent the size distinction, however, since in the males the external boss does not project as far from the level of the surrounding surface as in the females. In the male scute under consideration, the thickness at the interior border is $31 \mathrm{~mm}$, whereas the corresponding thickness for the posterior border scute of the female described above is $24 \mathrm{~mm}$. A typical male interior scute from this same assemblage (AMNH 95727, Figure 89) measures $51 \mathrm{~mm}$ in the transverse diameter and $23 \mathrm{~mm}$ in thickness, substantially greater, especially transversely, than in the female.

Although it cannot be determined from the available specimens whether the carapace of the male possesses a recurved posterior outline, it is probable that it does, on the basis of comparison with the females and with the Ingleside, Texas, specimen discussed below.

In comparison with the carapacial features of $G$. arizonae and $G$. cylindricum, the male representatives in the Seminole Field population exhibit no distinguishing characters for the species other than in the nature of the sculpturing. As in the
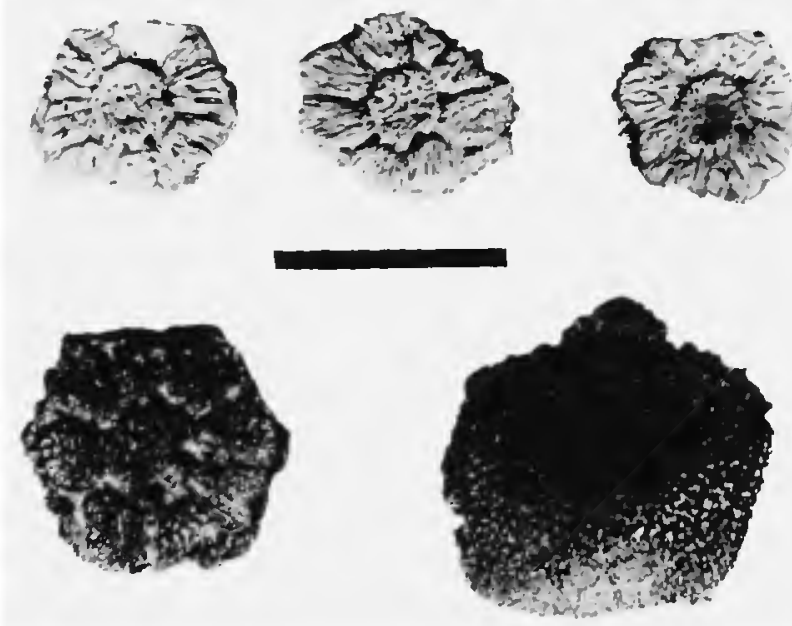

Figure 89.-Scutes of Glyptotherium foridanum from type-locality, Seminole Field, Pinellas County, l'lorida: upper row, three interior carapacial scutes from an adult female (AMNH 95726); lower left, intcrior carapacial scutc (AMNH 95727); lower right, posterior border scute (AMNH 95728) from adult males. (Bar $=5 \mathrm{~cm}$.)

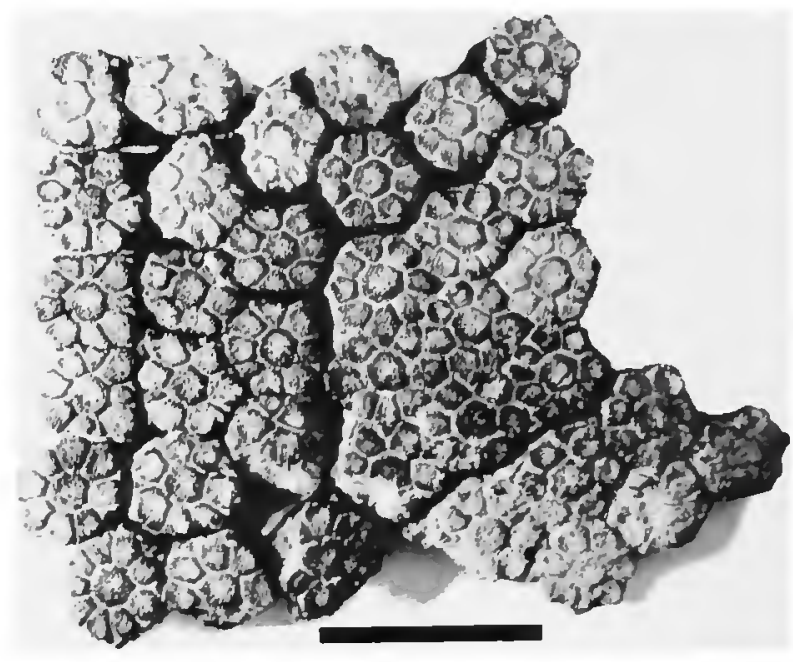

Figure 90.--Interior section of carapace of the Catalina Gardens, Pinellas County, Florida, representative of Glyplotherium floridanum (UF/FGS 6643 ). (Bar $=10 \mathrm{~cm}$.)

females, the central figure for the interior scutes is but slightly larger than the peripherals, and it is generally weakly depressed.

The virtually complete carapace from the nearby Catalina Gardens locality, Pinellas County (UF/FGS 6643, Figure 90) is referred to $G$. floridanum on the basis of comparison with the male scutes from the type-locality Scutes from comparable regions of the carapace are identical from these two localities when comparisons are made with scutes of the male variety from Seminole Field. Posterior border scutes, anterior border scutes, and interior scutes are identical in every respect including size, and they differ from the female scutes from the type locality in exactly the same fashion as do the males.

Unfortunately, this carapace is preserved in several flat sections of articulated scutes that are not sufficiently well preserved to allow for construction of a free mount. Lateral border scutes are missing and the anterior and posterior apertures are incomplete, precluding full comparison with $G$. arizonae and $G$. cylindricum; nor can it be determined whether there was a recurved posterior outline in this carapace. It appears, however, that the only distinction of this carapace from those of the other species lies in the external 
sculpturing, which is identical to that of the Seminole Field representatives and is characteristic for the species.

Gidley (in Hay, 1927:274) listed Glyptodon sp. in the fauna from Melbourne, Brevard County, Florida. Simpson (1929a) reported that these glyptodon remains were referable to Boreostracon floridanus. Gazin (1950) has supplied the only published information concerning the nature of this glyptodont material, stating that it consists of five or six scutes, and he concurred with Simpson's identification. These scutes are in the $\mathrm{Na}$ tional Museum of Natural History (Smithsonian Institution), in the Melbourne, 1928 collection (USNM 256750). Two scutes are from the posterior border, one is a typical interior scute, and two are small scutes probably from the cephalic shield. The two posterior border scutes are comparable in every detail to those of the female $G$. floridanum. They are small, the largest measuring $49 \mathrm{~mm}$ transverse diameter, $45 \mathrm{~mm}$ anteroposteriorly, and $32 \mathrm{~mm}$ maximum thickness, and they possess distinctly pointed, cone-shaped bosses. All five scutes are likely from a single individual.

Leidy (1889b) reported glyptodont scutes from Peace Creek, near Arcadia, DeSoto County, Florida, as Glyptodon petaliferus. Hay (1924) rejected Leidy's identification, apparently on grounds of geographic separation from the type locality for $G$. petaliferus and hastily erected $G$. rivipacis for the Peace Creek glyptodont. Simpson (1929b) rejected Hay's species as a nomen nudem and went on to describe the Seminole Field specimens as the types for his new species, which, by implication, was to include the Peace Creek, Florida, representative of $G$. petaliferus. The Peace Creek representative appears indeed to belong in Glyptotherium floridanum, the descriptions by Leidy (1889b) and Hay (1924) indicating a close resemblance to the carapacial materials described above. (The scutes have not been examined for the present study.)

Simpson (1929a) included Boreostracon floridanus in the faunal list for the fossils recovered from the mouth of Hog Creek at Sarasota, Sarasota County, Florida. In his description of the species,
Simpson (1929b) included a tooth from the "Moore Collection," which was apparently recovered from the same locality. Simpson's reference of that tooth, which he figured, was correct. Whether he had access to carapacial material is unclear, but at approximately the same time, both Gidley and Hay received together a total of seven scutes as gifts from the same Mr. Moore from the Sarasota locality (USNM 11675, 11975). To the best of our knowledge these have not been reported. There are two interior scutes, one with a relatively large central figure indicating a more marginal proximity; two border scutes from the lateral margin; one border scute from the posterior border; and one border scute from the posterolateral region of the anterior notch, and one interior scute from the anterolateral region. These are all large scutes, comparable to those of the Catalina Gardens male G. floridanum. The posterior border scute is typically large, with only a low, blunt external boss; it measures $57 \mathrm{~mm}$ in the transverse dimension, $59 \mathrm{~mm}$ in the externalinternal dimension, $37 \mathrm{~mm}$ maximum thickness, and $28 \mathrm{~mm}$ thickness at the interior suture. The border scute from the posterolateral margin is typically pointed in a downward-directed triangular projection, verifying the existence of conical posterolateral border scutes in this species. The interior scutes are thick and large and bear the typical $G$. floridanum sculpturing.

Two unreported glyptodont scutes from the Waccasassa River, Levy County, Florida (UF/ FSM 16379 , 18455) are referred to $G$. floridanum on the basis of their sculpturing.

The only eastern record of $G$. floridanum outside of Florida is from the Edisto Beach locality, South Carolina. One heavily abraded scute (ChM 2417) associated with skull ChM 2415 (CM 43.59 as reported by Ray, 1965) was recovered from this locality, and two other scutes (ChM 2418, 2090) have been recovered from the nearby Edingsville Beach. All three scutes exhibit typical $G$. floridanum sculpturing. The Edisto Beach scute is probably female, while the Edingsville scutes are larger and are probably from a male individual. As in Florida, Late Pleistocene glyptodonts in 
Texas are known from a variety of localities, of which several are recorded here for the first time. Lundelius (1972) has presented the most recent review of the Texas representatives. Primarily on the basis of carapacial features, he proposed synonymy of all the published Late Pleistocene records in Texas with Simpson's Florida species. The taxonomy proposed here is in essential agreement with Lundelius that the Texas and Florida representatives belong in the same species, referred to Glyptotherium floridanum.

The carapacial features in the Texas glyptodonts correspond closely with those from Florida. There seems to be a separation into two groups, larger males and smaller females, although the differences are not as pronounced as in the Florida population. Unfortunately there are no samples large enough to assume representation of more than one or two individuals at the same locality, so that it is difficult to assert with confidence that the postulated dimorphism is not instead attributable to separate species. By analogy with the Florida population, particularly the representation from Seminole Field, the Texas population of $G$. floridanum, which is identical in carapacial features (but not totally identical in noncarapacial osteology), is here assumed to exhibit sexual dimorphism. The argument for this assumption is the same as that forwarded for the Florida population. Additional support for this hypothesis is the low probability of sympatry over such a great distance. Furthermore, if indeed the Texas and Florida populations prove to belong to different species (closely related, distinguishable only by their dentition), and if the dimorphism were taken to represent two species in each state, then there would be four species in the Gulf Coastal Plain, a geographic area for which there is little evidence of barriers promoting isolation. Hence, as in the Florida population, male-female distinction seems more reasonable, and accounts for the general similarity of noncarapacial remains (unexpected if two species are represented).

Compared with scutes from the Florida $G$. floridanum, the Texas female scutes are not as easily identified, except on the basis of size. The peripheral grooves, located at the sutural contacts between scutes, are not as prominent in the Texas females, perhaps indicating either ontogenetic variation or less dimorphism in the Texas population.

Cope's (1888) type specimen of Glyplodon petaliferus from Nueces County, Texas (AMNH 14158, Figure $91 c$ ), is referred to $G$. floridanum. It consists of little more than half of an interior scute, with a relatively small central figure and four preserved peripheral figures. There probably were eight peripheral figures in this scute before it was broken. Despite Cope's description, the undersur-
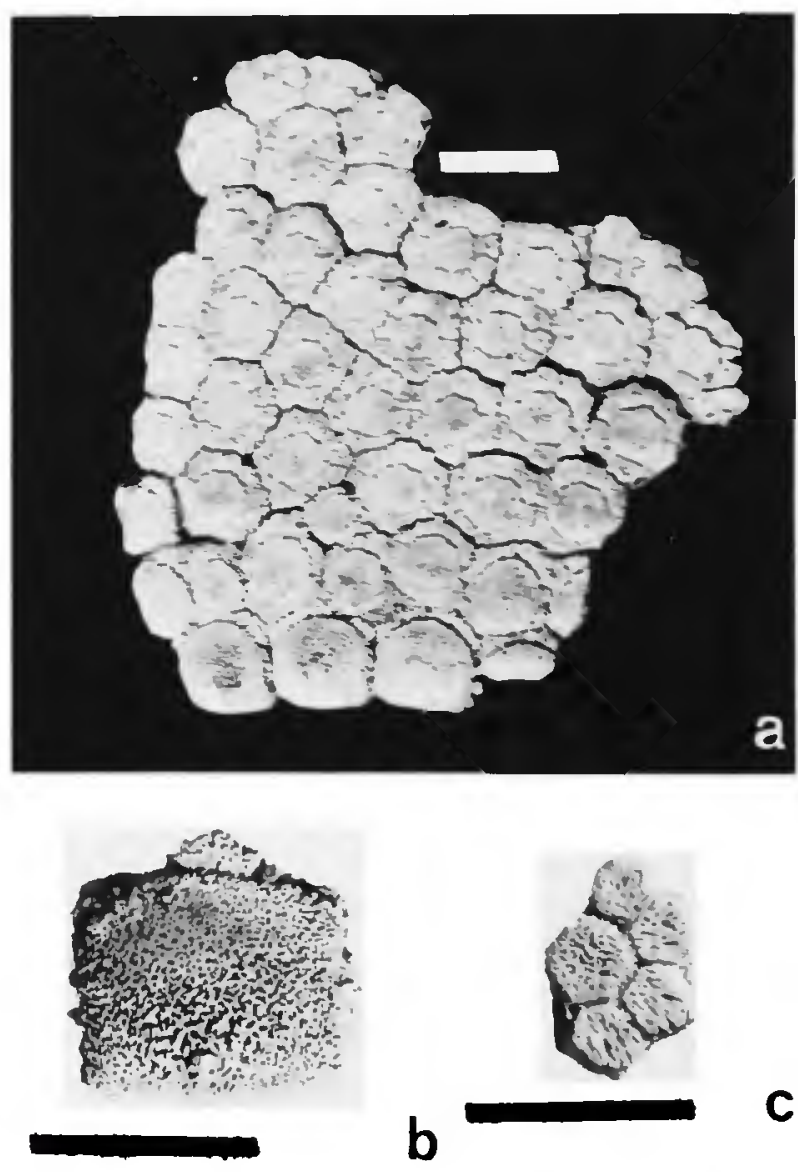

Figure 91.-Scutes from carapace of Glypiotherium floridanum from Texas: $a$, carapace fragment from posterior region along caudal aperture (TMM 30967-2088); $b$, border scute from caudal aperture (USNM 6071); $c$, interior carapacial scute fragment, holotype Glyptodon petaliferus (= Glyptotherium foridanum), AMNH 14158. (Bars $=5 \mathrm{~cm}$.) 
face is not preserved, and its thickness therefore cannot be measured. Its side-to-side diameter was at least $45 \mathrm{~mm}$. Its size corresponds to the males represented in the Seminole Field population. The central figure is raised slightly above the level of the peripheral figures, and there is a suggestion of a weak central concavity. Three hair follicles are preserved, and they are relatively small. Surface texture is pitted and punctate.

The carapace of the Wolfe City, Hunt County, Texas, glyptodont (USNM 6071), which Hay (1916) referred to Cope's species, is represented by approximately 80 isolated scutes, of which one is from the posterior border, two are from the first interior row along the posterior aperture, and several are from the anterior notch and caudal armor. Because there is no duplication of parts in the noncarapacial remains it is safe to assume that these represent only one individual. As indicated by their size, these scutes belong to a male individual. Measurements for the only posterior border scute (Figure $91 \mathrm{~b}$ ) are $57 \mathrm{~mm}$ transverse diameter, $52 \mathrm{~mm}$ exterior-interior diameter, 45 $\mathrm{mm}$ maximum thickness, and $31 \mathrm{~mm}$ thickness at the interior suture. These dimensions are nearly identical with those given for the corresponding male scute from Seminole Field. Interior scutes compare in exactly the same fashion. Sculpturing is identical to that in the Florida males of $G$. floridanum, i.e., lacking peripheral sutural grooves and otherwise typical for the species.

Hay (1926) described carapace fragments from the private collection of one Dr. Mark Francis of College Station, Texas. These remains were associated with fragmentary noncarapacial elements including five mandible fragments and a complete femur. They reportedly came from the Aransas River, near Sinton, Texas, not far from the Nueces County record. The whereabouts of these fossils is unknown. Hay" detailed the differences between the carapace fragments and teeth with corresponding elements of the Wolfe City specimen, which he had described earlier, and noted several distinctions in the anterior teeth and in the sculpturing of the scutes. He concluded that the differences probably represent variation, and that the Sinton and Wolfe City specimens likely belong in the same species. Hay mentioned two carapace fragments that Dr. Francis had donated to the United States National Museum, stating that they bear the catalog number USNM 11379. One of these, a single isolated scute, has been located. Another fragment, consisting of approximately six fused scutes from the ischiac or iliac region, bears the number USNM 11378 and is accompanied by a label that reads "gift of Dr. Mark Francis. . .Aransas River." This latter specimen is undoubtedly the second of the two that Hay had stated bore the same catalog number. Hay was correct in noting a difference in the sculpturing from that of the Wolfe City specimens. The central figures are relatively large, and they are depressed, similar to the depressions noted in other species. There are no peripheral grooves at the sutural contacts in the two specimens at hand, and the scutes are large. Sculpturing most closely resembles that of other $G$. floridanum specimens, and because of the Late Pleistocene age indicated by the associated fauna, these are referred to $G$. floridanum.

Not far from the Sinton locality in the same county is the Ingleside occurrence of $G$. floridanum, which Lundelius (1972) identified as conspecific with the Wolfe City and Florida Late Pleistocene representatives. Lundelius accurately described the portion of the carapace that is mounted as a display specimen (TMM 977-3). Apparently the only part of this reconstruction that is composed of actual bone is the posterior region of the carapace and the first six tail rings, as Lundelius maintained. Notable features on this carapace include a healed injury over the left iliac region, where the scutes are depressed and solidly fused; the weak recurved outline of the posterior border similar to that in the type specimen of $G$. floridanum; and the relatively large size, indicating a male individual according to the present propositions.

A carapace fragment from the same locality, consisting of three scutes from the posterior border and approximately 50 interior scutes (TMM $30967-2088$, Figure $91 a$ ), is from a second individ- 
ual, for there is duplication in the regions preserved between these two specimens. These apparently represent a female, as indicated by their size: posterior border scutes average $46 \mathrm{~mm}$ transverse diameter, $43 \mathrm{~mm}$ external-internal diameter, and $21 \mathrm{~mm}$ thickness at interior suture. These dimensions are nearly identical to those of the (female) type specimen of $G$. floridanum. These scutes differ in possessing only blunt projections, similar to those of males in the Florida population, and in mostly lacking development of peripheral grooves at the sutural boundaries, although there is the suggestion of this construction on the interior scutes. The age assignment of Late Pleistocene as indicated by the associated fauna further supports the $G$. floridanum identification.

The scutes Sellards (1940) mentioned from Bee County, Texas, not far from the San Patricio recoveries, have not been examined for the present study. The scutes were associated with a fragmentary mandible (TMM 31034-30) that resembles in all respects, as far as can be determined, mandible TMM 30967-1814 from Ingleside. This comparison, along with the Late Pleistocene age of the fauna, indicates an assignment as $G$. floridanum for the scutes and the mandible from Bee County.

The glyptodont remains that Hay (1924) reported from Jones County, Texas, include approximately 15 isolated scutes (USNM 8644). Hay identified these as Glyptodon petaliferus and Lundelius (1972) was unable to make a taxonomic assignment. Although heavily weathered, they seem to resemble closely scutes of $G$. floridanum males in possessing relatively flat and punctate surfaces for the central figures in addition to their large size. These scutes are here referred to $G$. floridanum on the basis of the sculpturing and the proximity of the locality to other recoveries of this species. These scutes represent the second inland recovery of $G$. floridanum in Texas.

Lundelius (1972) reported a collection of scutes from Cameron County in southernmost Texas near the mouth of the Rio Grande. On the basis of his determination thesc arc referred to G. floridanum.
Unreported recoveries of scutes referable to $G$. floridanum in Texas include a collection of 80 scutes from Laubach Cave, Williamson County (TMM 41343), associated with a Late Pleistocene fauna; approximately 25 isolated scutes (TMM 41075-14) from the "Eremotherium locality," Port Lavaca, Calhoun County, Texas; and three small scutes from the Runnels Pierce Ranch, near Whorton, Matagordo County (TMM 41530-6). With the exception of the Laubach Cave recovery, these are coastal records. The scutes from Laubach Cave are referable to $G$. floridanum on the basis of sculpturing. The locality is intermediate between the coastal records and the Wolfe City, Hunt County site, and therefore represents the third inland recovery of $G$. floridanum.

\section{Caudal. Armor}

Osborn (1903) accurately described and figured the caudal armor for the type specimen of $G$. lexanum. The caudal armor of the Arizona specimen is in most respects identical. However, there was also recovered the anterior "accessory ring," here considered as the first caudal ring. Although the accessory ring was not preserved with the type specimen, it is likely that there was one, for these two specimens are otherwise identical. The likelihood of an incomplete anterior ring, or accessory ring, can also be argued as a ncccssary consequence of the peculiar construction and support provided by the vertebrae, in which dorsally the rings are supported by the xenarthral processes of one vertebra, laterally by the transverse processes, and ventrally by the chevron articulating principally with the next anterior vertebra. Thus the first vertebra to possess a chcvron neccssarily lacked ventral support for a ring because its chevron supported the next posterior ring; hence the necessity for an anterior accessory ring as the first (but incomplete) caudal ring. An incomplete anterior ring is also known for $G$. arizonae. It is probably characteristic of the genus.

The accessory ring, or caudal ring 1 in $G$. texanum (F:AM 95737, Figure 92), is a short dou- 


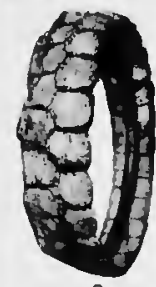

2
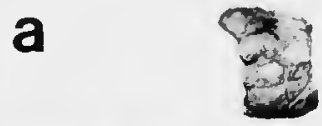

8

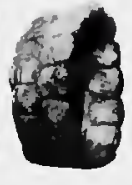

5

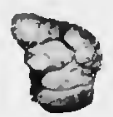

9

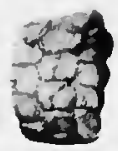

6

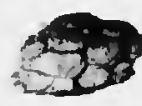

$10 / 11$

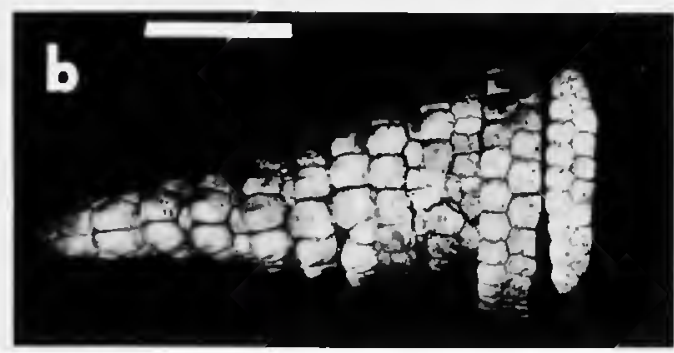

Figure 92.-Caudal armor of Glyplotherium texanum: $a$, isolated caudal rings 2-11 of type specimen AMNH 10704 (27 , dorsal aspect; $8-9$, right side; $10 / 11$, left side); $b$, articulated caudal armor including incomplete first ring of Arizona representative F:AM 95737, dorsal aspect. (Bar $=10 \mathrm{~cm}$.)

ble row of small scutes. The proximal row includes seven small five-sided scutes and a small fragmentary one near the left extremity; the distal row includes nine large five-sided scutes, including the scutes forming the extremities. Scutes of the proximal row are indistinctly sculptured with raised and convex upper surfaces. Each of the distal scutes bears a pair of large hair follicles, and the proximal scutes bear one at their interior apex near the contact with the distal scutes and one or two hair follicles at the sutural contacts with adjacent scutes of the distal row. The undersurfaces are weakly concave. The overall shape and size compare with a flattened half section of a banana peel. Its transverse length is $190 \mathrm{~mm}$ and its central width (anteroposterior diameter) is $42 \mathrm{~mm}$. In F:AM 95737 this accessory ring lay above caudal vertebra 2 . There is no indication on its undersurface of contact with the support processes of the vertebra, and presumably at least in the subadult condition its connection was cartilaginous or ligamentous. This ring lay well within the caudal aperture.

Ring 2 in F:AM 95737, the first complete caudal ring, is also the largest, measuring approximately $210 \mathrm{~mm}$ transverse diameter in both the type specimen and the Arizona specimen. It is formed by two complete rows of 24 firmly sutured scutes. The distal scutes are larger, and their free margins are rounded, producing a scalloped outline. The scutes are flat externally, with indistinct sculpturing indicating a single large scale covering each scute. The textures are pitted and punctate externally. Several large vascular pores mark the otherwise smooth internal surfaces. This ring, like the first, lay within the caudal aperture, as indicated by the pelvis-carapace geometry and by its lack of external ornamentation. Measurements for this and the other rings are provided in Table 70.

Ring 3 (second complete ring) is similar to ring 2 except that it is smaller (approximately $180 \mathrm{~mm}$ diameter) and some of the scutes of the distal row reach the proximal margin, crowding the proximal scutes and making the proximal row incomplete despite the same number of 20 scutes in both rows.

Rings 4-10 decrease in diameter and increase in maximum length rearward. The rings are all complete double rows, and the number of scutes in each row decreases from 19 in ring 4 to 10 in the penultimate ring (10). The scutes of the distal rows increase in absolute and relative size rearward, while there is little change in the absolute sizes of the scutes in the proximal rows. The dorsal pair of distal scutes in ring 4 are weakly conical, and the two adjacent are faintly conical. The corresponding scutes in rings 6-8 are increasingly more strongly conical, but the remaining outline of the free margin is scalloped as in the anterior rings. The dorsal pair of scutes of the distal row in ring 9 are greatly enlarged and markedly conical. They are expanded rearward and fit snugly into a corresponding notch of the terminal tube. In the terminal tube three succes- 
sive pairs of dorsal conical scutes complete the ornamentation.

The penultimate ring and the terminal tube are basically similar in the Texas and Arizona representative specimens, but they differ in detail. Ring 9 in the type specimen is composed of only one complete row of enlarged scutes, representing the distal row, and only two small scutes from the proximal row. In F:AM 95737, there are instead two complete rows of scutes in the penultimate ring, with full representation of the proximal row. However, the scutes of the first row of the terminal cone in the Arizona specimen correspond exactly in their construction to those of the penultimate ring in the type specimen. Hence the long terminal cone in F:AM 95737 in actuality appears to be the fused terminal cone and true penultimate ring. That they are truly fused is indicated by fusion of the last three caudal vertebrae.

The terminal cones are therefore different in these two specimens, apparently because of the lengthening of the tube by fusion in the Arizona representative. In F:AM 95737, the terminus of the tube is formed by two incomplete and two complete alternating rows of scutes. In the Texas specimen the entire tube is formed by two complete rings and an incomplete ring at the tip, with two small accessory scutes on the proximolateral angles. In both, the terminus is open, and it appears to have lacked a terminal scute. (Holmes and Simpson, 1931, reached a similar conclusion for G. floridanum.)

In $G$. texanum the caudal armor therefore exhibits minor variability, especially in the construction of the terminal tube. It is tempting to explain the lengthening of the tube in the Arizona representatives as an evolutionary trend related to decreasing number of caudal vertebrae, and as intermediate between the type specimen and $G$. arizonae.

The caudal armor of $G$. arizonae (Figure 93) is modified from that of $G$. texanum and is diagnostic for the species. In USNM 10537 there are eight complete rings and a terminal tubc consisting of the actual tube and the penultimate ring. Thus there may be considered nine complete rings plus the terminal tube. The accessory ring is only fragmentary and not well enough preserved for restoration. Isolated scutes from the accessory ring are identical to those of AMNH 21808, from the same locality. In the latter specimen the caudal ring count is the same as for the type specimen: an anterior accessory ring, eight complete rings, and a terminal tube formed by the fusion of the penultimate ring with the actual tube. Hence for both specimens there are 11 rings, of which the first is incomplete and the last two are conjoined to form the terminal base.

In UMMP 34826 there are 12 caudal rings, including the anterior accessory ring and the terminal tube. The penultimate ring is not fused to the terminal tube. The difference in total counts between these threc specimens is a consequence of the greater number of caudal vertebrae in the Seymour representative and is not necessarily indicative of species characterization. The construction of the caudal rings is the outstanding feature enphasizing the similarity between the Texas and Arizona representatives, the total caudal ring counts notwithstanding. As indicated in these three specimens, the scutes of the distal rows of all the rings cxcept the first three are extremely tubcrculate, in contrast to the smooth surfaces of the scutes of the distal row in $G$. texanum (excepting the pair of conical dorsal scutes).

The accessory ring, or ring 1 , is formed by a double row of smooth, quadrilateral scutes in the Scymour specimen and by a single row, with a few intercalated proximal scutes, in $\mathbf{A M N H}$ 2 1808. It is semicircular, and laterally more extensive than in $G$. lexanum.

Ring 2, the first complete ring, is composed of a doublc row of smooth, flat scutes, with a scalloped outline for the free margin, similar except for larger size to the corresponding ring of $G$. texamum. Caudal ring no. 3 is similar to the one preceding, but the scutes of the distal row are variously raised and convex, some suggestive of the conical bosses characteristic of remaining rings. As Mclton (1964) suggested, the first three rings cvidently lay within the caudal aperture, as 

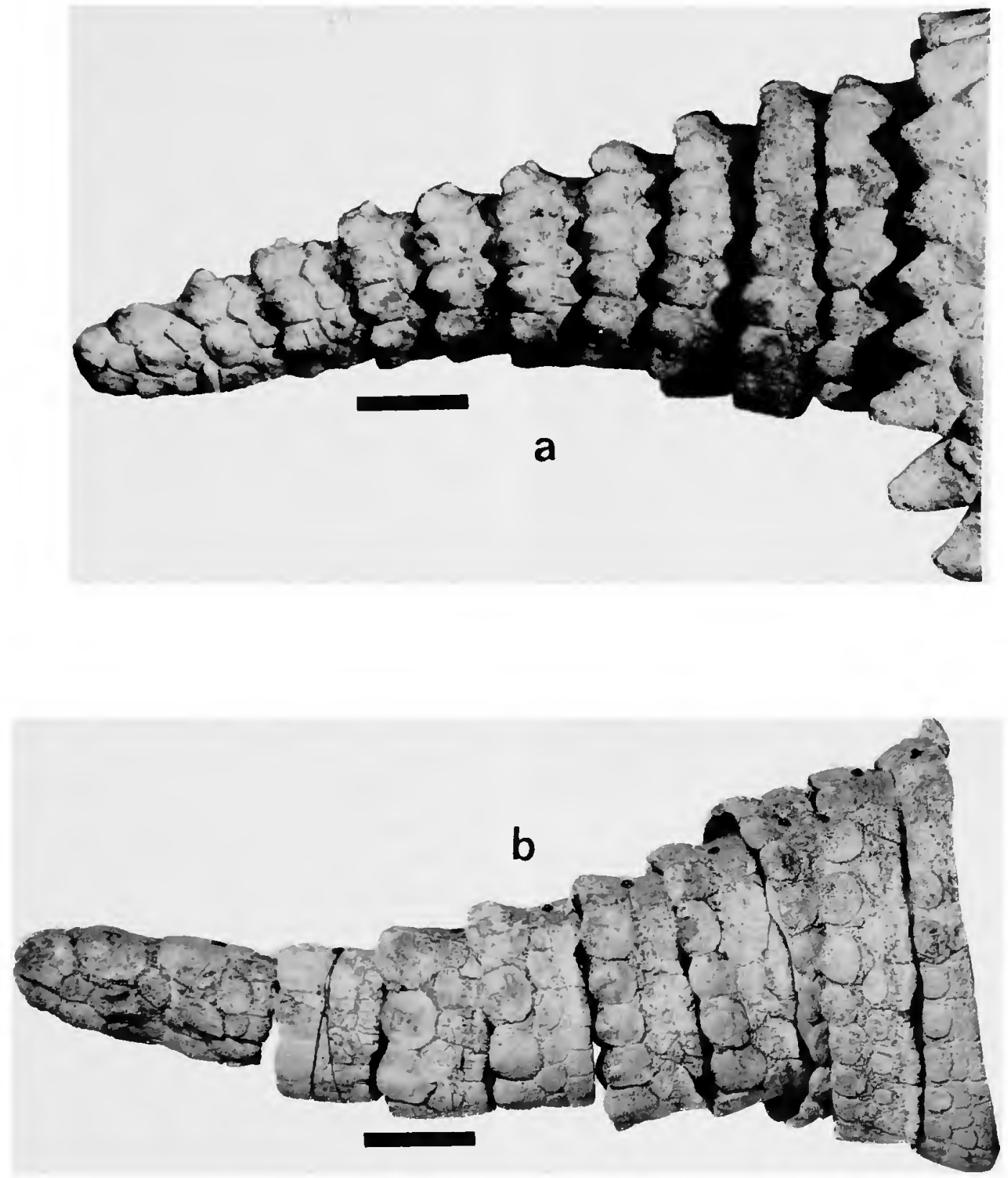

FIGURE 93.-Caudal armor of Glyptotherium arizonae from the Curtis Ranch, type-locality: $a$, USNM 10537, right side; $b$, AMNH 21808, right side. $(B a r=10 \mathrm{~cm}$.)

indicated by the smooth surfaces of the scutes. This conclusion is also supported by the positioning of the pelvis.

Caudal rings 4 to 10 are biseriate in the Seymour representative and in USNM 10537. Rings 4 to 7 are incompletely triseriate in AMNH
21808, a condition evidently attributable to intraspecific variation. Scutes of the proximal rows possess flat, oval figures covering approximately the distal half of the external surface of each scute. These scutes are flat and unbossed. The scutes of the distal rows are almost uniformly 
tuberculated, each one possessing a pronounced conical boss situated nearer the free margin than the sutural border. The dorsal pair are distinctly more conical in each ring, and the lateral and ventral ones are less well developed although the tubercles are distinctive. The free margins of the distal rows are scalloped, as in $G$. texanum.

The penultimate ring in all three specimens (fused to the terminal tube in the Curtis Ranch representatives) is biseriate, and each row is composed of six scutes. The dorsal pair in the distal row are enlarged and extremely pointed. They project rearward beyond the free margin of the remainder of the distal row, fitting snugly into a corresponding notch of the terminal tube. The lateral and ventral scutes of the distal row are indistinctly conical relative to corresponding scutes in the more proximal rings, and also relative to the distal pair on the same ring, emphasizing the marked asymmetry of the penultimate ring.

The terminal tube is formed by three rows of scutes with several accessory scutes. The dorsal pairs of scutes of the last two rings are conical, thus maintaining the pattern of the enlarged conical pair of each distal ring to the terminus. A small scute covers the tip. At its anterior margin there is a dorsal notch for the fit of the penultimate ring.

As Melton (1964:143) astutely observed, "in bony rings three to ten, the two ventral scutes are flat and smooth, and they join so that there is a noticeable $\mathrm{V}$ notch toward the rear where the chevron bone in the next anterior vertebrae [sic] articulated." This construction is not evident in G. lexanum.

The principal distinction in the caudal armor between $G$. texanum and $G$. arizonae, therefore, appears to be the development of pronounced tubercles on the scutes of the distal row in each of the rings postcrior to ring 3. The pair of enlarged dorsal tubercles on each distal row, the scalloped free outline, the nature of the accessory ring, the general lack of fusion of adjacent rings, the similarity in the terminal tubc, and the nature of the vertebral-chevron articulation all point to a basic similarity in the caudal armor of these two species. The only differences, those of size and the development of tubercles, are indicative of species distinction, but further taxonomic separation of these two species on the basis of the caudal armor is unjustified. Indeed the basic similarities may be used as important counterargument considerations when evaluating other differences that alone are suggestive of greater than species separation.

Included in the collection of remains of the type specimen of $G$. cylindricum (AMNH 15548), but unmentioned and undescribed by Brown (1912), is a series of 24 scutes, of which two groups of three and seven are articulated. Of the remaining 14 isolated scutes, at least eight can be articulated with confidence. The remaining scutes are of similar shape and size and apparently belong with the articulated scutes. All belong to the same caudal ring, by virtue of the uniform curvature of their undersurfaces and by the uniformity of the distal scutes, all of which lack bosses and are smooth and flat, as in caudal ring 1 and 2 of other North American glyptodonts. The construction of these scutes is no different from that of the more completely known scutes of the first and second caudal rings of $G$. arizonae, with which they closely compare.

Holmes and Simpson (1931) mentioned the recovery of a few caudal scutes in the Seminole Field glyptodonts. These are the only caudal scutes associated with the type specimens of $G$. floridamum; they afford no positive distinction from the corresponding scutes of $G$. arizonae, i.e., they arc simple, with minimal sculpturing, and the scutes of the posterior row bear large conical bosses.

Thc samc authors described a fragmentary caudal tube from the Sarasota locality and in the possession of a privatc collector. Of these two caudal scutes, they stated that they came from

the terminal part of the tail, which apparently was tube-like and not divided into definite movable rings. The beak-like posterior projection, prominent on the anterior rings, has flattencd out. The more anterior of these two scutes forms a $40^{\circ}$ arc of a circle, indicating a ring or row of nine scutes, 
while the more posterior forms a $60^{\circ}$ arc, indicating a row of six scutes. The two rows represented were apparently contiguous and the more anterior overlapped the other. The posterior end of the more distal row shows no sign of contact with other scutes, and nothing indicates the presence of bone beyond this point, which would leave a very small opening at the end of the tail tube, possibly capped by a scale (Holmes and Simpson, 1931:410).

These two scutes (not located for the present study) and the isolated fragmentary scutes are the only caudal scutes known from the Florida population of $G$. floridanum. The description of the two caudal scutes might apply to the ventral scutes of the terminal tube in $G$. arizonae and does not indicate primary distinction. (These are the only terminal tube remains in all of the $G$. flondanum population, Texas included.)

Lundelius (1972) figured and described the six anterior caudal rings of $G$. floridanum (Figure 94) from the Ingleside locality, Texas. These probably correspond to caudal rings 2 to 7 , as identified here, presuming that ring 1 , the accessory ring, is missing and that the first ring present is ring 2.

Measurements (Table 70) indicate that these caudal rings are slightly smaller than those of $G$. arizonae; this is the most notable distinction. The first ring (ring 2) is biseriate and the scutes are flat. Ring 3 is also biseriate, with unbossed but weakly pointed posterior scutes. Rings 4 to 7 are biseriate, with an incomplete third ring formed by the intercalation of proximal scutes. Scutes of the distal rows in these rings are strongly bossed, conical, and similar to those in $G$. arizonae. The only distinction other than size (which is minor) is a qualitative one: the scutes of the distal rows are not as exaggerated in their conical development as in G. arizonae. This difference is seemingly trivial and is useless taxonomically. As presented in the discussion of the caudal vertebrae, $G$. floridanum appears to have possessed individual rings for all but the last vertebra, as in other species of Glyptotherium, rather than having a terminal tube of coalesced rings.

Therefore, on the basis of these inferences and incomplete data, the caudal armor of $G$. floridanum appears not to differ significantly from that of $G$. arizonae.

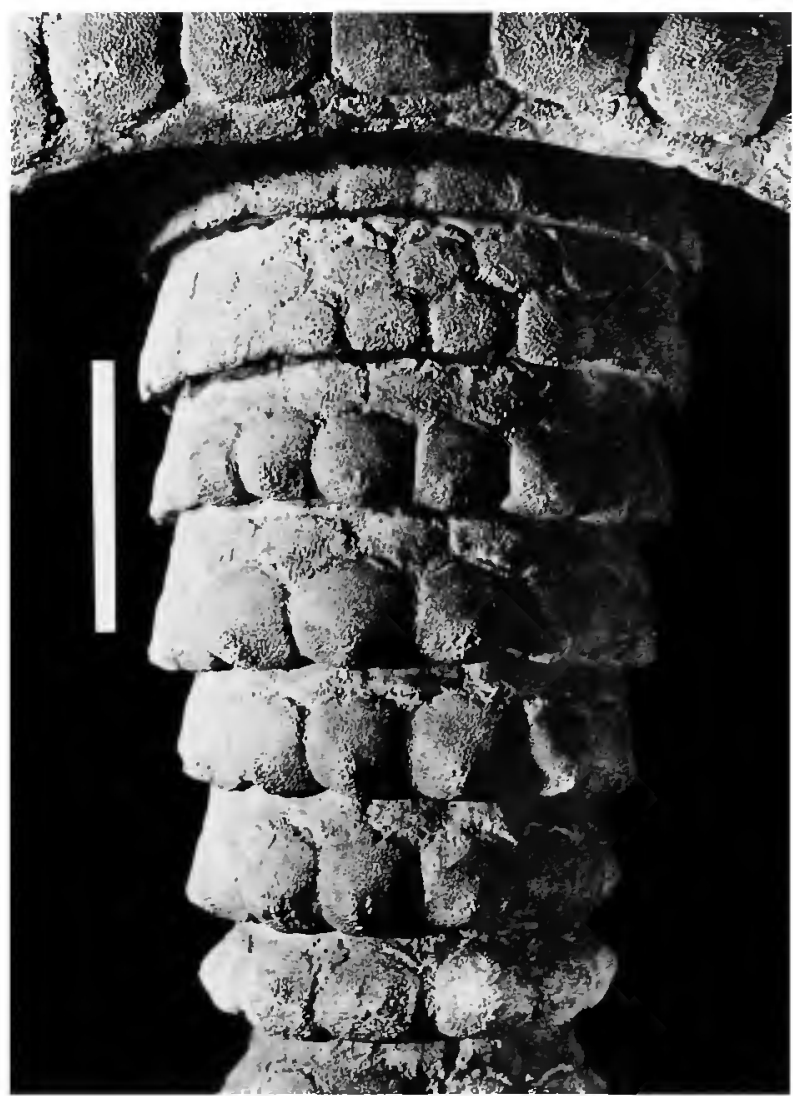

Figure 94.-Caudal armor of Glyptotherium floridanum from the Ingleside locality, San Patricio County, Texas (TMM 977-3), dorsal aspect; first 6 rings are actual fossils, remainder are reconstructed. (Photo courtesy Texas Memorial Museum; bar $=10 \mathrm{~cm}$.)

\section{Selected Aspects of Glyptodont Paleobiology}

Beyond occasional comments to the effect that glyptodonts were herbivorous, clumsy, and cumbersome, few modern authors have considered them as living animals. In an obscure paper that has gone virtually unnoticed since its publication more than a century ago, Senechal (1865) breathed life into these altogether unforgettable creatures.

Senechal described the biology of Glyptodon, as he perceived it in life. He compared the size of Glyptodon to that of a small hippopotamus, but its morphology to that of a giant tortoise. He also proposed that Glyptodon possessed a mobile snout, 
a conclusion that we have independently reached for Glyptotherium. Senechal was also impressed by the cumbersome carapace and its consequent effects on respiration, locomotion, feeding, overall agility, and protection. He pictured Glyptodon as restricted to flat terrain, an inoffensive quadrupedal fortress, "approximating the most extreme range of stupidity. One can wonder if a better intellectual apparatus would not have been a superfluous luxury" (Senechal, 1865:23, loose translation). Among other suggestions in this charming discussion, Senechal proposed that Glyptodon was adept at digging and was a seedeater. We have concluded that Glyptotherium was not restricted to granivory but instead ate vegetation in marshy lowlands and near permanent bodies of water.

In the following discussions we hope to stimulate interest in glyptodonts and perhaps to invite debate on edentates in general. We give brief consideration in the following pages to several aspects of the functional morphology of Glyptotherium, the inferred habitat requirements, and the evolutionary history of the genus.

\section{Functional Morphology}

Glyptodont anatomy is so peculiar as to invite inquiry from many viewpoints, among which masticatory function, locomotor function, and defense and protection promise to provide interesting insights into glyptodont paleobiology.

Masticatory Apparatus.-Clues to the feeding habits of glyptodonts are found in their dentition and in the construction of their mandible, portions of the skull, and axial skeleton. It is tempting on first examination to suppose that glyptodonts fed much as do the modern armadillos. Such a comparison is unwarranted, however, as indicated by the striking dissimilarities in the skeletal regions pertaining to feeding. The closest anatomical correspondence related to feeding habits between armadillos and glyptodonts is the construction of the front limb. The long olecranon process of the ulna of both groups is indicative of a strong digging ability. That armadillos dig in soft ground for food (primarily insects) is well established (Talmage and Buchanan, 1954). Armadillo dentition and mandibular construction are further reflective of their feeding habits. Although glyptodonts also possess an unusually long olecranon process, other regions of their anatomy are decidedly uncharacteristic of an entomophagous diet. Moreover, glyptodonts are so much larger than armadillos that digging for food seems improbable. Therefore, the apparent similarities between glyptodont and armadillo morphology relating to feeding habits, basically restricted to the construction of the olecranon process, are here interpreted as representing a parallelism arising from their common ancestry, not as indicating similar feeding habits.

In particular, the construction of glyptodont teeth precludes any dietary habit other than herbivory. The full dental battery, consisting of 32 molariform teeth, presents a grinding mill similar to that found in the cheek teeth of microtine rodents. The flat-crowned, hypsodont teeth exhibit an elaboration of the osteodentine core, which compensates for the lack of enamel, as discussed in the osteology section. The teeth maintained unclosed pulp cavities throughout life, in this respect surpassing the classic hypsodonty so often discussed for horses.

The maxilla and mandible are massive and deep-bodied to accommodate the long hypsodont teeth. The mandibular symphysis is solidly ankylosed in a spoutlike construction, indicating that the masticatory motion of the mandible was unified and inflexible at the symphysis. The principal masticatory motion was a forward grinding movement of the mandible, the upper and lower tooth rows maintaining surface-to-surface contact during the grinding motion. That this motion represents the primary movement is indicated by the wear facets of the occlusal surfaces of the teeth, by the construction of the mandible, and by the horizontal disposition of the masseteric musculature.

A detailed inspection of the attrition facets of glyptodont teeth reveals convincing evidence of this proposed masticatory motion. The osteoden- 
tine rim and core stand up in subdued, but nevertheless distinct, relief above the interior dentinal tracts (Figure 95). The dentine tapers gradually downward and rearward in the lower teeth, reaching maximum depth immediately anterior to the transversely disposed osteodentine ridges. Attrition facets of upper teeth exhibit an opposite arrangement for the taper of the dentine tracts, which reach maximum depth immediately posterior to the osteodentine ridges. This construction indicates that food particles were pushed toward the deep end of the dentine taper; as the forward motion of the mandibular teeth passed over the maxillary teeth, food particles were pushed rearward relative to the lower teeth and forward relative to the upper teeth, becoming lodged against the osteodentine ridges. Further motion crushed or sheared the food as each osteo-

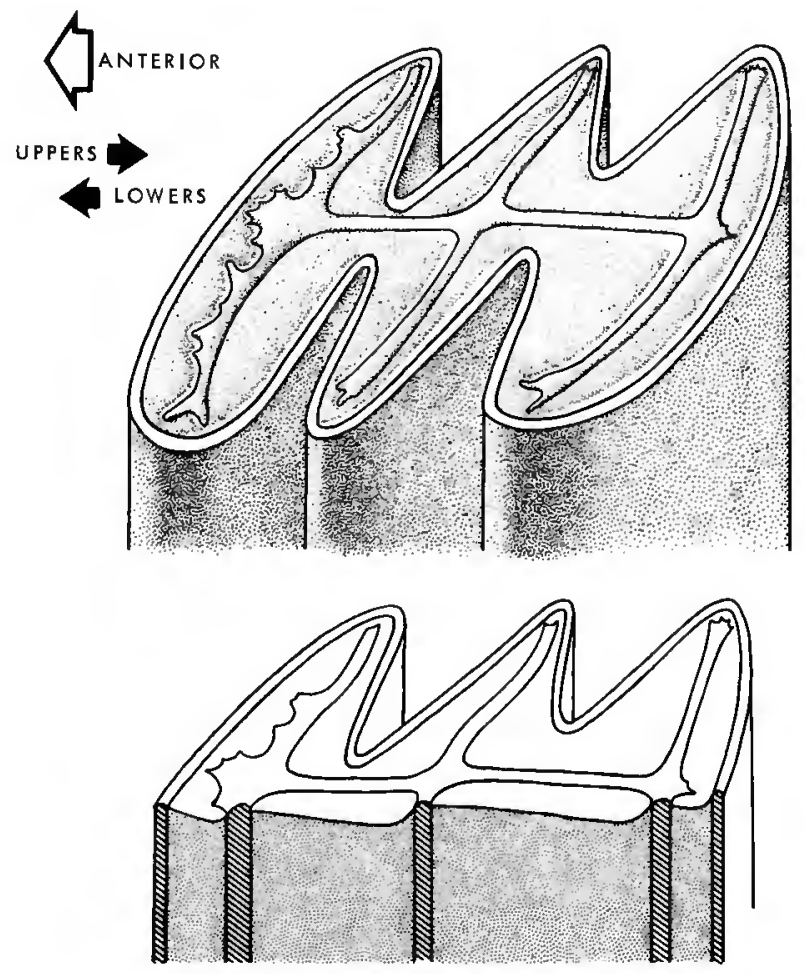

FIGURE 95.-Schematic perspective view of occlusal surface of an idealized lower tooth of Glyptotherium (above) and a parasagittal section through same tooth (below) to show nature of attrition. (Occlusal motion relative to upper tooth row indicated by arrows.)

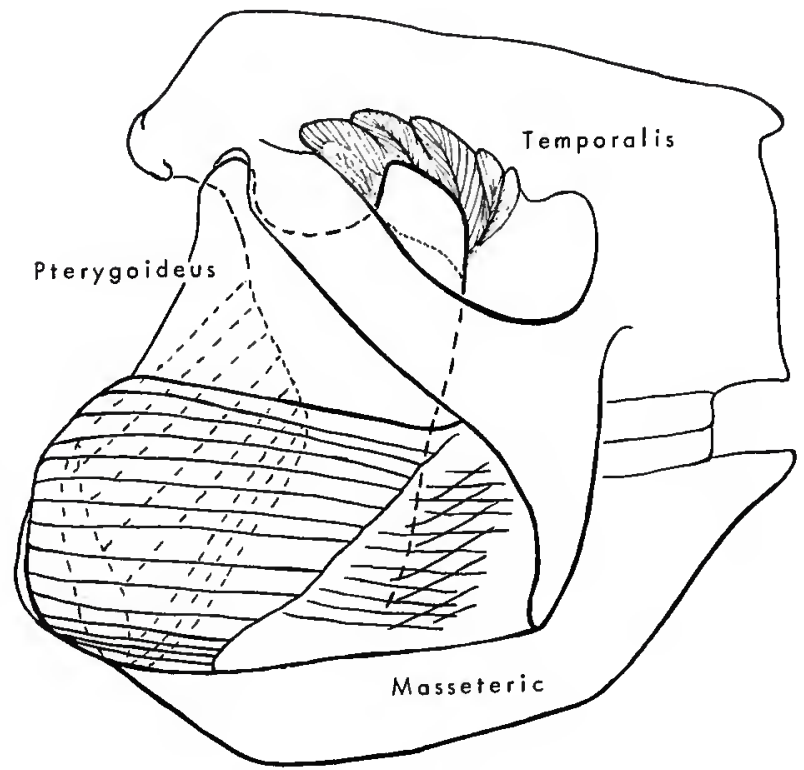

Ficure 96.-Schematic representalion of glyptodont masticatory apparatus (the pterygoideus musculature is situaled on interior side of ascending ramus and is indicated by diagonal, broken lines).

dentine ridge passed against an opposing one.

This horizontal motion was effected by the horizontally disposed masseteric musculature (Figure 96). Sicher (1944) established that the descending process of the zygomatic arch is a modification permitting a principal horizontal component in the masticatory apparatus in tree sloths. By lowering the area of insertion for the masseteric musculature to the level of the tooth row, and below it, the descending zygomatic process provided a key innovation in the masticatory motion in several edentate lineages, including tree sloths, ground sloths, to a lesser degree some armadillos, and to an exaggerated degree, the glyptodonts.

It is interesting in this context to apply Turnbull's (1970) classification of mammalian masticatory construction to glyptodonts. Glyptodonts belong in Turnbull's "Specialized Group III"; the "rodent-gnawing" or "anterior shift" type, represented principally by rodents and lagomorphs. This group is characterized by an overwhelming dominance of the masseter group, at the expense 
of the temporalis and pterygoideus groups. Capybaras exhibit the most extreme development of the masseter complex, which includes approximately 77 percent of the masticatory muscle mass, while the remaining 23 percent is unequally divided between the pterygoideus group (approximately 16 percent) and the temporalis group (approximately 7 percent) (data from Turnbull, 1970:277). The resemblance between capybara dentition and the glyptodont dentition has already been mentioned; it is apparent that the muscle mass proportions were also similar. The temporalis and pterygoideus muscles in glyptodonts were probably even more reduced, and the masseter group may have approached 90 percent in relative mass. This extreme modification may be viewed as a consequence of the lack of anterior teeth in glyptodonts, eliminating the necessity for strong leverage in food procurement, a function partially performed by the pterygoideus and temporalis complexes.

An additional consequence of the elaboration of the masseteric complex, with its origin surface largely confined to the descending zygomatic process, is that the anterior facial surface was not occupied by the masseteric origin. That is, since the masseter attached to the descending process, the pre- and suprazygomatic regions of the superior maxillary and frontal bones, respectively, were free of masseteric attachment. There is sufficient surface area in these skull regions left vacant by the rearrangement of the masseteric complex to accommodate an expansion of the snout musculature.

Thus, the lack of anterior teeth for participation in food procurement and the arrangement of the masticatory musculature are here interpreted as indicating the existence in glyptodonts of a well-developed snout musculature important in feeding. Extensive fusion of the cervical and thoracic vertebrae indicates a general lack of axial mobility, precluding cxtensive axial motion in feeding. Without benefit of a highly mobile neck region allowing reaching and bending during feeding, it is again plausible to assume an elaborate snout musculature, either "prehensile" or proboscis-like, as the primary food procurement device. Indeed, it appears that glyptodonts in standing position (i.e., feeding position) were incapable of reaching the ground with the muzzle, largely because of the extreme fusion and shortening of the cervical and thoracic vertebrae.

A final consideration concerning the masticatory apparatus is the function of the edentulous symphyseal region of the mandible with respect to the opposing premaxillary region. It is unlikely that both regions were occupied by a toughened pad thick enough and large enough to occlude with the one opposing. In Glyptotherium floridanum the symphyseal region is even anteriorly downturned, a construction unexpected if the opposing symphyseal and premaxillary regions were occupied by pads. Moreover, the relatively weak accessory masticatory musculature and the reduced (or absent) premaxillaries indicate that little food could have been obtained by simple pad-on-pad closure (if the existence of opposing pads is reasonable, but which we believe is not). Such a motion would necessarily involve unusually strong closure and would necessitate a tearing function, rather than a shearing or cutting function characteristic of most herbivores.

In summary, therefore, the glyptodont masticatory apparatus represents a somewhat aberrant example belonging in Turnbull's (1970) Group III; the aberration is the lack of anterior teeth. The construction of the teeth, mandible, and relevant portions of the skull certainly indicate a totally herbivorous diet. Because extensive cervical motion and the advantage of elaborate enamel infolding in the teeth are seemingly requisite for feeding on grasses, it is apparent that glyptodonts were not grazers, for they lacked these characteristics altogether. Instead they were probably browscrs, feeding selectively on vegetation along water courses or perhaps in shallow water, like capybaras. This postulated dietary preference is supported by faunal associations and sedimentological characteristics of glyptodont occurrences, as discussed elsewhere.

Locomotion.-Several locomotor aspects of the skeleton deserve special consideration, for in 
many respects glyptodonts exhibit unique axial and appendicular osteology. A critical consequence of an immobile carapace is the almost total exclusion of the precaudal axial skeleton in locomotor function. Glyptodonts represent the mammalian counterpart to turtles in this respect, although the fusion is neither as extensive nor as immobile as in turtles. Nevertheless there is a close parallel between turtles and glyptodonts in the functional participation of the axial skeleton. A rigid carapace precludes extensive trunk mobility. Hence, during locomotion there was no axial participation beyond maintenance of a static and rigid support posture of the vertebrae. Whereas fusion of the vertebrae to the carapace is an extreme condition exhibited by turtles, glyptodont vertebrae are largely free of fusion to the carapace. The trunk vertebrae, however, are extensively fused to each other, with only a single weak articulation occurring at the thoracolumbar joint. Cervical vertebrae exhibit various degrees of fusion in North American glyptodonts, and they have little bearing on locomotor function. The thoracic vertebrae are fused in to two sections, the so-called "trivertebral element" and the long thoracic tube. The anteriorly situated trivertebral element, like the cervical vertebrae, is unimportant in locomotor function, its principal significance probably relating to cranial support. The long thoracic tube articulates with the anterior extremity of the lumbar tube in a weak contact, and this is the only midtrunk axial articulation. The lumbar vertebrae are serially ankylosed, and the entire lumbar tube is fused to the anterior sacral vertebra. Thus the lumbar vertebrae are incorporated into the rigid framework of the pelvic skeleton, and the entire postthoracic and precaudal axial skeleton is a boxlike, immobile complex of static support structures for the heavy carapace and the massive soft-part anatomy. This construction is afforded even more rigidity posteriorly by the solid fusion of the iliac and ischiac crests to the undersurface of the carapace, further precluding axial mobility in the posterior region of the trunk. That there was limited anterior mobility of the axial skeleton, however, is indi- cated by maintenance of the thoracolumbar joint and by the free (unfused) scapular border.

The large and flexible glyptodont tail may be considered as an integral part of the locomotor complex insofar as it probably functioned as a counterbalance during movement. That is, the heavy tail, which seems otherwise to be without significant function, was probably swung from side to side during movement to keep the center of balance as close to the midline as possible. It is likely, therefore, that the tail offset the locomotor disadvantage of limited axial mobility, which usually allows lateral flexure and torsion. Furthermore, it may be postulated that the terminal "mace" in the South American genus Doedicurus originated because of this side-to-side motion of the tail and provided additional protection from rear-approaching predators. The North American genus Glyptotherium lacked the terminal mace, but this distinction has no significance to the locomotor function of the tail.

The limb proportions and their construction lend considerable support to the intuitive notion that glyptodonts were clumsy, slow-moving animals. As a guide to the significance of the various aspects of limb anatomy discussed below, Howell's (1944) comprehensive treatment is indispensable; the following comments are founded on the tendencies Howell observed in his excellent coverage. The characteristics outlined below are mentioned only for the purpose of establishing the basic locomotor plan of the glyptodont appendicular skeleton, and the treatment is in no way exhaustive.

Both fore and hind limbs are heavy and massive. The front limb is, as expected, somewhat more mobile and slightly lighter in build in comparison with the hind limb. Both exhibit extreme modifications for weight support, with pronounced graviportal tendencies.

The broad vertebral border of the scapula, apparently representing an extreme development among terrestrial mammals, indicates strong standing musculature, especially "the serratus anterior, the chief muscle supporting the anterior half of the body when a quadruped is standing. 
A heavy body needs a strong one; and the vertebral border of the scapula is very broad in graviportal animals, while it is narrow in the lighter, more agile ungulates" (Howell, 1944: 142). The spherical head of the humerus and its well-developed tuberosities are further indicative of a graviportal construction for the upper portion of the front limb, while the nearly equal sharing between the ulna and radius in the humeral articulation illustrates the strong support at the elbow joint. In addition, the distal articulation of the epipodials (ulna and radius) is also almost equally divided, another indication of graviportal construction.

The elements of the manus are short, broad, and stout; the principal articular facets are more flattened than rounded. The only indication of cursorial adaptation in the appendicular skeleton is the loss of digit I in the manus. Digits II and III are the largest of the manus, digit IV is somewhat smaller, and digit $\mathrm{V}$ is reduced and functionally unimportant. The terminal phalanges of the front foot were each encased by an ungual sheath more hooflike than either clawlike or nail-like. The huge palmar sesamoid bone and the full battery of digital bones at each of the joints in the manus indicate strong weight support and an unusually large mechanical advantage during articular motion.

The hind limb exhibits an even more striking exaggeration of graviportal features. Whereas the pectoral appendage retains at least minimal cursorial adaptation in the articular facets and reduction of lateral digits, the pelvic appendage has lost all cursorial advantage. The ilium is vertical and fused to the carapace. The ischium likewise bears a distinct vertical component in its orientation, and both of these pelvic bones serve to concentrate the weight of the rear half of the body on the massive femur. The straight, large femur possesses huge tuberosities and articulates equally with the tibia and fibula. The head of the femur is sphcroidal and is situated on a poorly defined, unconstricted neck. The lesser trochanter is underdeveloped, another feature peculiar to graviportal animals.
The patella is large and stout, and it forms a distinctive "patellar lock" in standing posture. This device allows the femur and tibiofibula to maintain a vertical, straight-line orientation in a standing, resting position. The tibia and fibula are equally developed. Both are large and massive, and they are proximally and distally fused to form the cylindrical tibiofibula. It appears that glyptodonts are a singular exception to the gencralization that in placental mammals the fibula is excluded from femoral articulation, for the articular surface of the tibiofibula is expanded far beyond the tibia to a position well above the fibular shaft. This construction is more fully discusscd by Howell (1944), who also mentions monotrcmes and some marsupials as exceptions. It therefore secms likely that the fibula actually participates in this articulation, and, hence, glyptodonts as placental mammals represent an exception to the usual condition. This modification is certainly important in weight support and in providing lateral flexibility, an important matter for a clumsy, ponderous animal. Furthermore, the fibular participation in the tarsal articulation is also unusual. Among mammals only elephants and artiodactyls cxhibit this arrangement; the condition in glyptodonts resembles that of the former group for weight support.

The elements of the tarsus are much more extensively modified for weight support than the corresponding bones of the front limb. The distal tarsals, in fact, possess almost no curvature in their articular surfaces. The flat articulations serve only to transfer weight and provide no mobility to the distal region of the tarsus. Proximal tarsal elements, the calcaneum and astragalus, are stout and massive, with no indication of cursorial advantage. The tibiofibula/astragalus articulation in the fore-and-aft plane is situated almost at a right angle to the astragalus-navicular articulation, an arrangement certainly adaptive for stability of the tarsus and decidedly inadaptive for running motion.

The metatarsals are nearly cubic in proportions, again an extreme among mammals and indicative of a graviportal condition. Lack of 
tarsal and metatarsal reduction or fusion is an indication of the "primitive," or generalized construction, in which static and dynamic flexibility, rather than stability, is the principal functional requirement. Thus the glyptodont tarsus and metatarsus permit the support of an enormous load, while they provide sufficient flexibility to adjust to minor substrate irregularities, which would be otherwise dangerous to so cumbersome an animal.

The five symmetrically disposed digits are complete and highly modified for weight support. The phalanges of the rear foot are even shorter and stouter than those of the front foot, and the terminal phalanges were encased in an ungual sheath rather intermediate between a nail and a hoof construction. The entire lower extremity of the pes closely resembles that of elephants, and the component bones are even more extensively shortened and modified for weight support. It appears that the spreading-retraction function of the digits is highly developed for the pes, and as expected, the pes is decidedly "more graviportal" than the manus.

Finally, a brief consideration of glyptodont limb proportions, utilizing Howell's (1944) observations, is instructive. In North American glyptodonts, the humeroradial index (radius/humerus $\times 100)$ varies between 50 percent and 55 percent. This figure is more extreme than for any quadrupedal, terrestrial living mammal (approximately 100 percent is the generalized index, the higher the index the more cursorial and the lower the index the more graviportal). Hippos possess the closest index among living mammals, a distant 68 percent. Only the distinctly graviportal notoungulate genus Pyrotherium among extinct mammals possessed a lower index, around 40 percent. The femoral-tibial index (tibia/femur $\times 100$ ) in glyptodonts also falls between 50 percent and 55 percent. Again this figure is an extreme compared to those of living animals, among which the decidedly graviportal hippos and elephants (indices around 63 percent and 54 percent, respectively) fall closest to glyptodonts in this proportion. The femoral-tibial index of 50 percent computed for one specimen of Glyptotherium texanum is an extreme among all terrestrial, quadrupedal mammals, living and extinct, if Howell's treatment is to be considered exhaustive.

Discussion of other indices measuring other limb proportions would be redundant. The inescapable conclusion is that glyptodonts possess an extremely graviportal construction as indicated not only by the morphology of individual elements but also by relative limb proportions. Thus the commonly held belief that glyptodonts were clumsy, cumbersome quadrupeds is here maintained, and no other conclusion seems possible.

The locomotor apparatus of glyptodonts therefore exhibits an unusual extreme for weight support, with little modification for cursorial habits. The feet are constructed in a fashion that permits extension and retraction of the digits and metapodials during advance and recovery of the foot, respectively. It is evident that this adaptation is useless in upland, hard-ground terrain and that the extreme graviportal proportions in the glyptodont limbs preclude occupation of irregular or hilly regions.

Glyptodonts probably inhabited lowland areas along primary water courses, frequenting lake and stream shorelines and perhaps even occupying shallow water, much as do modern hippos and capybaras. In this habitat, the "spreadingfoot" adaptation would be most useful (for passing over mud and soft, marshy areas otherwise uninhabited by most mammals, including predators), and there would be little necessity for either agility, in order to negotiate an irregular terrain, or running to escape from predators.

Defense And Protection.-Glyptodonts found little advantage either in running or in fighting to escape predation. Indeed it is unlikely that they possessed either ability, for it appears doubtful that glyptodonts could run at all, and they lack the necessary dental equipment and claw modifications for aggressive defense. The carapace, as an impenetrable covering, was certainly the most important protective device. Its inadequacies regarding total protection have been alluded to in the description of the skull, 
and it is necessary to consider additional modes of defense and protection.

The functional role of the glyptodont armor for predator protection is likely a secondary adaptation. The glyptodont armor probably evolved from an ancestral investment of isolated dermal bones, perhaps for protection from coarse vegetation. With increasing and more extensive coverage of the body, it is evident that the dermal armor would become bulky and heavy. This tendency likely resulted in a concomitant reduction in cursorial advantage in the limbs, further necessitating increased predator protection afforded by the rigid carapace. On the other hand, armadillos, with a more flexible and lighter carapace, retain considerable running ability (compared with glyptodonts) as reflected not only in their osteology but also in their observed behavior (Talmage and Buchanan, 1954). Hence, it is no accident that glyptodonts possessed, at the same time, extremely graviportal limb proportions and the heavy, rigid carapace.

The glyptodont carapace afforded excellent protection from predators. The cephalic shield and the elaborate caudal armor almost completely covered the body, leaving only the lower limbs and anterior facial region unprotected. The limbs were protected by a heavy investment of dermal ossicles, as mentioned in the description of the carapace, probably more for protection from vegetation than from predators. The fact that the dermal armor was not absolutely impenetrable was mentioned in connection with a skull of Glyptotherium texanum (F:AM 95737, Figure 9), in which two well-positioned holes in the skull roof indicate that the cephalic shield was not totally protective. Obviously, therefore, glyptodonts possessed additional predator protection, which we propose involved a combination of habitat preference and behavioral tendencies.

First, the habitat proposed here for Glyptotherium would be conducive to hiding or inaccessibility rather than running for predator avoidance. Occupation of soft-substrate terrain, in marshy or muddy lowland areas along primary water courses, would be a decided advantage for pro- tection over a more upland, hard-substrate terrain that large predators could more easily negotiate. Moreover, occupation of shallow-water areas, even occasionally, would reduce susceptibility to predation. Young individuals were likely especially susceptible to predators, for it was not until attainment of full adult size that the carapace became fully functional for protection.

Therein lies the reasoning behind the second suggestion-that glyptodonts relied heavily on behavioral means for predator avoidance. In particular, we propose that glyptodonts were gregarious, for the young individuals lacked even carapacial protection. Without the double advantage of gregarious habits and a favorable habitat, it is difficult to imagine infant and juvenile survival in an animal so large and so poorly adapted for predator protection in the immature state. Occupation of a terrestrial, shoreline habitat, frequenting both shallow water and lowland areas with dense vegetation would seem to be the optimal habitat for an animal with these combined characteristics.

A related, but peripheral, matter concerns the glyptodont protection from external parasites. Mostly lacking hair, at least dorsally, it is doubtful that glyptodonts were favorable hosts for fleas and lice; a similar conclusion has been documented for armadillos by Talmage and $\mathrm{Bu}$ chanan (1954). The smooth, uncreviced carapace, with its scaly covering, is also an obstacle to tick infestation. The undersurface of the body and the limbs, however, likely had considerably more hair than the carapace, and it seems that in these regions of the body, glyptodonts would be susceptible to ectoparasites. The general lack of axial mobility and the absence of caniniform or incisiform teeth surely presented serious difficulties at grooming (the lack of ectoparasites may have been an antecedent condition requisite for loss of anterior teeth; a similar statement could be advanced for the origin of alternative grooming habits prior to the total loss of anterior teeth). Perhaps if glyptodonts possessed a proboscis, as suggested elsewhere, it performed as a grooming dcvice. Alternatively, it is conceivable that glyp- 
todonts had a close commensal association with certain birds, much as that of oxpeckers with many elements of the modern African megafauna.

\section{HaBITAT}

Much of the foregoing discussion has alluded to the habitat requirements of glyptodonts. Deductions from anatomical conditions and inferred behavioral adaptations point toward a semiaquatic, semiterrestrial habitat in a region of dense vegetation. There is little reason to belabor the points and deductions already made concerning the glyptodont habitat, and the following comments are restricted to faunal associations and the limited available evidence of sedimentology.

Specific faunas that include glyptodonts were enumerated in the distribution section. The faunas are invariably composed of animals with southern affinities, either phylogenetic or ecologic, or both. The fact that glyptodonts are neotropical representatives of the Pleistocene is consistent with the overall composition of the associated faunas.

An overwhelmingly common association is the occurrence of glyptodonts with capybaras (the rodent genera Neochoerus and Hydrochoerus, family Hydrochoeridae), a circumstance which leads to several important conclusions. The occurrence of capybaras with Glyptotherium texanum is known from the Tusker fauna in Arizona (Wood, 1962) and from specimens (Ahearn and Lance, 1980) collected at the same time and found in the collections with the glyptodonts from the 111 Ranch area in the Frick Collection, American Museum of Natural History. Capybaras are also associated with $G$. arizonae at least in the Curtis Ranch fauna of Arizona (Lammers, 1970). Whether the Texas local faunas including $G$. texanum and G. arizonae also include capybaras is indeterminate, for small mammals are poorly represented in these faunas; this statement is inclusive for the Texas Blanco fauna (Johnston and Savage, 1955) and Red Light local fauna (Akersten, 1972), both for G. texanum; and the
Gilliland local fauna from the Seymour formation for G. arizonae (Hibbard and Dalquest, 1966). A similar statement can be made for the absence of capybaras associated with $G$. floridanum in the Ingleside fauna of Texas (Lundelius, 1972). Other Late Pleistocene faunas in both Florida and Texas have an unusually high frequency of this association. The relationship is all the more striking for the relative rarity of both capybaras and glyptodonts in continental United States. In fact, it may be reasonably assumed that where one is found, the other should be expected.

Partial explanation for the capybara-glyptodont association lies in the neotropical origins and centers of dispersal. Both are warm temperature animals, and the conclusion that they occupied the same habitat is inescapable. Indeed, the semiaquatic habits of capybaras are directly analogous to those suggested here for glyptodonts, and it is no accident that the two are often associated.

Another, almost expected, faunal association is with the giant tortoise genus Geochelone. These turtles have received extensive attention as indicators of a warm climate. Their common association with glyptodonts substantiates the assumption of a warm climate necessary for their existence. The fact that Geochelone is much more common than glyptodonts in the Pleistocene of North America is explained by the relative freedom of land tortoises from close proximity to water in comparison with glyptodonts, which are here asserted to have been limited to rather restrictive circumstances related to water accessibility and associated habitat. It is apparent that the habitat requirements of Glyptotherium were more restrictive than for some of the species of Geochelone, and the principal limiting factor was probably related to rainfall and humidity. Whereas glyptodonts, Geochelone, and capybaras are all indicative of warm, mild winters and moderate summer temperatures, it is evident that the distributional advantage of Geochelone over the other two groups is greater independence from water.

Sedimentological evidence, insofar as known, 
further substantiates these assertions. Both Wood (1962) and Seff (1962) have stated that the Arizona occurrences of $G$. texanum in the $111 \mathrm{Ranch}$ area (Tusker local fauna) are associated with lacustrine and fluviatile sediments. Mr. Ted Talusha (pers. comm.) has independently stated a similar belief for the glyptodont occurrences in the same area. Hibbard and Dalquest (1966) included stream and marshland communities in their discussion of the various habitats of the Gilliland local fauna, which contains $G$. arizonae, while Gidley (1926) and Lammers (1970) have stated that stream and lake communities are prevalent in the Curtis Ranch fauna of Arizona. Similar conclusions have been reached by Lundelius (1972) for the late Pleistocene sedimentary conditions at Ingleside, Texas, which includes $G$. floridanum. In all, there is a commonality of lacustrine and fluviatile conditions, indicating that sedimentological evidence is not contradictory to the proposed habitat for Glyptotherium.

Webb $(1977,1978)$ has presented a fertile summary of the evolution of savanna vertebrates in the New World, in which Glyptotherium is listed as a member of the generalized Plio-Pleistocene "interamerican mingled fauna," one of nine genera of savanna grazers (Webb, 1978:404, 405). We suggest that Glyptotherium belongs instead in the category of "aquatic grazers" along with two genera of capybaras, "which tended to graze "hippo-style' in the adjacent savannas," and the manatee, Trichechus, which was of course "wholly aquatic." We would add Glyptotherium to the same category as the capybaras, living and feeding in lowlands adjacent to watercourses.

It is reasonable and consistent to assume that Glyptotherium lived in the lake and strcam community, and that the climate was warm, mild, and relativcly humid to support tropical or subtropical vegetation at least near permanent bodies of water.

\section{Evolutionary History of Glyptotherium}

According to the taxonomic revision proposed in this study, what were previously considered as four or five genera of North American glyptodonts are now placed in a single genus Glyptotherium, containing four well-defined species, $G$. texanum, $G$. arizonae, $G$. cylindricum, and $G$. floridanum, and a fifth species, which is nominally retained, $G$. mexicanum. Originating from within the South American subfamily Glyptodontinae, Glyptotherium first appears in the earliest Pleistocene in Arizona and Texas. Glyptotherium texanum is the earliest species, and it represents the ancestral group for the remainder of the North American taxa.

The ancestral species is small in comparison with the descendant species; it nevertheless exhibits ncarly all of the features of the other taxa, but with less exaggeration. Differing primarily in larger size and attendant exaggeration of principal characteristics, $G$. arizonae soon replaced the ancestral species during Irvingtonian time, and, in the broad sense, occupied almost exactly the same geographic area. Thus with respect to each other, the carly Pleistocene taxa $G$. texanum and $G$. arizonae arc temporal, rather than geographic, species.

Because the paleontological record in southern United States and Mexico is highly incomplete, it cannot be determined whether Glyptotherium continuously occupied the Arizona-New MexicoTexas-Oklahoma region from the carly Pleistocene portion of the Blancan Land Mammal Age through the Irvingtonian Land Mammal Age. Such an assumption can bc neither proven nor denied. Since the faunas containing these two species were probably unaffected by glacial conditions to the north, there is lit tle reason to assume any pronounced habitat disruption in this region, and the suggestion that Glyptotherium more or less continuously occupied this area is at least a logical assumption. Stratigraphic details for the faunas containing $G$. lexanum and $G$. arizonae have not becn satisfactorily determined, and much of the "old dogma" rcgarding these faunas has recently come under critical rcview (e.g., Hibbard and Dalquest, 1973; Lindsay and Tessman, 1974; Lindsay, ct al., 1975). Thus it cannot be determined with certainty whether there is strati- 
graphic overlap between these two species. Our opinion is that these are strictly temporal species, and that specimens of intermediate age will also exhibit intermediate conditions. Thus it is our belief that $G$. texanum and $G$. arizonae are stratigraphically useful for establishing relative ages of faunas containing either of these two species. It is impossible to claim categorically that one or the other, or both, is restricted to either the pre- or the post-Blancan/Irvingtonian boundary, and accordingly neither is unequivocally useful as an index species, although in conjunction with other mammal taxa they are potentially valuable.

The existence of one of these two species during the Early Pleistocene in Florida has also been established; the age is known with a fair degree of confidence to be late Blancan and early Irvingtonian. Nevertheless, identification of the early representation in Florida is here suggested to be $G$. arizonae. If correct, the Florida record may be the earliest for this species, in which case a strong argument may be advanced for initial geographic isolation from the ancestral population of $G$. texanum to the west. Hence, there could well have been contemporaneous existence of both species, G. texanum in the West, G. arizonae in the East, during Blancan time, with subsequent deployment westward of the descendant species in Irvingtonian time, thus replacing the ancestral species. These thoughts are suggested as a parsimonious explanation for the early evolution of Glyptotherium in North America. In essence, this hypothesis couples initial geographic isolation, producing contemporaneous ancestral and descendant species, with further temporal speciation later in the West.

Glyptodonts apparently were absent in Florida during the Irvingtonian, and sometime during the course of this land mammal age, $G$. arizonae disappeared from the northern reaches of its distribution (United States), probably withdrawing southward into Mexico as a consequence of deteriorating climatic conditions ensuing from continental glaciation to the north.

Glyptotherium is known only poorly in Mexico, and accurate stratigraphic information for this area is wanting. At least two species, $G$. cylindricum and $G$. mexicanum, assuming that the latter is valid, appcar to be indigenous to Mexico and (likely) Central America during Middle and Late Pleistocene times. Neither species is well known; both arc probably derivative from either $G$. texanum or from $G$. arizonae.

Finally, in the Late Pleistocene, during the lattcr part of the Rancholabrean Land Mammal Age, Glyptotherium reappeared in the United States. This time, however, the distribution was limited to the Gulf Coastal Plain and the southern Atlantic coast. The Late Pleistocene representative is $G$. floridanum, and although known from a large number of localities, this species is less well defined than either $G$. texanum or $G$. arizonae. There is little doubt, however, that $G$. floridanum evolved from the ancestral stock, probably from $G$. arizonae rather than directly from $G$. texanum, since the former apparently survived longer than the latter.

The population of $G$. floridanum became extinct at the close of the Pleistocene, or sometime thereabouts, but not before having evolved morphological manifestation of sexual dimorphism, a characteristic apparently lacking in the earlier species. Glyptotherium floridanum probably also extended well into Mexico during the Late Pleistocene (correlating with the Wisconsin Glacial Age to the north), although substantiated identifications from this area have not been established.

Concerning possible causes of extinction for Glyptotherium, it is evident that climatic deterioration resulting from continental glaciation is sufficient explanation. As proposed here, the habitat occupied by glyptodonts was unusually restrictive, and even minor disruption of the lowland, warm temperature, humid and tropical circumstances under which they lived would bring about their local demise.

\section{Conclusions}

The intent of this study is to accomplish a three-fold, comprehensive review of North American glyptodonts: first, to review, in detail, the gross osteology of these heretofore poorly known 
animals; second, to establish a sound taxonomic framework; and third, to delve into a few of the more important aspects of glyptodont paleobiology, including their functional morphology, their habitat requirements, and the history of their evolution on the northern continent. To the extent that information is available, these objectives have been addressed with a fair measure of confidence, and the following are some of the more important results of this review.

1. Insofar as can be determined, all glyptodonts recovered in the Pleistocene of northern Mexico and southern United States belong in a single genus, Glyptotherium Osborn, 1903. Included in this genus are four well-defined species, $G$. texanum, $G$. arizonae, $G$. cylindricum (= Brachyostracon cylindricus), $G$. floridanum (= Boreostracon floridanus), and a fifth species of less certain standing, $G$. mexicanum (= Glyptodon mexicanus, = Brachyostracon mexicanus).

2. Xenoglyptodon fredericensis Meade, 1953, and Glyptodon fredericensis (Meade) are junior synonyms of Glyptotherium arizonae. The existence of the South American genus Glyptodon in North America remains doubtful, and until a thorough revision of South American glyptodont taxonomy is accomplished, retention of the generic name Glyptotherium for the North American representatives is the most advisable course.

3. The five species of North American glyptodonts evolved from an initial population of the ancestral species, Glyptotherium texanum, which migrated from South America during late Pliocene or earliest Pleistocene time. Subsequent evolution resulted in what appear to be at least two successive species here asserted to be primarily "temporal" species rather than "geographic" species: $G$. texanum, to $G$. arizonae, to $G$. floridanum. The other two species are poorly known, and their relationships are less certain, but they cvolved from within this complex.

4. A single invasion is sufficient to account for all of the North American specics through temporal and geographic speciation from the ancestral stock. There is no reason to assume multiple invasion from South America.
5. Gross osteology for all five species is known more or less comprehensively. Glyptotherium texanum and $G$. arizonae are the most nearly completely known; G. floridanum is reasonably well known; G. cylindricum is less well known, from a single specimen; and $G$. mexicanum is poorly known. Osteological details indicate a fundamentally close relationship among all five species.

6. As derived from osteological and sedimentological evidence, and from faunal associations, the habitat requirements of Glyptotherium were rather restrictive: proximity to standing water in a region with extensive lowland terrain; lush, tropical or subtropical vegetation; a warm climate without excessive extremes of temperature; and high, relatively constant moisture (for maintaining the permanent bodies of water and the abundant vegetation).

7 Glyptotherium was a strictly herbivorous, extremcly graviportal, heavy-bodied representative of the Pleistocene megafauna. These glyptodonts were largely devoid of predator protection except for their armor, and they lacked any capacity whatsocver to flee from an approaching predator beyond moving into shallow water.

8. Because of their restrictive habitat requirements, glyptodonts are relatively rare in the northern extent of their range, which reaches to Arizona, Oklahoma, and South Carolina. Their center of abundance in North America was probably in Central America and Mexico, with occurrence in continental United States more restricted and possibly intermittent.

It is impossible for any paleontological review to be totally comprehensive, and the present study is no exception. Accordingly, it is appropriate to point out what scem to be areas of special interest in particular need of further investigation.

Of coursc, the taxonomic framework proposed here, like any classification, is subject to further improvement. New material, especially skulls, pertaining to the group here identified as $G$. arizonae could well establish that this group actually includes two species, one from Arizona, the other from Texas. That both groups are closely 
related is certain, and for lack of evidence to the contrary, both are here assigned to the same taxon. Conversely, new material could also establish beyond doubt the identity of these two groups, and there would thus be a strong argument for near contemporaneity of the Curtis Ranch and Seymour faunas. Our opinion is that the latter circumstance will prove to be the case.

Another taxonomic problem concerns the loose assemblage here referred to Glyptotherium floridanum. Whether there are separate Texas and Florida species cannot be satisfactorily determined from the available specimens, nor is it possible to establish with certainty the postulated sexual dimorphism in this species. What has been labeled sexual dimorphism could well represent sympatric species, in which case a revision of the Late Pleistocene glyptodonts from the Gulf Coast would be called for.

Other taxonomic considerations that deserve special attention when additional material becomes available are the identity of the Florida
Blancan representatives and the relationships of the Mexican and Central American glyptodonts to the more northern species.

Further, the relationships between Glyptotherium and the South American glyptodonts remain to be established. This would of course entail a comprehensive review of the South American Glyptodontinae and would be a rewarding, though monumental, task, which must be carried out before the North American immigrants can be fully understood.

Concerning the paleobiology of glyptodonts, many potentially fruitful aspects deserve detailed inspection, including elaboration upon points touched on here regarding the masticatory apparatus, locomotion, defense and protection, growth and development, and habitat requirements. We hope that our descriptions, discussions, hypotheses, and speculations will provide a stimulus for renewed and more sophisticated research on these bizarre and unjustly neglected mammals. 


\section{Appendix}

\section{Tables of Measurements}

TABLE 1.-Measurements (mm) of the skull of North American glyptodonts

\begin{tabular}{|c|c|c|c|c|}
\hline \multirow[b]{2}{*}{ Characters } & \multicolumn{2}{|c|}{ G. texanum } & \multirow{2}{*}{$\begin{array}{l}\text { G. arizonae } \\
\text { UMMP } \\
34826\end{array}$} & \multirow{2}{*}{$\begin{array}{l}\text { G. floridanum } \\
\text { ChM } \\
2415\end{array}$} \\
\hline & $\begin{array}{l}\text { F:AM } \\
59583\end{array}$ & $\begin{array}{l}\text { F:AM } \\
95737\end{array}$ & & \\
\hline 1. Maximum transverse diameter of frontals & - & - & 106 & - \\
\hline $\begin{array}{l}\text { 2. Transverse diameter between inner margins of } \\
\text { infraorbital foramina }\end{array}$ & - & 90 & 130 & - \\
\hline $\begin{array}{l}\text { 3. Vertical length of descending zygomatic process } \\
\text { from lower margin infraorbital foramen (left/ } \\
\text { right) }\end{array}$ & - & $85 /-$ & $102 / 110^{*}$ & - \\
\hline $\begin{array}{l}\text { 4. Anteroposterior diameter from anterior margin of } \\
\text { base of descending zygomatic process to posterior } \\
\text { extremity, occipital condyle (left/right) }\end{array}$ & - & $210 / 202$ & $250 / 254$ & - \\
\hline $\begin{array}{l}\text { 5. Maximum transverse diameter between lateral } \\
\text { extremities, zygomatic arches }\end{array}$ & - & 176 & 254 & - \\
\hline $\begin{array}{l}\text { 6. Inferosuperior diameter from } N^{8} \text {-rear lobe occlusal } \\
\text { surface to sagittal crest junction with lambdoidal } \\
\text { crests (left/right) }\end{array}$ & $139 * / 137$ & $138^{*} / 138^{*}$ & $179 / 179$ & - \\
\hline $\begin{array}{l}\text { 7. Transverse outside diameter between paroccipital } \\
\text { processes }\end{array}$ & 115 & 117 & 160 & $132^{*}$ \\
\hline 8. Transverse outside diameter occipital condyles & 87 & 88 & 108 & 101 \\
\hline $\begin{array}{l}\text { 9. Transverse diameter, left facet for occipital } \\
\text { condyle }\end{array}$ & $30^{*}$ & 24 & 34 & 35 \\
\hline $\begin{array}{l}\text { 10. Transverse diameter, right facet for occipital } \\
\text { condyle }\end{array}$ & 25 & - & 33 & 36 \\
\hline $\begin{array}{l}\text { 11. Inferosuperior diameter, left facet occipital } \\
\text { condyle }\end{array}$ & 23 & 22 & 31 & 23 \\
\hline $\begin{array}{l}\text { 12. Inferosuperior diameter, right facet occipital } \\
\text { condyle }\end{array}$ & 21 & 21 & 29 & 23 \\
\hline $\begin{array}{l}\text { 13. Maximum transverse outside diameter between } \\
\text { crests of pterygoid tuberosities }\end{array}$ & 48 & 47 & 65 & - \\
\hline $\begin{array}{l}\text { 14. Inferosuperior diameter from lower margin man- } \\
\text { dibular facet to lower margin pterygoid tuberosity } \\
\text { near } N^{8} \text { - alveolus (left/right) }\end{array}$ & $-/ 67$ & $60^{*} / 60$ & $86 / 87$ & - \\
\hline $\begin{array}{l}\text { 15. Anteroposterior diameter, mandibular facet to in- } \\
\text { fraorbital canal, lower anterior margin (left/right) }\end{array}$ & $-1-$ & $127 / 125$ & $150 / 150$ & - \\
\hline 16. Inside transverse diameter, foramen magnum & $34^{*}$ & - & $38^{*}$ & $32^{*}$ \\
\hline 17. Inside inferosuperior diameter, foramen magnum & $22 *$ & - & $26^{*}$ & $20^{*}$ \\
\hline $\begin{array}{l}\text { 18. Maximum vertical diameter from center of palate, } \\
\text { posterior extremity, to sagittal crest }\end{array}$ & 102 & $115^{*}$ & - & - \\
\hline
\end{tabular}

* Approximate measurement. 
TABLE 2.-Measurements $(\mathrm{mm})$ of the mandible of North American glyptodonts

\begin{tabular}{|c|c|c|c|c|c|c|}
\hline \multirow[b]{2}{*}{ Characters } & \multicolumn{2}{|c|}{ G. texanum } & \multicolumn{2}{|c|}{ G. arizonae } & \multicolumn{2}{|c|}{ G. floridanum } \\
\hline & $\begin{array}{l}\text { JWT } \\
2330\end{array}$ & $\begin{array}{l}\mathrm{JWT} \\
1715\end{array}$ & $\begin{array}{l}\text { USNM } \\
10536\end{array}$ & $\begin{array}{l}\text { UMMP } \\
38761\end{array}$ & $\begin{array}{c}\text { TMM } \\
30967- \\
1814\end{array}$ & $\begin{array}{c}\text { USNM } \\
11318\end{array}$ \\
\hline $\begin{array}{l}\text { 1. Height of ascending ramus measured from con- } \\
\text { dyle through posterior lobe of } N_{7} \text { to lower margin } \\
\text { of horizontal ramus }\end{array}$ & - & - & 230 & 245 & 195 & 175 \\
\hline 2. Maximum transverse diameter, articular condyle & - & - & $49^{\mathrm{a}}$ & 39 & & - \\
\hline 3. Anteroposterior diameter, articular condyle & - & - & $16^{\mathrm{a}}$ & 17 & & - \\
\hline 4. Transverse diameter, horizontal ramus below $\mathrm{N}_{\overline{5}}$ & - & 31 & 33 & 33 & 25 & 25 \\
\hline $\begin{array}{l}\text { 5. Transverse diameter, ascending ramus opposite } \\
\mathrm{N}_{\overline{7}}\end{array}$ & $17^{\mathrm{b}}$ & - & 18 & 19 & - & - \\
\hline $\begin{array}{l}\text { 6. Vertical depth, horizontal ramus at } \mathrm{N}_{\overline{7}} \text { including } \\
\text { tooth }\end{array}$ & - & - & 107 & $100^{\mathrm{b}}$ & 77 & 51 \\
\hline $\begin{array}{l}\text { 7. Vertical depth, horizontal ramus at } \mathrm{N}_{5} \text { including } \\
\text { tooth }\end{array}$ & $70^{\mathrm{b}}$ & - & 106 & 104 & 75 & 58 \\
\hline $\begin{array}{l}\text { 8. Vertical depth, horizontal ramus at } \mathrm{N}^{-} \text {including } \\
\text { tooth }\end{array}$ & - & - & 96 & - & 78 & 67 \\
\hline
\end{tabular}

${ }^{\text {a }}$ Left/right average.

${ }^{\mathrm{b}}$ Approximate measurement. 
TABLE 3.-Measurements ( $\mathrm{mm}$; left/right) of the upper dentition of Glypotherium texanum

Axes
F:AM 59583
1. Maximum anteroposte-
rior diameter measured
through center (a-axis)
2. Maximum transverse

2. Maximum transverse diameter, anterior lobe (b-axis)

3. Minimum transverse diameter, anterior constriction (c-axis)

4. Maximum transverse diameter, middle lobe (d-axis)

5. Minimum transverse diameter, posterior constriction (e-axis)

6. Maximum transverse diameter, posterior lobe (f-axis)

F:AM $95737^{\text {d }}$
1. a-axis
2. b-axis
3. c-axis
4. d-axis
5. e-axis
6. f-axis

\section{WT $1837^{e}$}

1. a-axis

2. b-axis

3. c-axis

4. d-axis

5. e-axis

6. f-axis

\begin{tabular}{|c|c|c|c|c|c|c|c|}
\hline $14.1 / 14.2$ & $-1-$ & $19.0 / 19.8$ & $-/ 19.0$ & $-/ 19.2$ & $-/ 19.5$ & $-/ 19.1$ & $-/ 16.2$ \\
\hline \multirow[t]{5}{*}{$7.3 / 7.3$} & $-/ 8.2$ & $10.1 / 10.0$ & $-/ 12.6$ & $12.4 / 13.3$ & $14.0 / 14.4$ & $13.8 / 13.8$ & $-/ 13.9$ \\
\hline & $-/ 4.5$ & $3.9 / 3.2$ & $-1-$ & $3.0 / 3.3$ & $3.4 / 3.4$ & $-/ 3.3$ & $3.2 / 3.0$ \\
\hline & $7.8 / 7.9$ & $9.8 / 10.2$ & $-/ 11.2$ & $11.8 / 11.2$ & $11.9 / 12.4$ & $-/ 12.4^{\mathrm{a}}$ & $11.7 / 11.2$ \\
\hline & $4.6 / 4.7$ & $4.4 / 4.1$ & $-/ 3.8$ & $-/ 4.2$ & $-/ 3.9$ & $-/ 4.3$ & $4.0 / 4.0$ \\
\hline & $6.9 / 6.9$ & $9.1 / 9.1$ & $-/ 11.2$ & $-/ 12.9$ & $-/ 13.3$ & $12.9 / 12.9$ & $10.8 / 10.6$ \\
\hline
\end{tabular}

\begin{tabular}{|c|c|c|c|c|c|c|c|}
\hline \multirow{6}{*}{$\begin{array}{l}-/ 15.2 \\
-/ 7.0\end{array}$} & $16.6 / 16.7$ & $17.2 / 17.8$ & $-/ 18.4$ & $18.9 /-$ & $18.1 / 18.1$ & $-/ 18.0$ & $15.4 / 16.0$ \\
\hline & $7.5 / 7.0$ & $10.5 / 9.8$ & $-/ 11.7$ & $12.6 /-$ & $13.0 / 12.4$ & $-/ 12.5$ & $12.5 /-$ \\
\hline & $4.7 / 4.8$ & $4.5 / 4.1$ & $-/ 3.4$ & $3.3 /-$ & $3.4 / 3.6$ & $-/ 3.3$ & $-1-$ \\
\hline & $8.7 / 8.1$ & $10.7 / 11.1$ & $-/ 11.6$ & $12.2 /-$ & $12.0 / 12.2$ & $-/ 12.2$ & $11.2 / 10.9$ \\
\hline & $4.8 / 5.0$ & $4.4 / 4.3$ & $-/ 4.0$ & $3.8 /-$ & $3.9 / 3.7$ & $-/ 3.7$ & $3.6 / 3.9$ \\
\hline & $7.3 / 7.0$ & $9.6 / 9.7$ & $-/ 10.6$ & $12.0 /-$ & $11.8 /-$ & $-/ 12.0$ & $10.6 / 10.5$ \\
\hline
\end{tabular}

approximate measurement.

b a-axis: maximum length; b-axis: maximum width.

${ }^{c}$ Anteroposterior diameters: $N^{1}-N^{-}-$(g-axis); $N^{1}-N^{4}$ (h-axis); $N^{2}-N^{4}-\left(i\right.$-axis); $N^{2}-N^{6}-(j-a x i s)$ not applicable. Anteroposterior diameters $\mathrm{N}^{5}-\mathrm{N}^{6}$ (k-axis) $=40 / 43 ; \mathrm{N}^{5}-\mathrm{N}^{-8}(1-$ axis $)=87^{\mathrm{a}} / 87$.

$\mathrm{d}$ g-axis $=-/ 163 ; \mathrm{h}$-axis $=-/ 80 ; \mathrm{i}$-axis $=-/ 62 ; \mathrm{j}$-axis $=107 / 106 ; \mathrm{k}$-axis $=42 /-; \mathrm{l}$-axis $=81 /-$.

e Isolated posterior upper tooth, might be $\mathrm{N}^{5}$ or $\mathrm{N}^{6}$ instead. 
TABi. 4.-Measurements ( $\mathrm{mm}$; left/right) of the upper dentition of Glyptotherium arizonae (axes as defined in Table 3)

\begin{tabular}{|c|c|c|c|c|c|c|c|c|}
\hline Axes & $\mathrm{N}^{1}$ & $\mathrm{~N}^{2}$ & $\mathrm{~N}^{3}$ & $N^{4}$ & $N^{5}$ & N. & $\mathrm{N}^{2}$ & $\mathrm{~N}^{\mathrm{g}}$ \\
\hline $\begin{array}{c}\text { UMMP } \\
34826^{\mathrm{a}}\end{array}$ & & & & & & & & \\
\hline $\begin{array}{l}\text { 1. a-axis } \\
\text { 2. b-axis } \\
\text { 3. c-axis } \\
\text { 4. d-axis } \\
\text { 5. e-axis } \\
\text { 6. f-axis }\end{array}$ & $\begin{array}{l}19.4 / 18.6 \\
10.4 / 9.7\end{array}$ & $\begin{array}{l}-/- \\
7.2 /-\end{array}$ & $\begin{array}{c}22^{\mathrm{b}} / 26^{\mathrm{b}} \\
-/ 15.6 \\
-/- \\
-/- \\
-/- \\
/ 14.3\end{array}$ & $\begin{array}{c}23.9 / 24.8 \\
17.8 / 17.3 \\
2.6 /- \\
17.9 /- \\
-/- \\
-/ 16.3^{b}\end{array}$ & $\begin{array}{c}25.5 / 24.6 \\
18.0^{\mathrm{b}} / 18.7 \\
-/- \\
18.4 / 18.9 \\
5.2 /- \\
17.2 / 17.6\end{array}$ & $\begin{array}{c}24.2 / 25.0 \\
19.5 / 18.9 \\
4.3 /- \\
17.9 / 17.7^{b} \\
5.0 / 5.0 \\
17.5 / 16.5\end{array}$ & $\begin{array}{r}23.6 / 24.1 \\
18.8 / 18.0 \\
3.8 / 4.2 \\
18.1 / 17.5 \\
5.0 / 4.5 \\
17.7 / 17.5\end{array}$ & $\begin{array}{r}22.5 / 23.0 \\
17.2 / 17.1 \\
3.9 / 4.6 \\
15.5 / 15.8 \\
3.9 / 3.5 \\
15.3 / 14.8\end{array}$ \\
\hline $\begin{array}{c}\text { UMMP } \\
38761\end{array}$ & & & & & & & & \\
\hline $\begin{array}{l}\text { 1. a-axis } \\
\text { 2. b-axis } \\
\text { 3. c-axis } \\
\text { 4. d-axis } \\
\text { 5. e-axis } \\
\text { 6. f-axis }\end{array}$ & & & $\begin{array}{l}-/ 25.7 \\
-/ 13.2 \\
-/ 5.3 \\
-/ 15.6 \\
-/ 5.6 \\
-/ 14.8\end{array}$ & $\begin{array}{l}-/ 25.8 \\
-/ 19.4 \\
-/- \\
-/- \\
-/- \\
-/-\end{array}$ & $\begin{array}{l}-/ 26.2 \\
-/- \\
-/- \\
-/- \\
-/- \\
-/-\end{array}$ & & & \\
\hline
\end{tabular}

${ }^{a}$ g-axis $=200 / 200 ;$ h-axis $=92 / 93 ;$ i-axis $=73 / 74 ;$-axis $=132 / 133 ;$ k-axis $=54 / 54 ;$-axis $=106 / 108$.

${ }^{\mathrm{b}}$ Approximate measurement.

TABLE 5.-Measurements ( $\mathrm{mm}$; left/right) of the upper dentition of Glyptotherium cylindricum, AMNH 15548 (axes as defined in Table 3)

\begin{tabular}{|c|c|c|c|c|c|c|c|c|}
\hline Axes & $\mathrm{N} \mathbf{I} *$ & $\mathrm{~N}^{2 * *}$ & $\mathrm{~N}^{3}$ & $\mathrm{~N}^{4}$ & $\mathrm{~N}^{5}$ & $\mathrm{~N}^{6}$ & $\mathrm{~N}^{?}$ & $\mathrm{~N}^{8}$ \\
\hline 1. a-axis & $19.5 /-$ & $21.2 /-$ & $22.2 / 22.1$ & $-1-$ & $23.5 / 23.0$ & $24.1 / 23.2$ & $21.9 /-$ & $18.3 / 18.5$ \\
\hline 2. b-axis & $9.1 /-$ & $11.6 /-$ & $13.9 / 13.5$ & $-1-$ & $15.9 / 16.5$ & $15.5 / 15.5$ & $13.9 /-$ & $12.5 / 12.6$ \\
\hline 3. c-axis & & & $4.3 / 4.7$ & $-1-$ & $3.8 / 4.0$ & $3.8 / 4.0$ & $3.4 /-$ & $3.2 / 3.0$ \\
\hline 4. d-axis & & & $12.5 / 12.4$ & $-1-$ & $13.7 / 14.2$ & $13.9 / 13.6$ & $12.8 /-$ & $11.3 / 11.1$ \\
\hline 5. e-axis & & & $5.0 / 5.6$ & $-1-$ & $4.2 / 4.8$ & $4.0 / 4.4$ & $4.2 /-$ & $3.4 / 3.9$ \\
\hline 6. f-axis & & & $11.5 / 12.5$ & $-1-$ & $14.2 / 15.4$ & $14.2 / 14.5$ & $13.0 /-$ & $11.4 / 10.7$ \\
\hline
\end{tabular}

* a-axis and b-axis are maximum length-width, respectively.

TABLE 6.-Measurements ( $\mathrm{mm}$ ) of the upper dentition of Glyptotherium floridanum (axes as defined in Table 3)

\begin{tabular}{l|rrrr}
\hline \multirow{2}{*}{ Axes } & \multicolumn{2}{|c}{ USNM 6071 } & UF/FGS 6643 & TMM 31 186-19 \\
\cline { 2 - 5 } & $\mathrm{N}^{2}$ & $\mathrm{~N}^{4}$ & $\mathrm{~N}^{4}$ & $\mathrm{~N}^{4}$ (?) \\
\hline 1. a-axis & 19.0 & 22.1 & 20.5 & 21.7 \\
2. b-axis & 8.6 & 14.9 & 12.5 & 12.3 \\
3. c-axis & 4.9 & 4.1 & 3.1 & 3.8 \\
4. d-axis & 9.6 & 15.8 & 12.7 & 13.0 \\
5. e-axis & 4.6 & 3.5 & 3.0 & 4.3 \\
6. f-axis & 8.0 & 13.4 & 11.3 & 11.8 \\
\hline
\end{tabular}


TABLE-7.-Measurements $(\mathrm{mm})$ of the lower dentition of Glyptotherium lexanum

\begin{tabular}{|c|c|c|c|c|c|c|c|c|}
\hline Axes & $N_{1}^{-}$ & $\mathrm{N}_{2}^{-}$ & $\mathrm{N}_{4}^{-a}$ & $\mathrm{~N}_{5}{ }^{\mathrm{b}}$ & $\mathrm{N}_{\overline{6}}$ & $N_{\overline{7}}$ & & \\
\hline $\begin{array}{l}\text { JWT } 2330 \\
\text { (isolated teeth plus } N_{\overline{6}}, N_{\overline{7}} \text { in mandible fragment) }\end{array}$ & & & & & & & & \\
\hline $\begin{array}{l}\text { 1. Maximum anteroposterior diameter measured } \\
\text { through center (a-axis) }\end{array}$ & 16.9 & 20.9 & 20.4 & 17.5 & $18.7^{\mathrm{c}}$ & 18.2 & & \\
\hline $\begin{array}{l}\text { 2. Maximum transverse diameter, anterior lobe } \\
\text { (b-axis) }\end{array}$ & 8.8 & 7.3 & 9.4 & 11.4 & $12.7^{\mathrm{c}}$ & 12.7 & & \\
\hline $\begin{array}{l}\text { 3. Minimum transverse diameter, anterior con- } \\
\text { striction (c-axis) }\end{array}$ & & 4.1 & 3.7 & 4.1 & 3.9 & 3.8 & & \\
\hline $\begin{array}{l}\text { 4. Maximum transverse diameter, middle lobe } \\
\text { (d-axis) }\end{array}$ & & 8.7 & 12.1 & 12.6 & 13.4 & 13.2 & & \\
\hline $\begin{array}{l}\text { 5. Minimum transverse diameter, posterior con- } \\
\text { striction (e-axis) }\end{array}$ & & 4.1 & 3.1 & 3.7 & 3.8 & 3.5 & & \\
\hline $\begin{array}{l}\text { 6. Maximum transverse diameter, posterior lobe } \\
\text { (f-axis) }\end{array}$ & & 8.9 & 13.5 & 14.0 & 13.9 & 13.5 & & \\
\hline JWT $1715^{d}$ & $\mathrm{~N}_{\overline{1}}^{-}$ & $\mathrm{N}_{\overline{2}}$ & $\mathrm{~N}_{\overline{3}}$ & $\mathrm{~N}_{\overline{4}}$ & $\mathrm{~N}_{\overline{5}}$ & $\mathrm{~N}_{\overline{6}}$ & $\mathrm{~N}_{\overline{7}}$ & $\mathrm{~N}_{\overline{8}}$ \\
\hline 1. a-axis & 18.5 & 20.8 & 21.3 & 19.0 & - & 18.9 & 20.4 & - \\
\hline 2. b-axis & $10.0^{c}$ & 6.8 & 7.1 & 9.4 & - & $14.1^{c}$ & 12.6 & - \\
\hline 3. c-axis & & 4.2 & 5.0 & 4.1 & - & 4.8 & 3.9 & - \\
\hline 4. d-axis & & 8.8 & 10.0 & 11.9 & - & 13.5 & 12.9 & - \\
\hline 5. e-axis & & 4.6 & 4.5 & 4.3 & - & 4.1 & $3.0^{c}$ & - \\
\hline 6. $\mathrm{f}$-axis & & 9.5 & $11.4^{c}$ & 12.8 & - & 13.7 & 13.7 & - \\
\hline
\end{tabular}

${ }^{a}$ Position instead may be adjacent to $\mathrm{N}_{4}$.

${ }^{b}$ Position instead may be $\mathrm{N}_{4}$.

${ }^{c}$ Approximate measurement.

${ }^{d}$ Left mandible with broken teeth in alveoli; measurements taken on broken teeth within alveoli near alveolar border; anteroposterior diameters: $\mathrm{N}_{\overline{1}}-\mathrm{N}_{\overline{8}}$ (g-axis) $=157 \pm 5 ; \mathrm{N}_{\overline{2}}-\mathrm{N}_{\bar{k}}$ (h-axis) not applicable this specimen; $\mathrm{N}_{\overline{1}}-\mathrm{N}_{\overline{4}}$ (i-axis) $=80 ; \mathrm{N}_{\overline{5}}-\mathrm{N}_{\overline{7}}(\mathrm{j}$-axis) $=66$. 
TABLE 8.-Measurements ( $\mathrm{mm}$; left/right) of the lower dentition of Glyptotherium arizonae (axes as defined in Table 7)

\begin{tabular}{|c|c|c|c|c|c|c|c|c|}
\hline Axes & $\mathrm{N}_{\overline{1}}^{-}$ & $\mathrm{N}_{\overline{2}}$ & $\mathrm{~N}_{\overline{3}}$ & $\mathrm{~N}_{4}^{-}$ & $\mathrm{N}_{\overline{5}}$ & $\mathrm{~N}_{\overline{6}}$ & $N_{\overline{7}}$ & $\mathrm{~N}_{\overline{8}}$ \\
\hline $\begin{array}{l}\text { UMMP } \\
38761^{\text {a }}\end{array}$ & & & & & & & & \\
\hline $\begin{array}{l}\text { 1. a-axis } \\
\text { 2. b-axis } \\
\text { 3. c-axis } \\
\text { 4. d-axis } \\
\text { 5. e-axis } \\
\text { 6. f-axis }\end{array}$ & $\begin{array}{l}-1- \\
-1- \\
-1 \\
-1- \\
-1- \\
-1-\end{array}$ & $\begin{array}{c}21.7 /- \\
9.1 /- \\
5.2 /- \\
10.9 /- \\
5.9 /- \\
10.7 /-\end{array}$ & $\begin{array}{c}24.0^{\mathrm{h}} /- \\
10.5 /- \\
4.9 /- \\
14.0^{\mathrm{h}} /- \\
-/- \\
14.2 /-\end{array}$ & $\begin{array}{r}24.1 /- \\
11.1 /- \\
4.2 /- \\
14.8^{\mathrm{b}} /- \\
4.6 /- \\
16.7^{\mathrm{h}} /-\end{array}$ & $\begin{array}{l}-1- \\
-1- \\
-1- \\
-1- \\
-1- \\
-/ 18.3\end{array}$ & $\begin{array}{l}-/ 26.0 \\
-/ 14.2 \\
-/ 5.1 \\
-/ 17.7 \\
-/ 4.8 \\
-/ 17.7\end{array}$ & $\begin{array}{l}-/ 25.1 \\
-/ 14.8 \\
-/ 4.5 \\
-/ 17.6 \\
-/ 4.6 \\
-/ 17.7\end{array}$ & $\begin{array}{l}-/ 25.1 \\
-/ 16.0 \\
-/- \\
-/- \\
-/- \\
-/ 16.0^{b}\end{array}$ \\
\hline $\begin{array}{l}\text { USNM } \\
10536^{c}\end{array}$ & & & & & & & & \\
\hline $\begin{array}{l}\text { 1. a-axis } \\
\text { 2. b-axis } \\
\text { 3. c-axis } \\
\text { 4. d-axis } \\
\text { 5. e-axis } \\
\text { 6. f-axis }\end{array}$ & $\begin{array}{l}24.0 /- \\
9.1 /-\end{array}$ & $\begin{array}{r}21.7 / 23.2 \\
8.3 / 7.7 \\
4.4 / 4.8 \\
10.9 / 10.6 \\
4.9 / 5.0 \\
11.7 / 11.0\end{array}$ & $\begin{array}{r}24.0 / 23.8 \\
9.7 / 10.3 \\
4.5 / 4.7 \\
13.0 / 13.4 \\
4.0 / 4.6 \\
14.7 / 15.7\end{array}$ & $\begin{array}{c}24.8 /- \\
13.7 / 14.8 \\
4.6 /- \\
13.9 / 14.4 \\
4.6 /- \\
16.9 / 17.9\end{array}$ & $\begin{array}{c}23.0 / 23.2 \\
15.1 / 16.3 \\
4.7 / 4.6 \\
14.8 / 15.1 \\
4.3 /- \\
17.6 / 17.8\end{array}$ & $\begin{array}{r}24.0 / 23.5 \\
16.2 / 16.7 \\
-/ 5.3 \\
15.5 / 15.4 \\
4.6 / 4.2 \\
17.2 / 17.1\end{array}$ & $\begin{array}{c}23.5 /- \\
15.9 / 15.7 \\
4.6 / 4.7 \\
15.0 /- \\
4.5 /- \\
15.6 / 15.7\end{array}$ & $\begin{array}{r}24.5 /- \\
15.4 /- \\
4.0 /- \\
14.0 /- \\
3.8 /- \\
13.5 /-\end{array}$ \\
\hline
\end{tabular}

${ }^{a} \mathrm{~N}_{\overline{2}}-\mathrm{N}_{\overline{4}}$ measurements from left mandible; $\mathrm{N}_{\overline{5}}-\mathrm{N}_{\overline{8}}$ from right mandible; $\mathrm{j}$-axis $=66$.

${ }^{\mathrm{b}}$ Approximate measurement.

${ }^{\mathrm{C}} \mathrm{g}$-axis $=197 ; \mathrm{h}$-axis $=178 ; \mathrm{i}$-axis $=95 ; \mathrm{j}$-axis $=76$.

TABLE 9.-Measurements (mm; left/right) of the lower dentition of Glyptotherium cylindricum, AMNH $15548^{*}$ (axes as defined in Table 7)

\begin{tabular}{c|rrrrrrrr}
\hline Axes & $\mathrm{N}_{\overline{1}}$ & \multicolumn{1}{c}{$\mathrm{N}_{\overline{2}}$} & $\mathrm{~N}_{\overline{3}}$ & $\mathrm{~N}_{\overline{4}}$ & \multicolumn{1}{c}{$\mathrm{N}_{\overline{5}}$} & \multicolumn{1}{c}{$\mathrm{N}_{\overline{6}}$} & \multicolumn{1}{c}{$\mathrm{N}_{\overline{7}}$} & $\mathrm{~N}_{\overline{8}}$ \\
\hline 1. a-axis & $-/-$ & $-/ 18.6$ & $-/ 18.8$ & $-/-$ & $24.2 /-$ & $21.6 / 22.2$ & $21.2 / 21.5$ & $20.3 / 20.5$ \\
2. b-axis & $-/-$ & $-/ 6.0$ & $-/ 7.5$ & $-/-$ & $13.6 /-$ & $12.7 / 12.5$ & $12.6 / 13.4$ & $12.5 / 12.4$ \\
3. c-axis & & $-/ 5.0$ & $-/ 4.0$ & $-/-$ & $4.0 /-$ & $3.8 / 3.8$ & $3.3 / 3.6$ & $3.3 / 3.2$ \\
4. d-axis & & $-/ 9.0$ & $-/ 10.0$ & $-/-$ & $14.5 /-$ & $14.3 / 14.4$ & $13.0 / 13.8$ & $12.7 / 12.1$ \\
5. e-axis & & $-/ 5.1$ & $-/ 4.5$ & $-/-$ & $4.1 /-$ & $3.8 / 4.4$ & $3.5 / 4.5$ & $3.1 / 3.1$ \\
6. f-axis & & $-/ 10.0$ & $-/ 11.0$ & $-/-$ & $14.5 /-$ & $14.3 / 14.5$ & $13.7 / 14.7$ & $12.2 / 12.0$ \\
\hline
\end{tabular}

* Isolated teeth. 
TABLE 10.-Measurements ( $\mathrm{mm}$ ) of the lower dentition of Glyplotherium floridanum (axes as defined in Table 7)

\begin{tabular}{|c|c|c|c|c|c|c|c|c|}
\hline Axes & $\mathrm{N}_{\bar{i}}$ & $\mathrm{~N}_{\overline{2}}$ & $\mathrm{~N}_{\overline{3}}$ & $\mathrm{~N}_{\overline{4}}^{-}$ & $\mathrm{N}_{\overline{5}}$ & $\mathrm{~N}_{\overline{6}}$ & $N_{\overline{7}}$ & $N_{\overline{8}}$ \\
\hline \multicolumn{9}{|l|}{$\begin{array}{c}\text { TMM } \\
30967-1814^{\mathrm{e}}\end{array}$} \\
\hline $\begin{array}{l}\text { 1. a-axis } \\
\text { 2. b-axis } \\
\text { 3. e-axis } \\
\text { 4. d-axis } \\
\text { 5. e-axis } \\
\text { 6. f-axis }\end{array}$ & & $\begin{array}{c}18.9^{\mathrm{a}} \\
6.3\end{array}$ & $\begin{array}{r}20.0 \\
7.2 \\
3.6 \\
9.6 \\
3.5 \\
11.2\end{array}$ & $\begin{array}{r}22.0^{\mathrm{c}} \\
10.0 \\
3.4 \\
11.8 \\
3.4 \\
12.7\end{array}$ & $\begin{array}{c}21.7 \\
- \\
- \\
11.6 \\
3.9 \\
13.3\end{array}$ & $\begin{array}{c}- \\
- \\
4.9 \\
12.7 \\
- \\
13.3\end{array}$ & $\begin{array}{c}21.8 \\
11.6 \\
- \\
11.7 \\
- \\
12.3\end{array}$ & $\begin{array}{c}19.6^{\mathrm{a}} \\
- \\
- \\
- \\
- \\
-\end{array}$ \\
\hline $\begin{array}{c}\text { USNM } \\
6071 \\
\text { UF/FGS } \\
6643^{\text {b }}\end{array}$ & & & & & & & & \\
\hline $\begin{array}{l}\text { 1. a-axis } \\
\text { 2. b-axis } \\
\text { 3. e-axis } \\
\text { 4. d-axis } \\
\text { 5. e-axis } \\
\text { 6. f-axis }\end{array}$ & & $\begin{array}{r}19.9 \\
5.8 \\
4.5 \\
8.8 \\
4.5 \\
8.5\end{array}$ & $\begin{array}{r}20.6 \\
10.6 \\
3.3 \\
12.7 \\
3.5 \\
12.6\end{array}$ & & & $\begin{array}{c}20.0 \\
11.8 \\
- \\
13.4 \\
- \\
13.0\end{array}$ & $\begin{array}{r}19.9 \\
12.6 \\
3.1 \\
13.2 \\
- \\
12.6\end{array}$ & $\begin{array}{c}21.6 \\
12.7 \\
- \\
11.9 \\
- \\
10.8\end{array}$ \\
\hline \multicolumn{9}{|l|}{$\begin{array}{l}\text { USNM } \\
11318^{r}\end{array}$} \\
\hline $\begin{array}{l}\text { 1. a-axis } \\
\text { 2. b-axis } \\
\text { 3. e-axis } \\
\text { 4. d-axis } \\
\text { 5. e-axis } \\
\text { 6. f-axis }\end{array}$ & $\begin{array}{r}11.2^{c, d} \\
7.0^{c, d}\end{array}$ & $\begin{array}{r}15.7 \\
6.8 \\
5.3 \\
6.6 \\
4.5 \\
4.7 \\
\end{array}$ & $\begin{array}{r}18.0 \\
7.5 \\
4.1 \\
9.0 \\
4.3 \\
8.8\end{array}$ & $\begin{array}{r}19.4 \\
8.6 \\
3.5 \\
10.5 \\
3.3 \\
10.6\end{array}$ & $\begin{array}{r}20.5 \\
9.9 \\
3.3 \\
11.2 \\
3.2 \\
11.1\end{array}$ & $\begin{array}{l}- \\
- \\
- \\
- \\
- \\
-\end{array}$ & $\begin{array}{r}20.6 \\
10.8 \\
3.3 \\
11.9 \\
4.2 \\
11.8\end{array}$ & $\begin{array}{l}- \\
- \\
- \\
- \\
- \\
-\end{array}$ \\
\hline
\end{tabular}

${ }^{a}$ Measurement taken on alveolar border.

${ }^{b} N_{\overline{3}}$ (right) for USNM 6071, isolated tooth; $N_{\overline{2}}, N_{\overline{6}}, N_{\overline{7}}$ (left) and $N_{\bar{\gamma}}$ (right) for U1 $/$ FGS 6643 , isolated teeth.

'Approximate measurement.

dAlveolar measurement.

' $h$-axis $=157$.

${ }^{\prime} \mathrm{g}$-axis $=168^{\mathrm{c}} ; \mathrm{h}$-axis $=155^{\mathrm{c}} ; \mathrm{i}$-axis $=70 ; j$-axis $=71$. 
TABLE 11.-Measurements $(\mathrm{mm})$ of the atlas of North American glyptodonts

\begin{tabular}{|c|c|c|}
\hline Characters & $\begin{array}{l}\text { G. arizonae } \\
\text { UMMP } 34826\end{array}$ & $\begin{array}{l}\text { G. cylindricum } \\
\text { AMNH } 15548\end{array}$ \\
\hline 1. Transverse outside diameter of occipital facets & 116 & 99 \\
\hline $\begin{array}{l}\text { 2. Maximum dorsoventral diameter between tu- } \\
\text { bercles of dorsal and ventral arches }\end{array}$ & 68 & 62 \\
\hline 3. Maximum transverse diameter, neural canal & $46^{4}$ & $41^{\mathrm{a}}$ \\
\hline 4. Maximum dorsoventral diameter, neural canal & 36 & $31^{\mathrm{a}}$ \\
\hline $\begin{array}{l}\text { 5. Maximum transverse external-internal diame- } \\
\text { ter of left occipital facet }\end{array}$ & $38^{\mathrm{a}}$ & 50 \\
\hline $\begin{array}{l}\text { 6. Maximum transverse external-internal diame- } \\
\text { ter of right occipital facet }\end{array}$ & 39 & $37^{\mathrm{a}}$ \\
\hline $\begin{array}{l}\text { 7. Dorsoventral diameter, posterolateral-ventral } \\
\text { tubercle to upper extremity, alar process left } \\
\text { side }\end{array}$ & 74 & $61^{\mathrm{b}}$ \\
\hline $\begin{array}{l}\text { 8. Dorsoventral diameter, posterolateral-ventral } \\
\text { tubercle to upper extremity, alar process right } \\
\text { side }\end{array}$ & - & $58^{\mathrm{b}}$ \\
\hline 9. Dorsoventral diameter, odontoid process & 13 & 15 \\
\hline 10. Dorsoventral diameter, dorsa! arch & 12 & 14 \\
\hline 11. Anteroposterior diameter, odontoid process & 29 & 30 \\
\hline 12. Anteroposterior diameter, dorsal arch & 37 & 34 \\
\hline $\begin{array}{l}\text { 13. Transverse inside diameter between interver- } \\
\text { tebral foramina on posterior surface }\end{array}$ & 83 & 36 \\
\hline $\begin{array}{l}\text { 14. Maximum transverse diameter, lateral extrem- } \\
\text { ities axis facets }\end{array}$ & 107 & 93 \\
\hline
\end{tabular}

${ }^{a}$ Approximate measurement.

${ }^{\mathrm{b}}$ Upper extremity of alar process broken.

TABLE 12.--Measurements ( $\mathrm{mm}$ ) of the cervical tube of North American glyptodonts

\begin{tabular}{|c|c|c|}
\hline Characters & $\begin{array}{l}\text { G. arizonae } \\
\text { UMMP } 34826\end{array}$ & $\begin{array}{l}\text { G. floridanum } \\
\text { USNM } 6071\end{array}$ \\
\hline $\begin{array}{l}\text { 1. Oblique anteroposterior diameter, centrum articular } \\
\text { facet to anterior extremity odontoid process }\end{array}$ & 110 & 80 \\
\hline $\begin{array}{l}\text { 2. Maximum transverse diameter between lateral ex- } \\
\text { tremities of atlas facets }\end{array}$ & 102 & 79 \\
\hline $\begin{array}{l}\text { 3. Maximum transverse outside diameter, posterior } \\
\text { centrum facets }\end{array}$ & $101^{*}$ & - \\
\hline 4. Transverse diameter, left atlas articular facet & $34^{*}$ & 23 \\
\hline 5. Transverse diameter, right atlas articular facet & $34^{*}$ & 22 \\
\hline $\begin{array}{l}\text { 6. Oblique anteroposterior/dorsoventral diameter, } \\
\text { odontoid process to extremity of neural crest }\end{array}$ & - & 94 \\
\hline $\begin{array}{l}\text { 7. Oblique dorsoventral diameter, lower margin left } \\
\text { centrum facet to dorsal extremity neural crest }\end{array}$ & - & 79 \\
\hline
\end{tabular}

* Approximate measurement. 
TABLE 13.-Measurements ( $\mathrm{mm}$ ) of the scapula of North American glyptodonts

\begin{tabular}{l|cc}
\hline \multicolumn{1}{c|}{ Characters } & $\begin{array}{c}\text { G. lexanum } \\
\text { F:AM 95737 }\end{array}$ & $\begin{array}{c}\text { G. arizonae } \\
\text { USNM 10536 }\end{array}$ \\
\hline 1. Greatest vertical depth, measured from glenoid facet & 195 & 325 \\
2. Greatest anteroposterior length & 270 & 460 \\
3. Maximum anteroposterior diameter, glenoid facet & 68 & 83 \\
4. Maximum transverse diameter, glenoid facet & 45 & 59 \\
5. Length of acromion, measured on curve & $60^{*}$ & 120 \\
6. Length of spine, including acromion, measured along & 210 & 385 \\
curve & & \\
\hline
\end{tabular}

* Approximate measurement.

TABLE 14.-Measurements ( $\mathrm{mm}$ ) of the humerus of North American glyptodonts

\begin{tabular}{|c|c|c|c|c|c|}
\hline \multirow{3}{*}{ Characters } & \multicolumn{2}{|c|}{ G. texanum } & \multirow{3}{*}{$\begin{array}{c}\text { G. arizonae } \\
\text { USNM } \\
10536\end{array}$} & \multirow{2}{*}{\multicolumn{2}{|c|}{$\begin{array}{l}\text { G. floridanum } \\
\text { USNM } 6071 \\
\end{array}$}} \\
\hline & \multirow{2}{*}{$\begin{array}{l}\text { F:AM } \\
95737\end{array}$} & \multirow{2}{*}{$\begin{array}{c}\text { TMM } \\
40664-245\end{array}$} & & & \\
\hline & & & & right & left \\
\hline $\begin{array}{l}\text { 1. Maximum length from proximal articulating surface of } \\
\text { head to distal extremity of trochlear facet }\end{array}$ & 258 & - & 365 & - & - \\
\hline $\begin{array}{l}\text { 2. Maximum length from proximal articulating surface of } \\
\text { head to distal extremity of capitular facet }\end{array}$ & 250 & - & 356 & - & - \\
\hline $\begin{array}{l}\text { 3. Minimum diameter, proximal articulating surface of } \\
\text { head to distal surface of intercondylar groove }\end{array}$ & 249 & - & 354 & - & - \\
\hline $\begin{array}{l}\text { 4. Anteroposterior diameter of proximal extremity across } \\
\text { bicipital groove in sagittal plane }\end{array}$ & 63 & - & 81 & - & - \\
\hline $\begin{array}{l}\text { 5. Maximum anteroposterior diameter of head measured in } \\
\text { sagittal plane through lesser tuberosity }\end{array}$ & 51 & - & 76 & - & - \\
\hline 6. Maximum diameter from greater tuberosity across head & 73 & - & 105 & - & - \\
\hline $\begin{array}{l}\text { 7. Minimum transverse diameter of shaft below deltoid } \\
\text { ridge }\end{array}$ & 31 & - & 41 & - & - \\
\hline $\begin{array}{l}\text { 8. Minimum anteroposterior diameter of shaft below deltoid } \\
\text { ridge }\end{array}$ & 34 & - & 43 & - & - \\
\hline $\begin{array}{l}\text { 9. Maximum transverse diameter of the proximal shaft } \\
\text { across deltoid tuberosity }\end{array}$ & 59 & - & 82 & - & - \\
\hline 10. Maximum transverse diameter across condylar surface & 56 & 71 & 72 & 62 & 63 \\
\hline 11. Anteroposterior diameter of intercondylar groove & 28 & 33 & 32 & 32 & 32 \\
\hline 12. Maximum anteroposterior diameter of trochlear facet & 37 & 45 & $49^{*}$ & 47 & 48 \\
\hline 13. Maximum anteroposterior diameter of capitular facet & 31 & 39 & $45^{*}$ & 38 & 38 \\
\hline 14. Maximum transverse diameter across epicondyles & 85 & 119 & 114 & 103 & 104 \\
\hline $\begin{array}{l}\text { 15. Minimum diameter of medial supracondylar ramus mea- } \\
\text { sured obliquely on anteromedial surface to coronoid fossa }\end{array}$ & 30 & - & 37 & 31 & 32 \\
\hline $\begin{array}{l}\text { 16. Minimum diameter of medial supracondylar ramus mea- } \\
\text { sured obliquely on posterior surface from medial margin } \\
\text { to olecranon fossa }\end{array}$ & 26 & - & 23 & 31 & 33 \\
\hline $\begin{array}{l}\text { 17. Maximum diameter of articular surface of head from } \\
\text { anterolateral apex bounding greater trochanter to poster- } \\
\text { omedial margin }\end{array}$ & 60 & - & $80^{*}$ & - & - \\
\hline
\end{tabular}

* Approximate measurement. 
TABLE 15.-Measurements $(\mathrm{mm})$ of the radius of North American glyptodonts

\begin{tabular}{|c|c|c|c|c|c|c|c|}
\hline \multirow{3}{*}{ Characters } & \multicolumn{2}{|c|}{ G. texanum } & \multicolumn{3}{|c|}{ G. arizonae } & \multirow{2}{*}{\multicolumn{2}{|c|}{$\begin{array}{l}\text { G. floridanum } \\
\text { USNM } 6071\end{array}$}} \\
\hline & \multirow{2}{*}{$\begin{array}{l}\text { F:AM } \\
95737\end{array}$} & \multirow{2}{*}{$\begin{array}{l}\text { F:AM } \\
59585\end{array}$} & \multirow{2}{*}{$\begin{array}{l}\text { USNM } \\
10536\end{array}$} & \multicolumn{2}{|c|}{ UMMP 38761} & & \\
\hline & & & & left & right & left & right \\
\hline $\begin{array}{l}\text { 1. Maximum length measured from proximola- } \\
\text { teral extremity to distal extremity of styloid } \\
\text { process }\end{array}$ & 141 & $166^{\mathrm{a}}$ & 184 & - & - & - & 174 \\
\hline $\begin{array}{l}\text { 2. Maximum proximodistal diameter between } \\
\text { centers of articular facets }\end{array}$ & 109 & 134 & 156 & - & - & - & 146 \\
\hline $\begin{array}{l}\text { 3. Maximum transverse diameter, proximal ar- } \\
\text { ticular facets }\end{array}$ & 43 & 56 & 59 & $56^{\mathrm{h}}$ & 59 & - & $58^{\mathrm{a}, \mathrm{d}}$ \\
\hline $\begin{array}{l}\text { 4. Maximum transverse diameter, distal extrem- } \\
\text { ity styloid process to dorsal tubercle }\end{array}$ & 53 & - & 65 & - & - & 55 & 55 \\
\hline 5. Minimum transverse diameter of shaft & 15 & 22 & 25 & - & - & 21 & 21 \\
\hline 6. Minimum anteroposterior diameter of shaft & $16^{c}$ & $24^{b}$ & 23 & - & - & 25 & 25 \\
\hline $\begin{array}{l}\text { 7. Maximum anteroposterior diameter, proxi- } \\
\text { mal extremity }\end{array}$ & 23 & 36 & $39^{\mathrm{a}}$ & 31 & 32 & - & - \\
\hline $\begin{array}{l}\text { 8. Maximum midsagittal anteroposterior diam- } \\
\text { eter of distal articular facet }\end{array}$ & 26 & - & 42 & - & - & 33 & 33 \\
\hline $\begin{array}{l}\text { 9. Maximum transverse diameter, distal articu- } \\
\text { lar facet measured obliquely from the facet } \\
\text { border at styloid process to proximolateral } \\
\text { border }\end{array}$ & 41 & - & 55 & - & - & 52 & 49 \\
\hline $\begin{array}{l}\text { 10. Maximum anteroposterior diameter of prox- } \\
\text { imal articular facet }\end{array}$ & 23 & 33 & $32^{\mathrm{a}}$ & - & - & - & 27 \\
\hline
\end{tabular}

${ }^{a}$ Approximate measurement.

${ }^{b}$ Minimum occurs near proximal end of shaft.

${ }^{\mathrm{c}}$ Minimum occurs near distal end of shaft.

${ }^{d}$ Proximomedial tip broken away.

TABLE 16.-Measurements $(\mathrm{mm})$ of the ulna of North American glyptodonts

\begin{tabular}{|c|c|c|c|c|}
\hline \multirow{2}{*}{ Characters } & \multirow{2}{*}{$\begin{array}{c}\text { G. texanum } \\
\text { F:AM } \\
95737\end{array}$} & \multirow{2}{*}{$\begin{array}{c}\text { G. arizonae } \\
\text { USNM } \\
10536\end{array}$} & \multicolumn{2}{|c|}{$\begin{array}{l}\text { G. floridanum } \\
\text { USNM } 6071\end{array}$} \\
\hline & & & right & left \\
\hline 1. Maximum proximodistal length & 194 & 270 & 239 & 237 \\
\hline $\begin{array}{l}\text { 2. Minimum anteroposterior diameter of shaft distal to } \\
\text { semilunar notch }\end{array}$ & 42 & 59 & 51 & 49 \\
\hline $\begin{array}{l}\text { 3. Minimum anteroposterior diameter of shaft through } \\
\text { semilunar notch }\end{array}$ & 39 & 56 & 48 & 50 \\
\hline $\begin{array}{l}\text { 4. Minimum transverse diameter of shaft distal to sem- } \\
\text { ilunar notch }\end{array}$ & 18 & 22 & 19 & 18 \\
\hline $\begin{array}{l}\text { 5. Minimum transverse diameter of shaft proximal to } \\
\text { semilunar notch }\end{array}$ & 20 & 23 & 23 & 23 \\
\hline $\begin{array}{l}\text { 6. Transverse diameter of coronoid process to anconeal } \\
\text { process }\end{array}$ & 47 & 59 & 49 & 48 \\
\hline 7. Maximum diameter of cuneiform process & 31 & 44 & 32 & 31 \\
\hline 8. Maximum length of pisiform facet & 24 & 23 & 22 & 22 \\
\hline 9. Maximum width of pisiform facet & 11 & 18 & 15 & 15 \\
\hline $\begin{array}{l}\text { 10. Length of olecranon above semilunar notch (anco- } \\
\text { neal process to proximal extremity) }\end{array}$ & 59 & 98 & 71 & 69 \\
\hline
\end{tabular}


TABLE 17,-Measurements (mm) of the pisiform of North American glyptodonts

\begin{tabular}{l|cc}
\hline \multicolumn{1}{c|}{ Characters } & $\begin{array}{c}\text { G. lexanum } \\
\text { F:AM 95737 }\end{array}$ & $\begin{array}{c}\text { G. arizonae } \\
\text { USNM 10536 }\end{array}$ \\
\hline 1. Maximum diameter medial angle to lateral angle & $50^{*}$ & 58 \\
2. Maximum diameter lateral angle to anterodistal angle & $37^{*}$ & 51 \\
3. Maximum diameter anterodistal angle to medial angle & 29 & 33 \\
4. Maximum diameter anteroproximal angle to anterodistal angle & 15 & 22 \\
5. Maximum diameter anteroproximal angle to medial angle & 22 & 25 \\
6. Maximum diameter anteroproximal angle to lateral angle & $37^{*}$ & 58 \\
\hline
\end{tabular}

* Approximate measurement, tip of lateral angle broken.

TABLE 18.-Measurements ( $\mathrm{mm}$ ) of the cuneiform of North American glyptodonts

\begin{tabular}{l|ccc}
\hline \multirow{2}{*}{ Characters } & G. lexanum & \multicolumn{2}{c}{ G. arizonae } \\
\cline { 2 - 4 } & F:AM & USNM & UMMP \\
& 95737 & 10536 & 38761 \\
\hline 1. Maximum transverse diameter & 37 & 50 & 45 \\
2. Maximum anteroposterior diameter & 26 & 35 & 33 \\
3. Maximum proximodistal diameter & 15 & 21 & 19 \\
\hline
\end{tabular}

TABLE 19.-Measurements ( $\mathrm{mm}$ ) of the lunar of North American glyptodonts

\begin{tabular}{|c|c|c|c|c|}
\hline \multirow{3}{*}{ Characters } & \multirow{3}{*}{$\begin{array}{c}\text { G. texanum } \\
\text { F:AM } \\
95737 \\
\end{array}$} & \multicolumn{3}{|c|}{ G. arizonae } \\
\hline & & \multirow{2}{*}{$\begin{array}{l}\text { USNM } \\
10536\end{array}$} & \multicolumn{2}{|c|}{ UMMP 38761} \\
\hline & & & left & right \\
\hline $\begin{array}{l}\text { 1. Maximum transverse diameter } \\
\text { across proximal articular facet }\end{array}$ & 23 & 31 & 27 & 30 \\
\hline $\begin{array}{l}\text { 2. Maximum transverse diameter of } \\
\text { posterior tubercle measured } \\
\text { obliquely, medial to ventrolateral }\end{array}$ & 25 & 35 & 33 & 33 \\
\hline 3. Transverse diameter of constriction & 17 & 25 & - & 28 \\
\hline $\begin{array}{l}\text { 4. Maximum anteroposterior diame- } \\
\text { ter }\end{array}$ & 38 & 54 & 50 & 51 \\
\hline $\begin{array}{l}\text { 5. Proximodistal diameter of posterior } \\
\text { tubercle }\end{array}$ & 21 & 32 & 27 & 25 \\
\hline $\begin{array}{l}\text { 6. Minimum proximodistal diameter } \\
\text { of constriction }\end{array}$ & 13 & 16 & - & 19 \\
\hline $\begin{array}{l}\text { 7. Maximum proximodistal diameter } \\
\text { through centers of proximal and } \\
\text { distal articular facets }\end{array}$ & 17 & 22 & - & 25 \\
\hline 8. Maximum diameter scaphoid facel & 32 & 41 & 30 & 32 \\
\hline
\end{tabular}


TABLE 20.-Measurements ( $\mathrm{mm}$ ) of the scaphoid of North American glyptodonts

\begin{tabular}{l|ccc}
\multicolumn{1}{c|}{ Characters } & G. lexanum & \multicolumn{2}{c}{ G. arizonae } \\
\cline { 2 - 4 } & F:AM & USNM & UMMP \\
& 95737 & 10536 & 38761 \\
\hline 1. Maximum transverse diameter (measured slightly obliquely) & 26 & 32 & 34 \\
2. Maximum anteroposterior diameter, posterior tubercle to anterodistal & 34 & 49 & 45 \\
extremity & & & 28 \\
3. Maximum proximodistal diameter (radial facet to magnum facet) & 18 & 24 & 22 \\
4. Maximum transverse diameter, posterior tubcrcle & 16 & $*$ & 22 \\
5. Maximum proximodistal diameter, posterior tubercle & 14 & $*$ & 15 \\
\hline
\end{tabular}

* Tapers posteriorly, not knoblike, parameter unmeasurable.

TABLE 21.--Measurements (mm) of the trapezium of North American glyptodonts

\begin{tabular}{l|ccc}
\hline \multirow{2}{*}{ Characters } & G. lexanum & \multicolumn{2}{c}{ G. arizonae } \\
\cline { 2 - 4 } & F:AM & USNM & UMMP \\
& 95737 & 10536 & 38761 \\
\hline 1. Maximum anteroposterior diameter & 20 & 25 & $*$ \\
2. Maximum transverse diameter & 16 & 21 & $*$ \\
3. Maximum proximodistal diameter & 11 & 16 & $*$ \\
\hline
\end{tabular}

* Not measurable, see text.

TABLE 22.-Measurements ( $\mathrm{mm}$ ) of the trapezoid of North American glyptodonts

\begin{tabular}{|c|c|c|c|c|}
\hline \multirow{3}{*}{ Characters } & \multirow{3}{*}{$\begin{array}{c}\text { G. lexanum } \\
\text { F:AM } \\
95737\end{array}$} & \multicolumn{3}{|c|}{ G. arizonae } \\
\hline & & \multirow{2}{*}{$\begin{array}{l}\text { USNM } \\
10536\end{array}$} & \multicolumn{2}{|c|}{ UMMP 38761} \\
\hline & & & right & left \\
\hline $\begin{array}{l}\text { 1. Maximum anteroposterior diameter, } \\
\text { anterolateral angle to posteromedial } \\
\text { angle }\end{array}$ & 24 & 33 & 31 & 29 \\
\hline $\begin{array}{l}\text { 2. Maximum proximomedial to disto- } \\
\text { lateral diameter on anterior (dorsal) } \\
\text { extremity }\end{array}$ & 18 & 31 & $b$ & $b$ \\
\hline $\begin{array}{l}\text { 3. Maximum transverse diameter on an- } \\
\text { terior (dorsal) extremity, distomedial } \\
\text { to distolateral }\end{array}$ & 16 & 22 & 38 & - \\
\hline 4. Minimum proximodistal diameter & 6 & 9 & 8 & _ \\
\hline 5. Minimum transverse diameter & 10 & 16 & $b$ & $b$ \\
\hline $\begin{array}{l}\text { 6. Proximal anteroposterior length, tra- } \\
\text { pezium facet }\end{array}$ & 13 & $22^{\mathrm{a}-}$ & $b$ & $b$ \\
\hline $\begin{array}{l}\text { 7. Maximum proximodistal diameter, } \\
\text { anterior face }\end{array}$ & $b$ & $b$ & 19 & - \\
\hline
\end{tabular}

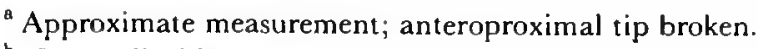

${ }^{\mathrm{b}}$ Not applicable. 
TABLE 23.-Measurements ( $\mathrm{mm}$ ) of the magnum of North American glyptodonts

\begin{tabular}{l|ccc}
\hline \multicolumn{1}{c|}{ Characters } & G. texanum & \multicolumn{2}{c}{ G. arizonae } \\
\cline { 3 - 4 } & F:AM & USNM & UMMP \\
& 95737 & 10536 & 38761 \\
\hline 1. Maximum anteroposterior diameter & 31 & 40 & 39 \\
2. Maximum proximodistal diameter through & 16 & 20 & - \\
$\begin{array}{l}\text { center of articular facets } \\
\text { 3. Maximum transverse diameter }\end{array}$ & 22 & 28 & 29 \\
\hline
\end{tabular}

TABLE 24.-Measurements ( $\mathrm{mm}$ ) of the unciform of North American glyptodonts

\begin{tabular}{l|cccc}
\hline \multicolumn{1}{c|}{ Characters } & G. texanum & \multicolumn{2}{c}{ G. arizonae } \\
\cline { 3 - 5 } & F:AM & USNM & \multicolumn{2}{c}{ UMMP 38761 } \\
\cline { 3 - 5 } & 95737 & 10536 & left & right \\
\hline $\begin{array}{l}\text { 1. Maximum proximodistal diameter, anterior face } \\
\text { 2. Transverse diameter of anterior margin of proximal articular }\end{array}$ & 24 & $23 *$ & 25 & 26 \\
$\begin{array}{l}\text { facet } \\
\text { 3. Maximum anteroposterior diameter from posterior angle of lat- } \\
\text { erat articular facet to anterodistal angle of distal articular facet }\end{array}$ & 24 & 40 & 29 & 31 \\
$\begin{array}{l}\text { 4. Oblique diameter from posterior angle of lateral articular facet } \\
\text { to medial extremity on anterior border of proximal articular } \\
\text { facet }\end{array}$ & 26 & 35 & 36 & 36 \\
\hline
\end{tabular}

* Approximate measurement; anterior proximomedial tip broken.

TABLE 25.-Measurements (mm) of the metacarpal 11 of North American glyptodonts

\begin{tabular}{|c|c|c|c|}
\hline \multirow[b]{2}{*}{ Characters } & \multirow{2}{*}{$\begin{array}{c}\text { G. texanum } \\
\text { F:AM } \\
95737\end{array}$} & \multicolumn{2}{|c|}{ G. arizonae } \\
\hline & & $\begin{array}{l}\text { USNM } \\
10536\end{array}$ & $\begin{array}{c}\text { UMMP } \\
38761\end{array}$ \\
\hline $\begin{array}{l}\text { 1. Maximum proximodistal diameter between lat- } \\
\text { eral articular facets }\end{array}$ & 46 & $47^{*}$ & 46 \\
\hline $\begin{array}{l}\text { 2. Maximum proximodistal diameter between me- } \\
\text { dial articular facets }\end{array}$ & 42 & 46 & 46 \\
\hline $\begin{array}{l}\text { 3. Maximum transverse diameter, proximal artic- } \\
\text { ular facets }\end{array}$ & 21 & 32 & - \\
\hline $\begin{array}{l}\text { 4. Maximum transverse diameter on posteroprox- } \\
\text { imal extremity across proximomedial tubercle }\end{array}$ & 25 & - & - \\
\hline 5. Minimum transverse diameter of shaft & 20 & $36^{*}$ & 31 \\
\hline $\begin{array}{l}\text { 6. Maximum transverse diameter across distal ar- } \\
\text { ticular facets }\end{array}$ & 25 & 32 & 32 \\
\hline 7. Minimum anteroposterior diameter of shaft & 22 & 28 & 25 \\
\hline $\begin{array}{l}\text { 8. Maximum anteroposterior diameter, proximal } \\
\text { extremity }\end{array}$ & 31 & 39 & 36 \\
\hline $\begin{array}{l}\text { 9. Maximum anteroposterior diamcter, distal ex- } \\
\text { tremity }\end{array}$ & 25 & 33 & 33 \\
\hline
\end{tabular}

* Approximate measurement. 
TABLE 26.-Measurements $(\mathrm{mm})$ of the metacarpal III of North American glyptodonts

\begin{tabular}{l|ccc}
\hline \multicolumn{1}{c|}{ Characters } & G. texanum & \multicolumn{2}{c}{ G. arizonae } \\
\cline { 2 - 4 } & $\begin{array}{l}\text { F:AM } \\
95737\end{array}$ & $\begin{array}{c}\text { USNM } \\
10536\end{array}$ & $\begin{array}{c}\text { UMMP } \\
38761\end{array}$ \\
\hline $\begin{array}{l}\text { 1. Maximum proximodistal diameter between } \\
\text { lateral articular facets }\end{array}$ & 36 & 40 & 34 \\
2. Maximum proximodistal diameter between & 35 & 38 & 35 \\
$\begin{array}{l}\text { medial articular facets } \\
\text { 3. Maximum transverse diameter, proximal ar- }\end{array}$ & 28 & 39 & 38 \\
ticular facets & 25 & 40 & 35 \\
4. Minimum transverse diameter of shaft & 29 & 38 & 39 \\
5. Maximum transverse diameter across distal & & & \\
articular facets & 23 & 32 & 29 \\
6. Minimum anteroposterior diameter of shaft & 28 & 37 & 36 \\
7. Maximum anteroposterior diameter, proximal \\
$\begin{array}{l}\text { extremity } \\
\text { 8. Maximum anteroposterior diameter, distal ex- } \\
\text { tremity }\end{array}$
\end{tabular}

TABLE 27.-Measurements (mm) of the metacarpal IV of North American glyptodonts

\begin{tabular}{|c|c|c|c|c|c|}
\hline \multirow{3}{*}{ Characters } & \multirow{3}{*}{$\begin{array}{c}\text { G. texanum } \\
\text { F:AM } \\
95737\end{array}$} & \multicolumn{3}{|c|}{ G. arizonae } & \multirow{3}{*}{$\begin{array}{c}\text { G. floridanum } \\
\text { USNM } \\
6071 \\
\end{array}$} \\
\hline & & \multirow{2}{*}{$\begin{array}{r}\text { USNM } \\
10536 \\
\end{array}$} & \multicolumn{2}{|c|}{ UMMP 38761} & \\
\hline & & & left & right & \\
\hline $\begin{array}{l}\text { 1. Maximum proximodistal length through } \\
\text { center }\end{array}$ & 23 & 20 & 19 & 19 & 18 \\
\hline $\begin{array}{l}\text { 2. Maximum anteroposterior diameter mea- } \\
\text { sured perpendicular to anterior face }\end{array}$ & 25 & 37 & 32 & 33 & 30 \\
\hline $\begin{array}{l}\text { 3. Diameter from posterior tubercle to anter- } \\
\text { odistal angle at center of angle }\end{array}$ & 29 & 37 & 34 & - & 31 \\
\hline $\begin{array}{l}\text { 4. Maximum transverse diameter across dis- } \\
\text { toanterior lateral/medial margin }\end{array}$ & 29 & 37 & 33 & 35 & 27 \\
\hline $\begin{array}{l}\text { 5. Maximum transverse diameter between lat- } \\
\text { eral and medial articular facets }\end{array}$ & 24 & 35 & 31 & $31^{*}$ & 27 \\
\hline $\begin{array}{l}\text { 6. Maximum proximodistal diameter, medial } \\
\text { articular facet }\end{array}$ & 15 & 16 & - & 15 & 10 \\
\hline $\begin{array}{l}\text { 7. Maximum anteroposterior diameter, medial } \\
\text { articular facet }\end{array}$ & 11 & 18 & - & $17^{*}$ & 12 \\
\hline $\begin{array}{l}\text { 8. Maximum proximodistal diameter, lateral } \\
\text { articular facet }\end{array}$ & 11 & 16 & $10^{*}$ & - & $11^{*}$ \\
\hline $\begin{array}{l}\text { 9. Maximum anteroposterior diameter, lateral } \\
\text { articular facet }\end{array}$ & $15^{*}$ & 15 & $17^{*}$ & - & 16 \\
\hline $\begin{array}{l}\text { 10. Maximum anteroposterior diameter, proxi- } \\
\text { mal articular facet }\end{array}$ & 22 & 32 & 27 & - & 25 \\
\hline
\end{tabular}

* Approximate measurement. 
TABLE 28.-Measurements ( $\mathrm{mm}$ ) of the metacarpal V of North American glyptodonts

\begin{tabular}{l|cc}
\multicolumn{1}{c|}{ Characters } & $\begin{array}{c}\text { G. texanum } \\
\text { F:AM } \\
95737\end{array}$ & $\begin{array}{c}\text { G. arizonae } \\
\text { USNM } \\
10536\end{array}$ \\
\hline 1. Maximum proximodistal diameter on medial border & 12 & (see text) \\
2. Maximum proximodistal diameter on lateral border & 9 & \\
3. Maximum proximodistal diameter through center of & 8 & \\
articular facets & & \\
4. Maximum anteroposterior diameter & 13 & \\
5. Maximum transverse diameter & 20 \\
\hline
\end{tabular}

TABLE 29.- Measurements (mm) of the phalanges I and II, digit II, manus, of North American glyptodonts

\begin{tabular}{|c|c|c|c|c|c|c|c|}
\hline \multirow{3}{*}{ Characters } & \multicolumn{3}{|c|}{ Phalanx I } & \multicolumn{4}{|c|}{ Phalanx II } \\
\hline & \multirow{2}{*}{$\begin{array}{l}\text { G. lexanum } \\
\text { F:AM } \\
95737\end{array}$} & \multicolumn{2}{|c|}{ G. arizonae } & \multirow{2}{*}{$\begin{array}{l}\text { G. lexanum } \\
\text { F:AM } \\
95737\end{array}$} & \multicolumn{2}{|c|}{ G. arizonae } & \multirow{2}{*}{$\begin{array}{l}\text { G. floridanum } \\
\text { USNM } \\
6071\end{array}$} \\
\hline & & $\begin{array}{c}\text { USNM } \\
10536\end{array}$ & $\begin{array}{l}\text { UMMP } \\
38761\end{array}$ & & $\begin{array}{l}\text { USNM } \\
10536\end{array}$ & $\begin{array}{l}\text { UMMP } \\
38761\end{array}$ & \\
\hline $\begin{array}{l}\text { 1. Maximum anteroposterior di- } \\
\text { ameter of proximal articular } \\
\text { facet, lateral side }\end{array}$ & 22 & 27 & - & 18 & 27 & 22 & 25 \\
\hline $\begin{array}{l}\text { 2. Maximum anteroposterior di- } \\
\text { ameter, distal articular facet, } \\
\text { lateral side }\end{array}$ & 19 & 28 & 30 & 18 & 26 & 25 & 25 \\
\hline $\begin{array}{l}\text { 3. Anteroposterior diameter, prox- } \\
\text { imal extremity through carina } \\
\text { to anterior tubercle }\end{array}$ & 23 & - & - & 16 & 22 & 26 & 23 \\
\hline $\begin{array}{l}\text { 4. Maximum diameter posterolat- } \\
\text { eral tubercle to anterior proxi- } \\
\text { momedial angle }\end{array}$ & 29 & - & - & 27 & 37 & 39 & 36 \\
\hline $\begin{array}{l}\text { 5. Maximum transverse diameter } \\
\text { across posterior tubercles }\end{array}$ & 24 & 36 & 37 & 27 & 36 & 38 & 35 \\
\hline $\begin{array}{l}\text { 6. Maximum transverse diameter } \\
\text { through center of articulation } \\
\text { proximal facet }\end{array}$ & 27 & 37 & 37 & 27 & 36 & 39 & 31 \\
\hline
\end{tabular}


TABLE 30.-Measurements (mm) of the ungual phalanx, digit II, manus, of North American glyptodonts

\begin{tabular}{|c|c|c|c|c|}
\hline \multirow[b]{2}{*}{ Characters } & \multirow{2}{*}{$\begin{array}{c}\text { G. texanum } \\
\text { F:AM } \\
95737\end{array}$} & \multicolumn{2}{|c|}{ G. arizonae } & \multirow{2}{*}{$\begin{array}{c}\text { G. floridanum } \\
\text { USNM } \\
6071\end{array}$} \\
\hline & & $\begin{array}{c}\text { USNM } \\
10536\end{array}$ & $\begin{array}{c}\text { UMMP } \\
38761 \\
\end{array}$ & \\
\hline $\begin{array}{l}\text { 1. Maximum diameter, proximoanterior prominence to distal ex- } \\
\text { tremity }\end{array}$ & 56 & 76 & 74 & 68 \\
\hline $\begin{array}{l}\text { 2. Maximum diameter, posteroproximal tendinal groove to distal } \\
\text { extremity }\end{array}$ & 49 & 65 & 66 & 62 \\
\hline 3. Inside diameter between subungual foramina & 14 & 18 & 20 & 21 \\
\hline $\begin{array}{l}\text { 4. Maximum transverse diameter across posteroproximal margin } \\
\text { through sesamoid facets }\end{array}$ & 25 & 36 & 38 & 35 \\
\hline $\begin{array}{l}\text { 5. Maximum anteroposterior (palmar-plantar) diameter, anterior } \\
\text { border to subungual base }\end{array}$ & 25 & 36 & 35 & 35 \\
\hline 6. Maximum oblique transverse diameter, subungual base & 18 & 43 & 43 & 39 \\
\hline $\begin{array}{l}\text { 7. Diameter from sesamoid tendinal groove to distal border, subun- } \\
\text { gual base }\end{array}$ & 27 & 33 & 35 & 29 \\
\hline $\begin{array}{l}\text { 8. Diameter from distal border of subungual base to distal extremity } \\
\text { of claw process }\end{array}$ & 23 & 34 & 34 & 33 \\
\hline
\end{tabular}

TABLE 31.-Measurements (mm) of the phalanges I and II, digit III, manus, of North American glyptodonts

\begin{tabular}{|c|c|c|c|c|c|c|}
\hline \multirow{3}{*}{ Characters } & \multicolumn{3}{|c|}{ Phalanx I } & \multicolumn{3}{|c|}{ Phalanx II } \\
\hline & \multirow{2}{*}{$\begin{array}{c}\text { G. lexanum } \\
\text { F:AM } \\
95737\end{array}$} & \multicolumn{2}{|c|}{ G. arizonae } & \multirow{2}{*}{$\begin{array}{c}\text { G. texanum } \\
\text { F:AM } \\
95737\end{array}$} & \multicolumn{2}{|c|}{ G. arizonae } \\
\hline & & $\begin{array}{l}\text { USNM } \\
10536^{a}\end{array}$ & $\begin{array}{c}\text { UMMP } \\
38761\end{array}$ & & $\begin{array}{c}\text { USNM } \\
10536\end{array}$ & $\begin{array}{c}\text { UMMP } \\
38761\end{array}$ \\
\hline $\begin{array}{l}\text { 1. Maximum anteroposterior diameter of } \\
\text { proximal articular facet, lateral side }\end{array}$ & 26 & 34 & $35^{\mathrm{b}}$ & 23 & 26 & $25^{b}$ \\
\hline $\begin{array}{l}\text { 2. Maximum anteroposterior diameter of } \\
\text { distal articular facet, lateral side }\end{array}$ & 20 & 26 & $24^{\mathrm{b}}$ & 20 & 26 & $24^{\mathrm{b}}$ \\
\hline $\begin{array}{l}\text { 3. Anteroposterior diameter, proximal ex- } \\
\text { tremity through center }\end{array}$ & 22 & 28 & - & 16 & 20 & - \\
\hline $\begin{array}{l}\text { 4. Maximum diameter, posterolateral tu- } \\
\text { bercle to anterior proximomedial angle }\end{array}$ & 34 & 44 & 45 & 33 & 47 & 45 \\
\hline $\begin{array}{l}\text { 5. Maximum anteroposterior diameter, } \\
\text { distal articular facet, medial rocker }\end{array}$ & 19 & 28 & 28 & 20 & 26 & 26 \\
\hline $\begin{array}{l}\text { 6. Maximum transverse diameter through } \\
\text { center of articulation, proximal facet }\end{array}$ & 29 & 41 & 36 & 28 & 41 & 38 \\
\hline $\begin{array}{l}\text { 7. Maximum transverse diameter, distal } \\
\text { articular facet }\end{array}$ & 27 & 39 & 36 & 25 & 37 & $34^{b}$ \\
\hline $\begin{array}{l}\text { 8. Maximum proximodistal diameter be- } \\
\text { tween articular facets, anterolateral } \\
\text { margin }\end{array}$ & 12 & 14 & 13 & 12 & 14 & 16 \\
\hline $\begin{array}{l}\text { 9. Maximum proximodistal diameter be- } \\
\text { tween articular facets, medial margin }\end{array}$ & 10 & 11 & 10 & 12 & 15 & 17 \\
\hline $\begin{array}{l}\text { 10. Central proximodistal diameter be- } \\
\text { tween articular facets }\end{array}$ & 10 & 13 & - & 11 & 14 & - \\
\hline $\begin{array}{l}\text { 11. Maximum anteroposterior diameter, } \\
\text { proximal articular facet, medial side }\end{array}$ & 23 & 28 & - & 20 & 23 & $17^{b}$ \\
\hline
\end{tabular}

"Extremely worn, pathologic, measurements estimated.

${ }^{b}$ Approximate measurement. 
TABLE 32.-Measurements (mm) of the ungual phalanx, digit 11l, manus, of North American glyptodonts

\begin{tabular}{|c|c|c|c|c|c|}
\hline \multirow[b]{2}{*}{ Characters } & \multicolumn{2}{|c|}{ G. texanum } & \multicolumn{2}{|c|}{ G. arizonae } & \multirow{2}{*}{$\begin{array}{l}\text { G. floridanum } \\
\text { USNM } \\
6071\end{array}$} \\
\hline & $\begin{array}{l}\text { F:AM } \\
95737\end{array}$ & $\begin{array}{c}\text { TMM } \\
40664-109\end{array}$ & $\begin{array}{l}\text { USNM } \\
10536\end{array}$ & $\begin{array}{l}\text { UMMP } \\
38761\end{array}$ & \\
\hline $\begin{array}{l}\text { 1. Maximum diameter proximoanterior promi- } \\
\text { nence to distal extremity }\end{array}$ & 63 & 81 & 77 & $51^{*}$ & 72 \\
\hline $\begin{array}{l}\text { 2. Maximum diameter posteroproximal tendinal } \\
\text { groove to distal extremity }\end{array}$ & 48 & 68 & 63 & - & 59 \\
\hline 3. Inside diameter between subungual foramina & 15 & 22 & 21 & - & 22 \\
\hline $\begin{array}{l}\text { 4. Maximum transverse diameter across postero- } \\
\text { proximal margin through sesamoid facets }\end{array}$ & 27 & 40 & 43 & 40 & 38 \\
\hline $\begin{array}{l}\text { 5. Maximum anteroposterior (palmar-plantar) } \\
\text { diameter, anterior border to subungual base }\end{array}$ & 26 & 35 & 36 & $38^{*}$ & 34 \\
\hline $\begin{array}{l}\text { 6. Diameter from sesamoid tendinal groove to } \\
\text { distal border, subungual base }\end{array}$ & 25 & 31 & 34 & - & 27 \\
\hline $\begin{array}{l}\text { 7. Diameter from distal border of subungual base } \\
\text { to distal extremity of claw process }\end{array}$ & 25 & 38 & 34 & - & 34 \\
\hline $\begin{array}{l}\text { 8. Transverse diameter through deepest portion } \\
\text { proximal articular facet }\end{array}$ & 29 & 43 & 43 & $40^{*}$ & 40 \\
\hline
\end{tabular}

* Pathologic, measurements approximate.

TABLE 33.-Measurements (mm) of the phalanges 1 and II, digit IV, manus, of North American glyptodonts

\begin{tabular}{|c|c|c|c|c|c|c|}
\hline \multirow{3}{*}{ Characters } & \multicolumn{3}{|c|}{ Phalanx I } & \multicolumn{3}{|c|}{ Phalanx II } \\
\hline & \multirow{2}{*}{$\begin{array}{c}\text { G. texanum } \\
\text { F:AM } \\
95737\end{array}$} & \multicolumn{2}{|c|}{ G. arizonae } & \multirow{2}{*}{$\begin{array}{c}\text { G. texanum } \\
\text { F:AM } \\
95737\end{array}$} & \multicolumn{2}{|c|}{ G. arizonae } \\
\hline & & $\begin{array}{c}\text { USNM } \\
10536\end{array}$ & $\begin{array}{l}\text { UMMP } \\
38761\end{array}$ & & $\begin{array}{c}\text { USNM } \\
10536 \\
\end{array}$ & $\begin{array}{c}\text { UMMP } \\
38761\end{array}$ \\
\hline 1. Maximum anteroposterior diameter & 23 & - & 26 & - & - & - \\
\hline $\begin{array}{l}\text { 2. Anteroposterior diameter through ten- } \\
\text { dinal groove }\end{array}$ & 18 & 24 & 23 & 16 & 22 & 24 \\
\hline 3. Maximum transverse diameter & 25 & 36 & 32 & 24 & 35 & 30 \\
\hline $\begin{array}{l}\text { 4. Maximum proximodistal thickness } \\
\text { through center of articular facets }\end{array}$ & 7 & - & - & 9 & 11 & - \\
\hline $\begin{array}{l}\text { 5. Maximum proximodistal thickness, } \\
\text { medial margin articular facets }\end{array}$ & 8 & 10 & 9 & 10 & 12 & 9 \\
\hline $\begin{array}{l}\text { 6. Maximum proximodistal thickness, lat- } \\
\text { eral margin articular facets }\end{array}$ & 8 & 9 & 9 & 9 & 12 & 12 \\
\hline $\begin{array}{l}\text { 7. Oblique diameter, posterolateral tuber- } \\
\text { cle tip to anteromedial margin }\end{array}$ & 27 & 38 & 33 & 27 & 36 & 31 \\
\hline $\begin{array}{l}\text { 8. Oblique diameter, posteromedial tu- } \\
\text { bercle tip to anteralateral margin }\end{array}$ & 24 & 35 & 31 & 24 & 34 & 30 \\
\hline $\begin{array}{l}\text { 9. Maximum anteroposterior diameter, } \\
\text { medial side }\end{array}$ & - & 29 & 25 & 20 & 26 & 25 \\
\hline $\begin{array}{l}\text { 10. Maximum anteroposterior diameter, } \\
\text { lateral side }\end{array}$ & - & 32 & $20^{*}$ & 18 & 26 & 22 \\
\hline
\end{tabular}

* Approximate measurement. 
TABLE 34.-Measurements ( $\mathrm{mm}$ ) of the ungual phalanx, digit IV, manus, of North American glyptodonts

\begin{tabular}{l|cc}
\hline \multicolumn{1}{c|}{ Characters } & $\begin{array}{c}\text { G. lexanum } \\
\text { F:AM } \\
95737\end{array}$ & $\begin{array}{c}\text { G. floridanum } \\
\text { USNM } \\
6071\end{array}$ \\
\hline $\begin{array}{l}\text { 1. Maximum proximodistal length from proximoanterior } \\
\text { prominence to distal extremity }\end{array}$ & 53 & 57 \\
2. Maximum proximodistal length from posteroproximal ten- & 44 & 52 \\
$\quad$ dinal groove to distal extremity & 12 & 18 \\
3. Inside diameter subungual foramina & 24 & 33 \\
4. Maximum transverse diameter, proximal extremity & 19 & 20 \\
5. Maximum transverse diameter, sesamoid facets & 25 & 26 \\
6. Diameter from sesamoid tendinal groove to distal border, \\
$\begin{array}{l}\text { subungual base } \\
\text { 7. Diameter from subungual base, distal border, to distal } \\
\text { extremity, claw process }\end{array}$ & 20 & 27 \\
8. Maximum diameter anteroproximal prominence to distal & 37 & 38 \\
$\quad$ border, subungual base & - & 28 \\
9. Maximum anteroposterior diameter from anteromedial \\
border to subungual base
\end{tabular}

TABLE 35.-Measurements (mm) of the phalanx I, digit V, manus, of North American glyptodonts

\begin{tabular}{l|cc}
\hline \multicolumn{1}{c|}{ Characters } & $\begin{array}{c}\text { G. texanum } \\
\text { F:AM } \\
95737\end{array}$ & $\begin{array}{c}\text { G.. arizonae } \\
\text { USNM } \\
10536\end{array}$ \\
\hline $\begin{array}{l}\text { 1. Maximum anteroposterior diameter } \\
\text { 2. Proximodistal diameter through center of articular } \\
\text { facets }\end{array}$ & 11 & (see text) \\
3. Maximum transverse diameter & 4 & \\
\hline
\end{tabular}

TABLE 36.-Measurements ( $\mathrm{mm}$ ) of the ungual phalanx, digit $\mathrm{V}$, manus, of North American glyptodonts

\begin{tabular}{l|cc}
\hline \multicolumn{1}{c|}{ Characters } & $\begin{array}{c}\text { G. lexanum } \\
\text { F:AM } \\
95737\end{array}$ & $\begin{array}{c}\text { G. arizonae } \\
\text { USNM } \\
10536\end{array}$ \\
\hline $\begin{array}{l}\text { 1. Maximum proximodistal length } \\
\text { 2. Diameter from anterior border articular facet to su- }\end{array}$ & 32 & 43 \\
$\begin{array}{l}\text { bungual prominence } \\
\text { 3. Diameter from subungual prominence to distal extrem- }\end{array}$ & 24 & 34 \\
ity & 13 & 36 \\
4. Maximum transverse diameter & & 25 \\
\hline
\end{tabular}


TABLE 37.-Measurements ( $\mathrm{mm}$ ) of the digital sesamoid bones, manus, of North American glyptodonts (upper number = F:AM 95737, G. lexanum; lower number = USNM 10536, $G$. arizonae)

\begin{tabular}{|c|c|c|c|}
\hline Characters & $\begin{array}{l}\text { Maximum } \\
\text { transverse } \\
\text { diameter }\end{array}$ & $\begin{array}{c}\text { Maximum } \\
\text { proximodistal } \\
\text { diameter }\end{array}$ & $\begin{array}{c}\text { Maximum } \\
\text { anteroposterior } \\
\text { diameter }\end{array}$ \\
\hline \multicolumn{4}{|l|}{ Digit II } \\
\hline \multirow{2}{*}{ 1. Medial proximal sesamoid } & 11 & 7 & 6 \\
\hline & 16 & 17 & 14 \\
\hline \multirow[t]{2}{*}{ 2. Lateral proximal sesamoid } & 11 & 10 & 10 \\
\hline & 18 & 14 & 14 \\
\hline \multirow[t]{2}{*}{ 3. Distal sesamoid } & 20 & 10 & 15 \\
\hline & 34 & 16 & 20 \\
\hline \multicolumn{4}{|l|}{ Digit III } \\
\hline \multirow[t]{2}{*}{ 1. Medial proximal sesamoid } & 9 & 6 & 8 \\
\hline & 15 & 12 & 11 \\
\hline 2. Lateral proximal sesamoid ${ }^{2}$ & 8 & 6 & 7 \\
\hline \multirow[t]{2}{*}{ 3. Distal sesamoid } & 21 & 9 & 13 \\
\hline & 34 & 19 & 20 \\
\hline \multicolumn{4}{|l|}{ Digit IV } \\
\hline 1. Distal sesamoid ${ }^{2}$ & 18 & 8 & 9 \\
\hline \multicolumn{4}{|l|}{ Digit V } \\
\hline \multirow[t]{2}{*}{ 1. Distal sesamoid } & 7 & 6 & 4 \\
\hline & 16 & 14 & 10 \\
\hline
\end{tabular}

'Diameters arbitrarily defined as three mutually perpendicular axes.

${ }^{2}$ Measurements are for G. texanum F:AM 95737; element unknown for $G$ arizonae. 
TABLE 38.-Measurements (mm) of the pelvis of North American glyptodonts

\begin{tabular}{|c|c|c|c|c|c|c|c|}
\hline \multirow[b]{2}{*}{ Characters } & \multicolumn{2}{|c|}{ G. texanum } & \multirow{2}{*}{$\begin{array}{c}\text { G. arizonae } \\
\text { AMNH } \\
21808 \\
\end{array}$} & \multirow{2}{*}{$\begin{array}{c}\text { G. cylindricum } \\
\text { AMNH } \\
15548 \\
\end{array}$} & \multicolumn{3}{|c|}{ G. floridanum } \\
\hline & $\begin{array}{l}\text { AMNH } \\
10704^{\mathrm{a}}\end{array}$ & $\begin{array}{l}\text { F:AM } \\
95737\end{array}$ & & & $\begin{array}{l}\text { UF/FGS } \\
6643\end{array}$ & $\begin{array}{l}\text { TMM } \\
30967\end{array}$ & $\begin{array}{c}\text { USNM } \\
6071\end{array}$ \\
\hline $\begin{array}{l}\text { 1. Anteroposterior length of } \\
\text { crest of sacral arch along } \\
\text { curvature from anterior il- } \\
\text { iosaucral vertebra to poste- } \\
\text { rior ischiosacral vertebra }\end{array}$ & 490 & - & - & $500^{\mathrm{b}}$ & - & $660^{b}$ & - \\
\hline $\begin{array}{l}\text { 2. Estimated anteroposterior } \\
\text { length, lumbar tube }\end{array}$ & $310^{b}$ & - & - & $270^{b}$ & - & $360^{b}$ & - \\
\hline $\begin{array}{l}\text { 3. Minimum transverse diam- } \\
\text { eter, ilium shaft }\end{array}$ & $75 / 75$ & $75 /-$ & $-/ 127^{b}$ & $115 / 109$ & $110 / 119$ & $112 / 118$ & - \\
\hline $\begin{array}{l}\text { 4. Anteroposterior diameter } \\
\text { (thickness) of ilium at posi- } \\
\text { tion of minimum transverse } \\
\text { diameter }\end{array}$ & $35 / 34$ & $30 /-$ & $-/ 48^{b}$ & $38^{b} / 38^{b}$ & $42 / 37$ & $39 / 36$ & - \\
\hline $\begin{array}{l}\text { 5. Maximum diameter (long } \\
\text { axis) acetabular fossa }\end{array}$ & $81^{b} / 80^{b}$ & $86 /-$ & $100 / 105$ & $103^{b} / 102$ & $89 / 89$ & $-/ 89$ & $-/ 91$ \\
\hline $\begin{array}{l}\text { 6. Minimum diameter, aceta- } \\
\text { bular fossa, approximated } \\
\text { by extension of circumfer- } \\
\text { ence through external notch } \\
\text { formed by lateral acetabu- } \\
\text { lar fossa }\end{array}$ & $63 / 63$ & $67 /-^{b}$ & $85 / 84$ & $85 / 85$ & $74 /-$ & $-/ 70^{b}$ & - \\
\hline $\begin{array}{l}\text { 7. Minimum inferior-superior } \\
\text { diameter, ischial neck }\end{array}$ & $50 / 48$ & $50 / 48$ & $76 / 65$ & $52 / 56$ & $62 /-$ & $62 / 66$ & - \\
\hline $\begin{array}{l}\text { 8. Minimum transverse diam- } \\
\text { eter, ischial neck }\end{array}$ & $19 / 19$ & $16 / 17$ & $39^{b} / 32$ & $30^{b} / 29$ & $27 /-$ & $20 / 21$ & - \\
\hline $\begin{array}{l}\text { 9. Anteroposterior diameter of } \\
\text { crest of ischium measured } \\
\text { along curvature }\end{array}$ & $230 / 220$ & - & - & - & - & $-/ 171^{b}$ & - \\
\hline $\begin{array}{l}\text { 10. Transverse diameter, anter- } \\
\text { osuperior angle ischiac crest } \\
\text { to neural spine, anterior is- } \\
\text { chiosacral vertebra (penul- } \\
\text { timate vertebra); i.e., "half- } \\
\text { width" of pelvis at ischiosa- } \\
\text { cral vertebra }\end{array}$ & $270 / 260$ & - & $250^{\mathrm{b}} /-$ & $270^{b} / 280$ & - & $-/ 270^{b}$ & - \\
\hline $\begin{array}{l}\text { 11. Minimum anteroposterior } \\
\text { diameter of transverse } \\
\text { process of anterior ischiosa- } \\
\text { cral vertebra }\end{array}$ & - & $9 / 9$ & - & $9 / 8$ & $-/ 12^{b}$ & $27 /-$ & - \\
\hline
\end{tabular}


Table 38.-Continued

\begin{tabular}{|c|c|c|c|c|c|c|c|c|}
\hline \multirow{2}{*}{\multicolumn{2}{|c|}{ Characters }} & \multicolumn{2}{|c|}{ G. texanum } & \multirow{2}{*}{$\begin{array}{c}\text { G. arizonae } \\
\text { AMNH } \\
21808 \\
\end{array}$} & \multirow{2}{*}{$\begin{array}{l}\text { G. cylindricum } \\
\text { AMNH } \\
15548 \\
\end{array}$} & \multicolumn{3}{|c|}{ G. floridanum } \\
\hline & & \multirow{2}{*}{$\begin{array}{c}\begin{array}{c}\text { AMNH } \\
10704^{\mathrm{a}}\end{array} \\
29 / 24\end{array}$} & \multirow{2}{*}{$\begin{array}{c}\text { F:AM } \\
95737 \\
31 / 33\end{array}$} & & & \multirow{2}{*}{$\begin{array}{c}\text { UF/FGS } \\
6643 \\
43 /-\end{array}$} & \multirow{2}{*}{$\begin{array}{c}\text { TMM } \\
30967 \\
36 / 38 \\
\vdots\end{array}$} & \multirow{2}{*}{$\begin{array}{c}\text { USNM } \\
607.1 \\
33 / 30\end{array}$} \\
\hline 12 & $\begin{array}{l}\text { Minimum anteroposterior } \\
\text { diameter of transverse pro- } \\
\text { cess of posterior ischiosacral } \\
\text { vertebra }\end{array}$ & & & $47 /-$ & $44 / 42$ & & & \\
\hline 13 & $\begin{array}{l}\text { Anteroposterior chord from } \\
\text { thoracolumbar facet to sac- } \\
\text { rocaudal facet }\end{array}$ & 620 & - & - & - & - & $840^{\mathrm{b}}$ & - \\
\hline & $\begin{array}{l}\text { Transverse diameter, iliac } \\
\text { crest measured along cur- } \\
\text { vature }\end{array}$ & $220 / 220$ & $215 /-$ & $230^{\mathrm{b}} / 230^{\mathrm{b}}$ & $230^{\mathrm{b}} / 230^{\mathrm{b}}$ & $250^{\mathrm{b}} /-$ & $280 / 290$ & - \\
\hline 15 & $\begin{array}{l}\text { Minimum transverse diam- } \\
\text { eter, pubic shaft }\end{array}$ & $11 /-$ & $5 / 6$ & -16 & $14 / 15$ & $11 /-$ & - & - \\
\hline 16 & $\begin{array}{l}\text { Minimum anteroposterior } \\
\text { diameter, pubic shaft }\end{array}$ & - & $12 / 12$ & $-/ 20$ & $25 / 24$ & $14 /-$ & - & - \\
\hline 17 & $\begin{array}{l}\text { Transverse diameter be- } \\
\text { tween posterior angles, is- } \\
\text { chiac crest }\end{array}$ & 370 & - & - & 460 & - & - & - \\
\hline 18 & $\begin{array}{l}\text { Transverse diameter be- } \\
\text { tween anterior angles, is- } \\
\text { chiac crest }\end{array}$ & 460 & - & - & 440 & - & - & - \\
\hline & $\begin{array}{l}\text { Transverse diameter be- } \\
\text { tween pubes measured from } \\
\text { inner surface of pubes at } \\
\text { midshaft }\end{array}$ & 210 & - & - & 190 & - & - & - \\
\hline
\end{tabular}

${ }^{a}$ Additional measurements in text.

${ }^{\mathrm{b}}$ Approximate measurement. 
TABLE 39.-Measurements (mm) of the femur of North American glyptodonts

\begin{tabular}{|c|c|c|c|c|c|c|c|c|}
\hline \multirow{3}{*}{ Characters } & \multirow{2}{*}{\multicolumn{2}{|c|}{$\begin{array}{l}\text { G. lexanum } \\
\text { F:AM } 95737\end{array}$}} & \multirow{3}{*}{$\begin{array}{l}\text { G. floridanum } \\
\text { USínM } \\
6071 \\
\end{array}$} & \multicolumn{5}{|c|}{ G. arizonae } \\
\hline & & & & \multirow{2}{*}{$\begin{array}{c}\text { USNM } \\
10536\end{array}$} & \multirow{2}{*}{$\begin{array}{c}\text { AMNH } \\
21808 \\
\end{array}$} & \multirow{2}{*}{$\begin{array}{l}\text { UMMP } \\
46231 \\
\end{array}$} & \multirow{2}{*}{$\begin{array}{l}\text { UMMP } \\
46233\end{array}$} & \multirow{2}{*}{$\begin{array}{r}\text { UMMP } \\
46376 \\
\end{array}$} \\
\hline & left & right & & & & & & \\
\hline $\begin{array}{l}\text { 1. Maximum proximodistal di- } \\
\text { ameter head to medial con- } \\
\text { dyle }\end{array}$ & - & 326 & 421 & 453 & 452 & 488 & - & - \\
\hline $\begin{array}{l}\text { 2. Maximum proximodistal di- } \\
\text { ameter greater trochanter to } \\
\text { lateral condyle }\end{array}$ & - & 331 & 443 & 484 & - & 527 & - & - \\
\hline $\begin{array}{l}\text { 3. Oblique proximodistal di- } \\
\text { ameter greater trochanter to } \\
\text { medial condyle }\end{array}$ & - & 344 & 454 & 523 & - & 542 & - & - \\
\hline 4. Transverse diameter head & 62 & 62 & 67 & 80 & 80 & 83 & - & - \\
\hline $\begin{array}{l}\text { 5. Anteroposterior diameter } \\
\text { head }\end{array}$ & 74 & 74 & 84 & 95 & 97 & 103 & - & - \\
\hline $\begin{array}{l}\text { 6. Transverse diameter medial } \\
\text { border of head to lateral ex- } \\
\text { tremity greater trochanter }\end{array}$ & - & 156 & 219 & 244 & - & 248 & - & - \\
\hline $\begin{array}{l}\text { 7. Proximal maximum trans- } \\
\text { verse diameter between lesser } \\
\text { and greater trochanters }\end{array}$ & - & 165 & 237 & 271 & - & 257 & - & - \\
\hline $\begin{array}{l}\text { 8. Anteroposterior diameter } \\
\text { midshaft }\end{array}$ & 41 & 42 & 52 & 55 & 63 & 61 & 66 & $64^{*}$ \\
\hline $\begin{array}{l}\text { 9. Minimum transverse diame- } \\
\text { ter midshaft }\end{array}$ & 65 & 62 & 81 & $90^{*}$ & 89 & $88^{*}$ & 101 & $103^{*}$ \\
\hline $\begin{array}{l}\text { 10. Maximum transverse diam- } \\
\text { eter medial condyle }\end{array}$ & - & 46 & 50 & 65 & 53 & $60^{*}$ & 66 & 63 \\
\hline $\begin{array}{l}\text { 11. Maximum transverse diam- } \\
\text { eter lateral condyle }\end{array}$ & - & - & 53 & 51 & $61^{*}$ & 63 & 67 & 66 \\
\hline $\begin{array}{l}\text { 12. Length supinator ridge } \\
\text { (third trochanter) to distal } \\
\text { extremity lateral condyle }\end{array}$ & - & 155 & 202 & 227 & - & - & 250 & 195 \\
\hline $\begin{array}{l}\text { 13. Maximum transverse diam- } \\
\text { eter distal articular facet }\end{array}$ & - & 101 & 122 & 132 & 135 & - & 161 & 145 \\
\hline
\end{tabular}

* Approximate measurement.

TABLE 40.-Measurements $(\mathrm{mm})$ of the patella of North American glyptodonts

\begin{tabular}{l|ccc}
\hline \multicolumn{1}{c|}{ Characters } & $\begin{array}{c}\text { G. texanum } \\
\text { F:AM } \\
\text { 95737 }\end{array}$ & $\begin{array}{c}\text { G. arizonae } \\
\text { USNM } \\
10536\end{array}$ & $\begin{array}{c}\text { G. floridanum } \\
\text { USNM } \\
6071\end{array}$ \\
\hline 1. Maximum proximodistal diameter & 81 & 100 & 84 \\
2. Maximum transverse diameter & 55 & 83 & 72 \\
3. Maximum anteroposterior (craniocaudal) & 41 & 56 & 46 \\
diameter & & & \\
\hline
\end{tabular}


TABLE 41.-Measurements ( $\mathrm{mm}$ ) of the tibiofibula of North American glyptodonts

\begin{tabular}{|c|c|c|c|c|c|c|c|c|c|c|}
\hline \multirow{3}{*}{ Characters } & \multicolumn{3}{|c|}{ G. lexanum } & \multicolumn{5}{|c|}{ G. arizonae } & \multicolumn{2}{|c|}{ G. floridanum } \\
\hline & \multicolumn{2}{|c|}{$\begin{array}{l}\text { F:AM } \\
95737^{a}\end{array}$} & \multirow{2}{*}{$\begin{array}{l}\text { JWT } \\
1723\end{array}$} & \multirow{2}{*}{$\begin{array}{c}\text { USNM } \\
10536\end{array}$} & \multirow{2}{*}{$\begin{array}{c}\text { UMMP } \\
46232\end{array}$} & \multirow{2}{*}{$\begin{array}{c}\text { UMMP } \\
46231\end{array}$} & \multirow{2}{*}{$\begin{array}{c}\text { UMMP } \\
33524\end{array}$} & \multirow{2}{*}{$\begin{array}{l}\text { MU } \\
2670\end{array}$} & \multirow{2}{*}{$\begin{array}{c}\text { USNM } \\
6071\end{array}$} & \multirow{2}{*}{$\begin{array}{l}\text { TMM } \\
31141- \\
19\end{array}$} \\
\hline & left & right & & & & & & & & \\
\hline $\begin{array}{l}\text { 1. Maximum transverse di- } \\
\text { ameter, proximal ex- } \\
\text { tremity through center } \\
\text { of articular facet }\end{array}$ & 105 & 107 & 111 & 135 & 146 & - & 151 & 102 & 119 & - \\
\hline $\begin{array}{l}\text { 2. Maximum anteroposte- } \\
\text { rior diameter, proximal } \\
\text { extremity through tibial } \\
\text { facet (excluding tibial } \\
\text { tuberosity) }\end{array}$ & 87 & $85^{b}$ & $114^{\mathrm{b}}$ & - & - & - & 124 & - & $99^{b}$ & - \\
\hline $\begin{array}{l}\text { 3. Minimum transverse di- } \\
\text { ameter of "midshaft," } \\
\text { exclusive of tibial crest }\end{array}$ & 78 & 78 & 99 & 112 & 112 & $140^{\mathrm{b}}$ & 130 & - & - & 112 \\
\hline $\begin{array}{l}\text { 4. Minimum anteroposte- } \\
\text { rior diameter, fibular } \\
\text { shaft }\end{array}$ & 47 & 46 & 49 & 51 & 66 & - & 61 & - & - & 56 \\
\hline $\begin{array}{l}\text { 5. Minimum anteroposte- } \\
\text { rior diameter on medial } \\
\text { surface of distal extrem- } \\
\text { ity of tibial shaft }\end{array}$ & 43 & 42 & 50 & 61 & 70 & $74^{\mathrm{b}}$ & 78 & - & 48 & 60 \\
\hline $\begin{array}{l}\text { 6. Maximum transverse di- } \\
\text { ameter, distal extremity } \\
\text { through malleoli }\end{array}$ & 105 & 105 & 116 & 133 & 131 & 151 & 140 & - & - & $118^{\mathrm{b}}$ \\
\hline $\begin{array}{l}\text { 7. Maximum anteroposte- } \\
\text { rior diameter, distal ex- } \\
\text { tremity through fibular } \\
\text { facet }\end{array}$ & 67 & 67 & - & 78 & - & 86 & 82 & - & - & - \\
\hline $\begin{array}{l}\text { 8. Maximum anteroposte- } \\
\text { rior diameter of fibular } \\
\text { facet, distal extremity }\end{array}$ & $50^{b}$ & 51 & $47^{b}$ & 66 & $73^{b}$ & 77 & 75 & - & - & $59^{b}$ \\
\hline $\begin{array}{l}\text { 9. Maximum transverse di- } \\
\text { ameter, distal articular } \\
\text { facet }\end{array}$ & 65 & 64 & 69 & 84 & 94 & 93 & $88^{b}$ & & - & 83 \\
\hline $\begin{array}{l}\text { 10. Proximodistal tibial } \\
\text { length measured from } \\
\text { posterior margin of } \\
\text { proximal articular facet } \\
\text { to posterior malleolus }\end{array}$ & $116^{\mathrm{b}}$ & 117 & $200^{\mathrm{b}}$ & 235 & $230^{\mathrm{b}}$ & $230^{\mathrm{b}}$ & $220^{\mathrm{b}}$ & - & $220^{\mathrm{b}}$ & $225^{b}$ \\
\hline $\begin{array}{l}\text { 11. Fibular length measured } \\
\text { from proximolateral in- } \\
\text { tercondylar prominence } \\
\text { through lateral malleolus }\end{array}$ & 181 & 181 & $220^{b}$ & 266 & $280^{b}$ & - & $250^{\mathrm{b}}$ & - & - & - \\
\hline
\end{tabular}

a Juvenile.

${ }^{\mathrm{b}}$ Approximate measurement. 
TABLE 42.-Measurements ( $\mathrm{mm}$ ) of the astragalus of North American glyptodonts

\begin{tabular}{|c|c|c|c|c|c|c|c|c|}
\hline \multirow{3}{*}{ Characters } & \multicolumn{3}{|c|}{ G. texanum } & \multicolumn{4}{|c|}{ G. arizonae } & \multirow{3}{*}{$\begin{array}{c}\text { G. floridanum } \\
\text { USNM } \\
6071\end{array}$} \\
\hline & \multicolumn{2}{|c|}{ F:AM 95737} & \multirow{2}{*}{$\begin{array}{l}\text { F:AM } \\
59586 \\
\end{array}$} & \multicolumn{2}{|c|}{ USNM 10536} & \multirow{2}{*}{$\begin{array}{c}\text { UMMP } \\
46231 \\
\end{array}$} & \multirow{2}{*}{$\begin{array}{l}\text { UMMP } \\
38761\end{array}$} & \\
\hline & left & right & & left & right & & & \\
\hline $\begin{array}{l}\text { 1. Maximum transverse di- } \\
\text { ameter, trochlear facet }\end{array}$ & 59 & 59 & 64 & 75 & 77 & 85 & $80^{*}$ & 74 \\
\hline $\begin{array}{l}\text { 2. Anteroposterior diameter, } \\
\text { medial rocker, trochlear } \\
\text { facet }\end{array}$ & 42 & 42 & $47^{*}$ & - & 64 & 74 & 65 & - \\
\hline $\begin{array}{l}\text { 3. Anteroposterior diameter, } \\
\text { lateral rocker, trochlear } \\
\text { facet }\end{array}$ & 50 & 50 & 51 & $65^{*}$ & 64 & $58^{*}$ & - & 59 \\
\hline $\begin{array}{l}\text { 4. Anteroposterior diameter, } \\
\text { navicular facet }\end{array}$ & 43 & - & .42 & 62 & 60 & 70 & - & - \\
\hline $\begin{array}{l}\text { 5. Transverse diameter, na- } \\
\text { vicular facet }\end{array}$ & 42 & 44 & - & - & 51 & - & 49 & 46 \\
\hline $\begin{array}{l}\text { 6. Maximum diameter, lat- } \\
\text { eral calcaneal facet }\end{array}$ & - & 48 & $48^{*}$ & $54^{*}$ & 57 & 57 & - & 42 \\
\hline $\begin{array}{l}\text { 7. Oblique diameter, medial } \\
\text { calcaneal tuberosity to na- } \\
\text { vicular tuberosity }\end{array}$ & 69 & 69 & 69 & - & 87 & 105 & $81^{*}$ & - \\
\hline
\end{tabular}

* Approximate measurement. 
TABLE 43.-Measurements (mm) of the calcaneum of North American glyptodonts

\begin{tabular}{|c|c|c|c|c|c|c|c|}
\hline \multirow{3}{*}{ Characters } & \multicolumn{3}{|c|}{ G. texanum } & \multicolumn{3}{|c|}{ G. arizonae } & \multirow{3}{*}{$\begin{array}{l}\text { G. floridanum } \\
\text { USNM } \\
6071 \\
\end{array}$} \\
\hline & \multicolumn{2}{|c|}{ F:AM 95737} & \multirow{2}{*}{$\begin{array}{r}\text { JWT } \\
1712 \\
\end{array}$} & \multirow{2}{*}{$\begin{array}{c}\text { USNM } \\
10536 \\
\end{array}$} & \multirow{2}{*}{$\begin{array}{c}\text { UMMP } \\
46231 \\
\end{array}$} & \multirow{2}{*}{$\begin{array}{l}\text { UMMP } \\
38761 \\
\end{array}$} & \\
\hline & left & right & & & & & \\
\hline $\begin{array}{l}\text { 1. Maximum diameter, astra- } \\
\text { galar facet (long axis) }\end{array}$ & 45 & 45 & 45 & 55 & $61^{*}$ & $55^{*}$ & 50 \\
\hline $\begin{array}{l}\text { 2. Width, astragalar facet (short } \\
\text { axis) }\end{array}$ & - & 28 & 27 & 33 & $34^{*}$ & $33^{*}$ & 31 \\
\hline $\begin{array}{l}\text { 3. Maximum length, sustenta- } \\
\text { cular facet }\end{array}$ & - & 31 & 27 & 40 & - & - & 38 \\
\hline $\begin{array}{l}\text { 4. Maximum width, sustenta- } \\
\text { cular facet along convexity }\end{array}$ & - & 20 & 17 & 25 & - & - & 25 \\
\hline $\begin{array}{l}\text { 5. Anteroposterior diameter, } \\
\text { cuboid facet }\end{array}$ & - & 27 & 28 & 33 & - & - & 35 \\
\hline $\begin{array}{l}\text { 6. Transverse diameter, cuboid } \\
\text { facet (through constriction) }\end{array}$ & - & 25 & 18 & 30 & - & - & 30 \\
\hline $\begin{array}{l}\text { 7. Diameter from astragalar } \\
\text { facet, perpendicular through } \\
\text { inferior tuberosity }\end{array}$ & - & 47 & 49 & 61 & 64 & 64 & 55 \\
\hline $\begin{array}{l}\text { 8. Transverse diameter, susten- } \\
\text { tacular facet through cuboid } \\
\text { facet to posterolateral tuber- } \\
\text { cle }\end{array}$ & 73 & 74 & 73 & 92 & - & - & - \\
\hline $\begin{array}{l}\text { 9. Superior-inferior diameter, } \\
\text { astragalar facet to neck }\end{array}$ & - & 45 & - & 57 & 59 & $60^{*}$ & 50 \\
\hline $\begin{array}{l}\text { 10. Superior-inferior diameter, } \\
\text { tuber calcis above astragalar } \\
\text { facet }\end{array}$ & 47 & 45 & - & 54 & $55^{*}$ & $52^{*}$ & 45 \\
\hline $\begin{array}{l}\text { 11. Maximum proximodistal di- } \\
\text { ameter }\end{array}$ & - & 99 & - & 137 & - & - & 133 \\
\hline
\end{tabular}

* Approximate measurement. 
TABLE 44.-Measurements ( $\mathrm{mm}$ ) of the navicular of North American glyptodonts

\begin{tabular}{|c|c|c|c|c|c|c|}
\hline \multirow{2}{*}{ Characters } & \multirow{2}{*}{$\begin{array}{l}\text { G. lexanum } \\
\text { F:AM } \\
95737 \\
\end{array}$} & \multicolumn{5}{|c|}{ G. arizonae } \\
\hline & & $\begin{array}{l}\text { USNM } \\
10536\end{array}$ & $\begin{array}{l}\text { UMMP } \\
46231\end{array}$ & $\begin{array}{l}\text { UMMP } \\
38761\end{array}$ & $\begin{array}{l}\text { UMMP } \\
46332\end{array}$ & $\begin{array}{l}\text { UMMP } \\
46331\end{array}$ \\
\hline $\begin{array}{l}\text { 1. Maximum proximodistal diameter, } \\
\text { posterior border astragalar facet to } \\
\text { posterior border middle cuneiform } \\
\text { facet }\end{array}$ & 22 & 31 & - & $30^{*}$ & 36 & 27 \\
\hline $\begin{array}{l}\text { 2. Minimum proximodistal diameter, } \\
\text { anterior border astragalar facet to } \\
\text { anterior border middle cuneiform } \\
\text { facet }\end{array}$ & 8 & 13 & 14 & 10 & 15 & 13 \\
\hline $\begin{array}{l}\text { 3. Minimum proximodistal diameter, } \\
\text { lateral angle astragalar facet to ex- } \\
\text { ternal corner ectocuneiform facet }\end{array}$ & 12 & 14 & 16 & 16 & 19 & 13 \\
\hline $\begin{array}{l}\text { 4. Maximum anteroposterior diam- } \\
\text { eter, anterior angle ectocuneiform } \\
\text { facet to lateral posterior tuberosity }\end{array}$ & 86 & $117^{*}$ & - & - & 132 & - \\
\hline $\begin{array}{l}\text { 5. Anteroposterior diameter, astraga- } \\
\text { lar facet }\end{array}$ & 44 & 59 & 67 & 58 & 68 & 55 \\
\hline $\begin{array}{l}\text { 6. Maximum transverse diameter, as- } \\
\text { tragalar facet }\end{array}$ & 51 & 57 & - & 55 & $60^{*}$ & 56 \\
\hline $\begin{array}{l}\text { 7. Maximum transverse diameter, me- } \\
\text { dial tuberosity to lateral tubercle at } \\
\text { external boundary between cuboid } \\
\text { facet and ectocuneiform facet }\end{array}$ & 65 & 82 & - & 91 & 101 & 80 \\
\hline $\begin{array}{l}\text { 8. Maximum diameter (long axis), cu- } \\
\text { boid facet }\end{array}$ & 44 & 49 & - & 50 & 65 & - \\
\hline $\begin{array}{l}\text { 9. Maximum transverse diameter, ec- } \\
\text { tocuneiform facet }\end{array}$ & 24 & 28 & $60^{*}$ & 47 & 59 & 45 \\
\hline $\begin{array}{l}\text { 10. Maximum anteroposterior diam- } \\
\text { eter, middle cuneiform facet }\end{array}$ & 48 & 60 & - & 64 & 69 & 59 \\
\hline $\begin{array}{l}\text { 11. Maximum transverse diameter, } \\
\text { middle cuneiform facet }\end{array}$ & 22 & 30 & $29 *$ & 26 & $28^{*}$ & $26^{*}$ \\
\hline $\begin{array}{l}\text { 12. Maximum transverse diameter, in- } \\
\text { ternal cuneiform facet }\end{array}$ & 19 & 24 & - & $20^{*}$ & $27^{*}$ & - \\
\hline $\begin{array}{l}\text { 13. Maximum anteroposterior diam- } \\
\text { eter, internal posterior tubercle }\end{array}$ & 40 & 53 & - & 48 & 59 & - \\
\hline
\end{tabular}

* Approximate measurement.

TABLE 45.-Measurements ( $\mathrm{mm}$ ) of the cuboid of North American glyptodonts

\begin{tabular}{l|cccc}
\hline \multicolumn{1}{c|}{ Characters } & G. texanum & \multicolumn{3}{c}{ G. arizonae } \\
\cline { 2 - 5 } & F:AM & USNM & UMMP & UMMP \\
& 95737 & 10536 & 46231 & 38761 \\
\hline 1. Maximum anteroposterior diameter & 71 & 63 & 81 & 78 \\
2. Maximum transverse diameter, calcaneal facet & 29 & 43 & 49 & 42 \\
3. Maximum anteroposterior diameter, calcaneal facet & 31 & 40 & 59 & - \\
4. Maximum proximodistal diameter, calcaneal facet & 29 & 37 & $49^{*}$ & $44^{*}$ \\
to distal articular facet & & & & \\
5. Maximum transverse diameter, posterior tubercle & 28 & 36 & 35 & 38 \\
\hline
\end{tabular}

* Approximate measurement. 


\begin{tabular}{|c|c|c|c|c|}
\hline \multirow[b]{2}{*}{ Characters } & \multirow{2}{*}{$\begin{array}{c}\text { G. texanum } \\
\text { F:AM } \\
95737\end{array}$} & \multicolumn{3}{|c|}{ G. arizonae } \\
\hline & & $\begin{array}{c}\text { USNM } \\
10536\end{array}$ & $\begin{array}{l}\text { UMMP } \\
46231\end{array}$ & $\begin{array}{l}\text { UMMP } \\
38761\end{array}$ \\
\hline 1. Proximodistal diameter at anterolateral angle & 17 & 18 & $22 \cdots$ & $\because 22$ \\
\hline $\begin{array}{l}\text { 2. Anteroposterior diameter, proximal facet from anterolateral angle to } \\
\text { posteromedial concavity }\end{array}$ & 30 & 35 & 34 & 33 \\
\hline $\begin{array}{l}\text { 3. Anteroposterior diameter, distal facet from anterolateral angle to } \\
\text { posteromedial concavity }\end{array}$ & 25 & 26 & 40 & \llcorner \\
\hline 4. Anteroposterior diameter, anteromedial angle to posterior angle & 44 & 57 & 75 & 61 \\
\hline
\end{tabular}

TABLE 47.-Measurements ( $\mathrm{mm}$ ) of the middle cuneiform of North American glyptodonts

\begin{tabular}{l|cccc}
\hline \multicolumn{1}{c|}{ Characters } & G. texanum & \multicolumn{3}{c}{ G. arizonae } \\
\cline { 3 - 5 } & F:AM & USNM & UMMP & UMMP \\
& 95737 & 10536 & 46231 & 38761 \\
\hline 1. Maximum proximodistal diameter at \\
$\begin{array}{l}\text { anteromedial angle of articular facets } \\
\text { 2. Minimum proximodistal diameter be- }\end{array}$ & 18 & 20 & 25 & 21 \\
$\begin{array}{l}\text { tween posterior regions of articular } \\
\text { facets }\end{array}$ & 7 & 10 & 9 & $7^{*}$ \\
$\begin{array}{l}\text { 3. Maximum transverse diameter, ante- } \\
\text { rior border }\end{array}$ & 22 & 30 & 35 & 29 \\
4. Maximum anteroposterior diameter & 48 & 63 & 65 & 57 \\
\hline
\end{tabular}

* Approximate measurement.

TABLE 48.-Measurements ( $\mathrm{mm}$ ) of the internal cuneiform of North American glyptodonts

\begin{tabular}{|c|c|c|c|c|}
\hline \multirow{2}{*}{ Characters } & \multirow{2}{*}{$\begin{array}{l}\text { G. lexanum } \\
\text { F:AM } \\
95737\end{array}$} & \multicolumn{3}{|c|}{ G. arizonae } \\
\hline & & $\begin{array}{l}\text { USNM } \\
10536\end{array}$ & $\begin{array}{l}\text { UMMP } \\
46231\end{array}$ & $\begin{array}{l}\text { UMMP } \\
38761\end{array}$ \\
\hline $\begin{array}{l}\text { I. Maximum anteroposterior di- } \\
\text { ameter }\end{array}$ & 35 & 41 & $52^{*}$ & $40^{*}$ \\
\hline 2. Maximum transverse diameter & 19 & 24 & $25^{*}$ & $30^{*}$ \\
\hline $\begin{array}{l}\text { 3. Maximum proximodistal diam- } \\
\text { eter }\end{array}$ & 24 & 30 & $34^{*}$ & $23^{*}$ \\
\hline
\end{tabular}

* Approximate measurement.

TABLE 49.-Measurements (mm) of the metatarsal I of North American glyptodonts

\begin{tabular}{l|cccc}
\hline \multirow{2}{*}{ Characters } & G. lexanum & \multicolumn{3}{c}{ G. arizonae } \\
\cline { 3 - 5 } & $\begin{array}{rlcc}\text { F:AM } \\
95737\end{array}$ & USNM & UMMP & UMMP \\
\hline 1. Maximum anteroposterior di- & 28 & 34 & 36 & 43 \\
$\begin{array}{l}\text { ameter } \\
\text { 2. Maximum transverse diameter }\end{array}$ & 20 & 29 & 25 & 28 \\
$\begin{array}{l}\text { 3. Maximum proximodistal diam- } \\
\text { eter }\end{array}$ & 18 & 32 & $24^{*}$ & 25 \\
\hline
\end{tabular}

*Approximate measurement. 
TABLE 50.-Measurements (mm) of the metatarsal II of North American glyptodonts

\begin{tabular}{l|ccccc}
\hline \multirow{2}{*}{\multicolumn{1}{c}{ Characters }} & G. lexanum & \multicolumn{4}{c}{ G. arizonae } \\
\cline { 5 - 6 } & F:AM & UMMP & UMMP & UMMP & USNM \\
& 95737 & 38761 & 46231 & 46234 & 10536 \\
\hline 1. Maximum anteroposterior diameter, proximal facet & 42 & 50 & 55 & 51 & 52 \\
2. Maximum transverse diameter, proximal facet & 24 & 27 & 33 & 32 & 29 \\
3. Maximum anteroposterior diameter, distal facet & 36 & 26 & 38 & 35 & 41 \\
4. Maximum transverse diameter, distal facet & 25 & 31 & 27 & 34 & 37 \\
5. Maximum proximodistal diameter & 42 & 48 & $52^{*}$ & 47 & 52 \\
\hline
\end{tabular}

* Approximate measurement.

TABle 51.-Measurements (mm) of the metatarsal III of North American glyptodonts

\begin{tabular}{|c|c|c|c|c|c|c|c|c|}
\hline \multirow{3}{*}{ Characters } & \multirow{3}{*}{$\begin{array}{c}\text { G. lexanum } \\
\text { F:AM } \\
95737 \\
\end{array}$} & \multicolumn{5}{|c|}{ G. arizonae } & \multirow{2}{*}{\multicolumn{2}{|c|}{$\frac{\text { G. floridanum }}{\text { USNM } 6071}$}} \\
\hline & & \multirow{2}{*}{$\begin{array}{c}\text { USNM } \\
10536\end{array}$} & \multirow{2}{*}{$\begin{array}{c}\text { UMMP } \\
38761\end{array}$} & \multirow{2}{*}{$\begin{array}{c}\text { UMMP } \\
46231\end{array}$} & \multirow{2}{*}{$\begin{array}{c}\text { UMMP } \\
46330 \\
\end{array}$} & \multirow{2}{*}{$\begin{array}{l}\text { UMMP } \\
46329\end{array}$} & & \\
\hline & & & & & & & left & right \\
\hline $\begin{array}{l}\text { 1. Maximum proximodistal } \\
\text { diameter from posterolat- } \\
\text { eral angle proximal facet to } \\
\text { posterior border distal facet }\end{array}$ & 42 & 58 & $51^{*}$ & $63^{*}$ & 60 & $60^{*}$ & 48 & 47 \\
\hline $\begin{array}{l}\text { 2. Minimum proximodistal di- } \\
\text { ameter, anteromedial angle } \\
\text { proximal facet to anterior } \\
\text { border distal facet }\end{array}$ & 20 & 28 & 25 & $27^{*}$ & 32 & 26 & 23 & 23 \\
\hline $\begin{array}{l}\text { 3. Anteroposterior diameter, } \\
\text { metatarsal II articular facet }\end{array}$ & 17 & 25 & $23^{*}$ & 26 & 30 & 30 & 22 & 21 \\
\hline $\begin{array}{l}\text { 4. Anteroposterior diameter, } \\
\text { metatarsal IV articular } \\
\text { facet }\end{array}$ & 19 & 25 & 27 & 32 & 37 & 31 & - & 25 \\
\hline $\begin{array}{l}\text { 5. Maximum transverse di- } \\
\text { ameter, cuneiform articular } \\
\text { facet }\end{array}$ & 33 & 53 & 46 & 49 & - & 56 & 46 & 45 \\
\hline $\begin{array}{l}\text { 6. Maximum transverse di- } \\
\text { ameter, proximal extremity }\end{array}$ & 43 & 58 & 56 & .61 & $60^{*}$ & 62 & 51 & 51 \\
\hline $\begin{array}{l}\text { 7. Maximum transverse di- } \\
\text { ameter, distal extremity }\end{array}$ & 33. & 45 & 41 & - & 42 & $49^{*}$ & 40 & 42 \\
\hline $\begin{array}{l}\text { 8. Maximum anteroposterior } \\
\text { diameter, distal facet (to tip } \\
\text { of sesamoid ridge) }\end{array}$ & 36 & 45 & $47^{*}$ & - & $52^{*}$ & 52 & 41 & 41 \\
\hline $\begin{array}{l}\text { 9. Maximum transverse di- } \\
\text { ameter, sesamoid articular } \\
\text { facets }\end{array}$ & 22 & 32 & $29^{*}$ & - & 34 & 36 & 30 & 31 \\
\hline $\begin{array}{l}\text { 10. Maximum proximodistal } \\
\text { diameter, sesamoid articu- } \\
\text { lar facets }\end{array}$ & 24 & 29 & $27^{*}$ & - & 29 & - & 27 & 26 \\
\hline $\begin{array}{l}\text { 11. Anteroposterior diameter, } \\
\text { proximal extremity sesa- } \\
\text { moid facets to anterior bor- } \\
\text { der proximal facet }\end{array}$ & 41 & 58 & 56 & 60 & $61 *$ & 59 & 52 & 52 \\
\hline
\end{tabular}

* Approximate measurement. 
TABLE 52.-Measurements ( $\mathrm{mm}$ ) of the metatarsal IV of North American glyptodonts

\begin{tabular}{|c|c|c|c|c|c|}
\hline \multirow[b]{2}{*}{ Characters } & \multirow{2}{*}{$\begin{array}{c}G . \text { texanum } \\
\text { F:AM } \\
95737 \\
\end{array}$} & \multicolumn{3}{|c|}{ G. arizonae } & \multirow{2}{*}{$\begin{array}{c}\text { G. floridanum } \\
\text { USNM } \\
6071 \\
\end{array}$} \\
\hline & & $\begin{array}{l}\text { USNM } \\
10536\end{array}$ & $\begin{array}{l}\text { UMMP } \\
46231\end{array}$ & $\begin{array}{l}\text { UMMP } \\
38761\end{array}$ & \\
\hline $\begin{array}{l}\text { 1. Maximum proximodistal diameter, posterolateral cor- } \\
\text { ner, proximal facet to posterolateral corner distal facet }\end{array}$ & 34 & 41 & 42 & 40 & 38 \\
\hline $\begin{array}{l}\text { 2. Maximum proximodistal diameter between anterior } \\
\text { borders of proximal and distal facets at anterolateral } \\
\text { angle }\end{array}$ & 23 & 35 & 38 & 34 & 29 \\
\hline 3. Maximum transverse diameter, cuneiform facet & 19 & 36 & 33 & 31 & 34 \\
\hline 4. Maximum anteroposterior diameter, cuneiform facet & 40 & 41 & 44 & 47 & 42 \\
\hline $\begin{array}{l}\text { 5. Maximum posterolateral/anteromedial diameter, } \\
\text { metatarsal III articular facet }\end{array}$ & 24 & 31 & $28^{*}$ & 32 & 26 \\
\hline $\begin{array}{l}\text { 6. Maximum anterolateral/posteromedial diameter, } \\
\text { metatarsal III articular facet }\end{array}$ & 21 & 25 & 25 & 24 & 20 \\
\hline $\begin{array}{l}\text { 7. Maximum anteroposterior diameter, metatarsal V ar- } \\
\text { ticular facet }\end{array}$ & 13 & 14 & 20. & 20 & $25^{*}$ \\
\hline $\begin{array}{l}\text { 8. Maximum anteroposterior diameter, distal articular } \\
\text { facet }\end{array}$ & 30 & 38 & - & - & 35 \\
\hline 9. Maximum transverse diameter, distal articular facet & 28 & 39 & $38^{*}$ & 36 & 36 \\
\hline 10. Maximum proximodistal diameter, sesamoid facet & 15 & 19 & $19^{*}$ & 17 & 22 \\
\hline $\begin{array}{l}\text { 11. Maximum oblique diameter, posterolateral tubercle } \\
\text { proximal extremity to anteromedial tubercle distal ex- } \\
\text { tremity }\end{array}$ & 47 & 60 & 67 & 65 & 57 \\
\hline $\begin{array}{l}\text { 12. Maximum transverse diameter, outer border meta- } \\
\text { tarsal III facet to metatarsal V facet }\end{array}$ & 32 & 46 & 50 & 46 & 45 \\
\hline
\end{tabular}

* Approximate measurement.

TABLE 53.-Measurements (mm) of the metatarsal $\mathrm{V}$ of North American glyptodonts

\begin{tabular}{l|cccc}
\hline \multirow{2}{*}{ Characters } & G. lexanum & \multicolumn{3}{c}{ G. arizonae } \\
\cline { 4 - 5 } & F:AM & USNM & UMMP & UMMP \\
& 95737 & 10536 & 46231 & 38761 \\
\hline 1. Maximum anteroposterior di- & 30 & 40 & 40 & 43 \\
$\begin{array}{l}\text { ameter } \\
\text { 2. Maximum transverse diameter }\end{array}$ & 20 & 33 & 35 & 34 \\
3. Maximum proximodistal diam- & 18 & 25 & 25 & 29 \\
eter & & & & \\
\hline
\end{tabular}


TABLE 54.-Measurements (mm) of the metatarsal sesamoids of North American glyptodonts

\begin{tabular}{c} 
Characters \\
\hline Sesamoid Bone, Metatarsal I
\end{tabular}

1. Maximum anteroposterior diameter

2. Maximum transverse diameter

3. Maximum proximodistal diameter

Medial Sesamoid Bone, Metatarsal II

1. Maximum anteroposterior diameter

2. Maximum transverse diameter

3. Maximum proximodistal diameter

Lateral Sesamoid Bone, Metatarsal II

1. Maximum anteroposterior diameter

2. Maximum transverse diameter

3. Maximum proximodistal diameter

Medial Sesamoid Bone, Metatarsal III

1. Maximum length articular facet

2. Maximum transverse diameter articular facet

3. Maximum proximodistal diameter

Lateral Sesamoid Bone, Metatarsal III

1. Maximum length articular facet

2. Maximum transverse diameter articular facet

3. Maximum proximodistal diameter

Medial Sesamoid Bone, Metatarsal IV

1. Maximum length articular facet

2. Maximum transverse diameter

3. Maximum anteroposterior diameter

Lateral Sesamoid Bone, Metatarsal IV

1. Maximum length articular facet

2. Maximum transverse diameter

3. Maximum anteroposterior diameter

\begin{tabular}{|cccc} 
G. texanum & \multicolumn{3}{c}{ G. arizonae } \\
\cline { 2 - 4 } F:AM & USNM & UMMP & UMMP \\
95737 & 10536 & 38761 & 46231 \\
\hline & & &
\end{tabular}

11

13

24

24

9

15

24

12

26

26

11

25

27

12

25

16
23
36

23

18

31

36

$$
-
$$

17

10

18

30

13

$$
27
$$

2
2
6

29

29

.

17

31

16

31

43

34

6

30
16

28

30

$$
31
$$

$29 ; 29 * \quad 35$

12

17

; 15

19

$25 \quad 30 \quad 31 \div 33$

$\begin{array}{rrrr}14 & 17 & 14 & 17 \\ 8 & 11 & 11 & 15 \\ 21 & 24 & 29 & 33\end{array}$

Sesamoid Bone, Metatarsal V

1. Maximum anteroposterior diameter

2. Maximum transverse diameter

3. Maximum proximodistal diameter

\footnotetext{
* Approximate measurement.
} 
TABLE 55.-Measurements ( $\mathrm{mm}$ ) of the phalanges I and II, digit I, pes, of North American glyptodonts

\begin{tabular}{|c|c|c|c|c|}
\hline \multirow[b]{2}{*}{ Characters } & \multirow{2}{*}{$\begin{array}{c}\text { G. texanum } \\
\text { F:AM } \\
95737 \\
\end{array}$} & \multicolumn{3}{|c|}{ G. arizonae } \\
\hline & & $\begin{array}{c}\text { USNM } \\
10536\end{array}$ & $\begin{array}{c}\text { UMMP } \\
46231 \\
\end{array}$ & $\begin{array}{l}\text { UMMP } \\
38761\end{array}$ \\
\hline Phalanx I & & & & \\
\hline $\begin{array}{l}\text { 1. Maximum anteroposterior } \\
\text { diameter }\end{array}$ & 21 & 37 & 40 & 27 \\
\hline $\begin{array}{l}\text { 2. Maximum transverse } \\
\text { diameter }\end{array}$ & 17 & 32 & 25 & 23 \\
\hline $\begin{array}{l}\text { 3. Maximum proximodistal } \\
\text { diameter }\end{array}$ & 17 & 22 & 20 & 22 \\
\hline \multicolumn{5}{|l|}{ Phalanx II } \\
\hline $\begin{array}{l}\text { 1. Maximum anteroposterior } \\
\text { diameter }\end{array}$ & 17 & 22 & 56 & 52 \\
\hline $\begin{array}{l}\text { 2. Maximum transverse } \\
\text { diameter }\end{array}$ & 29 & 50 & 23 & 24 \\
\hline $\begin{array}{l}\text { 3. Maximum proximodistal } \\
\text { diameter }\end{array}$ & 34 & 60 & 58 & 65 \\
\hline
\end{tabular}

TABLE 56.-Measurements ( $\mathrm{mm}$ ) of the phalanges I and II, digit II, pes, of North American glyptodonts

\begin{tabular}{|c|c|c|c|c|}
\hline \multirow[b]{2}{*}{ Characters } & \multirow{2}{*}{$\begin{array}{c}\text { G. texanum } \\
\text { F:AM } \\
95737 \\
\end{array}$} & \multicolumn{3}{|c|}{ G. arizonae } \\
\hline & & $\begin{array}{l}\text { UMMP } \\
38761\end{array}$ & $\begin{array}{l}\text { UMMP } \\
46231\end{array}$ & $\begin{array}{c}\text { USNM } \\
10536 \\
\end{array}$ \\
\hline Phalanx I & & & " & \\
\hline $\begin{array}{l}\text { 1. Maximum anteroposterior di- } \\
\text { ameter, proximal facet }\end{array}$ & 30 & 29 & $28^{*}$ & 40 \\
\hline $\begin{array}{l}\text { 2. Maximum transverse diameter, } \\
\text { proximal facet }\end{array}$ & 25 & 31 & 42 & 34 \\
\hline $\begin{array}{l}\text { 3. Maximum anteroposterior di- } \\
\text { ameter, distal facet }\end{array}$ & 24 & $34^{*}$ & $29^{*}$ & 32 \\
\hline $\begin{array}{l}\text { 4. Maximum transverse diameter, } \\
\text { distal facet }\end{array}$ & 26 & 35 & 47 & 36 \\
\hline $\begin{array}{l}\text { 5. Maximum proximodistal diam- } \\
\text { eter }\end{array}$ & 18 & 22 & 31 & 23 \\
\hline Phalanx II & & & & \\
\hline $\begin{array}{l}\text { 1. Maximum anteroposterior di- } \\
\text { ameter, proximal facet }\end{array}$ & 21 & - & - & 29 \\
\hline $\begin{array}{l}\text { 2. Maximum transverse diameter, } \\
\text { proximal facet }\end{array}$ & 27 & 34 & 47 & 36 \\
\hline $\begin{array}{l}\text { 3. Maximum anteroposterior di- } \\
\text { ameter, distal facet }\end{array}$ & 21 & - & - & 27 \\
\hline $\begin{array}{l}\text { 4. Maximum transverse diameter, } \\
\text { distal facet }\end{array}$ & 25 & 39 & 45 & 36 \\
\hline $\begin{array}{l}\text { 5. Maximum proximodistal diam- } \\
\text { eter }\end{array}$ & 13 & 23 & $20^{*}$ & 20 \\
\hline
\end{tabular}

* Approximate measurement. 
TABLE 57.-Measurements ( $\mathrm{mm}$ ) of the ungual phalanx, digit II, pes, of North American glyptodonts

\begin{tabular}{l|ccc}
\hline \multicolumn{1}{c|}{ Characters } & G. texanum & \multicolumn{2}{c}{ G. arizonae } \\
\cline { 3 - 4 } & F:AM & USNM & UMMP \\
& 95737 & 10536 & 38761 \\
\hline 1. Maximum transverse diameter & 47 & 66 & 50 \\
2. Maximum transverse diameter, articular facet & 30 & 39 & 36 \\
3. Maximum anteroposterior diameter & 23 & 28 & 49 \\
4. Maximum anteroposterior diametèr, articular & 19 & 26 & $30^{*}$ \\
facet & & 67 & 72 \\
5. Maximum proximodistal diameter & 47 & 66 & 7 \\
\hline
\end{tabular}

* Approximate measurement.

TABLE 58.-Measurements (mm) of the phalanges I and II, digit III, pes, of North American glyptodonts

\begin{tabular}{|c|c|c|c|c|}
\hline \multirow[b]{2}{*}{ Characters } & \multirow{2}{*}{$\begin{array}{c}\text { G. texanum } \\
\text { F:AM } \\
95737 \\
\end{array}$} & \multicolumn{2}{|c|}{ G. arizonae } & \multirow{2}{*}{$\begin{array}{c}\text { G. floridanum } \\
\text { USNM } \\
6071\end{array}$} \\
\hline & & $\begin{array}{c}\text { USNM } \\
10536\end{array}$ & $\begin{array}{l}\text { UMMP } \\
38761\end{array}$ & \\
\hline \multicolumn{5}{|l|}{ Phalanx I } \\
\hline 1. Maximum transverse diameter, proximal facet & 29 & 41 & 42 & 31 \\
\hline 2. Maximum anteroposterior diameter, proximal extremity & 36 & 41 & 44 & 34 \\
\hline 3. Maximum transverse diameter, distal facet & 32 & 42 & 43 & 31 \\
\hline $\begin{array}{l}\text { 4. Maximum anteroposterior diameter, distal extremity through } \\
\text { tubercles }\end{array}$ & 36 & 45 & 48 & 38 \\
\hline 5. Maximum proximodistal diameter, anterior border & 17 & 24 & 23 & 20 \\
\hline 6. Maximum proximodistal diameter, posterior border & 11 & 16 & $11^{*}$ & 11 \\
\hline \multicolumn{5}{|l|}{ Phalanx II } \\
\hline 1. Maximum transverse diameter, proximal facet & 31 & 44 & 42 & \\
\hline 2. Maximum anteroposterior diameter, proximal extremity & 24 & 32 & 36 & \\
\hline 3. Maximum transverse diameter, distal facet & 31 & 43 & 42 & \\
\hline $\begin{array}{l}\text { 4. Maximum anteroposterior diameter, distal extremity through } \\
\text { tubercles }\end{array}$ & 21 & 29 & 27 & \\
\hline 5. Minimum proximodistal diameter, anterior border & 4 & 7 & 3 & \\
\hline 6. Maximum proximodistal diameter, posterior border & 14 & 23 & $22^{-}$ & \\
\hline
\end{tabular}

* Approximate measurement.

TABlE 59.-Measurements ( $\mathrm{mm}$ ) of the ungual phalanx, digit III, pes, of North American glyptodonts

\begin{tabular}{l|ccc}
\hline \multicolumn{1}{c|}{ Characters } & $\begin{array}{c}\text { G. texanum } \\
\text { F:AM } \\
95737\end{array}$ & $\begin{array}{c}\text { G. arizonae } \\
\text { USNM } \\
10536\end{array}$ & $\begin{array}{c}\text { G. floridanum } \\
\text { USNM } \\
6071\end{array}$ \\
\hline $\begin{array}{l}\text { 1. Maximum transverse diameter } \\
\text { 2. Maximum transverse diameter, articular }\end{array}$ & 40 & 70 & 62 \\
facet & 32 & 48 & 43 \\
3. Maximum anteroposterior diameter & 35 & 46 & 44 \\
4. Maximum anteroposterior diameter, articu- & 22 & 27 & 27 \\
lar facet & 48 & 58 & 62 \\
5. Maximum proximodistal diameter & 23 & 39 & 34 \\
6. Minimum inside diameter between subun- & & & \\
gual foramina & & & \\
\hline
\end{tabular}


TABLE 60.-Measurements ( $\mathrm{mm}$ ) of the phalanges I and II, digit IV, pes, of North American glyptodonts

\begin{tabular}{|c|c|c|c|c|}
\hline \multirow[b]{2}{*}{ Characters } & \multirow{2}{*}{$\begin{array}{c}\text { G. lexanum } \\
\text { F:AM } \\
95737\end{array}$} & \multicolumn{3}{|c|}{ G. arizonae } \\
\hline & & $\begin{array}{c}\text { USNM } \\
10536\end{array}$ & $\begin{array}{c}\text { UMMP } \\
46231\end{array}$ & $\begin{array}{c}\text { UMMP } \\
38761\end{array}$ \\
\hline \multicolumn{5}{|l|}{ Phalanx I } \\
\hline 1. Proximodistal diameter, anteromedial border & 9 & 14 & 14 & 13 \\
\hline 2. Maximum transverse diameter, proximal facet & 23 & 36 & 41 & 37 \\
\hline 3. Maximum anteroposterior diameter, proximal facet & 30 & 36 & - & - \\
\hline 4. Maximum transverse diameter, distal facet & 26 & 42 & 39 & 35 \\
\hline 5. Maximum anteroposterior diameter, distal facet & 24 & - & - & - \\
\hline 6. Maximum anteroposterior diameter through tubercles & 32 & 39 & 42 & 38 \\
\hline \multicolumn{5}{|l|}{ Phalanx II } \\
\hline 1. Minimum proximodistal diameter, anterior border & 4 & 5 & 6 & 5 \\
\hline 2. Maximum transverse diameter, proximal facet & 25 & 37 & 37 & 33 \\
\hline 3. Maximum anteroposterior diameter, proximal facet & 21 & 28 & - & - \\
\hline 4. Maximum transverse diameter, distal facet & 27 & 39 & 35 & 35 \\
\hline 5. Maximum anteroposterior diameter, distal facet & 21 & 24 & - & - \\
\hline 6. Maximum anteroposterior diameter through tubercles & 23 & 28 & 31 & 30 \\
\hline 7. Maximum proximodistal diameter, lateral side & 11 & 19 & 17 & 16 \\
\hline 8. Maximum proximodistal diameter, medial side & 9 & 19 & 19 & 18 \\
\hline
\end{tabular}

TABLE 61.-Measurements (mm) of the ungual phalanx, digit IV, pes, of North American glyptodonts

\begin{tabular}{|c|c|c|c|c|c|}
\hline \multirow[b]{2}{*}{ Characters } & \multirow{2}{*}{$\begin{array}{c}\text { G. texanum } \\
\text { F:AM } \\
95737 \\
\end{array}$} & \multicolumn{3}{|c|}{ G. arizonae } & \multirow{2}{*}{$\begin{array}{c}\text { G. floridanum } \\
\text { USNM } \\
6071 \\
\end{array}$} \\
\hline & & $\begin{array}{c}\text { USNM } \\
10536 \\
\end{array}$ & $\begin{array}{l}\text { UMMP } \\
46231^{*}\end{array}$ & $\begin{array}{l}\text { UMMP } \\
38761\end{array}$ & \\
\hline $\begin{array}{l}\text { 1. Maximum proximodistal di- } \\
\text { ameter, medial border }\end{array}$ & 48 & 62 & 57 & 65 & 63 \\
\hline $\begin{array}{l}\text { 2. Maximum transverse diam- } \\
\text { eter, proximal extremity }\end{array}$ & 45 & 59 & 56 & 58 & 65 \\
\hline $\begin{array}{l}\text { 3. Maximum transverse diam- } \\
\text { eter, proximal facet }\end{array}$ & 27 & 36 & 32 & 33 & 39 \\
\hline $\begin{array}{l}\text { 4. Maximum anteroposterior } \\
\text { diameter, proximal facet }\end{array}$ & 18 & 22 & 23 & 25 & 26 \\
\hline $\begin{array}{l}\text { 5. Maximum anteroposterior } \\
\text { diameter, ungual hood }\end{array}$ & 38 & 46 & 52 & 46 & 45 \\
\hline
\end{tabular}

* Pathologic: degenerative resorption. 
TABLE 62.-Measurements ( $\mathrm{mm}$ ) of the phalanges I and II, digit V, pes, of North American glyptodonts

\begin{tabular}{l|cccc}
\hline & G. texanum & \multicolumn{3}{c}{ G. arizonae } \\
\cline { 3 - 5 } Characters & F:AM & USNM & UMMP & UMMP \\
& 95737 & 10536 & 46231 & 38761 \\
\hline Phalanx I & & & & \\
1. Maximum anteroposterior diameter & 19 & 23 & 34 & 32 \\
2. Maximum transverse diameter & 25 & 30 & 28 & 28 \\
3. Maximum proximodistal diameter & 8 & 10 & 11 & 10 \\
$\quad$ Phalanx II & & & & \\
1. Maximum anteroposterior diameter & 16 & 21 & 21 & 23 \\
2. Maximum transverse diameter & 20 & 28 & 28 & 28 \\
3. Maximum proximodistal diameter & 8 & 16 & 14 & 15 \\
\hline
\end{tabular}

TABLE 63.-Measurements (mm) of the ungual phalanx, digit $\mathrm{V}$, pes, of North American glyptodonts

\begin{tabular}{|c|c|c|c|c|c|c|}
\hline \multirow{3}{*}{ Characters } & \multirow{3}{*}{$\begin{array}{c}\text { G. lexanum } \\
\text { F:AM } \\
95737 \\
\end{array}$} & \multicolumn{3}{|c|}{ G. arizonae } & \multirow{2}{*}{\multicolumn{2}{|c|}{$\begin{array}{l}\text { G. floridanum } \\
\text { USNM } 6071 \\
\end{array}$}} \\
\hline & & \multirow{2}{*}{$\begin{array}{c}\text { USNM } \\
10536\end{array}$} & \multirow{2}{*}{$\begin{array}{l}\text { UMMP } \\
46231\end{array}$} & \multirow{2}{*}{$\begin{array}{c}\text { UMMP } \\
38761\end{array}$} & & \\
\hline & & & & & left & right \\
\hline $\begin{array}{l}\text { 1. Maximum anteroposte- } \\
\text { rior diameter* }\end{array}$ & 37 & 57 & 61 & 53 & 48 & 39 \\
\hline $\begin{array}{l}\text { 2. Maximum transverse di- } \\
\text { ameter* }\end{array}$ & 22 & 40 & 52 & 45 & 40 & 36 \\
\hline $\begin{array}{l}\text { 3. Maximum proximodistal } \\
\text { diameter }\end{array}$ & 31 & 56 & 59 & 50 & 54 & 53 \\
\hline
\end{tabular}

* Anteroposterior and transverse diameters are ontogenetic references corresponding to transverse and anteroposterior diameters in anatomical reference, respectively. 
Table 64.-Measurements ( $\mathrm{mm}$ ) of the distal digital sesamoid bones, pes, of North American glyptodonts

Characters
Digit I
1. Maximum anteroposterior diameter
2. Maximum transverse diameter
3. Maximum proximodistal diameter

Digit II

1. Maximum anteroposterior diameter

2. Maximum transverse diameter

3. Maximum proximodistal diameter

\section{Digit III}

1. Maximum anteroposterior diameter

2. Maximum transverse diameter

3. Maximum proximodistal diameter

\section{Digit IV}

1. Maximum anteroposterior diameter

2. Maximum transverse diameter

3. Maximum proximodistal diameter

\section{Digit V}

1. Maximum anteroposterior diameter

2. Maximum transverse diameter

3. Maximum proximodistal diameter
G. Lexanum G. arizonae

F:AM USNM UMMP UMMP

$\begin{array}{llll}95737 & 10536 & 38761 & 46231\end{array}$

$\begin{array}{rlll}9 & & & \\ 13 & - & 29^{*} & 14 \\ 11 & - & 28 & 17 \\ & & & 20\end{array}$

$\begin{array}{llll}13 & - & 18^{*} & - \\ 24 & - & 28 & - \\ 13 & - & 19 & -\end{array}$

$14 \quad-\quad 24$

$29 \quad-\quad 44$

$11 \quad 13$

$\begin{array}{lcll}12 & 18 & 18 & 16 \\ 23 & - & 39 & 39 \\ 12 & 12 & 13^{*} & 17\end{array}$

* Approximate measurement. 
TABLE 65.-Measurements ( $\mathrm{mm}$ ) of the caudal vertebrae of Glyptotherium texanum holotype

AMNH 10704

\begin{tabular}{|c|c|c|c|c|c|c|c|c|c|c|c|c|c|}
\hline Characters/Axes & 1 & 2 & 3 & 4 & 5 & 6 & 7 & 8 & 9 & 10 & $11^{\mathrm{a}}$ & $12^{a}$ & $13^{\mathrm{a}}$ \\
\hline $\begin{array}{l}\text { 1. Anteroposterior diameter through } \\
\text { centrum at base (a-axis) }\end{array}$ & 62 & 54 & 57 & 60 & 63 & 64 & 65 & 66 & 64 & - & - & 56 & 53 \\
\hline $\begin{array}{l}\text { 2. Maximum transverse diameter, cen- } \\
\text { trum anterior extremity (b-axis) }\end{array}$ & 62 & 57 & 53 & 56 & 50 & 47 & 45 & 43 & 37 & 33 & - & - & - \\
\hline $\begin{array}{l}\text { 3. Maximum dorsoventral diameter, } \\
\text { centrum anterior extremity (c-axis) }\end{array}$ & 43 & 45 & 50 & 50 & 49 & 46 & 43 & 41 & 39 & 35 & - & - & - \\
\hline $\begin{array}{l}\text { 4. Maximum transverse diameter, cen- } \\
\text { trum posterior extremity (d-axis) }\end{array}$ & 68 & 67 & 64 & 57 & 52 & 50 & 48 & 45 & 41 & - & - & - & - \\
\hline $\begin{array}{l}\text { 5. Maximum dorsoventral diameter, } \\
\text { centrum posterior extremity (e-axis) }\end{array}$ & 53 & 54 & 54 & 54 & 48 & 47 & 46 & 43 & 40 & - & - & - & - \\
\hline $\begin{array}{l}\text { 6. Maximum transverse diameter be- } \\
\text { tween angles of transverse processes } \\
\text { (f-axis) }\end{array}$ & 318 & 287 & $261^{b}$ & $202^{b}$ & 164 & $135^{\mathrm{b}}$ & $116^{\mathrm{b}}$ & - & 80 & 63 & - & - & - \\
\hline $\begin{array}{l}\text { 7. Maximum transverse diameter, an- } \\
\text { terior xenarthral processes (g-axis) }\end{array}$ & 52 & 77 & 80 & 82 & 71 & 72 & 56 & 50 & 50 & 31 & 26 & 19 & - \\
\hline $\begin{array}{l}\text { 8. Maximum transverse diameter, pos- } \\
\text { terior xenarthral processes (h-axis) }\end{array}$ & 35 & 38 & 39 & 33 & 27 & 20 & 11 & 9 & - & - & - & - & - \\
\hline $\begin{array}{l}\text { 9. Maximum dorsoventral diameter, } \\
\text { chevron (i-axis) }\end{array}$ & - & - & - & - & - & 53 & 39 & 27 & 26 & - & - & - & - \\
\hline $\begin{array}{l}\text { 10. Anteroposterior diameter, chevron } \\
\text { through articular facet ( } \mathrm{j} \text {-axis) }\end{array}$ & - & - & - & - & - & $\begin{array}{l}28 \\
2\end{array}$ & 30 & 35 & 36 & - & - & - & - \\
\hline $\begin{array}{l}\text { 11. Anteroposterior diameter, xenarthral } \\
\text { arch, midline (k-axis) }\end{array}$ & 55 & 56 & 57 & 57 & 67 & 73 & 70 & 70 & 58 & - & - & - & - \\
\hline
\end{tabular}

a Centrum reconstructed.

${ }^{\mathrm{b}}$ Tips restored, measurements include restoration. 
TABLE 66.-Measurements ( $\mathrm{mm}$ ) of the caudal vertebrae of Glyptotherium lexanum, F:AM 95737 (axes as defined in Table 65)

\begin{tabular}{l|rrrrrrrrrrrrr}
\hline Axes & 1 & 2 & 3 & 4 & 5 & 6 & 7 & 8 & 9 & 10 & 11 & 12 & 13 \\
\hline 1. a-axis & 57 & 58 & 64 & 64 & 65 & 64 & 62 & 60 & 59 & 58 & 1 & 123 & -1 \\
2. b-axis & 62 & - & - & 54 & 56 & 49 & 45 & 42 & 38 & 34 & 28 & - & - \\
3. c-axis & 44 & - & - & 45 & 44 & 42 & 42 & 38 & 36 & 31 & 25 & - & - \\
4. d-axis & 64 & - & - & 57 & 53 & 49 & 45 & 41 & 35 & 29 & - & - & - \\
5. e-axis & 50 & - & - & 46 & 45 & 45 & 43 & 41 & 35 & 29 & - & - & - \\
6. f-axis & 267 & 236 & 212 & 169 & 151 & 124 & 97 & 80 & 66 & 48 & - & - & - \\
7. g-axis & 64 & 69 & 71 & 73 & 68 & $63^{*}$ & 48 & 43 & 35 & 29 & - & - & - \\
8. h-axis & 43 & 41 & 40 & 33 & 27 & 23 & - & - & - & - & - & - & - \\
9. i-axis & -1 & 109 & 91 & 79 & 67 & 51 & 38 & 37 & 27 & 30 & 30 & 9 & - \\
10. j-axis & - & 20 & 25 & 21 & 22 & 24 & 26 & 31 & 36 & 21 & 21 & 26 & - \\
11. k-axis & 48 & 46 & 53 & 59 & - & $72^{*}$ & 61 & - & - & - & - & - & - \\
\hline
\end{tabular}

* Approximate measurement.

TABLE 67.-Measurements ( $\mathrm{mm}$ ) of the caudal vertebrae of Glyptotherium arizonae, UMMP 34826 (axes as defined in Table 65)

\begin{tabular}{l|rrrrrrrrrrrrr}
\hline Axes & 1 & \multicolumn{1}{c}{2} & \multicolumn{1}{c}{3} & \multicolumn{1}{c}{4} & \multicolumn{1}{c}{5} & \multicolumn{1}{c}{6} & \multicolumn{1}{c}{7} & 8 & 9 & 10 & 11 & 12 & 13 \\
\hline 1. a-axis & 77 & 80 & 84 & 85 & 89 & 92 & 90 & 88 & 86 & 81 & 82 & 75 & 85 \\
2. b-axis & 79 & 73 & 71 & 66 & 64 & 58 & 59 & 54 & 52 & 51 & 43 & 34 & 27 \\
3. c-axis & 55 & 63 & 66 & 65 & 64 & 63 & 61 & 54 & 53 & 47 & 43 & 36 & 32 \\
4. d-axis & 92 & 85 & 81 & 74 & 74 & 66 & 63 & 59 & 53 & 48 & 39 & 29 & 21 \\
5. e-axis & 66 & 65 & 65 & 64 & 63 & 63 & 58 & 55 & 52 & 42 & 38 & 27 & 20 \\
6. f-axis & 400 & 380 & 370 & 300 & 200 & 171 & 142 & 112 & 106 & 95 & 76 & 52 & - \\
7. g-axis & 91 & 112 & 133 & 137 & 111 & 107 & 89 & 79 & 66 & 55 & 42 & 28 & 21 \\
8. h-axis & 55 & 55 & 66 & 53 & 50 & 45 & 39 & 33 & 27 & - & - & - & - \\
9. i-axis & - & 168 & 138 & 115 & 89 & 77 & 56 & 43 & 31 & 25 & 19 & 21 & - \\
10. j-axis & - & 34 & 33 & 34 & 32 & 31 & 26 & 23 & 20 & 20 & 22 & 22 & - \\
11. k-axis & 74 & 79 & 85 & 88 & 90 & 97 & 106 & - & - & - & - & - & - \\
\hline
\end{tabular}


TABLE 68.-Measurements ( $\mathrm{mm}$ ) of the caudal vertebrae of Glyptotherium floridanum (axes as defined in Table 65)

\begin{tabular}{|c|c|c|c|c|c|c|c|c|c|c|c|c|}
\hline Axes & 1 & 2 & 3 & 4 & 5 & 6 & 7 & 8 & 9 & 10 & 11 & 12 \\
\hline \multicolumn{13}{|c|}{ TMM 30967-1926 } \\
\hline 1. a-axis & 63 & 71 & 76 & 80 & 82 & 81 & & & & & & \\
\hline 2. b-axis & 67 & 66 & 65 & 64 & 60 & 56 & & & & & & \\
\hline 3. c-axis & 62 & 63 & 63 & 39 & 57 & 52 & & & & & & \\
\hline 4. d-axis & 78 & 73 & 68 & 63 & 64 & 59 & & & & & & \\
\hline 5. e-axis & 64 & 62 & 61 & 58 & 54 & 51 & & & & & & \\
\hline \multicolumn{13}{|c|}{ USNM $6071^{\mathrm{c}}$} \\
\hline 1. a-axis & & & & & 67 & 75 & 78 & 82 & 82 & 82 & & \\
\hline 2. b-axis & & & & & 65 & 56 & 59 & - & 56 & 46 & & \\
\hline 3. c-axis & & & & & 64 & 58 & 57 & - & 48 & 38 & & \\
\hline 4. d-axis & & & & & - & 61 & 59 & - & 45 & 41 & & \\
\hline 5. e-axis & & & & & 60 & 60 & - & - & 55 & 38 & & \\
\hline 6. f-axis & & & & & - & $240^{b}$ & $175^{b}$ & - & - & - & & \\
\hline \multicolumn{13}{|c|}{ USNM 10537} \\
\hline 1. a-axis & $67^{\mathrm{b}}$ & 69 & 78 & 74 & 81 & 82 & 80 & 78 & 78 & 77 & 73 & \\
\hline 2. b-axis & 76 & 66 & 68 & 64 & 60 & 58 & 52 & 48 & 47 & 42 & 34 & \\
\hline 3. c-axis & 65 & 64 & 67 & 64 & 65 & 58 & 59 & - & - & - & 34 & \\
\hline 4. d-axis & 77 & 77 & 80 & 77 & 62 & 58 & 55 & 49 & 44 & 34 & 29 & \\
\hline 5. e-axis & $68^{\mathrm{b}}$ & 65 & 63 & 67 & 63 & 56 & 55 & 51 & - & 35 & 34 & \\
\hline 6. f-axis & 372 & 346 & $320^{b}$ & 219 & 167 & 136 & 101 & 78 & - & - & - & \\
\hline 7. g-axis & - & - & 122 & 118 & 102 & 97 & 75 & 55 & 46 & 40 & 27 & \\
\hline 8. h-axis & $49^{b}$ & $54^{\mathrm{b}}$ & 56 & 40 & 30 & 21 & 12 & 8 & - & - & - & \\
\hline 9. i-axis & - & $170^{\mathrm{b}}$ & $120^{b}$ & $95^{b}$ & $80^{b}$ & $70^{b}$ & $50^{b}$ & $25^{b}$ & $20^{b}$ & $18^{\mathrm{b}}$ & $15^{b}$ & \\
\hline 10. $\mathrm{j}$-axis & - & 28 & 24 & 30 & 28 & 23 & - & - & - & - & - & \\
\hline 11. $\mathrm{k}$-axis & $68^{b}$ & 67 & 69 & 78 & $100^{b}$ & 105 & 98 & 62 & - & - & - & \\
\hline \multicolumn{13}{|c|}{ AMNH 21808} \\
\hline 1. a-axis & 69 & 69 & 75 & 77 & 83 & 85 & 86 & 81 & 84 & 84 & 66 & $39^{b}$ \\
\hline 2. b-axis & 79 & 67 & - & - & - & - & - & - & 50 & 43 & 27 & a \\
\hline 3. c-axis & 47 & - & - & - & - & - & - & - & 45 & 34 & 31 & a \\
\hline 4. d-axis & 70 & - & - & - & - & - & - & 53 & 44 & 31 & a & - \\
\hline 5. e-axis & 50 & - & - & - & - & - & - & 89 & 37 & 33 & a & - \\
\hline 6. $\mathrm{f}$-axis & $440^{\mathrm{b}}$ & $400^{b}$ & 320 & 260 & 200 & 150 & 120 & 110 & - & - & - & - \\
\hline 7. g-axis & 54 & 81 & 119 & 116 & 100 & 94 & - & - & - & - & - & - \\
\hline 8. h-axis & 46 & 59 & 52 & 45 & 36 & - & - & - & - & - & - & - \\
\hline 9. $\mathrm{i}$-axis & - & - & - & 98 & 85 & - & - & 40 & 33 & 19 & 17 & - \\
\hline 10. $\mathrm{j}$-axis & 17 & 38 & - & 26 & $35^{b}$ & - & - & 55 & 36 & 28 & 25 & - \\
\hline 11. $\mathrm{k}$-axis & 66 & 66 & 67 & 78 & 89 & - & - & - & - & - & - & - \\
\hline
\end{tabular}

${ }^{\text {a }}$ Fused.

${ }^{\text {b }}$ Approximate measurement.

${ }^{\mathrm{c}}$ Position of vertebrae 5-10 questionable; see text for discussion. 
TABLE 69.-Measurements $(\mathrm{mm})$ and numbers of scutes of the carapace of North American glyptodonts

\begin{tabular}{|c|c|c|c|c|c|c|c|}
\hline \multirow[b]{2}{*}{ Characters } & \multicolumn{2}{|c|}{ G. texanum } & \multicolumn{2}{|c|}{ G. arizonae } & \multirow{2}{*}{$\begin{array}{l}\text { G. cylindricum } \\
\text { AMNH } \\
15548\end{array}$} & \multirow{2}{*}{$\begin{array}{l}\text { G. mexicanum } \\
\text { type }\end{array}$} & \multirow{2}{*}{$\begin{array}{l}\text { G. floridanum } \\
\text { TMM } 9773 \\
\text { (restored) }\end{array}$} \\
\hline & $\begin{array}{l}\text { AMNH } \\
10704\end{array}$ & $\begin{array}{l}\text { F:AM } \\
59599\end{array}$ & $\begin{array}{l}\text { USNM } \\
10537 / \\
10336\end{array}$ & $\begin{array}{l}\text { AMNH } \\
21808\end{array}$ & & & \\
\hline $\begin{array}{l}\text { 1. Anteroposterior length } \\
\text { along dorsal curvature }\end{array}$ & 1450 & 1440 & 1750 & 1900 & 1700 & $1830^{c}$ & 1800 \\
\hline $\begin{array}{l}\text { 2. Maximum transverse } \\
\text { half-circumference (mar- } \\
\text { ginal to marginal) }\end{array}$ & $1860^{a}$ & $1920^{a}$ & 2150 & $2300^{b}$ & 2480 & $2400^{c}$ & 3600 \\
\hline $\begin{array}{l}\text { 3. Number border scutes } \\
\text { along caudal aperture }\end{array}$ & 28 & 23 & 16 & 31 & 35 & $24^{d}$ & - \\
\hline $\begin{array}{l}\text { 4. Number border scutes, } \\
\text { nuchal scute to posterior } \\
\text { notch }\end{array}$ & 56 & 54 & 34 & 47 & 54 & $48^{d}$ & - \\
\hline $\begin{array}{l}\text { 5. Transverse diameter, ce- } \\
\text { phalic aperture }\end{array}$ & $\begin{array}{r}600^{a} \\
( \pm 200)\end{array}$ & - & $350^{\mathrm{a}}$ & $300^{a}$ & 450 & - & - \\
\hline $\begin{array}{l}\text { 6. Transverse diameter, } \\
\text { caudal aperture }\end{array}$ & $\begin{array}{r}300^{a} \\
( \pm 200)\end{array}$ & - & 420 & - & 700 & - & - \\
\hline $\begin{array}{l}\text { 7. Number scutes, maxi- } \\
\text { mum transverse count }\end{array}$ & 56 & - & - & 50 & 63 & - & - \\
\hline $\begin{array}{l}\text { 8. Number scutes along dor- } \\
\text { sal arch maximum count }\end{array}$ & 33 & - & 35 & 36 & 36 & - & - \\
\hline
\end{tabular}

approximate measurement.

${ }^{b}$ Laterally compressed in free mount; if properly restored, this measurement would be an estimated $300 \mathrm{~mm}$ larger.

c From Cuatáparo and Ramirez (1875).

d From Brown (1912). 
TABLE 70.-Measurements (mm) of the caudal armor of North American glyptodonts

\begin{tabular}{|c|c|c|c|c|c|c|c|}
\hline Species & Ring & Vertebra & $\begin{array}{l}\text { Average } \\
\text { inside } \\
\text { diameter }\end{array}$ & Species & Ring & Vertebra & $\begin{array}{c}\text { Average } \\
\text { inside } \\
\text { diameter }\end{array}$ \\
\hline \multicolumn{8}{|l|}{ Glyptotherium texanum } \\
\hline \multirow[t]{10}{*}{ AMNH 10704} & 1 & 4 & - & AMNH 21808 & 1 & 2 & - \\
\hline & 2 & 5 & 210 & & 2 & 3 & 365 \\
\hline & 3 & 6 & 170 & & 3 & 4 & 315 \\
\hline & 4 & 7 & 150 & & 4 & 5 & 260 \\
\hline & 5 & 8 & 130 & & 5 & 6 & 230 \\
\hline & 6 & 9 & 110 & & 6 & 7 & 190 \\
\hline & 7 & 10 & 90 & & 7 & 8 & 155 \\
\hline & 8 & 11 & 75 & & 8 & 9 & 130 \\
\hline & 9 & 12 & 55 & & 9 & 10 & 100 \\
\hline & 10 & $13 / 14$ & 40 & & $10 / 11$ & $11 / 12$ & - \\
\hline \multirow[t]{10}{*}{ F:AM 95737} & 1 & 2 & 190 & UMMP 34826 & 1 & 2 & - \\
\hline & 2 & 3 & 210 & & 2 & 3 & 380 \\
\hline & 3 & 4 & 190 & & 3 & 4 & 300 \\
\hline & 4 & 5 & 160 & & 4 & 5 & 240 \\
\hline & 5 & 6 & 130 & & 5 & 6 & 210 \\
\hline & 6 & 7 & 120 & & 6 & 7 & 170 \\
\hline & 7 & 8 & 100 & & 7 & 8 & 120 \\
\hline & 8 & 9 & 75 & & 8 & 9 & 110 \\
\hline & 9 & 10 & 65 & & 9 & 10 & 90 \\
\hline & 10 & $11 / 12 / 13$ & 45 & & 10 & 11 & 70 \\
\hline \multirow{11}{*}{$\begin{array}{l}\text { Glyplotherium arizonae } \\
\text { USNM } 10537\end{array}$} & & & & & 11 & 12 & 40 \\
\hline & 1 & 2 & - & & 12 & 13 & 30 \\
\hline & 2 & 3 & 310 & Glyptotherium floridanum & & & \\
\hline & 3 & 4 & $270^{*}$ & TMM 977-3 & 1 & 3 & - \\
\hline & 4 & 5 & 240 & & 2 & 4 & 280 \\
\hline & 5 & 6 & 200 & & 3 & 5 & 270 \\
\hline & 6 & 7 & 180 & & 4 & 6 & 260 \\
\hline & 7 & 8 & - & & 5 & 7 & 250 \\
\hline & 8 & 9 & - & & 6 & 8 & 220 \\
\hline & 9 & 10 & - & & 7 & 9 & 210 \\
\hline & $10 / 11$ & $11 / 12$ & - & & & & \\
\hline
\end{tabular}

* Approxımate measurement. 


\section{Literature Gited}

Ahearn, M. E., and J. F. Lance

1980. A New Species of Neochoerus (Rodentia: Hydrochoeridae) from the Blancan (Late Pliocene) of North America. Proceedings of the Biological Society of Washinglon, 93:435-442, 2 figures.

Akersten, W. A.

1972. Red Light Local Fauna (Blancan) of the Love Formation, Southeastern Hudspeth County, Texas. Texas Memorial Museum Bulletin, 20: 53 pages, 16 figures, 21 tables.

Alvarez, $\mathrm{T}$.

1965. Catálogo Paleomastozoológico Mexicano. Instituto Nacional de Antropologia e Historia, Publication (Mexico), 17: 70 pages.

Ameghino, $\mathrm{F}$

1895. Sur les Édéntes Fossiles de l'Argentine (Examen critique, revision, et correction de l'ouvrage de M. R. Lydekker "The Extinct Edentates of Argentina." Revista del Jardin Zoológico de Buenos Aires, III(4):97-192. [Also published in Ameghino Obras, XI:447-909.]

Brown, B.

1912. Brachyostracon, a New Genus of Glyptodonts from Mexico. American Museum of Natural History Bulletin, 31(17):167-177, 4 figures, plates 13-18.

Burmeister, $\mathrm{H}$.

1874. Monographia de los glyptodontes en el Museo Publico de Buenos Aires. Anales del Museo Nacional Buenos Aires, II: vi +412 pages, 42 plates.

1879. Mammiferes vivants et etients. In Description Physique de la République Argentine , 3(1): vi + 556 pages. Buenos Aires: Paul-Emile Coni.

Cantwell, R. J

1969. Fossil Sigmodon from the Tusker Locality, 111 Ranch, Arizona. Journal of Mammalogy, 50:375-378, 2 figures.

Castellanos, A.

1932. Nuevos géneros de Gliptodontes en relación con su Filogenia. Physis, 11:92-100.

1953. Anotacoes e retificacoes ao género Glyptodon Owen e a subfamilia "Glyptodontinae." Anales Academie Brasileira Ciencias, 25(4):391-410.

1954. Referencia a la subfamilia Glyptodontinae. Comples Rendus 19th International Geological Congress (Algiers, 1952), 15:35-43. [English summary.]

Cope, E. D.

1886. A Giant Armadillo from the Miocene of Kansas. American Naturalist, 20(12): 1044-1046.
1888. Glyplodon from Texas. American Naturalist, 22:345346.

1889. The Edentata of North America. American Naturalisl, 23:657-664, plates 31-32.

Cuatáparo, J. N., and S. Ramirez

1875. Descripcion de un mamifero fosil de especie desconocida perteneciente al genero "Glyptodon." Boletin de la Sociedad Mexicana de Geografia y Estadislica (Mexico), series 3, 2:354-362, 4 figures.

Cuvier, G.

1798. Tableau elementaire de l'histoire naturelle des animaux. xvi +710 pages, 14 plates. Paris: J. Bailliere.

Dalquest, W. W.

1961. Sylvilagus cunicularius in the Pleistocene of Mexico. Journal of Mammalogy, 42:408-409.

1975. Vertebrate Fossils from the Blanco Local Fauna of Texas. Occasional Papers of the Museum of Texas Tech University, 30: 52 pages, 7 figures, 1 table.

1977. Mammals of the Holloman Local Fauna, Pleistocene of Oklahoma. The Southwestern Naturalist, 22: 255-268.

Downey, J. S.

1970. Middle Pleistocene Leporidae from the San Pedro Valley, Arizona. United Stales Geological Survey Professional Paper, 700-B:131-136.

Evans, G. L., and G. E. Meade

1945. Quaternary of the Texas High Plains. University of Texas Publication, 4401:485-507, 9 figures, maps.

Evernden, J. F., D. E. Savage, G. H. Curtis, and G. T. James

1964. Potassium-Argon Dates and the Cenozoic Mammalian Chronology of North America. American Journal of Science, 262:145-198, 7 tables.

Felix, J, and H. Lenk

1899. Beiträge zur Geologie und Paläontologie der Republik Mexico. Leipzig, 2: 210 pages, 52 figures, 10 plates.

Flower, W. H.

1868. On the Development and Succession of the Teeth in the Armadillos (Dasypodidae). Proceedings of the Zoological Society of London, 1868:378-380.

Flower, W. H., and R. Lydekker

1891. An Introduction to the Study of Mammals Living and Extinct. xvi +763 pages, 357 figures. London: Black.

Gazin, C. L.

1942. The Late Cenozoic Vertebrate Faunas from the 
San Pedro Valley, Arizona. Proceedings of the United States National Museum, 92:475-518.

1950. Annotated List of Fossil Mammalia Associated with Human Remains at Melbourne, Florida. Journal of the Washington Academy of Sciences, 40:397404.

Gidley, J. W.

1922. Preliminary Report on Fossil Vertebrates of the San Pedro Valley, Arizona, with Descriptions of New Species of Rodentia and Lagomorpha. United States Geological Survey Professional Paper, 131E:119131, plates 34-35.

1926. Fossil Proboscidea and Edentata of the San Pedro Valley, Arizona. United States Geological Survey Professional Paper, 140B:83-95, 13 plates, 4 figures.

Gillette, D. D.

1975. A Review of North American Glyptodonts (Edentata, Mammalia): Osteology, Systematics, and Paleobiology. Dissertation Abstracts International, 35: 1659.

Hay, O. P.

1908. The Fossil Turtles of North America. Carnegie Institution of Washington Publication, 75: iv +568 pages, 704 figures, 113 plates.

1916. Descriptions of Two Extinct Mammals of the Order Xenarthra from the Pleistocene of Texas. Proceedings of the United States National Museum, 51(2147): 107-123, plates 3-7.

1923. The Pleistocene of North America and Its Vertebrated Animals from the States East of the Mississippi River and from the Canadian Provinces East of Longitude $95^{\circ}$. Carnegie Institution of Washington Publication, 322: viii +499 pages, 41 maps, 25 figures.

1924. The Pleistocene of the Middle Region of North America and Its Vertebrated Animals. Carnegie Institution of Washington Publication, 322A: viii +385 pages, 29 maps, 5 figures.

1926. A Collection of Pleistocene Vertebrates from Southwestern Texas. Proceedings of the United States National Museum, 68:1-18, 2 figures, 8 plates.

1927. The Pleistocene of the Western Region of North America and Its Vertebrated Animals. Carnegie Institution of Washington Publication, 322B: 346 pages, 21 maps, 12 plates, 19 figures.

Hay, O. P., and H. J. Cook

1930. Fossil Vertebrates Collected near, or in Association with, Human Artifacts at Localities near Colorado, Texas; Frederick, Oklahoma; and Folsom, New Mexico. Proceedings of the Colorado Museum of Natural History, 9(2):4-40, 14 plates.

Hibbard, C. W.

1955. Pleistocene Vertebrates from the Upper Becerra (Becerra Superior) Formation, Valley of Tequix- quiac, Mexico, with Notes on Other Pleistocene Forms. Contributions from the Museum of Paleontology, University of Michigan, 12:47-96, 5 figures, 9 plates, 12 tables.

Hibbard, C. W., and W. W. Dalquest

1966. Fossils from the Seymour Formation of Knox and Baylor Counties, Texas, and Their Bearing on the Late Kansan Climate of That Region. Contributions from the Museum of Paleontology, University of Michigan, 21(1): 1-66, 8 figures, 5 plates, 3 tables.

1973. Proneofiber, a New Genus of Vole (Cricetidae: Rodentia) from the Pleistocene Seymour Formation of Texas, and Its Evolutionary and Stratigraphic Significance. Quaternary Research, 3(2):269-274, 2 figures.

Hoffstetter, R.

1955. Sur le genotype de Glyptodon Owen. Bulletin du Museum d'Histoire Naturelle (Paris), series 2, 27:408413, I figure.

1958. Xenarthra. In J. Piveteau, editor, Traile de Paleontologie, 6(2):535-636, 64 figures.

Holmes, W. W., and G. G. Simpson

1931. Pleistocene Exploration and Fossil Edentates in Florida. Bulletin of the American Museum of Natural History, 59(7):383-418, 21 figures.

Howell, A. B.

1944. Speed in Animals, Their Specialization for Running and Leaping. xii +270 pages, 55 figures, 3 tables. Chicago: University of Chicago Press.

Huxley, T. H.

1863. Description of a New Specimen of Glyptodon Recently Acquired by the Royal College of Surgeons of England (Abstract of Huxley, 1865). Proceedings of the Royal Society of London, 12:316-326.

1865. On the Osteology of the Genus Glyptodon. Philosophical Transactions of the Royal Society of London, 155:31-70, plates 4-9.

Illiger, $\mathrm{C}$.

1811. Prodromus Systematis Mammalium et Avium Additis Terminis Zoographicis Utriusque Classis. xviii +301 pages. Berlin: C. Salfeld.

James, G. T.

1957. An Edentate from the Pleistocene of Texas. Joumal of Paleontology, 31:796-808, 4 figures, 9 tables, plates 101-102.

Johnston, C. S.

1944. The Upper Pliocene Cita Canyon Fauna from Randall County, Texas. D. E. Savage, editor. Unpublished thesis, University of Oklahoma.

Johnston, C. S., and D. E. Savage

1955. A Survey of Various Late Cenozoic Vertebrate Faunas of the Panhandle of Texas, Part I: Introduction, Description of Localities, Preliminary 
Faunal Lists. University of California Publications in Geological Sciences, 31:27-50, 6 figures, 5 maps.

Kaspar, T. C., and W. L. McClure

1976. The Taylor Bayou Local Fauna (Pleistocene) near Houston, Texas. The Southwestern Naturalist, 21:916,2 tables.

Lammers, G. E.

1970. The Late Cenozoic Benson and Curtis Ranch Faunas from the San Pedro Valley, Cochise County, Arizona. Unpublished doctoral dissertation, University of Arizona, Tucson.

Lance, J. F

1960. Stratigraphic and Structural Position of Cenozoic Fossil Localities in Arizona. Arizona Geological Society Digest, 3:155-159, 1 figure.

Leidy, J.

1889a. Fossil Vertebrates from Florida. Proceedings of the Academy of Natural Sciences of Philadelphia, 41:96-97.

1889b. Description of Vertebrate Remains from Peace Creek, Florida. Transactions of the Wagner Free Institute of Science (Philadelphia), 2:19-31, plates 4-8.

Lindsay, E. H., and N. T. Tessman

1974. Cenozoic Vertebrate Localities and Faunas in Arizona. Journal of the Arizona Academy of Science, 9:324.

Lindsay, E. H., N. M. Johnson, and N. D. Opdyke

1975. Preliminary Correlation of North American Land Mammal Ages and Geomagnetic Chronology. University of Michigan Papers on Paleonlology, 12:111119.

Lundelius, E. L., Jr.

1967. Late Pleistocene and Holocene Faunal History of Central Texas. In P. S. Martin and H. E. Wright, Jr., editors, Pleistocene Extinctions: The Search for a Cause, 1967:287-319, 11 figures, 1 table.

1972. Fossil Vertebrates from the Late Pleistocene Ingleside Fauna, San Patricio County, Texas. The University of Texas Bureau of Economic Geology, Report of Investigations, 77: vi +74 pages, 59 figures, 52 tables, 1 plate.

Lydekker, R.

1894. Contributions to a Knowledge of the Fossil Vertebrates of Argentina, Part II: The Extinct Edentates of Argentina. Anales del Museo de la Plata, 3 (Paleontologia Argentina): 118 pages, 61 plates.

MacFadden, B. J., and J. S. Waldrop

1980. Nannippus phlegon (Mammalia, Equidae) from the Pliocene (Blancan) of Florida. Bulletin of the Florida State Museum, Biological Sciences, 25:1-37, 16 figures.

Maldonado-Koerdell, $M$.

1948. Los Vertebrados Fosiles del Cuatcrnario en Mexico. Revista de la Sociedad Mexicana de Historia Natural, $9(1-2): 1-35$.
Meade, G. E.

1945. The Blanco Fauna. University of Texas Publicalion, 4401:509-556, 4 figures, plates 48-55.

1953. An Early Pleistocene Vertebrate Fauna from Frederick, Oklahoma. Journal of Geology, 61 (5):452-460, 1 plate.

Melton, W. G., Jr.

1964. Glyptodon fredericensis (Meade) from the Seymour Formation of Knox County, Texas. Papers of the Michigan Academy of Science, Arts, and Lellers, 49:129146, 3 figures, 3 plates.

Mooser, O., and W. W. Dalquest

1975. Pleistocene Mammals from Aguascalientes, Central Mexico. Journal of Mammalogy, 56:781-820, 12 figures, 4 tables.

Osborn, H. F.

1903. Glyptotherium texanum, a New Glyptodont, from the Lower Pleistocene of Texas. Bulletin of the American Museum of Natural History, 19(17):491-494, 1 plate.

Owen, R.

1838. Note on the Glyptodon. In W. Parish, Buenos Ayres and the Provinces of the Rio de la Plata, pages $178 \mathrm{~b}-\mathrm{e}$.

Pichardo de! Barrio, M.

1960. Proboscideos Fosiles de Mexico, una Revision. Instituto Nacional de Antropología y Historia México, Investigaciones, 4: 63 pages, 9 figures, 22 plates.

Ray, C. E.

1958. Additions to the Pleistocene Mammalian Fauna from Melbourne, Florida. Bulletin of the Museum of Comparative Zoology at Harvard College, 119:419-450, 5 figures, 3 tables.

1965. A Glyptodont from South Carolina. The Charleston Museum Leaflet, 27: 12 pages, 4 plates.

Roth, J., and J. Laerm

1980. A Late Pleistocene Vertebrate Assemblage from Edisto Island, South Carolina. Brimleyana, 3:1-29, 2 figures, 4 tables.

Seff, $\mathrm{P}$

1962. Stratigraphic Geology and Depositional Environments of the $11 /$ Ranch Area, Graham County, Arizona. Unpublished doctoral dissertation, University of Arizona, Tucson.

Sellards, E. H.

1940. Pleistocene Artifacts and Associated Fossils from Bee County, Texas. Bulletin of the Geological Society of America, 51:1627-1658, 7 figures, 2 plates.

Senechal, L.

1865. Notice sur l'armure ou le dermato-squeletle et le systeme dentaire $d u$ Glyptodon clavipes, et particularites biologiques de cel animal, deduites d'apres l'etudè de ses restes fossiles. 24 pages. Paris.

Sicher, $\mathbf{H}$.

1944. Masticatory Apparatus of the Sloths. Field Museum 
of Natural History, Zoological Series, 29(10):161-168, figures 23-25.

Silva-Barcenas, A.

1969. Localidades de Vertebrados Fosiles en la Republica Mexicana. Universidad Nacional Autonome de Mexico Institulo de Geologia y Paleontologia Mexicana, 28: 34 pages, 1 map.

Simpson, G. G.

1929a. The Extinct Land Mammals of Florida. Annual Report of the Florida State Geological Survey (20th Annual Report), pages 229-279, plates 30-40, 1 figure, 3 maps.

1929b. Pleistocene Mammalian Fauna of the Seminole Field, Pinellas County, Florida. Bulletin of the American Museum of Natural History, 56(8):561-599, 22 figures.

1931. A New Classification of Mammals. Bulletin of the American Museum of Natural History, 59:259-293.

1945. The Principles of Classification and a Classification of Mammals. Bulletin of the American Museum of Natural History, 85: xvi +350 pages.

Skinner, M. F.

1942. The Fauna of Papago Springs Cave, Arizona, and a Study of Stockoceros; with Three New Antilocaprines from Nebraska and Arizona. Bulletin of the American Museum of Natural History, 80(6):143-220, 19 figures.

Strain, W. S.

1966. Blancan Mammalian Fauna and Pleistocene Formations, Hudspeth County, Texas. Bulletin of the Texas Memorial Museum, 10: 55 pages, 8 figures, 13 plates.

Talmage, R. V., and G. D. Buchanan

1954. The Armadillo (Dasypus novemcinctus). The Rice Institute Pamphlet, 41(2): viii + 135 pages, 2 figures, 1 plate, 2 tables.
Trouessart, E. L.

1898. Catalogus Mammalium tam viventium quam fossilium. New edition (prima completa), part 5, pages 999 1264. Berlin: R. Friedlander und Sohn.

Turnbull, W. D.

1970. Mammalian Masticatory Apparatus. Fieldiane: Geology, 18(2):149-356, 48 figures.

Vinacci Thul, E. L.

1943. Nomenclature de los dedos de la mano de "Glyptodon." Physis, 19(53):391-401, 1 figure.

1945. Osteografia cefalica de Glyptodon reticulatus Ow. Physis, 20(55): 24-30.

Webb, S. D., editor

1974. Pleistocene Mammals of Florida. $\mathrm{x}+270$ pages. Gainesville: the University Presses of Florida.

Webb, S. D.

1977. A History of Savanna Vertebrates in the New World, Part I: North America. Annual Review of Ecology and Systematics, 8:355-380, 2 figures.

1978. A History of Savanna Vertebrates in the New World, Part II: South America and the Great Interchange, Annual Review of Ecology and Systematics 9:393-426, 1 table.

Weber, $M$.

1928. Die Säugetiere. Volume 2 (systematic part), 2nd edition, xxiv +898 pages. Jena: Gustav Fischer.

Weigel, R. D.

1962. Fossil Vertebrates of Vero, Florida. Florida Geological Survey, Special Publication, 10: viii +59 pages, 6 figures, 5 tables.

Wood, H. E., et al.

1941. Nomenclature and Correlation of the North American Continental Tertiary. Bulletin of the Geological Society of America, 52:1-48, 1plate.

Wood, P A.

1962. Pleislocene Fauna from /I/ Ranch Area, Graham County, Arizona. Unpublished doctoral dissertation, University of Arizona, Tucson. 